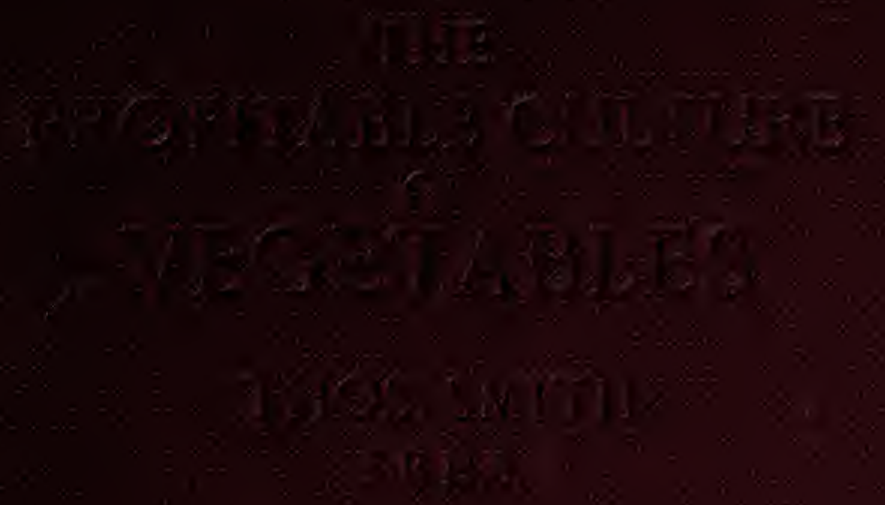

8 

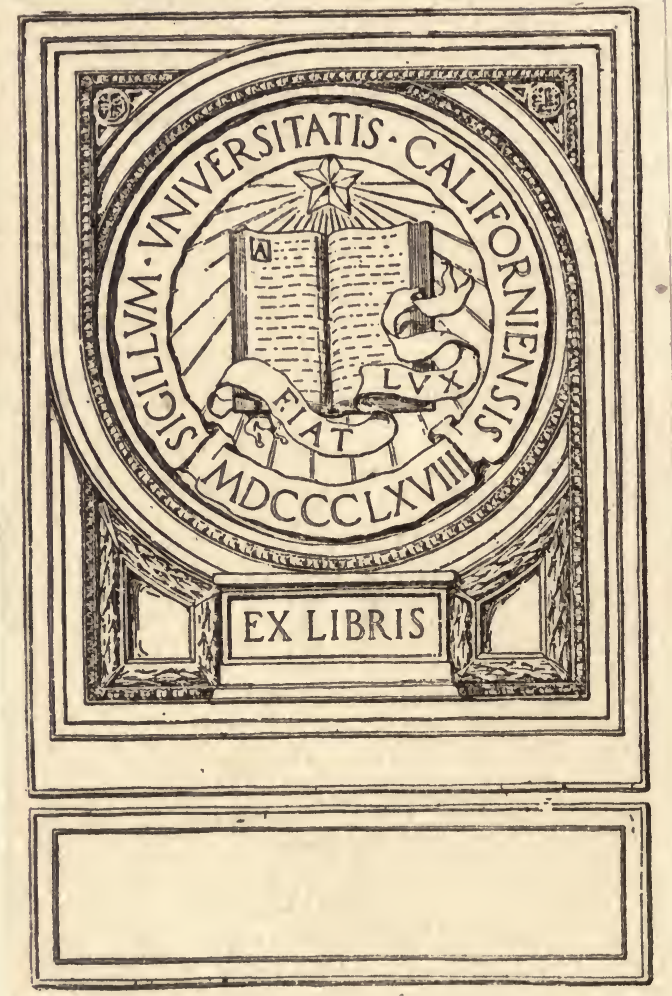


THE PROFITABLE

CULTURE OF VEGETABLES. 


\section{FOR GARDENERS AND AMATEURS.}

WOOD AND GARDEN : Notes and Thoughts, Practical and Critical, of a Working Amateur. By Gertrude Jekyll. With 71 Photographs. 8vo, 6s. net.

HOME AND GARDEN : Notes and Thoughts, Practical and Critical, of. a Worker in both. By GERTRUDE JEKYLL. With 53 Illustrations from Photographs. 8vo, 6s. net.

A PRACTICAL GUIDE TO GARDEN PLANTS. By John WeAThers, F.R.H.S. With 163 Diagrams. 8vo, 21s. net.

A PRACTICAL GUIDE TO SCHOOL, COTTAGE AND ALLOTMENT GARDENING. By JOHN WEATHERS, F.R.H.S With 66 Illustrations and Examination Questions on Cottage Gar dening. Crown 8vo, 2s. 6d. net.

GARDENING IN TOWN AND SUBURB. By HARRY H. Thomas, Assistant Editor of The Garden. With 17 Illustrations. Crown 8vo, 2s. 6d. net.

SPRING FLOWERS AT BELVOIR CASTLE: with Directions for Cultivation and Notes on the Gardens. By W. H. Divers, Head Gardener to His Grace the Duke of Rutland. With 32 Illustrations from Photographs by the Author. Crown 4to, 5 s. net.

ROSES : THEIR HISTORY, DEVELOPMENT AND AND CUltivation. By the Rev. Joseph H. Pemberton, President of the National Rose Society. With a Frontispiece in Colour, 9 Lithographic Plates, and other Illustrations in the Text. 8vo, 10s. 6d. net.

THE AMATEUR GARDENER'S ROSE BOOK. By Dr. Julius Hofrmans. Translated from the German by JohN WeATHERS, F.R.H.S. With 20 Coloured Plates and 16 Woodcuts. 8vo, 7s. 6d. net.

DISEASES OF PLANTS INDUCED BY CRYPTOGAMIC PARASITES. Introduction to the Study of Pathogenic Fungi, Slime Fungi, Bacteria and Algæ. By Dr. KARL FreIHERR von Tubeuf. English Edition by William G. Smith, B.Sc., Ph.D., Lecturer on Plant Physiology, University of Edinburgh. With 330 Illustrations. Royal $8 \mathrm{vo}, 18 \mathrm{~s}$. net.

A POPULAR TREATISE ON THE PHYSIOLOGY OF PLANTS. By Dr. Paul Sorauer. Translated by F. E. Weiss, B.Sc., F.L.S. With 33 Illustrations. 8 vo, 9 s. net.

LONGMANS, GREEN AND CO.

LONDON, NEW YORK. BONBAY, AND CALCUTTA. 


\section{THE}

\section{PROFITABLE CULTURE}

$\mathrm{OF}$

\section{VEGETABLES,}

FOR MARKET GARDENERS, SMALL HOLDERS, AND OTHERS.

BY

THOS. SMITH,

F.R.H.S.,

Manager of the Fels Fruit Farm and the Mayland French Garden. Author of "French Gardening."

FULLY ILLUSTRATED。 : "

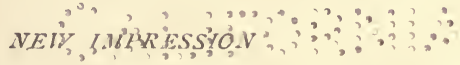

LONGMANS, GREEN AND CO.s 39, PATERNOSTER ROW, LONDON。 Neiv York, Bonbay, and Calcutta. 


\section{$S B 322$ 56}

"Ill fares the land, to hast'ning ills a prey, Where wealth accumulates and men decay. Princes and lords may flourish or may fade; A breath can make them as a breath has made, But a bold peasantry, their country's pride, When once destroyed can nerer be supplied." -

Goldsmith.

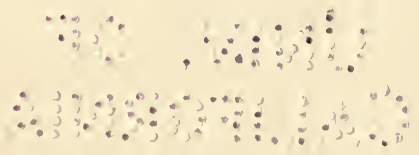




\author{
THIS BOOK \\ IS DEDICATED BY THE AUTHOR \\ TO HIS FRIEND \\ JOSEPH FELS, \\ IN ADMIRATION OF THE GALLANT FIGHT \\ HE IS MAKING \\ THROUGHOUT THE WORLD \\ TO BREAK DOWN \\ THE MONOPOLY IN LAND.
}





\section{PREFACE.}

MANY years of practical work in connection with market gardening and small holdings, both in actually cultivating the soil and in directing the work of others, have made me familiar with many of the needs and difficulties of those who gain their living from the cultivation of small areas of land, as well as having given me an insight into the factors which lead to success.

Amongst the greatest difficulties inexperienced men have to contend with are the want of direction as to general procedure and precise advice on points of detail. Even those who may fairly lay claim to experience often find themselves in doubt on subjects outside the usual routine. In many such instances collections of handbooks and periodicals on gardening matters are cursorily consulted, but it is seldom that any enlightenment can be discovered just at the moment it is needed, and as the matter is usually 
urgent such vague ideas as are already possessed constitute the only guide. As a consequence, many of the operations carried out under such circumstances come to an unsatisfactory conclusion.

The purpose of this book is to supply such information as the grower of vegetables is likely to require in connection with the productive part of his business, from the preparation of the soil to the marketing of the produce. Both ordinary and intensive culture are dealt with. I have endeavoured to convey the information clearly, in full detail but free from superfluities, and it is my earnest hope that it will be found of real help.

It was not without hesitation that I decided to add another to the long list of books on horticultural subjects, but I have made the venture because, in spite of their number and variety and the great value of some of them, I have hitherto failed to find one which satisfies me as being just the book those engaged in the culture of vegetables for a livelihood are in need of. The result may easily prove that I also have failed to produce what is required, but I shall at least know that I have tried, to the best of my ability, to do work which needed doing.

Throughout the production of the book practical friends have been very helpful, and I have consulted 
on numerous points a large array of authoritative works, the titles of which would need too much space to enumerate.

In preparing the chapters dealing with Soil and Manures I have drawn freely from Mr. A. D. Hall's books, The Soil and Manures. The section on Insect Pests and Fungoid Diseases is the work of my son, who from his training is much better qualified to deal with the subject than myself; and I am indebted to Mr. R. Coates, my late assistant, for compiling the Table giving the Approximate Cost of Fertilizing Units.

Of the illustrations of Vegetables the large majority appear by permission of Messrs. Vilmorin-Andrieux $\&$ Co., of Paris; most of the remainder are reproduced from photographs kindly provided by Messrs. Sutton \& Sons, of Reading; in each case this is indicated at the foot of the block. Of the illustrations in the section on Insect Pests and Fungoid Diseases, three have been supplied by Messrs. West, Newman \& Co., from Miss E. A. Ormerod's book on Agricultural Entomology; eight appear by permission of Messrs. Gurney \& Jackson, having been originally published in Mr. John Curtis's Farm Insects; the remainder in this section, with two exceptions, I am enabled to show by courteous permission of the Board of Agriculture, which Department has previously used 
them to illustrate some of its Leaflets, but in order to make them more manageable for my purpose I have had all those depicting fungoid attacks reduced in size, by woodcuts and line drawings.

The remainder of the illustrations throughout the book have, with very few exceptions, been prepared either from my own sketches or from photographs taken for me by Mr. E. Garrett, cashier and clerk to the Fels Fruit Farm, to whom I am also indebted for much valuable help in reading proofs.

THOS. SMITH.

Fels Fruit Farm,

Mayland, Essex,

April, 1911. 


\section{CONTENTS.}

CHAPTER I.

Pages.

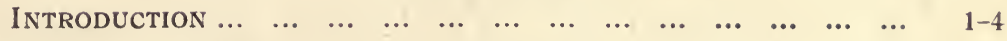

CHAPTER II.

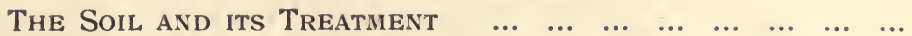

Origin of Soil-Composition of Soil - Subsoil-DrainageHow to Drain-Deep Cultivation-Bastard Trenching-RidgingTexture-Lime-Calcium Carbonate-Gas-lime-Soil BacteriaNitro-Bacterine Cultures-Soil Moisture-Autumn CultivationSpring Cultivation-Hoeing and Mulching.

CHAPTER III.

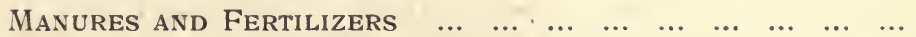

Composition of Plants-Plant Foods in the Soil-Farmyard $22-38$ Manure-Green Manure-Compost Heaps. Nitrogenous FERTILIZERS : Sulphate of Ammonia, Nitrate of Soda, Nitrolim, Dried Blood, Soot, Rape Dust, Castor Seed Meal, Shoddy. Phosphatic Fertilizers : Superphosphate, Limphos, Basic Slag, Bone Meal, Bone Flour, Dissolved Bones, Phosphatic Peruvian Guano. Potassic Fertilizers : Sulphate of Potash, Muriate of Potash. Kainit. Composite Fertilizers: Peruvian Guano, Dissolved Peruvian Guano, Fish Guano, Meat Guano. Notes on the Using of Fertilizers-Valuing Fertilizers-Approximate Cost of Fertilizing Units (Table).

CHAPTER IV.

The Suall Holder as a Market Gardener $39-41$

Conditions Necessary to Success-Capital Required-Physique -Industry and Concentration - Up-to-date Methods-Intensive Culture-Spade Work.

\section{CHAPTER V.}

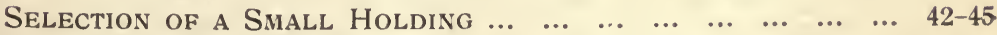

Situation-Aspect-Protection-Fences-Soil-Drainage Manure-Area-Tenure. 
CHAPTER VI.

The Business to BE CARried ON

Divisions into which the Business may be Separated-Grow. ing for Market-Advantages of Specialization-Glutted MarketsNeed for More Local Markets-Growing for Private TradeRegular Supplies and Numerous Varieties Essential-Increased Cost of Production, but Better Returns and Steadier MarketLimited Choice in Selection of Situation-Co-operation-Direct Supply.

\section{CHAPTER VII.}

Rotations of́ Cultivation, Manuring, and Cropping ... ... $50-52$

Reasons for Rotations-Difficulties in the Way of a Perfect Rotation-Why under certain conditions a Strict Rotation is not Essential-Rotation of Cultivation, Manuring, and Liming-Testing for Lime-Rotation of Crops.

\section{CHAPTER VIII.}

The Laying-out, Cultivating, and Cropping of a Holding...

Ideal Arrangement for a Marliet Garden Holding-PlanRotations of Cultivation and Manuring-Intensive Culture-Detailed Explanations of Plans-Plans of Intensive Cropping, with Rotations for Three Consecutive Years.

CHAPTER IX.

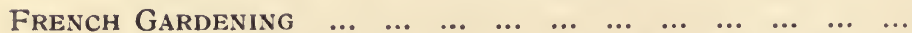
$63-67$

Brief Description of the Principles underlying the System and of the Methods adopted, with remarks on the Capital Required and the Financial Prospects of Similar Gardens in England.

\section{CHAPTER X.}

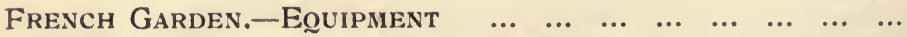
$68-80$

The Light: Structural Details-The Frame: Structural Details-The Cloche-Cloche Carrier-Cloche Peg-How to Store Cloches-How to Repair Cloches-Mats-Frame for Mat Making - How to Make Mats - Water - Plan of French Garden and Water System-Equipment of Two-acre Garden.

\section{CHAPTER XI.}

French Garden.-PREParation

The Beginning of the Gardener's Year - When Material should be Obtained-Situation-Outbuildings-Drainage-Wireworm-How to Prepare the Soil-How to Prepare Compost for Topping Beds-Manure: The Kind to Use, When to Get it, and How to Stack it. 


\section{CONTENTS.}

xiii.

CHAPTER XII.

Pages.

French Garden.-Preparing Plants for Early Crops ...

85-89

Scheme of Cropping - Seed Beds-Need for Attention to Details Emphasised - Raising Plants: Cauliflower, Cos and Forcing Cabbage Lettuce, Hardy Cos and Cabbage LettuceLettuce Mildew and the Preference for Cloches-Protecting the Plants from Frost-How Mats should be Laid so as to Resist Strong Winds.

\section{CHAPTER XIII.}

French Garden. - Crops Groivn on Hot-Beds, in Cold

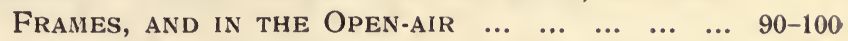

Intercropping and its Limitations-The Best Time for Beginning Hot-beds. HоT-BEDS FOR Frames: Arrangement of Compost-Sowing and Planting-Routine Work-VentilationGathering Radishes and Lettuces - Planting Cauliflowers Dressing the Beds-Watering-Clearing the Beds-Alternative Crops-Turnips. HOT-BEDS FOR Cloches : Compost-Arrangement of Cloches-Sowing and Planting-Water and Ventilation - How Cloches are Manipulated for Successional Crops-Covering and Shading Cloches-Clearing the Beds-Extra Early Cauliflowers.

$\begin{array}{llllllllll}\text { Plan of French Garden } & \ldots & \ldots & \ldots & \ldots & \ldots & \ldots & \ldots & \ldots & \ldots\end{array}$

CHAPTER XIV

A Quarter-Acre of French Garden $\ldots$...

Description and Explanation of Garden - Equipment Water-Manure-Prices of Produce-Average Crops-Size of Bunches-Details of Cropping-Estimated Produce and Values -Summary of Returns-Estimated Annual Income and Expen. diture-Approximate Cost of Equipment.

\section{CHAPTER XV.}

Intensive Culture on Allotments and Cottage Gardens ... 109-117

Forcing on Hot-beds Unnecessary-Great Increase in Quantity of Produce-Essential Features of the System: How to Secure Them at Small Expense-Suggestions for Practical Work with Schemes and Diagrams of Intercropping.

\section{CHAPTER XVI}

Seeds, Sowing, Thinning-out, and Transplanting $\ldots$...

The Necessity for Good Seed-Best Varieties to ChooseNovelties-Testing for Germination-The Seed Bed and its Preparation - Sowing - Thinning-out - Transplanting - How the Plants should be Trimmed-Dibbers and How to Use Them. 


\section{CHAPTER XVII.}

Devices for Forcing, Forwarding, and Protecting

$127-139$

Hot-beds: How to Make and Manage Them-Cold Frames :

Their Construction and Arrangement-The Cloche and its Uses - Shields of Calico and of Paper-Imitation Cloche-Calico Screen - Movable Shield - Straw Mats and Suggestions for Using-Glass-covered Plant Protector-Box Plant ProtectorGlass-covered Trench-Raised Beds with South Slope-Plan of Cropping the Beds-Cheap Method of Forcing in Pits.

Detalls of the Cultivation of Vegetables. Pages.

Articholie (Globe) 141-143 Lettuce 218-224

Artichole (Jerusalem).

144 Melons (Cantaloup) 224-230

Asparagus 145-154 Mushrooms 230-242

Beans (Broad) 154-156 Mustard and Cress 242-244

Beans (Dwarf or French) ... 156-159

Onions 244-252

Beans (Runner) 159-161 Parsley 252-254

Beet 161-163 Parsnips 254-255

Borecole, or Kale 163-165

Peas 256-265

Broccoli 165-167 Potatoes 265-283

Brussels Sprouts 167-169 Radishes 283-286

Cabbage 170-172 Rhubarb 287-294

Cardoons 173-174 Salsify 294-295

Carrots 174-179 Scorzonera 296

Cauliflower 180-183

Celery 184-195

Savoy Cabbage 296-297

Celeriac

196 Shallots 298-308

Chicory 197-198 Spinach 308-310

Cucumbers (Frame) 200-206

Spinach (New Zealand)..... 310-314

Cucumbers (Ridge) 207-209 Spinach Beet. 315

Endive 209-211 Strawberries 316

Herbs 212-214 Tomatoes 317-335

Horse Radish

215 Turnips 336-356 Leckis 216-217 Vegetable Marrows 357-362 362-365

Reminders of Work to Be Done, Month by Month ... ... 367-381

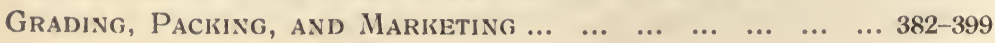


Insect Pests and Fungoid Diseases ivhich attack Vegetables.

Spraying Machines and their Use, ivith Materials and

FORMULA... $\quad \ldots \quad$...

Spraying Machines - Applying the Wash - Materials -

InsEcTICIDES: Arsenate of Lead-Carbon Bi-Sulphide-Hellebore Powder-Lime-Nicotine-Paraffin Emulsion. FungrCIDES: Bordeaux Mixture-Cupram-Sulphate of CopperSulphide of Potassium-Sulphur.

Insect Pests

Insects Harmful in General: Aphides-Chafer Beetles -Daddy Long Legs - Diamond Back Moth - Flea Beetles Millipedes and Centipedes-Red Spiders-Slugs and SnailsSnowy Fly-Surface Caterpillars-Wireworms-Woodlice.

Insects ivhich affect Particular Plants: Asparagus Beetle-Asparagus Fly-Bean Aphis-Beet and Mangold FlyCabbage Aphis-Cabbage Butterflies and Cabbage Moth-Cabbage Root Fly and Maggot-Cabbage and Turnip Root Gall Weevil-Carrot Fly-Celery and Parsnip Fly-Mushroom PestOnion Fly-Peà and Bean Thrips-Pea and Bean Weevils.

Fungoid Diseases ...

Asparagus Rust-Bean Pod Canker-Beet Rust-Cabbage Black Rot-Celery Leaf Diseases-Club Root or Anbury (Finger and Toe)-Cucumber and Melon Mildew-Cucumber and Melon Rot-Lettuce Mildew-Mint Rust-Mushroom Disease-Onion Mildew-Pea Mildew-Potato Black Leg or Stem Rot-Potato Black Scab or Wart Disease-Potato Disease (Blight or Rot)Potato Leaf Curl-Potato Scab-Potato Winter Rot-Sclerotium Disease-Strawberry Leaf Spot-Strawberry Mildew-" Potato Disease" on Tomatoes-Black Spot of Tomatoes-Violet Root Rot.

Miscellaneous INFORMATION $\ldots$
Quantity of Seed Required to Sow an Yield; Cost of Production, and Gross Returns per Acre-Average Time Required for Seeds to Germinate-Average Longevity of Garden Seeds-Sizes of Flower Pots-Number of Plants for an Acre-Receptacles, Weights, Measures, and Terms used in Marketing Produce-Avoirdupois Weight-Corn, Dry, or Heaped Measure-Long Measure-Surface Measure-Fertilizing Values of Poultry Dung and Farmyard Manure-Equivalent Dressings from One Square Yard to One Acre-Weather Indications.

$\begin{array}{llllllllll}\text { INDEX } & \ldots & \ldots & \ldots & \ldots & \ldots & \ldots & \ldots & \ldots & \ldots\end{array}$

List of Illustrations, Diagrans, and Plans $\ldots \ldots \ldots$... $451-452$ 


\section{ExTRACr from Sowerby's Thorough Cultivation :-}

If you cultivated the soil with the same skill that the manufacturers conduct their businesses, you would not have population enough to cultivate the land. Lord Ducie has given the same opinion, that if the land were properly cultivated there would not be sufficient labourers to till it. And yet, whilst that is the fact, you are chasing your population from village to village, and sending the people away to the Antipodes; whereas if your lands were properly cultivated you would be trying to lure them back as the most valuable part of your possessions.

\section{Extract from Kropotkin's Fields, Factories, and Workshops :-}

(1) If the soil of the United Kingdom were cultivated only as it was thirty-five years ago, $24,000,000$ people, instead of $17,000,000$, could live on home-grown food; and that culture, while giving occupation to an additional $750,000 \mathrm{men}$, would give nearly $3,000,000$ wealthy home customers to the British manufacturers.

(2) If the cultivable area of the United Kingdom were cultivated as the soil is cultivated on the average in Belgium, the United Kingdom would have food for at least $37,000,000$ inhabitants ; and it might export agricultural produce without ceasing to manufacture so as freely to supply all the needs of a wealthy population.

(3) If the population of this country came to be doubled, all that would be required for producing the food for $80,000,000$ inhabitants would be to cultivate the soil as it is cultivated in the best farms of this country, in Lornbardy, and in Flanders, and to utilise some meadows which at present lie almost unproductive, in the same way as the neighbourhoods of the big cities in France are utilised for market gardening. 


\title{
THE PROFITABLE CULTURE OF VEGETABLES.
}

\author{
Chapter I.
}

\section{INTRODUCTION.}

$A^{\text {LL history proves that a nation's well-being depends not }}$ A upon its industrial and intellectual pursuits only, but upon a judicious combination of these with agriculture, and that the neglect to cultivate its own land has always been the prelude to a nation's downfall.

The worker on the land is beyond question the ultimate source of the wealth, stamina, and reproduction of every nation, and yet for more than two generations we have permitted the rural districts of the British Islands to be become steadily depopulated, the inhabitants being dispersed, some to the slums of our large cities, where they speedily deteriorate in character and physique, and others to lands across the seas. This depletion of the country-side has gone on until some districts are now comparatively destitute of young able-bodied men, most who remain being either elderly and slow or in some way deficient. The extreme gravity of such a state of things must be apparent to everyone who will pause to give it consideration, matters having now come to such a pass that unless the outflowing stream of humanity is speedily checked the decadence of England as a great nation will soon be within measurable distance, if indeed it has not already begun.

Lack of opportunity for a full and prosperous existence in close relationship with the land has undoubtedly been the main cause of rural decadence, and it is obvious that the most natural and effective means of restoring the necessary balance between town and country is to afford opportunities for such an existence to all suitable persons desirous of obtaining a livelihood from work in connection with agricultural pursuits. 
That the rural depopulation problem can be solved in no other way has for some time been apparent to all who have been sufficiently interested to study it, and it is becoming surely, if somewhat slowly, the object of constructive legislation on these lines. The Allotments Act was a step forward, although a feeble and hesitating one. The Small Holdings Act is a bolder measure, although a very incomplete one when the magnitude of the problem it was designed to solve is considered, but unfortunately, modest as its provisions are even when carried out in the spirit in which it was framed, it meets with much opposition, both active and passive, from those whose duty and privilege it is to put it into effective operation.

But even were the Act administered with enthusiasm, provision of the bare land is not enough to meet the necessities of the situation, and unless something more is done progress must be very slow and uncertain. Men there are in plenty, of the most suitable type, ready and indeed anxious to change their mode of life and settle upon the land, but having little or no capital the majority are effectually debarred; of the few who by perseverance and strenuous effort are at length enabled to make the adventure, most, through ignorance of the business they have undertaken or from lack of sufficient means to bring it to a successful issue, either fail disastrously or are doomed to a life of unnecessary privation and hard unremitting toil. It appears to be overlooked that dwelling-house, out-buildings, tools and appliances, manure, and in some cases live-stock, are needed in addition to land, as well as a reserve fund to fall back upon in the event of bad seasons in the early years, and this calls for a considerable amount of capital in each case. The majority of the men most suitable for the purpose in view are comparatively poor-in the circumstances it could scarcely be otherwise-and it is useless to expect them to finance themselves. It is obvious that if the Small Holdings Act is to have any real chance of accomplishing its purpose it must not only be administered in the spirit in which it was conceived, but should be supplemented by a fund which will place such capital as is absolutely necessary within the reach of eligible men, under conditions which will provide for its repayment within a reasonable period. 
Such a system is at the present time in successful operation in New Zealand, and the experience there gained will prove of the utmost value in inaugurating a similar system here, but in any case it seems a mere mockery to give poor men access to the land without at the same time giving them access to capital with which to develop it.

But there is another factor of success which may still be lacking even though men are assured of access to both land and capital: that is, the knowledge of how to use them to the best advantage. Without such knowledge the small-holder is in much the same position as would be the captain of a well-found ship who was trying to reach harbour on an unknown and dangerous coast without a pilot. He might by great good fortune arrive safely at his destination, but it is much more probable that he would meet with disaster even in calm weather, and shipwreck would be practically certain in the event of a storm.

This points to the necessity for some systematized method of instruction in the numerous branches into which agricultural pursuits and rural industries are divided and sub-divided. With such instruction to supplement the provision of land and capital success would be assured, and the desert country-side would become peopled by industrous, thriving, and contented communities, who would not only form a bulwark to the state but would add materially to the wealth and prosperity of the nation.

Within recent years scientific men have devoted much time to the study of the soil and the laws and conditions which govern its fertility, and this and other similar invaluable information should be made known to all who are engaged in the business of farming or gardening, so that they may understand the true meaning of the operations they are engaged in and of the laws which underlie them and, by working with a definite purpose in view, the more easily and certainly attain their object.

The cultivation of the soil is beset with trials even for those who have made it their life's business, and it is obviously much more difficult for a person with little or no experience. It differs from most other occupations in that it deals with living things and ever-changing conditions. In the factory and workshop the materials dealt with are inert and the conditions fairly 
constant; calculations can be made and results obtained with a near approach to accuracy. But it is not so in cultivating the land. In this case it is impossible to forecast the result of any single operation. The most carefully laid plans may be made abortive by the vagaries of the weather. Insect pests are always at hand to take a heavy toll of the crop unless persistently battled with, and fungoid diseases are ever lurking near, ready to attack any crop subjected to unsuitable conditions.

Happily, there is another and brighter side to the picture, or the outlook would be hopeless indeed. The law of averages keeps the troubles of the cultivator within reasonable limits. There are in the long run few things more dependable than the average returns from the soil when crops are afforded the necessary conditions of healthy growth. Just as climatic vagaries and the numerous other difficulties happen with average frequency, so in like manner will crops properly handled produce an average of successful results. Even the prices obtained in public markets come, to a certain extent, under the same law-periods of glut when prices are low being followed by periods of scarcity when prices are high-and so we get from men of experience the sound advice to "follow the market, good or bad"; that is, providing a wise choice is made in the first place, the same staple crops should be steadily grown season after season, in spite of a fluctuating market, and the total cash receipts will be almost certain to work out satisfactorily in the end.

The lesson to be derived from this is that difficulties become manageable when faced with resolution and with knowledge. Success is always the ultimate outcome of sound work when the end in view is understood and details are properly attended to. Spasmodic effort or uncertainty both lead to failure; for success, industry and attention to the work in hand must be unremitting, and every operation carefully studied. Gardening is always more or less intensive culture, and differs mainly from extensive farming in that it adds to such culture numerous small but highly important details, to omit or neglect any of which frequently means loss or failure. The purpose of this book is to supply the knowledge necessary in one branch of agriculture-the culture of vegetables for profit. 


\section{Chapter II.}

\section{THE SOIL AND ITS TREATMENT.}

Origin of Soils-Composition of Soils-Subsoil-Drainage-How to Drain-Deep Cultivation-Bastard Trenching-Ridging-TextureLime-Calcium Carbonate-Gas-lime-Soil Bacteria-Nitro-Bacterine Cultures-Soil Moisture-Autumn Cultivation-Spring CultivationHoeing and Mulching.

RIGIN of Soils.-The accepted doctrine regarding the origin of soils, is that the exposed parts of the primitive rocks which at a very remote period in the history of the earth formed its entire surface, were broken down by the process known as "weathering," or, in other words, by the action of rain, running water, alternate heat and cold, air, and by the grinding motion of glaciers.

This pulverised material was carried down and deposited on the plains and in the valleys by wind, flood and gravitation, and in the course of ages the earlier deposits again became consolidated into rocks of a character distinctly unlike those from which the materials forming them were derived. The weathering process persisted throughout the ages during which this re-formation was taking place. In most cases the disintegrated material was deposited where it was formed, and we thus find that most soils bear a definite relationship to the rocks beneath them. In other cases the material was carried away by rivers and streams and deposited in low-lying situations, often at a considerable distance from the place of origin, thus accounting for instances of soils unrelated to the rocks underlying them.

The next step in the process of soil formation is obscure, involving as it does the problem of the origin of life upon the earth. Some hold to the opinion that lichens or similar low forms of vegetable life first grew upon the debris, and were the forerunners of higher forms, whilst others contend that as vegetable life is impossible without the assistance of the microorganisms of the soil, these must have had the precedence. 
For our present purpose, however, this is unimportant. By their life, death and decay, lichens assisted in soil formation and made the existence of mosses possible. The latter in like manner added to the bulk, and were in turn followed by more highly-organised plants and then by animals, and as each of these in turn grew, died and decayed, the mass was gradually increased and more or less perfect soils were produced as we know them to-day.

Composition of Soils.-The pulverised rocks which thus form the base of all soils consist of various mineral or inorganic compounds, whilst the remains of animals and plants, consisting of organic compounds, form the remaining portion. This admixture of inorganic and organic material contains, in a crude form, the foodstuffs which plants absorb from the earth.

When soils are chemically analysed it is seen that all bear a certain resemblance to each other in their composition, so far as the ingredients are concerned. There is, however, a very wide variation in the relative proportions of these ingredients, and it is this variation which makes all the difference between the many kinds of soil with which cultivators have to deal.

Soils are classified according to the predominance of the clay, sand, lime, or vegetable matter which they may contain, as follows:-

$\begin{array}{llllllll}\text { Clay soils } & \ldots & \ldots & \ldots & \text { containing above } 50 \text { per cent. clay. } \\ \text { Clay loams } & \ldots & \ldots & \ldots & , & 30 \text { to } 50 & , & \text { clay. } \\ \text { Loamy soils } & \ldots & \ldots & \ldots & , & 20 \text { to } 30 & , & \text { clay. } \\ \text { Sandy loams } & \ldots & \ldots & \ldots & , & 80 \text { to } 90 & , & \text { sand. } \\ \text { Sandy soils } & \ldots & \ldots & \ldots & , & \text { over } 90 & , & \text { sand. } \\ \begin{array}{c}\text { Marly soils } \\ \text { Calcareous or }\end{array} & \ldots & \ldots & , & 5 \text { to } 20 & , & \text { lime. } \\ \begin{array}{c}\text { chalky soils } \\ \text { che }\end{array} & \ldots & \ldots & , & \text { above } 20 & , & \text { lime or chalk. } \\ \begin{array}{c}\text { Vegetable or } \\ \text { peaty soils }\end{array} & \ldots & \ldots & \ldots & , & \text { above } 5 & , & \text { humus, or } \\ \text { decayed vegetable matter. }\end{array}$

Every known soil falls within the limits of one or other of the above classes, or of their gradations, although there are many intermediate variations between one type of soil and another.

The fertility of any soil is intimately connected with its composition and texture, apart from any plant foods it may contain. A soil of open texture-due to a large proportion of sand, gravel, or chalk-is easy to cultivate but has very little 
retentiveness, either of water or manure, whilst the opposite extreme, a soil of close texture, due to a large proportion of clay, is difficult to cultivate owing to its tenacity and "stickiness" when wet.

It is, therefore, easy to understand that a well-balanced mixture of sand, clay, and humus-known as loam-is the best soil, as not only can it be the most readily cultivated to suit the needs of the majority of plants, but the roots can easily work their way through it, and will find the necessary nutriment better than in a very porous soil, which is liable to become too dry, or in a close impervious soil, which in dry weather may become too hard for the roots to work through and in wet weather may become waterlogged.

Subsoil.-That portion of the soil which contains the material for plant nutrition in an available form is, as a rule, seldom more than a foot in depth, and is calculated to average no more than nine inches. Below this comes the subsoil, of which the composition and structure is of the greatest importance.

When a loose porous soil rests upon a clay subsoil excessive drainage is checked and the moisture retained is of great benefit to plants; or when a retentive clay loam rests upon a well-drained gravel or sand drainage is accelerated and the upper soil is relieved of surplus water. Either of these conditions may be said to be good. On the other hand when a sandy soil rests upon an open gravel or a heavy loam rests upon an impervious clay the conditions are very unfavourable, unless means are taken to make the former more compact and "holding" and to improve the drainage of the latter.

Drainage.-The first and most imperative condition of soil fertility is drainage, either natural or artificial. When land is in need of drainage there is no work the cultivator can engage in which is likely to give him so good a return for his labour.

The principal effect of drainage is to free the soil from stagnant and surplus water and to induce a passage of air through it, aeration of the soil being indispensable to the healthy growth of plants. If water cannot pass away freely it 
has to be evaporated, and the effect of evaporation from any surface is to make it colder. Therefore, well-drained soil is warmer than that which is undrained. The higher temperature of drained land has been frequently proved by experiment; it has been shown to be warmer by as much as six degrees over that of adjoining undrained land, and in addition the temperature of the air immediately above drained land is also several degrees warmer.

Draining should not be done without careful consideration. It is a costly operation when the area to be dealt with is large, and if not properly done may be practically useless. Moreover, there are many soils through which water percolates with sufficient freedom to make pipe-draining unnecessary, and some others of a very open nature where it would be harmful. There is no denying, however, that heavy clays would be improved by draining, always providing that the pipes are put in neither too far apart nor too deep. Many of the drains put in clay land by Government assistance about fifty years ago are far too deep and too wide apart to be of much use.

On such close-textured tenacious soils, when only shallow cultivation is practised, as in ordinary farming, the custom of laying the land in beds or."stetches," with furrows between connected with cross-furrows, or "water-furrows," is usually found sufficiently effective for all practical purposes, but for garden cultivation on such soil, where deep working is necessary, pipe-drains should never be omitted and the cost would soon be amply repaid.

How to Drain.-At various times there has been great difference of opinion as to the direction in which drains should run-whether in the direction of the slope or obliquely across it. Experience has proved that it is best to lay them in the direction of the greatest slope.

Drains are ranged under three classes-main-drains, submains, and small drains. The mains are those into which all the other drains deliver their water, and which lead the united flow to the point of outfall; these should invariably be along the lowest part of the field. Sub-mains should be laid along 
minor or secondary low places, and usually empty into the mains, but sometimes, when the contour of the field is very uneven, it is found more convenient to let them act as smaller mains, with a separate outfall. Small drains should not enter the larger pipes squarely, but at an angle in the direction of the flow of the water, otherwise there is a liability to block with silt or other obstructions. In forming junctions between two pipes a hole should be made through the larger one in a position which will bring the top of each pipe level, the lip of the small one being introduced into the larger one and the place of junction properly covered with pieces of broken tile to keep out soil and silt.

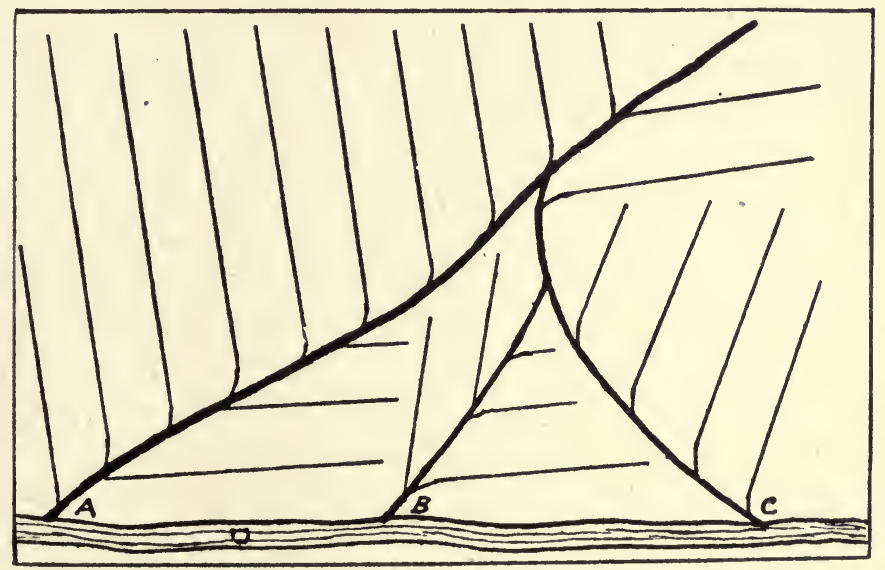

Plan of Draining of a Field with undulating surface.

A-Main drain. B, C-Sub-mains, used as Secondary Mains. D-Stream.

It is not considered good practice to have field drains longer than 250 yards without a break; when the distance is greater than this an intercepting main or sub-main drain should be put in pear the middle of the field.

The drains should empty at one or more main outlets. Where a number of small drains enter a ditch separately some of them, sooner or later, get choked by rubbish or lost sight of. It is much easier to attend to the outlet of one main drain than of a number of small ones.

Drains in clay, if well laid, will work fairly well with a fall of 
1 in 100 for the mains and 1 in 75 for the small drains; in lighter soils the fall should be more than this.

In stiff clays drains should not be more than $2 \mathrm{ft}$. to $2 \mathrm{ft}$. $6 \mathrm{in}$. deep and $15 \mathrm{ft}$. apart. In porous soil with a good fall they may be put in about $3 \mathrm{ft}$. to $3 \mathrm{ft}$. $6 \mathrm{in}$. deep and $20 \mathrm{ft}$. apart. In peaty soils of good depth the pipes should be one or two sizes larger than usual and may be put in from $5 \mathrm{ft}$. to $6 \mathrm{ft}$. deep and about $30 \mathrm{ft}$. apart.

The sizes of pipes commonly used are: for small drains 2in., for sub-mains $3 \mathrm{in}$., and for mains $4 \mathrm{in}$., but where the fall is slight it is advisable to use pipes a size larger all round.

Where clean stones are plentiful and cheap these may be used instead of pipes, laid in about 9in. thick, and they usually work very well.

In cutting trenches for the pipes always begin at the outfall, which should be at least $6 \mathrm{in}$. above the bottom of the ditch, to allow for silting. Proper draining tools should be used, and the bottom of the trench should be cut only just wide enough to lay in the pipes easily without any sideplay. If the bottom in any place should be cut too wide the pipes must be fixed in position by stones, lumps of clay, or pieces of broken pipe.

Drain pipes sometimes get blocked by the roots of trees and deep-rooting plants and grasses; it is, therefore, advisable in laying them to keep as far away as possible from such dangers.

Deep Cultivation.-When in addition to being freed from excess water by drainage the soil is deeply-pulverized the good effect is increased by more thorough aeration and a higher temperature. This is, therefore, the next step in promoting fertility, and indeed the full effect of putting in drain-pipes cannot be secured until the soil is brought into this condition. When this is done an enormously increased area is opened to the ramifications of the roots, which penetrate the soil in all directions, extracting food and moisture throughout the whole mass. Seeds sown in such soil germinate sooner and stronger and the plants grow more vigorously. Whether the season be wet or dry land which is drained and deeply worked shows earlier and better crops and finer fruits. 
Mr. A. D. HaLl, Director of the Rothamsted Experiment Station, in his book, The Soil, says that the surfaces of the particles in one cubic foot of ordinary light loam may be taken as equal in area to one acre! When the full significance of this statement is grasped it will be easy to realize the enormous difference in the chances for free vigorous growth between a plant in thoroughly cultivated soil and one in a soil which is shallow, cobbly, and ill-worked.

Bastard Trenching.-The most satisfactory method of deeply cultivating large areas of soil for gardening is by "bastard trenching," which consists of breaking up the soil two "spits" deep, but keeping the bottom spit still at the bottom and the top spit at the top. There are some soils where the top and bottom spits could be reversed with good results, but such are seldom met with, and for all practical purposes can be disregarded.

The top soil contains plant foods in an available form, but the underneath spit has probably never before been exposed to the light of day or been subjected to the sweetening and fertilizing influences of the weather; to bring such inert and barren stuff to the top would be to ruin the garden for many a year to come. In the course of time deep working, with the addition of manure, will aerate and sweeten the lower soil and improve the texture, and then it may very gradually be brought up.

The method usually adopted in bastard trenching is illustrated on the next page, the explanation being as follows: Divide the plot into two by a line down the middle, then at (A) take out the top spit a yard wide, and lay it down at (E). Now break up the bottom spit at (A), cover it with manure, and then cover this with the top spit of the next yard. Repeat this operation to the end of the first section, filling up the last trench (B) with a yard of top soil from the same end of the second section (c). Work back along this section until (D) is reached, where the soil (E) is used to fill the final trench (D).

This work should preferably be done in the autumn or early winter, and the surface left rough, so that frost and atmos- 
The Profitable Culture of Vegetables.

pheric influences can have full effect upon it; when this is done the physical character of the soil is greatly improved.

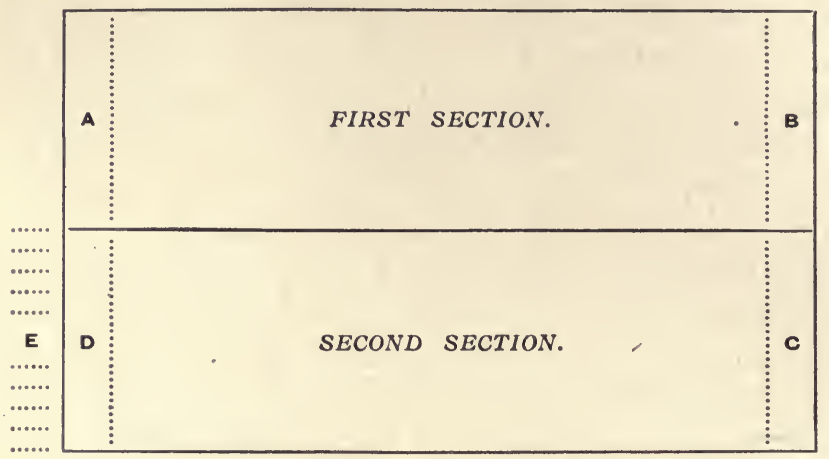

Plan showing method of Bastard Trenching a large piece of ground.

Deep cultivation on clay soil should never be attempted until provision is made for the removal of surplus water. In many instances enthusiastic novices have dug such land two and even three spits deep, but by neglecting draining have made the conditions worse than they found them. In the absence of under-draining deep working on clay soil simply forms a basin with impervious sides and bottom, which in a wet season becomes a veritable swamp. When pipe drains are omitted the land should be laid up in narrow beds with rather deep furrows between to draw off the water. The beds should run with the fall of the land, and all the furrows should be connected with cross furrows which lead the water away from the cultivated land to the nearest ditch or pond. In such a case care should be taken to keep an even fall in the furrows so that the water can get away readily, and the soil should never be worked lower than the depth of the furrow.

Ridging, particularly in the case of heavy soil, is a very valuable method of laying up land at the approach of winter; by this means a much greater extent of surface is exposed to the action of the weather than when the land is laid flat. If the ridges are not too wide the soil gets frozen through, the clods broken down, insect pests destroyed, plant foods liberated, 
and the whole thoroughly sweetened; in addition the surface soil is kept dry, and when the ridges are pulled down in the spring after one or two drying days a kindly working bed is at once secured either for seeding or planting.

There are various methods of ridging, but one of the best is the following, which completes bastard trenching and ridging in one operation :-

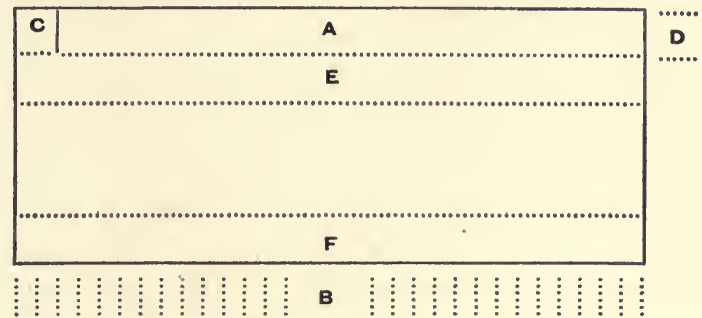

Plan showing method of Bastard Trenching and Ridging in one operation.

Mark out a strip 2ft. wide, running north and south, along one side of the plot (A) then take off the top spit from this strip and wheel it to the opposite side of the plot (B); now turn over the subsoil at (A) first removing enough from (C) to (D) to admit of easy working, returning the removed portion when the end of the trench is reached; now cover the worked subsoil with a layer of manure (the manure should be arranged in several convenient rows running across the plot from east to west); now remove the top spit from the next $2 \mathrm{ft}$. strip (E) laying it ridge shaped $(\Lambda)$ on $(\mathrm{A})$, and the first strip will be completed. Repeat the operations on each strip across the plot, using the soil which was wheeled to (B) to cover the manure in the trench at (F). The work is then completed, the whole plot being laid in alternate ridge and furrow, running north and south.

Texture.-The third essential to soil fertility is freedom of texture and the extent to which its mechanical condition is made free-working or friable. All soils must be made friable before they can become fertile. But this condition of friability must not be in excess; it is quite possible for a soil to be too open. Soils containing a large proportion of sand, gravel, or chalk are easy to cultivate, but through being too open in 
texture part with their moisture too readily, and the crops on them are therefore very liable to suffer from droughts in dry weather. To overcome this objection measures must be taken to make them more compact. The addition of powdered chalk to sand or gravel, and particularly of humus to all three will bring about the desired improvement. Humus can be added either by heavy dressings of yard manure or by digging or ploughing in at intervals quick-growing green crops.

But it is on clay soils that the greatest alteration in texture can be made. Such soils are tough and tenacious, and sticky in wet weather; liable to crack badly and to set into hard lumps when the weather is dry. They, however, possess inherent fertility to a greater degree and are less easily exhausted than light soils. They are capable of great permanent improvement, and when drained and deeply worked only need to be made friable to form one of the best soils for the growth of vegetables and fruit.

Lime.-It has been said that clay soils are a storehouse of plant food, the key to which is not always forth-coming, but, providing the preparatory operations already indicated have been duly performed, the addition of lime to clay soil will unlock the storehouse. Under the influence of lime such soil will become crumbly and friable and less retentive of water, so that it lies drier and warmer and is fit for cultivation earlier in the spring.

Apart from its physical effect lime has also a great influence in bringing inert plant foods into an available condition; on this subject more will be said in the chapter dealing with manures.

The method of liming formerly in vogue consisted in applying large quantities at long intervals, five tons per acre not being an unusual quantity, but recent investigation and experiment has shown that lime is more effective if applied in much smaller quantities at frequent intervals-say 5 to 10 cwts. per acre once in three years-and that calcium carbonate (ground limestone rock or powclered chalk) is for most purposes quite as effective, much cheaper, and easier to apply than quick-lime. 
Calcium Carbonate.-Quick-lime is obtained by "burning" or heating to redness any form of carbonate of lime (calcium carbonate). Limestone rock, chalk, marble, seashells, \&c., are all natural forms of carbonate of lime. The lime which forms part of these materials is combined with carbonic acid; under the influence of great heat the carbonic acid is driven off and only the quick-lime remains. As everyone who has any practical acquaintance with quick-lime is aware, it is only kept "quick" with difficulty ; if it is exposed to a damp atmosphere it rapidly becomes "air-slaked" and falls to a fine powder.

When quick-lime is applied to the soil it first absorbs water and becomes "slaked"; it then gradually unites with carbon di-oxide, and returns to its original form of calcium carbonate. Until this last change takes place the lime remains caustic and when in this condition is frequently injurious to the roots of plants. Therefore-unless for special reasons, such as when a soil is infested with disease, in which case quick-lime is best-it is better and generally cheaper to apply lime in the form of ground limestone or chalk.

Lime in any form should not be buried deeply, as it has a tendency both to sink further into the ground and to be dissolved out of the soil by the carbonic acid in rainwater.

Gas-lime or "blue-billy" is an evil-smelling substance produced by the use of lime in purifying coal-gas. In its fresh state it contains calcium sulphide and sulphite and it is then deadly to both plant and insect life. It is sometimes applied fresh to ground badly infested with some insect pest, in which case five tons to the acre should be evenly spread and immediately turned under, but the ground cannot then be cropped for several months after. By exposure to the air the poisonous substances are changed into sulphate of lime and it can then be used with perfect safety. To accomplish this change in the best way lay the crude material in heaps of about a ton, and after a month or so mix each heap with an equal quantity of soil, such as ditch cleanings and the like. Let it stand in these heaps for about a year and then apply the mixture at the rate of four tons per acre. 
Soil Bacteria.-The soil is not merely an inert mass of material serving as an anchorage for plants and a storehouse of the food which the plant requires. It is a complex workshop where many diverse processes are continually taking place. Many of these processes are chemical, whereby the mineral compounds derived from the rock debris which forms the base of soils are brought into the condition of solubility. But there are also many other processes which are not of a chemical nature. The surface soil is continually receiving additions of organic matter, such as decaying vegetation, falling leaves, the droppings of animals and birds, as well as the manures supplied during the operations of cultivation. These organic materials rapidly change into the dark-coloured body known as humus, which in its turn is further changed into carbonic acid, water, and nitric acid. All these changes in the form of organic material are brought about by certain minute micro-organisms known as soil bacteria.

These bacteria are universally distributed throughout cultivated soil; any soil in which they are not present would be sterile. They occupy the surface soil in almost countless numbers, as many as four millions having been estimated to occupy one cubic inch. Below the fertile surface soil they rapidly become less in number, comparatively few being present in the subsoil, which helps to explain why subsoil is sterile when brought to the surface before deep cultivation has had time to make it into a suitable breeding place for bacteria. These organisms are most active in a temperature of 65 degrees F. They cease to work when the temperature falls below 10 or rises above 100 degrees. To enable them to properly perform their functions it is necessary that the soil should be warm, moist, and well aerated, also that a certain amount of lime is present as a base to neutralise the acids which they produce.

Another variety of these bacteria enters into a sort of joint existence with plants of the leguminous species (peas, beans, clover, tares, \&c.) directly helping them to draw from the atmosphere the nitrogen which they require. The bacteria form colonies or communities in the nodules (little warts or lumps) which are more or less present on the roots of all 
leguminous plants. Many cultivators take advantage of this fact by growing and turning under a crop of leguminous plants as green manure and thus add to the soil not only the necessary humus but also a considerable amount of nitrogen.

Nitro-Bacterine Cultures.-These nitrogen-gathering bacteria have been artificially cultivated in gelatine broth by scientific men, and advantage has been taken of this circumstance by others to extensively advertise similar preparations for inocuulating farm and garden soil, accompanied by the statement that greatly increased crops of leguminous plants would result. The writer has very carefully experimented with these cultures but in no case has he found that the crops have benefitted from their use. Old cultivated soil already affords such a suitable environment for nitro-bacteria that nature has already provided them in as great numbers as the surrounding circumstances can sustain. The only method of profitably increasing their numbers and activity is by proper cultivation and manuring, which temporarily makes their environment suitable for a rapid increase, hence the improved crops following good cultivation. When working of the soil ceases their numbers fall to normal. Nitro-bacterine cultures are useless unless all the conditions of healthy plant growth are present and with these conditions they are unnecessary.

Inoculation by bacteria cultures would no doubt be of great service on barren soils, such as newly reclaimed land where nitrifying bacteria are not already established.

Soil Moisture.-One of the most important conditions of fertility in soils is their power of absorbing and retaining sufficient moisture for the needs of the crops they bear. A dry soil is a barren one no matter what the proportion of plant food it may contain or how good its physical condition, and it will not grow crops until moisture is present.

It is considered by scientific investigators that very few cultivated crops attain their fullest development for lack of sufficient moisture, and that much larger crops would be obtained if plants were supplied in the growing season with all 
they could use. Mr. Hall, of Rothamsted, an authority on soils previously quoted, says:-

"In all cases the amount of water transpired by the crop is a notable fraction of the total annual rainfall, particularly so in the case of a root.crop like mangolds, which in the south and east of England will often require a full half of the total rain falling within the year. As much of the rainfall runs straight off the surface into the ditches, and another portion is lost to the land by percolation into the springs, as again a considerable fraction is evaporated at certain seasons from the bare surface of the soil, it is evident that the water supply, even in our humid climate, is far from sufficient for the maximum of production and may easily fall below that which is required for an average crop. Indeed we may take it as a truism that the crop obtained is more often determined by the water available than by lack of the other essentials of growth-light and heat, manure, \&c. Of this we can have no better proof than the enormous crops grown by irrigation on sewage farms. Where the conditions are favourable, and the farm is situated on a free draining sandy or gravelly soil, so that the water can be often renewed and drained away to keep the soil supplied with air as well as water, the production of grass, cabbages, and other green crops is multiplied five or even tenfold by the unlimited supply of water. Speaking generally, over a great part of England, where the annual rainfall is from 35 to 25 inches, a large proportion of which falls in the non-growing season, it is necessary to husband the water-supply, and it will be found that one, at least, of the objects of many of our usual tillage operations is the conservation of the moisture in the ground for the service of the crop."

This evidence is corroborated and strengthened by that of Mr. F. H. King, Professor of Agricultural Physics in the University of Wisconsin, U.S.A., who says, in his book on The Soil :-

"There are very few countries, indeed, where the distribution of rainfall in time and amount is such as to permit fertile soils to produce the largest crops they are able to bear; and this being true, those soils which are able to store the largest quantities of rain in a condition which shall permit vegetation to use it to the best advantage are likely to be the most productive."

From this evidence it will be seen how extremely important it is that crops should have all the moisture they need at the time when they are making their most vigorous growth. In this matter land which has been drained of stagnant water and deeply worked shows an enormous advantage over land which 
has not been subjected to this treatment, whether the season be a wet or a dry one.

Autumn Cultivation.--Many inexperienced persons have the erroneous impression that the only effect of putting drain pipes in land is to leave it drier, but that is a very one-sided and incomplete statement of the case. No plants will thrive in a water-logged soil; although they need abundant supplies of moisture it must be in a moving condition and the soil in which they grow must be aerated. Land which is pulverized deeply has an immense number of particles, each separated from its neighbour by a tiny air-space. When the soil is broken up' in autumn the rains of winter sink in, and the soil becomes saturated to its full holding capacity, the surplus passing off in the drains. The water remaining in the soil is held in suspension as a film coating the surfaces of the soil particles, not as a body of water in which the soil is lying. The amount of water which the soil will hold depends upon the thoroughness of the pulverization. When soil is allowed to lie untilled through the winter water lies about on the top or runs off into the ditches, and although the surface may be wet, the soil below holds considerably less water than if it had been broken up.

Not only does drained soil when properly worked absorb and retain a large quantity of moisture, but both soil and water are thoroughly aerated, by the air-spaces between the particles and by the free oxygen which the film-water brought down during its passage as rain through the atmosphere.

Spring Cultivation.-Having secured an abundant supply of moisture in the soil as a result of autumn cultivation it is necessary to take steps to retain it there for the use of crops and at the same time to bring the surface into a warm and dry condition for the reception of seeds as early as possible in the spring.

The frosts of winter will have made the surface soil friable but the action of later rains will probably have beaten down and compacted this kindly surface so that it is " run together"; if left undisturbed in this condition the water below will rise to the surface by capillary attraction and a continuous evapo- 
ration will take place, which will keep the surface cold and will at the same time considerably diminish the storage of water in the soil. To prevent this loss of water and to make a bed suitable for the reception of seeds the strirace soil should be moved about as soon as it is dry enough to bear cultivation. The stirring of the soil cuts off the capillary ducts and so prevents evaporation, besides introducing air, drying the surface, and making the soil warmer. This early aeration and warming of the soil is a great help to the germination of seed and promotes vigorous growth by encouraging the nitrifying bacteria.

Hoeing and Mulching.--Having prepared a loose surface of fine soil for a seed bed, it is often necessary after sowing, particularly on light land, to press the surface down again firmly by rolling or treading or beating with the back of a spade. This is done to establish a connection between the surface and the capillary ducts below, so as to cause sufficient moisture to rise again for the germination of the seed. As soon as the rows of seedlings can be seen the surface soil should again be stirred by hoeing, and this stirring of the surface soil should be persisted in at frequent intervals during the summer. The loose tilth which hoeing produces upon the surface practically forms a mulch to the soil below, although the protecting medium is soil itself. In fact, anything which breaks the connection between the water-holding soil underneath and the evaporating surface would serve the same purpose, some things better, perhaps, than loose soil does, but the drawback to their employment is that they prevent the continual stirring about of the surface. By this means aeration of the soil and distribution of the nitrifying bacteria is effected; the surface layers of the soil become warm and this makes nitrification active and so brings into a readilyavailable condition the reserves of nitrogen in the humus. Frequent hoeing preserves soil moisture, increases fertility, encourages the growth of plants, and prevents weeds from growing; therefore it increases the crop, saves manure, keeps the ground clean, and makes the total work lighter and easier. 
There are certain crops which need, for best results (and less than the best should not satisfy), considerably more moisture than the soil alone can supply in an ordinary season. In such cases a mulch of straw manure is decidedly the best. When the plants have begun to grow freely the soil should be hoed clear of weeds and should then receive a thorough soaking of water. As soon as the surface has dried stir the soil again, then lay the manure well over the roots on each side of the row to the depth of three or four inches. This mulch not only prevents evaporation but also yields additional plant food and is useful in keeping the surface cool in hot weather. Although the plants will receive great benefit from a mulch of manure alone, even if no more water is given, occasional soakings will yield much better results. 


\section{MANURES AND FERTILIZERS.}

Composition of Plants-Plant Foods in the Soil-Farmyard Man. ure-Green Manure-Compost Heaps. Nitrogenous FerTilizersSulphate of Ammonia-Nitrate of Soda-Nitrolim-Dried BloodSoot-Rape Dust-Castor Seed Meal-Shoddy. Phosphatic FertilIZERS-Superphosphate-Limphos-Basic Slag-Bone Meal-Bone Flour-Dissolved Bones-Phosphatic Peruvian Guano. Potassic Fertilizers - Sulphate of Potash-Muriate of Potash-Kainit. Composite Fertilizers - Peruvian Guano-Dissolved Peruvian Guano-Fish Guano-Meat Guano. Notes on THE USING of FERtilizers-VAluing Fertilizers-Table of Unit-Values.

Composition of Plants.-Every plant has a living, organised body, built up of materials extracted partly from the air and partly from the soil. All are composed of the same ingredients, but in varying proportions. Nineteen parts out of twenty of these ingredients consist of water and carbon. The supply of water needs no explanation. Carbon is derived from the carbonic acid gas of the atmosphere, absorbed through the agency of the leaves. The remaining twentieth part is made up of ingredients taken from the soil. Most of these ingredients are present in almost all soils in more or less abundance, and need give us no further concern, but there are a few, absolutely essential to healthy growth, one or more of which are seldom present in available form in sufficient abundance to produce profitable crops. These exceptions are nitrogen, phosphoric acid, and potash, sometimes lime, and on rare occasions magnesia. It is the knowledge of how to make good any deficiency of these materials, in a way most likely to secure full crops economically, without impairing the continued productiveness of the soil, which constitutes the true science of manuring.

Plant Foods in the Soil.-Although it is necessary for the cultivator to supplement certain plant foods, it must not on that account be supposed that the soil is comparatively desti- 
tute of them. On the contrary, the upper six or eight inches of soil even in the poorest field usually contains sufficient of these materials to provide for a hundred crops, and yet, as we know, the yield is unsatisfactory unless manure is added. The reason for this is that although the soil already contains these food materials they are present in such a form that the plant cannot immediately make use of them; it can absorb them only as they become soluble. When they are in this condition they become dissolved in soil-water and are then drawn into the plant's system by the fine root-hairs. The condition of solubility is brought about very slowly by the action of the atmosphere, by the carbonic acid contained in soil-water, by the acid sap exuded from the root-hairs of plants, and by the work of soil bacteria.

Therefore, the elements of plant food in the soil may be regarded as so much locked-up capital, only a small portion of which is available at any given time, and it should be the object of the cultivator to so handle this capital that some of it, and a larger quantity of it, can be brought into immediate use, and by manuring to supplement such available foods as are insufficient in quantity for a full and paying crop.

When proper means are taken, by maintaining the soil in a sweet, friable, and deeply-pulverized condition, to increase the available plant foods less manure is needed and better crops are grown. Manure can never take the place of cultivation; indeed its full effect will only be obtained where it enters into combination with good cultivation. Additional plant foods should be given freely, as required, but it must be constantly borne in mind that they are only part of a complete whole.

Nitrogen is the most important element in plant nutrition. Its function is to build up the vegetable part of the plant. When the supply is insufficient for the plant's requirements growth is stunted and the leaves are of a pale and sickly colour. If nitrogen in a readily available form is supplied to a plant presenting this appearance its growth, which before was almost at a standstill, will speedily increase ; the plant will show greater vigour and will produce larger leaves of a darker green. This result must not lead cultivators to suppose that the application of nitrogen will always be beneficial. There 
are some cases, as for instance with spring cabbage or lettuce, where an extra vigorous vegetative growth is to be desired, but in many other cases a too-abundant supply of nitrogen would be harmful. Other plant foods such as phosphoric acid and potash, \&c., in whatever excess they may be present in the soil, are only taken up by the plant in proportion to its growth, which is dependent upon the nitrogen supply, but with an excess of available nitrogen the growth is luxuriant and sappy, and susceptible to the attacks of fungoid diseases; maturity is deferred and the crop is badly ripened. Therefore, when the growth of the plant appears to be healthy and sufficiently vigorous applications of nitrogen should not be given unless accompanied by other ingredients to make a well-balanced plant food.

PHosphoric Acid appears to have the function of causing fruitfulness. Its action promotes the formation of flowers and seeds. Whilst an excesss of nitrogen delays maturity the opposite is the effect of phosphoric acid as it hastens the process of ripening; consequently, when plants are growing too gross and sappy an application of a readily-available phosphatic manure will do much to correct this tendency and restore the balance. Phosphates also have a beneficial effect in encouraging root-growth in young plants.

PoTASH plays a very important part in the structure of plants. Whilst nitrogen promotes the growth of leaves, with that element alone they would lack substance, but potash adds strength. It assists in forming the fibre of the plant, making sound, fruit-bearing wood, strong tough straw, \&c. Potash also forms the base of fruit acids and flavours, and is particularly active in the formation of starch and sugar. Whilst phosphoric acid is active in the formation of seed, potash appears to be responsible for the pulp of the fruit, and for the starch and sugar contained in potatoes, beet, \&c. It also makes the plant more resistant to the attacks of fungoid diseases, and has a marked effect in promoting the growth of clover, peas, beans, and all leguminous plants.

Clay soils are usually rich in potash in a state of combination; by cultivation sufficient of this becomes soluble to supply, the needs of most crops, but there are some, such as potatoes, 
tomatoes, onions, and beet, which receive great benefit from an application of potash even when grown on clay; on such soils, however, potash salts should not be used too frequently on the same plot, as they have a tendency to destroy the texture, causing the soil to lie wet and sticky. Potash is usually deficient on soils containing much sand, gravel, peat or chalk, and these would prodice better crops if they received a moderate dressing of potash salts annually.

LIME is, in varying degrees, an essential constituent of all soils, but there are few which would not benefit by a periodical dressing for the purpose of improving their physical condition as well as developing their fertility. Lime releases the dormant plant foods in the soil, rendering them available. Soils which contain an excessive proportion of humus develop acids which are poisonous to plant life; when lime is applied to such soils these acids are rendered harmless and the soil is made sweet. Lime is necessary as a base to satisfy the requirements of certain artificial manures and is a preventive of several fungoid diseases. It is readily dissolved by the carbonic acid gas brought down by rain-water and so is constantly being carried away in drainage water; it also has a tendency to sink in the ground from mechanical reasons, hence the necessity for its frequent renewal.

Magnesia is usually present in most soils in sufficient quantity for all ordinary purposes. It is an important constituent in soils where vines are grown, and where this culture is intended it would be wise to procure an analysis of the soil before planting. Kainit contains about 14 per cent. of sulphate of magnesia, and when this potash salt is used to soil it ensures the presence of sufficient magnesia for all ordinary crops.

Farmyard Manure is the name given to the liquid and solid excrements of the different animals on the farm, mixed with litter of some kind, usually straw. It varies very much in character and composition, according to the age and variety of the animals producing it, the kind of food given, the quantity and kind of litter used, and the treatment it receives after being made; even when the manure produced is of a high fertilizing value it becomes much poorer when allowed to overheat or by long exposure to rains. 
Taking the average of a large number of analyses of farmyard manure, it is found that in each ton there are-

15 lbs. Nitrogen, 7 lbs. Phosphoric Acid, 11 lbs. Potash.

To obtain the same fertilizing materials in a concentrated form there would be required-

65 lbs. Sulphate of Ammonia (at $£ 12$ per ton) $\quad \ldots \quad \ldots 6 \quad 11 \frac{1}{2}$

56 lbs. Superphosphates ( $28 \%$ soluble at $52 / 6$ per ton) $\ldots 1 \quad 1 \quad 3 \frac{1}{2}$

$22 \frac{1}{2}$ lbs. Sulphate of Potash (at $£ 11$ per ton) $\quad \ldots \quad \ldots 2 \quad 2 \frac{1}{2}=10 / 5 \frac{1}{2}$

As farmyard manure can usually be bought at from $5 \mathrm{~s}$. to $6 \mathrm{~s}$. a ton delivered, it will be seen from the above that the plant foods it contains cost only about half as much as when bought in a concentrated form. But on the other hand some of the constituents of farmyard manure are very slow in action, whilst a large proportion of the nitrogen it contains is never recovered in the crop at all-not more than half of the proportion recovered from some of the concentrated nitrogenous fertilizers-so that the difference in cost is not so great as at first sight appears. But in addition to its value as a direct feeder of plants, its beneficial effects upon the soil can scarcely be exaggerated. It gives cohesion and water-retaining power to sands and makes clays more open and friable. It provides humus and encourages the multiplication of beneficial bacteria. Its weakness as a complete fertilizer lies in its deficiency in phosphoric acid, and to a lesser degree in its rather small proportion of potash. The best results are therefore obtained when its ingredients are supplemented by concentrated fertilizers in the proportions required by the needs of each crop.

Soils which regularly receive liberal applications of farmyard manure are very responsive to cultivation and yield early crops, besides being tillable in almost any kind of weather. It must, therefore, be conceded that although many market gardeners use manure rather extravagantly they have some justification. But when land has had heavy and continuous dressings for a number of years it becomes "manure sick" and no longer yields good crops; the humic and other acids with which it has become overcharged are detrimental to soil bacteria, and as a consequence the decay of organic matter is checked. The remedy is to cease manuring for one season, and to dress the soil with lime instead; this neutralizes the acids, sweetens the 
soil, allows the free entry of oxygen, and enables the bacteria to fully resume their functions. To allow the soil to get into this condition suggests bad management; a judicious use of fertilizers to supplement the manure, with frequent light applications of powdered limestone (calcium carbonate) would maintain fertility constantly at its highest pitch.

Green Manuring is an excellent substitute for farmyard manure where that material is difficult or expensive to obtain. It is good for both light and heavy soils. The crops most suitable for this purpose are mustard, rape, tares, peas, or clover; these are grown until just before the flowering stage is reached, then rolled down flat and dug or ploughed in. This method of manuring not only adds humus to the soil, but also the soluble plant foods which the crop collects during growth, and which otherwise may be washed out by rains when the soil is left bare. The leguminous or pod-bearing plants have the property of collecting nitrogen from the atmosphere by means of microorganisms attached to their roots, and when these are used for green manure the soil is additionally enriched.

Compost Heap.-Upon every holding a heap should be made of vegetable refuse, annual weeds, ditch cleanings, road scrapings, and other similar materials. To this should be added the ashes and charred refuse from the fires made of tree prunings, tomato and potato haulms, \&c. This heap should be turned occasionally, and at each turning a generous sprinkling of powdered limestone should be added.

In this way a large quantity of valuable fertilizing material can be accumulated in the course of a year.

\section{NITROGENOUS FERTILIZERS.}

Sulphate of Ammonia is derived from the distillation of coal, during the manufacture of coal gas. It should contain 20 per cent. nitrogen, equal to $24 \frac{1}{2}$ per cent. ammonia. It is a fine salt, generally grey or yellow, sometimes blue, and is easily dissolved in water. It is quite as effective and almost as quick in action as nitrate of soda, but is much more destructive of lime in the soil, and when it is frequently used liming should on no account be omitted. 
From 1 to 2 civts. to the acre, or from $\frac{1}{2}$ to $\frac{3}{4}$ oz. per square yard, may safely be given, preferably in two or three separate applications at intervals of two or three weeks, after growth has begun. Evenness of distribution is important and this is made easier and more certain by mixing with two or three times the bulk of fine dry soil, sand, or ashes.

Nitrate of Soda, imported from Chili, is a crystalline salt, of a whitish colour, formed by the combination of nitric acid and soda. It is sold on a basis of 95 per cent. nitrate and 5 per cent. impurities; it contains $15 \frac{1}{2}$ per cent. nitrogen, equal to 19 per cent. ammonia. It acts very quickly, becoming at once available as plant food. It should only be used when plants are growing, or much of it may be wasted, as it is very easily washed out of the soil by rain. On clay soils it has the effect of releasing inert potash, which is an additional advantage, but it should not be used on the same plot too frequently as it has a tendency to destroy the texture of clay soils, making them "run together."

Crush finely, then mix and use in the same quantities and in in the same manner as sulphate of ammonia.

Nitrolim is a new fertilizer in which nitrogen from the atmosphere has been chemically fixed. It is a dark grey, powdery substance, containing about 18 per cent. nitrogen, equal to 22 per cent. ammonia, and 20 to 30 per cent. of quicklime. In amount of nitrogen it is thus mid-way between sulphate of ammonia and nitrate of soda; it is used in a similar way and is said to be as effective as either. The free lime which it contains should make it very suitable for heavy soils.

Dried Blood, when a good sample, is a very valuable source of nitrogen, of which it usually contains about 11 per cent., equal to 13 per cent. ammonia. It is moderately quick in action, lasting, and does not wash out of the soil. It is a very suitable nitrogenous manure to use with potting soil or under glass. It may be used at the rate of from $\frac{3}{4}$ to $1 \frac{1}{2}$ ozs. to the square yard. 
Rape Dust is made from the residues of rape seed after crushing for the extraction of oil; also from waste fragments of rape cake. It contains about 5 per cent. nitrogen, and small quantities of phosphoric acid and potash. It quickly decomposes and supplies nitrogen to the plant throughout the season. For equal quantities of nitrogen it is almost as quickly effective as nitrate of soda or sulphate of ammonia, over either of which it has the advantage of being organic and so improving the texture of the soil; for the same reason it is good for use under glass. It cannot be washed out by rain. Some growers consider rape dust to be useful for the eradication of wireworm.

Use 5 to 10 cwt. per acre or 2 to 4 ozs. per square yard.

Castor Seed Meal is very similar in composition and action to the above, and is used in a similar way.

Soot is a very useful nitrogenous manure. It is not possible to give the percentage of nitrogen contained in soot, because scarcely any two samples are alike, some containing a large proportion of ashes or other useless material. It is usually sold by the bushel, which is of variable weight, about $28 \mathrm{lb}$. being the average; as a general rule the lighter a bushel weighs the more valuable is the soot, because it is purer. Soot is very useful as a top-dressing in spring, or at any time when the crop needs pushing along gently. It has a distinctly beneficial effect upon heavy soil by lightening the texture; also by darkening the colour of soils it causes them more readily to absorb and retain sun heat and thus raises the temperature. Soot is very distasteful to slugs and is useful to ward off such things as celery, carrot, and onion fly, by dusting over the foliage when it is wet with dew.

Shoddy or Wool Refuse is composed of fragments of wool which are too short or otherwise unsuitable for re-spinning, as well as any form of waste from silk or wool which is no longer profitable to work into cloth. It also frequently contains rags, hair, flock dust, fur waste, cloth clippings, and other similar materials, together with an admixture of dirt. Its composition is very variable and it may contain from 5 to 15 per cent. of nitrogen. It is a slow and lasting manure and is used by 
many hop and fruit growers as a substitute for farmyard manure, 1 ton of good shoddy being regarded as equal to 10 tons of manure. It should be applied early in the winter and ploughed or dug in as soon as possible.

\section{PHOSPHATIC FERTILIZERS.}

Superphosphate is usually made from mineral phosphates, or coprolites, ground finely and treated with sulphuric acid to render it soluble. It is in the form of a grey friable powder containing phosphates in variable quantities, usually varying between 20 and 40 per cent., 36 per cent. being about the standard. The price is governed by the amount of phosphates which are soluble. It is an acid manure and is most suitable for application to calcareous and loamy soils, or any which contain a fair proportion of carbonate of lime. When used on heavy clays, or on sands, gravels, or peats deficient in lime its use should always be preceded by liming. It is most effective when applied in the autumn but is very useful in spring.

Use 4 to 6 cwts. per acre, or $1 \frac{1}{2}$ to $2 \frac{1}{2}$ ozs. per square yard.

Limphos is a new fertilizer containing 40 per cent. phosphates, a part of which is immediately available whilst the remainder becomes gradually soluble during the growing season and so feeds the plant continuously. It also contains 35 per cent. of lime, which makes it additionally valuable for use in conjunction with fertilizers which require lime as a base before they can become effective.

Use 3 to 5 cwts. per acre, or 1 to 2 ozs. per square yard.

Basic Slag is a by-product obtained in iron and steel smelting processes. It comes on the market in the form of a dense black powder, and as its value largely depends upon the fineness to which it is ground it should be guaranteed to have passed through a seive containing 10,000 holes to the square inch. It should contain at least from 17 to 20 per cent. soluble phosphates, besides 40 to 50 per cent. lime, 14 per cent. iron, and 5 to 6 per cent. magnesia. On heavy or peaty soils it is much better than superphosphate, providing sufficient moisture is present; on dry soil it is practically useless. It is slow in action and should always be applied in autumn.

Use 5 to $10 \mathrm{cwts}$. per acre, or 2 to 4 ozs. per square yard. 
Bone Meal and Steamed Bone Flour each contains a small variable amount of nitrogen, but this is not in a very active condition, and so far as immediate results are concerned both should be considered solely for their value as phosphatic manures. They should be bought upon analysis; the former should contain about 45 per cent. and the latter from 55 to 60 per cent. of calcium phosphate, of which rather less than onehalf is soluble. Bones act best on light, free-working soils; on heavy soils they are very slow. Bone manures may be considered as the best phosphatic fertilizers for soils which are too poor in lime to be suitable for superphosphate and too dry for basic slag.

Use 4 to 8 cwts. per acre, or $1 \frac{1}{2}$ to 3 ozs. per square yard.

Dissolved Bones is the trade name for a substance obtained by the treatment of bones with sulphuric acid to make the phosphates soluble. | It is a rather damp and sticky material and should be mixed before use with sifted dry soil or something similar to make it handle better. It usually contains about 20 per cent. soluble phosphates and 2 per cent. nitrogen. It is the best phosphatic manure for use on chalky ground,

Use 4 to 8 cwts. per acre, or $1 \frac{1}{2}$ to 3 ozs. per square yard.

\section{POTASSIC FERTILIZERS.}

Sulphate of Potash is one of several potassic salts obtained from the Stassfurt mines, in northern Germany. All of these salts are white, grey, or pink gritty powders which dissolve readily. Sulphate of potash contains about 50 per cent. pure potash. It mixes well with other fertilizers. It is the best for use on heavy soils and under glass, and should always be used in preference to the muriate where quality of produce is of importance.

Like all the potash salts the sulphate is most effective when applied in autumn, but may be very usefully applied in spring, at the rate of 1 to $2 \mathrm{cwts}$. per acre, or $\frac{1}{2}$ to $1 \mathrm{oz}$. per square yard, using the smaller quantity on clay soils.

Muriate of Potash contains about 45 per cent. pure potash. With the exceptions mentioned above, it is used on all crops in a similar way and in the same quantities as the sulphate. 
Kainit contains about $12 \frac{1}{2}$ per cent. pure potash, 14 per cent. sulphate of magnesia, and 34 per cent. common salt.' It should always be used in autumn so that the rains of winter can wash away some of the injurious salts; it is then a very valuable fertilizer, being especially beneficial to clovers, mangolds, potatoes, asparagus, \&c., and to any crop needing magnesia as well as potash. Kainit is also credited with the property of checking both insect and fungoid pests in the soil. On heavy soil it should not be used too frequently on the same plot as it destroys the texture.

Use at the rate of from 3 to 5 cwts. per acre, or 1 to $3 \mathrm{ozs}$. per square yard.

\section{MISCELLANEOUS FERTILIZERS.}

Peruvian Guano is a fertilizing material consisting almost wholly of the-accumulated excreta of sea-birds, found on the islands and sea-coast of the comparatively rainless districts of Peru. The highest class of the original deposits has become exhausted, and since then much of that obtainable has had a very low percentage of nitrogen. In recent years, however, new deposits have accumulated and supplies with a high percentage of nitrogen are again obtainable. The best guano is a light grey powder and contains about 16 per cent. nitrogen and 9. per cent. phosphoric acid, but the bulk of the best imports contains rather less than half this quantity of nitrogen. As a rule both the nitrogen and phosphoric acid in the lower grades are much less soluble than in the richer ones, which also makes them still less desirable.

In a good guano the fertilizing properties are well balanced, some of them being immediately available whilst the remainder come into use continuously and equably, feeding the crop from seed to maturity. It is a safe manure and may be used with all crops.

To avoid chances of adulteration Peruvian guano should always be bought in the sealed bags in which it is distributed, and it should be accompanied by a guaranteed analysis.

Equalized Peruvian Guano is prepared by adding sulphate of ammonia to guanos rich in phosphates and poor in nitrogen. 
Dissolved Peruvian Guano has been treated with sulphuric acid to fix the ammonia so that it will not escape into the air and to make the insoluble phosphates available. It usually contains about 6 per cent. nitrogen and 10 per cent. phosphoric acid. It is a very useful manure.

Any of the above guanos may be used at the rate of 5 to 10 cwts. to the acre, or 2 to $4 \mathrm{ozs}$. to the square yard, worked into the top soil during preparation for sowing or planting; or $1 \mathrm{oz}$. to the square yard may be used as a top dressing and watered in about once every two weeks.

Phosphatic Guano contains a large proportion of phosphates, varying from 30 to 50 per cent., and a small proportion of nitrogen, varying from 1 to 5 per cent. These guanos are a very useful substitute for superphosphates, especially under glass, where they are to be preferred because they are organic and free from acid.

Use about 4 cwts. per acre, or $1 \frac{1}{2}$ ozs. to the square yard.

Fish Guano is made from fish residues. It contains between 6 and 9 per cent. nitrogen and from 13 to 20 per cent. phosphoric acid. When it is to be used alone it should be spread and turned in as soon as received, but if one of the potash salts is mixed with it a much better balanced manure is obtained that will keep better. It is fairly quick in action though rather slower than Peruvian guano, and it feeds the plants throughout the season.

Apply a few weeks before sowing or planting at the rate of 5 to $10 \mathrm{cwts}$. per acre, or 2 to $4 \mathrm{ozs}$. per square yard.

Meat Guano is prepared from slaughter-house refuse. It is very variable in composition, some samples containing as high as 12 per cent. nitrogen and 30 per cent. phosphates. A good standard sample known as Fray Bentos Guano contains 7 per cent. nitrogen and 30 per cent. phosphates. Like fish guano this should be turned under at once, and not allowed to lie about on the top of the soil or loss will result; birds eat both greedily.

Use in a similar way to fish guano, varying the quantity according to analysis. 
Mixtures of Manures.-In mixing manures together great care must be exercised. If the wrong kinds are put together certain chemical reactions will take place and much loss will result.

The following mixtures may be made with safety:-

Superphosphates with Sulphate of Ammonia.

Bones with Nitrate of Soda or Sulphate of Ammonia.

Bones with Basic Slag.

Basic Slag with Nitrate of Soda.

Fish Guano with any Mineral Fertilizer.

Phosphatic Guanos with Nitrate of Soda or Sulphate of Ammonia.

Kainit with Basic Slag.

The following mixtures should not be made:-

Farmyard Manure with Lime.

Guano with Lime.

Guano with Basic Slag.

Nitrate of Soda with Superphosphates.

Sulphate of Ammonia with Basic Slag.

Kainit with Nitrate of Soda.

\section{NOTES ON THE USING OF FERTILIZERS.}

Whenever artificial fertilizers are used an ample supply of moisture and a well-pulverized soil are of the utmost importance. Moisture by its dissolving action renders the manure soluble and brings it into a condition to be easily assimilated by the roots of plants.

No fertilizer can be effective unless it reaches the roots of the plants, therefore pains must be taken to distribute it evenly over the whole ground. To do this properly with small quantities of a highly-concentrated material is very difficult unless fine dry soil, sand, ashes, or something similar is added to increase the bulk.

Fertilizers which are readily soluble can be scattered over the surface and the first rains will distribute them uniformly through the soil. Fertilizers slowly soluble should be turned under at once, so that the soil constituents can immediately begin to act upon them.

A quick-growing plant needs a fertilizer which is more readily-available than does one which occupies the ground for a long period. 
Quickly-available nitrogenous fertilizers should preferably be applied in several small dressings at short intervals, but care must be taken not to apply them too late in the season, or there will be excessive growth of leaf and stem and the maturing of the crop will be retarded.

When the ripening of a crop is delayed beyond the normal period a dressing of a quickly-available phosphatic fertilizer will help to put matters right.

On soils of loose texture and small retentive power it is best to use those fertilizers which are not too readily soluble, in order that the losses caused by heavy rains shall be as small as possible.

Liquid manures should only be used during the growing period, and then at frequent intervals in a very diluted form, alternating with occasional soakings of clear water.

\section{VALUING FERTILIZERS.}

As a general rule it will be found to be more economical to purchase fertilizing materials of high grade. Bulk is desirable to ensure evenness of distribution, but as the fertilizing elements occupy very little space it is more economical to buy them concentrated and so save carriage and cartage expenses, afterwards giving bulk by the addition of dry earth, sand, coal ashes, or any similar substance.

When fertilizers are purchased they must always be accompanied by a guaranteed analysis, according to the Fertilizers and Feeding Stuffs Act. This analysis must be given in terms and percentages of nitrogen, soluble phosphates, and pure potash.

Many of the forms of analysis given are misleading, and by a bold array of figures cause the inexperienced to imagine that a poor material is a comparatively rich one. For instance, not only is the amount of nitrogen stated but also its equivalent in ammonia, which is merely expressing the same value in another way with larger figures; then the soluble and insoluble phosphates are given and this is frequently followed by total phosphates, which again is a repetition; pure potash will be re-stated as sulphate of potash, and the whole has a bewildering effect upon the unwary. 
In calculating the value of a manure from analysis all equivalents should be ignored, and a judgment formed solely upon the nitrogen, soluble phosphates, and pure potash. If these are satisfactory the insoluble phosphates may then be taken into consideration, as some portions become slowly soluble when buried in the soil, and they therefore have a certain value, but not enough to influence a decision as to the value of the active ingredients.

It is very desirable that the purchaser should be able to judge accurately of the comparative money-value of different samples of ready mixed fertilizers, as well as to be able to calculate what an equal fertilizing-value in materials would cost if bought separately and mixed at home. This is done by ascertaining the cost of a unit of each of the different fertilizing constituents and adding these costs together. The unit is the one-hundredth part of a ton, and the cost of a unit is known as the "unit-value." The cost of a unit is arrived at by dividing the market price of a ton of material by the percentage it contains of the particular fertilizing constituent required.

For instance, supposing it is desired to find the fair price of a mixed mineral fertilizer containing-

$\begin{array}{lrrrr}\text { Nitrogen } & \ldots & \ldots & 5 & \text { per cent. } \\ \text { Soluble Phosphates } & . . & 17 & , \\ \text { Insoluble } \quad, & \ldots & 3 & , \\ \text { Potash } & \ldots & \ldots & 6 & \end{array}$

What has to be decided is, What is a fertilizer containing the above ingredients worth? The percentages shown here have nothing to do with the unit-value; the item "nitrogen, 5 per cent." means that the mixed fertilizer in question contains that amount of nitrogen, and the object is to ascertain what that amount of nitrogen would cost if bought in the form, say, of sulphate of ammonia or nitrate of soda.

The nitrogen in this fertilizer will be derived from sulphate of ammonia, which contains ammonia equal to 20 per cent. nitrogen, and costs at present market prices about $£ 12$ per ton; the unit-value is ascertained by dividing $£ 12$, the price of a ton of sulphate of ammonia, by 20, the percentage of the nitrogen it contains; the result is $12 \mathrm{~s}$., which represents the unit-value of nitrogen derived from sulphate of ammonia. 
The phosphate ingredient will probably be derived from superphosphates, costing $£ 22$ s. per ton, and containing 30 per cent. total phosphates, of which 26 per cent. is soluble and 4 per cent. insoluble. The unit-value is ascertained by dividing the price, $£ 22 \mathrm{~s}$., by 26 , the percentage of soluble phosphates; the result is $1 \mathrm{~s}$. $7 \mathrm{~d}$., which is the unit-value. The insoluble phosphates in superphosphates are regarded as valueless.

The potash ingredient will probably be derived from sulphate of potash, which contains 50 per cent. pure potash and costs $£ 910$ s. per ton. By dividing $£ 910$ s. by 50 we arrive at $3 \mathrm{~s} .9$ d. as the unit-value of potash derived from sulphate of potash.

We can now form a clear judgment of the fair price of the mixed fertilizer, thus :-

Nitrogen, 5 per cent., at $12 \mathrm{~s}$. for each unit-

5 times $12 \mathrm{~s} .=\begin{array}{llllllllll} & \ldots & \ldots & \ldots & \ldots & \ldots & \ldots & £ 3 & 0 & 0\end{array}$

Soluble Phosphates, 17 per cent., at $1 \mathrm{~s} .7 \mathrm{~d}$.

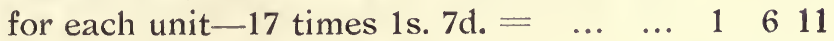

Insoluble Phosphates (valueless) ... $\ldots$... $\ldots$

Pure Potash, 6 per cent., at 3s. 9d. for each

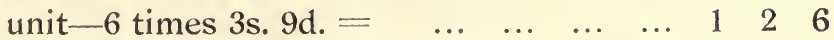

Add 25 per cent. to cover mixing, bags, waste, carriage and profit

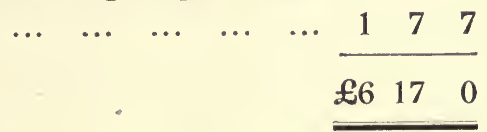

It will thus be seen that, at present mariket prices, a manure of the fertilizing value of that under examination, when compounded of mineral ingredients, ought not to cost more than $£ 617 \mathrm{~s}$. per ton, carriage paid to the purchaser's nearest railway station. When the fertilizer is compounded of organic ingredients the unit-values will average about 25 per cent. higher.

In judging the money-values of manures it must be constantly borne in mind that the unit-values will vary as the market prices of the materials fluctuate. They do not include the cost of carriage, and they are based on the price of mate. rials when bought in quantity. 
The Profitable Culture of Vegetables.

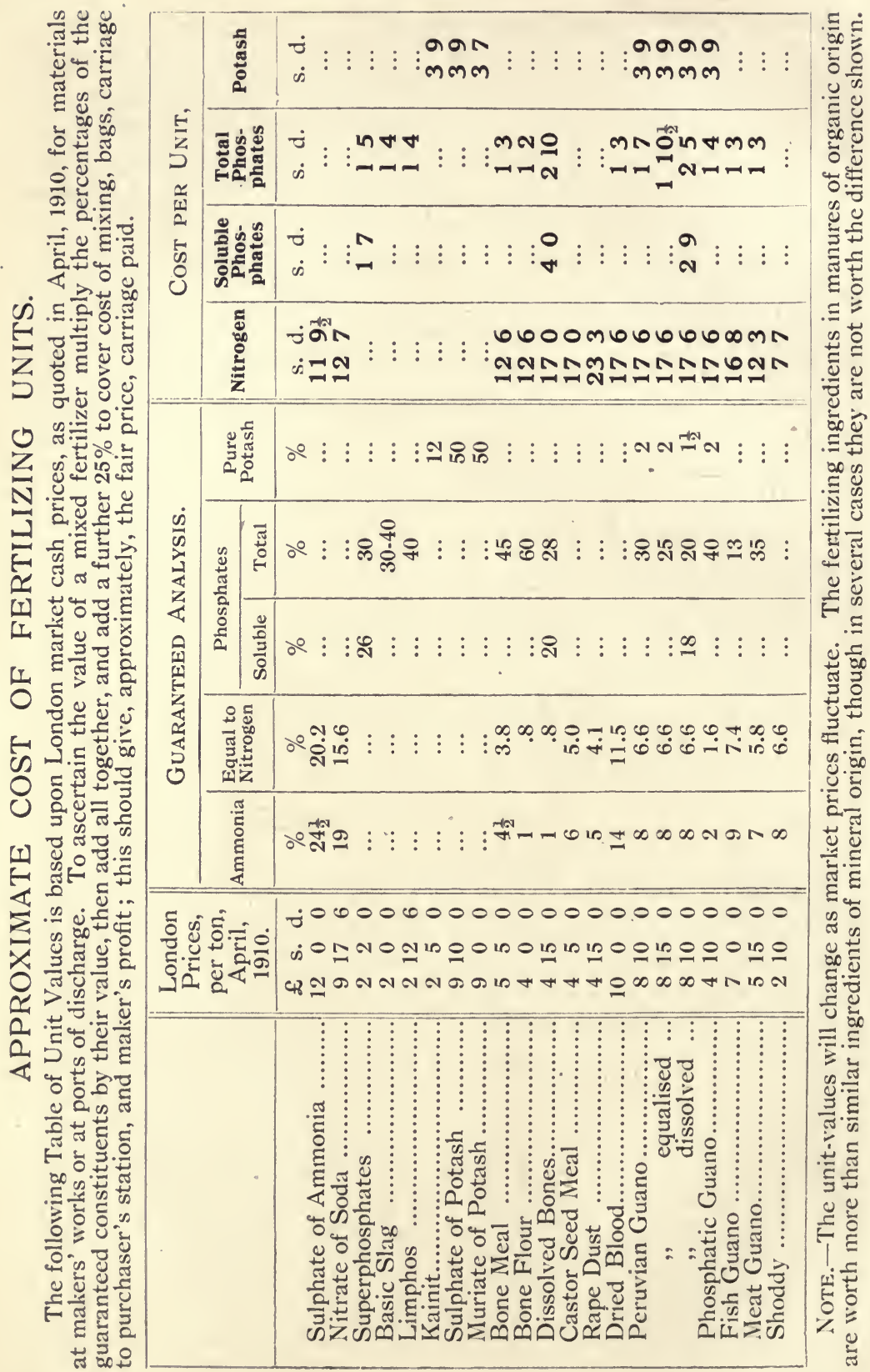


Chapter IV.

\section{THE SMALL HOLDER AS A MARKET GARDENER.}

Conditions necessary to Success-Capital Required-PhysiqueIndustry and Concentration-Up-to-date Methods-Intensive Culture -Spade Work.

THE ultimate success of the man who undertakes market gardening as a means of obtaining a livelihood largely depends upon his fitness for the work. It is an occupation which calls for judgment, foresight, resourcefulness, untiring industry, and unfailing optimism. If he is endowed with these qualities his prospects of success will then depend upon his aims, a thorough understanding of the manner in which he intends to realise them, and the means at his command.

Before embarking upon the serious business of cultivating the soil for a living, a man ought to have in hand not only enough capital to provide for rent, tools and appliances, manure, seeds, and live-stock, but also sufficient for his family's maintenance for at least one year. Although the average returns from well-cultivated land may be calculated with a near approach to accuracy when taken over a sufficient number of years, the returns in any given year are very. uncertain because of irregular climatic conditions. If the holding is a newly-formed one the first year's occupation of it is sure to be beset with innumerable unforeseen items of expense; if fruit trees are planted upon a portion of the holding these will be several years before yielding any appreciable return for the capital and labour expended upon them, and the cultivated land will probably require a season or two to bring it into good condition. In addition, there is always the possibility that the first season may be an exceptionally cold or wet one, with the returns from crops much lower than was calculated upon, and if this should be the case disaster 
will not be far away unless there is some reserve fund to fall back upon. Even if success is attained in the end lack of sufficient capital must entail much unnecessary privation and toil in the early years.

Few men have any conception of the labour required to make a small-holding successful. Given a strong constitution the work is healthful and adds to length of years, besides being pleasant enough when one's mind and body have become accustomed to it; but it is never other than laborious. No one should undertake to cultivate the soil for a living for the first time after middle age, and at no time is the work suitable for men of poor physique. The long hours of labour and the exposure necessary to success-for many of the operations, such as summer planting, are best done during rain--must tell heavily against a feeble constitution.

Still, when all has been said there still remains the undeniable truth that the most potent factor in the whole situation is the man himself. Many a one has started in a very modest way and by concentrating his energies upon only so much of his holding as the means at his command would enable him to do well, and adding to his income by working for others in his spare time, has extended his operations as his experience and profits have grown, until at last he has attained an assured position. It must therefore suffice to utter a grave warning to those who contemplate such an undertaking that it should not be entered upon without the fullest and most careful consideration.

Under any circumstances the best must be constantly striven for if lasting success is to be achieved. Spasmodic effort will not do; industry and attention to the work in hand must be unremitting, and every operation carefully studied. The man who means to prosper must learn and put in practice the principles underlying the production of profitable crops-soil management, manuring, the rotation of crops, the manipulation of tools and appliances, the methods of combatting plant pests, besides the general routine of work in the garden; last, but by no means least, he must learn the best methods of marketing his crops after he has produced them.

Intensive culture should also receive serious attention. It 
yields remarkable results as compared with ordinary culture, and its special value to the small-holder lies in the fact that its principles can be more readily and less expensively applied on a small than on a large scale. It is a system in which personal care is an extremely important factor of success, and it is just this personal attention which the small-holder is in a position to give.

Modern investigations confirm tne experience of past generations that the proper use of the spade by manual labour is the best means of increasing the productive power of the soil, and no mechanical appliance yet devised is equal to it for efficient work. Cultivated soil teems with minute organisms which are constantly engaged in maintaining its fertility, and spade cultivation surpasses every other method in producing the conditions in which these indispensable bacteria multiply most rapidly. As the cultivation of the soil by hand labour is a necessary part of intensive work, that becomes an additional reason why this system of culture should appeal strongly to the small-holder. 


\section{Chapter V.}

\section{SELECTION OF A SMALL HOLDING.}

Situation-Aspect-Protection-Fences-Soil-Drainage-ManureArea-Tenure.

THE first condition of success in a small holding is that it 1 should be in a suitable situation. Mistakes in this matter may cause failure even when all other conditions are favourable. The best position is undoubtedly one within a few miles of the market which is to be supplied, and this is especially necessary when the main produce consists of bulky green vegetables or quickly perishable articles, or when it is intended to develop a connection with shops, hotels, and restaurants.

Land near a large town will probably be highly rented, but a few extra pounds a year for rent is a small matter in comparison with the constant saving in cartage and charges for railway carriage, besides the great convenience of being able to take produce to its destination by road at any time most suitable to the grower or his customer. It also frequently happens that owing to scarcity or unusual demand prices in the markets are much higher on some days than on others and when the holding is situated within a few miles these increased rates can be at once taken advantage of. Besides this, manure can frequently be drawn back on the return journey and so obtained at a tithe of what it would cost if brought by rail.

If a holding cannot be secured near a populous centre the next best situation is one near a railway station which gives facilities for the conveyance of produce at reasonable rates to a number of provincial markets. Such a position, although not so good as one near a large town, has usually the recompense of a much better atmosphere and cheaper land. A situation of this kind would be suitable for the lighter and more valuable crops and those not quickly perishable, or for a direct supply business in small parcels by rail or post. 
The aspect of the land is of great importance, as it may make the difference of a week or more in the maturing of a crop even in the same locality, and it is surprising what a few days difference will effect in the prices realised for early produce. A square or oblong and fairly level piece of ground is the best for general purposes, as it is the most convenient form for ease and economy of working and the soil is not liable to be washed away by heavy rains, but for intensive work a gentle slope towards the south will greatly assist in securing early produce both from frames and from the open. Providing there is protection from cold winds a slight turn towards the south-east has some advantages over a full south aspect; the morning sun will then get sooner into frames in the early part of the year, and during the heat of summer the full glare of the sun is off the frames earlier in the afternoon, thus giving the plants more time to recover from intense heat. Failing either, a turn to the south-west is not to be despised. The worst aspects are those where the whole or greater part of the land has a decided inclination towards the north, north-east, or north-west, but where the ground is undulating such slopes can be turned to good account. In such a case the warmest spots would be selected for the earliest crops, the main crops would be put in a good open position, and the crops which stand in the open through the winter would go on the northerly slopes; in this position they would be more likely to pass safely through a severe winter, because if they get frozen they can then thaw out gradually before coming under the full power of the sun, the sudden thaw which comes when the sun's rays strike the plant doing more damage than the actual freezing.

Protection from cold winds is very necessary if forcing and the production of early vegetables is to form part of the business; this may be obtained by rising ground or a belt of trees on the north and east, or by a wall or close boarded fence all round; but protection does not imply a position hemmed in and overshadowed by tall trees or buildings, where sunlight is obstructed and the atmosphere is stagnant. For the production of good vegetables full sunlight and a buoyant moving air are essential, besides which insect and fungoid 
pests, particularly the latter, flourish most in dull confined places.

Good sound fences round the holding are not merely desirable but are absolutely necessary, and if not already in existence will mean a serious item of expense to the tenant, unless an an arrangement can be made for the owner to bear the cost.

The best soil for general purposes combined with intensive culture is a moderately light loam of good depth. It is not easy to secure a holding with such a soil and all other essential conditions; therefore one must be content with the nearest approach to it. Most soils, however unpromising, can be brought into fertile condition by draining, frequent deep working, liming, and the addition of heavy dressings of animal manure. but any substantial improvement can only be brought about slowly and is frequently a very costly business. The man with small means should avoid thin shallow soils, very open and dry sandy or gravelly soils, and heavy undrained clays, also run-down derelict land which is frequently little else than a nursery ground for twitch, thistles, briars, rabbits, and other abominations from the gardener's point of view; such land would sometimes cost more than the freehold is worth to bring it into good condition,

Whatever may be the description of soil it should have good drainage, either natural or artificial. If it is in need of drainage and that expensive operation has to be undertaken by the tenant there should be some allowance made or some important advantage should be present as a compensation. When draining has to be done care must be taken to see that there is fall enough to enable the water to get away easily; drain-pipes in the land are of no use without a proper outfall. Low damp situations and water-logged soils which cannot easily be drained should always be avoided, no matter how cheap or well-situated the land may be.

An unlimited supply of good water is essential, especially where intensive work is to be carried on, as copious waterings must often be given to these crops. Apart from the domestic supply this may be obtained from river, stream, or pond, or from public water mains; water from wells should only be used in the last resort, as it frequently contains salts which 
are injurious to plant life. Rainwater is the best, particularly for seedlings and plants in frames, and provision should be made, where none already exists, for catching and storing the rain which falls on the roofs of the various buildings.

High cultivation and early crops must usually be accompanied by a plentiful use of manure, therefore the possibility of obtaining a cheap and abundant supply must be carefully enquired into. The quantity required will depend upon the kind of culture undertaken. To carry out the scheme suggested later, of fruit and vegetable growing combined with a little intensive culture on seven acres, about one hundred tons will be required annually, but if a larger space is occupied by intensive work the amount of manure required will be increased proportionately.

Too much land should not be taken. Capital sufficient to properly work five or six acres would be totally inadequate for ten or fifteen acres in the same branch of culture, and whilst success might be attained on the small area the attempt to work the larger plot with insufficient capital would probably end in failure.

Finally, care should be taken that the tenure of the land is secure and properly safeguarded. 


\section{Chapter VI.}

\section{DISPOSAL OF PRODUCE.}

Divisions into which the Business may be Separated-Growing for Market - Advantages of Specialization-Glutted Markets-More Markets Needed-Growing for Private Trade-Regular Supplies and Numerous Varieties Essential-Increased Cost of Production but Better Returns and Steady Market-Limited Choice in Selection of Situation-Co-operation-Direct Supply.

LAVING secured a suitable and well-situated holding, the 1 next step is to decide upon the particular branch of market gardening to be undertaken, and this matter requires much thought and careful calculation before a decision is come to.

There are two distinct divisions into which the business of market gardening may be separated - that of growing produce for sale in public markets and that of growing it for sale in particular or special markets.

In growing for public markets the crops from any particular place are limited in number, and are individually much larger in extent than when grown for private trade, the aim being to produce at stated times large supplies of those things for which the land is best adapted or for which the situation is most convenient. In many districts predominating crops are a very noticeable feature, and this is also the case with many individual market gardens worked on a large scalecertain main lines are made a specialty, and this method is found to be the most profitable. Crops in which bulk is small in relation to value, or those which need not be put on the market immediately they have matured, are frequently grown in favourable situations remote from the markets, providing there is convenient access by railway, but most ordinary green vegetables are grown within a comparatively few miles of the greatest centres of population, where labour is plentiful, manure can be got on the ground cheaply, and the produce is 
conveyed to market by road. Under such circumstances the prices obtained for bulky green crops are, on the whole, profitable, but the same prices might be absolutely ruinous to a grower whose land is situated, say, fifty miles away.

With specialisation the varieties of crops are fewer in number and are therefore easier to cultivate and to handle, nor is the skill required so great or so varied as when more numerous varieties in smaller quantities have to be raised in regular succession; besides which neither time nor ability are called for in effecting sales, as this is done by the regular commission salesmen in the markets.

The grower who adopts this method of business can confine his attention almost entirely to the work upon his holding, with very obvious advantages. The great drawback is that the choice of markets is comparatively limited, the number of markets available to most growers being much too few to deal effectively and satisfactorily with main crop supplies, with the result that they become congested long before the demand of the consumer is satisfied. In most cases the produce must be sent when ready, no matter what the state of supply and demand may be, and it is sold for whatever it will bring. If it should arrive on a glutted market, the prices realised may be entirely unremunerative or, as sometimes happens, there may be no price at all.

An alternative method is that of direct sale to shops, hotels, restaurants, or private customers. When this line of business is adopted it is necessary to produce a wide range of varieties, combined with uniform and regular supplies. The grower cannot restrict his crops to those for which his soil and situation are best adapted; to create and maintain a thriving business he should be prepared to supply most of the vegetables and fruits required by any ordinary household, and to grow these well on soil which in the case of many of the crops is not the most suitable, calls for considerable skill and resourcefulness. Additional time and ability are also needed to find and secure regular customers. It is obvious that a considerable amount of time must be occupied in disposing of the produce in this manner and, of course, this seriously curtails the amount of work which the grower 
can do upon the land and unless he is blessed with children who are old enough to render him efficient assistance, or has some other source of help within his family circle, he will have to engage paid labour. This all tends either to decrease the output or to increase the cost of production. As a recompense this outlet for the produce is free of the ruinously low returns which too frequently come from a glutted market, and the grower is usually able to obtain prices which are fairly steady and remunerative.

The particular branch which will be adopted by the smallholder may be decided by circumstances over which he has little or no control. In many cases he is obliged either. to take whatever land is offered him by the authorities of his district, or other bodies or persons who have the disposal of land for this purpose, or go without a holding. Although such land may not exactly conform to his ideal either as regards quality or situation, it may yet be good in many respects and capable of being worked to profit along some lines, although not those desired. If a holding is taken under such circumstances and it is situated in a locality where market gardening is already carried on it would be wise to be guided by the practice of the neighbourhood, at any rate until experience is gained and personal initiative is safe.

It is obviously impossible to indicate any particular branch of the market gardening business which would be the most suitable in all circumstances, but it is certain that isolated individuals on holdings at a distance from markets will find it almost impossible to compete successfully with growers who work large areas with every advantage in the way of laboursaving appliances. That being so, it would appear that in the majority of cases, at least until the number of small local markets is greatly increased (and such a development is extremely desirable) the most promising methods by which to dispose of produce are either co-operation or direct supply. Co-operative distribution appears, theoretically, to make it possible for small-holders to secure some of the advantages arising from an aggregation of capital, but such schemes are still, more or less, in the experimental stage and are not sufficiently numerous at present to be of any assistance to the 
majority of small growers. The remaining alternative is that of direct supply, either by post or rail or by personal dealing with customers. In this direction there is a practically unlimited demand for produce of good quality, and this method of disposal, if followed with energy and persistence, should lead to success.

A scheme for laying-out a holding in a manner suitable for this class of business as well as for market work, together with full details of rotations and cropping, will be found in Chapter VIII, whilst full details of intensive work will be found in Chapter IX. 
Chapter VII.

\section{ROTATIONS OF}

\section{CULTIVATION, MANURING, AND CROPPING.}

Reasons for Rotations - Difficulties to the Gardener of a perfect Rotation-Why under certain. conditions a strict Rotation is not essential-Rotation of Cultivation, Manuring and Liming-Testing for Lime-Rotation of Crops.

NE of the first principles of agriculture is that one crop shall not be allowed to follow another of the same kind on the same soil. The basis of this principle is that although all cultivated plants extract the same foods from the soil there is a considerable variation in the quantities they use of any given kind-one variety using nitrogen in abundance, another phosphates, and a third potash, so that to avoid an undue depletion of any one food element, and to maintain a fairly correct balance, it is necessary to change the crops about, or, in other words, to have a rotation.

Another important reason for a rotation is that a change of crop assists to keep in check the insect and fungoid pests with which most cultivated plants are afflicted.

Not only does a rotation assist to preserve a proper balance between the plant foods in the soil, and to keep in check the numerous pests, but as different crops need widely varying methods of cultivation, manuring, and tillage, by moving them about so as to gradually apply the different operations to the whole area the soil is kept in a sweet and wholesome condition, it is more easily kept free of weeds, and the cultivator is enabled to maintain its texture and fertility on a much smaller outlay for manure and labour.

But a perfect rotation is practically impossible to the gardener who is obliged to produce a large variety of crops in constant succession from a small area. Not only has he to intercrop in order to make the most of the space at his command-and intercropping practically means that distinct 
classes of plants are standing together on the same bed-but the most carefully-planned scheme is liable to disarrangement by unsuitable weather, the attacks of birds or of insects, and other unforeseen circumstances which may make it necessary at short notice to discard one crop and substitute another of an entirely different kind.

There are also difficulties in the way of arranging a perfect rotation arising from the fact that the gardener must grow the various classes of crops in very unequal proportions to suit the demand. Fortunately, whilst he cannot altogether ignore rotations he is not bound to them to nearly the same extent as is the farmer. By deep and thorough cultivation and by systematically fertilizing the soil he can make it capable of continuously carrying crops in a way which cannot be done under shallow culture. A deeply worked and well fertilized soil will yield good crops in any season, even if a strict rotation is not followed, whereas a shallow soil in a dry season may be frequently more or less of a failure in spite of a rotation. The fact, however, still remains that the productiveness of the soil and the health and vigour of the crops are better maintained when a rotation of cultivating, manuring, and cropping is carried out

This fact should be constantly borne in mind when planning successional crops. By a carefully-arranged system it it quite possible to secure the advantages of a rotation whilst escaping any bad consequences which may arise from its omission. This desirable result may be secured by dividing the vegetable garden into three equal parts, each part to be bastard trenched and liberally dressed with farmyard manure once every three years. In the intervening years ordinary digging or ploughing with a dressing of lime would follow the trenching, and similar cultivation with fertilizers would follow the lime.

By this arrangement the soil is kept in high condition on the least expenditure of labour and manure. Every part of the ground is deeply worked periodically, whilst the farmyard manure which is given at the same time keeps up the necessary supply of humus. Lime follows the manure because it makes available the inert plant foods in the manure which were left behind by the previous crop, besides keeping the soil 
sweet and friable. Fertilizers follow lime because several of them need lime as a base before they can become available as food for the plants.

It is assumed that most soils will be benefited by frequent light dressings of lime in some form-either quicklime, ground limestone, or chalk. Peaty and clay soils would certainly be greaty improved by making liming a part of the rotation. There are, however, some which already contain sufficient lime. This is easily ascertained; shake up about an ounce of soil in a small quantity of water, then add a little hydrochloric acid (this can be obtained from any chemist). If there is a brisk effervescence sufficient lime is present, but if there is little or no effervescence then it may be taken for granted that dressings of lime will be beneficial.

Of course it is not intended that such a scheme of manuring should be rigidly adhered to. It would be impossible and inadvisable to confine either manure, lime, or fertilizers strictly to the sections assigned to them. A mulch of manure, an additional dressing of fertilizer, or a sprinkling of lime or soot may be given to any of the crops as the necessity arises. When this allowance is made the scheme will stand as a workable and economical basis for a rotation. But farmyard manure must be applied with no niggardly hand to the section which is double-dug. No system has been or can be devised which will enable good crops to be continuously grown unless the land is kept in "good heart." For heavy or peaty soils at least thirty tons to the acre should be given, and for light soils no less than fifty tons. It must be remembered that

Lime and lime without manure

Will make both farm and farmer poor.

The crops should be so arranged that they systematically follow the rotation of cultivation, placing them, as far as is practicable, on the sections which have been treated most in accordance with their requirements. Their positions would, however, be regulated largely by the necessity for a regular succession and constant supplies. A detailed plan for cropping on these lines is given in the following chapter. 


\section{THE LAYING-OUT, CULTIVATING, AND CROPPING OF A HOLDING OF FOUR ACRES.}

Ideal Arrangement for a Market Garden Holding-Plan-Rotations of Cultivation and Manuring - Intensive Culture-Detailed Explanation of Plans-Plans of Intensive Cropping, with Rotations for Three Consecutive Years.

THE market garden which is intended to produce a constant

succession of vegetables needs very careful planning, not only to ensure a suitable rotation, with economy of labour and manure, but also to utilize the best aspects and most protected positions for the earliest crops. As every situation has its own special features which must be dealt with on the spot, it is impossible to do more here than give an indication of the points it is necessary to observe. This is the purpose the following suggestions are intended to serve.

The Plan on the following page shows an oblong plot of four acres, broad sides facing north and south. The shape of the plot is important, a square or oblong being much more convenient and taking less labour to cultivate and plant than one of irregular shape, with numerous odd corners. The size is quite immaterial, and the same arrangement would do equally well for twenty or fifty acres, though four acres appears to be a convenient size for a small holding worked intensively and growing both vegetables and fruit. If worked as it ought to be to bring the greatest return for capital and labour expended, it is certainly large enough to fully employ and ensure a comfortable living to a shrewd hard-working man with a helpful family, assisted by a horse and occasional labour from outside.

On the west, north, and-east sides fruit trees and bushes occupy one-and-a-half acres. These will, after a few years, afford an appreciable amount of shelter to the remaining portion of the ground. The whole plot has a full exposure to the south; it is very important that nothing should be permitted to obstruct full sunlight to the main crops. 
The Profitable Culture of Vegetables.

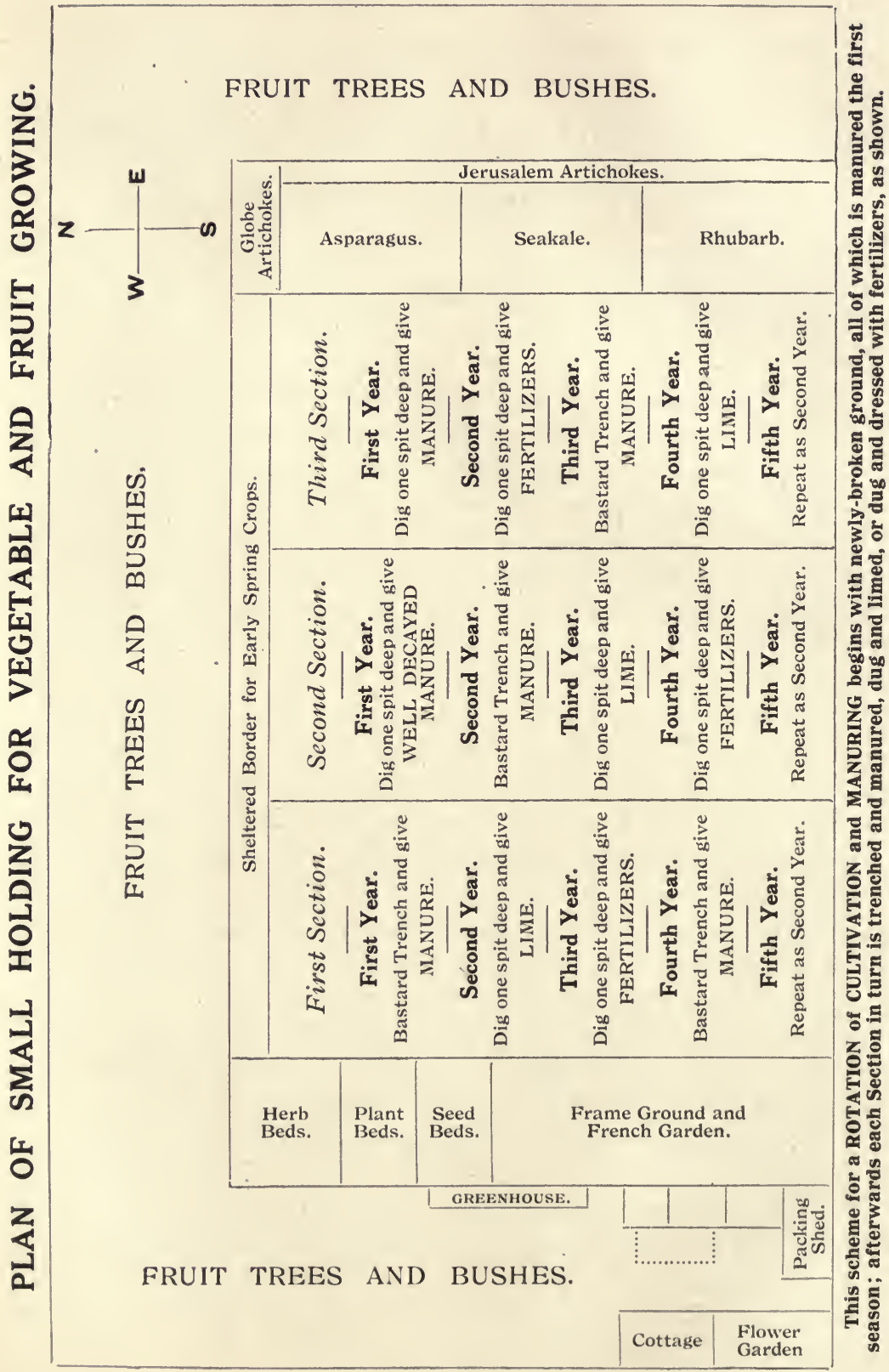


Across the north side of the enclosed portion, within the shelter of the trees, is a border for early spring crops. This position admits full sunshine and secures whatever shelter from the cold north winds the trees and bushes can give, but to make the protection effective a row of straw-covered hurdles should be placed along the north side of the bed until the weather becomes mild.

On the east side about a quarter of an acre is filled with such crops as asparagus, seakale, rhubarb, and artichokes.

On the south-west corner a cottage with flower garden, outbuildings, packing shed, \&c., are shown abutting on the high road; these take up about a quarter acre. The frame ground or French garden takes another quarter, whilst a quarter is allotted to seed beds, plant beds, herb beds, the early border and paths. The advantage of this arrangement is that the gardener's cottage is in the midst of all the things which are likely to require his personal attention at a moment's notice, whilst the west side of the holding has the advantage of catching the first rays of the morning sun.

A plot of one-and-a-half acres is thus left in an open and sunny position, but protected on three sides from cold winds; this is intended for vegetable crops. The plot is divided into three sections of half an acre each. One of these sections will each year in turn be bastard trenched and heavily dressed with farmyard manure-at the rate of from thirty to fifty tons per acre, according to the nature of the land. The remaining two sections will be dug or ploughed in the ordinary manner, the one which was double dug and manured the previous year receiving a dressing of ground lime, and that which received lime the previous year now getting fertilizers, in kind and quantity as required by the individual crops. This rotation of cultivation will, of course, not be complete until the third year, and as a preliminary, before the rotation is begun, the whole of the ground must be well manured, giving only thoroughly decayed stuff to the sections reserved for roots.

A system of cropping suitable to the suggested cultivation is shown in the Plans appearing at the end of this chapter, each of which gives the cropping of the same plot in the first, second, and third years respectively. On each plot there 
are three sections of half-an-acre each, with ten divisions in each section, each division representing the twentieth part of an acre or, say, a piece of land $300 \mathrm{ft}$. long by $7 \mathrm{ft}$. 3in. wide. All the crops are planted in long rows, running north and south, an arrangement which allows the sunlight to play equally on both sides of the row, and makes the work of cultivation, either by horse or hand labour, much easier than when the crops are put in beds.

The system of cropping and intercropping shown here, although not so highly intensive as French gardening, is planned so that the crops appear in regular and constant succession; they follow each at such frequent intervals and overlap in such a way that the soil is made to yield all that it appears capable of bearing economically. To carry it out satisfactorily the ground must be prepared, the seeds sown, and the plants set each at their appointed time; then, under normal conditions, there will be no confusion, and neither space nor effort will be wasted.

The scheme is particularly suitable for a garden which produces to supply private customers or shopkeepers direct, but with such modifications as may be necessary in the number and variety of the crops, it is equally applicable to a business where the whole of the produce is sent to market. By observing the respective proportions the scheme can be used on any scale, either large or small, and could be very successfully worked in a kitchen garden or allotment.

In actual working it may be found that the area allotted to each vegetable is too much in some cases and too little in others. The demand, which will vary according to the circumstances of the locality, will soon make this point clear. In making any alteration the succeeding crops need careful consideration.

\section{DETAILS OF ROTATION AND CROPPING.}

The scheme is based upon a system of cultivation whereby one-third of the land is bastard trenched (or subsoil ploughed) and manured each year, so that deep working and manuring are repeated on every part of the land once every three years. In the intervening period the sections are worked in the usual 
manner, whilst lime and fertilizers are given to the various crops as they may be required.

The land is supposed to be newly-broken, and in order to make a satisfactory beginning the whole is thoroughly manured before any cropping is begun-not less than thirty tons an acre where the land is heavy and of fair quality, nor less than fifty tons an acre to poor or light land. The explanation of the cropping rotation is as follows:-

Divisions 1 and 2.- These are planted with early potatoes; after the potatoes are lifted strawberry runners are planted in August; between the rows of strawberries winter spinach is sown in September and turned in early in April. In the second year the strawberries fruit, and winter spinach is again sown between in September. The third year the strawberries bear for the second time, and are then destroyed, thus completing the rotation. On studying the Plan it will be seen that when the rotation is complete strawberries occupy two divisions on each section-on one section they are newly planted, but on the other two sections there are always strawberries in bearing.

Division 3.--Mint is planted here, and remains until the end of the third year, when it is lifted for forcing. In the same way as strawberries, mint is planned to occupy a place on each section, in different stages, one being cleared and one replanted each season, To give these two subjects entirely fresh ground after bastard trenching any section the arrangement of the crops on the section should be reversed from right to left, 1 taking the place of 10,2 that of 9 , and so on.

Divisions 4, 5, and 6.-Second early potatoes are planted on 4 and 5 and shallots on 6 ; as soon as the ground is cleared cabbage is planted 18in. apart in the row on 4, and $15 \mathrm{in}$. apart in the row on 5 and 6 , with $2 \mathrm{ft}$. space between the rows. In each of these spaces a row of colewort is set, $1 \mathrm{ft}$. apart. From December onwards the "collards" are cut and sold. In February broad beans are dibbled between the cabbages in the rows on 4 . The ground between the rows on all three divisions is dug and limed, Early in May French beans are 
sown on 4 so that when the cabbages are gone broad and French beans stand in alternate rows. When these are cleared from this division the ground is pointed over and worked down fine and onions are sown. On 5 main-crop and late peas are sown from March to May; these may be grown without sticks to occupy the whole space, or on sticks with radish, lettuce, spinach and turnips between alternate rows.' On 6 runner beans are sown early in May; these are to be grown without sticks, the points of the shoots being taken out to keep them dwarf. In the spring of the third year the onions on 4 are thinned; part are left standing to make bulbs and the remainder are bunched and sold. When peas and runner beans are cleared from 5 and 6 in the second year the ground is dug and dressed with a fertilizer, then planted in October with suitable varieties of cos and cabbage lettuce in rows $3 \mathrm{ft}$. apart. In the following February the spaces between the rows are sown with radish and spinach, which come off in time to allow the ground to be prepared on 5 for vegetable marrows and ridge cucumbers and on 6 for tomatoes. If the district is too far north for tomatoes to ripen this division may be filled with transplanted onions, or potatoes, or short-horn carrots.

Divisions 7 and 8.-Autumn cauliflowers are planted on 7 and summer cabbage on 8 ; both are planted $2 \mathrm{ft}$. $6 \mathrm{in}$. between the rows, and a crop of turnips is taken from between. As soon as the ground is cleared it is dug and limed and lettuces are set out. At frequent intervals during February and March first and second early peas are sown. After these the ground is dressed with a suitable fertilizer, well hoed, and planted with Brussels sprouts, broccoli, savoy, and kale, with parsley and cabbage lettuce seed, mixed together, sown between the rows, the lettuce being thinned to $1 \mathrm{ft}$. apart as soon as it can be handled. After the brassicas are cleared in the following spring the ground is thoroughly worked and planted with main-crop potatoes, dressed with fertilizer.

Divisions 9 and 10.- On these two sections lettuce plants are set out in February and autumn-sown cauliflower plants set amongst them in March. The cauliflower are cleared early in 
July, when the ground is immediately prepared for celery in trenches; after the planting of the celery is completed lettuce are set out and spinach and radish sown between the trenches. The following season spring-sown onions occupy these two divisions, and in the third season they are filled with carrots, parsnips, beet, and leeks.

This completes the three-years' rotation on the first section; on examination of the Plan it will be seen that the second year crop on the first section is that of the first year on the third section, whilst the crop of the third year on the first section is that of the first year on the second section, with this slight difference, that until the rotation is established some temporary crops are grown on the second and third sections in the first and second years only; from the third year onward the crops and rotation as explained above in detail occupy in turn the sections shown in the accompanying diagram.

\begin{tabular}{|c|c|c|}
\hline First & Second & Third \\
Section. & Section. & Section. \\
1 & 3 & 2 \\
2 & 1 & 3 \\
3 & 2 & 1 \\
1 & 3 & 2 \\
2 & 1 & 3 \\
3 & 2 & 1 \\
\hline
\end{tabular}

The method of cropping the bed for the earliest spring crops and the treatment of asparagus, seakale, rhubarb, artichokes, \&c., will be found in the cultural details given later. 


\section{PLAN OF ROTATION AND INTENSIVE CROPPING.}

\section{FIRST YEAR (newly-broken ground).}

FIRST SECTION, Bastard Trenched and Manured.

\begin{tabular}{|c|c|}
\hline 2 Early Potatoes & $\begin{array}{l}\text { Followed by Strawberries, } \\
\text { with winter Spinach between. }\end{array}$ \\
\hline \multicolumn{2}{|l|}{3 Mint } \\
\hline 4 Second Early Potatoes & \multirow{3}{*}{$\begin{array}{c}\text { Followed by Colewort and } \\
\text { spring Cabbage. }\end{array}$} \\
\hline 5 Second Early Potatoes & \\
\hline 6 Shallots & \\
\hline 7 Autumn Cauliflowers & \multirow{2}{*}{ Followed by winter Lettuce. } \\
\hline 8 Summer Cabbage & \\
\hline $\begin{array}{c}9 \begin{array}{l}\text { Early Lettuce } \\
\text { Early Cauliflower between }\end{array} \\
10 \begin{array}{l}\text { Early Lettuce } \\
\text { Early Cauliflower between }\end{array} \\
\end{array}$ & $\begin{array}{l}\text { Followed by Celery with summer Lettuce, Radish, } \\
\text { and Spinach between. }\end{array}$ \\
\hline
\end{tabular}

\section{SECOND SECTION, Bastard Trenched and Manured.}

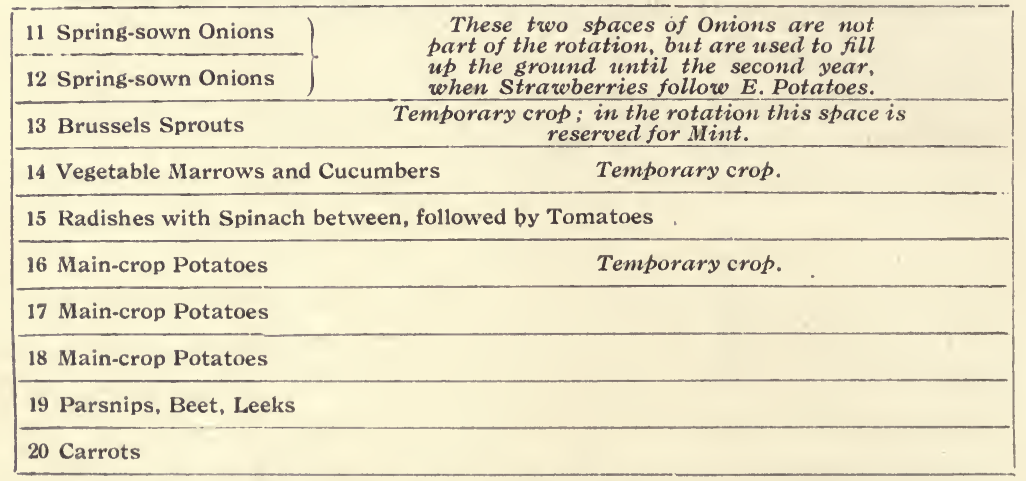

THIRD SECTION, Bastard Trenched and Manured.

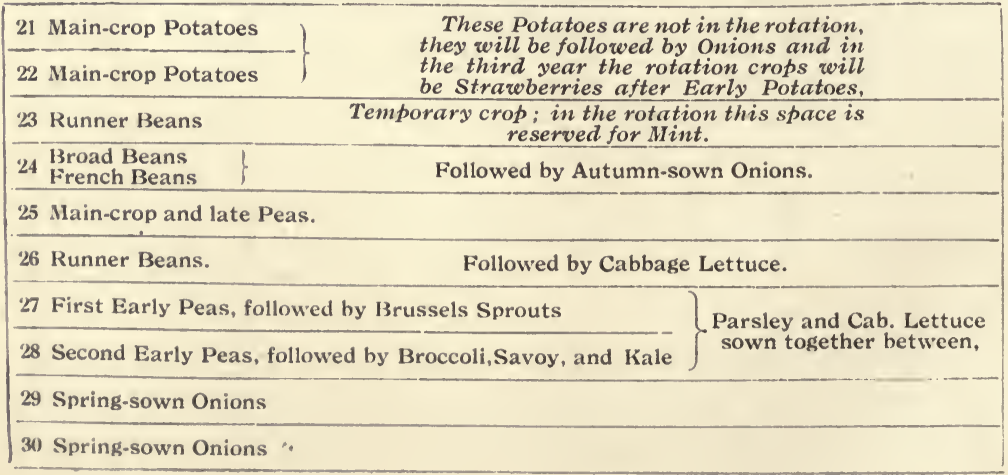


PLAN OF ROTATION AND INTENSIVE CROPPING.

\section{SECOND YEAR (incomplete rotation).}

FIRST SECTION, Dug and Dressed with Lime.

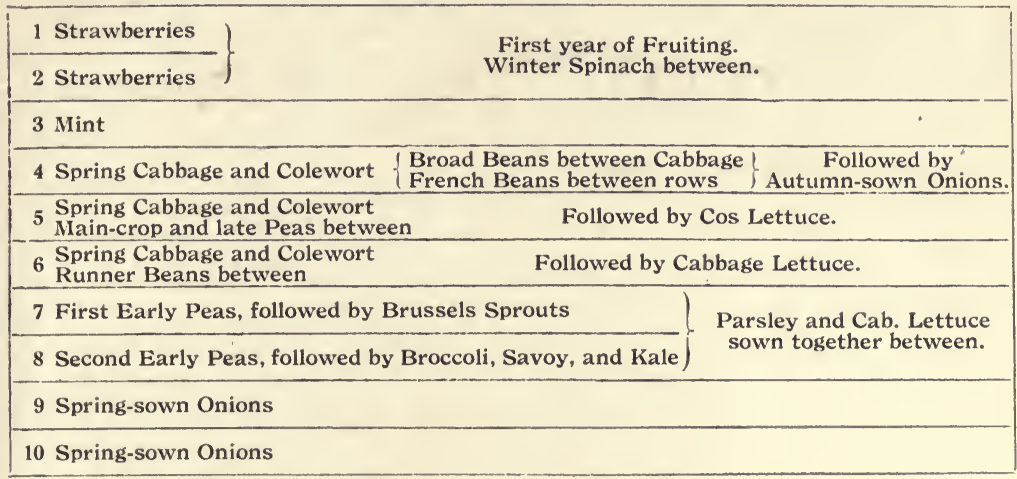

SECOND SECTION, Bastard Trenched and Manured.

\begin{tabular}{|c|c|}
\hline 11 Early Potatoes & \multirow{2}{*}{$\begin{array}{l}\text { Followed by Strawberries, } \\
\text { with winter Spinach between. }\end{array}$} \\
\hline 12 Early Potatoes & \\
\hline \multicolumn{2}{|l|}{13 Mint } \\
\hline 14 Second Early Potatoes & \multirow{3}{*}{$\begin{array}{l}\text { Followed by Colewort and } \\
\text { spring Cabbage. }\end{array}$} \\
\hline 15 Second Early Potatoes & \\
\hline 16 Shallots & \\
\hline 17 Autumn Cauliflowers ) & \multirow{2}{*}{ Followed by winter Lettuce. } \\
\hline 18 Summer Cabbage & \\
\hline $\begin{array}{c}19 \begin{array}{l}\text { Early Lettuce } \\
\text { Early Cauliflower between }\end{array} \\
20 \begin{array}{l}\text { Early Lettuce } \\
\text { Early Cauliflower between }\end{array}\end{array}$ & $\begin{array}{l}\text { Followed by Celery with summer Lettuce, Radish, } \\
\text { and Spinach between. }\end{array}$ \\
\hline
\end{tabular}

\section{THIRD SECTION, Dug and Dressed with Fertilizers.}

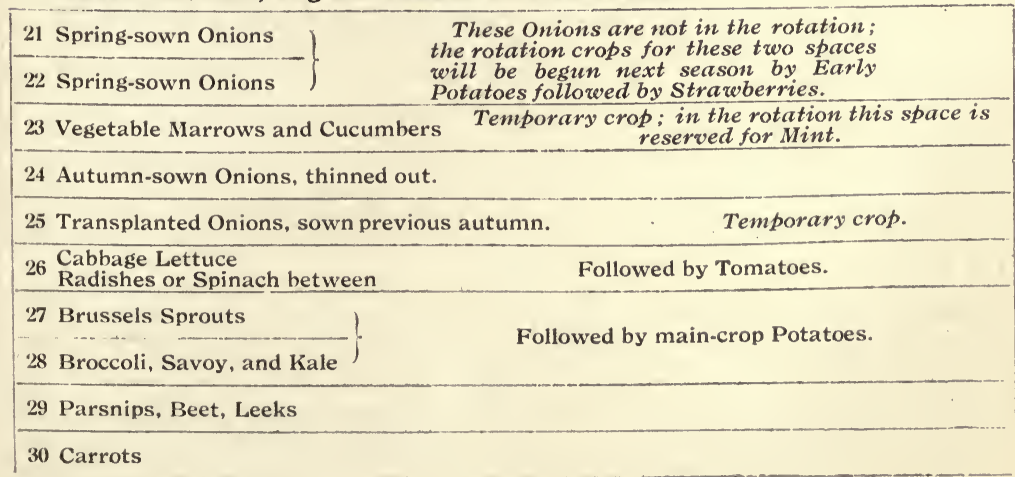




\section{PLAN OF ROTATION AND INTENSIVE CROPPING.}

\section{THIRD YEAR (rotation now complete).}

FIRST SECTION, Dug and Dressed with Fertilizers.

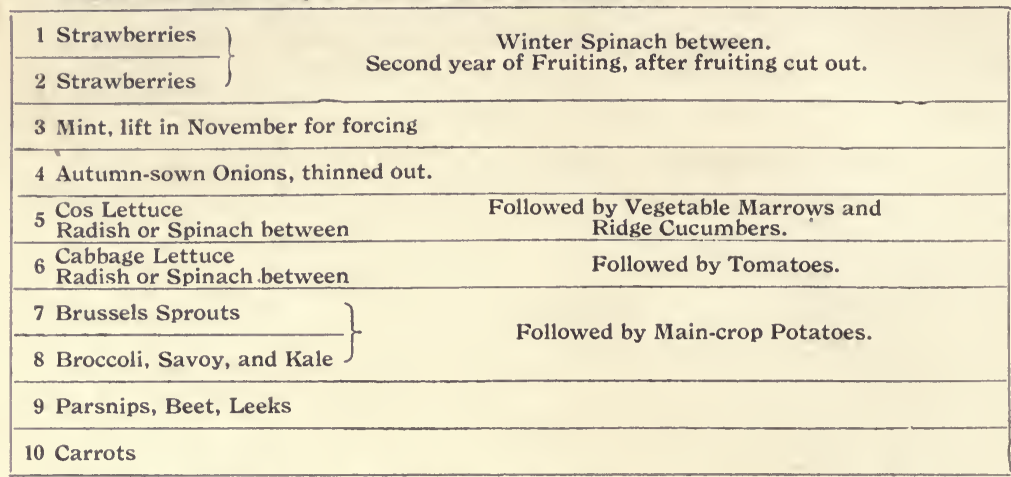

\section{SECOND SECTION, Dug and Dressed with Lime.}

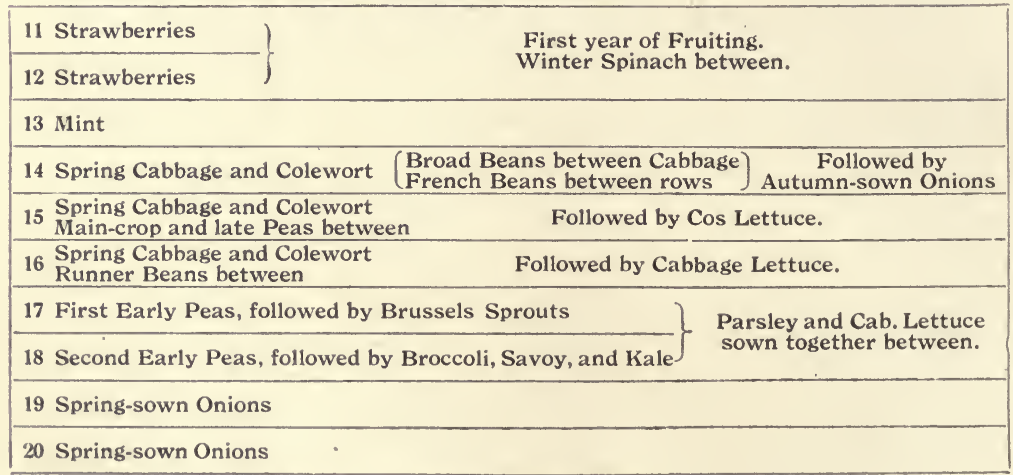

THIRD SECTION, Bastard Trenched and Manured.

$\left.\begin{array}{|l|l|}\hline 21 \text { Early Potatoes } \\ \hline 22 \text { Early Potatoes }\end{array}\right\} \quad \begin{gathered}\text { Followed by Strawberries, } \\ \text { with winter Spinach between. }\end{gathered}$

After a Section is trenched change the crops over from one side to the other. 


\section{Chapter IX.}

\section{FRENCH GARDENING.}

"While science devotes its chief attention to industrial pursuits, a limited number of lovers of nature and a legion of workers whose very names will remain unknown to posterity have created of late a quite new agriculture, as superior to modern farming as modern farming is superior to the old three fields system of our ancestors . . . They smile when we boast about the rotation system having permitted us to take from the field one crop every year, or four crops each three years, because their ambition is to have six and nine crops from the very same plot of land during the twelve months. They do not understand our talk about good and bad soils because they make the soil themselves. . . ." -

Kropotkin, Fields, Factories, and Workshops.

$\mathrm{IT}^{\mathrm{T}}$ was not until Kropotkin brought the achievements of 1 the Paris maraîcher in the cultivation of vegetables prominently before the notice of British readers that much attention was paid in this country to the system of intensive culture now popularly known as "French gardening." Following the publication of his book interest was gradually aroused, until at length a body of English horticulturists visited the Paris gardens to inquire into the matter for themselves. As a result, gardens were laid out and equipped on similar lines in 1905 at Evesham in Worcestershire, and in 1906 at Mayland in Essex, followed by a number of others, large and small, in various parts of the country.

Since that time French gardening has been made responsible for many exaggerated statements, especially relative to the profits to be derived from it, and many entirely unsuitable persons have thus been induced to spend their capital in projects which will, it is to be feared, in many cases end in serious loss.

But intensive culture needs no bolstering up by exaggeration. Providing the gardener is experienced and the situation suitable the crops which can be obtained under this system are astounding to a person who is only acquainted with ordinary 
methods. Under such conditions it is not at all difficult to take six or seven crops in the season from the same soil, and moreover the produce is earlier, of better average quality, stands thicker on the ground, and brings higher prices than does that grown in the usual way.

Cultivation on similar lines to those followed in the Paris gardens has been carried on for generations in many English gardens to a very limited extent and for special purposes, but French gardeners have elaborated the culture into a system which embraces the whole garden and the year round, until it has developed into an important national industry which produces both for home production and for export.

When first the French system of growing early salad crops was brought prominently before public notice many English gardeners asserted that our climate, being humid and scant of sunlight in the winter and early spring months, was quite unsuitable for this culture. Experience has proved that this objection is mistaken; during the few years in which the system has been in operation here on a commercial scale there has been no difficulty in placing on the market early produce quite equal in every respect to that which is imported.

If the wonderful crops obtained by the maraîchers cannot be ascribed to their climate neither can their natural soil be held accountable, because after a garden has been in operation for a few years the original soil is scarcely brought into use at all. In old-established gardens the whole of the open ground is practically a mass of light vegetable mould, a foot or more in depth. This mould was originally introduced into the garden as straw manure for hot-beds, but time and use have broken up and decomposed it so thoroughly that it has become a light, rich, porous soil, and the use of this material for all cultural purposes makes the maraîchers quite independent of the natural soil. So systematic has the manufacture of this artificial soil become that it is a regular stipulation that each may, on quitting his tenancy, carry his soil to a certain depth away with him.

The Paris gardens are, as a rule, comparatively small, varying from half an acre to two acres in extent. Each is 
surrounded by stone walls which reflect the light and heat of the sun and keep out the cold biting winds of spring. For the earliest crops the soil is warmed by beds of slowly-fermenting manure which retains some degree of warmth until the sun gets powerful in the spring. The plants on these warm beds are protected by frames or bell-glasses which retain the heat and moisture. On cold nights and during hard weather these appliances are covered closely with straw mats to conserve the heat and to keep out frost. Later in the season the plants are grown entirely in the open-air, but whether in the open or under glass they are never allowed to receive a check; they are kept steadily and rapidly moving from the time they are set out until the crop is gathered.

In these gardens it is an almost invariable rule to grow together on the same bed two or more crops, one of which is quickly ready whilst the other matures more slowly; by careful management this intercropping is accomplished without overcrowding and with very little inconvenience.

One of the most important factors of success in securing numerous and abundant crops consists in giving the plants all the water they require during the growing season. Under ordinary cultivation very few plants get anything like the quantity of water they need to bring them to perfection, but in the French garden their requirements in this respect are most assiduously attended to. The earliest crops on hot-beds seldom need watering, enough moisture being present in the manure to fully supply them, but later crops and those which stand in the open during the summer months are watered systematically; not in driblets, just to keep them alive during a drought, but in daily soaking showers. This watering is persisted in unless the weather sets in really wet, occasional slight falls of rain being taken little notice of. The result is continuous and rapid growth. Needless to say, under such circumstances ample drainage must be provided, particularly on heavy soil. No plants will thrive when their roots are waterlogged.

It will thus be seen that the whole system is comprised in the provision of shelter and protection, warm and rich soil, abundant moisture and good drainage, with a careful arrangement of inter- and successional ${ }_{5}$ cropping. 
Every detail of work and every appliance used is specially adapted to the purpose it has to serve, and is the result of continuous improvement through many years of experience. Only a limited range of crops is grown in one garden, and by the gardener devoting himself entirely to these he becomes super-skilled in producing them. In the particular kind of French gaiden which is being imitated in so many places in England at the present time the production of early salad crops, followed in summer by cantaloup melons or cucumbers, is made the principal feature.

The arrangement of the garden is planned so that the whole area is used to its utmost capacity for the production of crops in regular sequence, without waste of time, labour, or space. It is divided into equal sections, each of which will accommodate a certain number of frames or bell-glasses. On some of the sections these appliances are placed over hot-beds, on others they cover cold-beds, whilst the remaining sections are planted with open-air crops. The hot-beds are put on a fresh section each winter, so that they pass regularly round the garden, enriching and cleansing the ground as they go.

In every garden water is conveyed by underground pipes to numerous convenient points, so that every part of the garden can be watered easily by means of a hose-pipe. Large quantities of good straw stable manure are used annually, as much as five hundred tons per acre being not unusual. In some of the larger gardens a light tramway is laid to facilitate the removal of manure, soil, and produce from place to place.

It will be obvious that a large amount of capital is required to equip and carry on a French garden of from one to two acres-so much that such an undertaking is quite impossible to a person of limited means. The sum needed will vary considerably according to circumstances and situation, but the average is not likely to be less than $£ 800$ per acre to start and carry on through the first season, whilst the annual expenses afterwards for labour, manure, rent, water, carriage, and sundries will probably run to quite $£ 350$ per acre.

It naturally follows that the returns must be very high to make such a business profitable, but the difference between expenditure and income is not so much in the grower's 
favour as to warrant the absurdly high expectations which have been encouraged in connection with this culture. The first three years of a newly formed garden cannot show much, if any, profit at all, because during that time great quantities of manure must be brought into the garden so as to hasten the formation of that artificial soil which is one of the necessary conditions of success, and in other ways the expenditure is above the average, whilst production has not reached the maximum. Three years ago (1907) the expected net profit of the maraîchers amounted to between $£ 50$ and $£ 60$ an acre, which is not particularly high considering the large amount of capital at stake, and as good English produce realised equal or better prices than the imported, such a profit might reasonably be expected by the proprietors of well-managed and well-situated gardens in England. Since that time, however, the price obtained in Covent Garden market for early salads has shown a decided downward tendency, owing probably to increased supplies, whilst the cost of manure is rising. As a consequence the expectation of profits must be now set lower than was the case three years ago.

French gardening, as a specialised business, is therefore not to be recommended except under really favourable conditions, but the system is rich in hints and suggestions of great value, which can be turned to profitable account by the market gardener. It may not be wise to undertake on an extensive scale the culture of very early out-of-season vegetables which entail so much expense for appliances, manure, and labour, but the culture is remunerative when conducted on a small scale to supply a known demand, whilst there is not the least doubt that crops which are ready a week or two before those produced under ordinary conditions can be made to pay the grower handsomely. In the following chapters the appliances and methods which contribute to this desirable result will be described and discussed. 


\section{Chapter X.}

\section{FRENCH GARDEN.-EQUIPMENT.}

The Light: structural details-The Frame: structural detailsThe Cloche-Cloche Carrier-Cloche Peg-How to Store ClochesHow to Repair Cloches-Mats-Frame for Mat-making-How to Make Mats-Water-Plan of French Garden and Water System-Equip. ment of Two-acre Garden.

FVERY intensive grower of vegetables, no matter how E small his garden may be, needs some means of raising, growing-on, and hardening-off plants so as to have them ready for setting out in their permanent quarters in the open as soon as the weather conditions permit with safety. This need is even more imperative when crops are intended to be ready for use some time, whether it be long or short, before those which are produced under normal conditions. By the use of various protective appliances the gardener becomes, in a measure, independent of season and climate.

Amongst the numerous devices which are used for this purpose nearly all have glass interposed between the plant and the natural weather conditions. In most cases the glass is kept in position by means which cause some hindrance to the full and free access of daylight to the plants under protection, and in every case where green vegetables are being grown all such hindrances to light increase the difficulty of producing a really first-class sample.

For this reason, amongst many others, the "frame" is one of the most serviceable appliances the intensive gardener can use. The plants in them can be kept near the light, within a few inches of the glass, where they grow practically as robust and sturdy as they do later in the open-air, and their needs can be easily attended to, whether it be watering, ventilating, or transplanting. In frames crops can be forced, forwarded, or protected to perfection; they can be kept in use the year round, they can be easily moved from place to place, and they are cheap. 
The dimensions of the frame are regulated by the size of the lights in use. The size of these is immaterial, providing they are serviceable and convenient; but whatever the size used they should be uniform and interchangeable. When the lights and frames in a garden are of varying sizes the result is frequent confusion and loss of time.

If frames and lights are to be made or bought it would be advisable to have them somewhat of the size and construction of those used in the French garden, as these possess several advantages over ordinary ones. They are of a size which makes it possible for one man, whenever necessary, to move them from place to place, and where much of the work has frequently to be done single-handed the advantage of this is at once apparent. These French garden lights are made with narrower styles than ordinary ones, and have tee-iron sash bars, both of which differences have the effect of admitting more light, but as it is not easy to get such improvements unless orders are placed for fairly large quantities, it will be best for the man in a small way to be content with those made from material stocked by any horticultural builder, especially as excellent results can be obtained from their use. The dimensions following are calculated from stock material.

The Light should be made to take four rows of $21 \mathrm{oz}$. glass, $10 \mathrm{in}$. wide by $12 \mathrm{in}$. deep, with $\frac{1}{2} \mathrm{in}$. overlap; this gives sixteen panes to a light, and allowing for the wood gives a light $3 \mathrm{ft}$. $11 \mathrm{in}$. wide and $4 \mathrm{ft}$. 3in. deep. The glass must be bedded in putty, and should also have top putty, so as to prevent "drip." Each light should before use have three coats of paint or two coats of Stockholm tar put on hot. Once each year every light should be cleaned and re-painted, and all putty made sound where it is in any way faulty.

The "horn" or projecting wood at each

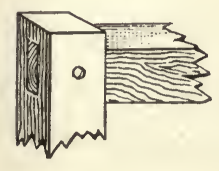
corner of a light which is left to strengthen the mortice and tenon joint, should not be more than lin. long, otherwise it interferes unduly with the pathway between the frames, which would have to be wider than necessary, "Horn" of Light. and so valuable space would be wasted.

Two handles are fixed on each light, one at the top and one 
at the bottom, on the upper surface, about 1 in. from the edge. These are made of $\frac{1}{4} \mathrm{in}$. round iron, and fit into galvanized screw-eyes. In putting on the handles the "eyes" are first screwed into position and the handle

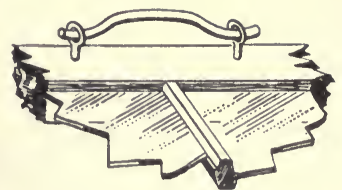

Handle of Light. is bent a little in the middle so as to get the ends into the eyes, when a sharp tap with a hammer in the middle of the handle makes it secure; when not in use the handle lies flat on the frame.

Unglazed lights of this size can be bought in moderate quantities at $3 / 9$ to $4 /-$ each, and the remainder of the material (paint, putty, glass, handles and tacks) will bring the total cost to about $7 /$. . If the prepared wood is bought and the lights made at home the total cost of each will be about 5/6.

The Frame is made of unplaned lin. yellow or red pine boards. It is made to take three lights, which touch each other when on the frame, having no "runners" to divide them, and they come flush with the outsides of the frame all round; allowing for three lights of the size given the frame will therefore be $11 \mathrm{ft}$. $9 \mathrm{in}$. long by $4 \mathrm{ft}$. $3 \mathrm{in}$. wide, outside dimensions. The back is $9 \mathrm{in}$. high and the front 7in., whilst the ends are, of course, cut to slope from $9 \mathrm{in}$. to $7 \mathrm{in}$.

At each corner of the frame, inside, is an oak leg, $2 \frac{1}{2}$ in. by $2 \frac{1}{2}$ in., to which the boards are firmly nailed or screwed. This leg comes within $\frac{1}{2}$ in. of the top of the frame and projects $1 \frac{1}{2}$ in. below it.

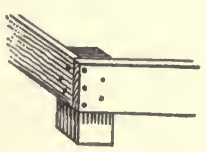

Leg of Frame,

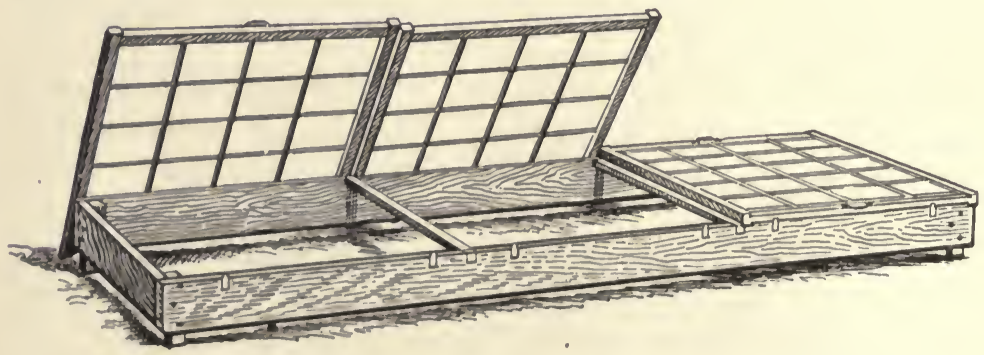

Frame and Lights. 
Two movable wooden cross bars, or supports, 2 in. by 2 in., on which the sides of the lights rest, divide the frame into three equal parts; they have iron ends, as shown in the sketch, to hook over the frame board; these ends must be let into the edge of the board so that they come flush.

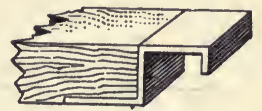

Cross Bar.

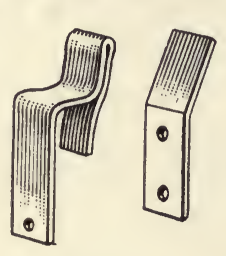

Stops.

Six iron "stops" are fixed to the top of the front board of the frame, two for each light (see sketch); these are held in position by one strong nail in the long end, which goes inside the frame. Or the simple piece of bent iron will answer the same purpose but is more likely to work loose after a time: The purpose of these is to prevent the light from slipping when it is held up at the back while attending to the plants-all work in the frames whilst the lights are on being done from the back (see illustration on next page).

The cost of the wood, iron, nails; \& $c_{\text {os }}$ for one frame of the dimensions given will be about $6 /-$.

It will be noticed that this frame is much shallower than the ordinary garden frame, and is very little higher at the back than at the front. This enables the plants to be grown near the light and so kept sturdy; as they become in danger of touching the glass, the frame is raised from the bed a little at a time, with hooks made for the purpose (see sketch). A tight wad of manure is placed under each leg to give it a solid base to rest upon, and the space between the bottom of frame board and bed is filled up

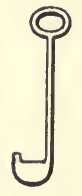

Frame Hook. with fresh manure.

To preserve the frames paint them with Stockholm tar, applied hot. Limewash mixed with carbolic acid (half a pint to 20 gallons), or with sulphate of copper (4lbs. to 20 gallons) is effective not only for preserving the frames but also for destroying any spores of fungi which may have lodged on the wood; it should be renewed each season. Neither creosote, gas-tar, or any wood preservative, unless guaranteed not to contain creosote, should be used on the frames, or the poisonous fumes which these give off when the sun is shining will cause serious injury to the plants. 


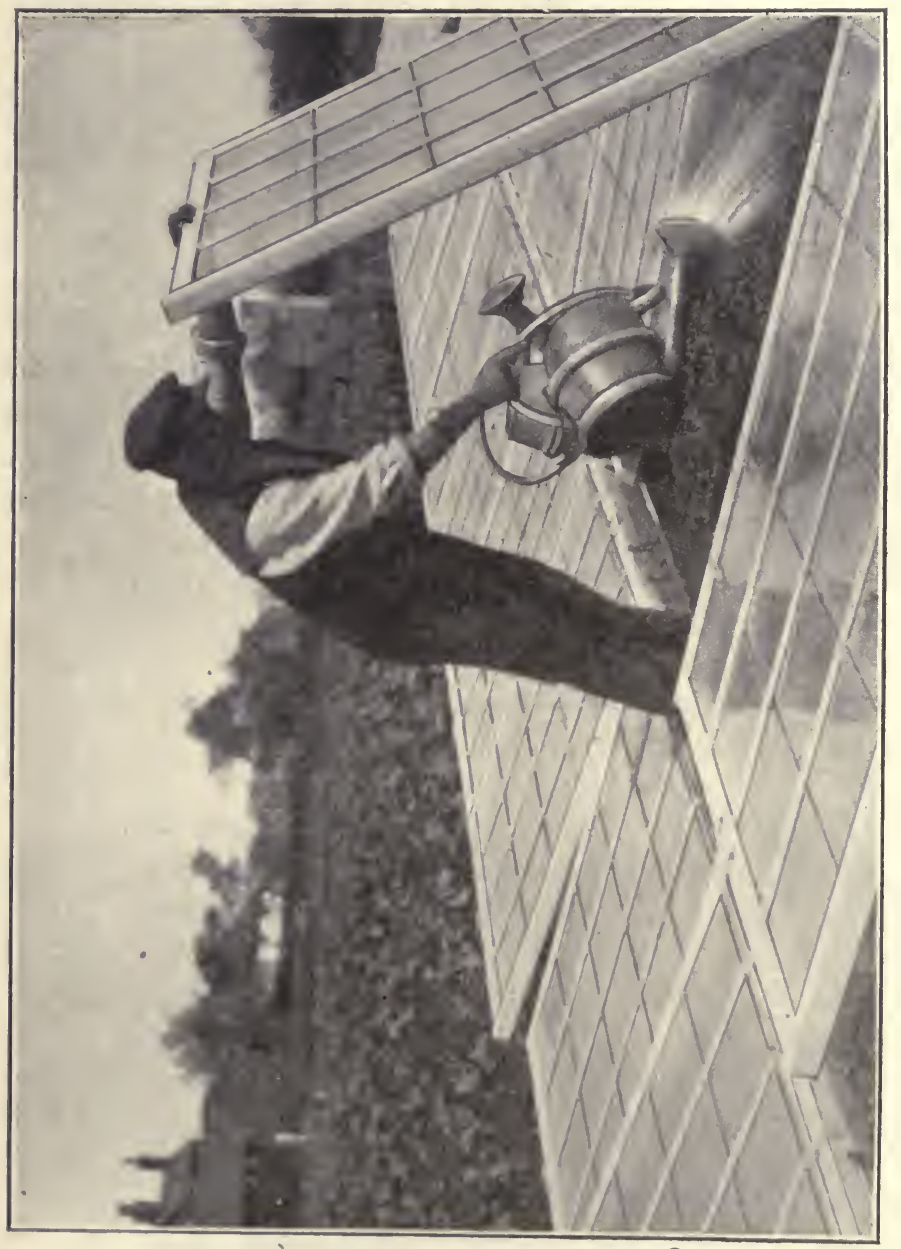

 
When the lights are in use they have frequently to be opened for ventilation at varying distances, according to the state of the weather. To effect this readily a "prop," shaped so that it can be used in several ways to make a different size of opening, accompanies each light. A useful size for this is a piece of wood $10 \mathrm{in}$. long, $2 \mathrm{in}$. wide, and 1 in. thick, with a rebate 4 in. deep cut in one end, as sketch.

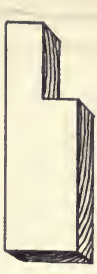

Prop for Light.

The Cloche or bell-glass is an appliance of special importance. It is not so useful as the frame for general purposes, but is even better for some things, such as cos lettuce. It is always ready for use, it is never the worse for wear, and with care breakages seldom occur. There are several sizes in use, but the one most generally employed is

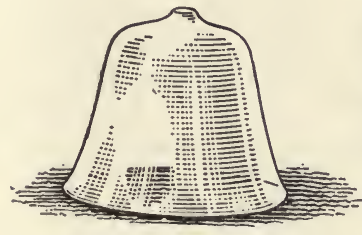

The Cloche. $16 \frac{3}{4} \mathrm{in}$. across the bottom, 15in. high, and weighs about $5 \frac{1}{2} 1 \mathrm{bs}$. Cloches of about this size, made in England, cost about $1 / 4$ each; they may be imported from France in quantity at an inclusive cost of about $1 /$ - each. They are usually made with a knob on the top, but it is best to buy them with this removed, as they are not only cheaper so, but the knob sometimes causes damage to the plants by acting as a lens in the sunshine; without the knob they also pack better for travelling and store away better and safer when out of use.

Cloches should be lifted by pressing a hand to each side. They are carried about the garden on a contrivance called a "cloche-carrier," which is a frame-work of wood with a space at each end on which to place six cloches, three and three, back to back, or twelve in all. There is a space in the middle for the workman to stand in and he raises the carrier by a handle on each side. The illustration on the next page gives a very good idea of the construction of the cloche-carrier and the way in which it is used.

When a cloche is in use it is necessary to tilt it frequently on one side or another, according to the direction of the wind, for the purpose of ventilation. To enable this to be done a "cloche-peg" always accompanies a cloche in use. It is made 


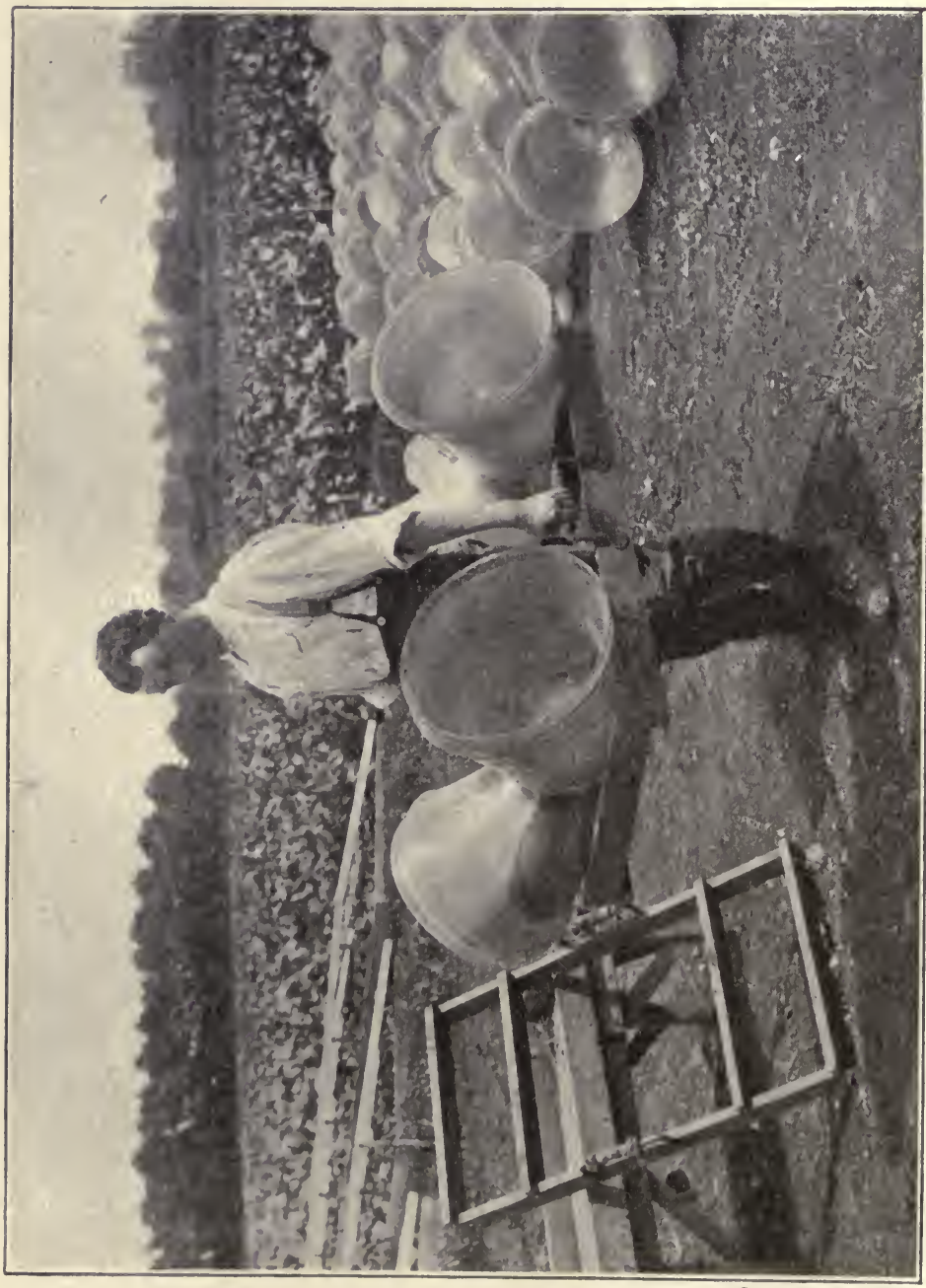

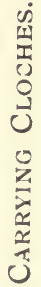


from a piece of wood about $1 \mathrm{ft}$. long, $1 \frac{1}{2}$ in. wide, and $\frac{3}{8}$ in. thick; it is pointed at one end to push into the soil easily, and has two or three notches cut in the upper part for the cloche to rest upon at the height required.
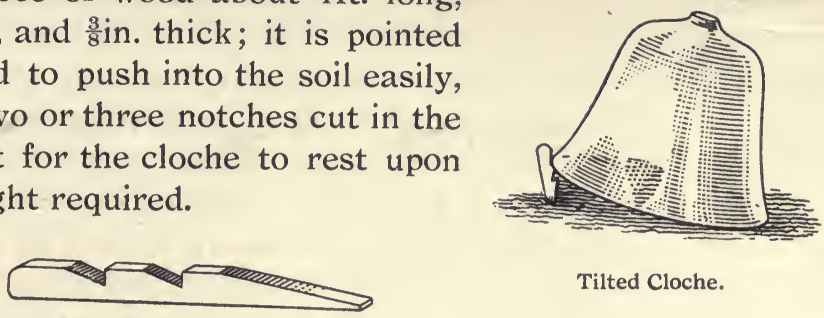

Tilted Cloche.

Cloche Peg.

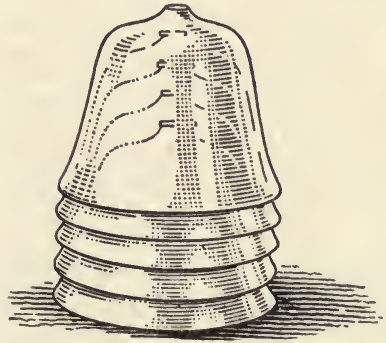

Cloches packed away.

When cloches are not in use they should be stacked away, four or five one above the other, standing upright, with a small square piece of thin wood, about $2 \frac{1}{2}$ in. by $2 \frac{1}{2}$ in. and $\frac{1}{2}$ in. thick, put between each, on the top, to prevent their touching. They should never be packed away on their sides, or many get broken or cracked through jarring, or if they are laid outside the rain-water which collects in them may freeze and break the glass.

When cloches get broken, providing they are not shattered, they may be repaired by rubbing a mixture of white lead and gold size on the broken edges, pressing them together, and binding them by running along the joint a strip

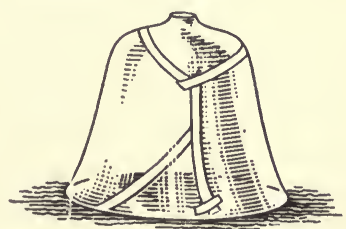

Repaired Cloche. of broad tape well smeared with the mixture. Cloches repaired in this way are almost as good as new ones.

When cloches are used in large numbers, twenty-seven may be calculated as occupying the same space as one three-light frame of the customary size, though only twenty-six can be put in the space of a single frame. The slightly smaller frame planned to be used here only affords space for twenty-four cloches. They are placed in beds of three rows, with a narrow path between each bed, arranged with the cloches in the middle row falling between those in the two outer rows, as shown in the diagram on page 98 . 
Mats.-Where frames and cloches are used the mat is indispensable, particularly during cold weather. When there is any fear of frost these appliances must be covered up closely every night, and sometimes also in the daytime if the weather is very severe. Later in the season, when the sun gets powerful, mats are useful to give shade for a few hours in the middle of the day to seedlings and newly-set plants in frames to save them from scorching. Useful mats of various kinds can be bought at very moderate prices, but it is strongly recommended that the gardener of limited means should make his own. When made at home they cost considerably less, they can be made to any size or thickness required, and a useful occupation is found for slack times in winter when work on the land is impossible. For a very moderate outlay a number of good warm mats can be accumulated which will be found of incalculable service for numerous protective purposes. Mats may be made of any material which is cheap, convenient to use, and affords efficient protection. Straw answers to this description; any kind will do, but rye straw is much the best, as it tougher, more flexible, and more durable than any other.

Whenever possible hand-threshed straw should be used, as that which is threshed by machine is badly broken, but at the outset this will probably be the only sort obtainable. Where there is ground to spare or arrangements can be made with a neighbouring farmer it is a good plan to grow a patch of rye for the especial purpose of mat-making. It should be cut before the grain is formed, so that it does not require threshing; whatever straw is used it is much the best when gathered in this way as it then lies perfectly straight and unbroken and no grain is left in the ear as an attraction for mice.

Mat Frame.-The only appliance it is necessary to have is a mat frame. Several different contrivances are used for this purpose but the one depicted on the following page is as good as any and is quite simple, both to make and to use. It is made of four pieces of wood, $3 \mathrm{in}$. broad and $1 \mathrm{in}$. thick. The size of the mats to be made regulates the dimensions of the frame; for the purpose in view a frame $5 \mathrm{ft}$. $6 \mathrm{in}$. long and $4 \mathrm{ft}$. $6 \mathrm{in}$. broad will be 1 required. Along the middle of the top and bottom boards five stout nails must be driven at $10 \mathrm{in}$. apart, leaving them projecting 
about $2 \mathrm{in}$. Tarred string is tied to each nail at the top then brought down tightly and tied to the corresponding nail at the bottom. To each bottom nail a further piece of string, $12 \mathrm{ft}$. long, is left attached, each of which is wound round a short piece of green wood with a slit in one end, in which the string is fixed to keep it from unwinding.

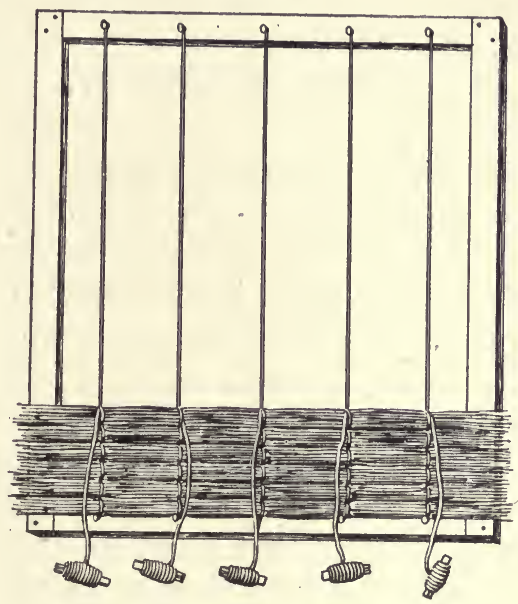

Frame for Mat Making.

Mat Making-After having shaken out of the straw any small and broken pieces, lay a bundle at each side of the frame arranged straightly, with the butt-ends all one way. Then take as much as can be held between finger and thumb, and lay it on the lower board, resting on the nails, with the butt-ends leve with one outer edge; repeat this with another bunch but place the butt-ends level with the opposite edge. Hold the straw near the middle with the left hand and with the right pass the centre ball of string over the straw and under the upright string, bringing it back under itself so that it will draw up and hold tight. Repeat this with all the other strings. Lay on more straw, as before, and repeat the tying, always taking the middle string first. Lay the straw in equal bunches and draw each down firmly upon the previous one so that the mat will be made of an even thickness of about $1 \mathrm{in}$. throughout. When the top row of nails is reached the mat is finished off by firm knots, and the sides are then trimmed level 
with shears, leaving it about $5 \mathrm{ft}$. $6 \mathrm{in}$. by $4 \mathrm{ft}$. $6 \mathrm{in}$. One ton of straw should make about 250 mats of this size. The materials for each will cost about $3 \mathrm{~d}$.

Before using, the mats should be dipped in a solution of copper sulphate (7lbs. to 25 gallons of water). This toughens the straw, retards decay, and destroys any spores of fungi which may be present. The dipping should be repeated each season. After dipping, the mats should be thoroughly dried. When not in use they should be dried, rolled up, and stored under cover.

Water.-A practically unlimited supply of good water is essential to French gardening. The numerous and abundant crops which are produced by this system depend for their rapid and perfect growth upon ample supplies of moistureindeed, the close planting and intercropping which is so marked a feature of the system could not possibly be brought to a successful issue without the assistance of regular and copious waterings. To make this possible, a system of pipes is laid in the earth for the conveyance of water, with hydrants or standpipes at suitable intervals, so that every part of the garden can be conveniently watered with a moderate length of hose-pipe. The quality of the water is an important matter, and it should be proved by analysis suitable for the growth of plants before the expense of laying pipes is undertaken.

When good water from public mains can be obtained at a reasonable price it will usually be found to be a convenient source of supply, but failing this it is necessary to raise the water into a tank elevated sufficiently to ensure a good pressure to every part of the garden.

The choice of motor for raising the water needs careful consideration; a pump worked by wind has attractive features, but a serious objection to its use is that the wind is most likely to fail in hot weather, just at the time when abundant supplies of water are most needed, and unless the storage tank is large enough to hold sufficient water to tide over a period of calm, the crops might be seriously damaged. In very hot dry weather it is not unusual to use as much as 10,000 gallons of water per acre of garden in one day, so that when the means of elevating the water depends solely upon wind power, it is obvious that 
either the storage tank must be very large and correspondingly expensive, or the crops run grave risk of going short of water at the time they need it most. There are many suitable engines driven by oil, petrol, gas, hot-air, steam, or electricity, any of which will be found more dependable than an engine driven by wind, and where one of these is used a tank holding 5,000 gallons per acre of garden will be found large enough.

For a garden of two acres the supply pipe from tank to ground should be $4 \mathrm{in}$. in diameter, mains $3 \mathrm{in}$., branches $2 \mathrm{in}$., stand-pipes or hydrants $1 \frac{1}{2}$ in., with $1 \frac{1}{4}$ in. cocks or taps, and the hose-pipe should be the same size. This arrangement will ensure ample pressure and permit of several hose-pipes being in use simultaneously. The plan below shows the general lines on which a French garden is laid out, with the arrangement of water-pipes.

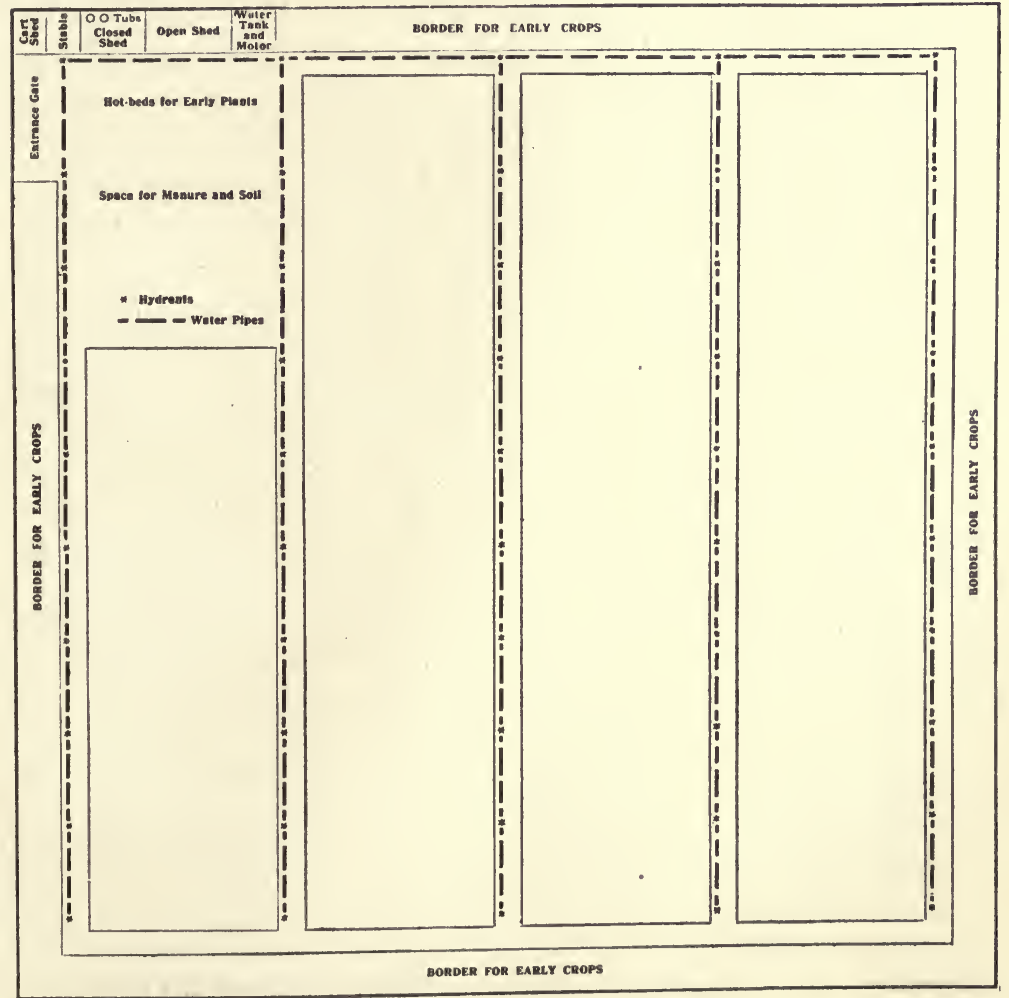


In French gardening nothing is done by haphazard, hence the hydrants have a definite position. In comparison with ordinary gardening this system calls for a large expenditure on labour, and unless great care is exercised the cost of this may easily become prohibitive in spite of the large returns. To keep such expense within reasonable limits nothing must be omitted which will facilitate the various operations and so save labour. To this end the garden is laid out, as shown on the plan, in sections of equal size, the dimensions being regulated by the size and number of the frames in use. When the system is properly carried out, the various crops each occupy a given spot in turn, and so the frame bed gradually passes round the whole of the garden. In a full-sized garden each section is of a width to take five 3-light frames end to end. A water-pipe is laid between each section, along the edge of a $3 \mathrm{ft}$. wide path which runs between them and, providing the frames are of the dimensions given-11ft. $9 \mathrm{in}$. long-the branch pipes would thus be $62 \mathrm{ft}$. apart. Hydrants are fixed on each of these pipes at regular intervals - usually one for each five rows of frames. As the frames are $4 \mathrm{ft}$. $3 \mathrm{in}$. wide, and a space of about $10 \mathrm{in}$. is allowed between the rows, this fixes the positions of the hydrants at $25 \mathrm{ft}$. $5 \mathrm{in}$. apart on each branch.

In planting open-air crops, an 18in. path is left opposite each hydrant, to facilitate watering; where this is not convenient a reel is fixed at the corner of the bed, round which the hose-pipe can be drawn without any fear of damaging the plants. The hose-pipe should have a rose fixed to the end, free from taps or anything which may obstruct a full flow of water.

Equipment.-The following is a list of the tools and material required for the complete equipment of a garden of two acres:

210 3-Light Frames

2,800 Cloches 1,000 Mats

4 Manure Baskets

4 Basket Stands

2 Hand Barrows

2 Cloche Carriers

Cloche Pegs, Props

2 Frame Hooks

4 Dibbers (2 sizes)

Plant Pots
$230 \mathrm{ft}$. length Hose-pipe with rose ends

4 Water Cans (3 gal.)

2 Hose-pipe Reels

4 Manure Forks

2 Bent Forks

4 Spades

2 Shovels

4 Hoes, 4 Trowels

Soil Thermometer

Horse, Cart, and Wagon
2 Fine, 2 Coarse Ralies Garden Line

Soil Firmer

Measuring Rod

Plant Marker

Planting Boards

Washing Brushes

Gravel Screen

Wheelbarrow

Raffia, Wood-wool and Packing Paper 


\section{FRENCH GARDEN.-PREPARATION.}

The Beginning of the Gardener's Year-When Material should be Obtained-Sitiation-Outbuildings-Drainage-Wireworm-How to Prepare the Soil - How to Prepare Compost for Topping Beds Manure: The Kind to Use, When to Get it, and How to Stack it.

THE French gardener's year begins in September, when seed is sown for the lettuce and cauliflower plants which are wintered in frames and under cloches, and by that time all the preparatory work should be either completed or in a very forward condition. For this reason work on the land should be commenced in the previous spring.

The lights, wood for frames, and straw for mats should be obtained in the previous winter, so that no opportunity shall be lost of getting these appliances ready for use. Cloches should be ordered by June at latest, otherwise the numerous orders for autumn delivery may prevent their being received in time; it would be a serious matter if either cloches or frames were not at hand when wanted for seedlings in the autumn.

The situation and aspect of the garden and the quality of the soil have been fully dealt with in previous chapters, and it is expected that the points there emphasised have received due attention. It is presumed also that the garden is, as it ought to be, either adjoining or within a short distance of the house of the gardener, so that the plants may receive immediate attention in any emergency. Close by there should be a roomy well-lit shed where vegetables can be washed and packed, tools and stores locked up, and the necessary work of making and mending performed when it is unfit to work in the open. If such a building does not exist, one should be erected.

If the soil is naturally well-drained that will be an important point secured at the outset, but if there is any doubt whatever about this matter drainage must be the first thing to receive attention, as success would be impossible on cold, inert, waterlogged land. If the soil is heavy neither time, trouble or expense should be spared to ensure good drainage. 
If the ground is old pasture it will probably be more or less infested with wireworm, and these pests will be sure to cause serious losses unless some decided means are taken to get rid of them. By far the best plan to effect this is to skim off the turf and burn or char it black. When this is done there is not only an assurance that the garden is started free of noxious insects and fungi, but if the soil is heavy its texture will be much improved and the inert potash it contains will be rendered available for plant food. Failing burning, one of the advertised wireworm specifics should be used.

With the exception of the two sections reserved for hot-beds the whole of the ground must be bastard trenched, and a dressing of good rich manure at the rate of two tons to each section, worked in between the top and bottom spits. If the land is in grass, and burning is not to be resorted to, the top two inches should be skimmed off at each spit, chopped up and put directly on the manure, and then covered with the next spadeful of top soil, adding a wireworm specific according to the directions of the manufacturers.

After the soil has been weathered for some time it must be dug over again, half a spit deep, so as not to disturb the sod and manure which lies below the top spit. The proper condition of the soil is a matter of the greatest importance and no effort must be spared to bring this condition about. It must be remembered that several crops of first-class quality are to be taken from the same plot of ground in the same season, and to accomplish this the soil must be not only well manured but it must also be mellow and friable. Plants cannot reach perfection unless all the conditions of growth are favourable, and experience proves that the texture and friability of the soil are of far greater importance than its character. Every particle of soil contains plant food, and it should therefore be thoroughly worked before planting, so that the delicate rootlets can penetrate it in all directions.

Manure for making hot-beds should be brought into the garden at convenient times from the end of September until the beds are started. The Paris gardeners accumulate it all through the summer, bringing it in load by load on the return journey from market. It is stacked in long, narrow, high 
ridges, with a sharp-pitched top to throw off rain. Stored in this way there is very little fermentation or decay and it does not lose much of its virtue. When the ridges are large ventilating shafts are made in them as they are built, every $10 \mathrm{ft}$. or so, to prevent overheating. These shafts are made by placing the manure round a bushel basket (or anything similar, a little wider at the top than at the bottom) as the stack is built, raising the basket each time the manure approaches the rim. When the hot-beds are made equal quantities of the newest manure and that which has been stacked the longest are mixed together, and it is found that the heat produced by this mixture is milder and more lasting than when fresh manure is used alone. Where tree-leaves are easy to obtain in quantity they may be substituted for about half the quantity of manure in making the hot-beds, and will give equally good results.

The quantity of manure required for the early hot-beds in the present scheme, and for raising seedlings in spring, is about 70 to 80 tons. Of this, about one-half should be accumulated by the end of December, and the remainder brought in during January, but if there is any uncertainty about getting the fresh manure when it is wanted, it would be much better to have the whole quantity stacked beforehand than to run the risk of the beds being delayed through waiting for the manure. A further 30 to 40 tons will be required by the beginning of April, for making the beds for cucumbers and melons.

The manure should be that from, stables where corn-fed horses are bedded with straw. There should be no peat, sawdust, shavings, or rubbish mixed with it.

In the French garden the soil which is solely used for making seed beds, covering hot-beds, and for surfacing all beds before plants are set out is made from exhausted hot-bed manure. This is repeatedly turned, beaten about and broken up, and finally passed through a screen to free it from lumps. It has then somewhat of the appearance and character of fine leaf mould. The results from the use of this material are all that can be desired. Seeds germinate in it quickly, evenly, and strongly; seedlings lift with a mass of fibrous roots, and plants grow quickly and mature early.

After the first season the old hot-beds will put sufficient of 
this material at the disposal of the gardener, but as a preliminary it will be necessary to procure some substitute. Where manure from old mushroom beds can be obtained it would answer the purpose admirably, and twenty loads should be got and worked up as described above. Failing that about ten loads of thoroughly decayed stable manure should be procured in the spring. Make this into a compact heap, shaking it out, breaking the lumps, and damping it well as the work proceeds. Repeat this operation several times during the summer, doing all possible to hasten its disintegration. As autumn approaches it must sifted through a gravel screen and the fine portion well mixed with an equal bulk of sifted garden soil.

The mixture or compost, if of a nice moisture throughout, should be made into a large ridge, with a sharp-pitched top to throw off rain. If rather dry it should be left spread out until well moistened by rain, then ridged up. It will then be ready to use at any time for the purposes mentioned above. The rough material which failed to pass through the screen can be re-made into a heap for further treatment during the winter.

This compost should be ready for use by the end of August. By this time frames, lights, cloches, and mats should also be ready and close at hand, with the woodwork of the lights well painted, the glass cleaned, and the cloches washed, so that they will admit all the light possible during the dark days of winter. Seeds should have been purchased, tools procured, and the ground thoroughly prepared, so that the work of seed sowing, plant raising, and the setting out of hardy plants to stand in the open-air beds through the winter, can proceed without any hindrance. 


\section{FRENCH GARDEN.-PREPARING PLANTS FOR EARLY CROPS.}

Routine of Wintering Plants-Cauliflower-Cos and Forcing Cabbage Lettuce-Hardy Cos and Cabbage Lettuce-Lettuce Mildew and the Preference for Cloches-Protecting the Plants from Frost-How Mats should be Laid so as to Resist Strong Winds.

THE equipment and preliminary preparation of our French garden are now completed, and we have arrived at the month of September. This is, for practical purposes, the beginning of the French gardeners' year, as in that month active operations are commenced by raising Cauliflower and Lettuce plants to provide a supply for the earliest crops of the following spring. Instructions for the preparation of seedbeds, sowing, and transplanting, will be found in Chapter XVI, to which the reader is referred. The seedlings are transferred to cold-beds, where they are enabled to pass safely through the rigours of winter under the protection of frames or cloches, which in periods of severe cold are covered by straw mats. There is no particular difficulty in successfully raising and wintering plants suitable for forcing, but care and attention to details must be continually exercised. The beds, both for sowing and transplanting, must be in proper condition and the dates of these operations duly observed. Overcrowding must never be permitted. Diseased, weak, or doubtful plants must be rigidly excluded, and all faded or decayed leaves removed as soon as seen. The plants must be grown as hardily as possible and whilst being protected from sharp frosts must not be allowed to suffer long from want of daylight through any protective covering being left over them too long. Finally, their quarters should be kept rather dry, as excessive damp is more dangerous to their well-being than cold.

Cauliflower.-The first sowing of cauliflower is made on or about the 14th of September, and another, as a precautionary measure to guard against failure, on the 20th. For these 
earliest batches, which are used for setting out in warm and cold frames after cabbage lettuce and on the cloche bed after the first batch of cos lettuce, a quick-heading compact variety should be selected, the large kinds not only taking longer to mature but for the earliest supplies are not appreciated on the market so much as the medium-sized ones. Another batch of a larger heading variety is sown at the beginning of October and pricked off in November; these plants are set out in the open-air beds the following spring. After the seed is sown, and at frequent intervals during the first three weeks, the seed bed is watered lightly to encourage even germination and strong growth, as well as to keep off the "fly."

Early in October the first lot of plants will be ready to prick out into their winter quarters. For this purpose a bed must be got ready to take as many frames as may be necessary to hold the required number of plants at $3 \mathrm{in}$. apart. Rake the soil down and place the frames on it square and level. Inside them put moist compost, 3in. deep; level this with a fine rake, remove the lumps, and then press with the firming board, after which prick out the plants. If the compost is moist, as it should be, no watering will be necessary, but if dry, water lightly to give the plants a start. When they have got root-hold they will require no more water all through the winter; in fact, the grower must strive by all the means in his power to prevent unduly moist conditions, as damp is more harmful than cold, and must be carefully guarded against.

As soon as the plants are pricked out put the lights on the frame to keep off rain, but give all the air possible by resting the lights at each corner on flower pots. When very cold or rough weather sets in, close the lights, and if severe frost threatens cover with mats. Do not coddle the plants; grow them as. hardy as possible, but avoid freezing. Give plenty of air whenever the weather will permit, and keep rain out of the frame by opening the light on the side opposite to that from which the wind blows.

Should the season be mild and the plants inclined to grow too freely they must be lifted and transplanted to give them a slight check; if this is done set them a little further apart, so that there will be no overcrowding. 
If from any cause there are any serious losses amongst the wintered plants, sow again in January, on a hot-bed. As soon as the seedlings can be handled, prick out on a bed with a mild warmth, and gradually harden.

Cos Lettuce and Forcing Cabbage Lettuce.-During the first week in October sow both cos and cabbage lettuce for growing on warm manure beds. In this case the seed is sown under cloches, in the following manner: A seed-bed is prepared, care being taken that the compost is moist, because lettuce plants should, if possible, be raised without watering. As many cloches as are necessary for the seed to be sown are put on the bed, gently pressed, and lifted away again. Each will have made a circular depression, and within this ring the seed is sown, thinly, lightly covered with compost, pressed down with the firming board, and the cloche replaced. Although late in the season, the sun is still hot in the middle of the day, and the cloches must be covered with mats from about 11 to 2 o'clock or the soil may get too dry and the sowing prove a failure.

In four or five days the seedlings will appear. About three or four days afterwards-just as soon as they can be handledthey should be pricked out under cloches, thirty plants to each, taking care to keep them quite $2 \mathrm{in}$. from the rim, so that the leaves, as the plants grow, may not touch the glass and get frozen.

Forcing cabbage lettuce remains under the cloches, without air, until wanted for the hot-beds. Cos must be given air on all mild days, and should be transplanted again towards the end of November, fifteen to a cloche. Sometimes cos lettuce is transplanted a third time, it being claimed that frequent transplanting causes earlier hearting besides an improvement in its size and solidity.

Hardy Cos and Cabbage Lettuce.-Seed of hardy lettuce, which are intended to stand unprotected in open beds through the winter, is sown about September 14th. As soon as the seedlings can be handled they are pricked out 2 in. apart on a nursery bed covered with compost. About the end of October they are planted out at $1 \mathrm{ft}$. apart in a sheltered and well 
drained position. For this crop it is a good plan to have beds slightly raised above the general level, so that they will be sure to stand dry; slugs and birds must also be guarded against. When the ground is dry in February or March hoe well. The cabbage lettuce should be ready in April and the cos early in May, and then usually realize good prices.

Although lettuce treated as directed above seldom get destroyed by frost, that mishap does sometimes occur when the winter is very severe, and as a safeguard another batch is wintered under cloches; part of these are planted in cold frames soon after the turn of the year and another part planted a little later in open beds.

Seed for these varieties is sown at the same time and in the same manner as described above for cos and cabbage lettuce intended for forcing, but fewer of the hardy than of the forcing cabbage are put under a cloche, as they grow larger; whilst the forcing cabbage lettuce is kept under the cloche entirely without ventilation, the hardy varieties are given air constantly except during frost. The lettuces grown in cold frames come ready earlier than those which stand out through the winter, but those planted outside after the end of January come a little later, and for this reason it is advisable to set out good strong plants as early in the new year as the condition of the soil will permit, so that they may be cleared not later than the middle of May, as after that time there is very little demand for cabbage lettuce.

\section{Lettuce Mildew and the Preference for Cloches.-Cloches} are used in preference to frames for protecting lettuce during winter because these plants are liable, especially under damp conditions, to be attacked by mildew. When this disease gets amongst the plants it is very destructive, often sweeping away an entire batch. When cloches are used the area of attack is kept within much narrower limits than if the plants are in a frame. Efforts to find a remedy have so far met with very indifferent success, and it is far safer to depend upon prevention than on cure. A damp position and a stagnant atmosphere are almost certain to breed mildew, and these conditions should be avoided. The bed on which the plants are pricked 
out should be kept free from excessive damp; if the soil is heavy the bed should be raised slightly above the ordinary level of the garden; it should be in an open position where the air can move freely and never in a sheltered corner or at the foot of a wall.

If the disease has shown itself previously the soil should be watered with Bordeaux mixture before planting. If the mildew appears remove and burn those plants attacked worst, then dust the remainder, through a powder bellows, with a mixture of equal parts of powdered quicklime and flowers of sulphur.

Protecting the Plants from Frost.-On the approach of winter every care must be taken to protect the plants from frost. Every night both frames and cloches must be covered with mats, and uncovered again in the morning. When severe frost threatens, dry litter should be scattered, three or four inches deep around and amongst the cloches, and up to the top of the frame board, and the mats should be laid on so that they not only cover the top but also reach the ground on either side. In laying on the mats, particularly if the weather is stormy, they should overlap with the exposed edge facing to leeward, or in the direction opposite to that from which the wind blows. Laid in this way and fastened down on the windward side high winds do not disturb them, whereas if these precautions are neglected the gardener may some morning find the mats scattered about the garden. The litter amongst the cloches must be removed as the weather gets milder, otherwise it would tend to hold excessive moisture, besides being an obstruction to light. In very keen frost the mats must only be removed for a few hours in the middle of the day. Constant watchfulness is required to ensure that the plants escape freezing and yet are grown hardily. 


\section{FRENCH GARDEN.-CROPS GROWN BY VARIOUS INTENSIVE METHODS.}

Intercropping and its Limitations-The Best Time for Beginning Hot-beds. HoT-BeDS FOR FRAMES: Arrangement of the CompostDiagram-Sowing and Planting - Routine Work-VentilationGathering Radishes and Lettuces-Planting Cauliflowers-Dressing the Beds-Watering-Clearing Beds-Alternative Crops-Turnips. Hot-BEDS FOR Cloches : Compost-Arrangement of Cloches-Sowing and Planting-Water and Ventilation-How Cloches are Manipulated for Successional Crops-Diagram-Covering and Shading ClochesClearing Beds-Extra Early Cauliflowers. Cold Frames-Warm Beds for Melons and Cucumbers-Various other Methods of Forcing and Forwarding-Open-air Crops.

INTERCROPPING is an essential feature of French gar1 dening, and it is by this means that the numerous crops which are so marked a feature of the system are obtained. But the experienced maraîcher recognises that the possibilities of intercropping has strict limitations, and whilst striving to get the utmost from the soil it is capable of yielding, he is very careful to avoid overcrowding. His ideal is to get not only quantity but quality also. It may appear to be a simple matter to grow together quickly and slowly maturing crops, and so obtain two or more from the space usually occupied by one, but this kind of thing is easily overdone. When too many plants are contending together for light and air-as well as for food and moisture, the gardener will find, in spite of care and attention, that the produce will not develop into the choice specimens he is anxiously hoping for, but comes poor and weedy and of comparatively little value.

For this reason beginners are urged to carefully carry out in their entirety the directions which follow as to times for sowing and planting, distances between the plants, and other similar details. There is no claim made that these instructions 
cannot be improved upon-the experienced gardener must use his own judgment in the matter-but as every detail has been tested and proved to work successfully it is advisable that the beginner should follow the instructions very closely.

Hot-beds are started at various times throughout the winter months, according to the ideas of the individual grower and his command of good stable manure. Where this can be obtained plentifully at a nominal price there is no reason why crops should not be produced the year round, but under ordinary conditions mid-winter crops cannot be produced at a profit. It has been found, by practical experience, that in a garden of moderate size the second week in January is the best time to begin, and the dates of sowing given in the previous chapter have been arranged with this time in view.

A week or two previous to commencing the hot-beds, the section intended for them should be covered a few inches deep with long manure, so as to prevent the ground from getting frozen. Before the bed is begun all necessary material should be collected and placed close at hand, so that when a start is made the work can proceed expeditiously.

Hot-beds for Frames.-These are made first. The prepared decayed manure or compost for topping the beds should have previously been laid on the section they are to occupy, in ridges about $3 \mathrm{ft}$. wide and $2 \mathrm{ft}$. $6 \mathrm{in}$. high, each ridge coming opposite the centre of the position to be occupied by a frame. The ridges should stop $6 \mathrm{ft}$. from the north end of the section, so as to leave room for making the first bed, and extra compost should be put at the south end of the ridges to afford sufficient to cover the last bed. If there is any likelihood of frost when the compost is wheeled out long manure should be laid over it.

In beginning to make the bed, lay across the north end of the section two rows of manure-one of new and one of that which has been stacked for the longest time (see page 82). Alternate forkfuls of each of these rows is shaken out, and laid in position about 9in. thick; this is beaten down with the back of the fork and then another 6in. or 9in. is put on top of it and also beaten down. As the work proceeds the manure is trodden down firmly and evenly, and hollow places are levelled 
by laying in a little more manure. At this date the manure bed should be finished at about 15in. deep. Earlier in the season it must be deeper. In February 12in. and in March 9in. will be sufficient. These are minimum depths, calculated for economy in the use of manure; where it is plentiful and cheap the respective depths may be increased with advantage.

FRAMES

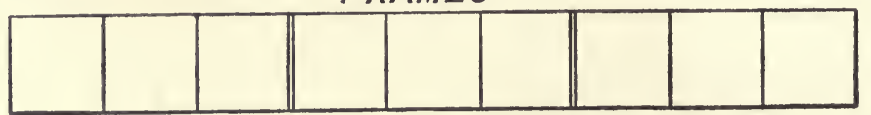

Space for next Bed
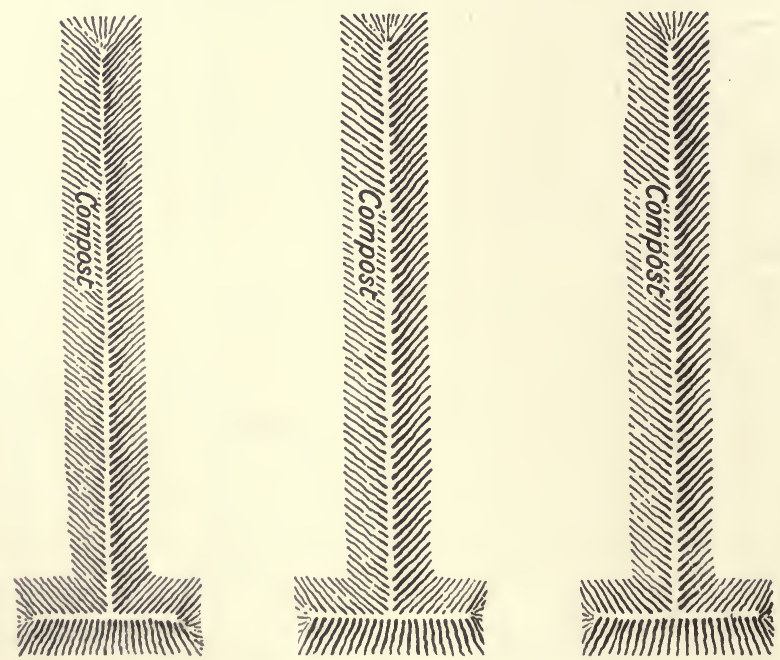

Soil laid ready for Covering Hot-beds.

The first portion of the bed laid down should be of such a length and width as will allow the manure to extend $9 \mathrm{in}$. beyond the frames all round. As soon as the first strip is ready the first row of frames should be put on, straight and level, and perfectly square with the section. Some trouble should be taken over this, as the first row forms a guide to the remainder, and no margin is allowed for careless fixing. When all are on the bed they should be true and square one with another. The same pains should be taken in levelling the frames, by standing on each corner to get them solid, and packing manure 
under the feet of the frame until the level is satisfactory. When finished the whole should present an even surface, and if properly placed on the bed they will retain this level to the end, but if insufficient care is exercised they will sink in some places and rise in others, which besides having a slovenly appearance will often cause rainwater to drip inside the frame, and so spoil the crop.

Set the frames end to end, about half an inch apart, so as to allow sufficient play for the lights' to move easily, as there are no runners between them. Having fixed the frames, throw inside compost from the ridges, until there is a depth of about 4in. all over the manure; then make all level with a fine rake, and remove all lumps. Put on the lights and cover with mats, then proceed to lay down the manure for the next row of frames. This is joined up to the first bed of manure, no gap intervening, so that when finished one large bed covers the whole section. This keeps the heat in better and allows the frames to be set closer together, 10in. only being allowed for walking space between two rows of frames.

The work should be so contrived that the portion of the bed for one row of frames is finished and covered before being left at night. This is of importance at this time of the year, when there may be rain or snow for days together; if this occurs when the beds are left uncovered they will be spoiled.

Sowing and Planting.-In two or three days after the first bed is covered the manure will begin to get warm, as may be seen by the moisture on the glass. Then is the time to sow and plant. Take off the lights and sow radish seed broadcast, very thinly and evenly, all over the bed. Follow this by sowing forcing carrot seed on the same bed and in the same way. Cover thinly with dry sifted compost, and press all over evenly with the firming board. Then plant the forcing cabbage lettuce from under the cloches on the same bed, five rows under each light and five plants to a row. The row at the south side of the frame should be set further away from the board than that at the opposite side so as enable sufficient direct sunlight to reach the plants. Only the strongest should be used for the earliest beds. All decayed leaves should be removed 
before planting. The roots should be carefully examined for red spots, and if any with this appearance are found they must be rejected and burnt, or the fungus which causes the spots will spoil the plants before they can mature.

The beds are sown and planted as they are made and become warm; by this method the crops mature in regular succession. When all the section is filled, and the beds are all sown and planted, the outsides of the frames must be banked up and the pathways between filled with fresh manure, almost to the level of the lights (see diagram).

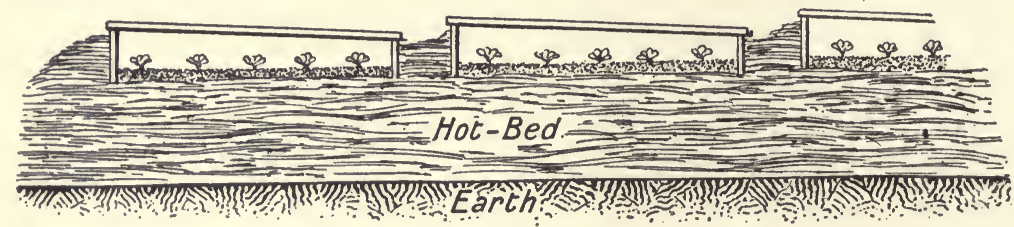

Diagram showing how Manure is packed on the outsides of the Frames.

Routine Work:- Cover the lights each night with mats and uncover each morning. In performing this operation roll up each mat tightly and lay it along the woodwork where two lights join. Here the mats are out of the way and cause very little obstruction to light. As soon as the radishes show, give air by raising the lights slightly on the side opposite that from which the wind blows. If the radishes near the outsides of the bed move slowly it is due to the cooling of the manure at that part, and when this occurs pull down the manure on the outside and bank up with some fresh. If the radishes in any part appear to be drawn it will be caused through too much heat, and a little more air must be given, but this must be done with caution as much ventilation is not good for the forcing cabbage lettuce. Look through the frames occasionally and remove any decayed leaves which may be seen amongst them.

Some radishes should be fit for gathering about four weeks after sowing; if the bed is warm the whole should be cleared away by the end of the fifth week, and this will be to the advantage of the carrots, which by this time will be showing all over the bed. So far no watering has been necessary, the manure having given off sufficient moisture for all the requirements of the plants, but after the radishes are gone the bed 
will probably need watering, unless the weather has been wet, in which case it will be damp enough. If water is needed choose a mild, dull day, and about mid-day lift off the lights separately, give water through a fine rose, and replace at once. The lettuce should be ready for market about six weeks after planting.

When the lettuce are gone clean the beds well, removing any weeds, leaves, or old roots which may have been left behind; thin the carrots in any places where they may stand too thickly. Then plant the cauliflowers, four to each light, so that they stand about $2 \mathrm{ft}$. apart both ways; water thoroughly, put on the lights, and keep close for two or three days.

From this time forward air and water must be given in constantly increasing quantities. The beds must never be allowed to get dry and ventilation must be gradually increased until the plants are thoroughly hardened. Early in April the frames and lights can be removed altogether to the section intended for melons or cucumbers.

Before this time some growers work fine soil amongst the carrots, bringing it up to the collar of the plants. This keeps the top of the roots from becoming green. The carrots should be ready for market early in May. Pulling should not be begun until the bulk are ready and then the bed should be cleared as the pulling proceeds, no small ones being left to get larger, as they would be in the way and would probably only make useless fibrous roots. Those too small for market should be thrown away.

When the carrots are gone hoe the bed all over and water well. The cauliflowers need careful watching, and whenever a head appears break a leaf over it to keep it clean and white. Water freely. Cut as soon as ready, as if overlooked only one day they may get too open and become spoiled, especially if the weather is warm. They should be cleared about the middle of June, when the bed is immediately hoed over and planted with other crops, as described later.

Alternative Methods.-The foregoing scheme of cropping is the most usual for this class of produce, and with proper attention to details will be found comparatively simple and 
easy to work. There may, however, be special circumstances which would make it advisable to get a particular crop earlier or in greater abundance than is here provided for, and where this is so the work must be arranged accordingly. If carrots are wanted in the early part of April the bed should be made up in the middle of December and the same routine followed, except that radishes should be omitted, lettuces planted a little further apart, and cauliflowers not set out until the beginning of March. Or a crop of radish and lettuce can be taken by the end of February and after the surface soil has been cleaned and stirred the same two crops can be repeated with carrot, intercropped with cauliflower at the end of April, though these latter would be a month later than under the regular scheme. A very useful plan is to make up the bed on the first of January, take a crop of radishes, and after clearing the bed sow with forcing turnips, which in turn would be followed by early celery and endive. Turnips usually sell well and realise good prices early in the season; it is also wise to include turnips in the series, because if the soil is cropped continuously with carrots it will, after a few years, begin to yield inferior crops.

Turnips.-Make a square lattice of laths, ten each way, just large enough to fit easily into the frame under one light. In the middle of each place where two laths cross fix a peg, to project one inch. Lay this frame or lattice on the soil, pegs downward, and press down. In each hole made by the pegs drop two or three turnip seeds. Rake gently to fill the holes, water, close the lights, and keep close until the seedlings show, then thin to single ones and give plenty of air. Keep the soil moist; in fact it is necessary to water daily. Take the lights off entirely whenever the weather is favourable. The turnips will be ready for sale about the end of April.

Hot-beds for Cloches.-Hot-beds for cloches are begun as soon as those for frames are finished-about the last week in January. All the operations are the same as for the frame beds, except that compost is spread on the manure three or four inches deep before the cloches are put in position. A garden line is used so that the cloches are set out neatly, true 
and straight. Three rows occupy the same space as a frame, those in the middle row falling between those in the two outer rows, with the rims about $1 \mathrm{in}$. apart, and a path about $18 \mathrm{in}$. wide between each three rows.

As soon as the first bed is ready the three rows of cloches are placed upon it and the next bed is proceeded with, in the same way as for frames. By the time the third bed is finished the first will be warm and ready for planting.

Remove the cloches, then sow carrot seed only very thinly, cover lightly, and press down with the firming board; set a cos lettuce in the centre of each cloche, and three cabbage lettuces at equal distances apart, around the cos. On one side of each cloche a depression is made in the soil to give air to the plants, and this will suffice until the weather becomes warmer; then air must be given by tilting the cloche on the cloche-peg. Water will be required as the plants increase in size and the need for it becomes evident. For the production of good cos lettuce air must be given freely on every occasion that the weather will permit.

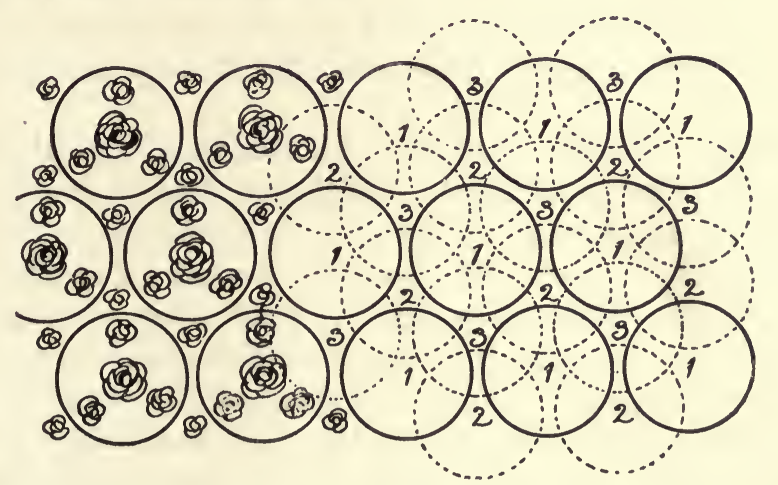

As soon as planting is finished on the last bed cos lettuce are set in the open in the spaces between the cloches. This is shown in the diagram above, where the cos under the cloche is numbered " 1 " and those between the cloches " 2 " and "3." The protection of the cloches combined with the warmth of the bed preserves these plants in the open from injury. The whole are covered closely with mats each night.

The cabbage lettuce should be ready for market by the 
second week in March. Then the carrots are thinned where they stand too thickly, and the south side of each cloche is whitened to prevent the unimpeded rays of the sun from scorching the tips of the cos leaves under the cloches.

The first batch of cos, numbered " 1 " should be ready early in April. When these are gone the cloches are put over those numbered " 2 " (shown by dotted lines in the diagram) and a cauliflower is set where " 1 " stood in the first and third rows, leaving the middle row free. When those numbered " 2 " are gone the cloche is put over "3." When this last batch are gone, which should be early in May, remove the cloches to the sections where they are required for covering French beans, tomatoes, vegetable marrows, \&c. Clean up the bed and water thoroughly and frequently.

The carrots should be ready early in June and the cauliflowers towards the latter part of the month, and immediately afterwards the bed is lightly forked over and replanted.

A much earlier crop of cauliflowers can be obtained if a cauliflower is planted under each cloche instead of a cos lettuce. Three cabbage lettuces are planted round it, and the general treatment is the same as in the preceding scheme.

Cold Beds or Cold Frames form a connecting link between the hot-beds and the open-air beds, and ensure a continuous succession of supplies: They are manipulated in much the same way as the hot-beds and may be used for similar crops, but these of course come later. Cold beds are extremely useful where it is difficult to obtain sufficient manure to make up many hot-beds, or where the demand for very early and high-priced produce is limited. But on the whole, although the gross returns are lower, the comparative net profits are higher than from hot-beds, and this is a very important consideration to those with a small working capital.

For this work the ground should be dug and left rough in the early part of the winter. On the 1st of January, or as soon afterwards as the ground is clear of frost and snow, level the soil, set the frames in position, and put under each light a barrow-load of old hot-bed manure. Level this and cover it with a little sifted compost, then put on the lights and keep 
closely matted up for a few days, when it will be found that the temperature in the frames is sensibly warmer than that outside. Then is the time to sow and plant. Hardy cabbage and cos lettuce, cauliflowers, stump-rooted carrots, radishes; turnips, peas and potatoes will all give very satisfactory results under this treatment, and come just at the time when there is a good popular demand, and yet early enough to realise comparatively high prices.

Forcing varieties of lettuce may be grown in cold frames if an extra barrowful of old hot-bed manure is put under each light and the paths between frames are filled with litter, so as to keep frost from penetrating the frame-board; in fact, this treatment will make the conditions inside a cold frame more congenial for any crop. In any case, during cold weather each frame should be covered at night with mats.

Spare frames may also be very usefully employed in pro. tecting beds of parsley or spinach through winter; or they may be used for covering mint or strawberry plants in March so as to forward them a week or two in advance of open-air crops. Where such forwarding is intended the beds should be planted of the proper size to be covered by a frame.

Warm Beds for Melons and Cucumbers.-During April the cauliflowers and carrots growing on hot-beds under frames are gradually hardened, until by the middle of the month the frames are removed entirely and the crops are left standing in the open. The frames thus released are taken to the section intended for melons or cucumbers. Here warm beds are made by putting hot manure in shallow trenches and covering with soil. The frames are put on these beds and the plants set out at once, yielding fruits during the summer. The frames are removed from the melons about the end of July or early in August, according to the weather, and cauliflower plants are then set on the beds amongst the vines, thus giving an autumn crop of cauliflowers to follow melons. Cauliflowers are not planted on the cucumber beds unless the crop shows signs of being over early. Full detailed instructions regarding melons and cucumbers will be found in the articles under their respective heads in the Details of Cultivation. 
Open-air Crops.-As soon as the last of the forced crops are gone, the hot-beds-now cold-are cleared of all roots and leaves, lightly forked over, raked level, and at once planted with crops which will mature before the following winter. These consist in the main of celery, celeriac, endive, cos lettuce, carrots, and cauliflowers, any of which may be intercropped with quickly-maturing subjects, such as radishes, spinach, cabbage lettuce, or turnips. Good well-grown plants should have been prepared in readiness for these beds, so that there will be no loss of time between one crop and the next.

In addition to those grown on hot-beds and on cold-beds under glass, and those which follow these on the same beds in the open-air, there are crops grown on ordinary well-manured soil entirely in the open. Some of these are planted out in autumn and have to take the chances of damage or destruction by exceptionally severe weather; in some cases provision is made for some form of protection by mats or dry litter, whilst in others the plants are not set out until all danger from frost is practically at an end.

\section{Various other Methods of Forcing and Forwarding.-Other} crops than those already mentioned are produced early in the French garden by methods more or less similar to those already described. Amongst these may be mentioned vegetable marrows, ridge cucumbers, dwarf beans, and tomatoes, all of which may be set out early over a little warm manure and protected by lights, cloches, or one of the protective devices described and illustrated in Chapter XVII. Then there are such subjects as seakale, chicory, asparagus, mint, and numerous others, all of which can be made to yield good profits by forcing, either in pits or on hot-beds.

For full detailed instructions respecting the intensive culture of any of the crops mentioned above, and not already fully dealt with, the reader is referred to Part II of this book, "Details of the Cultivation of Vegetables," where every item is treated separately under its own head. 


\section{Plan of French Garden, with Scheme of Cropping.}

\section{Total Area: Quarter of an Acre.}

Note.-A Rotation is obtained by each year moving the crops which in the previous year occupied sections 1 and 2 to sections 9 and 10 , and at the same time moving all the remainder from the section each occupies to the section above, as is shown in italics below.

\begin{tabular}{l}
\hline 1 \\
Open-air Bed, planted with hardy Cos \\
Lettuce at the end of October. \\
Radishes are sown in February be- \\
tween the rows of Lettuce. \\
After Lettuces are cleared, manure \\
is brought from section 5 and dug in, \\
then earlv Celery is planted. \\
After Celery, sow Radishes. \\
After Radishes are cleared, bastard \\
trench the ground, in readiness for \\
crops as on section 3 . \\
\hline \\
\hline \\
Open-air Bed, planted with hardy Cab- \\
bage Lettuce from Cloches at the end \\
of January. \\
Cos from Cloches are planted between \\
the Cabbage Lettuce early in March. \\
After Lettuces are cleared, manure is \\
brought from section 5 and dug in, \\
then Endive is planted; a fortnight \\
later set late Celery between Endive. \\
After Celery, this section is occupied \\
with the crops shown on section 5. \\
\hline 5
\end{tabular}

Hot-bed, made mid January, for 6 rows of Frames; 4 rows are sown with Radish and Carrot and planted with Cabbage Lettuce; as soon as Lettuce are ready, plant Cauliflowers.

2 rows are sown with Radishes only and planted with Lettuces; after Lettuces, sow Turnips.

Follow all with second early Celery.

After Celery, remove manure, raise plants, and prepare for wintering.

9

Lettuce and Cauliflower plants under Frames and Cloches for protection through the winter.

Follow with Melons on warm-beds in Frames.

When Melons are three-parts grown plant Cauliflowers on the beds.

After the section is cleared, take the manure out of trenches, spread it evenly over the bed, then dig, in readiness for crops as on section 1 .

Open-air Bed, planted with hardy Cabbage Lettuce at the end of October.

Radishes are sown between the rows of Lettuce in February.

After Lettuces are cleared, forward Tomato plants are set out under Cloches in the middle of May.

After Tomatoes are cleared, prepare Pits in readiness for crops as on section 4.

\section{4}

Pits, made in November, for forcing Rhubarb, Seakale, and Chicory.

In May level the ground, dig in manure, and plant early Celery about the end of the month.

Follow Celery with Batavian Endive.

The crops shown on section 6 follow Endive.

\section{6}

Hot-bed, made early part of January for 432 Cloches; sow with Carrot and plant with Cos and Cabbage Lettuce ; after Cos plant Caulifiowers.

When bed is cleared, fork over and plant with second early Celery.

After Celery, sow Radishes.

When bed is cleared, remove manure to section 4, then dig, to have soil in readiness for Cold-beds, as on section 8.

\section{8}

Cold-bed, made beginning of February, for 6 rows of Frames; sow with Radish and plant with Cabbage Lettuce; as soon as Lettuce are ready, plant Cauliflowers.

After Caulifiowers, sow Carrots, but on one corner raise Batavian Endive plants for section 4.

The crops as shown on section 10 follow on this section.

10

Sow Radishes on open bed in February and keep dry litter at hand for protection from frost.

After Radishes are finished, prepare warm-beds for Cucumbers.

When this section is cleared, take the manure out of trenches, spread it evenly over the bed, then dig, in readiness for crops as on section 2. 


\section{A QUARTER ACRE OF FRENCH GARDEN.}

Description and Explanation of Garden-Equipment - WaterManure-Prices of Produce-Average Crops-Size of BunchesDetails of Cropping-Estimated Produce and Values-Summary of Returns-Estimated Annual Income and Expenditure-Approximate Cost of Equipment.

$\mathrm{N}^{\mathrm{N}}$ the preceding page is a model plan of a French garden, with a scheme of cropping. The dimensions are a trifle over a quarter of an acre. There are 10 interchangeable sections, each $36 \mathrm{ft}$. by $30 \mathrm{ft}$. $6 \mathrm{in}$., any of which will afford space for 18 frames, arranged in 6 rows, 3 frames in a row, facing south, with a $10 \mathrm{in}$. path between the rows; or 486 cloches, in beds of 3 rows each, with an $18 \mathrm{in}$. path between the beds.

The reasons for setting forth the possibilities of a quarteracre French garden are: (1). because this represents the maximum area which one average man can manage on this system ; (2) because a French garden of this size is quite large enough for a small holding where it is worked in conjunction with ordinary market gardening. It must not, howevcr, be supposed that any person is advised to undertake this kind of work singlehanded. Many of the operations are done more conveniently by two persons working together, and when this is the only form of gardening carried on it will be found more economical to have the garden large enough to employ several persons, as then the time of the head man is not taken up with tasks which can be performed equally well by a labourer. One working head man can efficiently supervise about two acres.

The equipment consists of 40 3-light frames, 500 cloches, 250 mats, spade, digging fork, manure forks with straight and bent prongs, shovel, fine and coarse rakes, draw and push hoes, large and small dibbers, garden line and reel, trowel, measuring rod, soil thermometer, plant marker, planting board, firming board, sieve, gravel screen, watering cans, water barrow, props for lights, plant pots, pegs for cloches, a cloche carrier, and a wheel barrow, most of which are illustrated on the next page.

In a larger garden it would be necessary to have water laid on in pipes, but on this small area an energetic man could 
Specimens of Some French Garden Tools.

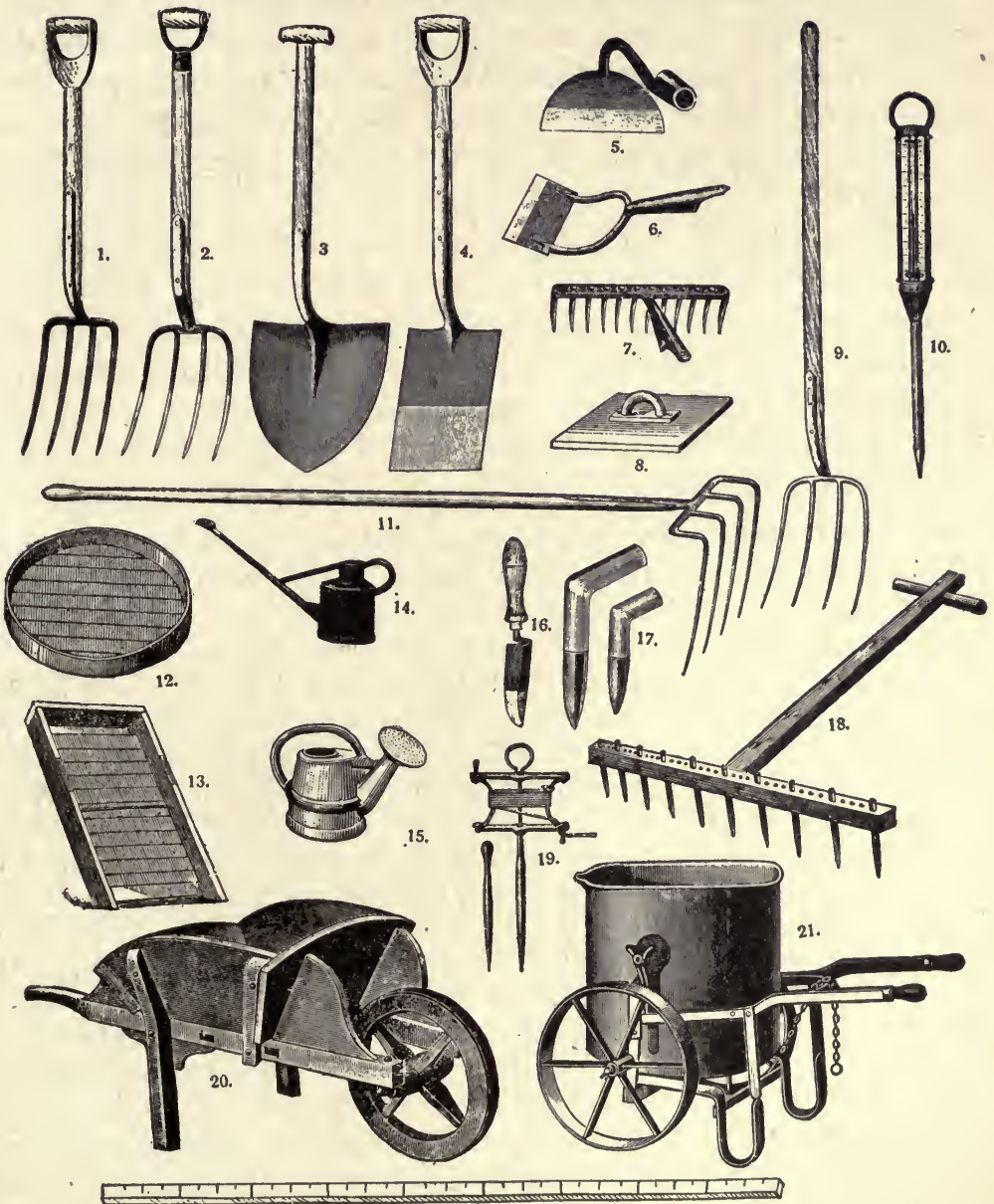

22.

1 Digging Fork.

2. Manure Fork-

3. Shovel.

4. Spade.
5. Draw Hoe.

6. Dutch Hoe.

7. Fine Rake.

8. Firming Boand
9. Long Manure Fork. 13. Gravel Screen. 10. Soil Thermometer. 14. Dew Pot.

11. Bent Prong Fork.

12. Sieve.

21. Water Barrow. 16. Garden Trow
17. Dibbers.

18. Soil Marker.

19. Garden Reel \& Line 20. Wheelbarrow.

manage very well with a 30 gallon water barrow and two 3 gallon watering cans. About 140 tons of manure will be required the first season, 40 tons for digging in, and 100 tons for hot-beds, the latter quantity being required each season. 
The prices obtained for French garden produce are subject to wide fluctuations, and the most careful estimate may be found unreliable in any given season. It is only by averaging the returns over a number of years that any fair estimate can be arrived at. This is the method by which the prices following have been fixed, and in all cases they are rather under than over-stated.

In calculating the quantity of saleable produce obtained from the garden a sufficient allowance has been made for waste. The average crop per light from frames is four bunches each of radishes and carrots when these are grown with lettuces, or eight bunches of radishes when carrots are omitted. When they stand thicker than this the lettuces are injured. Turnips grown alone yield seven bunches per light. The number of roots to a bunch is twelve each of radishes and turnips, and fifty of carrots, in two "half-bunches" of twenty-five, tied together.

No. 1 Section.-Open-air bed, planted at the end of October with hardy Cos Lettuce, $1 \mathrm{ft}$. between the rows, 10in. between the plants in the row. About the middle of February Radishes are sown thinly between the rows of Lettuce, every fifth row being left vacant for convenience in gathering. There are $96 \mathrm{doz}$. Lettuces planted, of which $80 \mathrm{doz}$. may be expected to pass through the winter successfully and realise an average price of $1 / 3$ per doz. The Radishes should yield 50 doz. bunches at $8 \mathrm{~d}$. per doz. After the bed is cleared of Lettuce it must receive a good dressing of manure from section $\mathbf{5}$ (where some of the hot-beds are by this time done with); this is forked in and the section is planted at the beginning of June with early Celery, in rows $12 \mathrm{in}$. apart. by $8 \mathrm{in}$. apart in the rows. This should be ready for sale in the latter part of August, and there should be $110 \mathrm{doz}$. saleable sticks, which will sell for an average price of $1 / 6$ per doz. When the Celery is gone clear the ground of rubbish, hoe well, and sow Radishes, which will be ready in October, and should yield $140 \mathrm{doz}$. bunches at $6 \mathrm{~d}$. per doz.

No. 2 Section.-Open-air bed, planted at the end of October with hardy Cabbage Lettuce (Passion), at the same distances apart as Cos on No. 1, and being earlier may be expected to realise the same price. Radishes also same as No. 1. This section will be cleared early in May, and in the middle of the month well-prepared forward Tomato plants are set out in double rows $2 \mathrm{ft}$. apart, $3 \mathrm{ft}$. between the double rows, and $18 \mathrm{in}$. between the plants in the rows, which run north and south. Each plant is covered with a cloche as it is set out. The section will accommodate 252 plants which will, if properly treated, bear ripe fruit early in July, and should yield, at a low average, 4 lbs. per plant at $2 \mathrm{~d}$. per $\mathrm{lb}$. 
No. 3 Section.-Open-air bed, planted at the end of January with hardy Cabbage Lettuce (from cloches) 14in. apart in each direction. Early in March Cos are planted in each direction between the Cabbage Lettuce. The latter should be ready to cut towards the end of April and the Cos by the latter part of May; they should each yield $47 \mathrm{doz}$. saleable heads at $1 /$ - and $1 / 3$ per doz. respectively. When the section is cleared of Lettuce, manure from the hot-beds on section $\mathbf{5}$ is spread, the soil is forked over and levelled, and Endive is planted in rows 15in. apart, 1ft. between the plants in the row. A fortnight afterwards, late Celery is set between the rows of Endive, 9in. from plant to plant. The saleable yield should be $55 \mathrm{doz}$. Endive at 1/- and $86 \mathrm{doz}$. Celery at 1/- per doz.

No. 4 Section.-On this section four pits are made in November, for forcing Rhubarb, Seakale, and Chicory. The method is described and illustrated in the article on the cultivation of Seakale. Each pit is $34 \mathrm{ft}$. long and 4ft. wide. Two and a-half pits are used for Rhubarb, one for Seakale, and a half one for Chicory, which proportion roughly represents the comparative demand. Planting is begun at the end of November, one quarter of the space allotted to each being planted every week so as to secure a regular succession. Six weeks may be reckoned as the time necessary to complete each crop, and if the warmth of the bed is maintained by renewal of the fermenting material at each fresh planting, three crops can be taken before the end of April. The number of roots required for the season are-1,500 Rhubarb (set as closely as they will stand), 3,600 Seakale (4in. apart), and 750 Chicory (6in. apart). The produce to be expected is 600 doz. bundles Rhubarb at an average price of 2/- a doz., 900lbs. Seakale at $6 \mathrm{~d}$., and $750 \mathrm{lbs}$. Chicory at $4 \mathrm{~d}$. This is a fair average yield and price when good roots are well grown. Each quarter of the pits should be boarded up so as to prevent light getting to the other parts when one is being manipulated. At the end of April the pits are dismantled, the ground levelled, and manure spread and dug in. About the end of May early Celery plants are set out as described for section 1. Immediately the Celery is cleared away fork the soil over and plant Batavian or other winter Endive 15in. apart each way. These should produce 40 doz. saleable at $1 /$-.

No. 5 Section.-This section is used for hot and warm-beds on which all the tender spring-sown plants are raised in frames. As the plants grow and need more room this can be provided by removing some of the frames from the cold-beds on section 8, early in April. The frames are removed from early Celery plants early in May, but protection is given at night by a covering of mats, laid over a framework of laths. When Tomatoes are planted out, the manure of the beds on which they stood is taken to No. 1 section. All vacant frames are taken to sections 9 or 10, to be used for Cucumbers or Melons. As soon as all plants are gone spread remainder of manure, dig in, and plant Celeriac, 1ft. apart each way. These will give say, 76 doz. roots at $1 /$.

No. 6 Section.-This section is covered at the beginning of February with a hot-bed for cloches, made and planted in accordance with the detailed 
instructions given on pages 96 to 98 . It should produce $100 \mathrm{doz}$. Cabbage Lettuce at an average price of $1 /$ - per doz., $100 \mathrm{doz}$. Cos Lettuce at 2/6, 14 doz. bunches Carrots at 3/-, and $22 \mathrm{doz}$. Cauliflowers at 2/9. After these are all cleared away the bed is forked over and planted with second early Celery, 1ft. between the rows, 10in. apart in the rows. There should be 90 doz. saleable sticks which will average out at $1 / 3$. After Celery, clear and hoe the bed and sow Radishes, which will yield as No. 1 section.

No. 7 Section.-The hot-bed on this section, which is commenced in the middle of January, accommodates 18 frames, in 6 rows of 3 frames each. Four rows are manipulated in accordance with the detailed instructions given on pages 91 to 96 , and produce $12 \mathrm{doz}$ : bunches Radishes at 1/-, $12 \mathrm{doz}$. bunches Carrots at 3/6, $70 \mathrm{doz}$. Cabbage Lettuce at $1 /-$, and $11 \mathrm{doz}$. Cauliflowers at $3 /$. . On two rows there are no Carrots, and Turnips are sown after Lettuce; these produce $12 \mathrm{doz}$. bunches Radishes at 1/-, $34 \mathrm{doz}$. Cabbage Lettuce at $1 /-$, and $16 \mathrm{doz}$. bunches Turnips at $4 /-. \cdot$ After all these, second early Celery is planted, as on section 6 , and realises the same price. When Celery is gone the manure is removed, broken up and sifted. The soil is then forked over so as to be in readiness for wintering next season's plants, and seed for them is sown on beds made at one end of the section.

No. 8 Section.-Cold-bed made early in January for 18 frames. Sow with Radish and plant with Cabbage Lettuce, 25 to a light; as Lettuce come ready plant Cauliflowers, 5 to a light. These should produce $18 \mathrm{doz}$. bunches Radishes at 10d., 104 doz. Cabbage Lettuce at 1/-, and $21 \mathrm{doz}$. Cauliflowers at 2/6. As soon as Cauliflowers are off, lightly fork over and sow broadcast short horn Carrots on $4 \mathrm{ft}$. beds, with $1 \mathrm{ft}$. paths between. On one corner of this section the Batavian Endive plants should be raised for setting out on section 4. The yield of Carrots should be $18 \mathrm{doz}$. bunches at $3 /-$.

No. 9 Section.-Here Cauliflower and Lettuce plants intended for the earliest crops of the following season pass through the winter on cold-beds, protected by frames and cloches. As soon as the plants are removed, the section is prepared with warm-beds and planted with Melons, according to the directions given on pages 224 to 229. About the middle of July Cauliflowers are planted amongst the Melon vines, four to a light. There should be about 180 good melons, which will sell at an average price of $1 / 3$ each, and $15 \mathrm{doz}$ Cauliflowers at $1 / 6$. The Cauliflower plants for this section can be grown on No. 2 section at the foot of the Tomato plants.

No. 10 Section.-Radishes are sown on this section in the middle of February on $4 \mathrm{ft}$. beds, protected by a light covering of litter. This is removed as soon as the seed has germinated, but replaced each night and when the weather is severe. The yield should be $120 \mathrm{doz}$. bunches at $8 \mathrm{~d}$. As soon as the Radishes are cieared warm-beds are prepared and planted with Cucumbers, according to the directions on pages 200 to 206. The yield should be 80 doz at $1 / 6$.

On the following page the estimated gross recurns from each section are summarised :- 
No. 1. $-80 \mathrm{doz}$. Cos Lettuce, at $1 / 3$...

$£$ s. d. $£$ s. d.

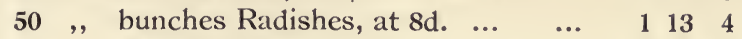

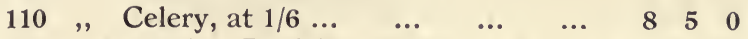

140 ", bunches Radishes, at $6 \mathrm{~d}$. ... $\quad \ldots \quad 310 \quad 0$

No. 2. -80 doz. Cabbage Lettuce, at $1 / 3 \quad \ldots \quad \ldots \quad \begin{array}{lllll}5 & 0 & 0\end{array}$

$\begin{array}{lll}18 & 8 & 4\end{array}$

$\begin{array}{lllllll}50 & , \text {, bunches Radishes, at } 8 \mathrm{~d} . & \ldots & \ldots & & 13 & 4\end{array}$

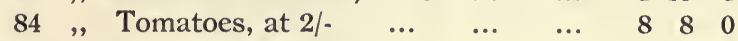

\begin{tabular}{rllllll}
\cline { 3 - 5 } No. 3. -47 doz. Cabbage Lettuce, at $1 /-$ & $\ldots$ & $\ldots$ & 2 & 7 & 0 \\
$47 \quad$ Cos Lettuce, at $1 / 3$ & $\ldots$ & $\ldots$ & $\ldots$ & 2 & 18 & 9
\end{tabular}

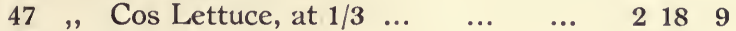

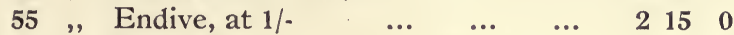

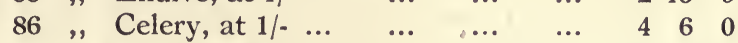

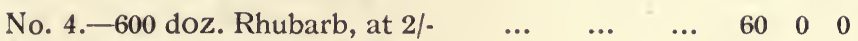

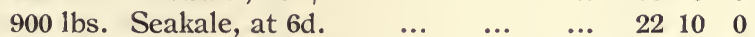

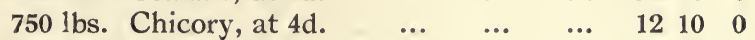

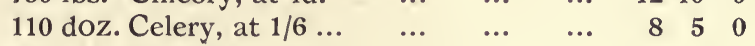

$\begin{array}{llllllll}40, & \text { Endive, at } 1 /-\ldots & \ldots & \ldots & \ldots & & \end{array}$

$\begin{array}{lllllllllll}\text { No. 5. }-76 \mathrm{doz} \text {. Celeriac, at } 1 /- & . . & \ldots & \ldots & 3 & 16 & 0 & 105 & 5 & 0 \\ \text { No. 6. }-100 \text { doz. Cabbage Lettuce, at } 1 /- & \ldots & \ldots & 5 & 0 & 0 & & 16 & 0 \\ 100, \text {, Cos Lettuce, at } 2 / 6 & \ldots & \ldots & \ldots & 12 & 10 & 0 & & \end{array}$

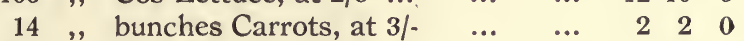

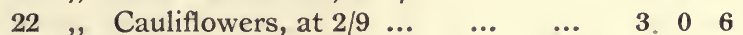

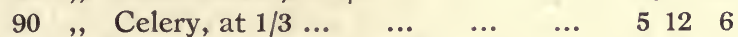

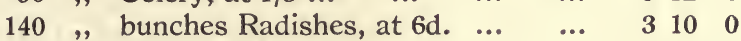

No. 7.- 12 doz. bunches Radishes, at $1 /$... $\quad \ldots \quad \ldots \quad 012 \quad 0$

$\begin{array}{lll}31 & 15 & 6\end{array}$

$\begin{array}{lllllll}12 & \text {, bunches Carrots, at } 3 / 6 & \ldots & \ldots & 2 & 2 & 0\end{array}$

$\begin{array}{lllllll}70 & \text {, Cabbage Lettuce, at } 1 /- & \ldots & \ldots & 3 & 10 & 0\end{array}$

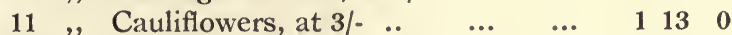

12 ", bunches Radishes, at $1 \%$...

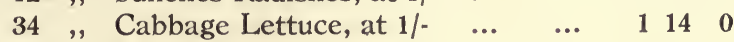

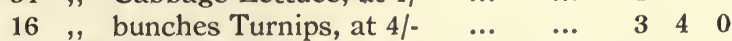

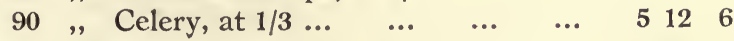

No. 8.- 18 doz. bunches Radishes, at 10d. ... $\quad \ldots \quad \begin{array}{llllll}0 & 15 & 0 & & 19 & 6\end{array}$

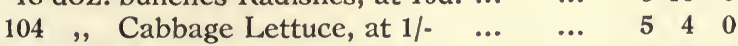

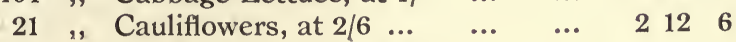

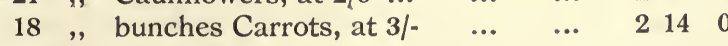

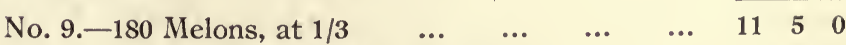

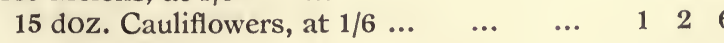

No. 10. -120 doz. bunches Radishes, at $8 \mathrm{~d}$. $\ldots . \quad \ldots \quad 4 \quad 4 \quad 0 \quad 0$

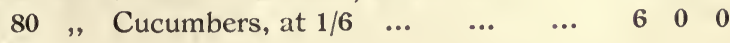

4




\section{ESTIMATED ANNUAL INCOME AND EXPENDITURE.}

Gross Returns, brought forward fram previous page $\ldots . \quad \ldots \quad \ldots \quad 239 \quad 5 \quad 5$ Expenditure :-

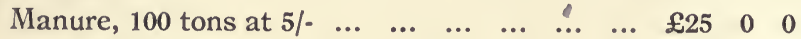

Roots for Forcing :-

Rhubarb, 1,500 at $£ 15$ per $1,000 \ldots £ 22 \quad 10 \quad 0$

Seakale, 3,600 at $70 / . \quad, \quad \ldots \quad 1212 \quad 0$

Chicory, 750 at 70/. $\quad$ ", $\quad \ldots \quad 212 \quad 6$

Carriage and handling of same... $\quad 5 \quad 5 \quad 0 \quad 0$

Seeds $\begin{array}{llll}42 & 14 & 6\end{array}$

Rent and Rates

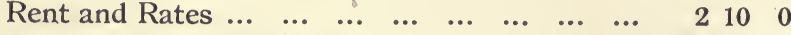

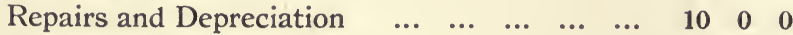

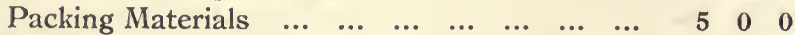

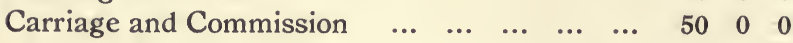

Total Expenditure, exclusive of labour $\quad \ldots \quad \ldots \quad 136 \quad 4 \quad 6$

Gross Profit

$\begin{array}{lllllllllllllllll} & \ldots & \ldots & \ldots & \ldots & \ldots & \ldots & \ldots & \ldots & \ldots & \ldots & \ldots & \ldots & 103 & 0 & 11\end{array}$

Labour, calculated at $30 /$ per week for one man $\ldots \begin{array}{llllllll}\ldots & \ldots & \ldots & \ldots & 78 & 0 & 0\end{array}$

$\begin{array}{llllllllllllll}\text { Net Profit } & \ldots & \ldots & \ldots & \ldots & \ldots & \ldots & \ldots & \ldots & \ldots & 25 & 0 & \text { 11 }\end{array}$

NoTE.-The profits would be much increased if the produce was sold locally instead of being sent to market, as then not only would higher prices be obtained but the expense of railway carriage and salesmen's commissions would be saved. Also, where the forcing of roots is carried on systematically, the gardener would raise his own, and so save very materially on that item.

\section{APPROXIMATE COST OF EQUIPMENT.}

40 Three-1ight Frames, at 6/- each for material, made at home... $\begin{array}{cccc}\qquad & 12 & 0 & 0\end{array}$ 120 Lights, bought ready-made, painted and glazed at home, at

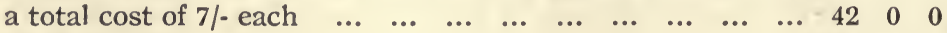

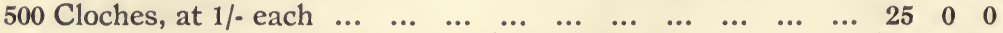

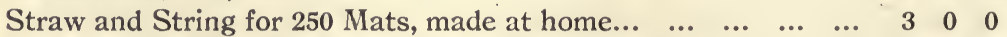

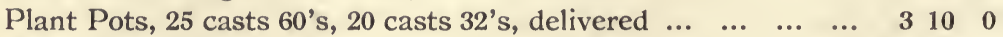

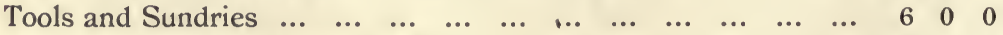

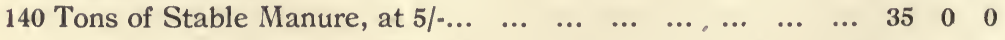




\section{Chapter XV.}

\section{INTENSIVE CULTURE ON ALLOTMENTS AND COTTAGE GARDENS.}

Forcing on Hot-beds Unnecessary-Great Increase in Quantity of Produce-Essential Features of the System-How to Secure Them at Small Expense - Suggestions for Practical Work with Schemes and Diagrams of Intercropping-Prince Kropotkin on Mutual Help.

WORKING men who have small gardens might, with great advantage, imitate many of the methods of the French gardener. It would be absurd to recommend that the system should be carried out to its full extent by those who seldom can afford to spend much upon their gardens beyond their labour, because of the outlay necessary, but there are many important features in it which can be adopted without incurring any more expense than is required in ordinary gardening. The popular idea that French gardening consists of huge hot-beds covered with frames and bell-glasses is only partly true. These things are important accessories, but are not the system itself; they are indispensable for some of the earliest crops, but practical experience goes to show that such crops, although they sell for high prices, are very little, if any, more profitable than those produced a little later at much less expense.

There has been much controversy with respect to the profits which may be derived from French gardening, and it is certain that where the cost of labour and manure, together with depreciation and interest on invested capital, are taken into careful account the profits can never be very large, but whatever difference of opinion there may be on this point, there can be none as to the great increase in the quantity of produce from each square yard of land cultivated under this system, as compared with that obtained by ordinary methods.

From this point of view alone intensive çulture on similar lines to those of the French gardener, but modified to suit the 
special circumstances of the case, would be of great benefit to the allotment holder, who would thereby be able to produce, without much extra outlay, a larger quantity of wholesome food for his family, as well as the probability of having some to offer for sale to his neighbours. In addition, the increased interest which arises from an occupation calling for forethought, judgment, and careful planning, and the pleasure and satisfaction to be derived from viewing the perfect vegetables mature in succession, with almost mechanical regularity, are in themselves ample recompense for any additional time and expense which may be entailed.

A few frames and lights (which can be made at home) to protect plants through the winter and to raise further batches in the spring, and which could afterwards be used to produce a summer crop of cucumbers, are all that are really neçessary in the present case. Every effort should be made to secure some, but even if that is impossible at the outset, a great deal can be done without them.

If reference is made to the chapter on French gardening, page 65 , it will be seen that the system is there summed up in the following words: "the provision of shelter and protection, warm and rich soil, abundant moisture and good drainage, with a careful arrangement of inter-and successional cropping." A study of these points will discover nothing impossible, even to the allotment holder.

Shelter and protection can easily be provided by the use of straw mats (which cán be made at a cost of $3 \mathrm{~d}$. each for material-see page 77). Where no frames are available, thousands of comparatively tender plants, such as lettuce and cauliflowers, if pricked out on a dry bed and sheltered on all sides save the south by mats fixed on hurdles, can be brought quite safely through an average winter, ready for setting out in February, and March. A few laths fixed over the bed, so that it can be covered in severe weather with mats or dry litter, will make all safe.

Warm soil implies not only beds of fermenting manure but also well-drained, well-worked soil, friable and kindly, and free from cold, stagnant moisture. By referring to the article on "Drainage," page 7, it will be seen that drained soil (and the 
air immediately above it) is several degrees warmer than similar adjoining land which is undrained. When the land needs draining, pipes should, if possible, be used, but if money is scarce fairly efficient drainage can be secured, providing there is a good fall for the water, by using plenty of rough stones instead; even brushwood or twisted straw if laid in the trench with the same care with which pipes would be placed will act almost as well for a number of years.

The soil must be made mellow and friable; if it is light this condition can be brought about by the addition of plenty of decayed vegetable matter and a little chalk; if heavy, add lime, road scrapings, sifted coal ashes, or charred rubbish.

Richness of soil of course implies manure, but then manure has to be given in any case if crops worthy of the name are to be regularly obtained; there may be a little additional expense at the outset for a few extra loads of manure but this is soon amply repaid by the heavier crops, and when once the soil is brought into a good rich condition it is easily kept so. With a little trouble and forethought there would be always on hand a compost heap, made up of garden refuse, annual weeds, leaves of trees, road scrapings, mud, poultry manure, house slops, and such like. A heap of this material, if turned occasionally with a good sprinkling of lime added at each turning; would, after one season for rotting down, be found a very valuable fertilizer, the use of which would greatly reduce the manure bill.

Abundant moisture, providing the soil is well drained and in good heart, is most essential for the production of heavy crops, and a special effort should therefore be made to supply it. There are few places where water cannot be obtained by taking a little trouble; with a yoke and two pails or a paraffin cask fixed on wheels a surprising lot of watering could be got through in a few hours, if the source is near by. When water is given the soil should be thoroughly soaked-driblets are useless. But it is only when there is close intercropping and for a few special crops that much additional water need be given. The moisture which is already in the ground should be retained there for the use of the growing crops, instead of being allowed it to evaporate into the atmosphere, and this 
can be effected to a large extent by the frequent use of the hoe and a judicious application of mulches (see pages 17 to 21).

Having secured a warm, friable, rich and well-drained soil, with arrangements for protection and shelter and increased supplies of moisture when required, the foundation has been well laid. With this to build upon pains and patience can accomplish wonders.

The Cropping of the garden may now be considered. By a careful examination of the "Plans of Rotation and Intensive Cropping" and the detailed explanation thereof on pages 58 to 62 , the chapters on Seeds and Sowing, the Routine Work of the French Garden, and the Details of the Cultivation of Vegetables, ample information of a clear and precise nature will be found which, if followed, will enable the allotment holder to successfully emulate the French gardener in most things except the earliest crops from hot beds, to his own profit and satisfaction.

In laying out the garden there should be set aside a space for seed and plant beds, herbs and mint; also for rhubarb and seakale, both of which, as well as many other things, may be forced or forwarded, easily and cheaply, by the methods described in the chapters dealing with those subjects. Suggestions for the arrangement and rotation of main crops will be found in previous chapters. The following suggestions for intercropping are recommended as being easy and profitable:-

1.--In February plant cabbage lettuce from frames or beds, $10 \mathrm{in}$. apart; in March set well-hardened cauliflower plants between every second lettuce and in every fourth row, then sow a line of short-horn carrots in the middle, between two rows of

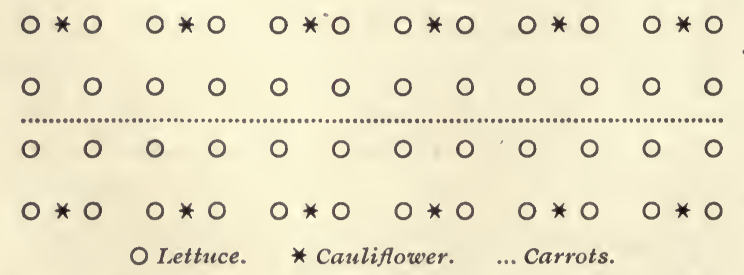

lettuce. By the middle of May clear the lettuce, hoe well, and set three dwarf beans from pots, triangular, between each 
cauliflower in the row. The cauliflower should be ready late in June, beans and carrots (pulled young) end of July, then prepare

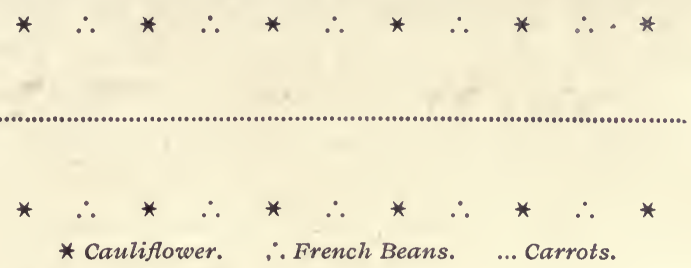

trenches for late celery, and run spinach, lettuce, or radish between trenches; after celery level ground and in the following March sow onions, or prepare the ground for parsnips, carrots, and beet.

2.--In March plant second early potatoes (sprouted); lift in August, then plant cabbage and colewort alternately, so that they stand $1 \mathrm{ft}$. apart in the row and $2 \mathrm{ft}$. between the rows; between these in October plant a row of cabbage lettuce at 8 in.

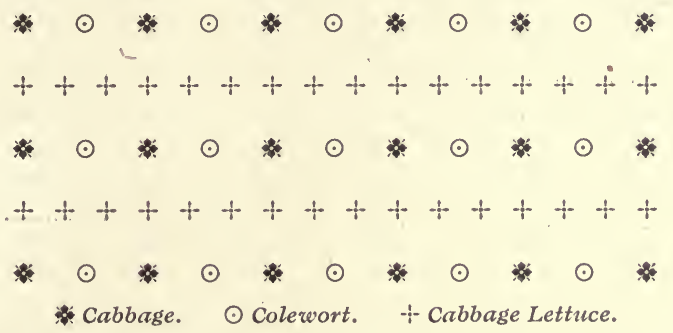

apart. Begin cutting colewort in December and clear early in February, then dibble three broad beans in each of the spaces where the colewort stood. The lettuce should be ready by the end of April, and as soon as they are gone manure and dig between the cabbage and sow a double row of runner beans,

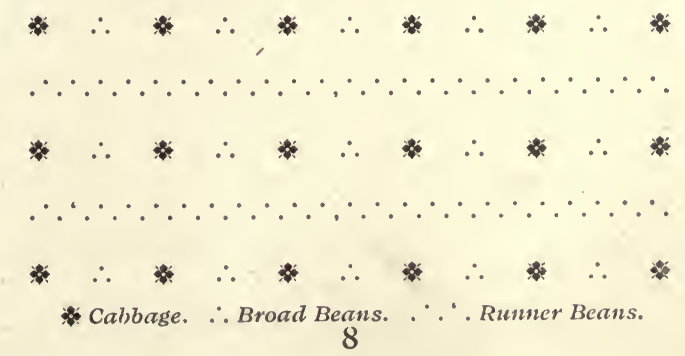


which must kept dwarf by pinching out the tops; these will fill the space when cabbage and broad beans are gone. After runner beans the ground should be dug and shallots planted on it about the 1st of January; the shallots are cleared about the end of June, then dig over at once, cover with two or three inches of manure and plant early celery all over the bed, 10in.

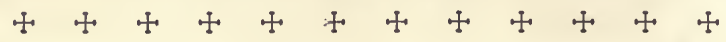

$$
\begin{aligned}
& \text { † † † † † † † † }
\end{aligned}
$$

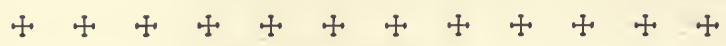

$$
\begin{aligned}
& \mp \text { Celery. ... Radish. }
\end{aligned}
$$

apart in the row, $15 \mathrm{in}$. between the rows, with radish sown between; water in well, and frequently afterwards.

3.--In October plant hardy cos lettuce $1 \mathrm{ft}$. apart each way. From beginning of February to end of March sow early dwarf peas between alternate rows. As soon as peas are gone hoe

\begin{tabular}{ccccccccccc}
$\odot$ & $\odot$ & $\odot$ & $\odot$ & $\odot$ & $\odot$ & $\odot$ & $\odot$ & $\odot$ & $\odot$ & $\odot$ \\
\hdashline & $\odot$ & $\odot$ & $\odot$ & $\odot$ & $\odot$ & $\odot$ & $\odot$ & $\odot$ & $\odot$ & $\odot$ \\
$\odot$ & $\odot$ & $\odot$ & $\odot$ & $\odot$ & $\odot$ & $\odot$ & $\odot$ & $\odot$ & $\odot$ & $\odot$
\end{tabular}

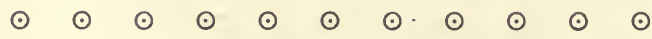
$\odot$ Cos Lettuce. . ... Peas.

well and dibble in Brussels sprouts or broccoli, 18in. apart in the row, $2 \mathrm{ft}$. between rows; then between each row sow parsley mixed with a little cabbage lettuce seed and as soon as lettuce are up thin to $1 \mathrm{ft}$. apart. Parsley is gathered during winter and spring. Clear ground beginning of May, manure and dig, then plant with ridge cucumbers from pots; early in August plant

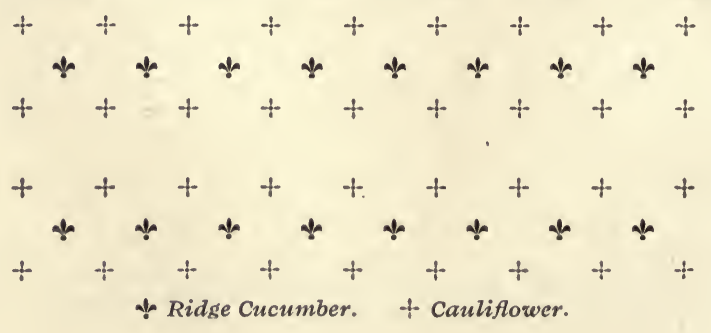


autumn giant cauliflowers amongst the cucumbers, 2ft. apart each way, watering in well; clear cucumber vines as soon as past their best. After cauliflowers double dig and manure.

4.--In February make beds $5 \mathrm{ft}$. wide, $1 \mathrm{ft}$. apart, with a board on each side standing up $1 \mathrm{ft}$., held in position with pegs; throw out $6 \mathrm{in}$. of soil, put in $6 \mathrm{in}$. of good warm manure and return soil. Plant four rows of early potatoes, previously sprouted, 9in.

\begin{tabular}{|c|c|c|c|c|c|c|c|c|c|c|c|c|}
\hline o & o & o & 0 & o & 0 & 0 & 0 & $\mathbf{o}$ & 0 & 0 & o & 0 \\
\hline o & 0 & o & 0 & 0 & o & o & o & o & o & o & o & o \\
\hline o & 0 & o & o & 0 & o & o & o & o & 0 & o & o & o \\
\hline o & 0 & o & o & o & o & o & o & o & o & o & o & o \\
\hline
\end{tabular}

o Potatoes. ... Radishes.

apart in the row, then sow radishes between rows. Nail laths to the top of the boards, across the bed, and cover with mats each night to protect from frost, but be sure to uncover in daytime after growth is seen, unless the weather is very severe. As soon as radishes are gone plant cauliflowers, 18in. apart,
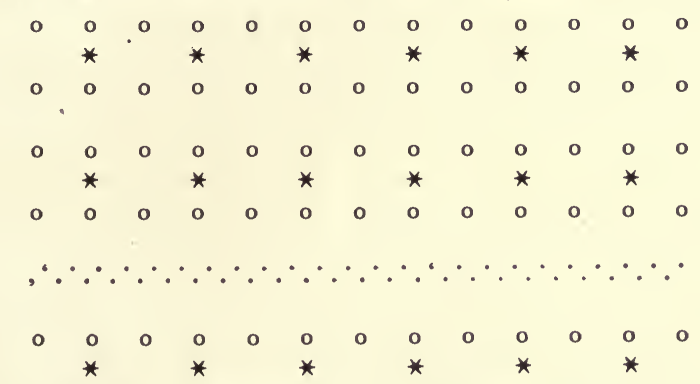

o Potatoes. * Cauliflowers. $\quad \because *$ French Beans or Peas.

between two outside rows. Early in May remove boards and then spread 3in. of manure on the paths and dig it in; then sow French beans or peas. Potatoes will be ready to lift in June, and when these are gone sow turnips in the spaces they occupied, then give all the bed a good soaking with water. When ground is clear manure and dig all over, then in October plant hardy $\cos$ and cabbage lettuce alternately $1 \mathrm{ft}$. apart both ways. 
In March radishes can be sown thinly between the rows of lettuce, then plant cauliflowers in the rows of lettuce, $2 \mathrm{ft}$. apart,

\begin{tabular}{|c|c|c|c|c|c|c|c|c|c|c|c|c|c|}
\hline 0 & * & o & 0 & * & 0 & 0 & * & 0 & 0 & * & o & 0 & * \\
\hline o & & 0 & o & & 0 & 0 & & 0 & 0 & & 0 & 0 & \\
\hline 0 & & 0 & 0 & & 0 & 0 & & 0 & 0 & & 0 & 0 & \\
\hline 0 & * & 0 & o & * & 0 & 0 & * & 0 & 0 & $*$ & 0 & 0 & * \\
\hline 0 & & 0 & 0 & & 0 & 0 & & o & 0 & & 0 & 0 & \\
\hline
\end{tabular}

$3 \mathrm{ft}$. between rows. The lettuce will be gone in May, then plant tomatoes, 18in apart, between the rows of cauliflowers, which will serve to protect the tomato plants until they get strong.

5.-In February sow early peas in shallow trenches, $3 \mathrm{ft}$. $6 \mathrm{in}$. apart; in covering the seed leave a little soil on each side of the trench, which is to be drawn up to the plants when they are a few inches high. In April plant a row of second early potatoes between each row of peas. When peas are over clear away, lightly fork the soil, and plant Brussels sprouts where the peas stood. Lift potatoes as soon as ready, digging ground properly at the same time, then sow winter spinach and onions where the potatoes stood.

6.-In March plant a cabbage lettuce, which was sown the previous autumn and wintered, $1 \mathrm{ft}$. apart each way; then plant a large variety of onion, sown the previous autumn, between each lettuce. When the lettuce are cleared hoe deeply between the rows of onions. In September plant a rosette colewort between each onion (these can be pulled at the end of the month). The coleworts will be cleared away in the following spring in time to prepare the ground for potatoes.

7.-In January plant shallots, $1 \mathrm{ft}$. apart each way. In March sow two broad beans $(:)$ between each shallot in every third row, so that the rows of beans stand $3 \mathrm{ft}$. apart. Pull shallots end of June and beans a month later. (When bean straw is 
pulled lay it straight and put it away in a dry place, as it can be used for making mats or other protective purposes.) Lightly fork ground and plant broccoli in rows $2 \mathrm{ft}$. 6in. apart, 18in. between plants in the row; then sow short horn carrots between rows of broccoli (these carrots will be fit for use in late autumn when early-sown carrots are large and coarse).

8.--In October plant hardy cabbage lettuce, $1 \mathrm{ft}$. apart each way. In January sow two broad beans (:) between each lettuce in every alternate row. When beans are cleared plant celery in trenches, $3 \mathrm{ft}$. apart, and crop the space between trenches with radish, spinach, or lettuce.

Enough examples have now been given to show how the ground can be almost constantly occupied and cropped to its full capacity. The plants must on no account be set closer than the distances indicated. The ground must be kept well supplied with manure, the plants well watered and in some cases mulched, and the surface of the soil frequently stirred with the hoe. Never allow the plants to occupy and exhaust the ground after the crop is ready for gathering, but clear away at once and prepare for another crop.

In conclusion, cottage gardeners, allotment holders, and indeed all workers on the land, are earnestly recommended to study the following remarks by Prince Kropotkin, and to put his suggestions into practice:-

"A necessary condition of success in work on the land is communicativeness - continual friendly intercourse with your neighbours. A book gives general advice only, while every acre of land has its own individuality, which depends upon the soil, the position, the prevailing winds of the locality, and so on. These things can only be learnt by local residents of a long experience-an experience which represents the collective lnowledge of the local population. Let every beginner remember that the superior gardening of the French, the Flemish, the Jersey and Guernsey gardeners, and the work of the English greenhouse growers and florists, is the result of their collective experience. Every gardener may have his own secrets on this or that special point, but the bulk of the general knowledge which has developed in a given locality is the result of collective experience, and of the continual talk among the gardeners about matters which interest them. Beginners who appreciate that talk and turn it to good account will find that advice is never refused by neighbours." 


\section{Chapter XVI.}

\section{SEEDS, SOWING, THINNING-OUT, AND TRANSPLANTING.}

The Necessity for Good Seed-Varieties to Choose-NoveltiesTesting for Germination-The Seed Bed and its Preparation-Sowing -Thinning Out-Transplanting-How the Plants should be Trimmed -Dibbers and How to Use Them.

COOD seed is one of the most essential conditions of success

$U$ in growing vegetables. For this reason great care should be exercised in selecting the source of supply, for although cheap seeds may be good they may also prove very dear in the end, and it is far safer to pay a little more to an established firm with a good reputation to uphold, and so obtain seeds of assured strain and high vitality, than to risk having only a partial crop or one of very poor quality.

Whenever possible, seeds should be purchased some time before they are required, not only to have them ready to hand but also to allow time to test for germinative power, if there should be any doubt on the subject. Testing the seeds is especially necessary in the season following a cold wet summer, as it is then frequently immature and unripened.

Some seeds retain their vitality for many years whilst others lose it quickly (see tables at end of book), but in any case it is safest and the most likely to be productive of good results if fresh and thoroughly ripened seed is always used.

The choice of varieties is a matter which largely depends upon local conditions, some doing better in one situation than in another; these peculiarities can be best ascertained by enquiry from gardeners in the neighbourhood, or by actually growing several kinds and selecting that which does the best. As a general rule, old-established varieties should always be preferred, particularly for the main-crops, for the fact that they 
have been long in favour of itself proves that they have some sterling merit or growers, being free to choose, would have discarded them long ago.

Novelties should be tried, but on a small scale only, and never for the main crop; by this means the gardener can keep well informed regarding new varieties without risking his crop.

Seed Testing.-A simple way to test the seed for percentage of germinative power is as follows:-Put upon a plate a folded piece of flannel, damped with warm water, and upon the flannel put a counted number of seeds. Stand the plate in a warm dark place and keep the flannel damp. In a short time (from one to several days, according to the variety) those containing life will sprout, and can then be counted. At the same time it should be remembered that this is no test of the actual number which will have strength to grow into good plants when sown under ordinary conditions in the open garden or field. In such circumstances there will be many losses through weakness, besides those which will occur through too deep or too shallow planting, too great extremes of temperature or moisture, or for many other reasons.

The Seed Bed.-Before seeds are sown it is necessary to properly prepare the soil for their reception. A sufficient amount of warmth, moisture, and air are the requisites of germination, and these conditions can best be provided when the surface soil is fine and powdery and free from large lumps. When it is rough and cloddy some of the small seeds fall into crevices or are buried under large pieces, and either fail to germinate or do so very irregularly. Heavy soil should be prepared some time beforehand, especially when intended for small seeds, so that the action of the weather, and particularly of frost, will have the chance to produce a tilth which no amount of labour can equal. In any case, the surface of the soil intended for seeds should be moved about with the hoe, rake or harrow before sowing, as seeds germinate better in freshly worked soil than in that which has lain long undisturbed. This stirring breaks any cap which may have formed, introduces air, dries the surface, and makes the soil warmer. 
Early aeration of the soil assists germination, and promotes vigorous growth by encouraging the nitrifying bacteria.

One of the best materials with which to form a seed bed, when the area to be sown is not too large, is finely sifted exhausted manure from an old hot-bed, as is always used in the French garden with excellent results. The ordinary soil should be covered with this material about three inches deep. Seeds germinate in it quickly, evenly, and strongly, and the plants lift easily from it with unbroken roots.

Seed Sowing.-Having prepared a loose warm surface, the soil should be raked down fine and the seed sown either broadcast or in drills. The depth at which it is covered depends upon the size and variety of the seed, the condition of the soil, and the period of the year. It may be sown shallower in the spring, when the ground is moist, than in the summer when the ground is dry. Very small seeds should, as a rule, be barely covered, whilst large seeds, such as peas or beans, may be put in from two to four inches deep. The cost of seed being small in comparison with the value of the crop, it is advisable to sow rather thickly so as to ensure a full plant.

The garden is not only more attractive but the work of cultivation is much easier when the plants are grown in straight

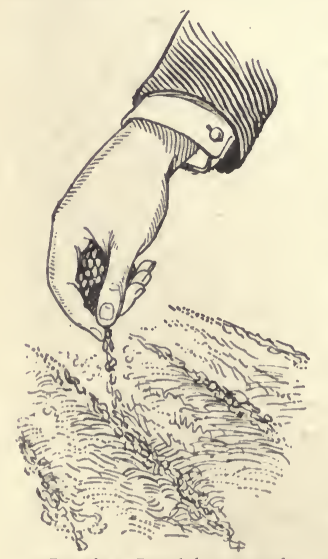

Sowing Seed by Hand. evenly spaced lines, therefore be careful to make a perfectly straight mark for the first row as a guide, then use a marker on the drill, and all the rows will be straight and at equal distances apart. If the sowing is done by hand, first mark out the rows and open the drills to the depth required, then taking the receptacle for seed in the left hand, walk along the row and drop the seed evenly from the right hand, held in the position shown in the illustration. The seed is held by the little and next two fingers, from whence it gradually works down, being evenly dropped by a slight rubbing motion of the thumb against the next two fingers. 
After sowing, cover up the seed, either by raking, by pulling soil into the drills, or, if the bed and seeds are small, by a thin scattering of fine dry soil. The soil above the seed must then be compacted, particularly when it is likely to become drier, rather than moister, as is the case in the spring and summer. On heavy soil considerable discretion must be used over this operation, as the soil will be liable to cake if it should happen to be too moist, and at all times on such soils pressing should be done gently. On light soils the rows should be trodden down, rolled, or beaten with the back of a spade. The reason for this is to induce the moisture in the soil below to rise to the surface by capillary attraction, and so afford sufficient for the germination of the seed. Since this compacting of the surface induces the soil moisture to rise, some of it passes away by evaporation into the atmosphere, and is thus lost to the plants. It is therefore important that the soil be stirred again as soon as the seedlings begin to show, so as to prevent an undue evaporation; indeed, the space between the rows should be kept stirred even before the seeds germinate, and those which are planted deep, as peas, may have the soil compacted about them and the surface layer may be loosened immediately afterwards.

When plants have to be transplanted, a space should be reserved for seed beds near the buildings and water supply; so that they can receive every necessary attention in watering, shading from the sun, and protecting from frost and from birds.

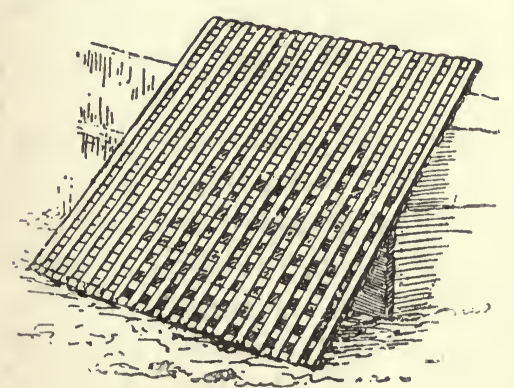

Lath Screen.

In hot dry weather the bed should be shaded until the seedlings appear. This may be done in many ways, but one of the best methods is to fix one or more lath screens, as illustrated, over the bed. This is laid on pegs, so as to stand from one to two feet above the soil. Such a screen, whilst giving partial shade, permits a free circulation of air, and can be removed at any time for watering or weeding. Another useful screen is 
one of brushwood, as depicted below. This acts in a similar

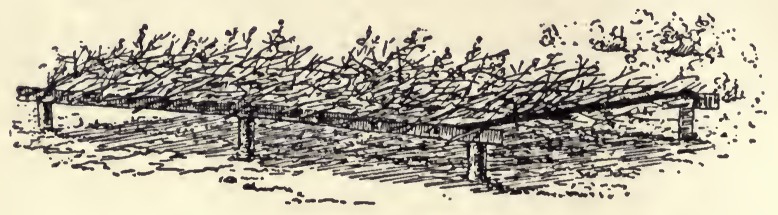

Brushwood Screen.

manner to the lath screen, but is not so convenient to remove and replace. Either of the above methods are much better than laying brushwood or litter directly on the soil, as the seedlings are not so liable to become drawn, nor the bed foul from lack of weeding. Another very successful method of raising small seeds is to cover them with cloches. These can be tilted for air, always with the raised part on the side opposite to to that from which the wind is blowing; they may be whitened on one side to break the sun's rays, or covered with mats to protect from frost.

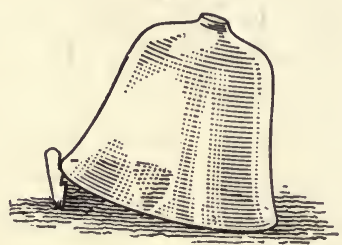

Tilted Cloche.

Seeds which germinate very slowly, such as parsnips, carrots, onions, and the like, when sown in the open ground should have mixed with them a few quickly-germinating seeds, such as radish or turnip. These serve to mark the rows, so that the soil may be hoed and stirred about before the main-crop seeds are up, and so prevent weeds from getting too far ahead. In this way a catch-crop of radishes can be obtained before they inconvenience the main crop.

For main crops the seed should always be sown in long lines the full length of the plot. This will greatly enhance the ease and efficiency of cultivation, by allowing a wheel-hoe or horse-hoe to pass along the rows easily. If the rows are too long for one kind of vegetable two or three different kinds may be put in the same row, providing the combination is of varieties requiring the same general treatment and length of season.

Thinning Out.-Having sown a liberal allowance of seed 
in drills where the plants are to stand, if the ground is in good order there will naturally be a great many more plants than are required. At first sight this may seem wasteful, but it is nothing compared to the loss incurred when there is "only half a plant." The surplus needs removing at once, otherwise the plants will speedily become drawn and weak. It is a great mistake to let young plants stand together too thickly; without a sufficient amount of light, air, and moisture it is impossible for them to develope properly.

Therefore, as soon as the seedlings can be handled, proceed to remove the weakest plants. Thinning should be a process of selection, the best being allowed to remain. At the first thinning the plants may be allowed to stand at half the distance apart it is ultimately intended to leave them for the main crop; by doing so not only will a full plant be assured, but in the case of such things as beet, onions, and carrots, which may be left until they attain a moderate size without overcrowding, a gathering of choice young roots can be made which will add materially to the profit of the crop. At the same time never delay the final thinning until the plants are unduly crowded, or the main crop will be sure to suffer.

Transplanting.-Good plants are necessary if transplanting is to be conducted successfully. To obtain such plants the seedlings must be thinned out without delay where they stand together too thickly. If grown in a frame or on a hot-bed they should be well hardened before removal, or they may collapse when fully exposed to sun and wind in the open.

The next important point is to have the land in good order; it should be in fine tilth, deeply worked, and freshly stirred. The plants will obtain a root-hold much quicker in soil which has been recently moved about on the surface than in one where the surface is beaten down and compacted.

The best time to transplant is in dull, cloudy or showery weather. If it must be done when the weather is hot and dry the roots, particularly of brassicas, should be dipped in a "puddle"-a mixture of clay and water of the consistency of thin cream-or the rows may be thoroughly watered after planting and the loose soil on each side afterwards drawn to 
the stems of the plants with a hoe. Sometimes under such conditions the hole into which the plant is put is filled with water before the soil is pressed up to the root.

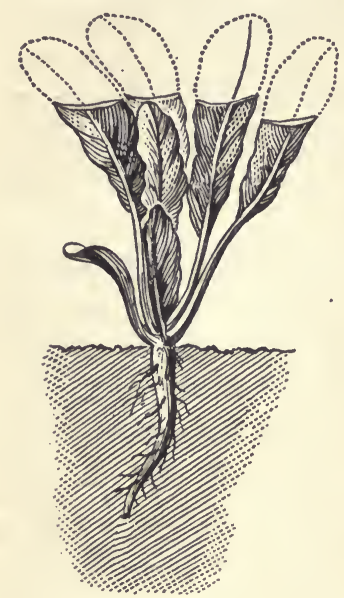

How Leaves and Root are Shortened.

The day before the plants are lifted the bed in which they stand should be soaked with water. The soil should then be loosened with a fork, when the plants will draw easily with the roots unbroken. Whilst the plants are out of the ground they should be kept moist, both roots and tops, and until removed for planting they should be covered with a wet sack.

If the plants are rather large, and particularly if the weather is dry, it is a good plan to shorten the large leaves to half their length and to cut off the end of the tap-root. In transplanting onions and other similar subjects which have a mass of fine roots, these may with advantage be cut off to within an inch of the base, and the tops shortened by onethird their length; the advantage of this treatment is that the roots are not so liable to be set turned upwards, the leaves are less likely to wilt or the plant to fall over, and the plants being more convenient to handle the work of setting them out proceeds quicker. Apart from convenience, practical experience proves that the plants benefit by the operation. When the number of plants to be dealt with is small, and each can be lifted with a ball of soil, this shortening process is unnecessary.

The best tool for opening the soil is the dibber, of which several of the most useful forms are here depicted. The one on the left is the kind used in the French garden, and is a very handy little tool; it may be bought in several sizes and has an iron-shod tip. The two others are samples of almost equally useful ones, shaped

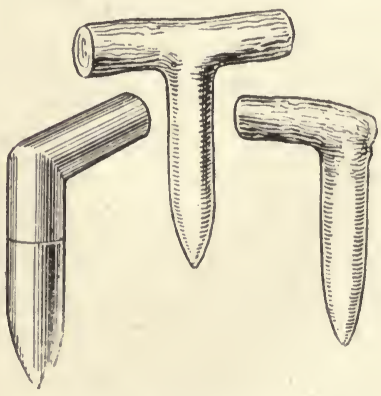

Samples of Dibbers. 
from the suitably-formed branch of a tree, preferably of hard wood. A number of such dibbers, in several sizes, should be kept ready for use.

When transplanting, it is customary for a boy to carry the plants in a covered basket, and to drop them at the right distances apart just ahead of the planters. Usually one boy will drop plants for two men; he should not drop faster than the plants are required.

To plant, hold the dibber in the right hand and the plant in the left; push the dibber straight downward into the soil with a half turn, so that it will enter more

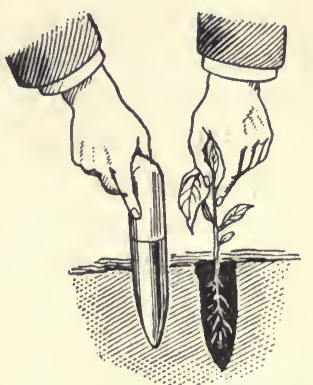

How the Dibber is used. easily; lower the plant into the hole and see that the roots enter easily and are not turned upward; set the plants deeply, up to the seed leaf; then again insert the dibber, a short distance away from the plant, and with it press the soil firmly against the root. The plant should be fixed so tightly in the soil that the top will break off before the plant will diaw. In dry weather loose soil should be drawn up to the stems on each side of the row when the planting is finished.

When there is no option and very long drawn plants must be set, they should be inserted in the ground in a slanting position, so that the whole of the stem is covered with moist soil. They take longer to plant in this manner, but it is well worth the trouble, as then roots form all along the buried stem, and the plant ultimately developes almost as well as though it had been sturdy when set out.

Pricking-out.-Transplanting has so far been considered only as a removal of the plant from the seed bed to its permanent quarters, but in gardens where the highest class of produce is raised it is customary to "prick-out" the seedlings into a nursery bed where, having ample light, air, and space for development, they grow into stocky and sturdy specimens. This system has much to recommend it where the operations are conducted on a moderate scale, and indeed it is probable that.it would pay to carry out even on the most extensive scale, 
for the time occupied is comparatively small, whilst the gain in securing sturdy plants of even quality and possessing an abundance of fibrous roots is great.

The method practised in the French garden yields such satisfactory results that it seems difficult to improve upon, and is as follows:-

Pricking-out is done as soon as the seed leaves are large enough to be taken between finger and thumb, or are fully developed, with the first rough leaves just showing. The soil in which the seedlings stand is loosened, then they are gently drawn and laid side by side in a small heap on a piece of board and carried to the nursery bed, the soil of which consists only of finely-sifted old hot-bed manure, in a moist condition. In this soil a hole is made with the first finger, or by a small dibber about the size of the finger, but a little more tapered. The seedling is taken by the leaves, and lowered into the hole up to the leaves, care being taken that the roots are not turned upward-then the soil is gently pressed to the stem. These tender seedlings require delicate handling, and must not be bruised in any way. Only good strong seedlings are used, sufficient seed having been sown to allow all weaklings to be discarded. Shade from bright sunshine is given, but no water, the moisture in the soil being sufficient until new roots are formed.

In some cases pricking-out is repeated a second and even a third time, it being claimed that frequent transplanting hastens maturity, improves the quality, and increases the fruitfulness of the plants subjected to it. 


\section{Chapter XVII.}

\section{DEVICES FOR FORCING, FORWARDING, AND PROTECTING.}

Hot-beds-How to Make and Manage Them-Cold Frames-Their Construction and Arrangement-The Cloche and its Uses-Shields of Calico and Paper-Imitation Cloche-Calico Screen-Movable Shield -Straw Mats and Suggestions for Using-Glass-covered Plant Protector-Box Plant Protector-Glass-covered Trench-Raised Beds with South Slope-Plan of Cropping the Beds-Cheap Method of Forcing in Pits.

THE up-to-date gardener strives, by means of forcing or the use of various protective appliances and devices, to place supplies on the market in advance of the normal season, and so secure better prices and larger profits than can be expected from main crops produced under ordinary conditions. Where there is a sufficient amount of capital at command, this presents very little difficulty to the experienced man who, by a judicious use of glass and heating apparatus in their various forms, can practically command success.

But the man in a humbler way of business, if he is not to be left hopelessly in the rear, must also have some means for producing conditions of warmth and shelter, whereby tender plants can be raised and grown on until the season is far enough advanced, and the weather sufficiently genial, to permit them to be set in the open ground with safety. Moreover, if he is alive to the possibilities of the situation, he will utilize every warm and sheltered position in his garden, and by the use of various cheap but effective devices to protect and forward early crops will to some extent neutralize, or even entirely overcome, the disadvantages arising from lack of means.

Some of the methods thus adopted are described and illustrated in the following chapter, and it is hoped that these suggestions may be the means of still further developing this interesting and profitable branch of intensive culture. 
Hot-Beds. - The purposes for which the hot-bed is used aré, in the main, the early raising of plants and the growing of certain crops to maturity, so as to obtain supplies more or less in advance of those produced under normal conditions. The heat for these beds may be supplied by means of flues or hotwater pipes, but it is more usually obtained from fermenting manure, tan-bark, or leaves.

The proper place for a hot-bed is on well-drained soil, with a south aspect, sheltered from cold winds by a building, fence, or tall close hedge; it should also be near the water supply.

The material most generally used for obtaining the heat is fermenting horse manure, and for the most satisfactory results it is important that this should be from well-fed horses and uniform in composition and texture. It should contain plenty of urine-soaked litter. The addition of half its bulk of dry treeleaves will contribute towards a steady and lasting heat, and this end may also be attained by mixing in a portion of unused manure which has been stored to keep dry and cool in narrow high-pitched stacks (see pages 82-83). In an emergency a third portion of cow manure containing plenty of litter may be well mixed with the fresh horse manure, though this is not recommended, as its action is slow and rather uncertain.

The object in view is the production of a uniform and steady heat throughout the bed. The first fermentation is nearly always irregular, beginning in isolated places in the heap whilst others remain cool. For this reason it should first be thrown into a large compact heap. As soon as fermentation has well begun, as may be seen by the issue of steam, it must be turned and thoroughly mixed, throwing that which was outside to the middle and breaking all hard lumps. This turning must be repeated several times at intervals of about two days to permit the escape of rank steam and noxious gas. Generally three turnings are sufficient, though sometimes, especially when the manure is very fresh and from highly-fed horses, it will heat so quickly and violently that it has to be wet in order to keep it from burning and will probably need turning five or six times before it is fit for use. If the weather is cold and fermentation is slow to begin, the addition of a little hen manure or wetting the heap with hot water will sometimes put matters 
right. When it is warm uniformly throughout the heap it is ready for making into the bed. From first to last, the preparation of the manure usually occupies about two weeks.

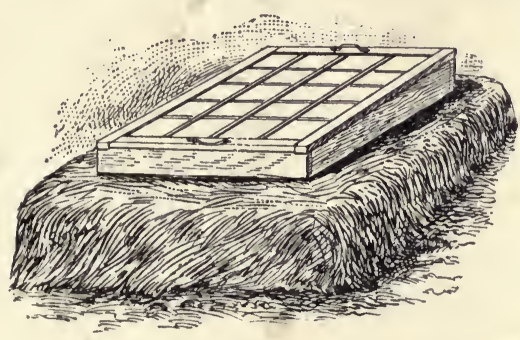

Manure Hot-bed on top of Ground.

Before beginning to make the bed, mark out accurately the space it has to occupy, allowing, if very early in the year and manure is plentiful, sufficient margin for it to project $18 \mathrm{in}$. beyond the lights all round, but if manure is scarce less margin must suffice, though it must never be less than 9in., or it will be found impossible to keep up the heat on the outsides of the frame. Use the longest stuff for the outsides of the bed, and keep this part a little higher than the remainder until the full height is reached. Except that on the outside, lay down alternate forkfuls of new manure and that which has been stacked (or of leaves) in layers about 6in. deep all over the bed, shaking it out so as to mix it well and break any lumps. Beat it down with the back of the fork as the work proceeds, and when it reaches the full height tread it all down firmly and evenly. Finish by filling up any hollow places with a little more manure. A bed made in this way will "hold together," and will retain heat on the outsides longer than when the manure is laid down indiscriminately.

The thickness of the bed depends upon the time of the year it is made and the purpose for which it is intended-the earlier the bed is made the thicker it should be. As a general rule, for the early forcing of salads, it will give good results if made 15in. thick in January, reducing in thickness about 3in. for each month it is made later. If made in March for cucumbers or melons $2 \mathrm{ft}$. is the minimum, and this can be gradually reduced to $1 \mathrm{ft}$. as the season advances.

When the bed is finished it should be covered with four to six inches of fibrous soil, consisting either entirely of sifted old hotbed manure as used in the French garden, or of a mixture of half that material and half good garden loam; then put on the frame, thrust a soil thermometer into the manure, and shut 
down the lights. For a few days the heat will probably rise very high, though this depends upon the thickness and composition of the bed. Neither sowing nor planting must be done whilst the heat is rising, but when it is falling, and has reached 85 deg. F., cucumber, tomato, and similar seed may be sown, and when it passes below 75 deg. it is ready for any other subjects.

From the time seeds or plants are put in the frame it must be covered up closely each night with mats, to keep out frost and to prevent the loss of heat by radiation. Of the various kinds of mats in use those made of rye-straw are the best. Full particulars for making and using these will be found on pages 76 to 78 .

When the bed begins to cool, or if the weather becomes severe, "linings" of hot manure must be put all round the frame, from the top edge of the bed to the level of the lights, and this lining must be renewed whenever any cooling takes place; if the lowering in the temperature is serious, pull down the sides of the bed all round to the level of the frame, and build it up again with fresh hot manure. If the bed is exposed to high winds a screen should be placed on the windward side or the temperature of the bed will be considerably reduced; brushwood or thatched hurdles, properly fixed, make an effective windbreak.

The Management of the Hot-bed.-The proper management of a hot-bed is only acquired by experience. Beginners are often impatient, and sometimes make the bed at a too early date, or do not give the manure enough preparation, or sow or plant before the heat is steady and so waste time and material. The thing to aim at is to secure sturdy plants which make a steady and healthy growth. This result is only to be secured by maintaining the proper temperature; by giving ventilation but avoiding draughts and chills; by never permitting the soil to get too dry whilst being careful never to get it very wet and cold by over-watering; by using only tepid water early in the day so that the leaves of the plants are dry when the lights are closed in the afternoon; by keeping the plants near the light and at the same time shading from a too hot sun; by never overcrowding, and by thoroughly hardening plants before 
transplanting to the open. By carefully observing these principles even a beginner may expect a reasonable amount of success, and experience will soon convert expectation into comparative certainty.

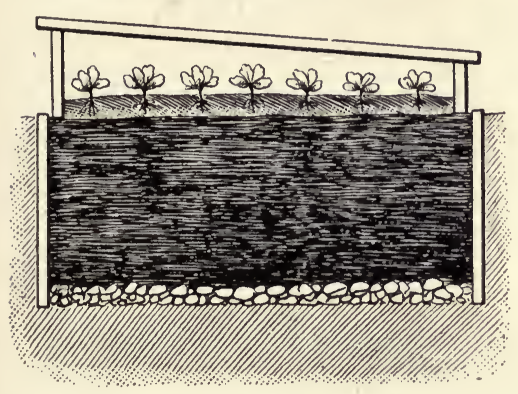

Cross-section of Sunk Hot-bed.

In some situations, where the ground is well-drained and there is no danger of the manure getting water-logged during a spell of wet weather, it is preferable to make the hot-bed in a pit instead of upon the surface of the ground. The pit is dug from $18 \mathrm{in}$. to $2 \mathrm{ft}$. deep and $6 \mathrm{in}$. wider than the frame all round. The sides are boarded up with rough timber and a few inches of rough material is placed on the bottom to keep the manure from the cold earth. It is arranged in layers as previously described, and packed firmly as the work proceeds, especially at the corners, which should receive extra attention, but it should not be trampled until the heat has risen again. A sunk hot-bed of this description, providing the site is dry, will generally give a more lasting and steady heat than one made entirely upon the surface. Where these sunk beds are used, it is worth while taking pains over their construction, as the same pits are available year after year.

Cold Frames.-The cold frame is in many respects similar to a hot-bed, both as regards management and uses, except that as there is no bottom heat it is not available for tender subjects in the cold months of the year. It is much used for carrying autumn-sown plants safely through the winter; for protecting parsley, winter spinach, late endive, violets, and similar subjects; for hardening off partially hardened plants which have been started early in hot-beds, and for raising early plants from.seed. It has a special value for use in forwarding numerous standing crops such as strawberries, mint, bulbs, \&c., to early maturity. Peas, beans, radishes, carrots, turnips, lettuces, potatoes, \&c., can all be grown to perfection 
in the cold frame, and although not so early as from hot-beds, by costing less to produce they yield as good profits.

The cold frame in construction is practically nothing more than glazed lights placed over and enclosing the interior of a bottomless box. This is all the French garden frame amounts to, and where their use is not extensive the dimensions and 'particulars given on pages 70 and 71 may be copied. Where, however, a large number of lights are used it will be found more economical to have instead of separate boxes two continuous rows of parallel boards, nailed to stakes driven into the ground at convenient distances apart. The size of the

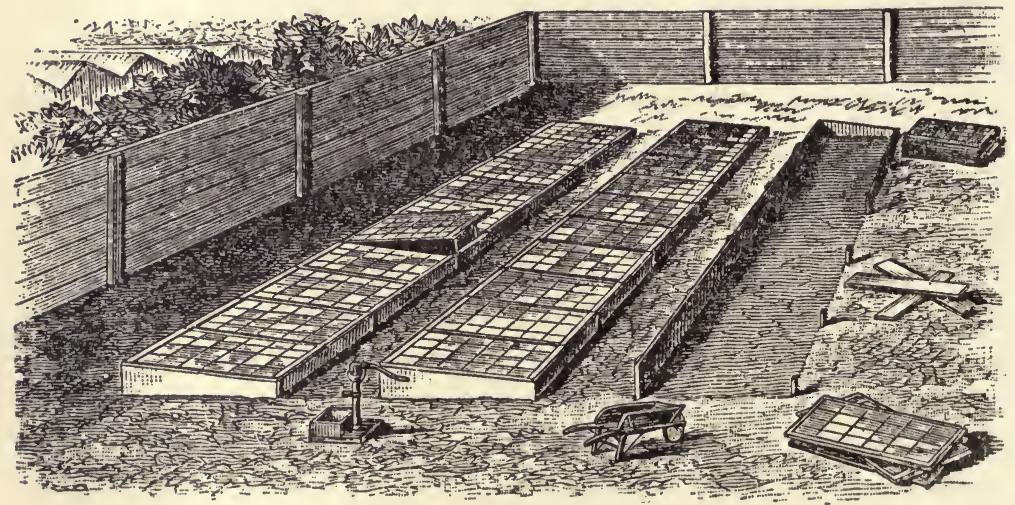

Arrangement of Cold Frames.

light regulates the width between the boards. The height of the boards depends upon the crops to be grown in the frames, $10 \mathrm{in}$. to $12 \mathrm{in}$. at the back and $7 \mathrm{in}$. to $9 \mathrm{in}$. at the front (according to size of light) being suitable for most purposes. For tallgrowing crops, such as cauliflowers, the height of the boards would have to be increased. The length is regulated by the circumstances of the case, and the ends are enclosed by boards cut to the required slope. Strips of wood $3 \mathrm{in}$. wide and $1 \mathrm{in}$. thick are fixed across from back to front board to receive the edges of the lights where they meet.

When used for forwarding purposes, the frames are fixed in position over the growing plants, wherever they may be standing, but when used for protecting plants through the winter, or for growing early crops in the spring, they should be 
placed in a sheltered, well-drained position, facing south. The soil should be specially prepared by the addition to the surface of sifted old hot-bed manure, about a barrow load to each light being none too much.

The management of the cold frame is very similar to that of the hot-bed. It should be closely covered with mats each night so long as there is any danger of frost The crops, being hardier, need considerably more ventilation than those on the hot-beds, whilst the water used need not be tepid. On the occasion of rain on mild days in the spring-time the lights may be removed entirely, so that the soil will get a good soaking; this tends to a more rapid and luxuriant growth.

Very good results can be obtained from cold frames covered with prepared paper or waterproofed calico. Either of these materials may be stretched tightly on a light wooden framework of the same size as an ordinary light, and used in the same way, except that during mild days they are removed entirely. Or calico may be attached to the back of the frame and drawn over at night, being rolled up out of the way whenever the weather is suitable.

The Cloche.-Although there are several millions of cloches in the gardens of France, where this appliance has been in use for generations, it is a comparatively new introduction into English gardens, and its merits are not yet fully appreciated; its uses, however, are so many, and the results from it so good that there is no doubt its stay will be permanent. Some of the uses it is regularly put to are described in the various chapters on French gardening, but it can also be used in many other ways which only become apparent with

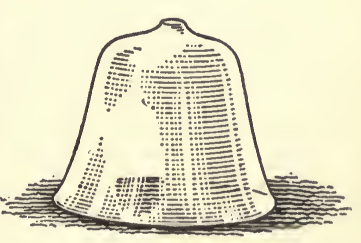

The Cloche. familiarity. It forms a complete little frame in itself, and for purposes in connection with forcing, forwarding, protecting, raising early seedlings and striking cuttings, is unsurpassed. For protecting and encouraging robust growth in vegetable marrows, ridge cucumbers, tomatoes, and similar plants when set out early in the open ground it is ideal. When used for 
covering plants which get too large for the cloche before it is safe to fully expose them, it is raised on three notched sticks, or "pegs," similar to those described on page 75 but, of course, as long as necessary.

Calico and Paper Shields.-Mention has already been made of the use of calico and paper in connection with cold frames, but in addition to this their uses at the hands of an ingenious and contriving person are manifold. With the specially prepared semi-transparent waterproof paper now on the market and a little wire, a very good imitation of the cloche can be made at little cost, which will serve admirably as a protector. A wire ring is made, $18 \mathrm{in}$. in diameter, and above this are three wires at equal distances apart, forming a tripod 18in. high. Below the ring the wires are prolonged for 6in., and these serve the purpose of attaching the protector to the soil, or it can be raised on them to give air. At the point where the

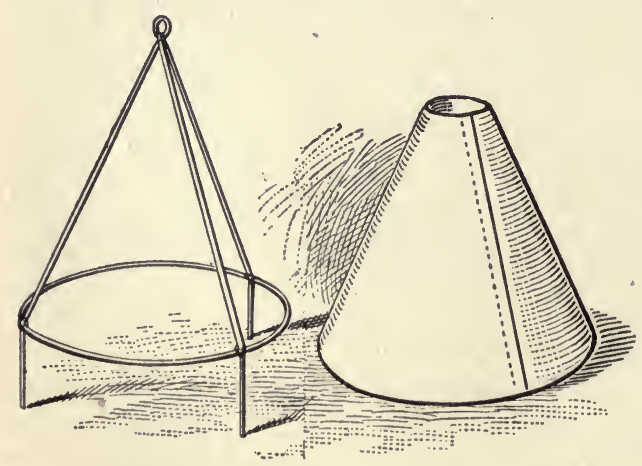

Imitation Cloche, made from Wire and Paper. wires join at the top a ring is made to carry it by. A paper cone, with a hole at the top to pass the ring through, makes the protector complete. When not in use these cones and wires pack away in very little space, one fitting easily inside another.

Another way in which paper cones may be used as protectors is to fix three sticks over the plant in the form of a tripod and place the cone over this.

Another useful protective device is illustrated on the following page. In this case willow wands are bent over a row of plants, and each hoop is connected to the next by a rod along the top. At each end of the row the bent wands are in pairs crossing in the middle as shown; this keeps all rigid. This framework is covered with calico each night and on very cold 
days, but the plants are exposed whenever the weather is mild. The edges of the calico rest on the ground, and are kept in place by stones, clods of earth, or pieces of timber. When the weather becomes warm, the calico is washed and dried and stored away for use the following season.

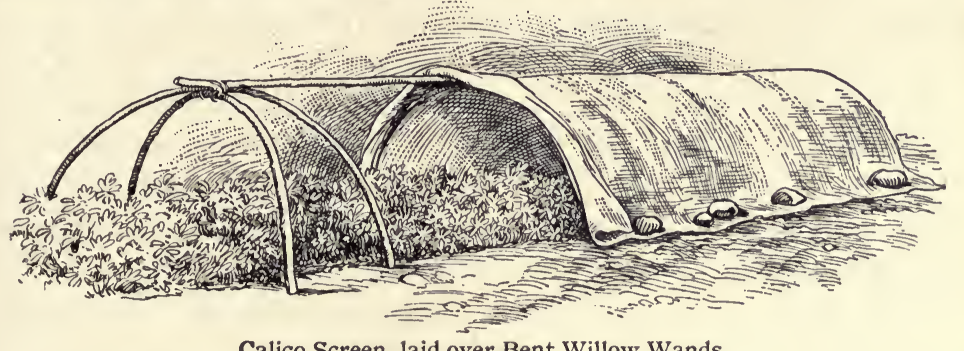

Calico Screen, laid over Bent Willow Wands.

The same idea carried out more elaborately is illustrated below. In this case the shields are made complete, with calico or other material attached to the framework, and are movable. Or they may be merely framework, covered at night with mats and uncovered in the morning. A useful size would be $2 \mathrm{ft}$. across the base and the same in height. If made in different lengths, say a series of four from $10 \mathrm{ft}$. to $12 \mathrm{ft}$., by knocking out all the cross-ties resting on the ground except those at the ends, they could be nested and packed away in small space.

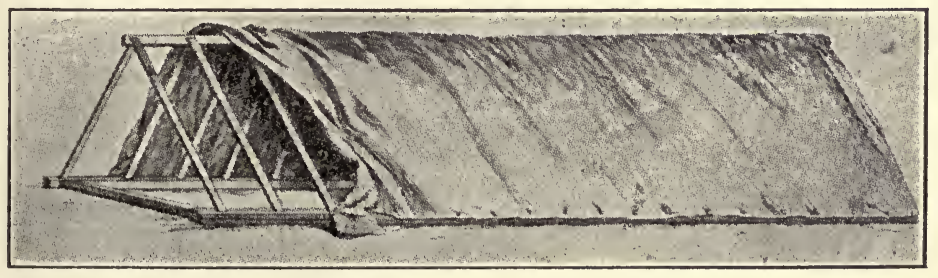

Movable Shield, covered with Calico or Mats.

Straw Mats.-Mention has already been made of the use of straw mats in covering frames and cloches, but they are also used in many other ways for protective purposes. In the latter part of April and during May frost is not much to be feared except during the night, and the straw mat forms an efficient protection to the plants they cover against any frost which is likely to occur at that period. When there is an insufficiency 
of cold frames, comparatively tender plants can be safely transferred to open-air beds in a sheltered position if a light frame-work of laths is placed over the bed, upon which mats can be spread at night. Early produce of various kinds, such as peas, beans, marrows, radishes, carrots, turnips, \&c., may be produced very successfully in trenches thrown out $18 \mathrm{in}$. deep, filled to half the depth with well worked hot manure, trodden in firmly, and covered with $3 \mathrm{in}$. of fine soil taken from the trench, the remainder of the soil being used to form ridges on either side. Sticks are laid across the trench, resting on the ridges, and mats are laid on these each night until danger of frost is past.

A practically frost-proof bed, in which tomatoes and similar tender plants can be set out early in May, can be made by enclosing it with mats on hurdles and then stretching wires at intervals along the bed upon which mats can be spread at night, to be rolled up again next morning. If a little warm manure is put under the plants to raise the temperature of the soil, this arrangement will answer almost as well as a cold house, and will entail much less labour.

Glass-covered Protectors.-Strawberries may be ripened in the open field from a week to ten days in advance of their normal season, in the following manner: Run two boards on edge parallel, 12in. apart, on each side of a row of strawberry plants set 9in. apart in the row. The boards are kept in

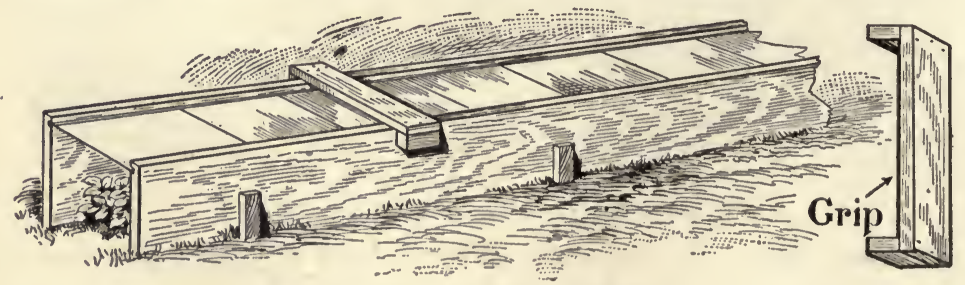

Glass-covered Plant Protector.

position by pegs, driven into the ground at convenient distances apart, to which they are nailed. The board at the north side of the row should be higher than that at the south, say 8 in. and $6 \mathrm{in}$. respectively, and each should have a groove run in, $\frac{1}{4} \mathrm{in}$. deep, $\frac{1}{2} \mathrm{in}$. from the top. Sheets of glass, resting in these 
grooves, cover the space between the two boards, and a short piece of board closes up each end. At intervals a "grip" is placed over the boards to keep them together; when the plants need attention the grip is removed and the board pressed gently back, so as to release the glass. This contrivance may be used for forwarding and protecting many other things besides strawberries.

In some gardens a small edition of the above contrivance is used in in the form of a box without top or bottom, with a pane of glass slipped into a groove at the top. This is very useful for protecting separate plants in the open ground, and has uses somewhat similar to a cloche.

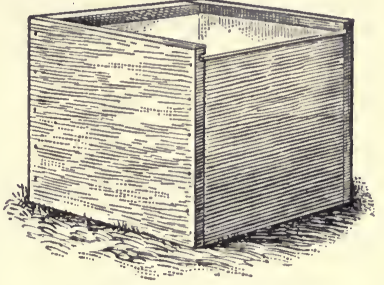

Box Plant Protector.

Another method of affording protection to plants set out early is to throw out shallow

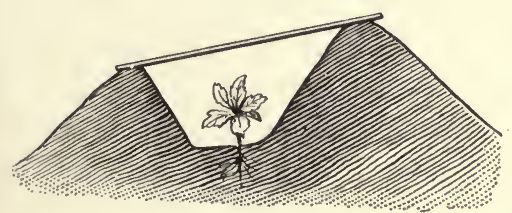

Glass-covered Trench. trenches, 9in. wide, running from east to west. The soil is banked up on each side of the trench, the larger portion being put on the north side. Panes of glass, butting together, rest upon the banks of earth.

Raised Beds with Slope to the South.-When a garden is so situated that there is an almost entire absence of sheltered borders, and the natural formation of the ground is not conducive to growing early crops in the open, the difficulty may be overcome in the following manner: The ground should be in good friable condition, having been well manured and dug some time previously. Trenches, 18in. wide and 9in. deep, running from east to west, are taken out at $4 \mathrm{ft}$. $6 \mathrm{in}$. from centre to centre, leaving a bed $3 \mathrm{ft}$. wide between each two trenches. The soil from the trenches is laid on the beds, being banked up 9 in. high on the north side and gradually sloped away to the ordinary level on the south side, as shown in the illustration on the next page. The north, east, and west sides of the plot should be screened with a good close fence of brushwood, or 
with thatched hurdles. The beds will then be well sheltered from cold winds, free from excessive moisture, with a slope and exposure to the south. The trenches form footpaths between the beds.
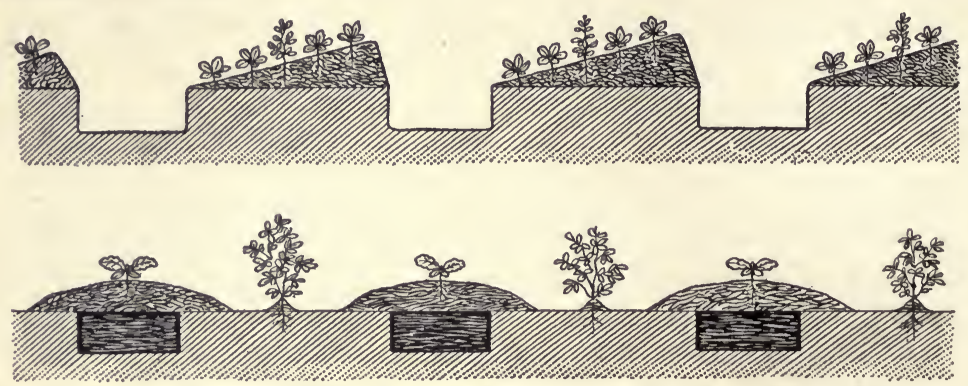

The upper diagram shows a section of Raised Beds, with slope facing south. The lower diagram shows the paths between the above Beds converted into Warm Beds.

These beds will be suitable for numerous early crops, which will readily suggest themselves to the gardener; one method of utilizing them is as follows: Plant four rows of cabbage lettuce, along the bed, $9 \mathrm{in}$. between the rows and $1 \mathrm{ft}$. from plant to plant in the row. Between the plants across the bed sow radishes. Along the middle of the bed between the lettuces

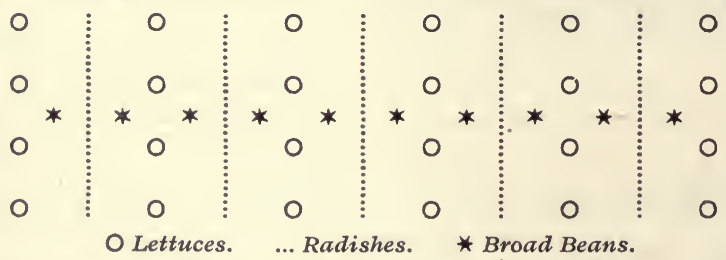

sow broad beans 6 in. apart. The radishes and lettuces will be gone by the end of April, then lightly fork up the bottoms of the trenches, lay in and tread down 6in. of warm manure, cover with the soil from the beds which was taken from the trenches, leaving the beans standing, slightly earthed up on each side. Now plant on the ridges over the manure bush marrow plants from pots, $2 \mathrm{ft}$. 6in. apart, and cover at night with cloches or one of the protecting devices previously described. With the screen round the plot, the shelter of the beans between the rows, and the protection afforded by the covering at night, the marrows make rapid progress, and begin to bear by the middle of June, when prices are high. 
Cheap Method of Forcing in Pits.-A very simple method of forcing in pits is fully described in the chapter dealing with the cultivation of seakale, to which the reader is directed for details. Besides seakale the method is equally well adapted to the forcing of rhubarb, asparagus, chicory, \&c., and may be made to yield really first-class produce from November to April, during which period three crops in succession can be taken. Being cheap and easy to work it is especially suited to the requirements of the man with very limited means.

The accompanying illustration is from a photograph of a forcing pit in actual operation; it will be observed that the materials used in its construction are of a rough and ready description, but it is none the less efficient on that account.

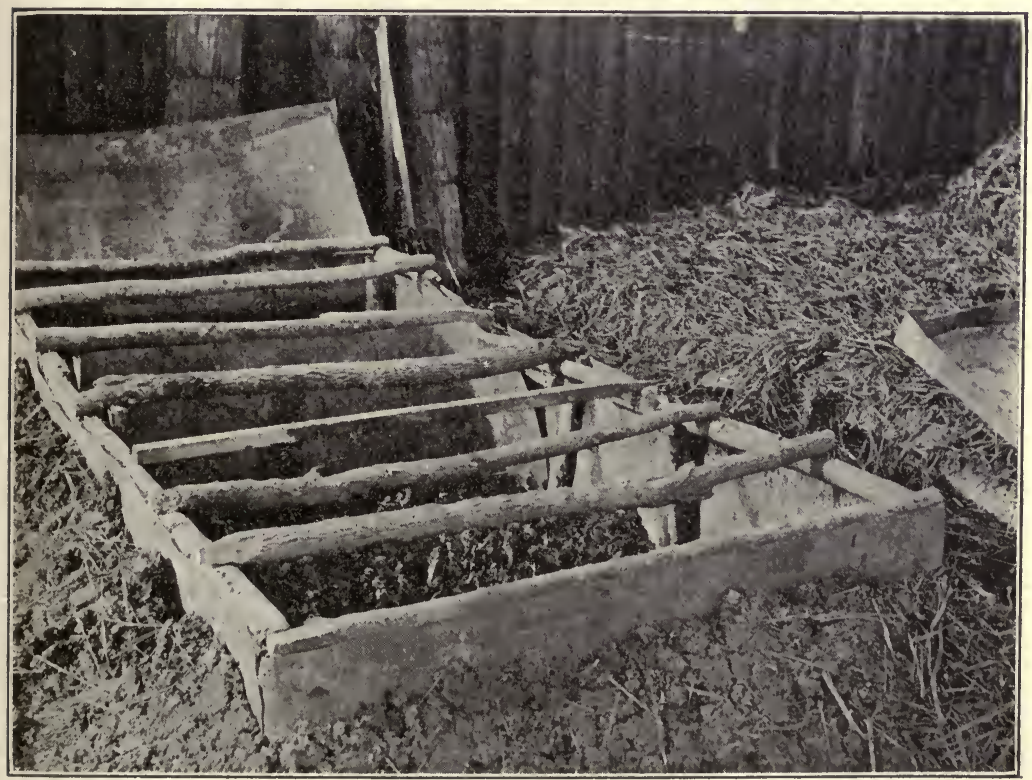

Rough Pit for Forcing Rhubarb, Seakale, Chicory, and Asparagus. 


\section{ESSENTIALS OF SUCCESSFUL GARDENING.}

(Extracted from the preceding pages of this book.)

DRAINAGE.-Be sure the land is well drained, either naturally or by other means. Drainage removes stagnant water and induces a passage of air through the soil. Plants cannot thrive with their roots in stagnant water, and aeration of the soil is indispensable to their healthy growth.

CULTIVATION.-Work the land deeply. By drainage and deep working the soil is made sweeter and warmer, and the roots of the plants have a much greater area from which to extract food. Although drained soil is relieved from stagnant and excessive moisture in wet periods it holds much more moisture for the use of the plants when the weather is dry. Thus, on such soil seeds germinate sooner and stronger, and plants grow more vigorously, whether the season is wet or dry.

LIME.-Always make sure that the soil contains sufficient lime; when there is any deficiency give regular applications every three or four years, because lime gradually dissolves and passes out of the soil in drainage water. Lime makes heavy soils more friable and sandy soils more compact; it sweetens sour land, makes inert plant foods available, and strengthens the structure of the plant.

MANURE.-The "thorough" gardener should continually strive to increase the fertility of the soil and to this end, so far as his means will allow, should be unsparing in the use of natural manure. Concentrated fertilizers when used with judgment are extremely useful and are often indispensable to the securing of a good crop, but they should only be used to supplement natural manure and not to take its place-that is, since different plants need the principal constituents of plant food in varying quantities the deficiencies of any of these in soil or manure should be made good. By substituting concentrated fertilizers for farmyard manure the store of fertility in the soil is reduced. It is only by the unsparing use of manure that the intensive gardener can take from his soil good crops in continuous succession. Farmyard manure not only provides plant foods but further increases the fertility of the soil by adding humus, which malies clays more open and friable and gives moisture-retaining power to sands. It should never be allowed to come in contact with the roots whilst in a rank condition, the nearer to the time of planting when applied, the more thoroughly decayed it should be.

SEEDS, SOWING, THINNING, and TRANSPLANTING.-Buy good seeds of established varieties from a reliable firm. Cheap seeds may also be good seeds, but often they are not, and then they prove very dear. Prepare a proper seed bed, and always sow in freshly stirred or aerated soil. Early in the season in the open-air sow rather thiclily, to provide against losses and to ensure a full plant, but thin out promptly and boldly to avoid overcrowding, or the seedlings will be drawn and weakly. Transplant early and firmly, in dull weather, into freshly.stirred soil,

MOISTURE, HOEING, and MULCHING.-Few cultivated plants get when growing all the-moisture they need to give the best results. Frequent hoeing not only prevents the growth of weeds, but by keeping a mulch of loose soil on the surface hinders the evaporation of soil moisture and so retains it for the use of the plants. A mulch of manure over the roots after hoeing is better still and saves much watering.

SUNSHINE and AIR.-Abundance of air and sunshine are quite as important for the production of healthy and vigorous plants as they are for animals. Therefore, always avoid overcrowding, and let each plant have room for its full development. Whenever possible, run the rows north and south, so that sunlight can fall equally on both sides 
PART II.

\section{DETAILS OF THE CULTIVATION OF VEGETABLES}

\section{ARTICHOKE (GLOBE).}

Cynara scolymus.

THE Globe Artichoke is a handsome and imposing plant.

It is grown for the flower heads, which form large scales, with thickened, fleshy bases, and are used as a vegetable. As it is not much in demand in this country very little space in the garden need be given to it. It is perennial, but may be grown as an annual or biennial at discretion. A deep, rich, moist soil, with full exposure to sunshine, is necessary for the production of the finest flower heads. In summer it needs plenty of moisture, but should be kept dry in winter. It is fairly hardy on dry soils, but on the moist soils which best suit its cultivation it needs protection in winter or the plantation may be lost if

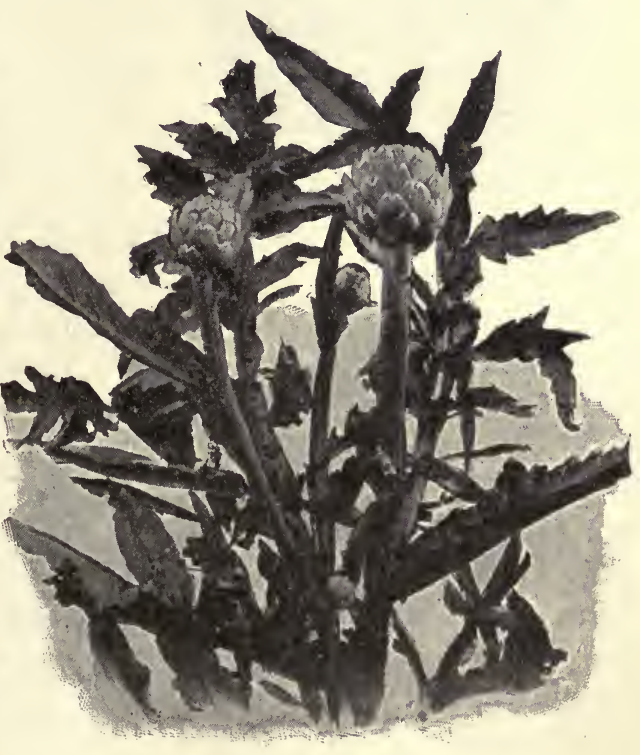

The Globe Artichoke. the weather is very severe.

Although the Globe Artichoke is readily raised from seed 
this method of propagation is seldom followed, because of the loss and disappointment occasioned through many of the seedlings coming poor and worthless. For this reason suckers are generally used in forming a new plantation; these are shoots produced underground around the neck of the old stool, and their use is the only means by which the different varieties can be relied upon to come true to their proper character.

Seed may be sown in the open in March, but it is best to sow on a hot-bed in February, pot the seedlings singly, and grow on in a cold frame, hardening them off so that they can be planted out in April.

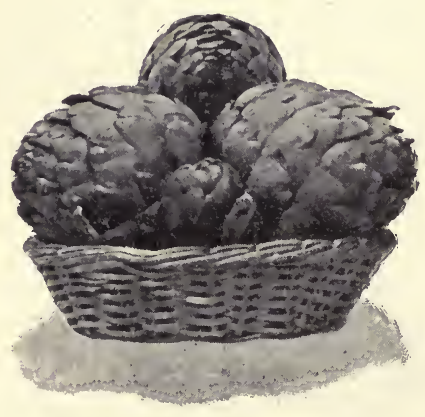

Copyright, S. \& S.

A Good Sample.

When the plantation is to be formed in the customary way from suckers, a batch should be planted in March, and for succession again in May; by this means, if there is already a batch of established plants, a supply of heads can be had for six months in succession.

Strong suckers are taken off with a strong sharp knife when about 9in. high, having a bit of root or heel of the old stool attached. These are planted singly, $4 \mathrm{in}$. deep, in rows, $2 \mathrm{ft}$. between the plants and $4 \mathrm{ft}$. between the rows; or they may be set in triangular clumps of three, $2 \mathrm{ft}$. between each plant and $4 \mathrm{ft}$. between each clump. The soil should previously have been prepared by deep digging and liberal manuring. After planting, the suckers should be trodden in firmly, well watered, and shaded from bright sunshine until established. Afterwards the ground should be kept thoroughly clean, with an open loose surface. Whilst the plants are making growth a quickly-maturing catch crop may be taken from the ground about them.

The heads must be cut as soon as fully developed, whilst.still young and tender; if left on the plant too long they get hard. If they cannot be disposed of immediately, instead of letting them remain on the plant the heads should be cut with a long 
stem and stood in water in a cool shady place, where they will keep good for a considerable time if the bottom of the stem is cut off as it shows signs of decay. The main heads will grow much larger if the laterals, or side heads, are taken off by the time they are an inch through. If when cutting the heads of the earliest batch the stems also are cut to the ground, a number of new suckers will appear; the weakest of these should be removed, and the remainder will then produce a late crop.

The plants will continue productive in good soil for five or six years, but as a rule three or four years is long enough for a plantation to stand without renewal.

Chards.-These are the summer suckers of the Artichoke when blanched, and are then scarcely to be distinguished from cardoons. Early in July the plants which have already produced a crop of heads are cut down to within a few inches of the ground, the surface soil is stirred and mulched, and copious waterings are given. Numerous shoots will spring up, the weakest of which are removed, and by the end of September those remaining will be ready for blanching. For this operation choose a fine day when the leaves and soil are dry. Draw the stems together and tie them with strong raffia; then put some dry hay or straw round the base of each plant and wrap up the stems with hay or straw bands, finishing by earthing up in the same way as celery. The bleaching will take five or six weeks. Before hard weather sets in any still unused must be protected by litter, or may be lifted and packed in sand in a dry cellar.

Manures :-A liberal dressing of stable manure and plenty of moisture are the principal requisites for the production of good heads; or a lighter dressing of manure may be supplemented by fertilizers as follows:-3oz. kainit, 2oz. superphosphate, per square yard applied in autumn; $\frac{3}{4} \mathrm{Oz}$. nitrate of soda, per square yard, applied when growth is beginning in the spring.

Varieties:-The Purple Globe and the Green are the two most popular varieties in British gardens, the former being perhaps the more popular of the two. 


\section{ARTICHOKE (JERUSALEM).}

\section{Helianthus tuberosus.}

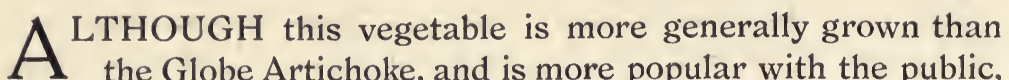
it usually meets with very indifferent treatment in the garden. It is very accommodating and will practically grow anywhere, and for this reason is usually relegated to odd corners and similar places where nothing else will thrive. Under such circumstances it is not to be wondered at if the quantity and quality of the tubers produced is somewhat disappointing. When grown on good but rather dry soil in an open situation it will produce an abundant crop of fine tubers.

Jerusalem Artichokes

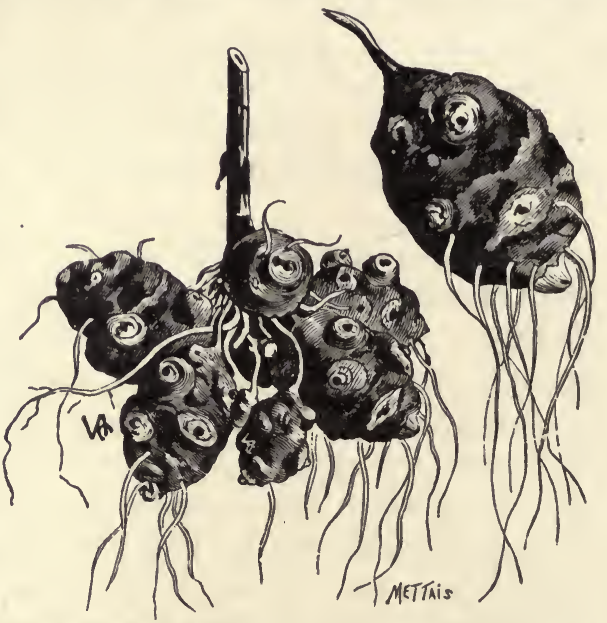

Copyright, V.A, \& Co.

should be planted any time from February to April-the sooner the better, as the tubers begin to grow early and the plant is quite hardy. Set in rows $2 \mathrm{ft}$. $6 \mathrm{in}$. apart, and $12 \mathrm{in}$. between the tubers, in ground which has been manured for a previous crop. They are ready for use as soon as the tops die down in the autumn, and may then be lifted and stored in sand, but are firmer and better flavoured when left in the ground and lifted as required. When lifting, care must be taken to clear the ground completely, as any left in will be troublesome.

Manures :-2oz. sulphate of potash, 3oz. superphosphate, per square yard before planting.

Varieties:-The purple variety is the most generally grown, but the principal seedsmen now offer a white-skinned variety which is a distinct improvement on the old purple. 


\section{ASPARAGUS.}

\section{Asparagus officinalis.}

$\triangle$ SPARAGUS is a profitable crop when well grown. Under A proper treatment it will thrive in any well-cultivated and moist soil, though a deep rich loam, inclining to sandy, is the most suitable. At the same time excellent Asparagus can be grown even on heavy clay soil, providing it is deeply worked and well drained. It is a crop which will pay for taking extra trouble with at the outset, as it may then be expected to remain in profitable bearing for twenty years or more. The small-holder should not undertake to plant a large breadth without serious consideration, because several years must pass before any appreciable return for the initial outlay can be expected. A few beds may, however, be planted without much expense or any great encroachment upon the other work of the garden, and as these come into profitable bearing the area could be extended with safety.

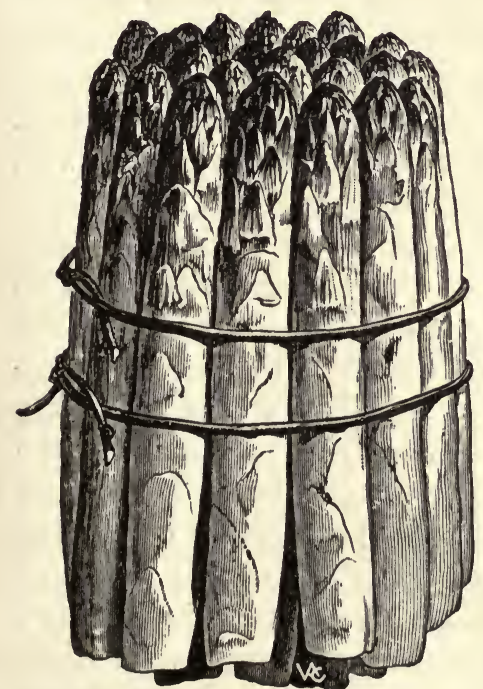

Copyright, V.A. \& Co.

A Bundle of Giant Asparagus.

An Asparagus plantation may be made either by sowing the seeds where they are to remain or by transplanting roots, either at one, two, or three years old. The method of sowing where the plants remain permanently has much to recommend it if the grower is prepared to wait at least three and possibly four years before getting any return beyond the catch crops which can be grown between the rows. If this method is decided upon the ground must be thoroughly prepared as described later for planting. The seedlings are thinned out early to 6in. apart, the superfluous ones being removed in the following spring. The advantage of raising the plants on a seed bed consists in the smaller space occupied by 
them during the period preceding their removal to permanent quarters. Some growers prefer to reduce the period of waiting by buying roots and so getting a cut about two years from the time of planting.

Raising the Plants.-The ground in which the seed is to be sown should be rich and well prepared by deep working during the previous winter, being left "ridged up" so that wind, rain, and frost may have full effect in rendering it mellow and friable. Previous to sowing, which should take place towards the end of March or early in April, when the surface soil is dry, the ridges should be pulled down and the soil raked level and smooth. Seed should be sown very thinly in drills from 1in. to $1 \frac{1}{2} \mathrm{in}$. deep and $1 \mathrm{ft}$. apart. After sowing, the seed is covered with soil by using the back of a rake or the side of the foot, and trodden in, the work being finished by rolling the whole bed. As the seed is slow to germinate it is a good plan to sow with it a few radish seeds; these soon appear, and by. marking the rows enable cultivation to be begun at once, so that weeds, which must not be tolerated at any time, have no chance to make headway before the seedlings show. After they are well up they should be thinned out by removing the weakest and leaving the strongest standing about 3 in. apart. When they are growing freely they should be dressed with soot, at the rate of 20 bushels to the acre.

During the summer, water should be given copiously in dry weather and the surface soil kept loose by hoeing, but this must be done carefully so as not to injure the roots of the plants, which run close to the surface. If the seedlings are treated in the manner indicated they will make good strong plants the first year and be ready to set out permanently the following spring, thus saving a year of time; not only that, but it has been fully demonstrated by many carefully conducted experiments, and is now recognized by many of the foremost growers of Asparagus, that strong, healthy plants of one year's growth, when transplanted strike root sooner and with more certainty and give better results than those of two years, whilst they are ready for cutting quite as soon.

Essential Points to be Observed in Forming a Plantation.The ground intended for the permanent plantation must be 
very thoroughly prepared in the preceding autumn by bastard trenching or subsoil ploughing and the addition of 15 to 30 tons to the acre of good manure, according to the class of soil. If it is very heavy its condition would be much improved by previously taking off a crops requiring manure and good cultivation, such as potatoes. The manner of planting should be determined by the nature of the soil. Light and naturally well-drained soils may be planted on the flat, but on heavy retentive soils the results will be much better if the plants are set on raised beds.

In most sections where Asparagus is grown there are special local customs in the matter of planting, though in all districts some growers have their individual preferences, and amongst all the leading growers it is gradually becoming recognized that too close planting soon becomes unprofitable. It is possible at first to get more bundles per acre from close than from wide planting, but the sticks are neither so early nor so large; the whole ground soon becomes a solid mass of roots for which both moisture and nutriment are insufficient, and after a few years the shoots become gradually smaller and tougher, until finally the plantation has to be broken up because it has become unprofitable.

Reviewing the various methods, for the production of an ordinarily good sample and a lasting plantation, the choice appears to lie between the following, and of these the first is the best:-

Single rows $4 \mathrm{ft}$. apart, $2 \mathrm{ft}$. between the plants;

Single rows $3 \mathrm{ft}$. apart, $18 \mathrm{in}$. between the plants;

Double rows $4 \mathrm{ft}$. apart, $18 \mathrm{in}$. between the rows, and $18 \mathrm{in}$. between the plants.

Treble rows $4 \mathrm{ft}$. apart, $15 \mathrm{in}$. between the rows and $18 \mathrm{in}$. between the plants in each row, the plants in the middle row being set midway between those in the two outer rows, so that there is a space of almost $18 \mathrm{in}$. in any direction between all the plants.

Where the production of extra fine stuff is desired the rows should be $4 \mathrm{ft}$. apart and at least $3 \mathrm{ft}$. between the plants. In in this case extra care should be taken in the selection of the roots, and when this is done and the plantation is supplied with 
sufficient moisture and assisted by judicious manuring, the effect of wide planting upon the size and number of the sticks is marvellous. In the districts around Paris where much of the "giant" Asparagus is produced which may be seen in our best shops early in the season, the plants are set $4 \mathrm{ft}$. apart in each direction.

Planting.-When the plants are raised at home in the manner previously described only strong healthy yearlings which have three or four buds should be used, but when plants are purchased it is better to get them two years old unless there is some certainty that younger plants are strong and well grown. Planting should be begun at the time when growth is just beginning to show, at the end of March or early in April, a mild day when the surface soil is dry being the most suitable. In the line where the plants are to stand a trench is taken out, 9in. wide and 9in. deep. On the bottom of the trench fine mixed compost or old hot-bed manure is spread about $1 \mathrm{in}$. thick, raised into a gentle mound about $4 \mathrm{in}$. high at each station for a plant. On each mound the roots of a plant are spread out, so that the crown is about $4 \mathrm{in}$. or $5 \mathrm{in}$. below the ordinary level, and the plant is at once covered up with $2 \mathrm{in}$. of fine weathered soil. When the whole of the trench is planted, the soil is sprinkled with superphosphate at the rate of 3 cwt. and sulphate of potash $1 \mathrm{cwt}$. to the acre, and it is then filled level with soil and pressed down moderately. The proper arrangement of the roots is one of the most important points in the planting of Asparagus, as the ultimate success and duration of the plantation depends very largely upon the manner in which this is done. Most other mistakes may be remedied by after treatment, but faulty planting it is impossible to alter.

The roots should never be allowed to become dry or exposed to parching winds whilst the work is proceeding; only a few at a time should be set in the trench before they are covered with soil, the remainder being kept covered with a damp sack.

When the planting is finished put a stake at each end of each row as a guide in cultural operations, and then rake the ground level. As growth becomes active $2 \mathrm{cwt}$. nitrate of soda to the acre should be given in two or three applications. 
After Treatment and General Routine--Cultural work on the Asparagus plantation during the first season consists in frequently stirring the soil, especially as soon as it is dry after rain, and keeping it free from weeds. Small crops, such as lettuce, onions, or radishes may be grown between the rows, but these catch crops must never be of such a kind nor occupy the ground in such a way as to interfere with the welfare of the main crop.

If it is found that any of the plants are not showing above ground by the middle of June they should be replaced by strong growing plants of the same age, some being kept for this purpose in a reserve bed. These must be lifted carefully so as not to damage the roots, and on a cloudy day, watering in well afterwards unless it is rainy.

When the foliage begins to change colour in the autumn it should be at once cut down close to the ground. If left standing longer the berries ripen and the seed drops, with the result that the ground gets filled with seedling plants, which are more obstinate and difficult to get rid of than weeds. As soon as the foliage is cut it should be removed to an open place and burned, so as to destroy any injurious insects or fungi which may be present.

In the second season the treatment is practically the same as in the first. The ground is again lightly dressed with fertilizers and kept well hoed, and small catch crops may be again taken off. Even with the most careful planting blanks will probably be seen in a few places where the plants have died. The rows should be carefully examined in the autumn and all such blank spaces marked with a stake; in the spring these dead plants should be replaced. It is not an uncommon occurrence even in the best kept plantations for these blank places to occur here and there even amongst established plants, and if replacements are neglected for a few years the shortage of crop will form a considerable item; therefore a small bed of plants should be raised periodically for the especial purpose of replacements.

In the autumn of the second year, and in all future years, after the rows have been cleared of foliage and weeds they should be covered about 2in. deep with good stable manure. 
At the end of the following February all loose litter should be raked off, all weeds cleared, and the beds covered 3in. deep with soil taken from the alleys; if the ground is heavy this soiling is best done in November, so that it will become friable by the influence of the weather through the winter. When cutting is finished the soil which was put on the beds is thrown back again into the alleys, and a dressing of suitable fertilizer given to encourage strong growth. The tops are then allowed to grow as they will, but weeds are kept down.

Cutting and Bunching.--If the plants have made strong vigorous growth, cutting may begin in the third year, but for the first cutting not more than two or three shoots should be taken from a plant, and none after the beginning of June. In the following years cutting should finish by the second or third week in June at the latest; if the cutting is prolonged to a later period than this the crop of the following season is sure to feel the effect of it, and fewer sticks of poorer quality will be obtained than would otherwise be the case. When the crop is being harvested every shoot should be removed, no matter how small it may be. If these small shoots are left to grow they reduce the quality of the larger sticks by taking strength from the roots.

Cutting begins when the strong brownish-green tips of the shoots are observed to have pushed three or four inches above the soil. The Asparagus knife is pushed into the soil obliquely and the shoot cut about $4 \mathrm{in}$. below the surface. This must be done with great care, so as not to injure the new shoots rising from the crown. The knife depicted is a pattern in common

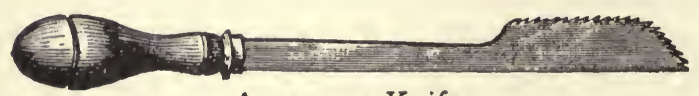

Asparagus Knife.

use, but any long strong knife, such as a butcher's knife, will serve the purpose equally well. On light mellow soils it is the custom with some of the best growers to break off the shoots close to the crown instead of cutting. There is then no danger of injuring the crown. A little of the soil is pulled away so that the finger and thumb can be easily pushed to the required depth, then the shoot is snapped off, and the soil replaced. 
The sticks should be graded into two and sometimes three qualities - "special," ordinary, and "sprue"- the thickness, length, and general appearance of the sticks being the guide.

A market bundle of "grass" varies in size according to the district from which it is sent, That sent from the district around Evesham is made up into bundles of 120 , formed of six smaller bundles of 20 each, and this is coming to be recognised as the

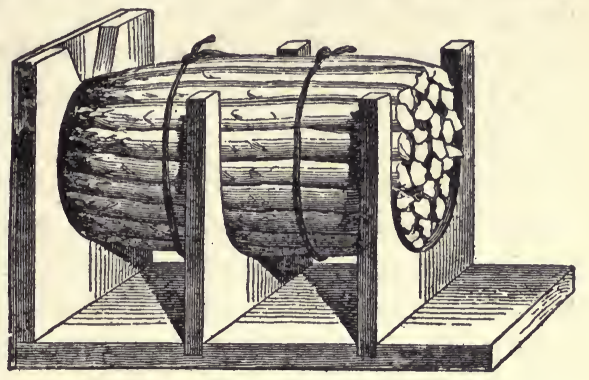

Cradle for Bunching Asparagus. regulation size of a market bundle. Early in the season the first few consignments are sometimes sent to market in bundles of 25 or 50 .

The "cradle" depicted above is one of many similar devices used for making up the bundles quickly and neatly. The heads are laid in the recessed part of the front board, the stalks resting in the two curved boards, and the bundle is secured with two pieces of strong raffia. The six small bundles of 20 are made into one bundle of 120 by encircling them with slender "twigs" of willow. The base of the bundle is then trimmed off straight with a sharp knife, though sometimes only the longest of the sticks are thus shortened. Asparagus should be marketed immediately after cutting, as it soon deteriorates.

Forcing.-There are numerous ways of forcing Asparagus, but none worth the consideration of the grower for market which does not entail considerable expense and a long period of waiting before there are any returns. At the same time if the business is properly systematized and the work done well, there appears to be no reason why the undertaking should not be productive of considerable profit.

Leaving aside the question of forcing in houses heated with hot water, the methods which seem to be the most suitable for the market grower are forcing on hot-beds, in pits, and in the open beds where the plants grow. Each of these methods depends for its success upon a sufficient supply of fermenting 
manure, and in the case of the two former upon a continuous supply, year by year, of four-year-old crowns grown especially for this purpose and previously uncut. When the roots are lifted they are of no further use after forcing, but when this operation is performed upon the plants as they stand in the beds it only takes place in alternate years and may be repeated indefinitely.

Where forcing is to be done in beds these must be made and planted specially to suit the size of the frame to be used, and for this purpose the French garden frame, $4 \mathrm{ft}$. $3 \mathrm{in}$. from front to back, is very suitable. The bed is made $5 \mathrm{ft}$. wide, with $2 \mathrm{ft}$. alleys between. The plants are set three rows to a bed, one down the middle and the other two $1 \mathrm{ft}$. from each side, with the plants $1 \mathrm{ft}$. apart in the rows. During November the beds are covered $2 \mathrm{in}$. deep with fine compost or sifted old hot-bed manure. At the beginning of January the frames are set on the beds, which are then covered with another 3 in. of fine soil. The lights are put on and covered closely with mats. The spaces between the frames and round the ends are then filled with fresh hot manure, which should come almost up to the level of the light when well trodden down. It is a great help to cover the beds with 6in. or so of fresh strawey manure the week previous to putting the frames on; this warms up the soil and keeps the frost out. When the frames are put on the bed this litter can be thrown into the alleys and mixed with the hot manure. When the shoots have pushed through the soil about $2 \mathrm{in}$. the mats should be rolled up in the daytime and the lights slightly raised, so that the tops will become green by the admission of light and air. If the manure gets cool before the crop is cleared, part of it must be removed and the remainder well shaken up and mixed with some fresh. When cutting is finished the frames and added soil are removed, then a little manure from the trench is scattered over the beds to keep out frost and the remainder is taken away. Forcing of open-air beds must only take place in alternate years, and therefore two sets are required; they should be started in rotation, so as to keep up a succession until the ordinary supplies come in.

Forcing on hot-beds may be begun from the middle of November to the middle of February. The earliest made beds 
should be from $2 \mathrm{ft}$. $6 \mathrm{in}$. to $3 \mathrm{ft}$. thick, but as the season advances the thickness may be gradually reduced. The bed should be 9in. wider than the frame all round. When the heat has fallen to 75 degrees the bed is covered with $4 \mathrm{in}$. of soil and the frame is put on. When the shallow French garden frame is used it is raised 3 in. above the soil by resting it on straw bands, or by putting an extra piece, 3in. deep, below it, so as to make a frame with deeper sides. In filling the frame with roots, a little soil is put against one side and the roots are placed against this as closely as they will stand, repeating the rows until the frame is filled up. A little fine soil is put amongst the roots and between each row. When the frame is full fine soil is worked amongst and over the crowns to the depth of 3in., then all is pressed down gently and a good watering is given. The lights are put on but are kept raised at each corner until the soil thermometer shows that the heat of the bed has fallen to 70 degrees, then $3 \mathrm{in}$. more soil is added, the bed is again watered thoroughly, and the lights are shut down and covered closely with mats. The first shoots will appear about three weeks afterwards, when light and a little air is given during the day to make the tops green, but all is covered up closely at night. Water is given frequently. The sticks should not be cut or many of the young shoots will be damaged through the roots standing so closely together; the preferable , way is to push the finger and thumb down to the crown and break them off.

The method of forcing in pits, with particulars of construction, will be found in the details of Seakale culture.

Roots for forcing should be lifted some time before they are wanted, with plenty of soil about each, care being taken not to injure them. They should be stored in a cool shed and covered with damp earth or sand to keep them moist. A little frost will do them no harm.

Manures:-It is impossible for an Asparagus prantation to maintain a supply of good sticks over a number of years unless it is generously and systematically supplied with fertilizing materials. Amongst these farmyard manure is to a certain extent indispensable and should be applied each autumn; this should be supplemented by artificial fertilizers-4 to 5 cwt. 
superphosphate and 3 to $4 \mathrm{cwt}$. kainit in the autumn and $2 \mathrm{cwt}$. nitrate of soda to the acre in the spring giving excellent results. It is wise to vary the fertilizers by sometimes supplying their equivalent from other sources. In some cases, particularly on. very light soils, the application of salt may be beneficial, though as a rule a dressing of kainit will supply all the salt necessary. When salt is given it should be in two or three light dressings at intervals of two or three weeks from the middle of April.

Varieties:-There is little to choose amongst the supposed different varieties, culture and soil being responsible for most of the differences existing. Connover's Collossal or Early Purple Argenteuil will be found to give as satisfactory results as any other variety.

\section{BEANS (BROAD).}

Vicia Faba.

THE Broad Bean is a very accommodating and easily grown plant, which will thrive in almost any kind of soil but is most partial to one which is strong, deep, and moist. For a heavy crop of fine pods deep cultivation and generous manuring are necessary. It is quite hardy and may be sown in the autumn with safety, and is frequently used in this way to afford protection to other early crops of a more tender nature. Considering its usefulness in this respect, combined with its productive nature and the comparatively short time it occupies the ground it is a profitable crop to grow, and is indispensable where the business of supplying shopkeepers or consumers direct is carried on.

For the earliest crops it is customary to make a sowing of one of the varieties of Long-pods in November, but unless the winter proves exceptionally mild there is usually very little time gained by sowing in autumn, and what advantage there may be in this respect is often counter-balanced by losses from various causes. When sowing is deferred until after the turn of the year there is also the advantage of leaving the ground which would otherwise be occupied by the seed ridged up, so as to get pulverized and sweetened by the weather. In 
cases where an extra early crop is desired, or where strong plants are wanted early for protective purposes, the seed may be sown from the beginning of December to the middle of January in a cold frame from which frost is excluded. By adopting this method of transplanting full even rows of strong well-hardened plants can be set out during favourable weather in the early part of March.

For successional crops one of the Long-pods may be sown at the end of January and in February, and one of the Broad Windsor type early in March. For the earlier sowings a rather light soil is preferable, but the heaviest soil in the garden may be devoted to the main crop. If the January sowing is made at double the customary thickness the extra plants may be carefully transplanted and will then give a successional crop instead of the February sowing.

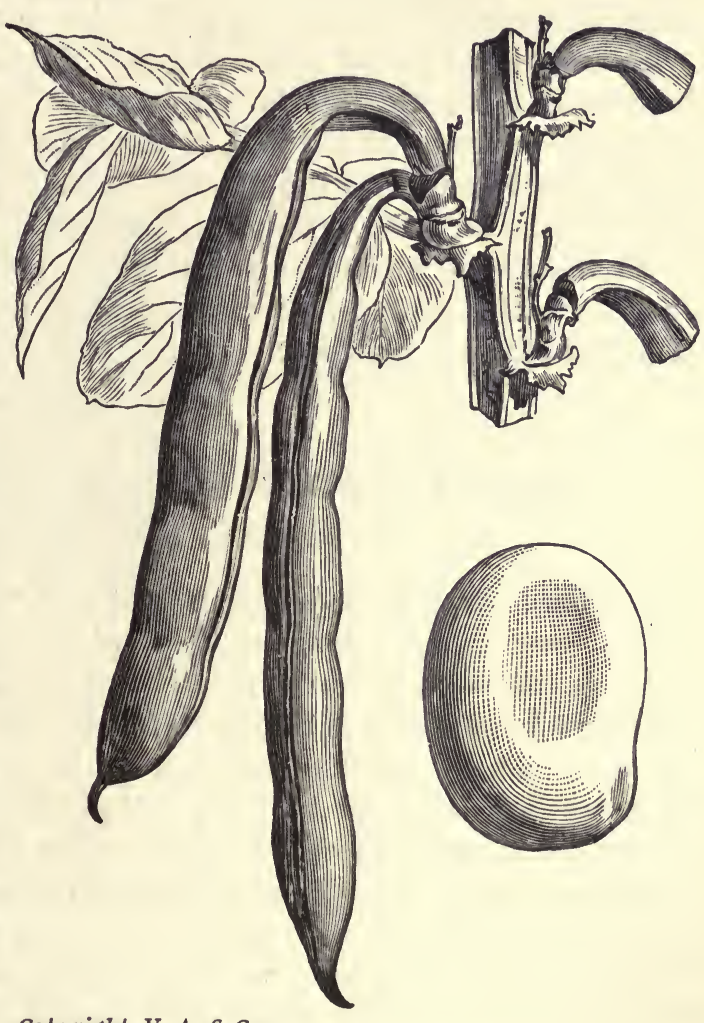

Copyright, V. A.\& co.

Seville Long-pod Bean.

Sow in double rows, $9 \mathrm{in}$. apart and $2 \mathrm{ft}$. $6 \mathrm{in}$. between the double rows; the seed should be $9 \mathrm{in}$. apart in the row, those in one row falling between those in the next. On heavy soil the seed should be sown in drills $3 \mathrm{in}$. deep, but on light soil it is better to dibble them in; after sowing make the seed-bed firm.

When the plants are a few inches high draw the soil to the 
stems on each side. Keep the soil stirred and clean by frequent hoeing. As soon as the blooms are set pinch out the tops; this will cause the pods to fill quicker and will check the ravages of the black fly. When this pest is present the tops should be put in a pail as they are removed and burnt at once. As soon as the pods are gathered the plants should be pulled up. If kept straight and dried this straw is useful for making rough mats and other protective purposes.

Manures:-On land manured for the preceding crop no further natural manure is required, or the growth may run too much to leaf. Basic slag 2 ozs., and kainit 1 oz. to the square yard applied to the ground in autumn or early winter will help the crop materially.

Varieties:-For November sowing, Early Mazagan; for January and February, Seville Long-pod and Green Long-pod; in March, Broad Windsor.

\section{BEANS (DWARF KIDNEY or FRENCH).}

Phaseolus vulgaris.

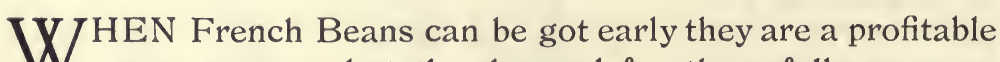
crop to grow, but the demand for them falls away as soon as runners become plentiful, and every effort should therefore be made to get them in full bearing well in front of the earliest pickings of runner beans. They do best on a rather light soil, but any ordinary loam will yield a paying crop if it is well prepared and is given a fair dressing of manure.

For the earliest crops some provision must be made to protect the plants from frost, as they are very tender. They may be grown in cold frames or under cloches, or failing either of these one of the protective devices described and illustrated in Chapter XVII may be used. The seed may be sown where the plants are to remain, about the middle of March, in a light rich compost. For frames sow in rows $1 \mathrm{ft}$. apart, $3 \mathrm{in}$. between the seed, and thin out to 6in., using some of the surplus plants to fill up blanks. Give no air until the seed has germinated. Exclude frost by covering closely each night with mats. When the plants are up give air on all favourable occasions, but 
carefully guard against cold draughts. As growth advances gradually treat them more hardily, until by the middle of May they may be completely exposed during the day but must be covered at night for a week or two longer. Plenty of water is necessary. Picking should commence soon after the middle of June. A still earlier crop may be obtained if seed is sown on a mild hot-bed early in March and the plants carefully lifted and set in their permanent quarters during mild weather about the end of the month.

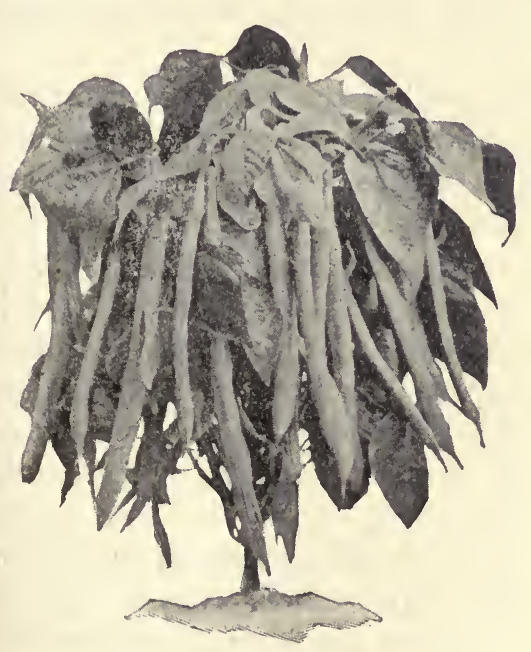

Copyright, s. \& S.

Dwarf French Bean.

For a successional crop to follow the above, but earlier than one grown entirely in the open, seed should be sown, 2in. apart both ways, early in April, in one or two cold frames, which should stand in a sunny position and be covered each night with mats to exclude frost. As soon as the seedlings are showing give a little air on all favourable occasions, and as the plants grow gradually but carefully give them more exposure. At the beginning of May the lights may be removed altogether during fine days, and by the second week, if the weather is mild, they may be set out in in a sheltered position in the open. They should be lifted with a ball of soil at the roots, and the soil in which they are set should be light, rich, and sufficiently moist to dispense with watering until the roots are working again. Shade from sun for a few days is advisable, and protection from frost at nights must be given for a week or two.

Sowing in the open may be done in the last week of April and the first week of May, and for a late crop in the first week of July. The earliest sowings may be made between rows of cos lettuce, spring cabbage, and similar crops which will afford 
protection to the tender young plants and yet be cleared off the ground before the beans are seriously inconvenienced. Sow in drills $2 \mathrm{in}$. deep, $4 \mathrm{in}$. wide, and $2 \mathrm{ft}$. $6 \mathrm{in}$. to $3 \mathrm{ft}$. apart. In each drill sow a double row of beans, thus -.${ }^{\circ}$ When growing, the plants should stand 6in. apart in each direction, but the seed should be sown double this thickness, and when they are well up the plants should be thinned out to the indicated distance apart; there is more lost than gained in allowing them to stand together too thickly. The thinnings may be used to make good any blanks and to plant elsewhere for a successional crop or for seed saving.

As soon as the ground is cleared of the previous crop the space between every alternate row of beans is forked over and filled with another crop such as lettuce or spinach. Alternate spaces are left blank so as to afford room for picking from the plants on each side.

Gathering the pods must be attended to systematically; if they are left on the plants too long they get tough and useless and the plants soon stop bearing. To obtain a long-continued supply of green and tender pods they must be picked closely as they come ready, even though they may not be immediately wanted.

When seed is to be saved a piece is either sown specially for this purpose or part of the main-crop is left ungathered as soon as prices fall low. When the beans are ripe the plants are pulled up and tied near the roots in little bundles. They are then put to dry, either spread out on a hard bottom or hung on a fence or over a rail. If the weather is wet they may be spread out thinly in a shed or in frames to dry. Afterwards they are stored in a dry airy place until winter when they are threshed and cleaned ready for sowing.

Manures:-French Beans pay for liberal treatment. The soil in which they are planted should be given plenty of wellrotted stable manure, as not only does this provide plant foods but it serves to keep the soil open and rich in humus, a condition of things in which these plants revel. Fresh manure is not suitable, and perhaps the best crops may be obtained from ground which has been deeply worked and heavily manured for a previous crop, followed by a dressing of lime before the 
seed is sown, with a mulch of short manure along each side of the rows as soon as the plants are growing freely. Ferlilizers calculated to give a profitable return are the following, applied before sowing: Superphosphate $1 \mathrm{oz}$., sulphate of potash $\frac{1}{2} \mathrm{oz}$., per yard run of row. When growth does not appear sufficiently vigorous nitrate of soda or sulphate of ammonia, $\frac{1}{2} \mathrm{oz}$. to the yard, watered in, will speedily improve matters.

Varieties :-For the earliest crop, Sutton's Superlative; for succession and main-crop, Canadian Wonder; for late crop, Negro.

\section{BEANS (RUNNER).}

Phaseolus multiflorus.

RUNNER Beans are easily grown, prolific, and popular. They always meet with a ready sale when young and tender, and when well grown are a profitable crop, as there is no great expense in their production.

The Scarlet Runner will do well in any good garden soil, though a rather light loam suits it best. Clay soils are the least suitable, though good crops may be taken from welldrained clay soils providing they have a thorough winter preparation, accompanied by liming.

Runner Beans are less hardy than dwarfs, and it does not pay to sow earlier than the first week of May in the southern counties, and the last week in the north. In many small gardens they are used to cover up bare unsightly places by being taken over roughly contrived screens or archways, and so serve the double purpose of converting ugliness to beauty whilst at the same time yielding a profitable crop; or they may be taken up three poles $6 \mathrm{ft}$. to $8 \mathrm{ft}$. long, set in a triangle $4 \mathrm{ft}$. apart and tied together at the top, three or four beans being planted at the foot of each.

When grown in rows on sticks or poles make two drills 3 in. deep and 9in. apart, and repeat with two more drills $3 \mathrm{ft}$. away, which gives two double rows with $3 \mathrm{ft}$. space between. Sow the seed $4 \frac{1}{2}$ in. apart in each drill, and when the plants are up thin out to 9 in. apart, so that they fall in the double row thus-. ${ }^{\cdot}$. 
Put the poles in early, about $1 \mathrm{ft}$. apart, between the two drills on each side; cross them at the top, pass a pole between the crossed tops and tie all together firmly. They will then resist any ordinary wind. Put small feathery stuff amongst the plants to lead them up the poles. These double rows should not be repeated nearer than $6 \mathrm{ft}$. and are better $9 \mathrm{ft}$. to $12 \mathrm{ft}$. apart, the intervening space being filled with other crops.

In growing for market, sticking is not practised, nor is it necessary. The seed is sown in drills 4 in. deep and 9in. wide. Two rows are sown in each drill, and the seedlings are thinned out so that they stand 6in. apart, any blank places being filled up with some of the surplus plants. The double rows stand $4 \mathrm{ft}$. apart. When the plants are up a ridge of earth is drawn to each side of the rows, and this serves, to somie extent, to protect them from cold cutting winds. As soon as the flowers begin to show the top of the plant is cut out. This causes the stem to

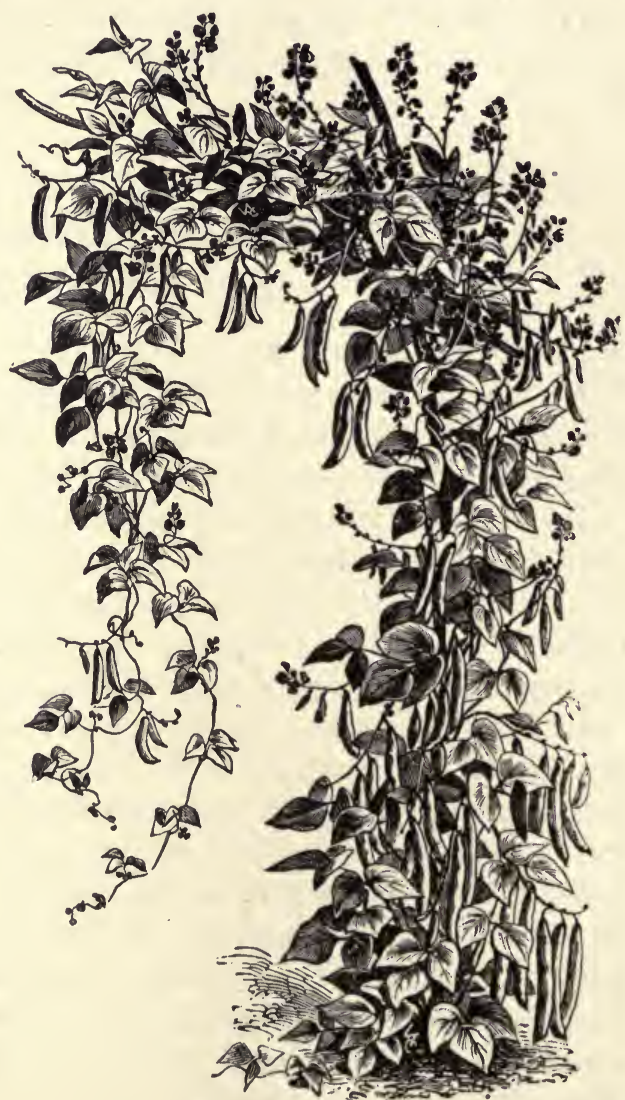

The Scarlet Runner Bcan branch and keeps the plant dwarf. Stopping of the running shoots must be repeated several times, or the plants will get into such a tangled mass that it will be extremely difficult to do anything with them. 
The pods should be gathered as soon as they are a fair size, and gathering should afterwards be continued regularly two or three times a week. If the pods are allowed to become too old not only are they worthless but the plants soon cease to bear. Any old pods that have been missed in a previous gathering should be thrown away or they will spoil the sample. If the pods should be gritty with earth they must be washed; they should be despatched to their destination as soon as possible after gathering, whilst they are still fresh and plump, as they soon lose in value if kept standing about.

Manures :-For a good crop of Scarlet Runners it is necessary that the ground should be deeply worked and well supplied with farmyard manure. If this has been given to the previous crop 5 cwt. ground lime, 3 cwt. superphosphate, and 1 cwt. sulphate of potash to the acre, harrowed in some time previous to sowing the seed, will give satisfactory results. If no manure was given to the previous crop, or if the land is poor, plough or dig in well-decayed manure at the rate of 15 tons to the acre, and in addition give the fertilizers mentioned above.

Varieties :- There are many good sorts, amongst the best of which are: Best of All, Scarlet Emperor, Ne Plus Ultra, The Czar, Painted Lady, and the common Scarlet Runner.

\section{BEET}

\section{Beta vulgaris.}

BEET is a profitable crop to grow, but as the demand for it $B$ is only moderate the space given to it should not be too large. It may be grown on any ordinary soil, though one of a rather light and sandy nature produces the neatest and bestshaped roots. Good Beet can be grown on strong clay soil if it is carefully prepared by deep working and ridging in the winter so as to get it thoroughly pulverized. On clay the seed should be sown a fortnight later than the usual time or the roots are apt to grow too large and coarse, especially if the season should happen to be wet. The only kind of roots likely to realise a profit are those of moderate size and good shape, and to produce these, no matter of what nature the soil may 
be, it should be well worked a full spit deep, in good tilth, and free from recent dressings of manure.

For an early supply of Beet, or where the grower does a private trade, one of the turnip-rooted varieties should be tried, especially if the soil is of a very strong nature. These are excellent in every way, but up to the present do not seem to be very popular in the markets.

Seed should be sown at the end of April or in the first week of May (or on strong land in the second or third week of May). Sow thinly, in drills $2 \mathrm{in}$. deep and $15 \mathrm{in}$. apart. Thin out early to $4 \mathrm{in}$. apart, and a few weeks later to $8 \mathrm{in}$. apart; the young roots removed at the second thinning can be disposed of for

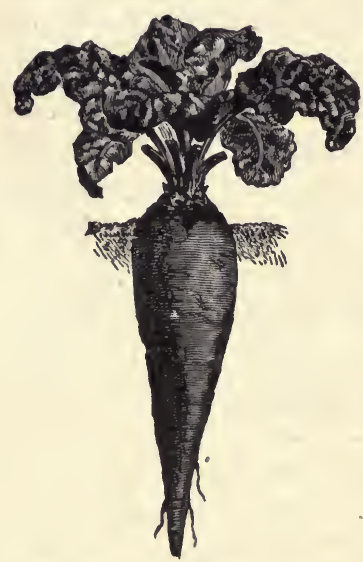

Copyright, V.A. \& Co.

Dell's Dark Crimson

Dwarf Beet. salads, and thus add to the profit of the crop. Throughout the summer the ground should be kept clean and the surface soil loose by frequent hoeing.

The roots should be lifted during a spell of dry weather in October. Great care must be taken to avoid damaging them in any way or they will be spoiled. To this end, if the soil is not light enough to permit them to be drawn by the tops, a trench should be thrown out close alongside one row, and then by using a spade behind the roots but well away from them, the soil may easily be loosened and the roots lifted without injury. The leaves should be removed by twisting in preference to cutting. They may be stored in an ordinary clamp in the same way as potatoes are stored, that is, they should be laid on a dry bottom in a round or oblong heap, about $4 \mathrm{ft}$. through at the base, then covered with straw and the straw in turn covered with about 4 in. of earth. Or they may be stored in dry earth or sand in a shed. Wherever the storing is done it is essential that the place be dry and cool, as damp may cause decay and warmth will induce growth.

Manures:-It is important that freshly manured ground should be avoided, though the soil should be in good heart by having been manured for the preceding crop. In most cases 
Beet.-Borecole, or Kale.

on such soil it will be found profitable to add before sowing $2 \mathrm{ozs}$. superphosphate and $1 \mathrm{oz}$. sulphate of potash to the square yard. When the ground is poor this should be supplemented by $\frac{3}{4} \mathrm{oz}$. to the square yard of nitrate of soda or sulphate of ammonia, given in two applications with an interval of two weeks, the first immediately after the first thinning.

Varieties:-Dell's Crimson Dwarf, Nutting's Dwarf Red, Sutton's Market Favourite, and Cheltenham Green Top are all good amongst many others. For a turnip-rooted variety use Red Globe.

\section{BORECOLE, or KALE.}

\section{Brassica oleracea acephala.}

KALES are of importance in any place where a supply of 1 green vegetables must be maintained during the winter. They always sell readily enough in cold weather, amongst the poorer classes of the population, though the returns in a mild season are usually so low as to leave very little, if any, profit. When, however, severe frost cuts down most other things the hardier kinds of kale stand unharmed-indeed a sharp frost improves their quality for the table-and in such a case, when there is a scarcity of other green vegetables, a breadth of kale will realise a handsome profit. They will provide a serviceable

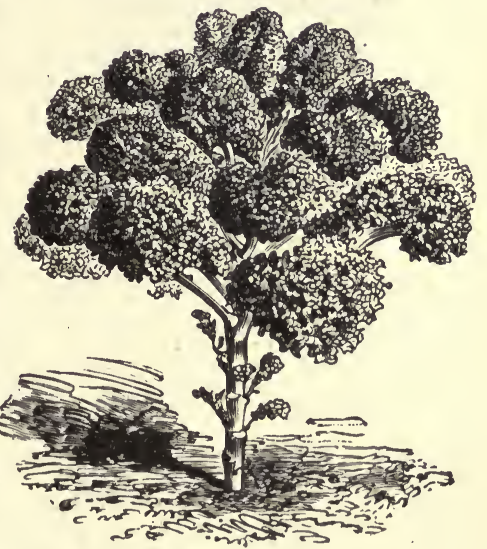
Copyright, V.A. \& Co.

Intermediate Moss-curled Kale. crop on almost any soil, but like all brassicas a strong deeply worked loam suits them best of all.

Seed should not be sown too early, the latter part of March or beginning of April being quite soon enough. Sow thinly on a seed bed and thin out early so that they may develop into sturdy stuff before transplanting. This should be done as opportunity occurs, choosing showery weather when possible. 
Kales are usually planted between other crops which are cleared off the ground in the early part of summer, so as to save space, intercropping with early potatoes being very usual. The distance apart depends upon the variety grown, some being much more spreading than others, but as a general rule they should be set from $2 \mathrm{ft}$. $6 \mathrm{in}$. to $3 \mathrm{ft}$. between the rows and $2 \mathrm{ft}$. between the plants. It is generally possible to snatch a

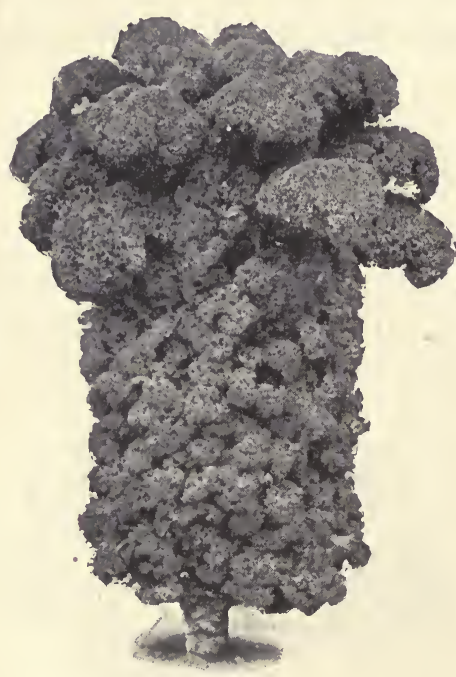

Copyright, s. \& S.

Sutton's A 1 Kale. quick-growing crop, such as lettuce, spinach or turnips, from between the rows after the earlier crop has been cleared, before the Kale needs all the space. Set out the last batch in the most exposed and northerly aspect, so that they will not be inclined to bolt so early in the spring.

Manures:- Whilst starved and stunted specimens are of very little use, on the other hand luxuriant and soft growth must be avoided or the plants will not have that hardiness which constitutes their especial value. This indicates that whilst well cultivated fertile soil is essential that which has received recent dressings of strong manure should be avoided, as should all fertilizers of a nitrogenous nature, except in cases where the soil is poor. On soil of fair quality the application of 4 cwt. superphosphate and $1 \frac{1}{2} \mathrm{cwt}$. sulphate of potash to the acre, or $1 \frac{1}{2} \mathrm{ozs}$. and $\frac{3}{4} \mathrm{Oz}$. respectively to the square yard, will ensure a satisfactory crop.

Varieties :-There are many varieties of Kales, but for practical purposes these may be reduced to two classes - the tall and the dwarf. The tall Kales give the heaviest crop, because the removal of the heads as a first crop is speedily followed by a heavy crop of side shoots; they also pass through a wet winter more successfully than the dwarfs. Some of the tall 
varieties, however, grow inconveniently high, and one of an intermediate type is much to be preferred, such as Sutton's A 1, Hardy Sprouting, or Curled Scotch. Among the dwarfs Dwarf Green and Dwarf Purple will pass through the severest winter without injury.

\section{BROCCOLI.}

Brassica oleracea botrytis asparagoides.

THE Broccoli is, for all practical purposes, a hardy winter cauliflower. It is very valuable to the market grower, and especially so to the gardener who caters for a private or shop trade, on account of the long period during which it is available for use-practically for the whole of the six months during which most other vegetables are difficult to get.

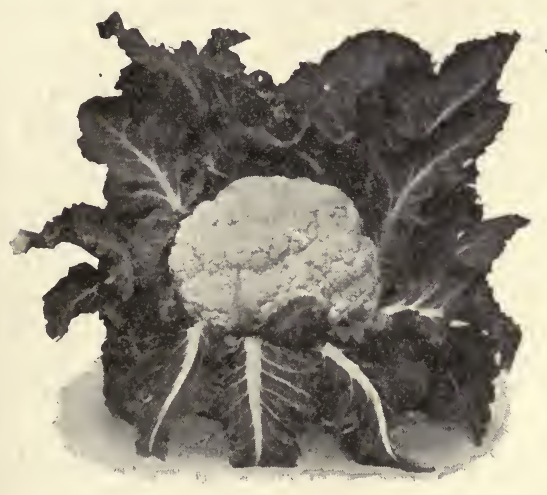

Copyright, S. \& S,

Sutton's Snow-white Broccoli.

The best crops of Broccoli are taken off a rather heavy loam inclining to clay, providing it is in a suitable condition for the crop. It should have been well manured and deeply cultivated for a previous crop, so that it is free from rank manure but is in good fertile condition and has settled down again firmly. Under such conditions fine close compact heads are produced. When the soil is rich and loose the heads come open and ill-shaped, the growth is luxuriant and soft, and the plants are liable to be completely spoiled in a spell of severe frost. When Broccoli is grown on light land a dressing of fresh manure may be given, supplemented with fertilizers, and if the soil is well rolled afterwards a satisfactory crop will usually be obtained.

The seed should be sown on a seed-bed in shallow drills, 9in. 
apart, from the middle of March to the middle of May, according to the variety and the time it is required to be fit for use; for autumn cutting sow from beginning to end of March, for winter sow in April, for spring in April and the beginning of May, and for summer in the middle of May. It is of great importance that the plants should be short-legged and sturdy. To secure this condition thin out the seedlings early, and if possible transplant at $3 \mathrm{in}$. apart on a nursery bed, where they remain until their permanent quarters are ready to receive them. Both seed and nursery beds should be kept free of weeds, with a loose surface.

In the usual course of things Broccoli follows upon some crop which has been cleared in the spring or early part of the summer, such as peas, early potatoes, or dwarf beans. Plant out at $2 \mathrm{ft}$. apart in the rows and about $2 \mathrm{ft}$. $6 \mathrm{in}$. between the rows, choosing for the operation dull showery weather when possible, so that watering in will be unnecessary, as it is better omitted. When, however, the ground is very dry and hard, holes for the plants may be made with an iron bar; then fill each hole to the brim with water and "puddle" the roots of the plants. An open exposed situation should be selected for the latest batches as this ensures hardiness and tends to prevent premature heading. As the heads begin to form the midrib of a large leaf should be broken and the leaf bent down over the heart of the plant; this helps to keep the head clean and white and prevents injury by frost.

Heeling-in is practised by some growers as a method of protection from the rigours of a severe winter, whilst many others say such a course is unnecessary and let the plants take all risk of the weather, trusting to the self-protecting character which many of the best strains now possess, or if the weather seems likely to be very severe they give protection by scattering a little light litter over the heads. Where heeling-in is practised it is done during mild weather in November. A trench a spit deep and the width of the spade is taken out along the north side of the row. The soil is laid close to the edge of the trench and the plants are then pressed over so that they rest on the ridge of soil with the heads sharply inclined to the north. This prevents the rays of the sun striking on the heart of the plant 
and injuring the head by alternate frost and thaw. The soil from the second trench is placed over the roots of the plants in the first row, where it helps to keep them in position and also forms a support for the second row, and so on until the whole of the plants are heeled over.

Sprouting Broccoli yields a heavy and useful crop during late winter and early spring. In mild open seasons the prices obtained are low, but in times when other vegetables are scarce these are eagerly sought after, and in such circumstances prove very remunerative.

Manures :-As already stated, over-richness and looseness of soil should be avoided in growing Broccoli. Fresh manure should never be given except when the soil is of a hungry nature, in which case a moderate dressing of well-decayed manure may be given, the soil being made firm by rolling afterwards. The best paying crops are obtained from a rather heavy soil which has been well cultivated and manured for the preceding crop, with $3 \mathrm{cwt}$. superphosphate and $1 \mathrm{cwt}$. sulphate of potash to the acre, applied previous to planting. In cases where these fertilizers have already been applied to the preceding crop and it is considered that a considerable residue remains in the soil, they may be reduced by one-half or omitted altogether.

Varieties:-The following are good successional varieties amongst a large number, many of them equally good: September to December-Sutton's Michaelmas White, Veitch's SelfProtecting Autumn, and Carter's Autumn; January to AprilVeitch's Early Market, Sutton's Winter Mammoth, Snow White, and Leamington; April to June-Satisfaction, Champion, and Late Queen. Sprouting Broccoli is practically confined to two varieties, White and Purple, and each of these is sub-divided into Early and Late, so that by using judgment a supply may be had throughout the winter and early spring.

\section{BRUSSELS SPROUTS.}

Brassica oleracea bullata gemmifera.

RRUSSELS Sprouts are indispensable to the grower engaged in supplying a retail or shop business, and a well managed crop usually shows substantial profits either to him 
or to the grower for market. They form one of the best green vegetables for autumn and winter use, and at that time are always in good demand by all classes of the community.

The main requirements for success in the cultivation of Brussels Sprouts are a deeply-worked rich and firm soil, room for development, and a long season of growth. The disregard of any or all of these conditions frequently results in disappointment-loose rich soil produces over-luxuriant plants with soft open sprouts which are practically useless; overcrowded plants yield sprouts few in number and only partially developed, whilst plants raised late in the spring, even if they should ultimately give a good crop, do so probably at a time when the most pressing demand is past and prices have fallen low.

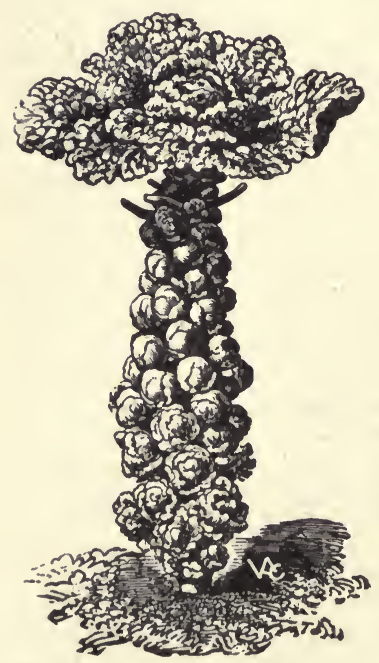

copyright, V.A.\& Co.

Dwarf Brussels Sprouts.

For a long succession sow batches from the end of February to the middle of May, putting the first in a cold frame, but for ordinary purposes one sowing in the middle of March is quite enough. Sow on a bed of light rich soil, in a sheltered position in the open. Before the seedlings crowd each other transplant the strongest to a similar bed, 3in. apart; a week or two later transplant the next strongest in a similar manner. By this means three successive batches of sturdy plants are obtained which will yield good sprouts from top to bottom if well treated afterwards.

Set out the plants in their final stations during May, if possible, and never later than the early part of June. Sometimes these plants are put between rows of potatoes, but such a position is not a good one, as crowding by the potato haulms has a tendency to cause the stems to become drawn instead of retaining that sturdy short-jointed character which is so desirable. Set the plants out in an open situation, 2ft. 6in. apart in each direction. Dibble them in carefully and in case the weather should prove very dry "puddle" the 
roots. Single lines of quick-growing catch crops may be sown between the rows as soon as planting is finished. After cultivation consists in keeping the ground free of weeds and the surface soil loose by frequent hoeing. The bottom leaves should be removed as they become yellow.

Some growers remove the head of the full-grown plant under the impression that doing so makes the Sprouts develop earlier, but the practice is a bad one. The head of leaves is not only required to assist the plant in the formation of the Sprouts, but it also serves to a certain extent to protect them during sharp frosts. The Sprouts should be gathered as they come ready. It is customary to break them off with the thumb and fingers but this is a mistake, they should be cut off with a sharp knife, leaving a piece of the stalk attached to the stem. By gathering them in this way a second crop follows, which lengthens the season and adds to the profits.

Manures:-The soil for Brussels Sprouts should always be deeply worked and contain a fair amount of organic manure, but neither the preparation nor the manuring of the ground should be done specially for the Sprouts when it can be avoided; this is much better done for the preceding crop so that the soil has become compact and all rankness has passed away from the manure. This objection to recent manuring does not apply in the same degree to soil of a sandy, hungry nature, which may well have a dressing of from 10 to 15 tons of farmyard manure, but whenever manure is applied specially for this crop it should always be thoroughly decayed. Before the plants are set out on the ground which has had no manure immediately preceding, the following fertilizers should be spread evenly over and be hoed or harrowed in:-Superphosphate 3 cwt., sulphate of potash $1 \mathrm{cwt}$. (or the equivalent in other phosphatic and potassic fertilizers of a readily-available nature) to the acre. Where manure has been given it should be supplemented by half the quantities of the above fertilizers.

Varieties:-Wroxton, Dalkeith, and Aigburth are all good reliable sorts which have stood the test of time, whilst there are numerous selected strains sent out by the leading seedsmen which are well worth a trial, such as Sutton's Matchless, Carter's Perfection, Veitch's Paragon, and Webb's Pride of the Market. 


\section{CABBAGE.}

Brassica oleracea capitata.

THE Cabbage is one of the most important vegetables in the garden; in fact, next to the potato, it may be said to be the most important vegetable grown, as it supplies green food unfailingly in constant succession throughout the year, and is popular with all classes of the community. It can be grown almost anywhere, but like most of its tribe it gives the most satisfaction on a moist retentive loam, deeply worked to provide it with an ample root-run and supplied generously with manure.

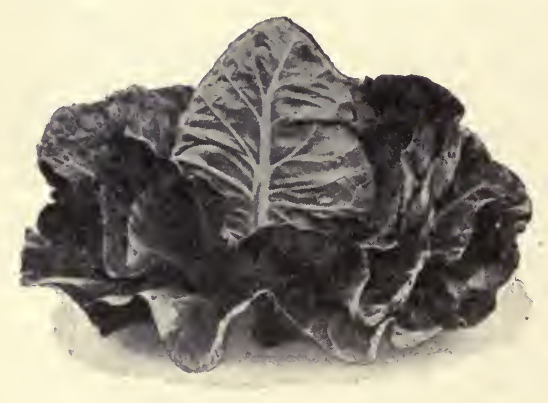

Copyright. S. \& S.

Sutton's Flower of Spring Cabbage.

The grower who does a general trade should seldom be without cabbages, and so must make several sowings over an extended period, but both for this business and for ordinary market work the spring supplies are by far the most important, and when well grown and early, invariably bring substantial returns. As soon as the demand in spring begins to slacken prices fall and profits are correspondingly low, but the demand revives somewhat as the supply of peas runs short, and gradually strengthens as the summer passes.

The most important sowing of the year, therefore, is that intended for spring supplies, and the exact time:for sowing needs careful consideration. Strong plants are wanted before the cold weather comes, but they should not be too advanced or they may suffer severely from prolonged frosts, and there is also a decided tendency for plants which are too forward to "bolt" as soon as growth begins in the spring. On the other hand if the sowing is too late winter comes before the plants 
have much strength, with the result that many fall victims to slugs, birds, and excessive wet or sharp frosts, whilst those which survive mature late the following spring and so miss the best prices.

From the middle of July to the middle of August is the usual time for this sowing, the exact date depending upon the season, the soil, and the locality. The earlier dates are for the north of the kingdom, gradually getting later towards the south. In a hot summer or on an early soil it would be wise to defer sowing a week or two later than the usual time. The seed-bed should be light and rich. After raking down to a fine tilth, the seed should be sown very thinly, in shallow drills $9 \mathrm{in}$. apart. The seedlings are frequently left standing in the seed-bed until planting out time arrives, and provided they are thinned out sufficiently to avoid overcrowding, not much can be said against the practice, but where the quantity to be dealt with is not too large, much sturdier plants are obtained if the seedlings are pricked out on a bed similar to the seed-bed as soon as they can be handled. The plants should be set out in September, choosing a rainy period when possible. For these plants the

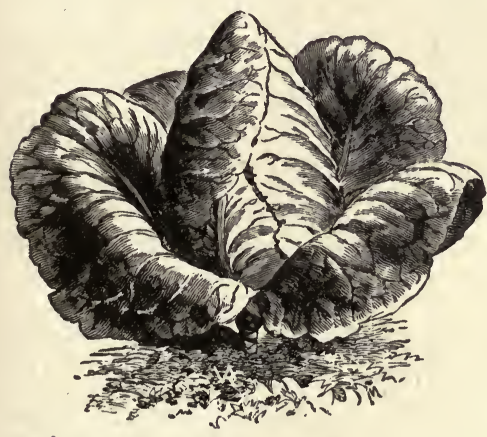

Copyright, V. A. \& Co.

Early Etampes Cabbage. soil should be in a firm condition; if it is loose they do not heart up so well. The distance apart depends upon the variety grown. Cabbage which grow to an average size are usually set $18 \mathrm{in}$. apart in each direction; or they may be $18 \mathrm{in}$. apart in the row and $2 \mathrm{ft}$. between the rows, with coleworts set $1 \mathrm{ft}$. apart between the rows of Cabbage; or again they may be planted from $1 \mathrm{ft}$. to $14 \mathrm{in}$. apart in each direction, every alternate plant being cut as soon as growth commences in the spring and sold as "bag greens." If the "greens" are removed so that the plants remaining stand in quincunx form the remaining plants will stand about 17in. or 20in. apart in each direction, which allows them ample space for development. 
For summer and autumn supplies seed should be sown early in March and at intervals afterwards. The plants are set out in small batches wherever ground becomes vacant.

In some gardens the surplus plants from the August sowing are pricked out in rather poor soil so as to keep them in good but hard condition, and these are set out in any mild spell through the winter as a piece of land is got ready. Some of the plants are not put into their final quarters until spring, when they come ready before those raised from spring sowing.

In places where a private or shop trade is catered for it will be found a good plan to cut off in succession part of the Cabbages just below the head, leaving a few of the bottom leaves. These presently break out with a number of tender small heads, much valued by those who appreciate young and tender cabbage sprouts. If the ground they occupy is not immediately wanted these stumps will yield a second crop of small heads after the first are removed.

Manures:-Cabbage are gross feeders, and the soil must receive liberal quantities of farmyard manure if their cultivation is to be conducted successfully. The presence of lime in the soil is essential to their healthy growth, and for this reason the phosphates in the supplementary fertilizers necessary to a good crop should be derived from basic slag or limphos. A suitable dressing would be $8 \mathrm{cwt}$. basic slag or $3 \frac{1}{2} \mathrm{cwt}$. limphos and 4 cwt. kainit to the acre, spread and harrowed in before planting in September, with from 1 to 2 cwt. nitrate of soda, in two dressings, the first as soon as growth has started well in the spring and the second two or three weeks afterwards.

Varieties:-For autumn planting: Myatt's Early Offenham, Sutton's Flower of Spring, Hurst's First and Best, Mein's No. 1, Webb's Emperor, Wheeler's Imperial, Evesham Early. For spring and summer sowing: Early Etampes, Ellam's Early, Express, Nonpariel, Early Dwarf York, Glory, Enfield Market, Sutton's Imperial, Daniel's Defiance.

Red Cabbage for pickling is sown in July and August. It is treated in a similar manner to the ordinary Cabbage, but needs more room and occupies the ground longer. It needs rich and deeply worked soil. Set the plants out at least $3 \mathrm{ft}$. apart and take catch crops off the space between. Variety:-Red Dutch. 


\section{CARDOONS.}

Cynara Cardunculus.

THE Cardoon is a close relation of the globe artichoke, and 1 has much the same appearance when growing. It is not much cultivated in this country, but as it is occasionally in demand it has been thought best that its culture should be described.

Whilst the artichoke is usually propagated from offsets, the Cardoon, on the contrary, is always grown from seed. Trenches are prepared as for celery, $18 \mathrm{in}$. wide, $1 \mathrm{ft}$. deep, and $4 \mathrm{ft}$. from centre to centre. The soil at the bottom of the trench is well mixed with 3 in. of good rotten manure. At intervals of $18 \mathrm{in}$. a patch of fine soil is laid down, and in each of these patches, at the end ' of April, three or four seeds are sown, well watered in, and

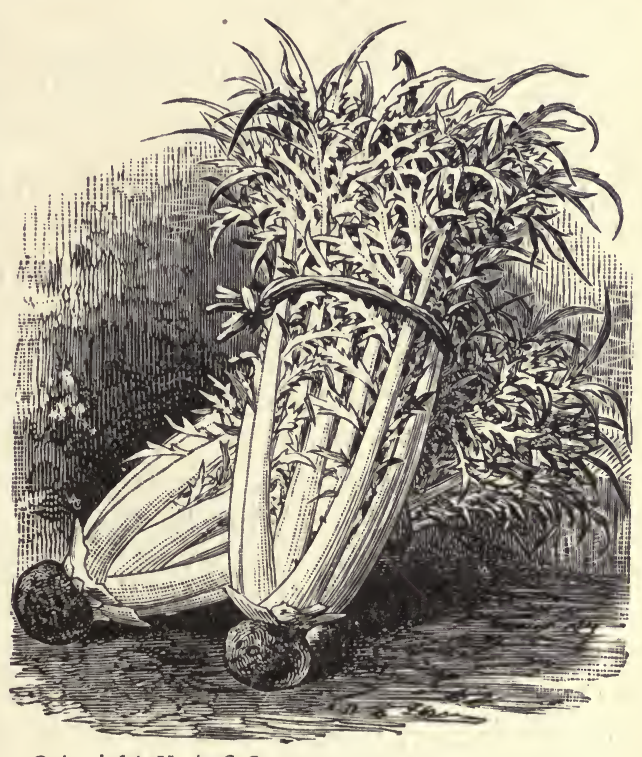

Copyright, V.A, \& Co.

Ivory-white Cardoon. covered with a flower-pot until the seedlings are up, when the pots are removed, and the plants thinned out to the strongest one at each station. Some light feathery branches should be put over the trench to protect the plants from sun for a few days after the pots are removed, and each night until the beginning of June, to protect them from frost,

During the summer the Cardoons must have frequent and copious waterings. By about the middle of September growth will be completed, and they will be ready for blanching. For this operation choose a fine day when the foliage and the soil are dry. Then draw the leaves together and tie them firmly 
with strong raffia. Each plant is then covered from the base to the tips of the leaves with dry hay or straw, 3in. thick, kept in position by raffia, and the whole is then covered with soil from the sides of the trench, in the same way as celery is earthed up. Blanching is completed in about a month. Put litter over the tops of the ridges to protect from frost.

\section{CARROTS.}

Daucus Carota.

FXCELLENT crops of Carrots can be grown-on any well E cultivated garden soil, though a deep sandy loam suits them best, and it is on this class of soil that the most handsome roots of the long varieties are produced. On soil of a heavy nature the varieties grown should be confined to those which are short or stump-rooted, and if before sowing it is well pulverized and made free of lumps, crops quite as satisfactory and profitable can be obtained as on lighter soil. Whatever its nature may be the soil should always be free of fresh manure near the surface or the roots will fork badly. When the soil is so poor as to be in need of manure this may safely be placed beneath the top spit, or thoroughly decayed manure which has been well broken up may be dug in, but it is always better, especially when the long-rooted varieties are to be grown, to select ground which was deeply dug and manured for some other crop at least six months previously.

The demand for Carrots in some form is fairly constant throughout the year, so that it is a safe crop to grow. When the soil is of a suitable description all the land that can be spared from other crops may be profitably devoted to Carrots.

The culture of the Carrot in the garden may be divided into three well-defined sections-forcing in frames, early crops on sheltered beds, and main crops in the open ground, but in addition to these the intensive gardener will find it profitable to have a few beds of tender young Carrots ready for use in the autumn, when the main-crop roots are getting large and coarse. 
Forcing in Frames.-Mild hot-beds for forcing Carrots may be made at any time from the middle of November to the end of February. Full particulars respecting the preparation for and making of these will be found in pages 82-84 and 92-94. After the frame is put on the bed the manure is covered with about $4 \mathrm{in}$. of light rich soil, or preferably with the finely-sifted thoroughly decayed manure described on page 83 ; this is raked down smooth and fine and all lumps removed, then the frame is shut up closely for a few days. When the bed is nicely warm sow seed of one of the forcing varieties broadcast, very thinly, cover lightly with dry finely-sifted decayed manure, and press down evenly with the firming board. It is a good plan to sow radish seed thinly along with the Carrot, as they are up very quickly and cleared off the bed before the Carrots are inconvenienced in any way, and add so materially to the profit of the crop. French gardeners, after sowing carrot and radish, also set lettuce plants on the same bed, and as soon as the lettuce are ready for cutting follow these up by planting cauliflowers amongst the Carrots. These additional crops, whilst in no way injuring the quality or quantity of the Carrots on the bed, have a decided effect in retarding their growth, and when Carrots are wanted early all additional crops except radishes are best omitted.

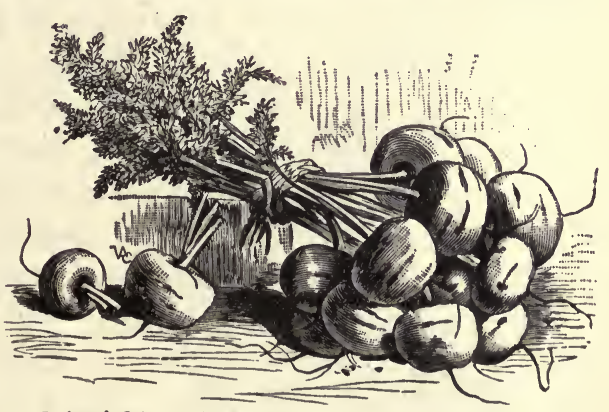

Copyright, V.A.\& Co.

Parisian Forcing Carrot.

As soon as the seed is sown the frames are shut up closely and covered with mats until germination has taken place, after which the mats are removed in the daytime, but replaced each night to conserve the warmth and protect from frost. If the manure and soil are in the right condition no water will be needed, but if the soil gets dry give a little through a fine rose. If the heat of the bed rises above $60 \mathrm{deg}$. by day or $50 \mathrm{deg}$. by night a little air must be given, and in any case air should be given on all favourable occasions as soon as the plants have 
made three or four leaves. At this stage, too, the plants should be thinned out to $1 \mathrm{in}$. apart, and later, when some of the most forward are ready, these may be removed for use and the remainder left standing at $2 \mathrm{in}$. to $3 \mathrm{in}$. apart. Air must be given whenever the weather is mild and water when the soil appears dry. Ventilation must be gradually increased until by the beginning of April the lights can be removed completely on fine warm days, and by the middle of the month the frames can be removed altogether, and the crop left standing in the open. It is a good practice to work a little fine soil in amongst the tops of the roots to prevent them becoming green.

Good and early crops can also be obtained from cold frames. The bed is made up and managed in a precisely similar way to that on the hot-bed, except that no hot manure is used. The frame should face south and the seed should not be sown before February. This crop will come in just before the earliest one from protected beds in the open.

Early Crops from Protected Beds and Warm Borders.-The earliest open-air sowing may be made with one of the stump-

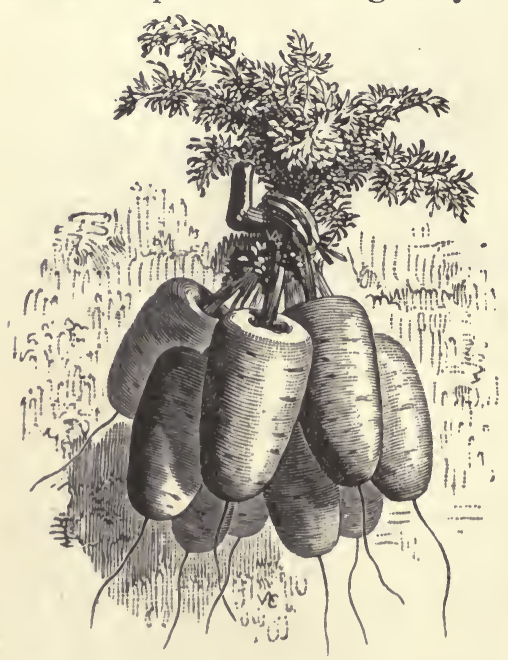

Copyright, V.A. \& Co.

Dutch Horn Carrot. rooted varieties, such as the Dutch Horn, any time after the beginning of March, on a warm dry border. The soil should be in a dry and crumbly condition or the seed will not germinate well. If it is wet and cold a change of weather should be waited for, or, to avoid delay, excellent results may be obtained when the bed is covered with $2 \mathrm{in}$. of prepared soil. If the soil is fairly free of weeds sow broadcast, or in drills $6 \mathrm{in}$. apart. Radishes may be sown with the Carrots. If rain threatens do not sow until the weather clears; or cover the beds immediately after sowing with mats, for if a heavy rain beats on the bed soon 
after the seed is put in it will probably fail to germinate, and will have to be re-sown, thus causing delay and loss. When the plants are well up they should be thinned out, first to $2 \mathrm{in}$. apart, and afterwards by bunching the most forward, to $4 \mathrm{in}$. The crop from March sowings will be forwarded considerably if the bed is surrounded by thatched hurdles to keep off cold winds and if each night protection from frost is given by mats resting on a framework of laths. Further sowings may be made on unprotected beds from the beginning April.

All the early Carrots, as well as the suitable thinnings of the main crops, are tied in bunches of varying sizes, according to the requirements of the respective markets (the forced Carrots consigned to Covent Garden from the French garden being in bunches of 50-two half bunches of 25 being tied together); they are always washed before being packed, so as to present a bright and attractive appearance.

Main Crops.-The land for the main-crop Carrots should be well drained and have been deeply worked some time previously, so as to get it into a mellow and friable condition. It is useless to put this crop into cloddy, illworked or wet land. The soil should be in a fine tilth, and the seed should not be sown unless it is in a dry crumbly condition, with no immediate threat of rain.

Sow from the middle March to the end of April (the earlier dates being suitable for light warm soil) in drills from $9 \mathrm{in}$. to $12 \mathrm{in}$. apart and $\frac{1}{2}$ in. deep. One of the varieties of Intermediate will be found the most suitable for all medium soils; on light land one of the longer sorts may be grown, and on land of a clayey nature a shorter root of the Chantenay type will be found the most suitable; or if a

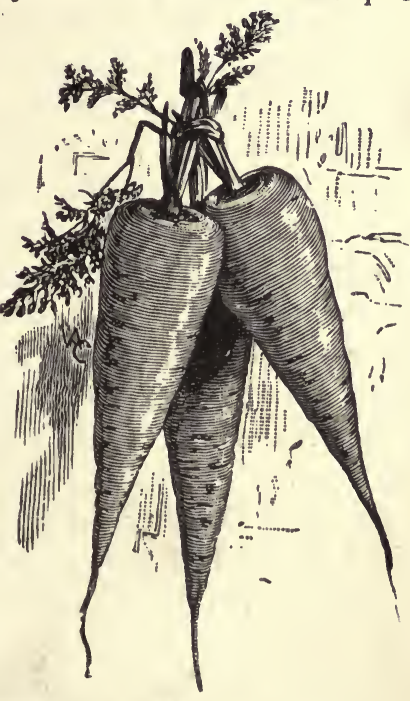

Copyright, V.A. \& Co.

James' Scarlet Intermediate Carrot. longer root is wanted the seed may be sown on ridges, $15 \mathrm{in}$. to 
18in. apart. As soon as the seedlings are large enough to handle they should be thinned without delay to $2 \mathrm{in}$. apart, and as soon as they are seen to be large enough for bunching they are thinned again from $4 \mathrm{in}$. to $6 \mathrm{in}$. apart. This second thinning should never be omitted and should be done thoroughly, or numbers of the plants are left to grow huddled together, where they make only small useless roots. After thinning, the soil should be drawn with the hoe to each side of the rows, so as to fill up all spaces left by the removal of the roots, and so help to keep the carrot fly at bay.

Further cultivation during the summer consists in keeping the plants free of weeds and the spaces between the rows in a loose condition by frequent hoeing. The mulch of loose soil thus formed helps to conserve the moisture in the soil below, and by ensuring a steady growth does much to prevent the splitting of the roots which takes place when a drought is followed by a period of wet.

Choice young roots can be had in autumn and the early part of winter from a sowing of one of the early varieties on good rich soil in the first or second week of July. They must not be allowed to suffer from lack of water. If the sowing is made on a sheltered bed, where they can be easily protected on the approach of frost, the supply can be prolonged. A further sowing can be made in August in open frames, or on beds which can be covered by box frames. On the approach of frost the lights are placed over these, though plenty of ventilation is given whenever the weather will permit. As the weather gets severe the frames are covered with mats. By careful management this will give a supply of tender roots until the turn of the year.

Early in October, in fine weather, the main-crop roots are lifted, cleared of soil, and the leaves cut off to $\frac{1}{2}$ in. of the top. When the quantity is only moderate they may be stored in a dry shed or cellar. Here a foundation of dry earth or sand is laid down on which the roots are placed in regular layers with earth or sand between each layer until they are about $3 \mathrm{ft}$. deep. The tops of one layer alternate with the bottoms of the next. A few rough boards are fixed at the front and ends of the heap to keep them in position. When the quantity to be dealt with 
is large, the roots are stored in clamps like potatoes; the site for the clamp should be dry, the heap not more than $4 \mathrm{ft}$. wide at the bottom and $3 \mathrm{ft}$. high, with the roots laid carefully and arranged so that the tops are turned to the outsides. Cover the roots with $4 \mathrm{in}$. of straw and the straw with $4 \mathrm{in}$. of earth, which may be taken from outside the site of the clamp so as to form an open drain and so help to keep the interior dry. Along the ridge, at intervals of $6 \mathrm{ft}$., ventilation shafts should be made by building the earth round a drainpipe or a tuft of straw.

Manures:-Crops grown on manure beds in frames do not require any additional fertilizers. "Early crops in the open-air should be grown on rich soil and will receive great benefit from an application of $\frac{1}{2}$ to $1 \mathrm{oz}$. per square yard of sulphate of potash, using the heavier application on the lighter soils; if the soil is of a poor nature and growth is slow it may be stimulated by $\frac{1}{2} \mathrm{Oz}$. to the square yard of sulphate of ammonia, given in two applications with a fortnight's interval, and watered in, but this should only be given after potash, or the plants will make more leaf than root. For main-crops, on soil where the preceding crop received manure, the ground should be dressed at least a month before sowing with 3 cwt. basic slag (or 2 cwt. superphosphate) 5 cwt. kainit, and $6 \mathrm{cwt}$. rape dust or castor meal. If it is impossible to apply these fertilizers until just before sowing use an equivalent quantity of sulphate of potash in place of kainit. If the soil is poor increase all the fertilizers by about one-third. All these quantities are for one acre. A light dressing of soot at intervals during the early part of the summer will increase the vigour of the plant and assist to keep away the fly.

Varieties:-For frames: Parisian Forcing, French Horn (grelot), or one of the numerous forcing strains supplied by the leading seedsmen. For cold frames and protected borders: French Horn (grelot), Early Nantes, and Dutch Horn (Bellot). For early unprotected borders: Dutch Horn, Guerande or Sutton's Early Gem, and Veitch's Model. For main-crops on heavy soil: Chantenay, Early Market, Sutton's Favourite. On medium soil: James's Intermediate, Daniels's Telegraph, Sutton's New Scarlet. For deep sandy soils : Improved Altrincham, Veitch's Matchless, Long Surrey. 


\section{CAULIFLOWER.}

Brassica oleracea botrytis cauliflora.

THE Cauliflower is one of the most important crops grown 1 in the market garden. It is a vegetable which is always appreciated by the consumer, and a good sample usually commands a ready sale. It can be grown successfully on almost any class of soil if its requirements are attended to, and although these are simple they are imperative. They consist of abundant food supplies and sufficient moisture, with conditions which will permit growth to proceed rapidly, without any check. The land on which Cauliflowers are to be planted should be well drained, deeply worked, and rich with manure, though this should not be of a fresh or rank nature, and the purpose is best served when the land is dressed with thoroughly decayed manure or when it has been applied fresh to a preceding crop.

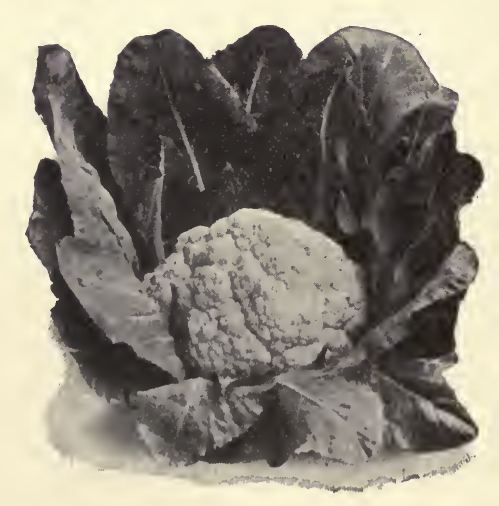

Copyright, s. \& S.

Sutton's Magnum Bonum Cauliflower.

Sowing resolves itself into three periods. Two are made with an interval of three weeks between, from the last week in August to the first week in October, according to the locality (the more southerly the situation the later the sowing); these are for the early spring supplies, partly grown under protection. The next sowings, to raise plants for the summer crops, are made on a mild hot-bed in February and March. The third are made in the open during April and up to the first week in May, for autumn supplies.

For the first sowing prepare a seed-bed of light rich material. Sow the seed broadcast, thinly, cover lightly with sifted decayed manure, press down with the firming board, and water well. 
Cover the bed with netting to keep off birds. If the sun shines very strongly give shade in the middle of the day until the seedlings are up well. During the next three weeks water lightly at frequent intervals, to strengthen growth and keep insect pests away. The next sowing should be made on a similar bed in a cold frame.

For the winter quarters of the plants prepare a bed in a sheltered position. This should be raised from 6in. to $9 \mathrm{in}$. above the general level, so that it will be free from excessive damp. Cover it with 2 in. of coal ashes, beaten down firmly. Stand shallow frames on this, and put inside each 3 in. of fine rich soil, which should be moist, so that no watering is required. The plants should be pricked out here as soon as they can be handled, about three weeks after sowing; set them $3 \mathrm{in}$. apart, then put on the lights, and shade lightly for a few days. If the soil is moist, as it should be, no watering will be required, and they are better without, but if it is rather dry the plants must be watered to give them a start. In a few days the roots will begin to work, then raise the lights at each corner so that a current of air can blow right through. The plants must be grown as hardily as possible all through the winter, the frames being kept fully ventilated during mild weather. Driving rains must be excluded by keeping the lights down on the windward side. In times of frost the lights must be closed, and when it is severe they should be covered with mats or litter. If the weather is very mild and they are growing too freely, lift and transplant a little further apart, to give them more room and a slight check. If white fly attacks the plants dust them over with soot occasionally.

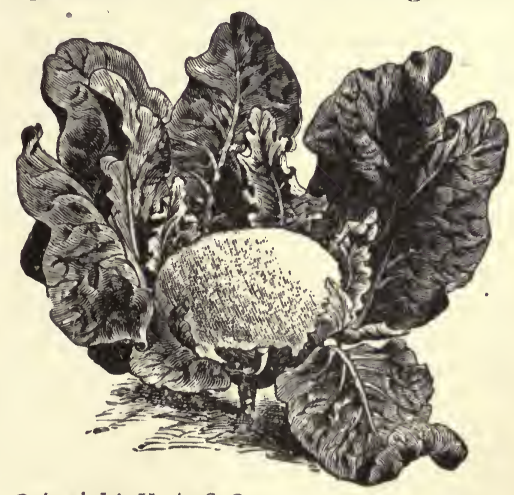

Copyright, V.A. \& Co.

Early Dwarf Erfurt.

The first batch of plants is used to set out early in March in any position in which they can receive protection for a few weeks. Special efforts should be directed to obtaining good 
supplies of these early heads, as the prices they realise are an ample recompense for any extra trouble taken over them. In the French garden they are usually set out four to a light in the shallow frames standing on beds of warm manure; here they are planted amongst carrots immediately after cabbage lettuce are cleared (see page 96) and are ready for cutting about the beginning of June. They are also set out on a similar warm bed amongst the cloches (but not covered by them) at the end of March or early in April, to follow the earliest cos lettuce (see page 99) and are ready for cutting towards the end of June. Much earlier supplies can be had by planting in February on a bed of warm manure under cloches. In this case one cauliflower plant is set in the centre and surrounded with three or four cabbage lettuce of a small forcing type. Very early supplies may also be had by planting in March over a trench filled with warm manure and employing for protection one of the devices described on pages 134-5.

The plants from the second autumn sowing are set out in sheltered positions in the open as soon as genial weather comes towards the end of March or beginning of April. They may be set about $2 \mathrm{ft}$. apart each way amongst cabbage or cos lettuce which will be cleared before they seriously interfere with the cauliflowers; or they may be planted alone, in rows $2 \mathrm{ft}$. apart, $18 \mathrm{in}$. between the plants in the row; or they may be set $6 \mathrm{in}$. further apart in each direction amongst a crop of radishes, and as soon as the radishes are cleared they are intercropped with a row of lettuce between the rows of Cauliflower and one set alternately between the plants in the row.

Summer and autumn supplies are provided for by the plants raised in frames in February and March and those raised in the open in April. As stronger growing sorts are employed for summer than for spring, and still stronger for autumn, they must be planted at proportionately greater distances apart, $2 \mathrm{ft}$. by $2 \mathrm{ft}$. $6 \mathrm{in}$. in the former case and $2 \mathrm{ft}$. $6 \mathrm{in}$. by $3 \mathrm{ft}$. in the latter being none too much. Both plantings may be intercropped with advantage, the ground to be occupied by summer Cauliflowers being previously sown with rows of summer spinach at suitable distances apart, which becomes exhausted by continual picking before the Cauliflowers need all the space, 
and the autumn plantation may be intercropped with French beans, lettuces, late celery, \&c.

Copious supplies of moisture during the growing period is an essential part of the successful cultivation of Cauliflowers. If the weather is dry planting must be accompanied by a good watering-in. Where the area devoted to the crop is only of moderate extent further supplies of water, accompanied by surface mulches, present no serious difficulties, but the moisture for crops on a more extensive scale usually depends upon the natural rainfall, and unless evaporation of soil moisture is prevented by keeping the surface soil in the condition of a mulch by frequent stirrings with the hoe, summer crops may prove unsatisfactory.

When a head shows, a large leaf should be broken over it to keep it clean and white. At this time the plants should be examined frequently and cut as soon as ready, as if overlooked for a day or two they may be quite spoiled through getting too open, especially if the weather is warm. Cutting should always be done in the early morning, as soon after daybreak as possible, whilst the dew is upon the plants, and they should be taken under cover at once. If cut under a hot sun, after the dew has evaporated, the quality will be deteriorated.

Manures :- It is useless attempting to grow Cauliflowers on poor land; it should be rich with manure, preferably by a heavy dressing given to a preceding crop. When applied specially for Cauliflowers it should be well-rotted, 20 loads to the acre on good land and double that quantity on poor land being none too much, supplemented by $3 \mathrm{cwt}$. superphosphate and $1 \mathrm{cwt}$. sulphate of potash, applied previous to planting. If the land is properly prepared, nitrogenous fertilizers will not be required, but if for any reason growth is too slow give $\frac{1}{2} \mathrm{cwt}$. nitrate of of soda or sulphate of ammonia to the acre, applied in a ring around the foot of each plant.

Varieties :-For the earliest supplies: Early London, Snowball, Magnum Bonum, Salomon. For early summer: Sutton's Purity, Carter's Mont Blanc, Webb's Peerless, Lenormand's, Early Dwarf Erfurt. For late summer and autumn: Early Emperor, Walcheron, Kinver Monarch, Eclipse, Autumn Giant, Autumn Mammoth. 


\section{CELERY.}

Apium graveolens.

CELERY may be classed amongst the more important and profit-making crops of the garden, and should never be omitted by the grower who undertakes to supply direct. When well grown and properly blanched it is a favourite with almost everyone, and if offered in this condition the supply is seldom, if ever, in excess of the demand. It has the further advantages of being one of the very few products which are free from foreign competition; of the main-crop selling in the winter and thus producing a welcome addition to the income when most other things are over; and of leaving the ground in first-rate condition for any crop which follows.

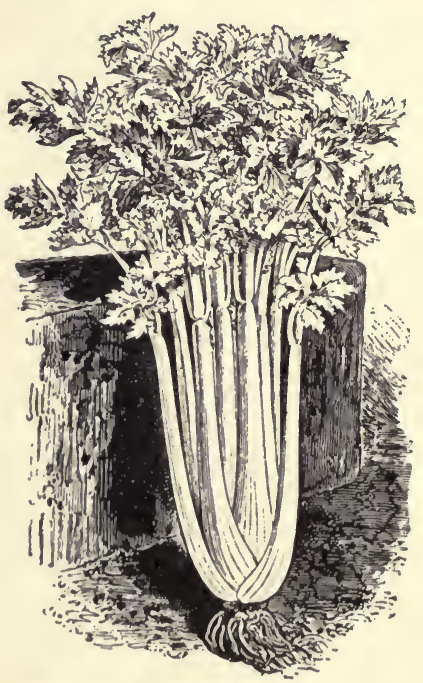

Copyright, V.A.\& co.

Golden Yellow Large Solid Celery.

The best main-crop Celery is grown on soil which is deep and rich, rather heavy and moist, but well drained, for although Celery is a moisture-loving plant-being in fact a semi-aquatic-it will not thrive in a water-logged soil. By the methods followed in the French garden, as will be described later, excellent and very profitable early crops are taken from beds consisting almost entirely of thoroughly decayed manure, and in this case the character of the soil is not taken into consideration, the only other thing needful for the production of a good sample-in addition to proper care in cultivation-being copious supplies of water.

For the earliest crop, to be lifted in August, sow late in February, very thinly, on a mild hot-bed, an early variety of dwarf Celery. Cover the seed lightly with compost, press down with the firming board, and water well. Shut up close and cover at 
night with mats. As soon as the seedlings show give a little air if the weather is mild, at first very cautiously, but more freely as the weather gels warmer. Keep the bed moist. By the middle of April the lights may be taken off the frame on mild days, but must be replaced each night. When the plants are about $2 \mathrm{in}$. high they must be pricked out, 3in. apart, in a cold frame, either on a bed of old decayed manure or on one of light rich compost. Water well; keep close and shaded for a few days to induce root action, then grow as much as possible in the open-air, but cover with lights each night for fear of frost. Keep the bed uniformly moist.

For the main-crop make another sowing, of white and pink varieties, on a similar hot-bed, in the middle of March. When these seedlings are ready to prick out, if the number is not very large, cold frames are used as before, but where the quantity is considerable a piece of ground in a sheltered position is trodden down firmly and then covered with $6 \mathrm{in}$. of well-decayed manure, which is also trodden down, and then covered with $2 \mathrm{in}$. of fine compost. Here the seedlings are pricked out in rows $6 \mathrm{in}$. apart and $3 \mathrm{in}$. apart in the rows, and watered in well. The most forward should be selected and pricked out first, then the next strongest, leaving the smallest to get a little stronger, and so securing three successive batches, each of equal size. Some form of protection, such as old lights or mats, should be provided, so that the earliest batches can be covered each night for a week or two.

For the latest crop sow on a sheltered border in the open, in the second week of April. The soil should be rich and light and made firm by treading or rolling. ,Give protection during cold weather. From this bed also, three selections for pricking out should be made, on a bed prepared in a similar manner to the preceding, the last being in an exposed position, so as to ensure a prolonged supply in regular succession. The seedlings must always receive abundance of water, so as to keep them growing steadily, a check at any period of their growth, either in the plant bed or in their permanent quarters, being very detrimental, and causing them to run to seed or the stems to grow hollow.

When the time for planting out has arrived a sharp spade 
is run between the rows of plants and then a good soaking with water is given. After about two days the plants in the cold frames are carefully lifted with a trowel, or if on beds a spade is pushed under the plants, which are then carefully separated so as preserve the roots, and are taken in baskets, boxes, or on hand-barrows to the planting ground. If the plants are well advanced in growth, it is a good plan to cut off part of the larger leaves; they will then feel the shock of removal much less than when the leaves are left entire.

The manner of planting out the Celery calls for serious consideration. There are two entirely different methods, either of which will give satisfactory results if properly carried out. The customary way is to grow the plants in trenches containing one or more rows, single rows being the most usual in market garden work. The space from centre to centre of single row trenches varies from $3 \mathrm{ft}$. to $4 \mathrm{ft}$., and the space between the plants from $8 \mathrm{in}$. to $1 \mathrm{ft}$., according to the variety grown, the closer planting being for dwarf early varieties and the wider for main-crops.

In the other method the planting is done on the flat, in broad beds, the plants being set at distances apart varying from $10 \mathrm{in}$. to $14 \mathrm{in}$. in each direction. It is obvious that the number which can be grown on a given area is enormously increased by this method, and that the labour involved is much less than when a similar number is grown in trenches, though the quality, even under the best culture, is not so high as when the "sticks" are well blanched by earthing-up. With proper care, however, they are good and meet with a ready sale, the early crops realising very good prices, and it would therefore appear to be only a question of time for the broad bed system to largely displace planting in trenches, at least for the earliest supplies. A description of the more customary methods of growing will, however, be given first.

Preparation of Trenches.-The ground intended for Celery should be in an open position, with a good supply of water available, abundant moisture being indispensable to its production. The soil should be deeply worked and heavily manured. If it is of a kindly free-working nature this operation may be arranged so that a spring crop of onions, collards, cabbage, 
cauliflowers, lettuce, peas, or early potatoes is taken off first, so making Celery the second crop. Heavy soils should, when possible, be prepared in autumn, by being manured and bastard trenched, the surface being thrown up in ridges so that the weather may bring it into good friable condition. As soon as the soil is dry in the spring it is levelled and harrowed, and trenches are thrown out a spit deep, $1 \mathrm{ft}$. wide for single rows, 18in. for double rows, and $3 \mathrm{ft}$. for four rows, with the spaces between the trenches correspondingly increased, according to the quantity of soil needed for earthing-up, and the kind and extent of the intercropping in the alleys (if any) which is to be done. Well-rotted manure is laid in the trenches 6in. deep, trodden in firmly, and covered with soil almost to ground level. Market gardeners never plant Celery in deep trenches, particularly the late crops; the position of the roots is so arranged that when the crop is earthed up they are above the bottom of the furrows between the ridges (see diagram, page 189). When the position of the roots is below this level, late crops are very precarious, particularly in a wet season, or on badlydrained land.

Planting Out.-This operation should be performed in dull or showery weather when possible, from the middle of May for the earliest crops to the middle of July for the latest. In single rows plant from $6 \mathrm{in}$. to $1 \mathrm{ft}$. apart, according to the size and vigour of the variety grown. Where there are two or more rows in the same trench they are put from $6 \mathrm{in}$. to 9in. apart, with $10 \mathrm{in}$ to $1 \mathrm{ft}$. between the plants in each row, those in one row standing between those in the next, thus- ${ }^{\circ}{ }^{\circ} \cdot$. Each plant is set carefully with a ball of soil, watered in as planted, and the soil round the roots well "firmed." If the weather is hot and dry shade must be given for a few days, and water given generously at least once in three days, but if it is dull, watering once a week will be sufficient. The strongest plants should be selected and planted by themselves, as also should the weaker ones. In this way uniformity in the size of the "sticks" is secured, and a whole row of plants becomes marketable at one time.

As soon as planting out is finished, the soil between the trenches is levelled and planted with cauliflower, French beans, 
lettuce, or some similar crop which will be cleared off the ground before the soil is wanted for "earthing-up."

General Treatment.-The summer culture consists in keeping the ground free from weeds by frequent hoeings, and copious waterings are given, twice a week if the weather is very dry, or once if it is dull. Suckers are removed as they appear. A sharp look-out should be kept for evidences of the celery fly. On the first appearance of the maggot, the affected portions of the leaves should be picked off and burnt, and the plants lightly dusted over with soot whilst they are wet with dew. Dusting with soot occasionally acts to some extent as a preventative, by making the plant distasteful to the fly, but care must be used not to put it on too thickly or it may do more harm than good. Other remedial measures are suggested in the section dealing with Pests.

Earthing up.-The first operation in the direction of earthing up should take place when the plants are growing freely and are about $1 \mathrm{ft}$. high. On a fine dry day remove all suckers and small leaves, then chop up the earth at the sides of the trench and after it has dried for an hour or two, working from the opposite side, draw it gently with a broad hoe towards the

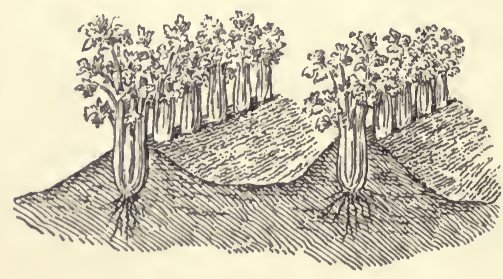

Celery after the Second Earthing. bottom of the plant, but leave a space for watering. The next operation takes place a fortnight afterwards. When the spaces between the rows are cleared of plants, a horsehoe is run up and down several times in the early part of the day, or the soil is well and deeply hoed by hand, so as to get it fine and friable. After lying for a few hours to get dried it is drawn to each side of the rows, half-way up the stems, with a broad hoe, and pressed well round the plants; or a mould-board plough may be used to do the work. The next earthing is the final one, and takes place when the plants are fully grown, about a fortnight after the second. On this occasion the whole of the stems are covered, the soil being brought close up under the top leaves, and the ridges being made firm and smooth, in such a way as to 
effectually throw off rain. Each time earthing-up is done the plants should be dry and the soil dry and crumbly-if done when plants or soil are wet decay is almost sure to set in.

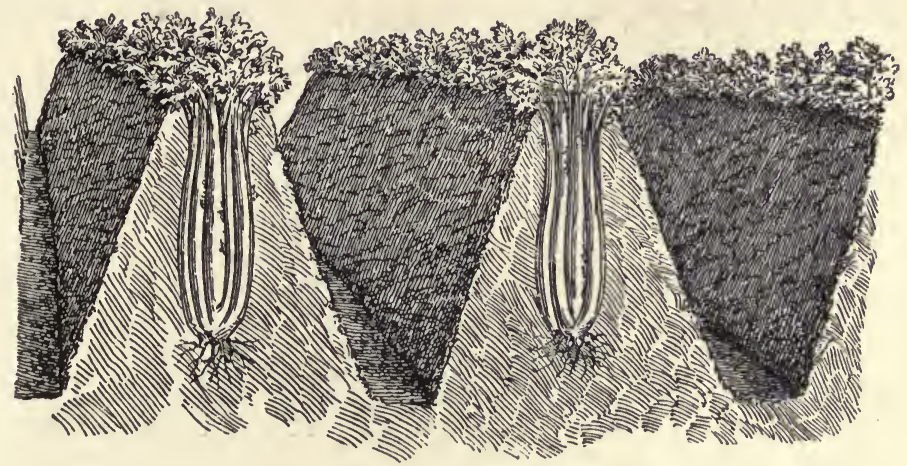

Celery finally Eartned-up.

Great care must be taken not to allow the soil to get into the heart of the plants. For this reason earthing is generally done by two persons, one to hold the tops together and the other to put on the soil; or better still, when there is a large breadth to do, two can put on the soil-one at each side of the row-whilst a third holds the tops. The work can, however, be done by one person if the stems are previously drawn closely together and tied. American growers have a simple

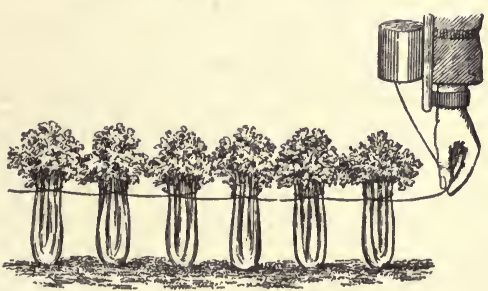

American Method of Tying Celery. and expeditious method of tying Celery. A tin containing a ball of twine is attached to a piece of wood, by which it is strapped to the wrist. At the bottom of the tin is a hole for the twine to pass through. The twine is fastened to the first plant, or to a peg pushed into the ground, then passed rapidly round each plant without tying until the end of the row is reached.

The Broad Bed System.-This system has been carried out for a long time in England in some few places, particularly for late crops, but is the only' method practised in the French garden for all plantings, whether late or early. The main 
difference between the two methods consists in the means adopted for blanching. In English gardens this is done by the usual means of covering the stems with earth, whereas in French gardens this end is attained by other means, covering with earth being considered unnecessary.

The English method is to make the beds from $4 \mathrm{ft}$. to $10 \mathrm{ft}$. wide and any convenient length, with spaces between each bed varying from $2 \mathrm{ft}$. to $4 \mathrm{ft}$. wide. Soil to the depth of $6 \mathrm{in}$. is taken from the beds and laid in these spaces or alleys, and the beds are then covered thickly with manure, which is dug in. The banks of soil in the alleys are levelled and planted with quickgrowing crops. The Celery is set in rows across the bed, from $6 \mathrm{in}$. to $10 \mathrm{in}$. apart, and from $12 \mathrm{in}$. to $15 \mathrm{in}$. between the rows, according to the variety. The plants stand so closely together

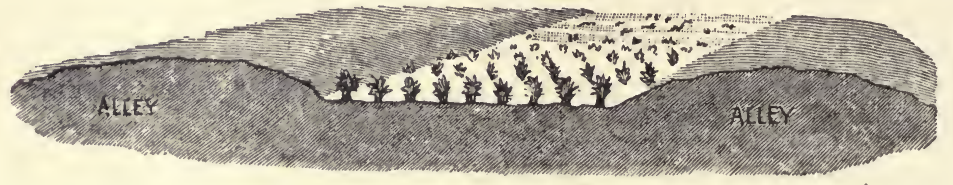

Celery Planted in Broad Beds.

that they grow upright with partially blanched stems. The beds need hoeing two or three times whilst the plants are young, but as soon as the leaves of two rows touch, hoeing ceases. In this system, where the ground is covered with a dense mass of plants and foliage, it is absolutely essential to success that the ground is made very rich with plant foods, either in the form of large quantities of manure, or a moderate quantity supplemented by suitable fertilizers, and that they have in addition, copious supplies of water. Unless these two conditions are properly carried out it is useless to attempt to grow Celery on this system.

Earthing-up offers difficulties, but these can be overcome in the following manner: Get two boards, each 10in. wide and as long as the bed is wide, with pieces projecting from the upper part of each end for handles to lift them by. These are set up on edge between two rows of plants, one on each side, pegs being pushed in at each end to hold them in position. The space between the boards is then filled up with soil thrown 
in from the alleys. Two men are required to do this work properly, one at each end. When the space is full, each man takes the boards by the handles, and by pressing them upon the soil they are easily lifted out and placed between the next

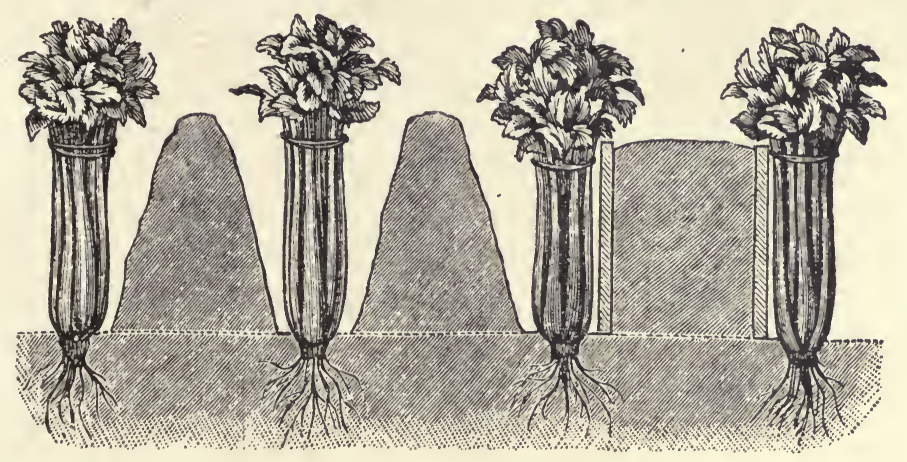

Cross-section showing Method of Earthing-up Celery on Broad Beds.

two rows. After soil has been thus placed between all the rows, it is brought close up to and between the plants by hand, more soil being added as necessary. The plants standing together so compactly makes it convenient to give protection from heavy rains or severe frost, whilst the alleys, being now lower than the roots of the plants, drain off all surplus moisture and thus help to prevent decay.

In the French garden the Celery is planted on beds of rich mould composed largely, and sometimes entirely, of thoroughly decayed manure; in fact, the earliest crop, generally of the variety known as Paris Golden, is planted on the hot-beds (now cold) which are the first to be cleared of early salad crops. This is usually about the first or second week of June, which would be considered late in an English garden, but under the forcing influence of extremely rich soil and frequent heavy waterings, this quickly maturing variety becomes ready for use by the middle of August; it is planted 10in. apart in each direction.- Second and third plantings of suitable varieties are made from the end of June to the middle of August; for these the distances apart are generally about $1 \mathrm{ft}$., though sometimes they are planted at $15 \mathrm{in}$. apart, with endive or other salad 
plant set alternately with the Celery in both directions. The beds are made about $10 \mathrm{ft}$. wide, but in this case, as blanching is effected without earthing-up, no alleys for soil are left between the beds, a space or path about $18 \mathrm{in}$. wide, from which water is given with a hose-pipe, being all that is necessary. It is worth while again emphasising that no trouble must be spared in keeping the plants well supplied with moisture, and unless this is done it would be much better to leave this method of culture severely alone.

Blanching is done by resting mats on the tops of the plants as they stand in the bed, bringing the mats down to the earth all round the sides, and so covering them up closely. A reproduction from a photograph showing a bed of Celery being blanched in this way is shown on the opposite page, and will assist to make the matter clear; on the left of the picture may be seen a bed of plants ready for covering, and on the right a bed which has just been cleared. This photograph was taken about the middle of August. In the summer, when growth is rapid, the Celery is fit for use in about two weeks after covering, but as the season advances, and growth becomes slower, it is necessary for the mats to remain on longer.

In the case of the latest crop, which does not complete its growth until well into November, blanching by covering with mats is not suitable, because the length of time necessary to complete the operation and the excess of damp which collects and is held by the mats induces decay; blanching is therefore accomplished in the following manner:-Frames of sufficient depth to accommodate the Celery standing upright are knocked together, or two ordinary box frames are placed one above

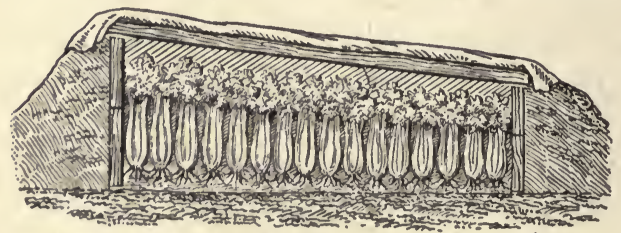

Celery Stored in Frame. the other. A few inches of moist soil is put at the bottom. In the middle of November the Celery is lifted, with the roots intact, and packed as closely as it will stand in the frame. The soil is worked amongst the roots, row by row, but none is allowed to get between the stalks. 
Celery.

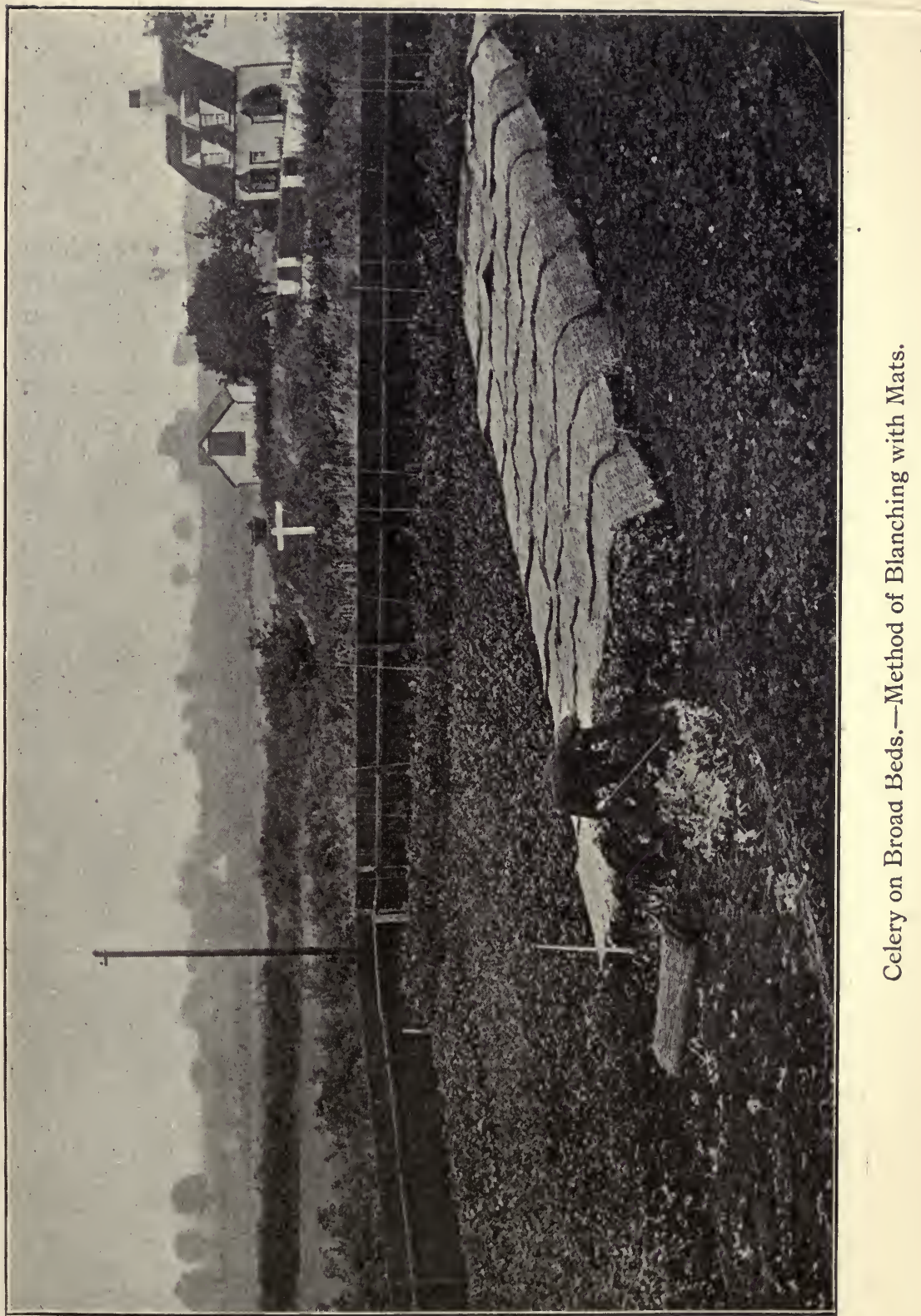


The lights are put on, but are raised at each corner to allow a current of air to pass through and so keep damp away. The sides and ends of the frame are banked up with earth and the lights are covered with mats. The Celery will be ready for use about the end of December. Great care must be taken that the Celery is not bruised, and that no decayed or diseased plants are stored away.

Another way of storing Celery for winter, and one which seems worthy of attention, is described in the following extract from Peter Henderson's "Gardening for Profit," an American publication. After describing how the Celery is grown $1 \mathrm{ft}$. apart in each direction, without earthing-up, he goes on to say:

"When a few hundred roots only are to be stored it can be placed in narrow boxes, say nine inches wide, four or six feet in length, and of a depth a little less than the height of the Celery. A few inches of sand or soil is placed on the bottom of the box, but none must be put between the stalks of the Celery, and the Celery is packed in the box upright, the roots being placed on the sand at the bottom; the Celery must be packed in as tight as possible, but without bruising. Boxes thus packed and stood on the cool floor of the cellar, if put away in November, will be "blanched" fit for use during January, February, and March. If put in sooner than November it will blanch earlier, and if stored later it will keep later. If larger quantities are to be kept in the cellar, the cheapest practicable way to do so is to begin at one side next the wall, furthest from the entrance, and erect boards across the cellar, nine inches from the wall, and of a height a little less than the length of the Celery-that is, if the Celery is twentyfour inches in length, the boarding may be eighteen or twenty inches high. In this narrow division the Celery is packed in upright, as above described for packing in boxes. As soon as the first tier is filled, erect another board trench or division at nine inches distant from the first, and so on until the whole space to be used is filled up. It will be understood that no soil or sand is packed between the stalks of Celery, only two or three inches being strewn on the floor, on which the roots are placed. Simultaneously with the formation of the white rootlets the blanching process begins, which is simply the plant making an effort to grow in the dark, and thus becoming blanched or whitened. We have sometimes complaints that Celery fails to blanch or whiten. In all such cases the roots must have been injured by being frozen or dried too much while being lifted from the field, but this should never happen with ordinary care. A cellar or root-house twenty by twenty feet, so packed, will hold from 3,000 to 5,000 roots of Celery, according to their size. Care must be taken not to get the board partitions forming the trenches, or divisions between the tiers of Celery, more than nine or ten inches apart, for if at much greater distance the stems and leaves would be in too large masses and would generate heat and rot. 
As the cellar or root-house is usually a damp and dark apartment, there will generally be no necessity to water the Celery after it is packed. Every means of ventilation should be used, even in cold weather, for it must always be borne in mind that Celery is a vegetable that will stand quite a sharp frost without injury, so if the temperature of the cellar falls five or six degrees below the freezing point no injury will be done."

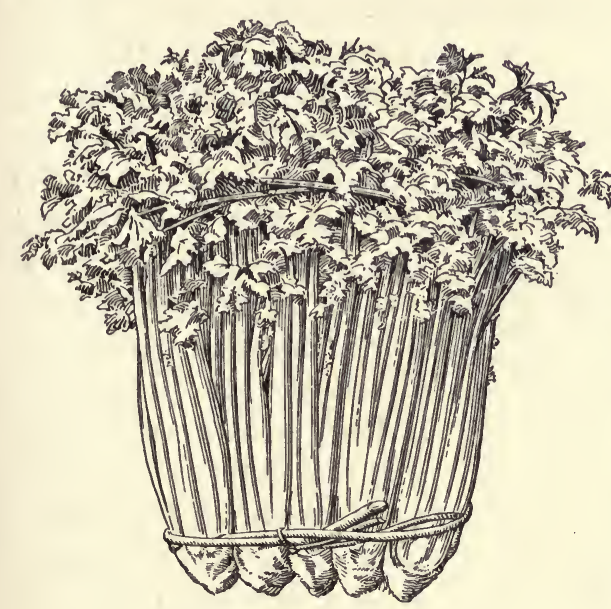

Market Bundle of Celery.

Marketing.-Celery is sent to market in bundles containing from eight to twelve "sticks" or heads, according to size. They should be graded into two qualities so that the heads in each bundle are of even value and then realise better prices. Before the bundles are made up, loose rough leaves should be removed, the roots trimmed off, and the stems washed. Sometimes

Celery is sent to market in a rough unwashed condition, but it is a great mistake to do this, as it is sure to result in poor prices.

Manures:-If the ground is properly prepared, with the dressings of well-decayed manure already advocated, very little more will be required to secure good "sticks" beyond due attention to watering. When extra large samples are required liquid manure may be given alternately with clear water, or the following fertilizers may be dissolved in each gallon of water and used twice during early growth, with a fortnight's interval :-Superphosphate 1oz., nitrate of soda $\frac{1}{2} \mathrm{Oz}$., sulphate of potash $\frac{1}{4} \mathrm{Oz}$.

Varieties:-For the earliest crop, Paris Golden (Chemin), Sandringham White, Sutton's White Gem, Clarie's Extra Early Market White. For main-crop: Solid White, Wright's Giant White, Bibby's Defiance White, Cole's Crystal White, Standard Bearer Red, Covent Garden Red, Major. Clarke's Red, Manchester Solid Red. 


\section{CELERIAC, or Turnip-rooted Celery.}

CELERIAC is a very similar plant to celery, the principal difference between them being that in this case the root is developed into a mass resembling a turnip, and is the part used as a vegetable, whilst the stems are rejected. As Celeriac

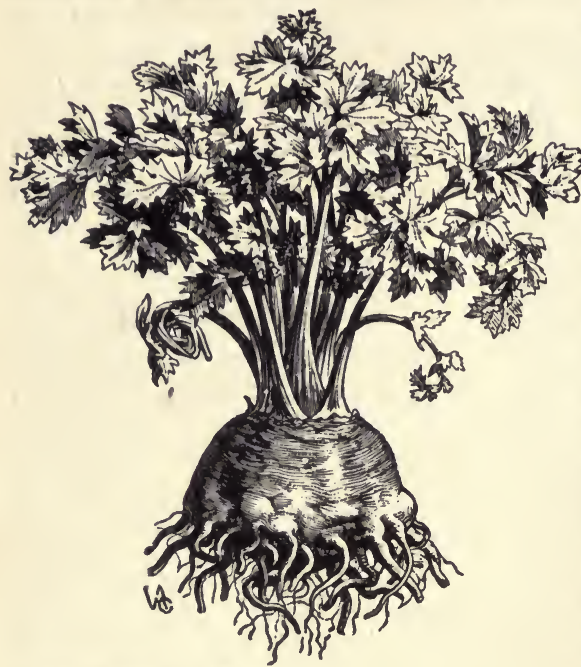

Copyright, V. A. \& co.

Celeriac, or Turnip-rooted Celery.

is grown on the flat, and does not need blanching, it is much easier to grow than celery, though as the demand for it is limited the space devoted to it should be very moderate. Well-manured ground, an abundance of water, and a long season of growth are the requisites for the production of fine roots. Seed is sown in a gentle heat about the middle of March and the seedlings are treated in the same manner as celery. As soon as suitable ground is at liberty after the beginning of June it is planted out, $12 \mathrm{in}$. by $12 \mathrm{in}$., or $12 \mathrm{in}$. by $15 \mathrm{in}$. apart when standing alone, or it may be set at a greater distance from row to row with a catch crop between. Sometimes it is set 18in. apart each way with summer endive set between. The plants must be carefully trimmed before planting, all lateral shoots being removed; they must be set as shallow as possible and watered in well. During the summer never allow them to stand still for want of water and keep the ground clean by frequent hoeing. All old sprawling leaves and lateral shoots must be removed once or twice during growth.

The largest roots will be ready for use from the middle of September onward. Early in October the crop may be lifted and trimmed of the thongs and outer leaves, then stored in sand or earth in a dry cool shed or cellar. 


\section{CHICORY.}

\section{Chichorium Intybus.}

WHEN forced and blanched, Chicory makes a very wholesome and acceptable salad for the winter and early spring months, and as it is easy to grow and appears to be increasing in favour with the general public, attention should be paid to its cultivation.

As good strong roots should be available for forcing, the soil for this crop should be well manured, deeply dug, and moist, so that a free growth may be obtained. Seed should be sown in the latter part of May or early in June, in rows $1 \mathrm{ft}$. apart, and the plants thinned out to 9in. apart in the row. The only attention needed during growth is hoeing and, if the season is exceptionally dry, occasional watering, though Chicory, being deep-rooted, is better able to thrive in a drought than most plants.

When the leaves have died down, about the beginning of November, the roots can be lifted. They should then be about $2 \mathrm{in}$. through at the top. Trim off any leaves remaining to within $\frac{1}{2}$ in. of the top, and rub off all small shoots, leaving only the main crown. Cut all the roots at the bottom to bring them to one uniform

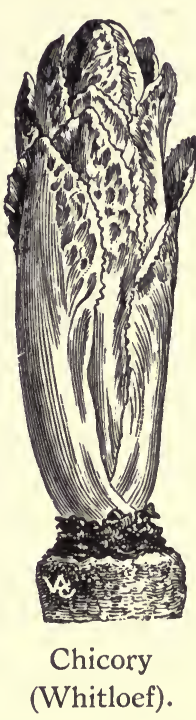
length of from 8in. to 10in. They can then be stored away until wanted for forcing, in fine moist soil or sand, and as a very little increase of temperature is sufficient to excite growth, they should be put in a position which although safe from hard frost is still cold, such as the foot of a wall or in an open shed, or in a trench in the open covered with 6in. of ordinary soil.

Forcing can be carried on from the time the roots are lifted, and with good management an unbroken supply can be maintained from November to May. The operation may be done in numerous ways, according to the quantity to be handled, always remembering that whatever method is adopted, absolute darkness is essential. One method is to plant them in a box 
about $1 \mathrm{ft}$. deep, in moist sandy soil, $5 \mathrm{in}$. apart each way, leaving the tops standing $1 \mathrm{in}$. above the surface. After a gentle watering, another box, about 10in. deep, is inverted on top of this, and it is then placed in a cellar or mushroom house, or in any dark position where a temperature of about 45 degrees may be relied upon. Or, if a larger quantity has to be forced, a trough can be made with two boards stood on edge, $2 \mathrm{ft}$. deep, and any convenient length and width. This should be divided by boards into four sections. One section is half filled with moist light soil or leaf-mould, and the roots are set in this with the tops about 10in. below the top of the boards. The roots are then watered and the section filled to the top with similar soil. A fresh section can be filled each week. If a moderate and even temperature is maintained the heads will be ready for cutting in four weeks, and as one section is cleared it can be filled again, and so a constant supply be kept up.

Forcing may be done in the open-air as follows :-If the soil is well-drained, make a trench 16in. deep and 2ft. wide. Partly fill this with light fine dryish soil. Set roots in this at $5 \mathrm{in}$. apart both ways, with the tops 8in. below ground level. Fill up over the roots to ground level with similar light soil, then build over the trench a hot-bed, $4 \mathrm{ft}$. wide, $2 \mathrm{ft}$. deep, and as long as will cover a week's supply of heads. Each succeeding week cover a further length of the trench, joining up to the preceding hot-bed. Each lot will be ready about a month after covering. On heavy soil it is better to set the roots within boards, on the surface of the ground, as a sunk trench may become waterlogged during heavy rains if the drainage is slow, in which case the heads would be liable to decay

When ready, cut off the blanched heads, with a piece of root attached.

\section{COLEWORTS or COLLARDS.}

COLEWORTS or Collards are a small distinct variety of cabbage, hardy and quick to mature. They have many valuable features for the market grower, particularly where the circumstances call for regular supplies of green vegetables through autumn and winter, or where the situation offers 
facilities for placing bulky produce on the market without much expense. They are of rapid growth and take up little room, and are frequently used for planting amongst other crops, being removed before the principal crop needs all the space. They are often set out a few at a time whenever any plot becomes vacant and is not immediately wanted for some other purpose.

The soil and treatment required for Collards is exactly the same as for cabbages, except that when they are planted separate from cabbages less manure is required, because they occupy the ground a much shorter time.

Seed may be sown in small batches in March, April, and May, for planting vacant spaces during the summer, but the main sowing takes place about the middle of July, for September planting. Seed may be sown as late as the middle of August when the plants are intended to be pulled as "greens," before the hearts are fully developed.

The main crop is frequently planted amongst cabbages in such a manner that when the Collards are pulled the cabbages are left to grow to maturity without much loss of space. This may be done in various ways, the aim being to allow about $1 \mathrm{ft}$. space in each direction, more or less, between all the plants in the combination. If Collards and cabbages are planted alternately $1 \mathrm{ft}$. apart, in rows $2 \mathrm{ft}$. apart, with a row of Collards only, at $1 \mathrm{ft}$. apart, set between the rows of cabbage,

$$
\begin{aligned}
& +\%+\%+\%+4+ \\
& ++\div++\div+1+\div+\div+1
\end{aligned}
$$

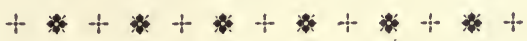

$$
\begin{aligned}
& ++\div++\div+4++\div+
\end{aligned}
$$

Diagram showing Collards and Cabbages planted alternately.

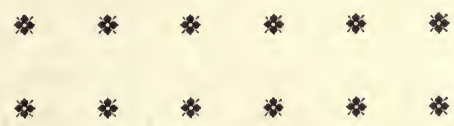

Diagram showing Cabbage only, after Collards have been pulled.

+ Collards. Cabbages.

the cabbage would ultimately be left to mature at $2 \mathrm{ft}$. apart in each direction. Other methods of planting on similar lines will readily suggest themselves as circumstances arise.

Varieties :- - Hardy Green and Rosette. 


\section{CUCUMBERS (FRAME).}

Cucumis sativus.

$A$ the Cucumber is a favourite with all classes of the comA munity, it is essential for the grower who caters for a private or shop trade to make provision for a sufficient and steady supply, particularly during the summer months, when salads are eagerly sought after.

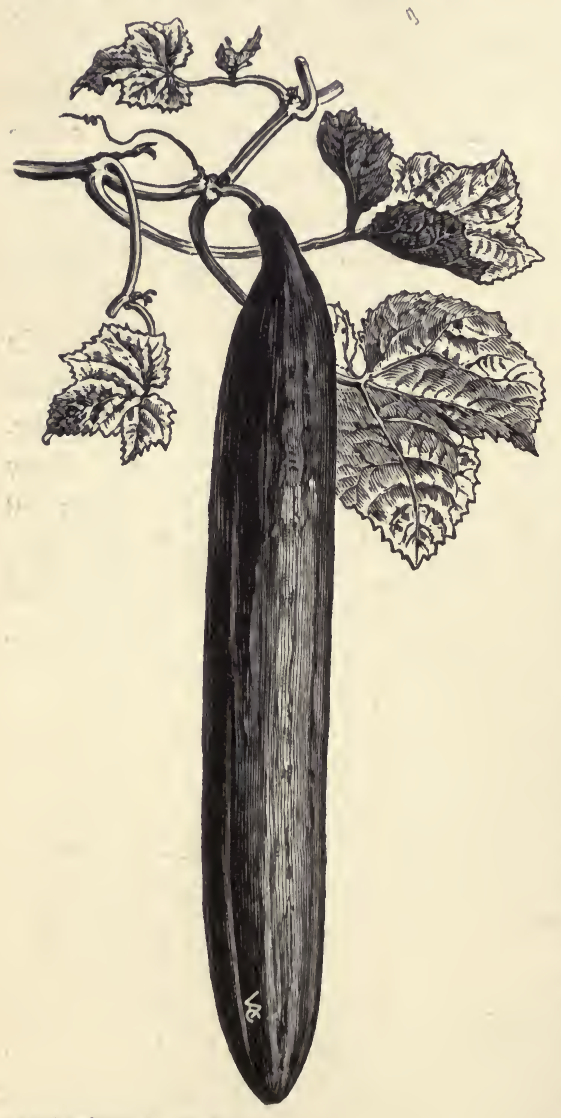

Copyright, V. A. \& Co.

Cucumber,

Rollison's Telegraph.

By far the greater part of the Frame Cucumbers sold in the public markets are grown in glasshouses specially adapted to this culture, but in thousands of gardens they are grown in frames, in some cases on quite a large scale, and as glasshouse culture does not come within the scope of this work, we shall confine our remarks to a description of their cultivation and management in frames.

The site selected for the frames, especially for those which are to be planted early, should be sheltered from cold winds, free from shade, and facing the south. The ground should be well drained, so that the water, of which they need copious supplies, will pass away freely; on ill-drained soil the base of the bed becomes sodden with stagnant moisture and under such circumstances the bed soon gets 
cold and the plants become unhealthy. It will seldom be found profitable to start the beds before the beginning of April, and for ordinary purposes the end of April will be found quite soon enough. At this date less manure will be required for the hot-beds and the plants will grow away more freely and be easier of management, whilst frames which have been used in the production of early salads and similar crops will be empty by the middle of April and will then be available for growing Cucumbers.

Sowing.-Seed should be sown four weeks before the beds are ready for planting, so that by the time the beds have got warmed through there will be good strong plants ready to set out. When there are a good number of frames to fill, the seed should be sown in small batches every two or three days, so that they may be planted in regular succession as they become ready, otherwise some may get pot-bound before they can be planted, and this must be avoided if possible, because the best results are always obtained when the plants never experience any check, particularly in the early stages.

Where a heated greenhouse is available, this should be taken advantage of for raising the plants, but where there is none a small hot-bed must be made for this purpose. Even in a greenhouse it is a good plan to make up a small hot-bed in which to plunge the pots, so as to afford a moist bottom heat of about 75 degrees. The hot-bed in the open should be made in the last week of

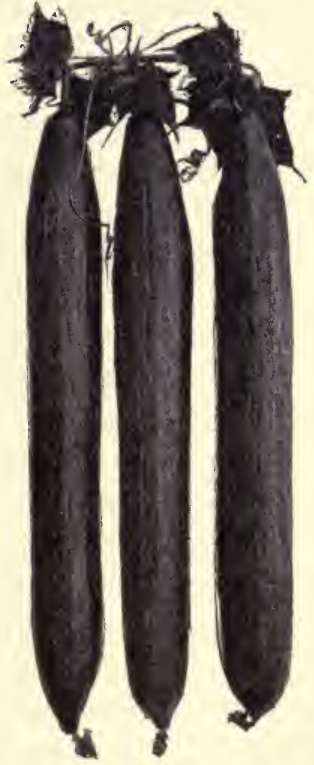

Copyright, S. \& S.

Cucumber.

Sutton's Every-day. March, in a sheltered position. It should be at least $3 \mathrm{ft}$. thick, and large enough to accommodate the number of plants required after they are potted up. It should project $18 \mathrm{in}$. beyond the frame all round. (Full instructions for the making and 
management of hot-beds will be found on pages 128-131.) When the bed is made, put on the frame and stack fresh manure all round it up to the level of the lights; then put inside $4 \mathrm{in}$. of light rich compost and plunge in a soil thermometer. Put on the lights, leaving them open about 1in. at the top to allow for the escape of strong heat, and cover all up with mats to ground level. For a few days the heat will probably rise to a considerable height; as soon as it has fallen to 80 degrees the seed may be sown. This may be done directly in the bed, at 2 in. apart, or separately in small 60 's pots, well crocked and half filled with soil. Both methods have their advocates. The advantage of sowing separately directly in the pot consists in the avoidance of any check which the seedling may receive when it is lifted from the seed bed for potting up, but on the other hand the seedlings generally grow stronger in a mass of soil which maintains a more even moisture than is possible in a pot. In either case the soil must be moist, so that no watering is needed until after the seed has germinated.

Management of the Young Plants.-As soon as the seedlings show give them all the light possible, removing the mats during the day but replacing them at night. In eight or ten days they should be growing strongly; if they are in pots fill these with soil to within half an inch of the rim; if they are in the bed lift them carefully without hurting the roots and pot them up to the seed leaves in large 60's. The soil used for this purpose should be moist and should have stood in the frame for a few days previously so as to get to the same temperature. After potting plunge the pots up to the rims in the same bed, water with tepid water, and shut up closely. For a few days, until the roots begin to work again freely, scatter a little light litter over the lights to break the direct rays of the sun, after which they must be grown in full light, near the glass, so as to keep them dwarf and stocky.

No effort should be spared to avoid everything which is likely to check the growth of the young plants. A fine still day should be chosen for the transplanting operations and a screen of mats should be fixed round the frame to shield the plants from cold draughts. If the heat in the frame is found to decline below 65 degrees the manure stacked round the sides 
should be pulled down and replaced with fresh. Keep the plants evenly moist, but not wet, always using tepid water, and raise the lights slightly at the top for a few hours in the middle of the day, but take careful precautions against draughts. As soon as the first two rough leaves are well formed, pinch out the tip or centre of the plant above the second leaf. This will cause two lateral shoots to break away, one from the axil of each leaf.

Preparing the Beds.-By the second week of April make preparations for the beds on which the plants are to be set out permanently. The materials should be at hand, consisting of equal parts of fresh stable manure and of leaves, or if no leaves are available, then of old hot-bed manure. Throw these roughly together in a compact heap, sprinkling plenty of water upon them during the process, if at all dry. In a few days the heap will be very hot, when it must be turned and thoroughly mixed again, giving more water if still on the dry side. Unless more than half the heap consisted of fresh manure it will need no further turning, but will be ready for use in the course of three or four days.

Let the frame ground be arranged so that the frames can stand in a compact body. For instance, if there are twelve three-light frames they should be placed in four rows of three frames each. When a large number is to be used they should be arranged in sections. Three three-light frames end to end to form one row, and ten rows, or thirty frames in all; will be found sufficient in one section for convenient working. Between the rows should be a space $12 \mathrm{in}$. to $15 \mathrm{in}$. wide, and between the sections a pathway $4 \mathrm{ft}$. wide.

The ground having been well dug and manured some time previously, set one row of frames exactly in position, then mark out down the middle of the frames, from end to end of the row, the position for a trench $2 \mathrm{ft}$. wide. Remove the frames for convenience of working, and dig out the trench a good spit deep, wheeling the soil to the other end of the section. Then fill the the trench with the prepared manure, shaking it out well. Tread it in evenly and firmly, filling the trench to 6in. above ground level, and also lay 6in. of manure over the earth on each side of the trench, including the space between the frames, 
so that it all presents a level surface. Set the first row of frames on the manure straight and level, and square with the section; then take out the second trench, and throw the soil

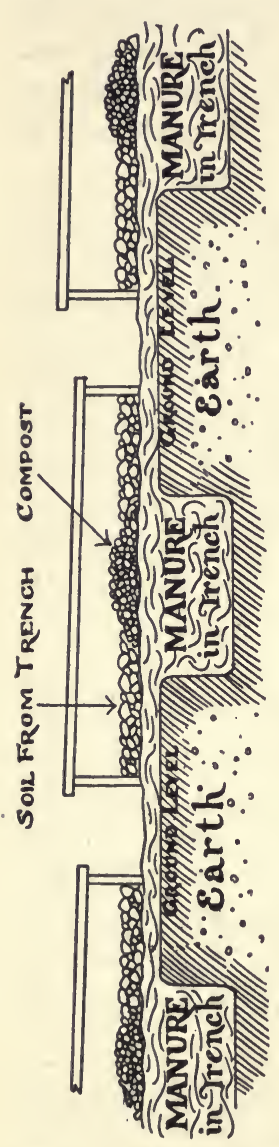
from this on the manure inside the first frame. Repeat this operation until the section is finished, the soil from the first trench being used to put inside the last frame.

The soil in the frames must be well broken up and levelled; in the centre under each light open a space, about 9in. across, and fill it with light rich compost. As each bed is finished put on the lights and cover with mats.

Planting.-A few days after covering the soil will be warm, and then the plants can be set out in the compost, one plant under each light, with one lateral directed towards the back and the other towards the front of the frame. Care must be taken that the roots are not disturbed. After planting, water gently with tepid water, then shut down the lights closely for three or four days, cover with mats at night, and shade from strong sunshine during the day by scattering litter over the lights. When growth has started freely give air and water, very little at first but gradually increasing with the growth of the plants. The soil should be kept moist but never sodden, and if the weather should become very dull and cold watering should cease altogether or be given in great moderation. If, as sometimes happens, severe weather returns late in spring, the spaces between the frames and round the ends should be filled with warm manure. Covering with mats at night should never be omitted until well into June.

Training and General Management.-If the laterals are strong when the plants are set out they should be stopped at the second leaf, or if not strong enough at that time then about a week after planting. This will cause four shoots or 
sub-laterals to break away, which can be trained one to each corner of the light. Let them go until within 9in. of the corner when they must be stopped. These will throw out shoots which must be regulated according to the space available, being stopped or removed altogether, when there is danger of overcrowding. Fruit will now begin to show; none should be allowed on the main stems, and only three or four to each quarter, the rest being picked off. The plants should never be allowed to bear too heavily or they will soon become weak and cease to bear altogether, whereas when they are cropped in moderation and the fruit is cut as soon as it is ready, the plants continue vigorous much longer, the fruit is of better quality, and the total crop ultimately gathered is much greater.

The main shoots should be pegged down to the bed, which will cause roots to form at each joint and thus give the plant new accessions of strength. Keep the growths well thinned out and evenly disposed over the soil, never allowing them to become a tangled mass. Cut out shoots which have fruited and train new ones in their place. When the leaves are crowded a few of the oldest may be removed, so that all may get a full exposure to sunlight, but remember that whilst it is courting failure to allow the plants to become a jungle of growth, it is equally bad to overdo the thinning, a sufficiency of healthy foliage being necessary to the well-being of the plant and the production of fruit.

The next matters of importance are the ventilation, the temperature, and the watering. The temperature to be desired is 70 degrees by day (which may rise 15 degrees higher by sun heat without injury) and 60 degrees by night. For the first few weeks there should be no difficulty in maintaining the necessary warmth by the aid of the manure under and the linings round the frames, assisted by the covering of mats at night.r. By the middle of June the heat in the manure will have passed away, and the best will have to be made of the natural weather conditions. As a rule there is little to fear in this respect, though if the weather should prove cold ventilation and water must both be given very sparingly.

With free growth and genial weather water must be given without stint each morning to the plants requiring it, but those 
already moist need only a sprinkling. As they gain strength more air must be given, by raising the lights a little in the morning and increasing the opening as the day advances. Once before noon and again in the middle of the afternoon the plants and the whole of the inside of the frame should be well syringed or watered through a fine rose. Immediately after the second damping the lights should be shut down close; this will raise the temperature and give the plants the moist atmosphere which is so congenial to them.

Weak guano-water may be occasionally substituted for the clear water used in damping down. This invigorates the plants and is also useful in preventing red spider. When this pest is at work it is easily detected by the rusty appearance of the leaves, in which case remove and burn the worst and syringe thoroughly underneath the remainder with guano-water (one teaspoonful to two gallons) three times a day for several days, keeping the frame close and shaded in the meantime. If any plant should become badly affected it should be removed and burnt. Should the summer be very hot and bright it will be very helpful to the plants if the lights are shaded a little; this can be done most economically as regards labour by splashing thin whiting over them, but do not brush the glass all over.

By the middle of August the crop on the beds made first will be failing. Those planted at the beginning of May will carry on into September. Where a long succession is desired it is a good plan to start a few frames at the beginning of June, and if well treated these will continue the supply into autumn, though they will require to have linings of warm manure round the frames and be covered up when the cold nights set in.

Manures :-Providing the soil used for the bed was previously treated to a liberal dressing of well-decayed stable manure, no other fertilizer is likely to be wanted beyond occasional waterings with liquid manure, and for this purpose equalised guano is the best, $\frac{1}{2} \mathrm{Oz}$. to the gallon of water. This may be varied at times by substituting the equivalent in other soluble fertilizers.

Varieties:-One of the numerous varieties of Telegraph will be found the best for frame culture, and of these Sutton's Matchless, Veitch's :Sensation, Lockie's Perfection, Daniel's Duke of Edinburgh, and Rollison's Telegraph are all good. 


\section{CUCUMBERS (RIDGE).}

R IDGE Cucumbers are generally classed amongst the salads R suitable for the poor man's table. So far as the distinction is made on account of the low price at which they can be profitably sold in comparison with frame cucumbers this classification cannot be objected to, but as a matter of fact the flavour of a well-grown Ridge Cucumber is considered by many good judges to be distinctly superior to that of its relative.

Of course much, both in the matter of flavour and of profitmaking, depends on the way in which the plants are grown. When they are set out by acres in the open field, where they are neither watered nor mulched, and where they receive very little after-cultivation beyond an occasional hoeing, the best results cannot be expected, though should the summer be warm and the plants be kept in vigorous growth by occasional showers, even this rough and ready mode of culture sometimes yields fair crops. There is no doubt, however, that this is a plant which

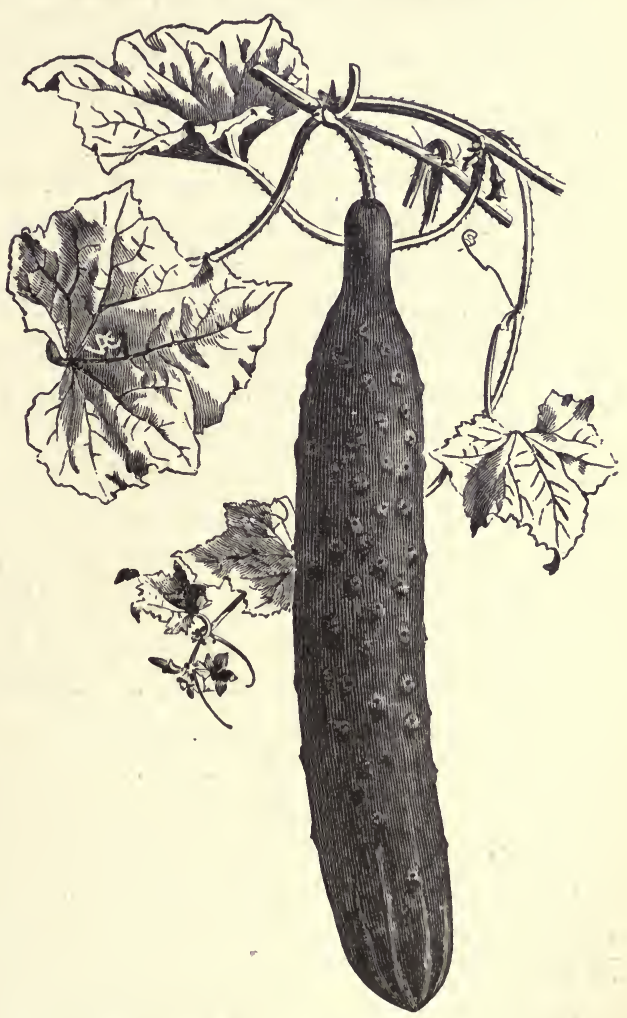

Copyright, V.A. \& Co.

Green Giant Ridge Cucumber. always pays for good treatment, and when this is so the fruits can be grown long and shapely, so as not to be very far behind a frame cucumber in appearance. 
There are various methods of growing the Ridge Cucumber, - on hillocks, on beds or in long single rows-but whatever the method adopted may be, where profit is aimed at the crop should be early. To secure earliness, strong plants must be raised in warmth, set out after being well hardened on a site of which the soil is warmed by having fermenting manure put underneath, and sheltered from frost and cold winds until full exposure becomes safe.

To prepare good plants sow the seed in the middle of April, on a hot-bed, and handle the plants in precisely the same manner as frame cucumbers, except that during the week before planting out they must be given plenty of air on all suitable occasions.

The plants are set out in rows $6 \mathrm{ft}$. apart, running north and south. A row of peas or broad beans should previously have been set between the positions intended for the Cucumbers, as these afford much welcome protection from cold winds and are off the ground by the time the Cucumbers are well established and begin to run. In the centre of each $6 \mathrm{ft}$. space take out a trench $18 \mathrm{in}$. wide and a spit deep. Fill this level with fermenting manure, or with half manure and half leaves, grass, mouldy hay, or any other similar material which will give off the necessary warmth during the process of fermentation. Tread this down firmly, and cover it with the soil from the trench, broken up well. This should be done about the end of April or the first week in May, When the soil is warm set the plants along the centre of the mound, singly at 18in. apart, or in pairs at intervals of $2 \mathrm{ft}$. 6in. Water in well and cover with cloches or with one of the other devices for protection described and illustrated in Chapter XVII.

If the plants are strong, pinch out the centres before setting them out; or this may be done as soon as they start growing in the bed. Any further stopping or training is unnecessary.

For a few days after setting out keep the plants closely covered, then begin to give air in the middle of the day, gradually giving more as the days get warmer, until by the end of the month the plants are exposed all day and only covered up at night. After the beginning of June protection can be dispensed with altogether. 
The plants should receive good soakings with water two or three times a week, according to the weather. This may be varied by giving liquid manure occasionally in place of clear water. As soon as the plants begin to run, the ground should be mulched all over with long manure, which will have a marked effect in preserving the moisture in the soil and maintaining the vigour of the plant.

Gather the fruits three times a week. Remove at once any ugly or distorted ones, and never leave any to become old or yellow, unless specially wanted for seed.

Varieties :-King of the Ridge, Stockwood Long Ridge and Carter's Best of All Ridge.

\section{ENDIVE.}

\section{Chichorium Endivia.}

$\longrightarrow$ NDIVE is steadily advancing in popularity as a salad plant E and it therefore behoves the grower of general supplies to cater for the demand, though as this so far only is moderate the space given up to it need not be large.

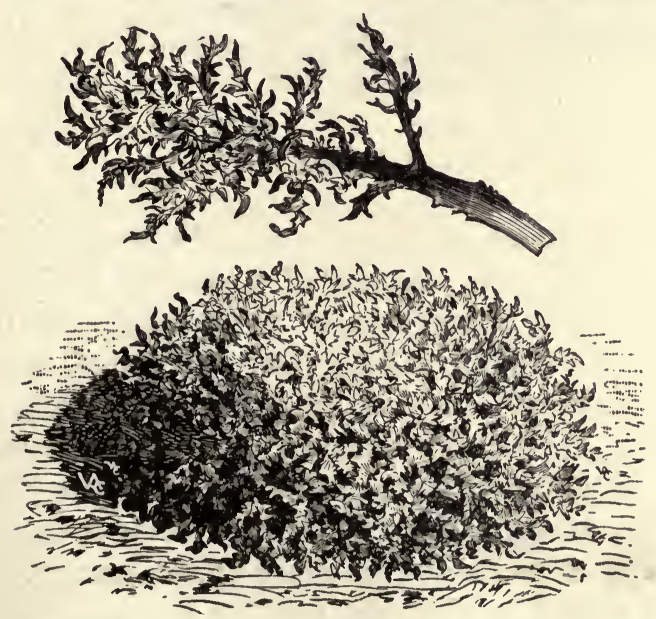

Copyright, V.A, \& Co.

Green Curled Paris Endive.

It is chiefly used as an autumn and winter salad, the demand for spring and summer supplies being very small, and therefore, unless there is some special call for it, cultivation should usually be restricted to the autumn and winter supplies.

Another reason for not attempting to produce Endive earlier is that any sowings made before the middle of July are 
very liable to "bolt" if they receive the slightest check of any kind, and to counteract this tendency it is customary in many places to sow where the plants are to remain, thinning them out to the required distance apart. This plan is very wasteful of seed, but ensures a steady growth to the plants, free from the check caused by transplanting. At the same time it is quite possible by exercising proper care to keep bolting down to a very small percentage, the main points being to transplant whilst small to a bed of rich soil, to set out in the final position early, and never at any time to allow the plants to suffer from a shortage of water.

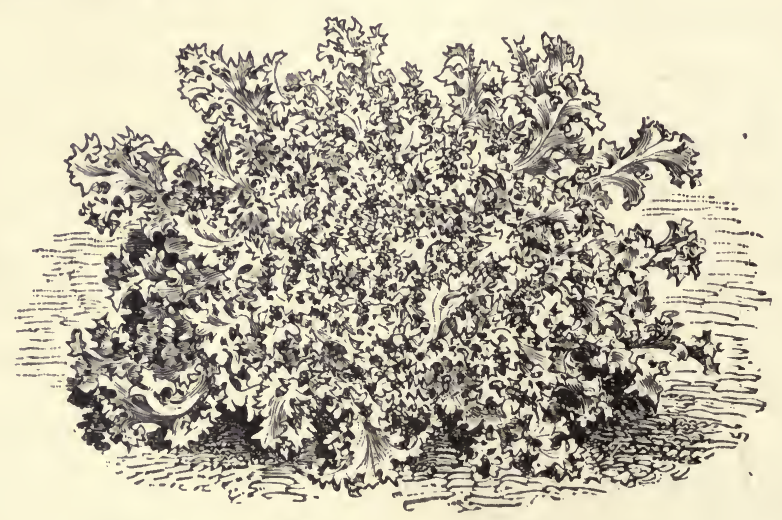

Copyright, V.A. \& Co.

Ruffec Green Curled Endive.

For general purposes a small sowing of one of the fine curled varieties should be made in June, another of a similar variety about the middle of July, and two sthers of hardy varieties at the beginning and in the middle of August. The seed-bed, which should consist of good rich soil, must have the surface made firm after sowing by beating with the back of a spade. Unless the seed-beds are quite moist they. should be thoroughly watered before sowing, and during August it is often a good plan to water the drills before sowing to ensure germination.

The soil for Endive should be rich but not too heavy. The earlier plantings are best made in a moist position at $1 \mathrm{ft}$. apart each way. The later varieties, which are of stronger growth, should have $15 \mathrm{in}$. space each way. As these have frequently to 
pass through severe weather they should be planted on a bed raised somewhat above the general level, so as to ensure thorough drainage and a dry surface.

Blanching.-Endive is useless unless it is properly blanched. This operation is easy in the case of the earlier supplies. On a day when the plants are quite dry the leaves are gathered together and tied round with raffia. They are fit for use in a week or ten days in the summer, but as winter approaches and growth becomes slower the time required for blanching may be extended to three weeks. The latest supplies may be blanched as they stand in the bed, either by tying or by covering with pieces of slate, boards, or litter, or by any other means which will effectually exclude light from the hearts, but in wet seasons this method has disadvantages, as decay quickly sets in when the heart gets wet after being covered, and the plant is then spoiled. A good plan for the latest supplies is to lift and store them packed closely together in cold frames. On a day when the plants are quite dry they are carefully tied up, lifted with a good ball of earth at the roots, and planted in the frames as closely as possible. Moist soil should be used, into which the Endive soon pushes fresh roots. As soon as the frames are filled the ties are removed, and the lights are put on, raised a little at each corner to allow a current of air to pass through. The plants are blanched in batches, as required, by being covered with hay. In severe weather frost must be excluded by covering up the frames with mats. The hardy varieties of Endive should be selected for storing and with care will keep sound until well past the turn of the year. When sufficient frames are not available the plants will keep a considerable time if stored in a similar manner in a dry shed. Under any method of storing the plants should be dry when lifted and free from any bruising or decay.

Varieties :-For earliest supplies, Moss Curled; for summer, Green Curled Paris, Green Curled Summer; for late summer and autumn, Rouen or Stag's Horn, Green Fine Curled Winter ; for winter, Ruffec Green Curled, Broad Leaved Batavian. 


\section{HERBS.}

THOSE gardeners who do a direct trade will often be asked 1 to supply small quantities of various herbs for flavouring and other purposes, and it is therefore advisable to have a bed containing a small collection. A selection can be made from the following:-

Basil, Sweet (Ocymum Basilicum).-Tender annual, dwarfgrowing. Sow in heat in April and transplant to the open, in light rich soil, sin. apart, at the beginning of June. Water until well established. As soon as the plants come into bloom cut them down to within a few inches of the ground, tie up in small bunches and dry in the shade. After cutting stir the soil and fresh growth will be made. If potted up in September and put in a greenhouse a supply of green leaves may be had far into the winter. The leaves are aromatic and are used for seasoning.

Borage (Borago officinalis).-Hardy annual. This plant requires no trouble in culture; it will grow in any odd corner and when once established self-sown plants come almost as freely as weeds. It is a strong grower and should be thinned to about 15in. apart. Used in summer drinks and in claret cup, and is a favourite flower with bee-keepers.

Chervil (Anthriscus Cerefolium).-Annual, dwarf. May be sown frequently for a regular supply, at any time when the ground is fit, and is grown in rows like parsley. In hot weather it should be sown in a shady position, and needs frequent watering. The leaves may be cut from six weeks to two month after sowing, according to the season. It is aromatic, and is used for salads, garnishing, and seasoning. The "curled" variety should be used.

Chives (Allium Schoenoprasum).-Perennial, dwarf. Often grown as an edging plant and does well in that position. It grows in thick tufts or clumps, and is propagated by lifting and dividing these, which should be done every three or four years. To maintain a supply of young and tender leaves the clumps should be cut down regularly with a knife. Used as a mild substitute for onions in salads and soups. 
Fennel (Fœniculum vulgare).-Hardy perennial. Very easy to cultivate and will thrive almost anywhere. Sow in April and thin out to $1 \mathrm{ft}$. apart. It should be renewed by fresh sowing every two or three years. The feathery leaves are used for garnishing and for flavouring fish sauces.

Marjoram, Pot (Origanum Onites).-Perennial. May be grown from seed sown in April, but a stock is usually obtained from purchased roots. Plant at 10in. apart each way. The leaves are used for flavouring, both in the green state and when dried.

Marjoram, Sweet or Knotted (Origanum Majorana).-This plant is a perennial in the countries of which it is a native, but in Europe is grown as an annual. Sow in March or April in warmth, or early in May in the open, and thin to 10in. apart. Leaves may be-gathered for using green in June. When the flowers appear cut the plants down, tie in bunches and dry. Fresh growth will be made after cutting down, and if necessary the plants can be potted up to supply green leaves through the winter. Used for the same purposes as the preceding.

Mint.-See article under this head.

Parsley.-See article under this head.

Sage (Salvia officinalis).-Perennial. This plant can be easily raised from seed sown in the open in April or May, and when so raised is often satisfactory; sometimes, however, the leaves of such plants are narrower than a good sample should be, and to obtain a stock it is considered wiser to buy a few good plants in the autumn to propagate from. To do this, take cuttings of young soft growths during spring and early summer, and insert them in sandy soil, in a frame or under a cloche. When rooted, transplant, 15in. apart, to permanent quarters, which should be well drained and rather dry. In the spring, just as growth commences, cut old plants down to 6in. from the ground. The plants will last several years, but where any business is done in this herb it is best renewed each year. When in full leaf cut and dry. Used principally for flavouring with pork, sausages, and similar meats.

Savory, Summer (Satureia hortensis).-Annual. Sow in the middle of April, in a warm and well-drained situation, in drills 10in. apart, and thin out to $8 \mathrm{in}$. apart. The leaves, which are 
aromatic, are used for flavouring, either in a green state or when dried. For the latter purpose cut the plant down when in flower. When wanted fresh in winter sow at the beginning of September and pot up for the greenhouse.

Savory, Winter (Satureia montana).-Perennial. A hardy dwarf shrub, which can be propagated either from seed sown in spring, from cuttings, or from division of the roots. The plants should stand from $14 \mathrm{in}$. to $16 \mathrm{in}$. apart, and should be cut down in spring to within $4 \mathrm{in}$. of the ground so as to induce a crop of fresh young shoots. The soil and situation required are the same as for summer savory, and the leaves are also used for similar purposes.

Tarragon (Artemisia Dracunculus).-Perennial, but although established plants will stand for several years without any particular attention, it is much more satisfactory when propagated annually, either by division in March or April or by cuttings inserted in sandy soil under cloches early in summer. The plants need about $1 \mathrm{ft}$. space in each direction. The leaves are generally used green, for steeping in vinegar, or for flavouring and similar purposes. When wanted in winter it can be lifted and forced in a gentle heat, either in a greenhouse or on a hot-bed.

Thyme, Common (Thymus vulgaris).--Perennial. This plant can be easily raised from seed sown in April, or it can be propagated by division of the roots in March or April. It is often used for edging beds, and does well in that position if the soil is fairly dry and well drained, but should be taken up and re-planted in fresh soil every three or four years. About 4 in. space should be allowed between the plants. It is a general favourite for its fragrance and flavour, and no vegetable garden can be considered complete without it. It is used in various ways for seasonings, both fresh and when dried; for the latter purpose, cut and bunch when in flower.

Thyme, Lemon (Thymus Serpyllum vulgaris).-All that has been said in the preceding paragraph regarding common thyme applies equally to this, its near relative. The chief practical difference between them is that Lemon Thyme has the more delicate aroma of the two, and for that reason is preferred by some people. 


\section{HORSE-RADISH.}

Cochlearia Armoracia.

UORSE-RADISH is not a subject of particular importance 1 to the grower for market. The trade in it is now practically in the hands of continental growers, and with so many other much more important vegetables to engage his attention he may disregard this. But in the case of the grower who does a direct trade the matter is different. It is quite possible that he may be able to create a small trade in fresh homegrown roots with some of his customers, particularly if restaurant or hotel keepers are numbered amongst them. It is to meet such cases that the following particulars are given.

The plant delights in deep, rich, moist soil, and preparation for its culture should include trenching to at least $2 \mathrm{ft}$. It is propagated from pieces of the root, preferably strong crowns with $2 \mathrm{in}$. or $3 \mathrm{in}$. of root attached. Trenches are thrown out, $15 \mathrm{in}$. to $18 \mathrm{in}$. deep and $2 \mathrm{ft}$. apart, and the pieces are placed at the bottom of these, 12in. apart. Sometimes the planting is done on the flat, by dropping the pieces of root to the bottom of holes made with long dibbers, and filling up with prepared soil. The planting is done early in spring, and with strong setts and good soil some of the roots will be

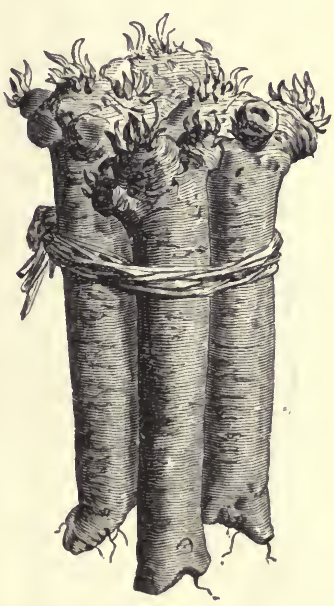

Copyright, V.A.\& co.

Horse-radish. fit for use the following autumn, but are much better left for another year. When the roots are taken up the whole bed should be cleared thoroughly as any pieces left in may become a nuisance. To keep up a regular supply a fresh bed should be made each year.

Roots for sale should be straight, $10 \mathrm{in}$. or 12in. long, and from $1 \frac{1}{2} \mathrm{in}$. to $2 \mathrm{in}$. in diameter. When not to be disposed of immediately they can be kept in good condition for several weeks in moist sand. 


\section{LEEKS.}

\section{Allium Porrum.}

I EEKS are not greatly in demand in the south of England, Lut are much appreciated in the northern counties and in Scotland and Wales. They are very hardy, being uninjured when standing in the open in the severest winter. They can be grown successfully on almost any kind of soil, but are worthy of and pay well for generous treatment. To produce the best and most profitable crops the ground should be deeply worked and receive a good dressing of well decayed manure, and above all it should be well drained, for although Leeks require plenty

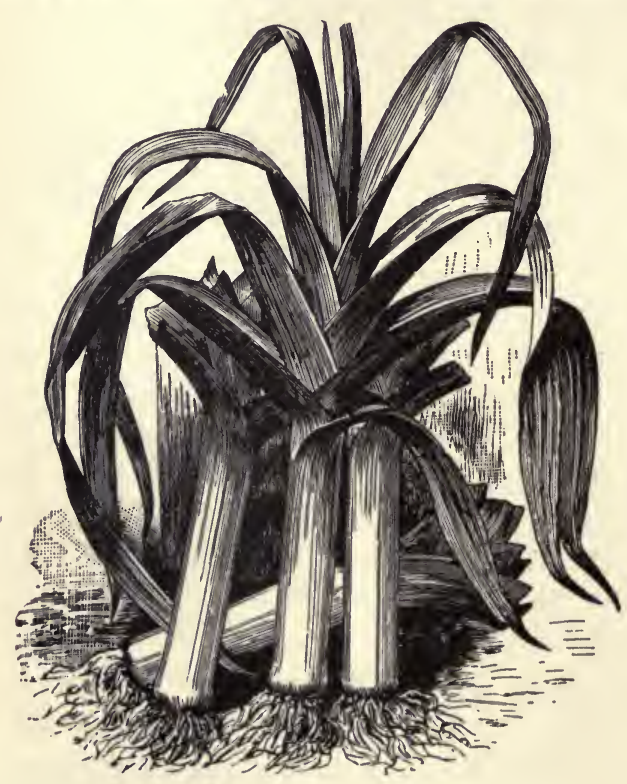

Copyright, V.A.\& Co. of moisture until their growth is completed, the water in the soil must never be stagnant, or the plants are liable to be attacked by rot at the heart. Given suitable conditions, Leeks are remarkably free from insect or fungoid attacks.

For general purposes, sow about the middle of March, in drills $18 \mathrm{in}$. apart. As soon as the seedlings can be handled easily the strongest must be transplanted to their permanent London Broad Flag Leek. position, then the next strongest when they have grown about 6in. high, finally thinning the remainder so that they stand about $8 \mathrm{in}$. apart. These will mature where they stand, lettuces or some similar crop being grown between the rows. After the catch crop is gone the soil is gradually drawn up to the rows until the stems are covered to a height of 6 or 7 inches. 
The seedlings which are to be transplanted may be set out according to one of the following methods :-

In well manured ground make drills $12 \mathrm{in}$. apart and 6in. deep, and set the plants in these, $8 \mathrm{in}$. apart, Frequent hoeing, which is very important, gradually fills the drills, and as growth nears completion the earth is drawn up to the neck of the plants on each side. This method may be varied by giving $18 \mathrm{in}$. space between the rows and intercropping with lettuces.

Another plan is to thoroughly manure and dig the ground and then to make holes at the required distance apart with a blunt dibber, about $2 \mathrm{in}$. through and 9in. long. The plants are dropped to the bottom of the holes and sufficient loose soil is pushed in to just cover the roots. During the course of cultivation the holes become filled, and the earth is finally drawn to the sides of the rows to complete bleaching.

- By far the finest specimens are grown in trenches formed as for celery, but only the width of the spade and about $2 \mathrm{ft}$. from centre to centre. About 6in. of well-rotted manure is put at the bottom of the trench and dug in, so that when finished the trench is $6 \mathrm{in}$. below the ordinary level. The plants are set at $10 \mathrm{in}$. to $12 \mathrm{in}$. apart, according to the vigour of the variety. A catch-crop is grown on the soil between the trenches. By frequent hoeing weeds are kept down and the trench is gradually filled with earth, cultivation being completed by earthing up the plants to the base of the leaves.

In every case transplanting should be done in showery weather when possible, and whatever the system of growing adopted, the plants must be supplied abundantly with moisture, especially during dry weather. Liquid manure applied once a week adds considerably to their size and quality. They can be left standing without protection, to be lifted as required, or if the ground is wanted they will keep for a month or more stored in dry sand.

Manures :-Decayed natural manure is the best fertilizer for Leeks, but when it is scarce a moderate dressing can be profitably supplemented by $10 \dot{z}$. superphosphate and $\frac{1}{4} \mathrm{Oz}$. sulphate of potash per yard run of row.

Varieties :-London Flag, Musselburgh, Renton's Monarch, and The Lyon. 


\section{LETTUCES.}

Lactuca sativa.

THE Lettuce is one of the most indispensable plants in the garden. It is a universal favourite, and when well grown and offered to the consumer in a fresh crisp condition is always appreciated and meets with a ready sale.

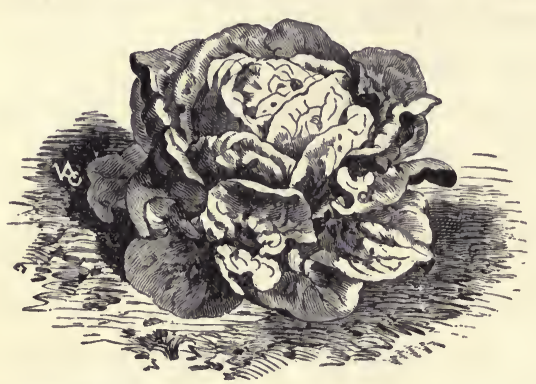

Copyright, V. A. \& Co.

\section{Cabbage Lettuce,}

Hammersmith, or Hardy Green Winter.

The greatest demand is naturally in the spring and eariy summer months, and enormous quantities are produced to meet the requirements of that period, so many, in fact that after the beginning of June the markets are frequently glutted with them, and prices fall to a very low and unremunerative point unless the garden of the grower is situated so that the cost of carriage is very low. This arises mainly from a faulty system of distribution, and whilst the grower for market must take especial note of the fact if he wishes to avoid loss, the caterer for a direct trade will find it to his interest to keep up a constant supply from early in spring until the end of summer, though even in this case he must be prepared to meet the much greater demand which exists in the early part of the season.

The early crops sell for the largest prices, and in a normal season under good management they yield a substantial profit. The demand for cos lettuce continues fairly good and steady throughout the summer, and as the supplies sent to market after the end of $\mathrm{July}$ are seldom 'excessive there is practically no fear of further gluts during that season, and although prices generally rule low a very fair profit can be made by those whose soil can be kept in a cool and moist condition during summer.

Apart from the value of the Lettuce as a main crop it has an especial value to market gardeners, and particularly so to those who aim at cropping their ground intensively, in the facility 
with which it can be employed as a catch-crop. In this respect it is probably the most useful plant in the garden, as it takes up little space, is easy to grow, quick to mature, meets with a ready sale, and thus makes it easy to put to a profitable use many spaces between slower developing main crops which would otherwise remain unoccupied.

Almost any kind of soil may be so prepared that it will grow good lettuces, although the finest are usually produced on soil answering the description of a light sandy loam, But whatever may be the kind of soil employed, it is essential for really good results that it is rich with manure, is well-drained, and is well supplied with moisture in the warm months, so that all the conditions favour quick growth.

Lettuces are grouped into two classes-Cabbage Lettuce and Cos Lettuce. The former is mostly used in mixed salads at all seasons and alone as a simple salad in the early spring months, before the latter can be produced at a price which brings them within the means of the general public. As soon, however, as Cos Lettuces become cheap the Cabbage variety is immediately discarded by the multitude, who prefer the more crisp and juicy leaves of the Cos, and for that reason every effort should be made to so arrange matters that the supply of Cabbage Lettuce intended for market terminates by the middle of May, after which date the demand speedily

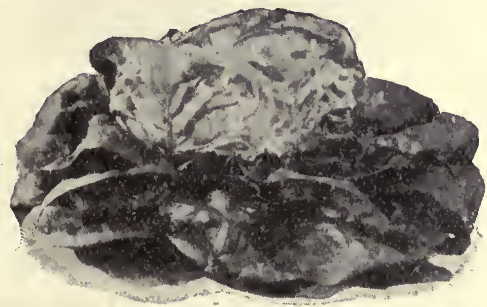

Copyright, S. \& S.

Cabbage Lettuce, Sutton's Heartwell. diminishes and soon practically ceases.

Forced Lettuces.-The earliest supplies are those of Cabbage Lettuce forced on mild hot-beds, either in frames or under cloches. These are followed by Cos raised under cloches. With a sufficiency of warm manure, Cabbage Lettuce may be obtained at any time during the winter, but for practical purposes, where the resulting profits must necessarily be the controlling factor, they can scarcely be produced before the early part of March, nor are supplies of Cos practicable before 
the end of March or the early part of April. The most profitable method of obtaining these early Lettuce is that followed by the French gardener, who makes them part of a series of early crops raised on hot-beds, as is fully described in Chapters $\mathrm{XI}, \mathrm{XII}$, and XIII, to which the reader is referred for full details in connection with the forcing of Lettuces.

Cold Frames.-Immediately following the supplies from hotbeds come those from cold frames. Excellent Lettuces are produced in this way, and although a little later are quite equal to those from hot-beds, and being superior to and much earlier than any grown in the open-air are sure to find a

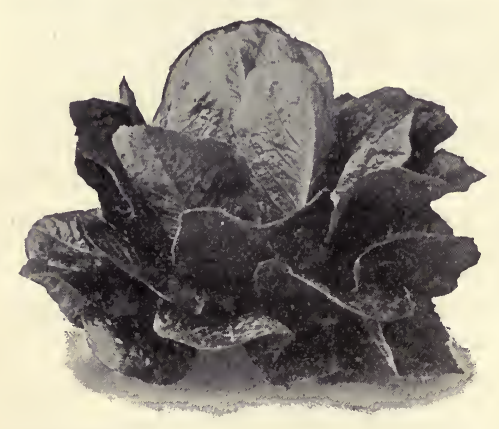

Copyright, S. \& $S$.

Cos Lettuce, Sutton's Whiteheart. ready market at excellent prices. Indeed, when the cost of production of each method is considered, it is probable that on the average crops from cold frames yield quite as much net profit as those from hot-beds.

Seed for this purpose is sown - in the first week of October in the following manner: A seed-bed of light rich compost is prepared. Care should be taken that the bed is moist, particularly below the surface, because the plants should, if possible, be raised without watering. After the soil has been pressed down evenly with the firming board, cloches are placed upon it and by being pressed make circular marks in the soil. Within the rings so made the seed is sown broadcast, thinly, covered lightly with compost, pressed down with the firming board, and covered with the cloches. Mats are laid over all until the seed germinates, when they are at once removed, but if the weather is bright they are replaced for two or three hours in the middle of each day to prevent the tender young seedlings from being scorched by the sun, or the soil made too dry.

The seedlings show in four or five days after sowing, and a few days after they are up, as soon as they can be handled, they 
are pricked out 2 in. apart under cloches or in cold frames, in light rich soil, where they remain until planted out permanently. They must be grown as hard as possible and be given plenty of air on all suitable occasions, but driving rains must be kept from them by tilting the cloches or lights so that they have their "backs to the wind." In times of severe frost they must be protected by mats.

The ground where the cold frames are to stand should be well manured and dug at the approach of winter, being left rough for a time so that the weather may mellow it. As soon as the ground is in a fit condition after the beginning of January break the soil down and level it, then set the frames in position and put a barrow load of moist old hot-bed manure under each light. Level this and cover it with a little fine compost, then put on lights and mats and keep all close for a week, at the end of which time there will be a sensible increase of temperature inside the frames; then plant the Lettuce. The distances apart depend on the variety and whether radishes or carrots are sown at the same time. Either may be sown but not both. Without this intercropping, Cabbage Lettuce can be planted from 6in. apart for the smallest varieties to $10 \mathrm{in}$. apart for the strongest growers, but when radishes or carrots are sown with them they must be given $2 \mathrm{in}$. more space all round. Cos Lettuce can be grown in the same way, but are much more difficult to manage; they need $12 \mathrm{in}$. space each way, should be grown alone, and must have abundance of air; if the atmosphere in the frame is at all confined when the sun gets hot in March many of them will be sure to bolt, but by constant care in giving ample ventilation this can be prevented. Early Cos of good quality sell for such good prices that any trouble taken over them is amply repaid when they are well done.

Unless the season is exceptionally dry the Cabbage Lettuce will probably need no watering, the soil below yielding enough moisture, at any rate until growth is nearly completed. Cos Lettuce will probably need watering several times during the latter part of their growth, as they occupy the ground longer. When either of the varieties become almost ready for cutting it is advisable, unless the ground is wanted for other purposes, to set cauliflower plants, $2 \mathrm{ft}$. apart, amongst the Lettuces. 
Early Lettuces from the Open.-Apart from those matured on hot-beds or in cold frames, it is quite possible, by taking advantage of every situation which is free from excessive damp and will give protection from cold winds, to obtain batches of Lettuce from the open-air sufficiently early to be disposed of at very remunerative prices. Plants which have passed through the winter under protection may, instead of being set out in cold frames, be kept back until there is a spell of mild weather in February or March and then planted in the open. Sunny beds protected by a wall or fence, or by a hedge or belt of trees, or the spaces between rows of cabbage from which collards have been removed, are all situations which may be turned to advantage for growing early Lettuce.

It is advisable also to plant batches of hardy varieties of both Cos and Cabbage Lettuce to stand in open beds through the winter. These should be sown on a well prepared seed-bed about the 14th of September, pricked out on a nursery bed as soon as the seedlings can be handled, and set out permanently at the end of October. Sometimes, when a wet time is followed by hard frost, they suffer severely, but more often they pass through the winter safely and give a very early crop. There is, however, the danger of destruction by birds to which winter Lettuces- are always subject, to circumvent which depends upon the resourcefulness of the individual grower. Near populous districts sparrows often do them a lot of damage, and in the open country skylarks are even more destructive, it being not uncommon, especially after a slight fall of snow, for flocks to descend upon a patch of Lettuce and speedily clear away every vestige of green leaf.

Main-crop and Summer Lettuces.-Seedlings for the maincrop are sometimes sown in heat, but unless in comparatively small numbers which can be given proper attention in watering this plan is not advisable, as the plants have a tendency to bolt if the weather should come hot and dry. It is a much better way to make provision for early crops by the methods already indicated and to sow the seed for the maincrops on a properly prepared bed in the open. This should be done each month from March to June, regulating the quantity according to the space available and the market to be supplied. The bed sown 
in March should be in a sheltered position, and means to afford it protection, if necessary, should be ready to hand. These sowings should be made in drills $6 \mathrm{in}$. apart, and the seedlings thinned out to $1 \mathrm{in}$. apart as soon as possible after they are up. This will ensure hard, sturdy plants with plenty of roots, which, if transplanted to their final quarters with due care, will go rapidly ahead and bring credit and profit to the grower. Still better results are obtained, or at least there is more freedom from bolting in hot dry weather, if the later batches of seed are sown where the plants are to remain. The plants should be thinned out well and early, and the best of the thinnings could be used for intercropping in places where sowing would be unsuitable.

Unless for a special trade, it is advisable that these maincrop and late sowings should consist almost entirely of Cos. There is always some demand for Cabbage Lettuce for salading, but in the summer it is limited and may be easily over-supplied, whilst the popular demand ceases almost entirely after the middle of May.

Set out the Cos Lettuce $1 \mathrm{ft}$. apart, and during 'growth hoe frequently, both to destroy weeds and to prevent undue evaporation of soil moisture. During warm weather, where possible, liberal soakings of water should be given, especially on light soil. Some varieties of Cos are self-folding, and so bleach the heart without any assistance, but as a general rule it is best to tie all with raffia, half-way up; they then handle and carry better and meet with more approval in the market.

When slugs are very troublesome in the seed-beds, pour boiling water over the soil a day or two before sowing, then dust over with soot.

Manures:-The most satisfactory fertilizer for Lettuce is a liberal dressing of good farmyard manure. When the available quantity of this is small and the ground rather poor, 3 to 5 cwts. kainit and 5 to $10 \mathrm{cwts}$. basic slag to the acre, according to the nature of the soil, applied in the autumn, or 1 to 2 cwts. sulphate of potash and 4 to $6 \mathrm{cwts}$. superphosphates applied in the spring, with 1 to 2 cwts. nitrate of soda sprinkled over the roots just previous to hearting, will do much towards ensuring a good crop. 
Varieties :-Hardy Cabbage: Hammersmith, All the Year Round, Sutton's Giant, Lee's Immense, Passion. Forcing Cabbage: Paris Market Forcing, Milly Forcing, Tennis Ball, Earliest of All. Spring and Summer Cabbage: Sutton's Supreme, Daniel's Continuity, Chavigny, Webb's Wonderful, Vauxhall Defiance. Hardy Cos: Black-seeded Bath, Green Winter, Winter White, Hardy White, Balloon, Sutton's Whiteheart. Forcing Cos: Gray Paris, Early French Romaine. Spring and Summer Cos: Paris White, Paris Green, Superb White, Prince of Wales, Balloon, Sutton's Peerless.

\section{MELONS.}

Cucumis Melo.

WHiLST Melons cannot be classed as vegetables, they generally form, in gardens where early salads are grown in frames, a part of the rotation of crops, and it would therefore be absurd to omit a description of their culture on the plea that they are classed as fruits.

The English Netted Melon can be successfully grown in frames provided with a bottom heat of not less than 65 degrees, but on the whole it is not sufficiently hardy to constitute a reliable market garden crop except in glasshouses, in which its commercial culture is almost entirely carried on.

The Cantaloup Melon, known to fame as the Rock Melon of Paris, lends itself much more readily to frame culture. In the market gardens around Paris the majority of the frames which are used in the spring for salad growing are afterwards used to produce a summer crop of Cantaloup Melons, and great numbers are raised in this way, both for consumption at home and for export.

Until a very short time ago it was considered useless, owing to unsuitability of climate, to attempt to grow these Melons in England in accordance with the methods of the French gardener, but this conclusion has been proved entirely wrong. During the past four years large numbers have been so grown in a garden at Mayland, in Essex (and probably also in other gardens), which have ripened perfectly and have met 
with a ready sale in the face of large importations. This has been accomplished easily in two of the years, when there was a normal amount of sunshine, and without any great difficulty in the other two years, which were very wet and cold.

In the Paris gardens Melon growing is divided into three periods - a "forced crop," the seed for which is sown in January and the fruit expected to ripen in May; an "early crop," for which seed is sown in the latter part of February and gives ripe fruit late in June and early in July ; and the "main-crop," the sowing for which takes place from the last week in March to the last week in April, and from which ripe Melons are gathered during July, August, and September.

The method of treatment is much the same in each case, except that for the earlier crops the hot-beds are made deeper, so as to afford a greater and more lasting warmth than in in the case of the maincrop, and for the forced crop the warmth is still further augmented and maintained by linings of warm manure packed all round the frame, up to the level of the lights. The instructions which follow are for the main-

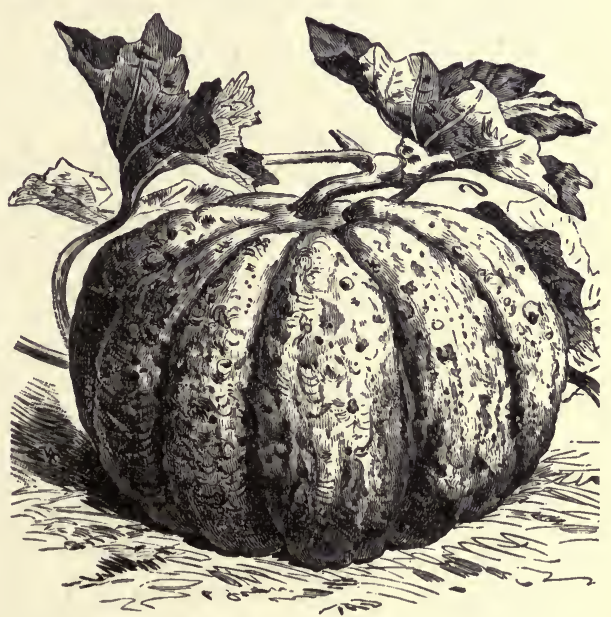

Copyright, V. A. \& Co.

Large Rock Prescott Cantaloup Melon. crop, which is by far the most important, and they are, with the differences indicated, equally applicable to the earlier crops.

For directions as to sowing the seed, management of the young plants, preparing the beds, and planting, the reader is referred to the chapter on Frame Cucumbers, the treatment of which in these stages is precisely the same as for Cantaloup Melons, except that instead of one plant under each light, as directed for Cucumbers, two Melon plants are set side by side, a few inches apart. 
The general management of the two crops varies, however, from the time the young plants begin to make growth in their permanent quarters. Before planting, the centre of each plant is cut above the second rough leaf. Two laterals are soon formed, and these are led one towards the back and the other towards the front of the frame. When six or eight leaves are formed on the laterals they are stopped at the fourth leaf. Sub-laterals break away and these are stopped at the third leaf.

These sub-laterals bear female flowers, which may be distinguished from the male by the small fruit which is formed beneath them. For the forced and early crops it will be necessary to fertilize or "pollinate" the female blooms to ensure the fruit developing properly. This is best done about noon of a clear bright day, when several bold female blooms stand fully open. A well-developed male flower is taken and after removing the outer petals its pollen-laden pistils are inserted within the female flower and a slight turn gently given. One male flower will serve for all the female flowers on each plant.

It is not necessary to fertilize the blooms on the main-crop plants; perfect fertilization takes place naturally owing to the fact that pollen forms more readily under the influence of increased sun-heat, and the free admission of air to which the plants are subjected causes it to be freely distributed.

When the female flowers appear, look over the plants carefully and remove any fruits which may have formed on either of the main stems. When fruit has formed on the sub-laterals to the size of a pigeon's egg select and retain the best-shaped one on each side of the plant and remove all the others. No more than two fruits to a plant should be retained at any time and then only on those of mid-season crops; on very early or very late crops no more than one fruit to a plant should be retained. With a sharp knife cut away all extra shoots which may have formed, and as soon as the fruit has attained the size of a large orange, stop the shoot which bears it at the first leaf past the fruit. In relation to this continuous stopping of the shoots there are two main objects in view which should be constantly borne in mind. The first is that frequent stopping is necessary in order to hasten the branching and consequent 


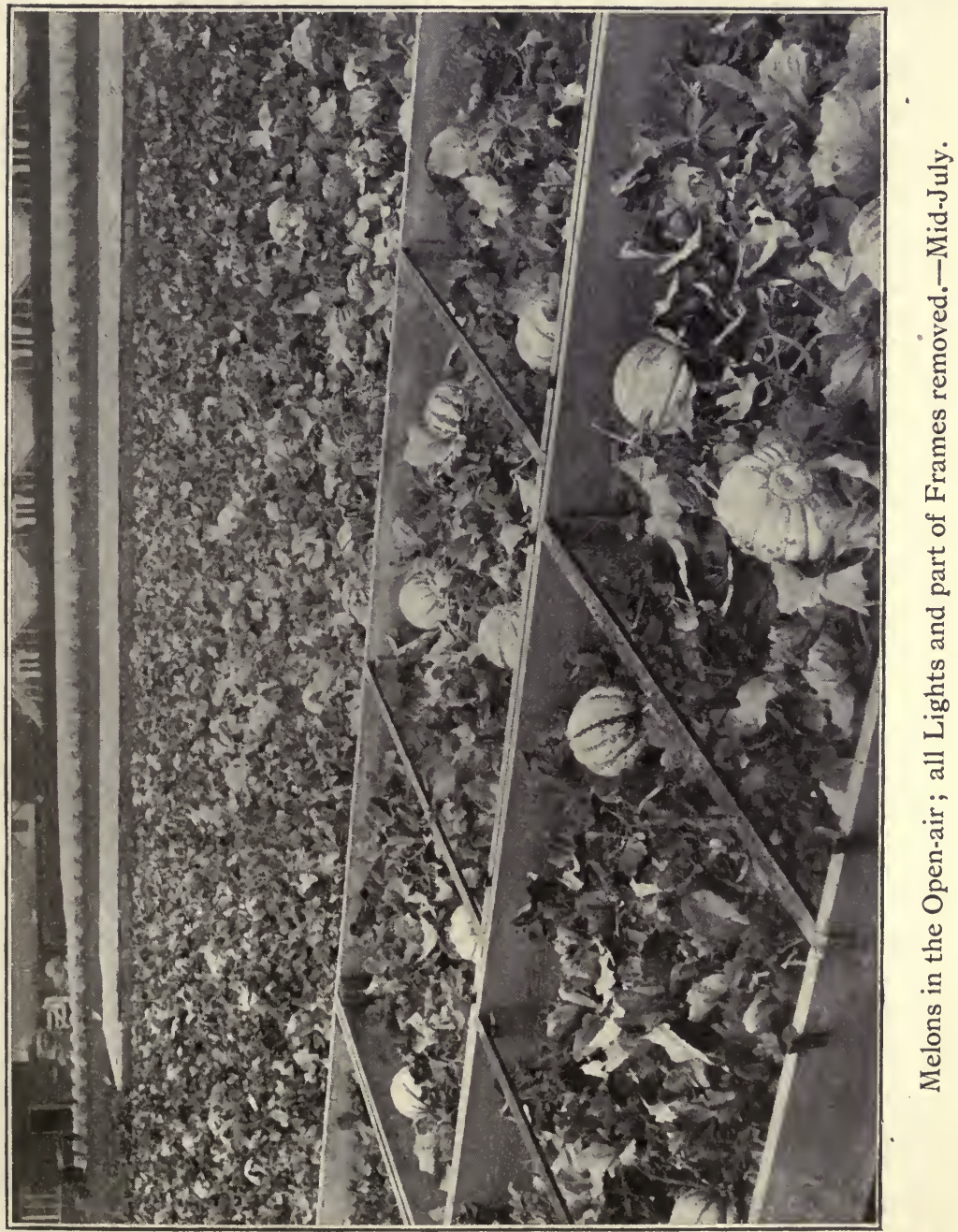


fruiting of the plants, so that the fruits may have the chance to ripen properly during the warm weather; the second is that plenty of healthy well-grown leaves are indispensable for the production of fine fruit, and that therefore cutting away must not be carried to an excess.

As the fruit grows large it should be raised off the bed and laid on a small piece of board, so that the colouring and ripening may take place equally; it should be turned so that the eye (the part on the opposite side to the stalk) will show uppermost.

It requires some judgment and experience to know the exact time when the Melons should be cut. The indications of approaching ripeness are a change in the colour of the fruit to a more or less yellow tinge; a softening of the part of the fruit surrounding the eye, which yields slightly under pressure from the fingers; a number of cracks in and around the stalk, as if the fruit were about to separate from the plant; and lastly, a slight perfume, which grows stronger as the fruit gets more fully ripe. The fruit should not be left until it is perfectly ripe before gathering it, but it should be cut just as it is on the turn and laid in a dry place, where it will ripen in a short time, slowly or quickly according to the temperature maintained; when it cannot conveniently be disposed of for a a few days during warm weather the storage place should be cool, so that ripening may be somewhat retarded.

Throughout the whole time, until the fruit is almost fullgrown, the soil of the beds must be maintained in a moist but not wet condition, particularly avoiding keeping the soil wet immediately around the stem. Water in the morning, if possible between 6 and 7 o'clock, so that the plants may get dry before the sun gets hot. Air must be given on all suitable occasions, at first only a little and with care, but as growth gets stronger and the weather more genial it must be gradually increased, as the Melon requires drier and more airy conditions than the cucumber. In July, or as soon as the weather appears settled, the lights may be removed altogether and the plants allowed to stand in the open-air. Should, however, the weather become cold or stormy the lights must be replaced.

From the end of June to the end of July, according to the 


$$
\text { Melon.-Mint. }
$$

condition of the fruit which should be three-parts grown, cauliflower plants may be set amongst the melon vines, $2 \mathrm{ft}$. apart. As the Melons mature, water is withheld to promote ripening, but as soon as the fruits are gathered the ground is cleared of frames and vines and the cauliflower plants are given a good watering. There is thus a crop of cauliflowers immediately following the Melons, and they should be ready for market in September.

Varieties :-For the forced and early crops, Prescott Early Frame and Early Black Rock. For moderately early and main crops, Large Rock Prescott Cantaloup, Silvery Prescott Cantaloup, and Parisian Cantaloup.

\section{MINT.}

\section{Mentha viridis.}

MINT (known also as Spear-mint, Pea-mint, and Lambmint) is a very popular herb; it can be made a source of considerable profit when grown and forced for market, and its culture should never be omitted by the grower who does a direct trade.

The plant, which is a perennial, will grow in almost any soil, but thrives best in one which is damp, cool, and fairly rich. It is propagated by division of the creeping roots in October or March, or by cuttings dibbled in during the early part of the summer. When the former method is adopted lay the roots thinly in wide drills, $3 \mathrm{in}$. deep and $12 \mathrm{in}$. apart, then cover with soil and make all level. In the latter case set the cuttings $3 \mathrm{in}$. apart in the row and $1 \mathrm{ft}$. between the rows. Water well in dry weather. The soil should be quite free from weeds, as a plantation is difficult to clean when the Mint begins to grow freely, and when choked with weeds it soon becomes useless. In the autumn cut down and burn the tops and cover the bed all over with $2 \mathrm{in}$. of well-decayed manure.

A bed, if properly attended to, will last in good condition for several years, but in gardens where the growing of mint is made a regular feature it should form part of the regular rotation. If a fresh bed is laid down each year, one can be 
lifted for forcing at the end of the third season, and each year afterwards.

Forcing and forwarding is carried on from November to May. Both operations are quite easy of accomplishment. To force, make up a hot-bed from $1 \mathrm{ft}$. to $2 \mathrm{ft}$. thick according to the season, and cover with 6in. of soil. Put a box-frame on this, and when the heat has fallen to 65 degrees lay the roots inside, closely together, then cover with fine soil, water well, and put on the lights, leaving them open slightly at the top. Cover at night with mats. Cut when the shoots are 5in. or 6in. long. For a continuous supply a fresh bed should be made up each month through the winter. If only a small quantity is required, this may be obtained by putting the roots in a box of moist soil, and keeping it in a temperature of about 60 degrees.

Forwarding is done by placing shallow box-frames over open-air beds at the end of February. The frames should be covered with mats until growth begins and each night afterwards. With this purpose in view, beds of the proper dimensions should be planted.

\section{MUSHROOMS.}

Agaricus campestris.

THERE is scarcely any fear of over-doing the production 1 of Mushrooms, as the supply is seldom equal to the demand, which is constantly increasing. Moreover, it is a culture of the greatest importance to the grower who aims at working the ground intensively, for not only is a Mushroom crop profitable in itself, but the spent manure which is left after the crop is gathered forms an ideal material for carrying out most of the intensive operations mentioned in this book, and viewed from this standpoint the culture yields double profits. Indeed, since spent manure is so largely used in intensive work there must be some regular source of supply, and it is usually obtained either from exhausted hot-beds or from Mushroom beds which have ceased bearing. In the latter case Mushroom culture might be regarded as the foundation of intensive culture, and if the crop did no more than clear 
expenses and supply the garden with spent manure free of cost, such a result, although not wholly satisfactory, would at least be a long step in the direction of ultimate profits.

Mushroom growing is not at all difficult, providing a supply of good horse manure and good spawn can be obtained, and the proper conditions are carefully observed, but as so many who have tried to grow them have met with failure, or with indifferent success, it is necessary to exercise caution, and the inexperienced person should be content to make his first attempts on a moderate scale. At the same time, if the following directions are carried out in every detail there is very little doubt of a satisfactory result.

Although Mushrooms can be grown at any season of the year the most suitable period for general purposes is in autumn, winter, and spring. As, however, one of the chief difficulties of Mushroom growing in the winter is the maintenance of a proper temperature, it will be best for the beginner to start making his beds about midsummer. This will ensure them being made under the best

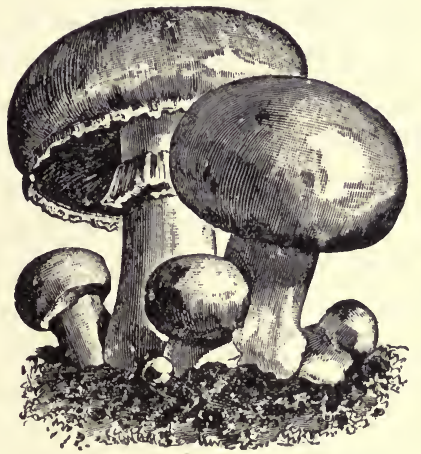

Mushrooms. natural conditions, and they will begin to bear before the cold winter days come, thus making success more certain in the beginning and enabling the grower to gain valuable experience in favourable circumstances.

Mushroom growing can be carried on practically anywherein cellars, sheds, frames, glasshouses, or in the open-air-the essential point being to maintain an even temperature of from 55 to 60 degrees. For winter production it is very advisable that the beds be made under cover, as then the proper temperature can be more easily maintained and the work of gathering can proceed more conveniently and without the many interruptions caused by bad weather. When the beds are made in the open-air or in an unheated structure they should be in the form of a ridge, but when in a place where the surrounding 
temperature can be maintained artificially, such as a heated greenhouse, they may be made flat. The advantage of the ridge-shaped bed over a flat one for a cold situation is that by having a greater and more compact mass of fermenting manure in a given space it maintains its heat longer, and when in the open it throws off the rains and is not liable to become saturated and spoiled by wet. The advantage of a flat bed for a warm structure is that it is much more easy to make and attend to, although as it loses its heat quickly the crop is sooner over. Whatever may be the situation selected for the beds, it is essential that the ground be dry; if it is wet the damp will rise in the bed and destroy all prospect of a crop.

Manure.-A supply of suitable manure is the most important preliminary step in Mushroom growing. It should come from the stables of horses fed on hard corn and hay and littered with straw; manure containing peat, sawdust, or shavings is quite unsuitable and should never be used. When the culture is to be undertaken systematically it is best to arrange for a regular supply in large or small quantities either from one of the manure contractors who attend to this business in most large towns, or from a local stable. By such an arrangement there is always the certainty of having the manure ready to hand at the time when it is wanted, and irritating delays and loss of valuable time are thus avoided. When it cannot be immediately used it should be put in high narrow stacks with the tops sharply pitched to throw off rain, and with "chimneys" or ventilating shafts at intervals to prevent it from overheating. Stored in this manner the manure remains dry and retains most of its virtues. When the beds are to be made, the longest stored of this dry manure is mixed with an equal quantity of fresh, and although the resulting heat is not so great as when it is all fresh, it needs less turning and the bed keeps a gentle warmth for a longer period.

Mushroom Spawn.-The cultivated Mushroom is the same. kind as that which grows in the open fields in the autumn. The Mushroom itself is really only the flower or bloom, the real plant being the fine network of whitish threads which run in the fibrous soil below. Those threads form the spawn or "mycelium" of the mushroom. The growth of this spawn is 
suspended in dry weather or in a low temperature, but becomes active when under the influence of warmth and moisture, and it is during this activity that the flowers or Mushrooms are produced. These, as they become matured, yield from the "gills" beneath the "cap" vast numbers of spores, which in a state of nature serve to perpetuate the plant. Although the Mushroom may be grown from these seeds or spores this is never done except for experimental or scientific purposes; in all ordinary methods of culture artificially propagated spawn is used. This spawn is prepared by persons experienced in its manufacture, and is sold ready for use in the form of bricks or cakes, which vary slightly in size, but are usually about $9 \mathrm{in}$. long, 6in. broad, and $2 \mathrm{in}$. thick; sixteen of these bricks are reckoned as a bushel. The spawn is made by the admixture of certain proportions of manure and soil, formed into cakes and inoculated with the mycelium of previous spawn. Under proper conditions of warmth and moisture these cakes or bricks become permeated with the web-like film of the Mushroom plant. Good spawn is quite as essential to success as is good manure. Experienced persons can, by breaking and examining a brick of spawn, readily form an opinion as to its quality, but the beginner must trust to supplies obtained from some firm of good repute, doing a large and steady business. Fresh spawn should always have the preference, but when more has been obtained than can be used at the time, the surplus can be kept in good condition for a long time if stored in a place which is cool, dry, and dark.

Soil.-The best soil for covering the beds is a good loam containing plenty of fibre. An ideal soil for the purpose would be one obtained from the top spit cut from a rich old pasture. This should be stacked grass side downwards for a year, with a good sprinkling of lime between each layer, and then be broken down fine when wanted for use. It is not always possible to obtain such choice material, in which case the best at command must be used. Recently manured soils or any of a peaty nature are unsuitable. Clay, too, should be avoided, as it frequently produces a fungus which destroys the Mushrooms. Any ordinary garden soil, or the surface soil from a ploughed field, so long as they are free from manure, will do 
for the purpose. The quality of the soil has an influence in determining the number and size of the Mushrooms. If light sandy soil is used they will be plentiful but small, whilst with a heavy soil they will be less numerous but large and fleshy. When the soil is very heavy the admixture of a small portion of sand will improve it; in any case it should be prepared beforehand, by being finely broken, mixed with a little powdered lime, and made moist, but not wet, throughout.

Preparation of the Manure.-When the bed is to be made, select a piece of ground close at hand which is hard and dry. On this place the fresh manure and if some that has been stored is to be mixed with it place the two heaps side by side. Next proceed to shake the manure out, breaking all lumps and throwing out all long straw. When there are two heaps take some from each alternately, so that the fresh and the stored will be well blended. As the work proceeds, all dry parts must be watered, as although eventually the manure must not be too wet, it is a much more serious mistake to have it too dry. Do not saturate the manure with water, but give sufficient to make it nicely moist throughout. Make it into a compact heap, beating each layer a little with the fork as the heap is built up. In from one to three or four days, according to the newness or otherwise of the manure, the heap will have become very hot, when it must be again turned, and if still too dry watered again. This second watering must be the last, as repeated waterings have a tendency to make the manure sour. It must be turned from two to four times, or until it is in a proper condition, and at each turning the outside of the heap should be thrown to the middle and that which was at the middle brought to the outside, so that all may undergo the fermenting and sweetening process. When the manure is in a fit condition for making into the bed it will be of an even dark brown colour, soft and moist, cohesive under pressure but not so wet as to part with any moisture even when tightly squeezed in the hand; lastly, it should be almost free of smell, and what remains should be rather sweet and suggestive of Mushrooms. When the manure is in this condition, and not until, it is ready to be made into beds.

Ridge Beds. - The situation for beds in the open-air should 
be, when possible, one which has shelter of some sort on the north and east, so that the heat may not be driven out by cold winds. When made in the summer months a ridge bed should be $2 \mathrm{ft}$. $6 \mathrm{in}$. wide at the bottom and the same in height, but when made to stand the winter, say from the middle of September to the end of January, it should be $3 \mathrm{ft}$. wide and 3ft. high. The length is immaterial and may be made to suit convenience. Before beginning to make the bed mark out the site carefully, by putting in pegs at each end and at intervals along the length. If the ground is flat the bed should run north and south, so that the sun may play equally on both sides of it, but if the ground slopes it is best to let the bed run in the direction of the slope, especially when there are several side by side, so that rainwater may pass away freely. Begin making the bed by shaking out a layer of manure 6in. thick, and on this shake out a second layer of 6in., then tread it down firmly and whilst standing on the bed beat the sides into shape with the back of the fork. Add another foot in the same way, afterwards treading and beating it as before. This operation is repeated a third time, when the bed will have risen to within 6in. or so of the top. The sides should have been sloped inwards, like the roof of a house, but not so much so as to

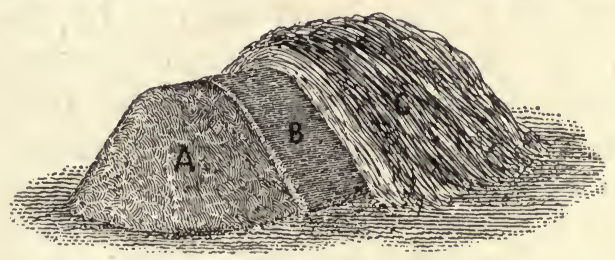

Ridge-shaped Mushroom Bed.

A-The Manure. B-The Soil Casing. C-The Straw Covering. make the apex too narrow; when the bed is built to within 6in. of the intended height it should be 1ft. across and the remaining portion is added in order to round it off. Before this last layer is put on the sides of the bed should be smoothed and loose manure removed; this, and any which has been scattered on the ground along the margin of the bed, can be gathered together and will generally be found sufficient for the top layer. After this is put on it is well beaten with the back of the fork, no more treading being done. As soon as finished, cover the bed with litter to prevent the rain from wetting or the sun or wind from drying it. 
Flat Beds.-These are made in sheds, barns, cellars, glasshouses, and in fact in any places which afford protection from the weather. The length and width is determined by the space available, but the thickness is regulated by the time of the year and the temperature which can be maintained. Beds made in July and August need not be more than 6in. to 9in. deep; in cold structures from September to end of February they should be made 15in. deep. During the same period in places where the temperature does not fall much below 55 degrees, the depth need not be more than 10in. to 12in., but they should be made a little deeper on the side which comes in contact with an outside wall. In making the bed the manure should be shaken out and well trodden down in successive layers of about 6in. until it has reached the desired depth. When finished it should be uniform in depth, well compacted throughout, and with a level surface.

Spawning.-During the first few days after the beds are made the temperature will rise to a considerable height and will then begin to fall. Sometimes when the bed gets very hot it is necessary to make ventilating holes in it to let off some of the surplus heat as quickly as possible. This is not likely to happen to a flat bed unless made extra thick. To reduce the heat in a ridge bed get an iron bar about lin. in diameter, and make-holes along the ridge about $1 \mathrm{ft}$. apart, from the top to within 9in. of the bottom. When the heat has fallen to 80 degrees 3in. below the surface the bed is ready for spawning. Each brick of spawn should be broken into eight or ten pieces; very small pieces should be avoided as much as possible as they generally result in small Mushrooms. The spawn is set in the bed in rows 9in. apart and the same distance between the pieces, each row being placed so that the pieces fall opposite the interval between the pieces in the next row. Each piece is buried about its own depth below the surface of the manure. Holes are made in the manure with the left hand and the pieces of spawn are inserted with the right hand, then the manure is pressed tightly round it and all made level again. Never use a dibber to make the holes, as the smooth sides of the hole so made offer an obstacle to the growth of the mycelium. When the spawn is hard and dry, especially in the warm 
months, the bricks should be put to soak in tepid water for an hour or so before being broken. As soon as spawning is completed, cover outside beds again with litter.

Casing or Soiling.-In about a week after spawning the films of the mycelium will begin to run if the spawn is good and the work has been properly done, and the time has arrived when the bed must be covered with a layer of soil, which should be in a rather moist condition but not wet. The covering of flat beds presents no difficulty. The soil should be put on evenly about lin. thick and beaten lightly with the back of a spade so as to present a smooth even surface. In the case of ridge beds the operation is not so easily done, especially for beginners, but like most other things it becomes easy with practice. A good plan is to lay a plank flat on the ground with the edge $2 \mathrm{in}$. from the bed. This serves as a guage for the thickness of the casing besides helping to keep the first layer of soil in position. The soil should be $2 \mathrm{in}$. thick at the bottom of the bed, gradually reducing in thickness 'until it is only $\frac{1}{2} \mathrm{in}$. thick over the top. The reason for the reduction in thickness is to provide for the shrinkage of the bed, which always takes place to some extent, and if the casing was very stiff and solid it might be left standing independent of the bed. The soil is thrown into place and by a quick turn of the wrist the operator catches it with the back of the spade and fixes it. It is then lightly beaten, and after a section is put on the beating is repeated so as to ensure all being firm and even. Care must be taken that the soil is in the right condition. When so wet as to be pasty it cracks badly as the heat from the bed drives off the excess of moisture, and the cracking breaks the threads of mycelium and so impairs the crop. On the other hand, when the soil is too dry it is not only difficult to make a satisfactory job of the casing, because being crumbly it will not adhere properly to the sides of the bed, but the mycelium does not run freely through it. It greatly facilitates the work if the spade used is kept clean and bright.

Covering the Beds.-As soon as soiling is finished, beds in the open-air should be at once covered with litter to keep in the heat and to prevent the surface from becoming too dry. When the weather is warm this covering need not be more than $6 \mathrm{in}$. 
thick, but accordingly as the the weather is colder or the wind strong the covering must be thicker, until in severe weather as much as $15 \mathrm{in}$. or even $18 \mathrm{in}$. is required. The longest of the litter should be placed over the top of the bed in such a way as to throw off rain and prevent it saturating the bed. During winter outside beds should have tarpaulin, canvas, or mats put over the litter to give additional protection against cold, rain, snow, and keen cutting winds. Such coverings should be securely fastened down by strings, pegs, or other means, so as not to be disturbed by the wind.

Beds in buildings do not need covering whilst the weather is mild, and in houses where a proper temperature is maintained by the aid of hot-water pipes they do not need covering with litter at any time. Beds in cold houses and sheds must, however, be well protected with straw or litter according to the season, from $6 \mathrm{in}$. to $1 \mathrm{ft}$. in depth being required.

Heat of the Bed.-It is always possible that the heat of the bed may rise again after casing and covering, or in cold weather it may fall below the point where the mycelium will work and the Mushrooms grow. For this reason sticks should be inserted at intervals along the bed, and these should be withdrawn and felt daily for the first week or so. If the heat has risen to over 80 degrees, some of the covering must be thrown off, but if it has fallen below 60 degrees, more must be added. If it goes down and remains at a point where the Mushrooms cannot grow, say below 45 degrees, there is nothing for it but patience. Providing the spawn was good and has not been destroyed by overheating or by the bed becoming saturated with moisture, it will lie dormant until there is a natural rise of temperature, and will probably bear well in the following spring or summer. Ordinarily, when the conditions are right, the Mushrooms begin to appear in six or eight weeks after spawning. Under very favourable conditions they will sometimes appear in four weeks, though this is rare. In any case, it is certain that if the spawn is good and the manure properly prepared the Mushrooms will appear sooner or later, and therefore patience should be exercised, and every effort made to maintain the proper temperature of the bed by suitable coverings or otherwise. 
Watering.-Moisture in the beds is essential to success. A bed which is too dry will be unproductive. But in many cases an otherwise good bed is frequently spoiled by the too frequent use of the water can. No water at all ought to be necessary during the first month after soiling. At the end of that time if the soil appears to be getting dry a little may be given through a fine rose, but if the soil is still moist this will not be necessary. Another watering may be given after the first abundant gathering of Mushrooms. Always use tepid water and give sufficient to moisten the soil. In dealing with open-air beds or those in cold houses it is better to give the water over the litter instead of directly on the surface of the bed, and in that case the water given should be quite hot. In any case, immediately after watering the coverings of the bed must be restored or the temperature will be seriously lowered by rapid evaporation. Each of these waterings should be done with clear water only, but when the crop begins to diminish it may be stimulated and made to last a longer time if, after the bed is cleared of Mushrooms, the soil is saturated with weak liquid manure; or a weak solution of guano or saltpetre will have the same effect.

It must be constantly borne in mind that whilst the beds should not become too dry, the greatest care must be exercised to see that they do not get over-wet, as there is almost sure to be a failure if they are drenched. A moist atmosphere should be maintained; this is provided for to some extent by the covering on the beds, which keeps the air close to the surface in a moist condition, but in houses where no covering is used, it is necessary to occasionally sprinkle water on the walls and paths, so that the right conditions may be maintained by evaporation, and where hot-water pipes are used in the winter they should have evaporating troughs placed on them, kept filled with water. On the other hand, where the conditions appear to be too damp and the atmosphere stagnant it is advisable to give a little ventilation.

Beds in Odd Places.-Provided the mode of procedure and the conditions prevailing are such as are suitable to their requirements, Mushrooms may be grown almost anywhere and the beds may be of any size or shape desired. They may be grown in the cellar of an ordinary dwelling-house without the 
manure being in any way objectionable, as it can be prepared outside and the beds carried in ready-made, in boxes, in old

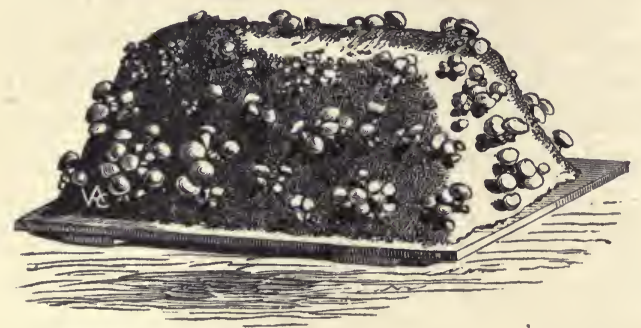

Copyright, V. A, \& Co.

Movable Mushroom Bed on Flat Board. tubs, or on plain flat boards. Space for beds may not only be found on the floors of stables, sheds, and out-houses, butwhere this is limited the walls may also be utilised, by fitting them up with shelves made of stout boards.

These should not be fixed, but should be arranged on brackets so that they can be readily carried outside for cleansing and renewal of the beds. In all such cases the shelves should have ample space left between them for convenience in giving necessary attention and gathering, and the details of culture already given fully carried out, the manure being made compact by being beaten with a mallet. Space may also be economised by making beds in boxes and standing these one above another, with a space between each. Ordinary frames are

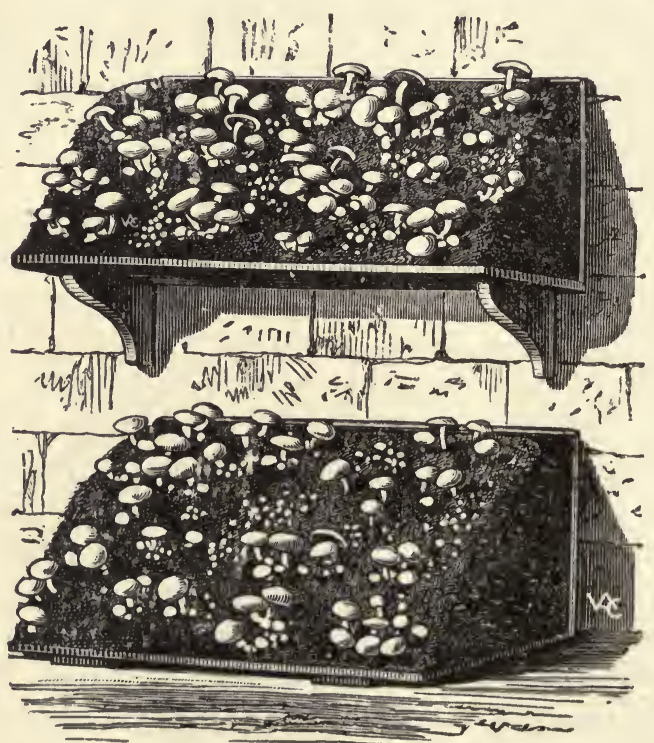

Copyright, V.A.\& Co.

Movable Mushroom Beds against a Wall. serviceable for the same purpose, and crops may be obtained in autumn by inserting lumps of spawn during the summer in melon or cucumber beds. 
Gathering and Packing.-When the beds begin to bear, the Mushrooms should be gathered regularly and frequently-at least two or three times a week. To allow them to get too far open before gathering tends to exhaust the bed and shorten the crop. Every one that is gathered should be pulled out with a slight twist, so that the base of the stem comes clean away. It is a great mistake to cut or break the stems and to allow the bottoms to remain in the bed with the idea of later getting the few small ones which generally show at the foot of a large one. Such a plan, by leaving the old stumps in the bed to decay, encourages insect pests and fungoid diseases, and thus materially lessens the crop. The person who is gathering should always carry a knife for the purpose of cutting clean out the roots of any which have broken off, and all Mushrooms which are looking dead and withered should also be dug completely out in the same way. A basket containing moist soil similar to that used in casing the bed should always be kept at hand so that all holes made in the bed may be filled at once. Great care is needed in handling the Mushrooms to avoid bruising them, the least tounch on the tender gills causing them to become discoloured:- They should be gathered into three separate baskets, in one of which would be put the largest and best looking fully open ones, known as "broilers," in another the smaller half-opened and small round undeveloped ones, known as "cups" and "buttons," and in the third the rough and broken ones. They must be very carefully placed in the baskets stem downwards to prevent any soil falling into the gills, any adhering soil being cleaned off in the packing shed with a piece of flannel. When they are gathered under cover it is a good plan to cut off the bottom of the stem at once as soon as they are removed from the bed and before putting them in the basket." When gathering from outside beds in severe weather they should be picked very closely so as not to have to expose the bed too frequently, and only a small portion should be uncovered at one time, and this should be re-covered as soon as the Mushrooms are gathered. The produce after being graded as indicated above is packed, stalks downwards, in "handle baskets" supplied by the market salesmen, generally in quantities weighing from $4 \mathrm{lbs}$. to $61 \mathrm{lbs}$. 
Cleanliness.-Strict cleanliness is essential to continued success in the culture of Mushrooms. When stems and roots are dug out of the beds, or when the base of the stalk is cut off whilst gathering, every fragment must be put into a basket kept at hand for that purpose, and carried away to the rubbish heap. Houses, paths, and in fact the whole surroundings of the beds must at all times be kept clear of the dead fungus. After beds in sheds and houses have finished bearing and the manure is cleared away, they should be thoroughly cleaned out and ventilated, the walls limewashed, and the ground sprinkled with lime. Shelves on which Mushrooms have been grown should also be subjected to thorough cleansing and limewashing. In this way, and by the use of lime in the soil used for casing the beds, the various insect pests and fungoid diseases to which Mushrooms are subject will never assume formidable dimensions.

\section{MUSTARD and CRESS.}

Sinapis alba. Lepidium sativum.

THE grower who does a direct supply trade will find it to his advantage, both as regards satisfying his customers and in the resultant profit, to produce regular supplies of Mustard and Cress, especially during winter and spring. It is easily grown, either in glass-houses or on mild hot-beds during the winter, in cold frames later in the spring, and in the open air as soon as the weather becomes warm and genial.

When Mustard and Cress is done well it is tender, with good bold leaves, and to get it in this condition it must be grown quickly. To this end it needs light rich soil, a temperature hovering round 60 degrees, and a rather moist but buoyant atmosphere. When there is a heated greenhouse available it may be grown in any vacant spaces, either in boxes, directly on the ground, or on benches, but where there is no such convenience for winter work hot-beds must be used. These should be made in the manner described for French/gardening work, and the following description of the preparation of the seedbed applies equally to any of the methods adopted. 
Break up with a fork some old hot-bed manure, repeating the operation several times until it is fairly fine and damping it well during the process. Then sift it, and use $2 \mathrm{in}$. of the lumps'as a foundation directly on the hot-bed, or in any other place where the seed-bed is to be made, and on this put $2 \mathrm{in}$. of the fine sifted material. Then press down evenly all over with the firming board. The seed may now be sown directly upon this or, as is now frequently done in market places, the bed may first be covered with a piece of open-meshed sacking, previously soaked in water. This prevents any possibility of soil being carried upward amongst the stems or leaves during. germination.

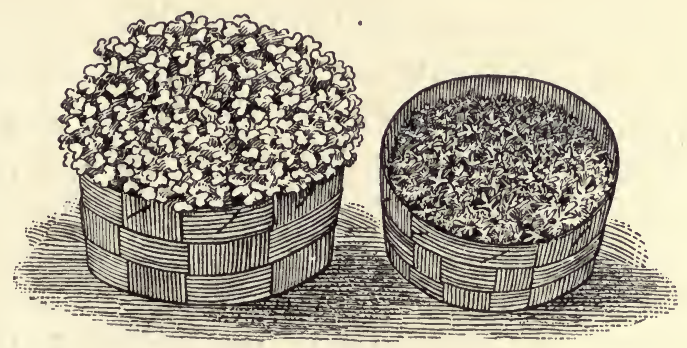

Mustard and Cress, in Punnets.

The Cress being slower to move should be sown three days before the Mustard, in order that both may be ready to cut at the same time, and one-third less of the former should be sown. Sow thickly and evenly, but do not cover with soil. Cover the seed with brown paper, or if sown in a frame cover it with mats. Remove these when the Mustard has been sown three days. Covering in this manner has the effect of lengthening the stems. A little air must be admitted to the frames each day. If the soil and sacking are properly moist no watering will be required. Several crops in succession can be grown on the same bed, but all roots must be cleared, the soil stirred, moistened, and pressed down, and the sacking damped anew for each crop. In the proper temperature the Mustard will be ready for cutting in seven or eight days after sowing, and the Cress in ten or eleven days. 
When ready, the crop is cut half an inch above the roots with a large sharp knife, taking a breadth of about $3 \mathrm{in}$. at one cut. It is then packed upright, with the tops as level as possible, in punnets made for the purpose, the Cress going in a shallow punnet and the Mustard in a deeper one. These are known to the makers as punnets for "Hot and Cold," and the produce is also dealt with under this name by market salesmen.

Varieties :-White Mustard and Curled Cress will give satisfactory results, though many market growers now substitute Rape (Brassica napus) for the Mustard, because it is cheaper and is said to serve the purpose equally well.

\section{ONIONS.}

Allium Cepa.

NIONS are appreciated in one form or another by almost everyone, and it is therefore necessary that the grower of general supplies should devote a fair-sized area to their culture. Fortunately, they will grow and do fairly well on almost any soil, although one of medium texture, inclining to sandiness, yields the best and most profitable crops; but even a clay soil, with good preparation, may be made to produce a very satisfactory crop of Onions.

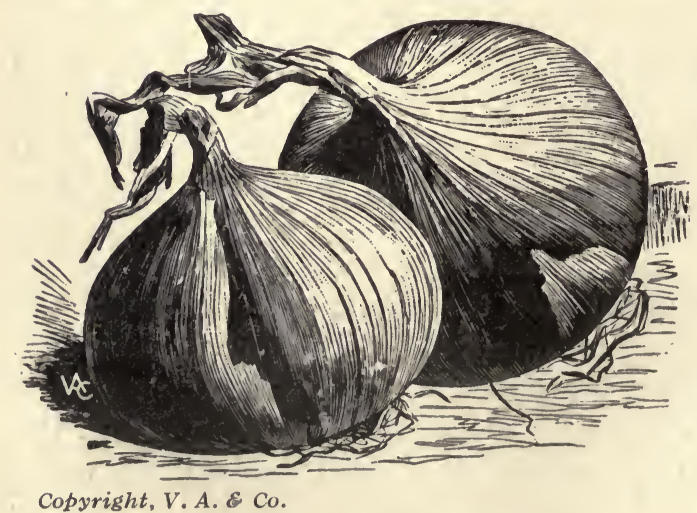

Giant Zittau Onion.

The production of Onions for sale may be considered as occupying three main divisionsthose which are sown towards the end of the summer for transplanting early in the spring (these are known as "autumn sown"; those sown at the same date to be pulled for bunching in spring; and the main sowing which takes place early in spring to produce Onions for storing and sale in 
the winter and spring following. In addition, a special business is made of growing Onions for pickling, and this as well as several other methods of growing them will be dealt with in due course.

Preparation of the Soil.-Adequate preparation of the soil is necessary to the production of a good crop of Onions. With proper treatment almost any kind of soil may be brought into suitable condition, and although on some soils this may be a heavy and somewhat expensive matter in the beginning, it has the redeeming feature that as Onions may be grown year after year on the same ground, if the crop does not make profits the first year it will probably do so later, and further that if Onions are included in the rotation, as is recommended, the proper preparation of the ground for this crop will put it into firstrate condition for any other crop in the garden.

As a preliminary, see that the drainage is good, because where there is stagnant moisture success is impossible. Next, work the soil deeply, breaking all the lumps, and put a good dressing of manure between the top and bottom spits. This should, if possible, be in a well-decayed condition, but if such is not available the manure may be given fresh providing it is put into the ground in autumn for spring sowing. If it is the first time of preparing the ground for Onions, manure at the rate of at least 20 tons to the acre should be given, with 10 to 15 tons each year afterwards. Should the soil be very light it will be greatly improved if a dressing of clay or marl is spread over and thoroughly mixed with the top spit; sand or road grit may in the same manner be used to lighten clay. On heavy land, in addition to the usual pipe-drains, it is advisable to arrange the ground in beds with rather deep furrows between, which will ensure the soil being soon free of excessive moisture after heavy rains. The beds should be left ridged up for the weather. to act upon through the winter, and then if pulled down and levelled when the surface is dry in the spring, it will be found mellow and well-pulverised, and in a kindly state for receiving the seed.

Spring-sown Onions.-When the ground has been prepared as indicated, seed may be sown at the first favourable opportunity after the end of February, but it is very unwise to hurry 
this operation by putting in the seed before the soil is in the proper condition; the surface should be dry, friable, and free from stickiness; it is better to defer sowing for a week, or even two, if necessary to get a really good seed-bed. Drill the seed in rows from $9 \mathrm{in}$. to $12 \mathrm{in}$. apart, according to the variety to be grown and the cleanliness of the ground. When the variety is one which attains only a moderate size and the ground is clean the smaller distance, with the plants ultimately thinned out to 3 in. or 4 in. apart, will answer very well, but when the ground is not particularly clean or one of the larger sorts of Onions is grown, 12in. between the rows, with the plants standing 6in. apart, is close enough. Make the drills very shallow, so that the seed is only just covered, and then, if the surface is dry, tread it in or pass a roller over the ground. On heavy ground the treading or rolling must be done very lightly, or omitted altogether if the surface is not quite dry. As soon as the lines can be seen, the soil between should be gently hoed, and immediately the seedlings are well above the ground they should be thinned with a 2 in. hoe, but care should be taken to leave a good plant. A few weeks later the final thinning can take place, and on this occasion the surplus may be bunched as "Spring Onions," though in some seasons it scarcely pays to send them into the market so late. The hoe must be kept going at frequent intervals to keep the weeds in check, for nothing is more detrimental to an Onion crop than to allow weeds to make headway. In hoeing, be careful not to move the soil deeply nor to draw it towards the bulbs, which ought to be on top of the soil and not buried in it.

Harvesting.-In a normal season the Onions will begin to ripen soon after the middle of August, which is seen by the tops changing colour, but if the weather is cool and moist ripening may be considerably delayed, in which case growth should be checked by bending over the tops at the necks. This may be done with a wooden rake, held teeth upwards. When the tops are yellow and the necks shrunken, usually about the middle of September, they are ready for pulling, and advantage must be taken of fine weather to draw them and lay them out to dry. If the quantity is not large they will finish off better if carried to a piece of hard dry ground, and laid with their 
roots turned to the south, but when a large breadth is grown they must be ripened where they grew. After a few days, when thoroughly dry, they should be topped, cleared of loose skins, and stored in a dry, cool, airy place. They should never be laid more than a few inches deep and on a floor or in trays having a bottom of narrow laths with spaces between, so that a current of air can play freely around them. Damp must be carefully guarded against or they will not keep. One of the very best ways to keep Onions sound through the winter is to bunch or rope them. When bunched they may be strung on poles, and in this way a large quantity may be stored overhead in a comparatively small shed without interfering with the floor space; or they may be hung on pegs on an outside dry wall. A few degrees of frost will not harm them, and if it comes severe they can be carried inside and piled in a heap until the weather changes, when they can be returned to the wall again.

Autumn-sown Onions.-For these select ground which has been liberally treated for a previous crop. As soon as possible after the ground is cleared it should be dug or ploughed, but not deeply, or there may be some difficulty in the dry summer weather in getting a tilth suitable for sowing. If the land is ploughed, cross-ploughing is advisable, followed by rolling, harrowing, and working about to break all clods and get a fine tilth. During this time spread and work in suitable fertilizers, as indicated at the conclusion of this article. Finish the work by levelling and then rolling again to get a firm seed-bea, such as this plant prefers. Drill in the seed in the same way as advised for spring sowing. This should be done in August, near the beginning of the month in the north and towards the end of the month in the south. The advantages attending autumn.sowing are that the bulbs grow larger, they ripen earlier and are thus better suited than spring-sown ones for places subjected to a heavy average rainfall, and they are seldom, if ever, attacked by the Onion Fly.

As soon as the rows can be seen, weeding must be attended to and persisted in, so that the plants are left in a perfectly clean condition to face the winter. During winter and spring a portion can be drawn for bunching, and early in the spring they should be finally thinned to 6in. apart in the row, the 
best of the thinnings being transplanted to a well-prepared plot, in rows from $12 \mathrm{in}$. to $15 \mathrm{in}$. apart, with the plants from 6in. to 9in. apart in the rows, according to whether the variety is a large or medium sized one.

Large Onions.- - Of late years there has been a steady and increasing demand for large and mild Onions, of which the Spanish Onion may be taken as the type. Huge quantities of this class of Onion are imported annually into this country, and it has now become quite customary with many housewives when ordering Onions to stipulate for Spanish. This being so, it is necessary that growers should make some attempt to supply the demand, or the trade may ultimately pass almost entirely out of their hands. There is all the more reason for the effort when it is known that Onions of the type required can be grown in this country quite equal to the imported ones, and what is still more to the point so far as the market gardener is concerned, they can be grown to show good profits.

There are three points of vital importance which must be observed if success is to be assured in this special culture, and those are-first, a deeply worked, thoroughly pulverized, and very rich soil; second, a good strain of seed of a large-growing pedigree variety, one of a globular form for preference; and third, a long season of growth.

Where this culture is seriously intended the preliminary preparation of the ground must be given special attention. Bastard trenching is necessary, with a generous dressing of . good "fat" manure between the top and bottom spits. This should be done in October, if possible, with the surface left rough so that the weather can have full effect upon it. If the soil is of a heavy description, apply to the surface, immediately after digging, a dressing of basic slag at the rate of $5 \mathrm{cwt}$. to the acre, and in February add $1 \frac{1}{2} \mathrm{cwt}$. sulphate of potash. If the soil is light give 5 cwt. kainit in the autumn and $3 \mathrm{cwt}$. superphosphate in February. In addition to the preceding, on any soil, give 5 cwt. soot about the turn of the year, and another 5 cwt. mixed with 1 cwt. salt at the beginning of April, after which, as soon as the surface is dry, rake the ground level and roll it, thoroughly if the soil is light, gently if heavy, and it will then be ready for planting. 
A long season of growth is secured in several different ways. One method is to sow thickly on poor ground about the middle of May, and so get a crop of very small bulbs, about $\frac{1}{2}$ in. to $\frac{3}{4}$ in. through, the same season. These are thoroughly dried and stored away in small lots in a dry, cool, airy place until spring, when they are planted out in March, in a similar manner to shallots. A few of these will probably bolt, in which case the flower stem should be cut out as soon as seen, when the bulb will swell out from one side and will become a good Onion by the end of the season, though one side will be slightly flattened. The remainder will grow to a large size. Another way is to sow very thinly in a cold frame in October, giving plenty of air and growing as hardily as possible, but giving protection from severe frost by a covering of mats, finally planting out in April. A third method, and the one which has most to recommend it, especially as it practically ensures freedom from bolting, is to sow at the beginning of January in a warm greenhouse or frame. Fill shallow boxes, $2 \frac{1}{2}$ in. to $3 \mathrm{in}$. deep, with light rich compost (sifted old hot-bed manure with a dash of sand will be just the thing), and in this sow the seed all over about $\frac{1}{2}$ in . apart, and water gently but thoroughly with tepid water; no more watering will be required until the seedlings are through the soil, then water as before. Always apply the water slowly through a fine rose, and stop the moment it ceases to sink into the soil. If any of the seedlings come up closer than $\frac{1}{2}$ in., thin them to that distance apart. When they are $2 \mathrm{in}$. high, transplant them into other boxes, 3in. apart, using the same soil as before with half its bulk of loam added. In pricking-out, the soil must be made quite firm and the plants gently watered as soon as the operation is completed. A week or so afterwards, when they have recovered from the shift, hardening-off, should begin. Do this very carefully, so that the plants are not suddenly exposed to cold draughts, but thoroughly, so that when they are planted out they receive no check.

Set out the plants as soon after the middle of April as soil and weather permit, in rows $15 \mathrm{in}$. apart, by $9 \mathrm{in}$. between the plants in the row. It is a good plan to shorten the leaves, but the roots should be preserved intact when only a moderate number have to be set out. When a large piece of ground has 
to be planted the roots may be shortened to $1 \mathrm{in}$. and the plants carefully set with a dibber. They must on no account be set deep, but as shallow as possible and quite firmly. During the summer the ground must be kept free of weeds by hoeing, but the soil must not be moved deeply, nor must any be drawn to the bulbs, which should grow on the top and not partly in the soil. No watering or further feeding is necessary, but frequent stirring of the surface soil with the hoe will be found very helpful in preserving soil moisture and promoting growth.

Spring or Green Onions.-For "Spring Onions" select very rich, clean, and well-drained soil, and give it the treatment recommended for autumn-sown Onions. Sow in drills, 9in. apart, rather thickly, and after sowing roll lightly. Hoe as soon as the plants are up and as often as possible before the autumn rains set in, so as to leave the ground quite clean for the winter. Hoe again in spring as soon as the ground is dry enough to bear treading on. Early in spring one or two light dressings of nitrate of soda will make the plants move along quickly. When the crop is ready for marketing, loosen the soil with a fork so that the plants will draw easily. Tie them in bunches of twelve, then wash them, and tie twelve bunches together to form a market bunch or bundle. The size and arrangement of the bundle differs in different markets, and it is always best make enquiries as to what is wanted before sending.

Pickling Onions.-For this crop the ground should be rather poor and dry, and worked to a very fine tilth. Sow in April, thickly but evenly, broadcast if the ground is clean, but if there is any doubt of this sow in drills, 6in. apart. The seed should be only just covered, and the soil made firm by rolling. Weeding must be well attended to, but no thinning is required except in places where the plants may stand unduly close.

Potato Onions.--This Onion, although not much grown now, is mild and sweet, and gives a good crop with a minimum of trouble. It should be planted, just below the surface, early in January, in rich deeply-worked soil, and is ready to take up about the beginning of July; indeed, old cottage gardeners who favour this variety plant on the longest and take up on the shortest day. If the bulbs are kept out of the ground much 
longer than the end of January they begin to go soft and useless. When very small bulbs are planted they grow into large ones, but large bulbs multiply into numerous others. Plant in rows $12 \mathrm{in}$. apart, 9in. between the setts. As severe frosts will sometimes destroy the bulbs, it is wise to scatter litter along the rows after planting.

Manures:-To get a satisfactory crop of Onions the soil should be rich in plant foods in the most available form. What would be considered sufficient to produce a good crop of ordinary vegetables is not nearly enough to obtain the best results from Onions, and as the heaviest item in the cost of producing a crop is labour, and as the labour bill is not much heavier for a large than for a small crop, it is obviously a mistake to economise on the manure bill; if sufficient manure is not available to properly prepare the area intended for Onions, it would be better and more profitable to put all the manure on only half the space and limit the crop to that. On soils which naturally contain a large amount of humus a good crop may be obtained by the addition of suitable concentrated fertilizers, but on most soils the addition of natural manure is indispensable. This may be either applied direct for the particular crop or as the residue from a heavy dressing given to the preceding crop. Almost any kind of manure will do providing it is well-rotted before use; when heavy dressings of coarse rank manures are given the frequent result is either failure through disease or a large proportion of bull-necked bulbs which refuse to ripen. But natural manures, when used alone, are not sufficiently well-balanced in the necessary plant-foods to do full justice to this crop, and the best results consistent with economy are obtained when a moderate dressing of well-decayed natural manure (say 20 tons to the acre) is supplemented with suitable fertilizers. What form or proportions these should take depends upon the soil, in which sometimes one and sometimes another of the three principal plant foods is deficient, and this can only be correctly ascertained by analysis, though a few experiments will settle many doubtful points. Additional potash in some form should never be omitted, whatever the nature of the soil. For general purposes, on light to medium soil, in addition to natural manure, 
give 5 cwt. kainit and 3 cwt. superphosphates, and for heavy soils give $1 \frac{1}{2}$ to $2 \mathrm{cwt}$. sulphate of potash and $5 \mathrm{cwt}$. basic slag, each quantity being for one acre. These should be spread evenly over the surface of the soil immediately after digging or ploughing, and should be followed, soon after the turn of the year, with 5 cwt. soot. Just before sowing or planting, another 5 cwt. soot mixed with 1 cwt. salt should be spread. Hen manure is very much valued by some Onion growers. It will give the best results when dried and pulverised and mixed with twice its bulk of dry soil, then broadcasted as a top-dressing before planting. Good guano may be used in the same way; at the rate of 2 to $3 \mathrm{cwt}$. per acre. When either of these topdressings are used the first dressing of soot may be omitted.

Varieties:-For spring sowing, good keepers: Bedfordshire Champion, Giant Zittau, James's Keeping, Brown Globe, White Spanish, Danver's Yellow. For autumn sowing: Sutton's A 1, Lemon Giant Rocca, Trebons, Giant Zittau. For early sowing in heat to make extra large bulbs: Ailsa Craig, Wroxton Improved, Cranston's Excelsior. For bunching green: White Lisbon. For pickling: Silver Skinned, New Queen.

\section{PARSLEY.}

\section{Carum Petroselinum}

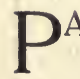

ARSLEY should have a place in every marker garden, as it is in constant demand. If the soil is suitable and there is a reasonable prospect of a good market it can be grown as a special crop to occupy large breadths, and can be made to pay well, but it must be good, well-grown, clean stuff, or it will often be found that a consignment does not clear the cost of carriage. On small holdings the preferable method of culture is to sow frequent small batches in March, June, and August, so as to have a supply all the year round.

Parsley is said to grow anywhere, and to a certain extent this is true, but there is a wonderful difference between plants grown on different soils. Some authorities advise light sandy loam, but the writer has grown some of the finest Parsley he ever saw on heavy clay, not in one season only but for several 
successive seasons and not only in summer, but also in very wet winters. To grow this plant really well the soil should be inclining to heavy, deeply worked, well manured, and free from stagnant moisture. Light soil should be made as firm as possible before the seed is sown, by rolling or treading.

Seed should be sown in March, for summer supplies, in June for winter, and early in August for the following spring. Before sowing, the surface soil should be brought to a fine tilth. Sow thinly, lin. deep, in rows $12 \mathrm{in}$. apart, and thin out to 4in. to 6in. apart, for summer and spring, but for winter, as the plants do not grow so strongly, and as they should be

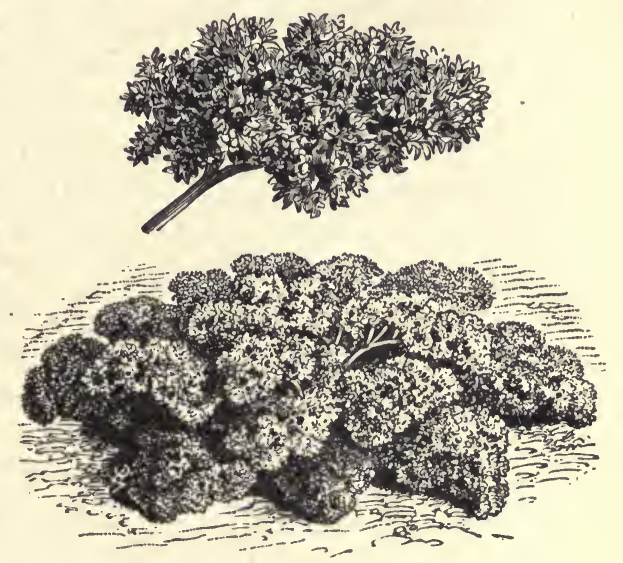

Copyright, V.A. \& Co.

Double-curled Dwarf Parsley. kept compact so as to be readily protected, $10 \mathrm{in}$. by $3 \mathrm{in}$. will be sufficient. The seed is slow to germinate, usually from five to six weeks, and if the weather is very dry this may be prolonged to seven or eight weeks. If the soil is very dry for the August sowing, and the area is not large, the drills may be watered before the seed is sown. In order that the soil may be stirred and the weeds kept down before the Parsley appears, a little cabbage lettuce or radish seed may be sown with the Parsley; this germinates quickly and serves to mark the rows so that hoeing may be proceeded with, and if thinned out well and promptly will give a light catch crop without injuring the main crop. Transplanting is sometimes practised, and this answers very well if done with care in moist soil during dull weather, but sometimes the plants run prematurely to seed, and when possible it is better to sow where the plants are to remain. A frequent practice, particularly with those who do not grow in large quantities, is to sow Parsley as an edging to beds occupied by other plants, and it does well in such places and takes up 
very little room, but the position should be well considered or it may interfere with the cultivation of the ground later on. The August sowing, which has to pass through the winter for use the following spring, should be in an open situation but sheltered from northerly and easterly winds.

The winter crop should have all the largest leaves removed during September, so that a fresh crop of leaves will be made for use in the winter. It should be sown in beds so that some form of protection can be given it in hard weather. Where frames are available, the beds should be of such a size as can be conveniently covered by these, but the lights should not be put on except during frost or snow, and then a little air should be given unless the weather is very severe. If frames cannot be had, a bed may be very efficiently protected by driving in short stakes at each side of the bed, connecting these with crosspieces, and in hard weather laying on mats, straw, or other covering. All such coverings should be at once removed when the weather conditions become milder.

Varieties:-Dwarf Double Curled, Perennial Moss Curled, Giant Curled, Myatt's Garnishing.

\section{PARSNIPS.}

\section{Pastinaca sativa.}

No grower doing a general business should neglect the heavy crop, and is profitable. It is not so popular as it ought to be, for it is a cheap vegetable, delicious and nourishing when properly cooked. It is a native plant but seems to have been largely pushed aside and forgotten, which is a pity. Nevertheless, there is always a steady if not a very large sale for it, and the grower may sow a moderate breadth without fear of loss.

The Parsnip will do well on almost any soil which has been properly prepared, and this implies thorough working to a good depth, so that the long root can descend straightly and without obstruction. "The soil should be in good fertile condition, though not necessarily rich; no manure should be applied directly to the crop, or the roots are liable to become fanged 
and cankered. The best results are obtained from a soil of medium texture which has been manured for a preceding crop.

About the beginning of March, as soon as the ground is dry enough for working, rake down the surface fine and level. If the state of the ground is not suitable for working it is better to wait for a few days rather than sow when the soil is too wet. Sow in drills lin. deep and 18in. apart. After sowing, cover with fine soil and roll lightly. Care should be taken to use only good new seed, as old will frequently fail to germinate. When the seedlings are well up thin out to from $8 \mathrm{in}$. to $10 \mathrm{in}$. apart. The culture afterwards consists in an occasional hoeing to keep the bed free of weeds. The roots will be ready for use in October, and may be lifted and stored in November. They may be left in the ground with safety, to be lifted as required, and are then of a better flavour than when stored, but as the ground ' needs preparing for spring

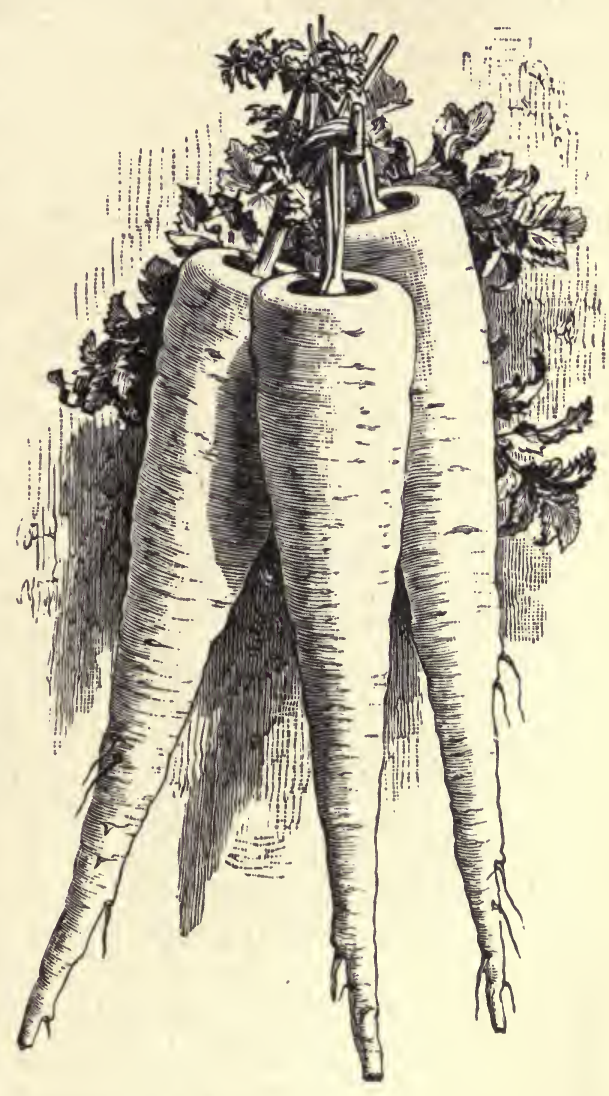

Copyright, V.A.\&.Co.

Hollow Crowned Parsnip. crops this is not often practicable. The roots may be stored in clamps, like potatoes, or stood in a trench upright and covered with soil, or they may be stored in layers in soil or sand in a cool shed.

Varieties:-Hollow Crown and Lisbonnais. 


\section{PEAS.}

Pisum sativum.

PEAS hold an important place in the garden. They are favourites with almost everyone, and are always in great demand so long as they can be supplied fresh and young.

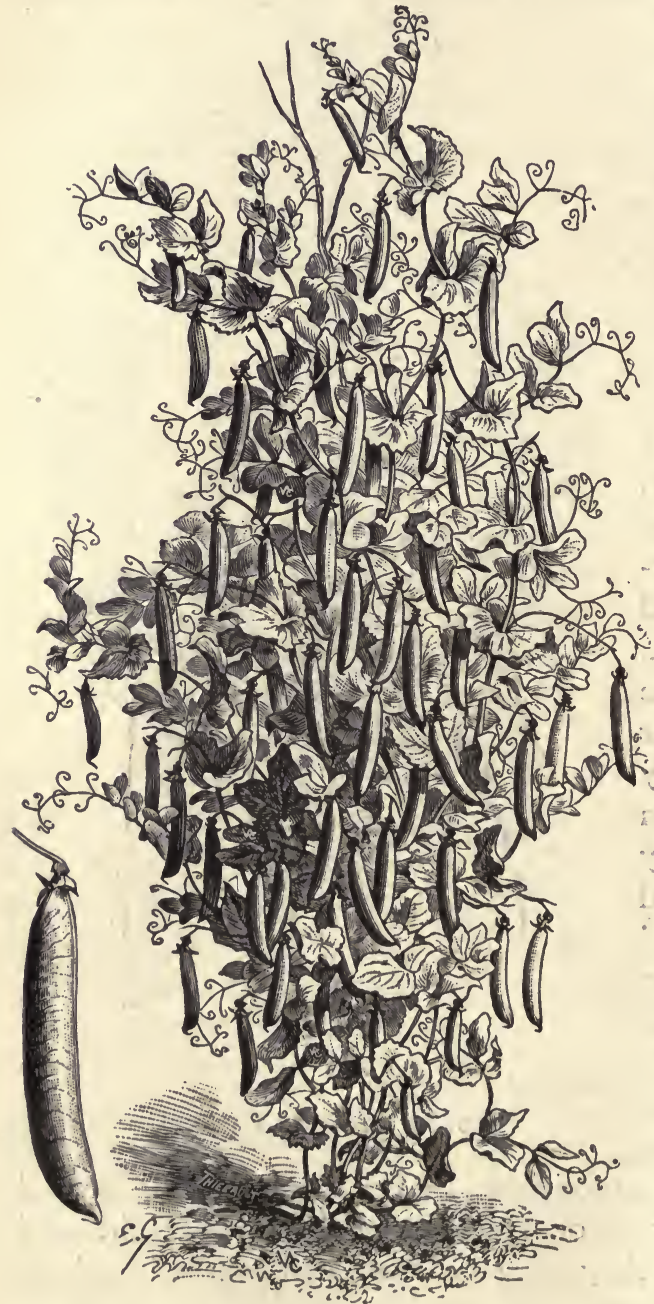

Copyright, V. A. \& Co.

Gradus Pea.
When grown extensively they are a speculative crop, by reason on the one hand of uncertain weather conditions, especially when an attempt is made to get them very early in open field work, and on the other hand from the frequent gluts to which markets are subject during the few weeks whilst the bulk of the main-crop supplies are being poured in. Still, there is the fact that Peas will always. sell at some price, even if it is not a very remunerative. one; whilst on the: occasions when a good crop can be got: on the market early. the returns are very satisfactory.

The grower who works his ground, more or less intensively can to a large 
extent produce early crops with a measure of certainty and thus escape undue risks, though since his operations are on a comparatively small scale he misses the "scoops" which the extensive grower is sometimes fortunate enough to secure.

In any case, Peas should always be given a prominent place in the garden of any grower engaged in a general trade, both for their profit-making possibilities and for the important part they play in any well-arranged system of rotation and cultivation. They not only lend themselves admirably to intercropping, but the preparation of the soil necessary to the production of a good crop of Peas ensures its being left in capital condition for any crop which may follow, whilst since Peas collect and leave behind them nitrogenous matter in the soil, their occupation of it increases rather than decreases its fertility.

Soil.-Any ordinary soil which has received proper preparation will grow Peas fairly well. For the earliest crops a warm, dry, and rather sandy soil is to be preferred, though on heavier staples good early crops can be obtained by growing on ridges or on raised beds. For the main-crops light sandy soil is unsuitable, unless specially prepared, the ideal one being a rich and rather retentive loam, deeply worked and well drained. It is not desirable to apply heavy dressings of manure directly to the crop, as it would have a tendency to cause the Peas to run too much to leaf, the best conditions being secured when Peas follow a crop for which the

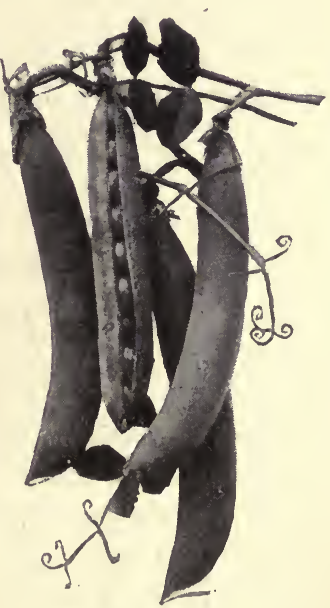

Copyright, s. \& s.

Gladstone Pea. soil was liberally manured, in which case all further plantfoods necessary would be best supplied by suitable concentrated fertilizers; but when the soil is in poor condition, free manuring is absolutely necessary to a good crop, though only old and well-decomposed manure should be used.

Preparation of the Land.-This should be taken in hand in autumn, when it should be ploughed or dug (bastard trenched 
if that operation has not been performed within the past three years) and left ridged up so that as much surface as possible will be exposed, to be pulverised and sweetened by the frost. When Peas are to be sown between rows of standing crops, such as cabbages, the space allotted to them should be ploughed or forked over so that the soil will become sweet and crumbly against seeding time. Lime in the soil is essential to the healthy growth of Peas, and where this is lacking or is present in insufficient quantity it should be spread on the surface as soon as the soil is turned over, at the rate of from 3 to 5 tons. per acre.

Sowing in Pots.-Where there is convenience for the work the best and most certain way to secure early crops is to start the Peas in pots in frames, and thus be in a position to set out strong well-hardened plants in the latter part of March or early in April. By this means a crop is assured which will, as a rule, be ready for gathering from ten to fifteen days in advance of any sown in the open-air. To do this, fill some hundreds of large 60 's (3in.) pots half full of soil, then on this put eight or ten seeds, fill up to within $\frac{1}{2}$ in. of the top with more soil, and water well. This work can be done either early in November or at the beginning of January, according to whether the pots are to be stood in a cold frame or on a gentle hot-bed. There is no better way of raising them than in a cold frame, where they make fine sturdy plants by the time they are wanted, without expense or trouble beyond an occasional covering with mats during a severe spell of weather, and judicious ventilation on all fine days. When they are sown in January the heat in the bed should not exceed 50 degrees, which will gradually decline with their growth until they will be standing on a cold bed before planting-out time arrives. The pots should be stood close together and within 6 or 8 inches of the glass. Be careful not to have the bed too warm, or the Peas will grow weakly and bloom badly; they should be grown slowly and steadily, with all the light and air possible, and strong, vigorous plants will then be the result.

The plants should be set out during mild weather any time after the middle of March. Make a shallow trench and turn out each potful without disturbing the roots, placing them 
about 9in. apart. After planting, put a few short feathery sticks along each side of the row, and give them a mulch of short old manure.

Sowing in the Open-air.-The first sowing in the open-air may take place any time from the beginning of November to the beginning of March, providing the soil is suitable and in proper condition, but it is probable that if some of the same kind of Pea was sown on both these dates there would not be more than ten days' difference in the time of gathering the first pods, and very little difference at all between those sown in November and a similar lot sown in January or February. Even sowings made on the latter dates cannot always be relied upon unless both situation and weather are favourable, to say nothing of the chances of destruction by birds or mice. Successful results from very early sowings in the open may be looked for with some degree of confidence where there is light soil in a warm sheltered position, but in other situations, and particularly on stiff soil, it is best to defer the first sowing until the latter part of February or the beginning of March. In any case it is always unwise to sow when the soil is cold and wet, as under such conditions there is the probability of a weak plant if not a complete failure. To overcome this difficulty it is the practice with many gardeners, when making the earliest sowings, to draw out the drills in the forenoon and leave them open until the afternoon, so that the soil in them may become drier and warmer, the seed being sown and covered up before work is finished for the day. Later in the season, if the soil should be very dry, the drills should be well soaked with water, as a soil which is too dry is as bad as one which is too wet. The drills should in no case be less than 3in. deep. When sowing is done in the autumn or very early spring months plenty of seed should be used to provide against the numerous losses which such early sowings are subject to, but later in the season it is best to sow thinly, so as to allow room for each plant to grow vigorously, which is impossible when a mass of plants are growing thickly together, choking and weakening each other in the struggle for existence. When the plants come up too thickly they should be thinned so that they stand from $2 \mathrm{in}$. to $3 \mathrm{in}$. apart. 
Intercropping.-The question of whether or no the Peas are to be intercropped must be decided before the distances apart at which the rows are to stand can be settled. In open field culture, where large breadths are sown, the ground is usually occupied for the time being by the Peas only, and in such cases the rows are from $12 \mathrm{in}$. to $18 \mathrm{in}$. apart, according to individual preference, the greater distance being the best. In more limited undertakings, however, intercropping is often practised, to the advantage of the grower, for he not only makes a greater use of his ground whilst the Peas are in the early stages, but the Peas themselves benefit and crop heavier by standing ultimately at a greater distance between the rows than would otherwise be the case. As a rule the early varieties are allowed from $2 \mathrm{ft}$. to $3 \mathrm{ft}$. $6 \mathrm{in}$. between the rows, according to the vigour of the sorts and the kind of intercropping intended. In these spaces lettuces, spinach, turnips, or radishes are grown. Later sorts are planted from $3 \mathrm{ft}$. to $4 \mathrm{ft}$. apart, the spaces between being usually filled with cauliflowers. Sometimes the main-crop sowings are made between rows of spring cabbage, and thus get the advantage of a certain amount of protection from cold winds and late frosts, but in this case the cabbage must, of necessity, be cleared early or more harm than good will probably result. Where tall-growing Peas are grown they are allowed more room still, from $6 \mathrm{ft}$. to $8 \mathrm{ft}$. between the rows being customary, with a bed of other vegetables between.

Succession.-A regular succession of fresh plump pods is of great importance, particularly where a general business is done. To secure this there should be frequent sowings from March to June. Prior to March frequent sowings will not accomplish the object aimed at, the best way to obtain a succession from earlier sowings being to put in seed of early, mid-season, and late varieties about the same time, and they usually bear in succession. From April to June a good plan is to make another sowing when the preceding one is just showing through the ground. For the last sowings, made in the first or at the very latest in the second week of June, first or second early varieties are generally used, because when grown under identical conditions they come into bearing quicker than maincrop or late varieties. The following are the approximate 
dates of sowing and gathering, but it must be understood that the period of bearing is largely under the influence of the weather and that the wrinkled sorts are more tender than the round:- First early varieties, raised in cold or warm frames, sown in November or January, should be fit to gather from the 15 th to the 31st of May; if sown in the open ground on same dates, from the 21 st of May to the 14th of June. Second early varieties, sown from beginning of February to beginning of March should be fit to gather from the 10th to the 21st of June. Main-crop varieties, sown from middle of February to middle of March are ready from the 14th of June to the 14th of July. Main-crop and late varieties, sown from middle of March to end of April, come ready from July 14th to August 31st. First and second early varieties, sown again from the beginning of May to the middle of June should be fit to gather from the 1st of August to end of September, or later, but it must be remembered that these late crops are very uncertain, being subject to mildew, particularly in dry weather; this may be counteracted to some extent, though not entirely, by copious waterings.

It may be mentioned that some growers make a practice of pinching out the tops of the more vigorous-growing early varieties as soon as they show bloom, and by this means keep the plants shorter and hasten podding by several days.

Mice and Sparrows.-Mice are frequently very destructive to Peas in the open ground, especially to those sown in the winter and early spring months. A customary way to prevent attacks is to moisten the Peas in water and then to stir them about in red lead until all are thoroughly coated with it, afterwards allowing them to dry for two or three hours before sowing. Another method of protecting the seeds is to cover them with petroleum, allowing them to remain in it for ten or fifteen minutes.

As soon as the plants are up they should have an occasional slight dusting with lime and soot whilst they are wet with dew. This will make them distaseful to sparrows and slugs, besides being beneficial in assisting growth. Care must be taken that these dustings are really light and evenly spread; if put on heavily and carelessly growth will be checked and more harm than good will be done. Other birds may occasionally attack 
the young pea plants but sparrows are by far the worst culprits, and will sometimes work havoc in spite of the dustings. In this case the best preventative is to cover the rows with fish netting, laid over bent sticks and pegged down at the sides. The plants are generally safe from the time they are a few inches high until peas begin to form in the pods, when the birds again become troublesome, and sparrows again generally do the most damage. When this happens lines should be stretched along the rows, to which are attached at intervals various bright objects, such as white feathers, pieces of tin, or strips of paper which, being kept in motion by the slightest wind, often prove an effective bird scare. Of course these measures only apply to Pea culture on comparatively small areas; in field work a boy is employed to scare the birds when necessary. When sparrows are particularly mischievous and numerous serious measures should be taken during the winter to reduce their numbers.

Sticking.-Peas in market gardens are usually grown without sticks, the haulm being allowed to rest upon the ground. For this reason the tall-growing sorts are never employed in field work. At the same time, where the grower does a private trade and depends more upon a moderate quantity in constant succession throughout the season than upon a large quantity for a short period, he will find it to his advantage to use sticks (when they can be got cheaply), because then the pods are finer and the Peas bear a better crop. The dwarf varieties do well and crop abundantly without any support, but even these do all the better for having a little feathery stuff placed along the rows to keep them off the ground. The sticks should be placed to the rows soon after they are through the soil. They are usually inserted in the ground about 6in. away from the Peas, about $1 \mathrm{ft}$. apart, inclined at an angle of 45 degrees, each side being inclined in a reverse direction, and each row parallel. Small stuff, cut from the tops of the longest sticks, is inserted in the gaps at the base of the sticks to help the young plants to climb upwards. Before putting in the sticks hoe the ground well and then draw the loose soil, 3in. deep, to the stems of the plants on each side of the row. When the haulm grows long, and no sticks are used, it is laid over on one side of the 
row; in this way the flowers, by getting more light and air, set better and so are more productive, and the pods can be more easily gathered.

General Culture.-As soon as the rows of Peas can be seen, the ground should be hoed, and afterwards kept well stirred throughout the growing season. In field work a horse-hoe is run between the rows, the work being finished by hand-hoeing close to the base of the plants. This work must be persisted in whilst the plants are young, as the time soon comes when the close rows in the fields can no longer be hoed without damaging them. It must not be forgotten that frequent cultivation of the surface soil, especially in the early stages of the plants' growth, has a very beneficial effect on the ultimate crop, both by reason of aeration making the soil warmer and so increasing the activity of the nitrogen-collecting bacteria, and by the fact that a loose surface soil acts as a mulch and checks the evaporation of soil moisture, thus being a great help to the plants in a dry season.

Watering and Mulching.-Abundant moisture is absolutely essential to the production of a satisfactory crop of Peas. This is the reason why a well-worked retentive loam containing plenty of humus is more suitable to their culture than is a lighter staple. In a dry season Peas on soil that has been moved deeply will continue to flourish, even if they receive no further help beyond frequent surface stirrings, whereas under the same conditions on poor shallow soil they would be a failure. But even on the best soil, when a heavy crop is being formed, a good soaking with water, followed by a mulch of manure on each side of the row, is of the greatest possible benefit.

Gathering.-As the pods approach maturity they must be carefully watched. They swell rapidly towards the end and must be gathered as soon as large enough, whilst still young. When once begun, the gatherings should be made every two or three days, so that none of the pods become too old, and this not only ensures more valuable produce which commands better prices in the markets, but invariably results in a heavier crop, because the period of production is then prolonged beyond what it would be if the pods were allowed to ripen on the plants. Different varieties should not be mixed together, 
and where a good class trade is done it is sometimes advisable to divide the pods of one variety into two grades. It is the custom in many places where Peas are grown in large breadths to defer gathering until the bulk of the crop appears ready, then a large number of "pickers"-principally women and children-are turned into the fields, who clear the ground as they go. A handful of haulms are pulled up by the roots, and being held in the left hand, roots upwards, are stripped of the pods with the right hand. This appears a wasteful method, but it results in a large saving in the labour bill and the ground becomes much sooner available for other crops. The haulm is cured on the ground as it lies, and then is carted away and made into stacks of " pea straw," which when cut into chaff and mixed with other materials is a valuable food for cattle.

Manures :-For a good crop of Peas it is essential that the soil contains an abundance of plant foods, but it should not be overloaded with manure or the crop will be likely to run to leaf instead of pods. When a good dressing of manure has been given to the preceding crop, very satisfactory results can be obtained from concentrated fertilizers alone, and in any case manure alone should not be relied on, as a better crop is obtained when it is supplemented with fertilizers. When manure it given to this crop it should be at the rate of about 10 tons per acre on heavy soils up to from 15 to 20 tons on thin sandy soils. This should be applied, if possible, in the autumn, remembering that the nearer the time of sowing the greater the necessity that it should be in a thoroughly decayed condition. The next point is to ensure that sufficient lime is present in the soil. This may be readily ascertained by applying the simple test given on page 52. When lime is needed it may be given in the form of quicklime, either ground or in the lump, in quantities varying from 1 to 2 tons per acre, or as ground limestone or chalk at from 2 to 4 tons per acre. Fertilizers to supplement the manure must contain phosphoric acid and potash, with nitrogen in the spring if growth appears backward. For heavy soil this may be given in the form of $5 \mathrm{cwt}$. basic slag evenly distributed over the surface in the autumn, and 1 cwt. sulphate of potash similarly applied soon after the turn of the year. For light land give from 3 to 5 cwt. kainit in the 
autumn and 3 cwt. superphosphate just before sowing. When no manure is given these quantities may be increased by onehalf, and if the soil is in poor condition they may be doubled, and $1 \mathrm{cwt}$. each of nitrate of soda and sulphate of ammonia given in two separate dressings with an interval of two or three weeks, the first being given when the plants have made three or four inches of growth. These nitrogenous fertilizers must, however, be used with judgment, and only when they appear necessary, or the plants will make a rank soft growth which is not conducive to pod-bearing.

Varieties :-The following are excellent amongst many others equally good:-First early (round) : Ameer, 2ft. 6in., Bountiful, 2ft. 6in., William I, 2ft. 6in.; (wrinkled): Chelsea Gem, 1ft., William Hurst, 1ft., Little Marvel, 2ft., Pioneer, 1ft. 6in., Early Giant, 3ft., Sutton's Seedling, 1ft. 6in. Second early: Gradus, $3 \mathrm{ft}$., Daisy, 2ft., King Edward, 2ft. 6in., Senator, 2ft. 6in., Stratagem, 2ft., Sutton's Superlative, 3ft. Main-crop: Yorkshire Hero, 3ft., Duke of Albany, 3ft. 6in., Alderman, 5ft., Sutton's Magnum Bonum, 3ft. 6in., Eureka, 3ft., Quite Content, 5ft., Sutton's Matchless Marrowfat, 4ft. Late: Gladstone, 4ft., Autocrat, 3ft., Late Queen, 3ft. 6in., Glory of Devon, 3ft.6in.

\section{POTATOES.}

\section{Solanum tuberosum.}

$\mathrm{T}$ would be a waste of time and space to dwell upon the importance of the Potato, either as an article of food or as regards its place in the garden. Of all cultivated vegetables it is in the greatest demand, and as a consequence enormous areas are devoted to its cultivation. It can be grown more or less profitably on many diverse soils. It is especially suitable as a cleansing crop for newly broken-up land, especially when such land is foul with weeds. The Potato crop forms an essential part of any well-considered system of market garden rotation, the cultivation and manuring necessary forming one of the best preparations for any other crop which may follow. Finally, the demand for Potatoes is constant and unfailing, and as they are ready for use immediately they are lifted, or can be stored and disposed of at any time until the new crop comes round 
again, few market growers can afford to neglect their culturecertainly not those who cater for a direct trade.

Soil and Situation.-Abundant crops of Potatoes can be grown on almost any soil which has received adequate preparation, but its character has a great influence on the quality of the tubers,- -those grown on retentive staples, such as peat or bog lands or heavy clays, being generally of an inferior flavour or of a soapy or waxy character,-though much depends upon the weather, and in a dry season such soils will often produce crops which leave little to be desired. Damp, badly drained, or low-lying land should be avoided, as although such situations may be productive of good and sound crops when the summer is hot and dry, they are always the first to be attacked by fungoid disease in an average season and seldom escape it when the summer is wet, besides being very liable to serious damage from late spring frosts. Situations which are very confined or overhung by large trees are also unsuitable, as the stagnant atmosphere and the damp from dripping trees, which the sun and wind never get the chance to thoroughly dry, keeps the foliage very soft and, especially in a wet season, makes them very susceptible to fungoid attacks.

The ideal conditions for producing heavy crops of good sound Potatoes are an open, sunny, slightly elevated situation and a deep, well-drained, medium soil, neither a decided clay nor sand; at the same time the fact cannot be overlooked that excellent crops are often taken off well-worked clays, poor sandy soils, thin chalky soils, and newly-reclaimed bog lands. In fact, a friable clay soil will so frequently produce crops good both in quantity and quality that the only serious objection to its more extensive use for Potato culture is that its condition depends too much upon the state of the weather, as it often becomes practically unworkable in wet periods, both at planting and harvesting times, whilst if it is poached about when wet it sets so hard when dry as to be impossible of proper summer cultivation and is very difficult to work when the time has arrived for the crop to be lifted.

Preparation of the Soil.- The site selected should be open and fully exposed to the sun and, as an aid in the prevention of disease as well as contributing to a better crop, it should be 
one on which Potatoes were not grown the previous season. The best preliminary preparation is deep working, and for all but the very lightest soils this should generally be done in the autumn, leaving it ridged up so that frost, air, and rain can penetrate and sweeten it. In field work this will, of course, be done with the plough, but in gardens it is accomplished by digging, and once in every three, or at most four, years this should take the form of bastard-trenching (as described on pages 11 to 13); the ridges should run, as nearly as possible, due north and south, so that the sunlight may fall equally on both sides of the rows. The autumn, too, is the best time to apply manure to most soils, especially when it is not much decayed. There are, however, some light soils facing south or south-west, on which the culture of early Potatoes can be carried on profitably, and on these it is better to apply the manure in the spring. The land should be ploughed in the autumn and left ridged up, then after spring cultivation furrows are struck out with a plough fitted with a double mould-board, and well-rotted manure is spread evenly along these previous to laying in the sets. A suitable mixture of fertilizers is also given at the same time, before the ridges are split, either on the manure in the furrows or broadcasted over the whole area. There are also some districts which are subjected to a heavy rainfall where it is found easier to bring the soil more quickly to a fine tilth early in the spring if not broken up until wanted, and in this case also when manure is required it is given at the time of planting. Whatever the nature of the soil may be, it should be worked about as soon as the surface is sufficiently dry to bear cultivation after the beginning of March, and this working should be repeated, if necessary, until the surface is brought to a fine tilth for a good depth.

The "Seed" and its Preparation.-The first point to decide in connection with the seed is the variety to be grown. This matter must be left to the judgment of the grower, because the number of sorts in commerce is now so large, and the success of different sorts in different districts is so variable, that it is a matter of impossibility to give a selection which would do well under all circumstances; moreover, all are subject to a process of natural deterioration, and a variety 
which fulfils every requirement may, after the lapse of a few years, be found quite disappointing. This decadence varies very much with different sorts, some passing their best very quickly whilst others appear to be equally good after quite a number of years, but all the same the tendency is present, and no grower should pin his faith blindly to certain sorts, but should experiment with others, if only in a small way, so that they may have tried sorts to fall back upon when their favourites disappoint them. A grower commencing in a new district will find it to his advantage to make enquiries from his neighbours as to the sorts which do the best, and should follow their advice until he has acquired experience for himself.

Having decided on the variety, the next matter for consideration is the district from where the seed is to be procured. This is of great importance, as a change of seed at frequent intervals often results in a decided improvement both in the bulk of the crop and of its quality. Many growers too often neglect this point, and for the sake of a fictitious cheapness either continue to use seed of their own growing or obtain it from a neighbouring grower. This is a "penny wise and pound foolish" policy. A change of seed should be made at least every third year, and it should be from a locality with an entirely different soil and climate. For many years past Scottish seed has been in high favour with many English growers, and Irish seed has now many advocates, both having been proved to give much better crops than seed saved in the southern parts of England. Quite as good results have, however, been obtained from seed procured from some of the more northerly English counties. The underlying principle appears to be that immature tubers grow stronger and give a better crop than those which are allowed to become fully ripened before they are lifted, and the shorter and cooler summers in the northerly parts of the kingdom provide automatically for such immaturity. Where a grower wishes, for some special reason, to save some of his own stock for seed the necessary immaturity could be secured by late planting, or by cutting off the haulms before the tubers are fully developed.

The next point to consider is the size of the sets. Here again we find many growers err by using "chats" for seed, 
either because they can be bought cheaply or because they are using seed of their own crop and all larger Potatoes have been sold off the place as "ware." Such small seed should never be used, as they necessarily produce weakly shoots and the resulting crop is smaller, both in bulk and in the size of the individual tubers, than when larger seed is used. Other growers sometimes use full-sized tubers for seed, but this also is a mistake, as unless several of the "eyes" are removed, which is obviously impossible when a large breadth is being planted, each tuber throws up a large number of shoots which tend to rob each other of light, air, and nutriment, and the usual result is a large crop of undersized tubers; besides which to use large-sized seed is wasteful, as a much greater weight is required to plant a given area than when medium-sized tubers are used. As the result of numerous experiments it has been conclusively proved that the best results are obtained from whole tubers weighing between 2 and $3 \mathrm{oz}$. each, which will pass through a riddle with a $2 \mathrm{in}$. mesh, but not through one of $1 \frac{1}{2} \mathrm{in}$. As to cutting large tubers, this practice is not advisable except when seed of the proper size cannot be got, or where the seed has run out and it is desired to finish a row. When tubers are divided it is a good plan to dip the cut portion in air-slaked lime, to prevent an undue loss of sap.

Boxing and Sprouting.- There are numerous ways of storing seed Potatoes through the winter, all of which to be effective must provide for the exclusion of frost and damp. The worst way is to allow the tubers to remain in an ordinary out-door clamp until planting time, with the usual accompaniment of sweating, disease, and premature growth-often into a tangled mass of shoots which have to be removed before planting, with the result that the seed is much weakened, to the ultimate detriment of the crop. The best and most up-to-date method is to sort out the seed as soon as it is dry after lifting and place it directly into boxes or trays; but whilst this has much to recommend it, and may be considered indispensable for the early crops, it is a rather serious business when large areas have to be planted, particularly when the amount of frost-proof storage space is limited. As a matter of fact excellent crops can be grown from seed carefully kept in store in a dry cool 
place, without any preliminary preparation whatever, either of sprouting or disbudding, and as Potato growing on anything like an extensive scale is never other than laborious and costly, it is important that the grower should in times of pressure be in a position to decide as to which operations are essential to a profitable result and which are optional. At the same

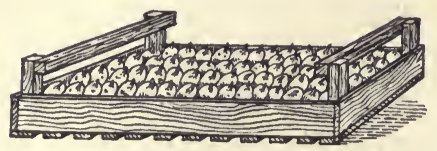

Potatoes Sprouting in Tray. time there is no doubt whatever as to the great value of boxing and sprouting seed Potatoes. The tubers are stood "rose" end (that is, the end containing most eyes and opposite to the end which was attached to the root) upward, close together in rows across the tray until it is quite full. The trays are then stood one above another in any cool, light, airy place where they are safe from frost, such as a loft, barn, or shed. Wood for making these trays, cut into lengths and ready for nailing together, can be obtained from most box makers, or the trays will be supplied ready-made at from $7 \mathrm{~d}$. to $8 \mathrm{~d}$. each. This is for one measuring $2 \mathrm{ft}$. $6 \mathrm{in}$. long, $1 \mathrm{ft}$. $6 \mathrm{in}$. wide, and $3 \frac{1}{2} \mathrm{in}$. deep, with corner-posts standing up 3 in. above the sides. When stood above each other a large quantity of the trays can be stored in a small space, whilst a free circulation of air throughout the entire mass is ensured. These conditions keep disease at bay and prevent premature growth, so that when planting time arrives the tubers are plump and sound, with one or more dark-coloured

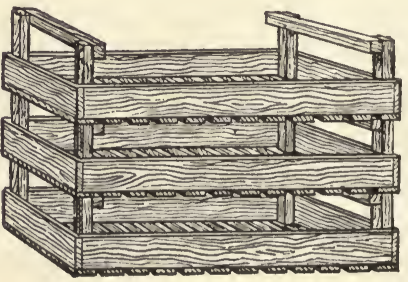

Potato Trays, stacked one above another. sturdy shoots. When thus stored they should be looked over occasionally, especially after the turn of the year, and if the sprouting appears to be pushing too rapidly move the trays into a position where they will get more light and air, but if they appear too backward arrange for the surrounding atmosphere to be kept slightly warmer; the 
proper condition of the sprout at planting time is clearly shown in the illustration below. When several shoots rise from the same tuber, all but one or two of the strongest should be rubbed off. The seed should be carried in the trays to the field, and carefully placed in the furrows without breaking off the shoots, or all the care and trouble spent upon them will be thrown away. The advantages gained by sprouting are threefold. A few weeks' growth is secured before the seed is planted, and the crop from sprouted seed is thereby ready for lifting several weeks earlier than that from seed which is unsprouted. When at planting time the soil is wet and cold that operation can be deferred until the conditions are more favourable and yet no time is lost because growth is still proceeding; this is a great advantage where the soil is of a

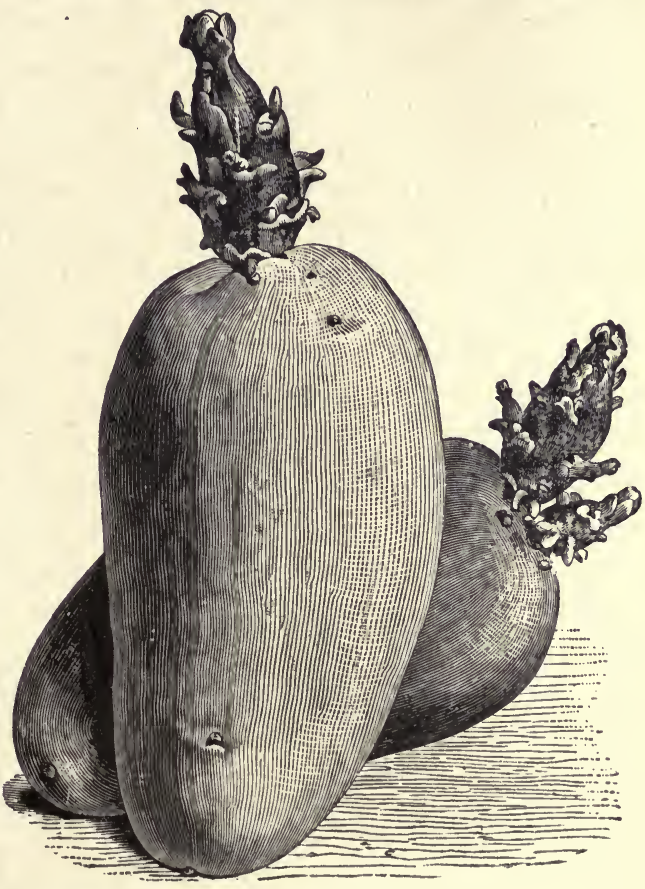

Copyright, V.A. \& Co. heavy nature. And it has been proved by a number of experiments that plants from sprouted seed continue more vigorous throughout the season and ultimately yield a crop noticeably heavier than that from unsprouted seed, amounting in some cases to an increase of 25 per cent.

Distances apart and Depth for Planting.-The distances apart at which the sets are planted depends upon the variety, their natural vigour of growth, and the richness of the soil. In favoured spots, where soil, situation, and climate conduce 
to the production of very early supplies, sprouted seed is planted in rows about $18 \mathrm{in}$. apart by $9 \mathrm{in}$. to $1 \mathrm{ft}$. apart in the rows, but this is exceptionally close and only suited to shorttopped varieties which are to be lifted before the tubers are fully grown. As a general rule first earlies should be $1 \mathrm{ft}$. $9 \mathrm{in}$. to $2 \mathrm{ft}$. by $9 \mathrm{in}$. to $12 \mathrm{in}$. apart, second earlies $2 \mathrm{ft}$. $3 \mathrm{in}$. to $2 \mathrm{ft}$. $6 \mathrm{in}$. by $12 \mathrm{in}$. to $16 \mathrm{in}$. apart, and main-crop and late varieties from $2 \mathrm{ft}$. $6 \mathrm{in}$. to $3 \mathrm{ft}$. by $14 \mathrm{in}$. to $18 \mathrm{in}$. apart. In no case ought the sets to be covered with more than 4 in. of soil (apart from that which is added in earthing-up) and for early sorts about $3 \mathrm{in}$. is sufficient, because then the roots are more under the influence of the sun's warmth. The distance between the sets is a matter of great importance, for if the crop is overcrowded the majority of the tubers will be small, whilst on the other hand if the spaces are wider than necessary the total crop will be less than it might have been. The ruling principle should be to allow every plant ample room to spread, with a sufficiency of air and sunshine. With overcrowding, the haulm grows into a tangled mass and being weakly from want of air is weighed down to the earth in heavy rains. There is thus a constantly damp and stagnant atmosphere below the surface of the foliage, in which fungoid disease finds congenial surroundings and soon runs rampant. It is always safer to allow too much rather than too little space, and the rows should run north and south, so that the sun can have full effect on both sides of the rows, in warming the soil, drying and strengthening the foliage, and invigorating the whole plant, keeping it more resistant to disease, and thus making a large contribution towards a heavy crop of sound tubers. It is no exaggeration to say that, other conditions being satisfactory, the abundance and healthiness of the Potato crop is, in the climate of the British Isles, dependent upon the amount of direct sunlight each plant receives.

Planting and General Culture.-The time of planting varies with the district and the condition of the soil. In favoured places with a kindly soil planting is commenced in the middle of March, whilst in others, when the circumstances have been unfavourable, it is often deferred until as late as the middle of May. All things considered, for ordinary culture the first week in April is quite soon enough, and a week or two later than 
this is better still in a district subject to late spring frosts. Amongst old gardeners it is a maxim in ordinary open-air culture to "plant late Potatoes early and early Potatoes late," and contradictory as this may appear it is sound advice and based upon the results of experience. Early varieties, being more precocious in growth than late ones, and being usually planted in the kindliest soil and most favourable situation, are in comparison much more quickly through the ground, and if planted early are more liable to be cut down by late frosts, unless given some kind of protection.

The methods of planting vary according to the locality, the extent of the area under cultivation, the nature of the land, and the kind of Potatoes grown. These may be classified into three systems - the Ridge, the Flat, and the Lazy-bed.

The Ridge System.-The system of planting in ridges is the most generally practised, either in garden or field, and is the one most likely to give satisfaction. In ordinary field culture, when the soil has been brought into suitable condition, furrows are made with a double-breasted plough and wellrotted manure, if that is the time chosen for applying it, is spread in the furrows. Women and girls or boys then drop the seed at the required distance apart and another plough follows which splits the ridges and throws the soil over the seed in the furrows on either side. When all are covered the seed lies under the ridges and the furrows now are where the ridges stood before. The work is then finished by rolling. On weedy land harrowing with a saddle-back harrow is beneficial both before and after the plants show through the ground. As soon as the foliage shows plainly a horse-hoe is run between the rows and hoeing by hand follows. If there is any fear of frost soil should be lightly drawn over the tops at the same time. Hoeing is repeated if the state of the ground requires it, as weeds must be kept down and the soil maintained in a loose condition. When the haulms are about half grown earthing-up is done with a double-breasted plough. Too much earth must not be given, 6in. in depth being ample; if more than this is given it will probably cause a decrease in the crop. Frequent and thorough stirring of the soil until earthing-up is necessary is always beneficial. Many growers complete the 
process of earthing-up gradually, in several operations, going a little deeper each time, and by this meaus destroy weeds and prevent the earth from getting caked on the sides of the ridges. In Lincolnshire and other districts where the soil is easy to work, some growers favour the practice of covering the sets with large Potato hoes or Canterbury hoes, instead of the the moulding plough. Two men work on opposite sides of a row, and each pulls sufficient earth over the sets to keep them moist. The work is done by the piece and proceeds rapidly, as the men take a stroke with each stride. As the shoot is appearing the work is repeated, this time sufficient earth being drawn to the plants to mould them up. By this system hoeing is rendered unnecessary and trampling by horses avoided. Its cost differs very little from that of the usual methods employed. In any case, it is essential that all such work between the rows is completed early in the season. As soon as the tops are likely to be bruised, work amongst them must stop.

Some of the earliest open-air crops of Potatoes are grown in localities where the ameliorating in luence of the sea is felt, and severe or inopportune frosts are rarely experienced, such as the west coast of England and Scotland, the southwest of Ireland, and the island of Jersey. Districts farther away from the sea, although they may have greater sun-heat, are very liable to sharp frosts in the nights of May, and sometimes early in June, when early crops are partially or even completely destroyed, and sometimes even the second earlies do not escape serious damage. In some of districts in Scotland suited to the production of early crops a system is followed which enables the grower to take two crops of Potatoes from the same field in one season. The land having been well prepared, a heavy dressing of short manure is put in the furrows, and on this well-sprouted sets are laid and the ridges split to cover them, about the beginning of March. As soon as the trays are emptied of the early variety they are again filled with maincrop sets, which are sprouting while the earlies are growing. The first crop is lifted by the end of May, whilst prices are high, and the ground is at once ploughed again into ridge and furrow, care being taken that the furrows are this time exactly between where two rows of Potatoes stood before. These 
furrows are then dressed with manure on which sprouted sets are placed as before and the soil split over them. Planted in this way they are practically on fresh soil. The plants are quickly through and in a few weeks appear quite as forward as unsprouted sets which were laid in at the usual time. Although there are heavy expenses for manure and labour in connection with this system it is said to be very profitable, and might be tried in other districts not liable to late frosts.

The Flat System.--Planting on the flat is mostly followed on light land which is apt to dry out quickly if laid in ridges. The land is previously manured and brought to a good tilth, and the rows are marked out at the required distance apart. Shallow holes are then dug along the first line, one for each set, which another person following drops in the holes. The soil from the second row of holes is used to cover up the sets in the first row, and so on to the end of the plot. An active man can in this manner spade-in an acre of potatoes in a day. Dibbling-in is performed in a somewhat similar fashion except that holes, about $4 \mathrm{in}$. deep, are made with a Potato dibber and the sets are covered by hoeing. This method is only suitable for very light soils, or such as are in a good freeworking condition, otherwise the pressure required to make a hole with the dibber so compacts the soil surrounding the set that the roots are unable to run freely, to the detriment of the crop. When planting is done on the flat the spading-in method will be found the best. After cultivation consists of hoeing and gradual moulding-up.

The LAZY-Bed System.-This system is useful on soil where the water level is near the surface, such as newly-reclaimed bog land. It consists in making beds $4 \mathrm{ft}$. to $5 \mathrm{ft}$. in width with deep trenches between, which serve to drain away superfluous moisture. The sets are placed on the surface, one row at each side of the bed. Soil is taken from between the beds to cover the sets and again to earth up the plants, and in this way the trench is formed. The system appears to serve the particular purpose for which it is intended very well, and is in common use in the west of Ireland where, however, probably from the force of habit, it is also frequently met with on soils where it serves no particular purpose and where other methods might 
be substituted with advantage; no doubt, under the beneficent guidance of the Irish Board of Agriculture this change will soon take place. It is difficult to understand why the system should be given such an objectionable title, except that it is frequently associated with slovenly farming; at all events, there is nothing "lazy" about it when properly carried out.

Early Potatoes in the Garden.-Particulars of the field culture of early Potatoes have already been given, but smaller lots of extra early tubers may be produced in the garden in various ways, none of which present much difficulty. The first essential thing is to secure some good sound seed of an early variety, and pack them closely in trays, one layer deep, as described on pages 269 to 271 . This should be done as soon after the beginning of January as possible, and the trays stood in full daylight in a cool place, but quite safe from frost. Here by the time they are wanted each will make a number of short stout shoots, all of which except two of the strongest should be rubbed off before planting. Next, select a piece of ground in a sheltered position, which lies dry and is inclined to the south or south-west, and fork this up lightly, having previously spread over it thoroughly decayed manure, about $2 \mathrm{in}$. thick. Then prepare a heap of compost, using about one-half decayed manure and making up the other half with the residue from rubbish fires, decayed vegetable rubbish, road sweepings, or any similar lightening material. About the middle of February draw the ground up into ridges about $8 \mathrm{in}$. high and 20in. apart; this will cause the soil to lie drier and warmer than when lying flat. In the first week of March make a drill, 4in. deep, at the top of each ridge, and lay $2 \mathrm{in}$. of compost at the bottom of each. Lay the sprouted sets on this, 10in. apart, cover them with $2 \mathrm{in}$. more compost, and then make the ridges trim and neat by drawing soil from the sides over the compost and forking over the ground again between the rows. As the tops begin to show draw a little fine earth over them; when frost threatens lay along the ridges a few inches of dry litter, which must be removed each morning. Or a light framework of laths can be fixed $1 \mathrm{ft}$. above the top of the ridges on which mats can be laid. The Potatoes should be ready for lifting by the middle of June. This arrangement can be modified, and considerable 
protection given to the Potatoes, by planting broad beans or early peas on every second, third, or fourth ridge.

Forcing in Frames.-Although the forcing of early Potatoes in frames has hitherto been relegated to the private gardener, it is by no means certain that the grower for market is not neglecting the opportunity for doing a profitable business. In the island of Guernsey many of the growers regularly crop their cold glasshouses with Potatoes during the winter and find it a profitable business, and although they have a great advantage over growers on the mainland in a comparative immunity from severe frosts, this is not a matter of the first importance when growing in frames, because frost can be excluded by the use of straw mats. The high prices which early Potatoes realise are sufficient to tempt French growers, who are now forcing them, and if they can find a satisfactory profit in the business it ought to be possible for us to do the same. The fact that some of our growers can now hold their own against imported early frame-grown salads is an argument in favour of extending the effort to frame-grown Potatoes.

The crop can be grown either on mild hot-beds or in cold frames; in the former case the tubers are ready for lifting in the early part of May, and in the latter about the end of May or the beginning of June. The shallow frames already fully described on pages 68 to 71 will serve admirably for this purpose if a $6 \mathrm{in}$. board is temporarily fixed round the bottom to increase their depth. The hot-bed is made in the second week of February, about $1 \mathrm{ft}$. thick, as described on pages 128 and 129 , then the frame is put on, and about 9in. compost, as described on the preceding page, is put inside. A few days afterwards, when the soil is warmed through, well-sprouted sets are planted $4 \mathrm{in}$. deep and $9 \mathrm{in}$. apart, this giving twenty-five to each light. The frames are kept closely covered with mats until the tops begin to show, when the mats are removed each morning but replaced each night. Ventilation is given daily, from an inch on rough cold days to three or four inches when the weather is mild, removing the lights altogether during the daytime as the weather becomes genial. When the haulms reach the glass, the frames are raised on a brick at each corner. If the tubers show through the soil or there is any 
danger of their becoming greened, another $2 \mathrm{in}$. of moist compost must be spread all over the surface. Great judgment is required in giving water; if the weather is wet or dull probably none will be required, whilst if it is dry and bright several waterings may be needed. In any case, every care must be taken to keep the soil nicely moist but not sodden. A light crop of radishes can be taken from between the rows whilst the Potatoes are growing. By the middle of May the frames will be available for growing cucumbers or vegetable marrows.

For cold-frame work, when the equipment of ordinary frames and lights is insufficient, two rows of parallel boards and any old but sound lights will answer very well (a detailed description of this method of constructing cold frames will be found on pages 132 and 133). Where lights are not available the frames alone, covered with mats each night, will produce crops earlier than when the beds are entirely in the open-air. For cold-frame work it is necessary to lay down a bed of rich compost, 9in. deep, on top of the ordinary soil, and to plant well sprouted sets at the beginning of March.

Spraying.-There is an ever-present enemy of the Potato crop which no up-to-date grower can afford to disregard-the Potato disease, Phytophthora infestans. The crop is subject to attack from several other fungoid diseases, but this one is the most to be feared, for whilst it is always present in some degree in various parts of the country, occasionally its ravages are very serious, few crops escaping altogether. At the same time, if the conditions of healthy growth, already indicated, are carefully observed and only good sound seed of vigorous varieties used, although immunity cannot be expected a long step will have been made in that direction. But beyond this, the careful grower ought to do everything that lies in his power to protect his crops from serious infection by systematically spraying the haulms with Bordeaux mixture, made according to the directions given in the section on Insect and Fungoid Pests. Where Potatoes are cultivated on large areas one of the modern implements designed especially for spraying this crop will naturally be taken advantage of, but for small places one or two ordinary knapsack machines will be found to fulfil all requirements. 
Lifting and Storing.--Lifting begins with early Potatoes, which are dug "green" for the early market as soon as the tubers have grown to a saleable size. They should be lifted with a broad-tined fork, as they are easily damaged and need careful handling. This work should be done on a fine dry day, when the soil is in a nice workable condition, as then the tubers turn out clean and bright, and are more readily saleable than when there is a lot of dirt adhering to them. Potatoes should not be lifted for storing until the haulm has died down, when they will be grown to their full size and have firm skins. When the crop is intended for seed purposes, a certain degree of immaturity is desirable, as already indicated, in which case the crop would be lifted whilst the tops are still green. Small crops are, of course, lifted with the fork, but on large areas Potato ploughs or Potato diggers are now extensively used for lifting the main crops. Unless the Potatoes are turning out clean and the weather is settled it is best not to lift more than can be dealt with each day, or the soil may get dried on to them; or rain may fall on them whilst lying on the newly-turned soil, and the task of collecting and cleaning them would then be made more difficult and disagreeable. When the tubers are coated with dirt, this is usually rubbed off with the hands before clamping. In wet weather or on heavy land the tubers are sometimes in such a dirty condition that it is necessary to wash them before they are presentable, in which case it is best to dispose of them without storing, as they do not keep well after being washed.

Women are usually employed for picking up the Potatoes, one collecting the "ware," or largest sound tubers, another the "seed," or middle sized ones, and a third the "chats" and "tail," in which is included all the smallest, as well as diseased and broken ones, which are usually reserved for pig feeding or disposed of locally. Any handy-sized baskets are used for collecting them, but some growers provide the women with a strong apron made of sacking, with a piece of strong netting in the middle to allow the dirt to pass through. When prices are good a portion of the crop is usually despatched to market direct from the field, in which case a weighing machine is kept close to the pickers and the ware is put into bags, weighed, 
tied, and labelled on the field.' In packing for market care should be taken to see that the tubers are clean, sound, and fairly even in size. When the size is very irregular it pays to grade them into two samples. The Potatoes not sold directly from the field are stored for disposal as opportunity and prices dictate. The seed is sometimes put into a clamp, or it may be stored in a dry cool shed, safe from frost. On some places where sprouting is made a feature, the seed is placed directly into sprouting trays on the field, and then needs no re-handling after being carted to the store.

The usual position for a Potato clamp is the headland of the field in which the crop grew, providing there is a gate conveniently near and a good road leading from it; such a position saves a lot of unnecessary carting. The ground on which the clamp is to stand should be, if possible, slightly higher than the

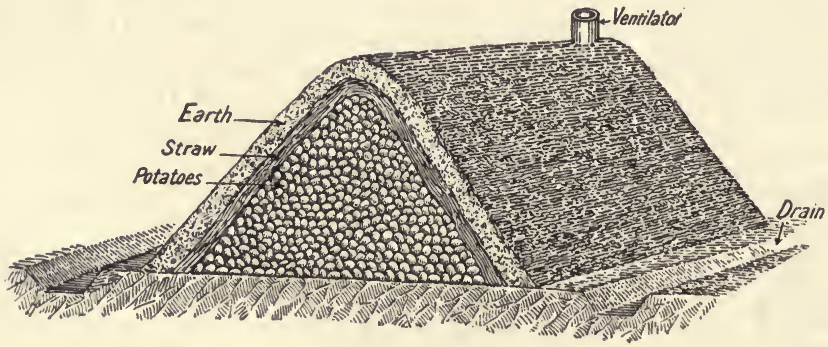

Section of Potato Clamp.

general level; in no case should it be lower, as the Potatoes must be kept dry, and the tendency should be for rain-water to run away from and not towards the clamp. Before clamping, the Potatoes must be fairly dry and all showing any trace of disease carefully picked out; when affected tubers are mixed with sound ones the disease often spreads through the whole. They are piled up in a long ridge-shaped heap, from $3 \mathrm{ft}$. to $5 \mathrm{ft}$. wide at the base, according to the quantity to be stored, the height being regulated by the width, as they are piled up as high as they will lie. They are then covered with straw, bracken, or other dry litter about $6 \mathrm{in}$. deep, and over the straw a 6 in. covering of soil is put in a trim and regular ridge form, the surface being made firm and smooth with the spade so that 
rain will run off. Soil for covering is taken from the ground outside the clamp, and in the operation a trench is cut all round to carry away water and so keep the contents dry. After the clamp is covered with earth, ventilating holes are cut through along the top of the ridge, about $6 \mathrm{ft}$. apart, and a tuft of straw is pulled through each hole and allowed to project, or a drain-pipe is inserted. In case of a spell of severe weather the ventilating holes should be closed to keep out frost, and as an additional safeguard when frost is very severe, it is advisable to put a covering of straw or litter over the clamp.

About the beginning of February, or earlier if there was much disease present when the crop was lifted, the clamp should be opened and the Potatoes examined. It will often be found that many are infected and that most have begun to make shoots. They are shovelled into a riddle, where they are turned over by hand and carefully examined; the shoots are rubbed off and the tubers showing disease are thrown out. If they are to be kept for a further period the clamp is re-made on the same site, gradually working through the old clamp and making a new one as the work proceeds. This opportunity is usually taken to send a portion of the stock to market. When the Potatoes were put into clamp without being properly graded, they are now sorted into different grades and clamped separately. The sorting is done either by passing them over hand riddles, each with a different sized mesh, or by employing a more elaborate device known as a Potato sorter, of which there are numerous variations in use. The shovel used is one fronted with a steel tip and backed with bars about in. apart, through which the dirt will fall.

Where there is enough room in good dry buildings, these may be used for storing the Potatoes in, instead of clamping, as the labour is less and they can be more conveniently got at in any condition of the weather. A good thickness of straw or litter should be put between the Potatoes and the outside walls and they should be well covered over the top to protect them from frost and to exclude light.

-Manures:-Much has been said and written at different times against applying manure directly to Potatoes, under the impression that it induces disease, but since it has been proved 
by experiment that excellent crops of good sound Potatoes can be grown in thoroughly decayed manure alone, it would seem that such advice is misleading. Well-decayed farmyard manure is the best practical means known for supplying to the soil the physical condition and the plant foods necessary to the production of an abundant crop of Potatoes, but it is not a perfect manure because it contains, proportionately, an insufficient quantity of phosphoric acid and potash, and these ingredients need supplementing, according to the nature of the soil, with suitable artificials. The mischief which sometimes arises in connection with its application to Potatoes is not from the quantity, but rather from the crude, rank condition in which it is given, often combined with overcrowding and with badly-drained land. Excessive moisture at the roots causes unhealthy growth, and when this is coupled with a damp and stagnant atmosphere in and around the foliage, the conditions are such as to foster the incubation and cause a rapid spread of the disease. Therefore, the primary conditions for heavy crops of sound Potatoes are (1) deeply worked and well drained soil, (2) ample space between rows and sets, and (3) liberal dressings of well-rotted farmyard manure. If the manure is not well decayed it must be turned under in the autumn; the nearer to the time of planting, the more thoroughly decayed it must be. Good crops can be grown without any manure on newly-broken old pasture land or on any other soil which contains an accumulated store of fertility, or on most ordinary soils with the aid of concentrated fertilizers only, but consideration will make it apparent that such a procedure is a temporary expedient, and that crops so obtained draw upon and reduce that store of fertility in the soil which it ought to be the aim and ambition of every "thorough" gardener continually to increase by every means in his power.

The average yield of Potatoes per acre throughout the whole of Great Britain is between 5 and 6 tons, but this, of course, includes the results from poor land and insufficient manuring. On better soil with more liberal treatment the yield often runs as high as 10 or 12 tons per acre over a large area. Under special conditions from 15 to 20 and more tons per acre have frequently been grown, but such yields are always the result of a thorough working of the soil accompanied by generous 
applications of manure, supplemented by such concentrated fertilizers as will make a perfect balance of the necessary plant foods.

Varieties:-There are now such a bewildering number of good varieties in cultivation that the task of selecting a few of the best is not an easy one. Moreover, no matter how carefully the selection may be made, the tendency to gradual deterioration and the constant introduction of new varieties will cause many of those in any list given now to be superseded after the lapse of a few years. The following is a selection of a few of the best in use at the present time. First earlies for forcing or close planting on a warm protected border: Early Ashleaf, Sutton's Ringleader, Sharp's Victor, Sutton's May Queen. First earlies for open-air culture: Sutton's A 1, May Queen. Gladiator, First Crop, Midlothian Early, Duke of York, Ninetyfold, Early Puritan. Second earlies (first division) : Sir John Llewelyn, Sharpe's Express, Myatt's Ashleaf, Dalmeny Early, Recorder, Early Rose, Early Regent; (second division): Nobleman, Dalmeny Acme, Duchess of Norfolk, Snowdrop, Pride of Tonbridge, Cigarette, British Queen. Main-crop (first division): Royal Kidney, Beauty of Hebron, Windsor Castle, Supreme, King Edward VII; (second division): Table Talk, Up-to-date, The Factor, Evergood, Scottish Triumph, Warrior, Peckover, Future Fame, Dalmeny Beauty, Dalmeny Hero, Webb's Goldfinder, Sutton's Superiative, Sutton's White City.

\section{RADISHES.}

\section{Raphanus sativus.}

THE Radish is one of the most useful and popular of salad crops. It is very simple of cultivation, quick to mature, and may be had without any great difficulty all the year round. It is useless now-a-days to grow big coarse Radishes, strong in flavour; what the public want are the crisp, tender, delicateflavoured ones, in regular succession, and the secret for getting these is by quick growth, making small sowings on rich moist soil at frequent intervals. Poor soil and that which has been recently dressed with rich manure should both be avoided, the 
former producing small, stringy roots, and the latter mostly leaves. The best soil for the purpose is a porous, easily-worked one, rich in humus from previous generous dressings of manure, and brought to a fine tilth. The ideal soil is one approximating

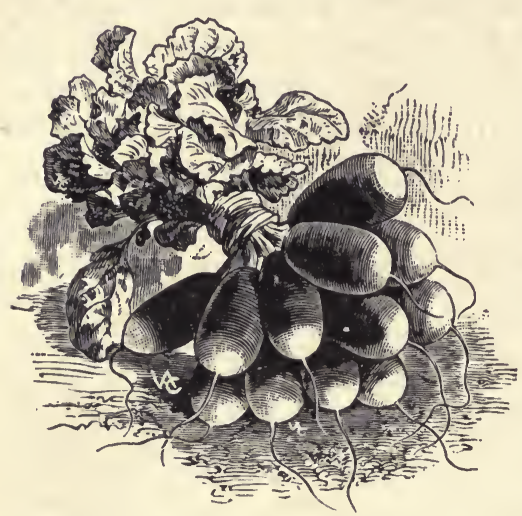

Copyright, V. A. \& Co.

French Breakfast Radish. closely to that used in the French garden, which consists entirely of well-broken and sifted manure from exhausted hot-beds. The seed should always be sown thinly and not be covered with more than $\frac{1}{2}$ in. of soil, made firm on the surface after sowing, as the roots do not bulb up well when the soil is too loose. Never allow Radishes to be short of water, and draw them immediately they are large enough for use.

Crops from Hot-Beds. - The earliest crops of Radishes are grown in frames on hot-beds. It is seldom that a frame is used exclusively for them, sufficient early supplies being usually taken when they are sown with other crops. In this way, owing to the quickness with which they form, a profitable catch-crop of Radishes can be had without in any way interfering with the more slowly-moving occupants of the frame. This method is described in detail on pages 93 and 94 , and can be easily applied to most crops grown early in frames, either warm or cold. A frequent mistake, however, in trying to grow early Radishes in this way is in sowing too thickly. This is fatal to success

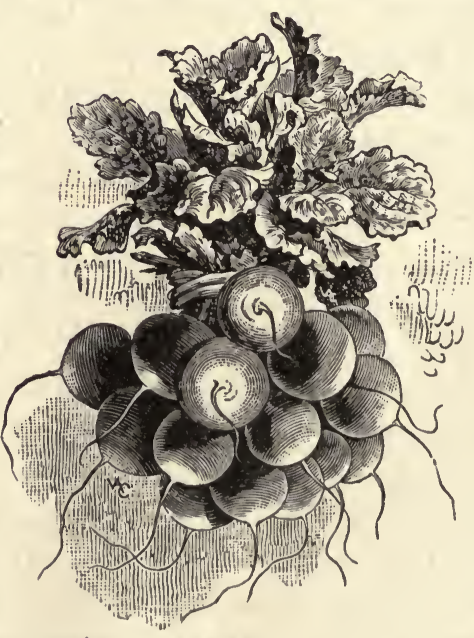

Copyright, V.A. \& Co.

Scarlet White-tipped Turnip Radish. 
as it is impossible for useful roots to form under such conditions, and the other occupants of the frame are injured by overcrowding. When grown with other crops, Radishes should not stand closer than $3 \mathrm{in}$. apart on the average, and when it is seen that they come up closer they should be at once thinned to this distance, but thick sowing under such circumstances is wasteful of both seed and labour. Another frequent mistake, attributable solely to carelessness, is to omit properly clearing the bed of all small immature Radish plants when the bulk of the crop is taken; these should never be allowed to remain, or they quickly make large tops which overshadow and injure the other plants.

Another way in which early supplies may be obtained is to make a hot-bed, about $1 \mathrm{ft}$. thick, at the beginning of February, either on the surface of the ground or in a shallow trench. On this is put 3in. of light soil, and after the seed is sown cover the bed with litter, or with mats laid on a light framework of laths. The coverings must be removed in the day-time and replaced each night. With careful management the crop will be ready in about five weeks from sowing.

Early Crops from the Open.- It is useless attempting to get very early crops of Radishes from land of a heavy sticky nature unless special preparation is made to get rid of excessive damp and to make the surface friable. In addition to being well drained, for early work such soil should be laid in raised beds and the surface should be covered with $4 \mathrm{in}$. of light compost. Naturally light, warm, well-drained soils need no special preparation beyond reducing the surface to as fine a tilth as possible before the seed is sown, though even these are all the better for having sunk pathways between the beds to take excessive moisture away quickly.

The earliest sowings are made from December to February, in the most sheltered and sunny positions available, which are generally found between rows of fruit trees and bushes or at the foot of walls or fences. The beds are made from $4 \mathrm{ft}$. to $5 \mathrm{ft}$. wide, as is most convenient, the crop being gathered from the pathways, without treading on the beds. Seed is sown broadcast, thinly, raked in with a wooden rake, and then slightly covered with fine soil. After sowing, the bed is covered with 
long litter, 3in. or 4in. thick. This is left on until the seed has germinated, after which it is raked off into the alleys daily, but immediately replaced on the appearance of frost or snow. Some thinning of the seedlings will probably be necessary, $1 \frac{1}{2}$ in. apart each way being about the right distance for the small-topped varieties, which should be used for the earliest crops. When the plants have become fairly strong, coverings are dispensed with if the weather is mild, but the litter is kept close at hand, to be used again in case there is a return of frost.

Successional Sowings are made in open situations in March and April. From May to August the seed must be sown in cool moist places, as Radishes do not succeed well if fully exposed to the sun in hot dry weather. When suitable places can be found, a summer crop is sometimes very profitable, especially in a dry season, but for really satisfactory results frequent waterings will be found necessary. Being so quickly off the ground they can often be advantageously sown between rows of lettuces, cauliflowers, peas, French beans, and similar crops, the shade afforded being an advantage, provided they are sown thinly.

Sowing on open ground recommences at the end of August, after the soil has been moistened with a few good showers, and goes on to the end of October, but the latest sowings will again need the protection of litter. Suitable ground will be found where crops which have required heavy manuring have been recently cleared, such as early celery, French beans, and vegetable marrows, the soil being deeply dug and levelled and the surface brought to a fine tilth.

Varieties:-For hot-beds, forcing varieties of French Breakfast, Scarlet White-tipped Turnip, Red Turnip, White Turnip, Wood's Early Frame (long), Scarlet Olive, and White Olive. For sheltered beds, any of the preceding varieties in ordinary selections. For open situations and summer crops, any of the preceding ordinary selections and Long Scarlet, White-tipped Long Scarlet, and Long White. 


\section{RHUBARB.}

Rheum hybridum.

$R$ HUBARB is in such general use that it would be difficult $R$ to find an old-established kitchen garden without a bed. It will grow well in most kinds of soil which have received a reasonable amount of preparation, and it seldom suffers seriously either from the weather or from pests or diseases. Its culture frequently forms an important part of general market gardening, whilst in some districts the forcing of early supplies has become a specialised industry with an enormous output. The demand for Rhubarb during the early part of the season is constant and steady, the prices realised do

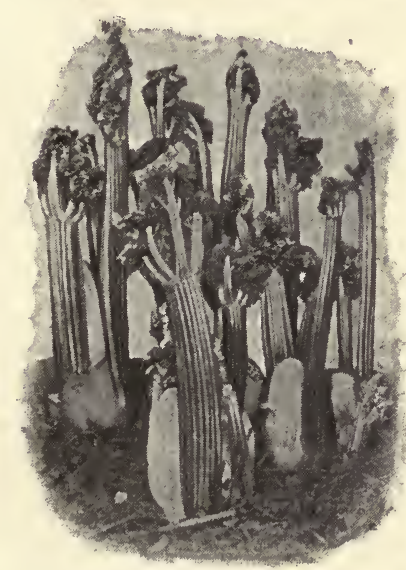

Forced Rhubarb. not often fluctuate very widely and usually show a good margin of profit. On the other hand it is a crop which takes up a comparatively large area of land when worked for market, and where the holding is small this is a matter needing serious consideration, because a limited area (if it is subjected to good culture) can be made to yield a much greater profit when cropped with other vegetables. Another matter of great importance is the weight and bulk of the crop, which cause heavy expenses for carriage when the garden is situated at a considerable distance from the market. At the same time, when the crop can be disposed of locally, or when markets are within a reasonable distance, Rhubarb, either forced or grown naturally, is well worth the attention of every market gardener.

Preparation of the Soil.-The ideal soil for Rhubarb is a deep rich loam, cool and moist, and well-drained. Where such a soil does not exist steps should be taken to make the conditions answer to this description as nearly as possible, because the deeper and richer the soil the finer will be the quality and size 
of the produce. The land should be bastard trenched or subsoiled in the autumn, and well enriched with a liberal dressing of manure, as the plants have to stand in the ground for a number of years, and top-dressings afterwards will not compensate for neglect to enrich the soil before planting.

Propagation.-The most common method of propagating Rhubarb is by root division, and when the grower's object is to get a thrifty, vigorous plantation in a short time this is the best method to adopt. Strong old roots are cut with a sharp knife or spade into as many portions a's there are crowns to it, and each slice forms a set for planting. These sets should be carefully trimmed up, removing any parts that may be broken or mangled, but leaving to each set as much root as possible. Where a stock of old roots is not easily procurable, sets ready for planting may be obtained from most of the large growers. An alternative method of obtaining sets, practised by some growers, is to purchase large roots for forcing, and when the supply of stalks begins to decline, remove them to a shed where they will be slightly protected from too severe a change, and at planting time divide them in the manner described above. Such sets are not, of course, as vigorous as those from unforced roots, but if planted out in good soil and well cared for afterwards they soon render a good account of themselves, and in the second year make fine plants.

Where economy on the immediate outlay is of greater importance to the grower than an additional year or two of waiting, the necessary stock can be easily and cheaply raised from seed, the plants coming fairly true to character when the seed is obtained from a reliable source, though in this respect perhaps Myatt's Victoria is the most dependable variety. The seeds should be sown thinly in rich soil, early in October, or in February or March as soon as the conditions of weather and soil are favourable. Sow in rows $1 \mathrm{ft}$. apart, and thin the seedlings early to $6 \mathrm{in}$. apart in the rows, afterwards thinning again to about $10 \mathrm{in}$. apart by removing the least vigorous or those which are untrue to character. Through the following summer the surface soil must be kept loose and free of weeds by frequent hoeing, and the plants will then be ready to set out in their permanent quarters in the following spring. 
Planting.-The work of setting out the plants in their permanent positions should be done whilst growth is dormant; in light ground it may be done after the leaves have died down in late autumn, but in heavy or moist ground it is best deferred to the end of winter or early in spring. The distance apart at which the plants are set depends upon the sorts grown, the more vigorous late varieties needing, as a rule, much more space than the smaller early varieties. A mistake frequently made is in planting too thickly, under the impression that this gives a greater yield, but under crowded conditions the individual plants do nof yield so many or such fine stalks as when they have more room, nor does the plantation continue so long in profit. The aim should be to set the plants at such a distance apart as will yield the greatest amount of good quality produce, and this may be best attained by planting the smaller varieties in rows $3 \mathrm{ft}$. apart by $2 \mathrm{ft}$. $6 \mathrm{in}$. apart in the row, and the stronger growers $4 \mathrm{ft}$. between the rows and $3 \mathrm{ft}$. between the plants. Mark out the position of the lines and then throw out a furrow with spade or plough, according to the extent of the area to be planted. The depth of the furrow is regulated by the size of the roots, the topmost crown of which should be covered with about $2 \mathrm{in}$. of soil. After planting press the soil firmly round the roots. A warm, well-drained position, protected from cold winds and facing south should, when possible, be given to the early varieties, as gatherings may, be made a week or more earlier from such a position than from a damp, exposed field, and early gatherings usually mean better prices. Later varieties should be given the more open positions and heavier soil. Rhubarb needs an abundance of moisture all through the growing season, and although a low wet situation holding stagnant water is unsuitable, a very dry soil is practically useless for this culture:

Routine of Cultivation.-The object sought is to secure the largest possible growth, and to this end tillage and feeding must be thorough. The larger the leaves, the stronger will be the crowns for the following season. As soon as planting is finished the surface of the soil should be hoed to prevent caking, and hoeing to check the growth of weeds and to keep the surface soil loose should be persisted in during the summer. 
During the season following planting, a catch crop may be grown between the rows. Each winter, as soon as time can be spared, during a spell of open weather the ground between the rows should be forked over and each crown covered a few inches deep with littery manure; this will help to feed the roots and hasten the formation of early stalks, which will come long, clean and crisp through the litter, and better altogether than if none was used. When the Rhubarb is in bearing, surface cultivation should begin as soon as gathering is finished. All flower stems should be removed as soon as they appear, as the formation of seed is very exhausting to the plant.

Gathering.-When to gather, how to gather, and when to cease gathering, are all matters worthy of more attention than they usually receive. No stalks whatever should be pulled in the first season after planting, and in the second season the gathering should be very moderate; when the roots are to be forced it is much better not to gather any the second season, as the removal of any leaf from the plant tends to weaken it. Some consumers prefer Rhubarb when the stalks are only half-grown, whilst others prefer them fully grown, but there is a great waste if they are gathered before they reach their full length, and it is just at that stage when they are in the best condition and should be gathered. The proper method of pulling is to give the leaf-stalk a half-turn and a sudden jerk outward and downward at the same moment. When pulling is done carelessly the crown is often torn off at the base of the stalk. Too many leaves should not be pulled from a plant at one time; if there are a dozen leaves to a plant not more than six should be taken, and time allowed for new leaves to form before any more are pulled. Gathering should cease at latest by the early part of August, and for the rest of the season the plants should be left to grow as they will, except cuting off flower-stalks as fast as they show. This allows quite little enough time for the last crop of leaves to make good crowns for the next season's crop. When Rhubarb is wanted for wine-making, well-matured stalks are usually pulled at the end of August, and a plot should be kept for that purpose in preference to pulling so late in the season from the ordinary plantation. Where Rhubarb is grown on a 
large scale it is a good plan to leave at intervals in the field spaces wide enough to allow a waggon to be drawn down for convenience in loading.

Forcing.-Rhubarb forcing is very easy and simple. If the roots are lifted after the leaves have died down in the autumn, and put in any place which has a temperature of from 50 to 60 degrees, growth will immediately begin again. This prompt response to an increased temperature is even more marked and vigorous when the roots have been frozen before being introduced into heat. Darkness is not essential, but the stalks come longer, straighter, and of a better colour and appearance when grown in complete darkness, and therefore in forcing for market light is carefully excluded. For the earliest supplies roots may be put in a shed or cellar, under a greenhouse bench, in a boiler house, in frames or pits, on a bed of warm manure in the open, or in fact in any place where the necessary protection, warmth, and darkness can be obtained. Where forcing is done on a large scale, special cheaply constructed houses, warmed by hot-water pipes, are employed, though this is a matter of convenience and economy of labour and not of necessity. Rhubarb is also forced as it stands in the ground, without disturbing the roots, and though it cannot be got so early in this way as when the roots are lifted, the stalks come much finer and are generally of better quality.

Forcing may therefore be divided into two distinct methods(1) Lifting the roots and placing them in artificially heated structures; (2) Applying to the roots where they grow a covering to protect from the weather and exclude light, with linings of fermenting materials to generate warmth and excite growth. Both systems are good when properly carried out, and a judicious combination of the two would appear to offer advantages to the grower whose business requires a steady supply in regular succession. In either system it is useless to expect profitable results from unsuitable roots, - either those which lack maturity and strength or those which are enfeebled by age and too close pulling,--they should be grown three years from seed or two years from planting, have had good cultivation and an abundant supply of rich food, and few or no leaves should have been pulled from them in the preceding season. 
Lifted roots usually occupy, after trimming, a space of from 9in. to $1 \mathrm{ft}$. square. They are packed as closely together as they will stand on a few inches of moist soil, and similar soil is worked into the spaces between them, up to the level of the crowns. Where the prevailing temperature is too low, the necessary warmth may be supplied by slow combustion stoves or petroleum heaters, both of which have been used successfully, though provision must be made for the escape of noxious fumes and the maintenance of a moist atmosphere. The heat should be kept as steadily as possible between 55 and 60 degrees, though no harm has resulted when it has risen as high as 80 or fallen as low as 40 degrees. The soil about the roots should be kept in a nicely moist but not wet condition. Thin useless stalks should be removed as soon as seen, so as not to waste the energy of the root. The stalks should be gathered immediately they are ready or they soon become soft and spongy. When production begins to decline the roots should be removed to a place where they will be protected from frost, and will then be available for making new plantations in the spring. Two or three crops in succession can be forced in the season. No ventilation is needed beyond that which is given when attending to or gathering the crop.

When forcing on hot-beds, a trench is made about $4 \mathrm{ft}$. wide and $2 \mathrm{ft}$. deep. In this, warm manure or other fermenting material is placed about $18 \mathrm{in}$. deep, and after the heat has worked through it is well trodden down and covered with 3 in. of soil. Rough boards, $2 \mathrm{ft}$. high at the front and $3 \mathrm{ft}$. at the back, are fixed round the bed and the roots put inside. The outsides are banked up with hot manure, and the top covered with wooden shutters or corrugated iron, on which a few inches of litter is put to keep out the frost. Very good Rhubarb is produced by this method. A second crop may be taken from these beds if the manure in the trench is well shaken up and a little fresh strawey manure added to renew the fermentation; fresh linings of manure must also be put outside. A modification of the above method is to omit the boards, cover the crowns with $18 \mathrm{in}$. of litter, and over all put hoops of willow branches and mats.

When forcing the roots where they grow, the crowns are 
covered deeply with litter, or with boxes, baskets, or tubs, which are banked up and covered with litter. It is obvious, however, that no great quantity can be economically forced in this manner. To do the work profitably the roots should be planted closer together, say $2 \mathrm{ft}$. each way, in double rows with $5 \mathrm{ft}$. spaces between. Soon after the turn of the year fix boards at each side of the beds and take out a trench, $1 \mathrm{ft}$. wide and a spit deep, along the outside of each board. Then put hot manure in the trenches and bank it up to the top of the boards, then cover the bed over in the manner described for hot-beds in the preceding paragraph. When the forced crop has been gathered the boards are removed, the manure spread, the alleys dug and levelled and planted with summer crops. The Rhubarb should then be allowed to grow as it will, without further pulling, and the bed will last for several years without renewal.

A few years ago handsome profits were made in connection with this industry, but under the stress of ever-increasing competition the margin of profit has become narrower, and it behoves the grower who enters upon the business to carefully. study ways and means. By judicious planning many suitable places for forcing Rhubarb can usually be found on most holdings, and a special expenditure on buildings or appliances thus avoided. On the other hand, labour is the most expensive item, and it may pay better, by saving labour, to do the forcing in close proximity to, or even directly upon, the ground where the roots are grown. Of one thing we may be sure,-it will not pay to produce a partial crop or one of indifferent quality from the same space and with the same expenditure of labour which might and ought to have produced a good crop. Complete and not partial success must be striven for, and whilst in Rhubarb forcing this goal is not difficult of attainment, it can only be arrived at in this as in other things, by a careful and thorough attention to details.

Manures:-Abundant supplies of well-decayed farmyard manure are necessary in Rhubarb culture, and it is far better not to embark in the business at all than to grow the stunted and starved plants which one sees occasionally. Rhubarb is a rank grower, and when it is remembered that for many weeks 
in the early part of the season the plant is stripped of its leaves as fast as they are made, it is obvious that it requires a large amount of rich food to stand the strain and maintain its productiveness year after year. There is practically no danger of giving too much manure; on land of average quality at least from 30 to 40 tons per acre, accompanied by $8 \mathrm{cwt}$. of bone meal, and 4cwt of kainit, should be incorporated with the soil before planting. On very heavy soil it would be advisable to substitute 10cwt. basic slag for the bone meal. Each winter at least 15 tons of manure should be given, applied along the rows, and in the spring 3cwt. of superphosphate. An occasional dressing on light land of 3cwt. kainit in the autumn, and on heavy land of $1 \frac{1}{2} \mathrm{cwt}$. sulphate of potash in the spring will be found very beneficial. On plantations of early varieties $3 \mathrm{cwt}$. nitrate of soda, in the spring after growth has begun, will be found very serviceable in pushing along the early supplies.

When forcing Rhubarb mix a little dissolved bone with the soil (about a 48's potful of dissolved bone to a barrowful of soil). The application of nitrate of soda ( $1 \mathrm{oz}$. dissolved in each gallon of water) to the roots after growth has commenced, is a good stimulant.

Varieties :-The varieties in greatest favour amongst growers are Mitchell's Royal Albert, Hawke's Champagne, Myatt's Linnæus, and Myatt's Victoria, but there are now numerous other varieties of equal merit.

\section{SALSIFY.}

\section{Tragopogon porrifolius.}

SALSIFY (also known as the oyster-plant) is a root which

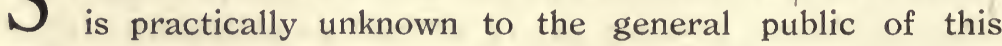
country, and therefore there is not sufficient demand to make it worthy of the attention of every grower for market. Those, however, who have direct dealings with well-to-do private customers, or with good shops and hotels, might profitably turn their attention to its production, and then take the opportunity of pushing its sale into quarters where at present it is a stranger. Properly cooked, it is wholesome and possesses an 
agreeable flavour, and should form a welcome addition to the somewhat restricted list of winter vegetables.

The best roots of Salsify are grown in a deep, moist soil of rather light texture, although a heavy soil will produce good roots providing it is deeply and well worked and made friable throughout. It should be in good fertile condition but free

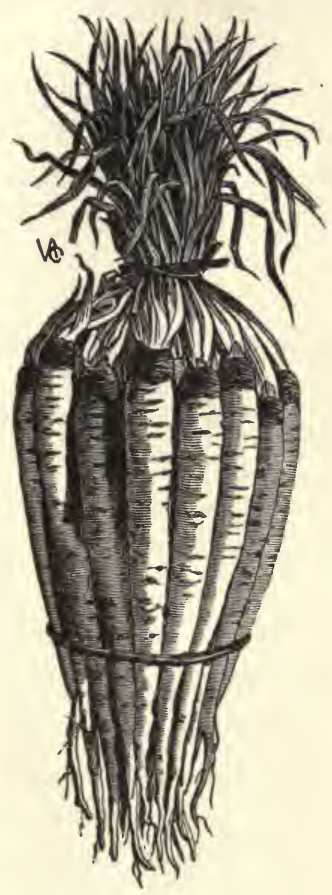

Copyright, V. A. \& Co.

Salsify, or

Vegetable Oyster. from recently-applied manure. Fresh manure in the soil causes the roots to grow fanged and to have an earthy flavour; good specimens should be long, tapering, and straight. The best preparation for the soil is to bastard-trench and ridge it in the autumn; if a coat of manure is put under the top spit it will assist the formation of fine roots, but this addition is not essential.

Seed should be sown in April, in drills 10in. apart and $1 \mathrm{in}$. deep, afterwards lightly rolling, if the surface of the soil is dry, as it should be. As soon as the seedlings can be handled, thin out to a few inches apart, and when they have grown a little stronger thin finally to $8 \mathrm{in}$. apart.

No weeds must be allowed to grow with the crop, and through the summer the surface soil must be kept in a loose crumbly condition, so as to preserve the soil moisture for the use of the plants, which are liable to run to seed if too dry at the roots.

The roots are ready for use by the middle of October. They are treated in the same way as parsnips; they may be stored in a clamp, or in moist sand or earth in a shed, or they may be left in the ground to be lifted as required, and this is the best method when the ground they occupy is not required. Great care should be taken not to damage the roots in lifting, or they will bleed from the broken parts and lose flavour.

Varieties:-Sandwich Island Mammoth, Giant French. 


\section{SCORZONERA.}

Scorzonera hispanica.

SCORZONERA and Salsify are usually classed together, but this must not be taken to imply anything more than convenience, as they are quite distinct in appearance, and each belongs to a different family of plants. The Salsify root is of a pale yellowish colour, and the leaves are long and narrow and of a greyish green. The root of Scorzonera is of a dark purplish colour, whilst the leaves are broader and shorter than those of Salsify. Both plants are grown and treated in exactly the same way and have the same uses but, when necessary, Scorzonera may be left in the ground for a second season when the root, although much increased in size, will be equally fit for use.

Varieties :-Giant Russian and Ordinary.

\section{SAVOY CABBAGE.}

Brassica oleracea bullata.

$\mathrm{O}^{\mathrm{F}}$ $\mathrm{F}$ the green vegetables which are available throughout the winter, the Savoy Cabbage is one of the most useful. It has a milder flavour and is hardier than the ordinary cabbage; indeed, the Savoy is not at its best until it has been subjected to frost. The ordinary cabbage has smooth leaves, whereas

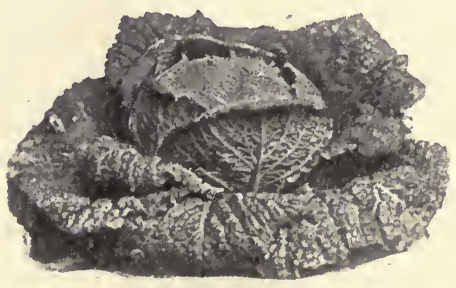

Copyright, S. \& S.

Savoy Cabbage, Sutton's Best of All. in the Savoy they are more or less deeply crinkled.

The soil for Savoys should be somewhat heavy, deeply cultivated, rich, and firm. Ground which has previously been well prepared and cropped with early peas would carry this crop well, if assisted with suitable fertilizers. Failing this, it is best to prepare the ground before winter, so as to secure the good effect of the weather 
in rendering the soil mellow and friable, but whether prepared in autumn or spring it should receive heavy dressings of manure and be ploughed deeply. The manure should not be in a fresh, rank condition, particularly when given in spring, or a soft loose growth, instead of firm compact heads, will probably be the result. When ploughing is done in dry weather, clods must be reduced by rolling, then harrow well to obtain a fine tilth.

For ordinary purposes the seed should be sown about the middle of March, but for a long succession make three sowings, one in the midddle of March, a second at the beginning of April and a third at the end. Sow thinly, on well-prepared ground, in drills 8in. apart. Thin the seedlings to avoid overcrowding, dress them occasionally with a sprinkling of lime and soot, both as a stimulant and to keep insect pests away, and keep the soil free of weeds and loose by frequent hoeing, as it is very important that the plants should be sturdy and strong before being set out in their permanent quarters.

Plant out during June and July, and to make a succession take the largest plants first. For this work choose dull, cloudy days, when the ground is moist; if the planting must be done in hot, dry weather, the roots should be "puddled" (see pages 123 and 124). The smallest varieties are set out 15in. apart in the rows and $18 \mathrm{in}$. between the rows, the distance apart being increased according to the vigour of the variety, until those of the "drumhead" type are planted $2 \mathrm{ft}$. apart each way.

Manures:-Farmyard manure, at the rate of from 20 to 40 tons per acre, according to the nature and condition of the soil, is the most suitable fertilizer for this crop. When, however, the soil is in good heart from previous manuring, the quantity may be reduced by one-half, and be supplemented on light soil by $5 \mathrm{cwt}$. superphosphate and $4 \mathrm{cwt}$. kainit, or on heavy soil by $10 \mathrm{cwt}$. basic slag and $1 \frac{1}{2} \mathrm{cwt}$. sulphate of potash, distributed over the surface in each case immediately before ploughing.

Varieties:-Dwarf Ulm (early and small), Dwarf Green Curled (medium-sized, fine flavour, a favourite for main-crop), Best of All (large and early, drumhead type, very good), New Year (large, late, and good), Drumhead (early and late, rather coarse, frequently grown for main-crop), Ormskirk (late and large, often used for latest supplies in market growing). 


\section{SEAKALE.}

Crambe maritima.

SEAKALE is a very popular winter vegetable amongst the $\checkmark$ well-to-do classes, and it appears to be increasing in public favour. It is easy to grow, simple and inexpensive to force, is practically free from pests and diseases, and is a very wholesome vegetable to consume, so that there is every reason why the market gardener, and particularly the direct trader, should consider the advisability of undertaking its production.

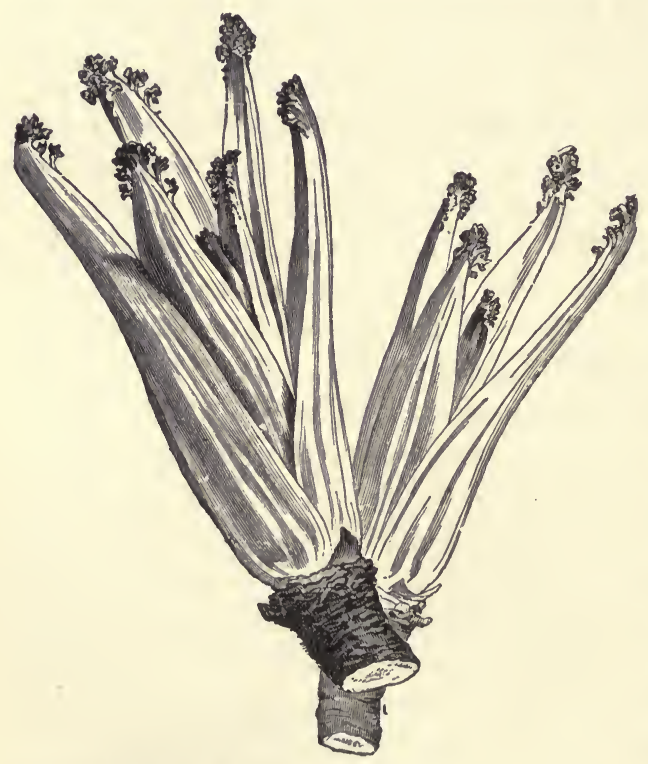

Copyright, V. A. \& Co.

Seakale, blanched.

There are few soils in which Seakale cannot be satisfactorily grown if it receives proper attention. A well-cultivated, deep, and rather heavy soil will grow the finest roots, but an easilyworked sandy loam will be found the best all round, because much of the work of lifting roots has to be done in winter, when the ground is wet. In any case, the soil must be deep, rich, well-drained, in an open situation free from trees, and with a sunny aspect.

Preparation of the Soil.-Thorough preparation and liberal manuring of the soil are absolutely necessary to the production of strong crowns suitable for forcing. Although Seakale is not particular as to the conditions under which it grows, this must not be allowed to influence the treatment it receives. The leaf-stalks when bleached should be large, thick, and 
crisp, or they are practically useless, and the grower should set out to do all necessary to obtain such produce or he will be well advised not to enter upon the business. To this end the ground should, in the first instance, be bastard trenched or subsoil ploughed, if deep working has not been done recently; but where the soil has received such treatment within the past three years ordinary digging or ploughing will be sufficient. Abundant supplies of farmyard manure are essential in every case, assisted judiciously by concentrated fertilizers, and these, in the quantities mentioned later, should be well distributed over the surface previous to digging or ploughing, so that the roots of the plants can find and utilize them at once and continuously. This work of preparation should be done before winter, and the soil left ridged up so as to get the full benefit of weather influences. When soil is put in ridges it not only has the advantage of exposing a greater surface to the atmosphere, but it also lies drier, so that it is fit for working earlier in the spring. About the first week of March, if the weather conditions permit, the soil should be levelled by harrowing, after which it may be marked out both ways with lines $15 \mathrm{in}$. or $18 \mathrm{in}$. apart, every point where the lines cross being the position for a plant to be set, and all will then be in readiness for the work of planting out.

Propagation by Seed.-Raising Seakale plants from seed is not often practised in market gardens, as it takes two years' growth from seed to obtain crowns large enough to force satisfactorily, whereas one season is sufficient to obtain them from "thongs," or root cuttings. Still, when it is the grower's intention to enter upon the business thoroughly, it is advisable to raise plants from seed occasionally, so as to keep the stock in a vigorous condition. On a bed of rich, clean soil, in a fine tilth, sow the seed in March, in drills 1 in. deep and 12in. apart, gently rolling afterwards. When the seedlings are well up, thin out, and leave only the best standing about 6in. apart in the rows. During the summer hoe frequently to keep weeds down and to promote growth. One or two light sprinklings with nitrate of soda and an occasional watering with liquid manure will be amply repaid by the increased vigour of the plants; indeed, under such treatment, if given more space for 
development, some of the crowns would be found large enough to force at the end of the first season. In the following March the plants may be set in their permanent quarters, first cutting off the top just below the crown, as then fewer shoots will grow and there will be less liability to flower.

Propagation from "Thongs."-New plantations of Seakale are usually made from "thongs." These are clean straight pieces selected from the side roots, which are cut away from the main root when that is trimmed up for forcing. These trimmings are thrown in a heap in a shed whilst the work is proceeding, where they lie until time can be spared to attend to them. The best are then selected, from the thickness of a lead pencil upwards, and cut up into pieces 5in. or $6 \mathrm{in}$. long. The top, or thickest end of the thong, is cut across level, and the bottom, or thin end, is cut slanting. They are then tied in bundles and stood in layers in damp sand or fine soil, with about 3 in. space between each layer, and there they remain until planting time. Some growers prefer to make up a bed in the open, about $4 \mathrm{ft}$. wide and raised about $8 \mathrm{in}$. above the general level to keep the thongs free from excessive wet, and after laying them thickly all over the surface, cover with about 3in. of soil. In either case, when the thongs are uncovered for planting, each will be found to have made several "eyes," all of which must be rubbed off except the strongest one at the top.

About the third week in March the thongs are dibbled in at equal distances apart in each direction, the crowns being put about lin. below the surface and the soil closed quite firmly around them.' The culture through the summer consists of hoeing frequently and thoroughly, and cutting out all flower stems as soon as they are seen, as if allowed to bloom and form seed much of the strength of the crown will be lost.

Forming a Plantation.-The methods of obtaining blanched heads of Seakale may be classed under two divisions, (1) Lifting the roots for forcing in heat, and (2) Leaving the roots in the ground and either forcing growth with hot manure or letting them grow naturally, blanching the heads by coverings of soil or other materials. Both methods are necessary to obtain a succession over the longest period, and this must be kept in view in arranging a plantation. Seakale is often 
planted too closely to allow it to reach its full development. In market gardens it is planted from $12 \mathrm{in}$. to $18 \mathrm{in}$. apart in each direction, whether it is to be lifted or blanched where it grows, but some authorities insist that this close planting is a mistake, and that $20 \mathrm{in}$. or even $24 \mathrm{in}$. apart would be more profitable, as although more crowns are obtained from the same space by close planting, the greater distance apart would produce finer crowns, the heads from which would be superior and realise better prices in the market. This matter must be left to the judgment of the grower, 15in. apart in each direction being suggested as the minimum, whether the roots are to be lifted or to be blanched where they grow.

On some places where intensive cultivation is practised, the soil is levelled early in March and then planted with alternate rows, $18 \mathrm{in}$. apart, of cauliflower and cos lettuce, the cauliflower standing $3 \mathrm{ft}$. apart in the rows and the lettuce 18in.; then a cos lettuce is planted alternately with the cauliflowers, in the same row the cauliflowers occupy; all the plants then stand 18in. apart both ways over the whole plot. After this, a Seakale thong is dibbled in alternately with every plant in the rows, but not between the rows. The diagram below makes this

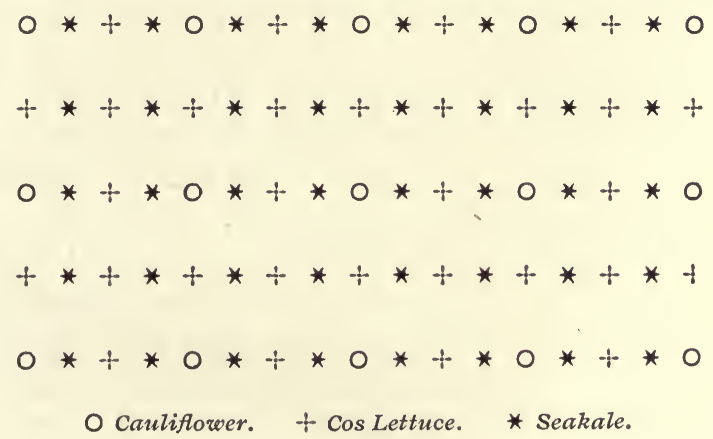

Diagram illustrating the Arrangement of Plants.

perfectly clear. Both lettuces and cauliflowers are gone by the end of June, and the Seakale, which is then growing freely, is left in sole occupation of the ground at 18in. apart. A thorough hoeing, accompanied with a dressing of nitrate of soda, sets the plantation in good trim, and hoeing to encourage 
growth must be done frequently to the end of the season. Satisfactory crowns may be grown in this way when the soil is rich and full of humus and copious waterings are given to supply the pressing and heavy calls of the various plants, and if these necessary conditions are thoroughly complied with this is obviously a very profitable way to occupy the space in the early part of the season, but on the average it will be found that the production of good Seakale crowns is more certain when they are grown alone.

Having formed a plantation with the plants at equal distances apart in each direction, the grower must decide what portion of the crowns are to be lifted for forcing or selling and what portion is to be left in the ground. Those not lifted will provide supplies to follow in succession after the earliest forced batches. Part of these will be pushed along with hot manure and the remainder used for the production of "natural" Kale. In the former case every fourth row is lifted, leaving three rows at 15in. apart, then an alley of $2 \mathrm{ft}$. $6 \mathrm{in}$., and so on. In the latter case two rows are lifted and three left, so that the alleys are $3 \mathrm{ft}$. $3 \mathrm{in}$. wide. When the alleys are cleared, dress the soil with ground lime and dig it well to within $6 \mathrm{in}$. of the plants on each side, ridging up the middle and leaving it rough for the weather to act upon.

In smaller plantations the plants may be set in clumps, to be covered with Seakale pots or boxes. In each clump set three or four plants $4 \mathrm{in}$. apart, leave $2 \mathrm{ft}$. between each clump, and leave $3 \mathrm{ft}$. between each row of clumps.

Forcing under Cover.-Seakale is very easy to force; the crowns begin to move as soon as they are subjected to a slight rise of temperature. The best samples are produced when grown slowly, a steady temperature of from 50 to 55 degrees being sufficient for really satisfactory work, and 60 degrees should never be exceeded at any time, or the stalks will come thin and without substance. The heat, which may be supplied either by hot-water pipes or by fermenting manure, should be a moist one, and acts best when applied underneath the roots, although forcing may be done without bottom heat, if necessary. Absolute darkness is essential, or the heads will not be perfectly blanched, and in no other condition can they be considered as 
marketable. By observing these simple conditions creditable samples of Seakale may be forced in all sorts of places-frames, pits, mushroom houses, glasshouses, cellars, boxes, barrels, flower pots-any of which may be pressed into service with satisfactory results. Regular forcing begins about the middle of November, and for the earliest batches the very best and strongest crowns are selected.

As soon as the leaves die down in the autumn the roots are lifted and trimmed, leaving only about $5 \mathrm{in}$. of the main stem, with the crown on top. Those not immediately wanted are packed away in moist sandy soil either in a shed or in a trench in the open, with a layer of dry litter over the crowns to protect them from frost. Light, fine, rich soil should be specially prepared for forcing operations some time beforehand-half of sifted old hotbed manure, one-quarter sifted garden soil, and one quarter sand, with a little air-slaked lime added, will be found to be just the thing. This soil should be laid down to the depth of $8 \mathrm{in}$. or $10 \mathrm{in}$. in the position or the receptacle in which the crowns are to be forced. These are then placed in the soil 3in. apart, and with the crowns level with the surface. Moisten the bed with tepid water, taking care not to make it too wet, then cover the crowns with $3 \mathrm{in}$. of fine dry soil, cocoanut fibre, or similar material. When the stalks begin to grow through, give another light watering. If there is certainty of no light getting to the stalks they need no further covering, but where there is any doubt on the subject a further 4in. layer of material should be added. If the details are properly carried out, perfectly blanched heads should be ready to cut in four or five weeks from the time the roots were planted. The heads are cut when about $6 \mathrm{in}$. long, or as soon as the tips begin to push through the covering material; the cut is made below the crown so that a small piece of root is attached.

Forcing on Hot-beds and in Pits.-Where manure is plentiful forcing Seakale on hot-beds is an excellent method (full details of construction will be found on pages 128 to 131). The width and length of the beds is, of course, determined by the number of crowns to be forced and the materials or appliances at hand. Where there are a number of movable box frames available 
those will serve admirably if the lights are covered with mats; or wooden lids would do instead of lights and mats. Inside the frame 8in. of the prepared soil is put on the manure, in which the crowns are planted in rows, as described above. Where frames are not available, $9 \mathrm{in}$. boards on edge, supported by pegs driven in the ground, are run round the beds, and laths are nailed across the top, from side to side, at intervals of about 18in. The surface of the beds is strewn with short litter and then mats are laid on the laths, a further covering of long litter being put over the whole. Sometimes, in place of the boards and laths, the mats are laid over hoops. About four weeks after making up a bed the crowns should be examined, when probably some will be fit to cuit. The litter on the bed must be lifted away to get at them, but must be re-placed as soon as possible, as all are not ready to cut at the same time.

A simple and economical method of forcing Seakale is in roughly-constructed temporary pits. Trenches are thrown out $18 \mathrm{in}$. deep, $4 \mathrm{ft}$. wide, and any convenient length, with $4 \mathrm{ft}$. space between each trench, on which the soil is thrown. Rough boards or old sheets of iron are used to hold up the sides; these are supported by stakes and the whole stands about $1 \mathrm{ft}$. above ground level, the earth which was thrown out being used to bank up the sides. At the bottom of each pit $9 \mathrm{in}$. of hot manure is put and well trodden down, and then covered with 8in. of soil, in which the crowns are planted. The pits are covered with boards on which is laid about 6in. of litter. A crop is cleared in about six weeks from planting, and three crops can easily be taken from a pit during the winter season. After each crop, the exhausted manure must be removed and the bed re-made with fresh. These pits are equally suitable for forcing rhubarb, asparagus, and chicory; they are easily constructed, at practically no expense beyond labour, and the quality of the produce taken from them is all that can be desired, being quite equal to any grown under the most elaborate system. The illustrations on the opposite page, which were taken from pits in actual operation for commercial purposes, show the method of construction very clearly; the lower one also gives some idea of the quality of the Seakale, part of which had been cut before the photograph was taken. 


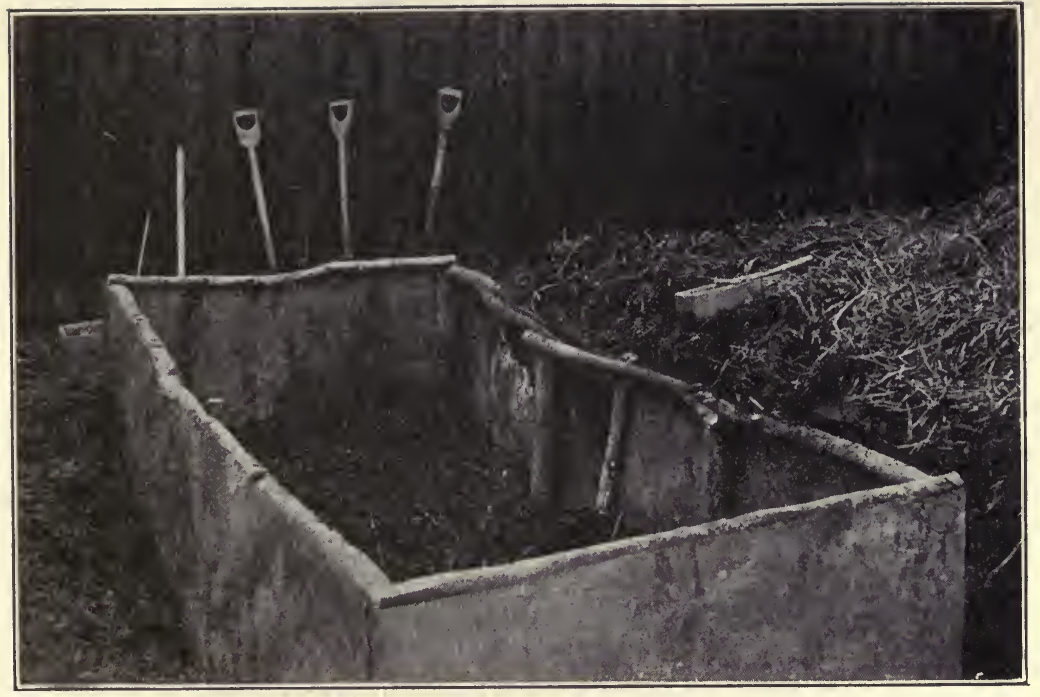

Rough Pit for Seakale, in course of construction.

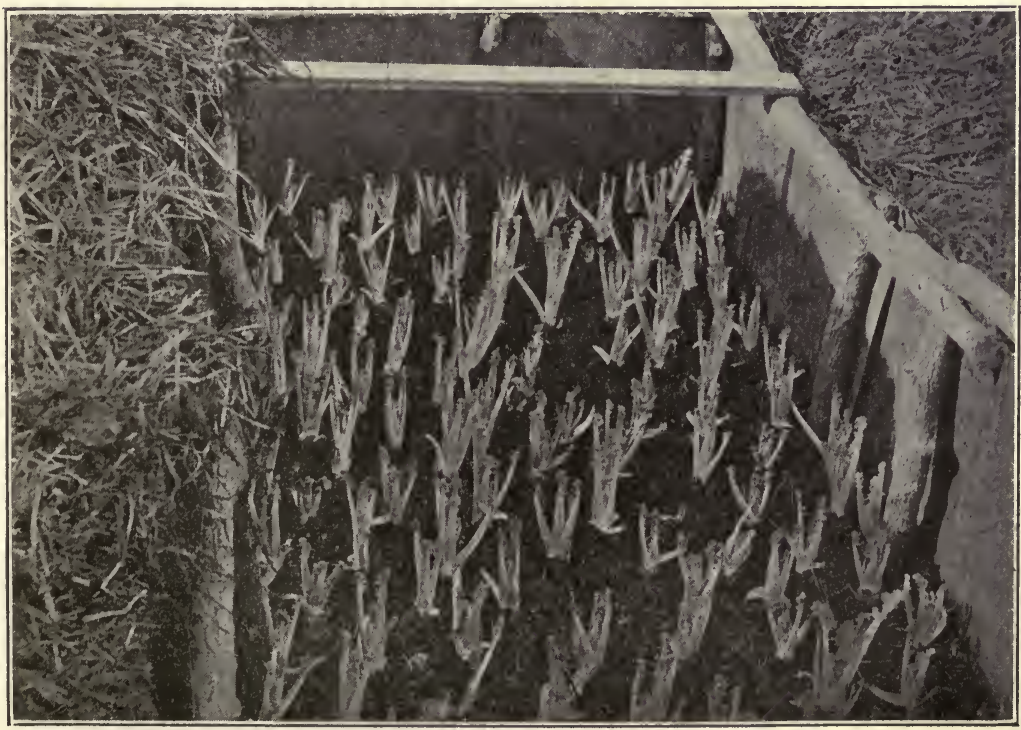

The same Pit, after part of the crop has been cut. 
Other Methods of Forcing in the Open.-In localities where stable manure is expensive, and the quantity used must be limited for the sake of economy, lifted crowns of Seakale may be forced on cold beds. Ground convenient to the manure supply is selected, and marked out into beds $4 \mathrm{ft}$. wide, with $2 \mathrm{ft}$. alleys between. The soil in the alleys is broken up finely to the depth of $1 \mathrm{ft}$. and then put on the beds, so that the alleys will then be about 20in. deep. The crowns are then set in the soil on these beds in the same manner as on the hot-beds, leaving a space of 5 or 6in. along each side empty. All the beds are planted, and a little litter strewn over to prevent the soil and the dormant crowns from being frozen. A portion of the beds are then covered with frames or with mats, exactly as the hot-beds are covered, and the alleys are filled with good hot manure, well trodden down. Fresh beds are started in succession, so as to keep up a regular supply until the "natural" Kale comes in. The growth is slower than on hot-beds, but the quality is good, and when cutting is begun the supply from successive beds goes on without a break.

Precisely the same system of forcing and blanching is followed with the beds where the roots are left in the ground, except on those beds where the Kale is grown naturally. As already described, at the end of the first year after a plantation is laid down one row between each three is lifted for forcing, and the soil in the alley dug and ridged up. After the turn of the year this soil is put on the bed to the depth of 8in., after being well broken up, and the procedure of covering the bed and filling the alleys with hot manure is the same as given above. The advantage of forcing the roots where they grow is that they are available for five or six years in succession, with a minimum of trouble and expense. On the other hand, by lifting the roots the same amount of fermenting manure and covering will force and blanch ten times the number as when left where they grow, and the beds may be made.where one chooses, in a place convenient to manure and packing shed, which in good weather is a great advantage, whilst the difference in bad weather is best left to the imagination. The balance of advantage is therefore very largely in favour of lifting the roots.

It should be pointed out that the above system of forcing is 
only suitable for well-drained soil. Should the manure in the alleys become wet and cold after heavy rain or snow it will be necessary to fork it up so that the wind can blow through and dry it. A little fresh mixed with it before it is trodden down again will revive the heat.

To force the crowns which were planted in clumps, each is covered with litter a few weeks before a start is intended, to keep frost out of the soil. Then at starting time the litter is removed and each clump covered with a box with a movable lid or with a Seakale pot. These are surrounded with hot manure, and litter should be put over the tops to conserve the warmth and to prevent any light getting in. In the course of a few weeks well-blanched heads will be ready for cutting.

"Natural" Seakale.-A portion of a plantation is usually reserved for growing Seakale naturally, that is, allowing it to remain in the same beds year after year and to make its customary 'spring growth at the usual time, without artificial heat; this is known as "natural" Kale. In the instructions for making a plantation (page 300) it was suggested that the rows of plants be $15 \mathrm{in}$. apart, that beds of three rows be left for natural Seakale, and that two rows be lifted to form alleys $3 \mathrm{ft}$. 9in. wide between the beds. The surface of each bed is raked clean in the autumn and the soil in the alleys, within $6 \mathrm{in}$. of the bed on each side, broken up well and ridged. When the soil has become mellow by weathering it is laid on the bed to the depth of $8 \mathrm{in}$. (not more), with the sides sloped a little to prevent it falling away. This work must not be done in wet weather and the soil must be fine and crumbly. Cutting begins from the middle to the end of March, according to the earliness of soil and season, and continues to the end of April. When cracks are seen in the surface of the soil, owing to the growth of the shoots, or the tips are just showing through, cutting may begin. If the beds are of any extent and likely to be several weeks in cutting, those coming last should be covered with a few inches of short litter to exclude light. Cutting is done with a sharp flat spade, the heads being cut about $\frac{1}{2}$ in. below the crown. The soil is thrown into the alley, but about $\mathrm{kin}$. is returned to the bed to cover up the cut stumps. When cutting is finished, the alleys are given a $3 \mathrm{in}$. coat of well-rotted manure 
and planted with summer crops. A bed of this description will last about six years without renewal.

Lifted roots are of no further use after forcing, and should be put in a heap by themselves and not mixed with the manure or they will grow again and cause a lot of trouble and annoyance in the future. Or they may be taken to the pigsties, where they will soon be destroyed. When roots are lifted the greatest care should be taken to clear the ground of all broken pieces, as they grow again and are troublesome to get rid of.

Manures:-Seakale is a crop which needs plenty of rich food and moisture-holding humus, and this is best supplied by heavy dressings of well-decayed farmyard manure, particularly for the sandy soils on which this crop is often grown. For soil in good heart and not too light 15 tons per acre would be enough, but on light land or that which is not in really good condition 30 tons would be none too much. In either case the manure should be supplemented before ploughing with $3 \mathrm{cwt}$. kainit, and in the spring 5 cwt. superphosphate should be harrowed in before planting. After growth has begun $2 \mathrm{cwt}$. nitrate of soda per acre may be given with great advantage. Common salt, at the rate of 5 cwt. per acre, applied in the spring, is often recommended for Seakale, but when kainit or nitrate of soda are given salt is unnecessary.

Varieties :-There are very few varieties of Seakale in cultivation. The Common or Ordinary is largely grown; the Fulham, Lily White, and Ivory White are all improvements upon the common 'stock.

\section{SHALLOTS.}

Allium ascalonicum.

HE Shallot does not call for much comment. It is very
generally grown in cottage gardens, but has no considerable sale in the markets. There are some growers, however, who do a good and profitable business in producing it for direct disposal to manufacturers of pickles, for which purpose it is much esteemed on account of its mild flavour. There is 
also the possibility of doing a moderate business in supplying retailers or householders direct.

The Shallot is easy to grow and gives very little trouble if its requirements are complied with. It needs an open, sunny position and a rather light soil, deeply-worked and well-drained; heavy, damp soil is unsuitable. To obtain good crops the soil should be prepared and manured in the same way as for onions, with the difference that it does not need to be quite so rich, particularly when the crop is intended for pickling.

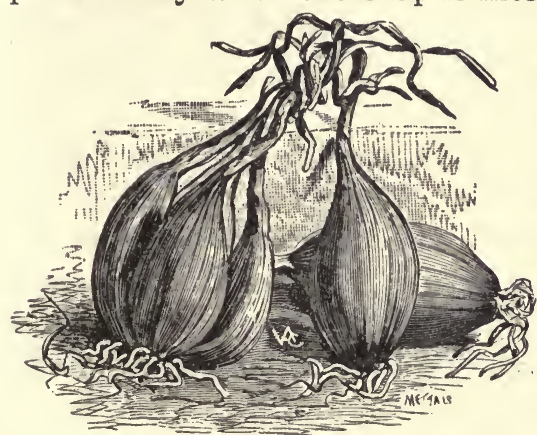

Copyright, V. A. \& Co.

The True Shallot.

The Shallot may be grown either from seed or from bulbs, but as seeding offers no advantages, and as propagation is much more easily effected by planting the bulbs, this is the method always followed, except for special purposes.

Early planting is essential, as the bulbs begin to go soft very early in the spring and are then comparatively use-

less for planting. Plant at the first opportunity, in a spell of open weather, during January or early in February, in rows from $9 \mathrm{in}$. to $12 \mathrm{in}$. apart, with $4 \mathrm{in}$. to $6 \mathrm{in}$. between the bulbs in the row, according to the variety grown and the richness of the soil. Before planting, the soil should be lightly rolled, and the bulbs then inserted to half their depth, either by the aid of a dibber or, if the soil is free enough, by simply pressing them in. Dry, loose skins and dead tops should be removed, or worms, by trying to draw

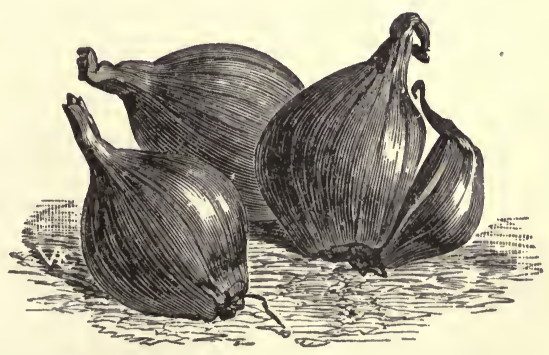

Copyright, V.A. \& Co.

The Jersey, or False, Shallot. these parts into their holes, will often pull the bulbs out of the ground, and the soil should be closed firmly around them or 
the growth of the roots will sometimes lift them out. In any case, the bed should be examined frequently for a few weeks after planting, and any which have been disturbed replaced.

During growth keep the weeds down by frequent hoeing, but take care not to cut into the soil deeply or to bury the bulbs, which should grow on the surface.

The crop will begin to ripen in July, which may be seen by the leaves turning yellow; by the middle of the month these will have withered considerably, and the bulbs may then be lifted. Spread them on the ground to dry in the sun for a few days, turning them over two or three times: then divide and top them, and store in a dry cool place.

Varieties:-The two leading varieties are the true Shallot and the Jersey, or false, Shallot. The Russian Shallot and the Dutch Shallot are practically the same variety as the Jersey. A full-grown bulb of the true Shallot is about the size of a small walnut, with rather long thin neck and russetty skin, which is copper-coloured at the bottom, gradually becoming much lighter towards the top; when growing, its leaves are bright green. This variety usually has the preference for pickling. The bulbs of the Jersey Shallot are larger and rounder than those of the true variety, in fact, they more nearly resemble a small onion. The skin is thin, of an even coppery red, and when growing the leaves are of a greyish green. This variety needs more space than the true Shallot, as it yields a heavier crop, but does not keep so well, the bulbs beginning to grow earlier in the spring.

\title{
SPINACH.
}

Spinacia oleracea.

\begin{abstract}
$\Lambda$ LTHOUGH Spinach cannot be regarded as a staple crop $A$ in the market garden it is nevertheless a very useful one. It cannot be included amongst the vegetables very popular with the general public, and therefore the demand for it is not great; still, there is always a more or less steady sale for it in moderate quantities. It is produced easily and quickly, the summer crops being usually grown in the spaces between
\end{abstract}


rows of other vegetables, where it only requires a few weeks from sowing to gathering, and is cleared away before its presence can injuriously affect its neighbours. For this reason it is regarded in many market gardens as one of the indispensable catch crops, as it enables a return to be obtained from spaces which would otherwise be wasted for some time after planting the main-crop.

Spinach is not very exacting in its requirements, but like most other things it pays for a certain measure of attention. What is wanted is a quick growth and a few heavy pickings of large succulent leaves, and to obtain these, ample supplies of moisture and quick acting manures are necessary. Ground well 'prepared and manured, and planted with a main crop which has a foot or

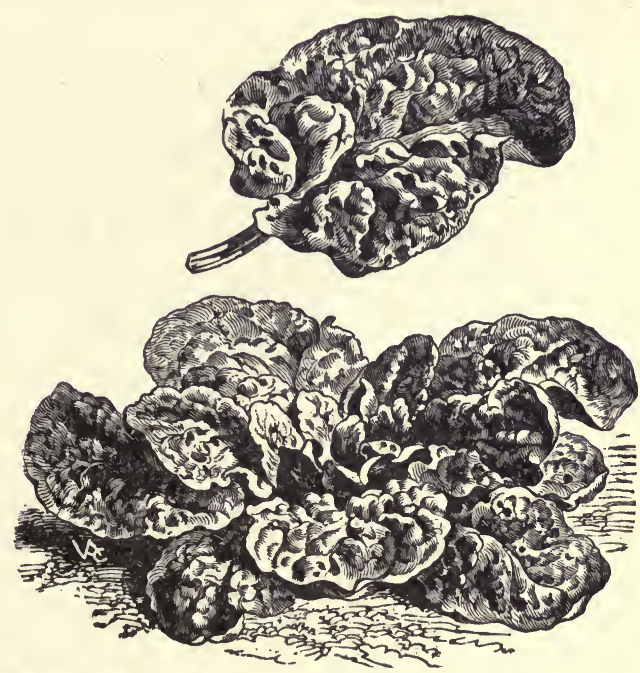

Copyright, V.A.\& Co. more clear space between the rows, may be depended upon to yield satisfactory crops of Spinach, but on badly-worked, dry, scantily-manured soils the leaves will be small and of poor quality, and the plants will quickly run to seed.

Summer Spinach.--The first sowing is made towards the end of February, on warm soil in a sheltered sunny position; a regular succession of supplies is secured by sowing further small batches every two or three weeks from early in March to the beginning of July. These small and frequent sowings are necessary because of the liability of summer Spinach to quickly run to seed, especially in hot dry weather; to counteract this tendency as much as possible, sowings should be made in cool moist situations as the weather grows warmer. If the seed 
is soaked in water for twenty-four hours before sowing, it will germinate more quickly and evenly and make stronger growth. Except when used as a catch-crop, Spinach is sown in drills $1 \mathrm{in}$. deep and $1 \mathrm{ft}$. apart. When the seedlings are well up they should be thinned to from $6 \mathrm{in}$. to $8 \mathrm{in}$. apart, according to the vigour of the variety and the richness of the ground. The proper thinning of Spinach is often neglected under the

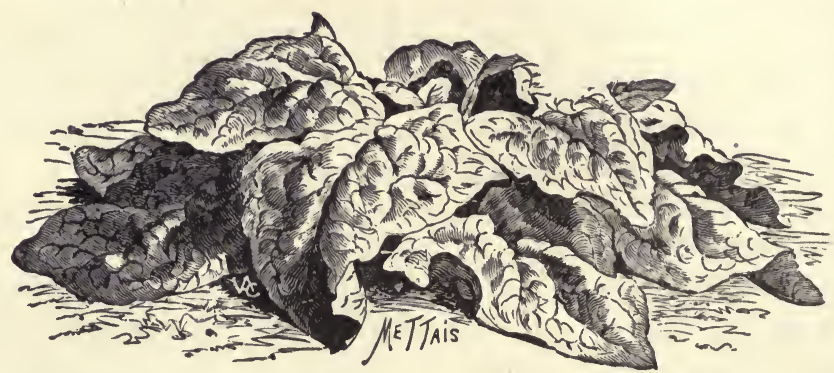

Copyright, V.A. \& Co.

Viroflay Giant Spinach.

impression that the closer the plants stand the heavier will be the yield of leaves, but this is a great mistake as over-crowding seriously reduces production, the leaves coming much smaller and thinner than when afforded proper space, as can be readily understood when it is remembered that each plant when given room will measure at least $1 \mathrm{ft}$. across, some very vigorous varieties taking up considerably more space even than this.

Winter Spinach.-To provide a succession of pickings from October to May (by which time the spring-sown crop will be ready) three sowings should be made, at intervals of a fortnight, from the first week in August to the middle of September. The ground for this purpose should be deeply dug and well enriched with decayed manure, and laid up in raised beds, $5 \mathrm{ft}$. to $6 \mathrm{ft}$. wide, to enable the rain water to pass away quickly and the crop to be gathered without treading on the soil. In this case the plants may stand closer together, say $9 \mathrm{in}$. between the rows by $4 \mathrm{in}$. in the rows, because the growth is naturally less vigorous in winter than in summer. Care should be taken to afford timely protection to a portion of the crop, so that pickings may be obtained throughout the winter. This may be 
given in a variety of ways, according to the circumstances of the grower and the materials readiest to hand; the shallow box frames meet every requirement, but efficient protection can also be readily devised by using straw, heather, bracken, furze, or similar material, in conjunction with short stakes, so as to make low wind-proof fences; in the case of severe frost or snow a number of straw mats laid on cross battens will make the protection complete. Care must be exercised not to

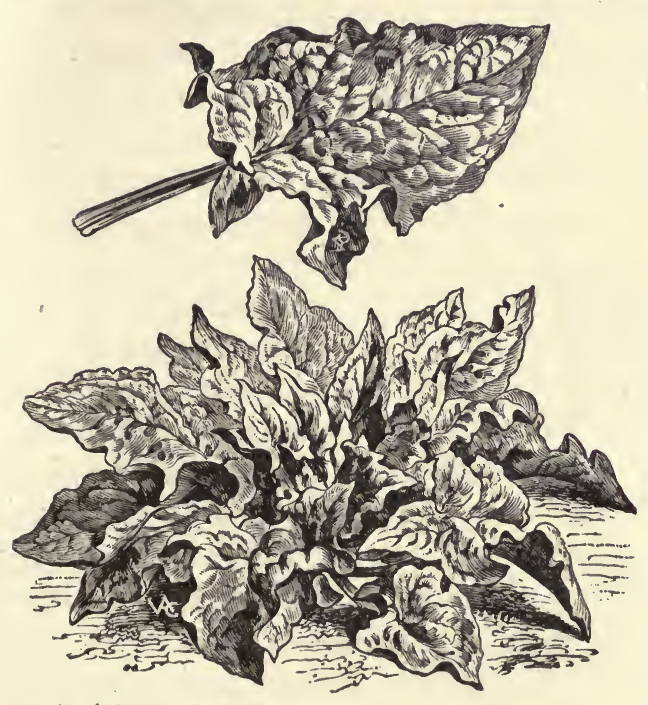

Copyright, V.A. \& Co.

Large Prickly or Winter Spinach. overdo the picking of the winter crop or the plants will soon be spoiled. Only the largest leaves should be taken and they should be picked singly, so as not to cause any injury. Growth in the winter is slow, and to meet the demand, which at this season often exceeds the supply, increased breadths should be sown in the autumn, in accordance with the expected requirements.

General Culture.-This, in the main, consists of keeping the soil free of weeds and the surface frequently stirred, especially in the early stages, so as to encourage rapid growth. As the weather gets warm and dry the effect of indifferent preparation will be at once seen by the plants immediately bolting, and the crop thus completely lost; the only way to ensure an abundant growth of large succulent leaves in the hot summer months being by deep working of the soil, assisted by mulches and frequent waterings. In a cold wet season, Spinach makes an abundant growth without much help, and being. very plentiful, realises a poor price in the market; in such circumstances, apart from keeping weeds down, it may be left to take its own 
course, but in hot droughty periods the general supplies are scarce, when the value of good cultivation will then be quickly apparent, and the extra pains bestowed amply repaid.

Manures:-The whole culture of Spinach should be directed towards obtaining a quick growth of large fleshy leaves. To secure this result the soil must be made rich and retentive of moisture in a state of movement, not stagnant, and the best way to bring this condition about is to first see that the soil is well drained, then work it deeply, double-digging being advisable when it can be done, adding at the same time generous dressings of farmyard or stable manure. Deep working combined with the humus of manure enables the soil to hold more available moisture, provides an ample root-run, and supplies an abundance of plant food, all of which are necessary to vigorous leaf growth, and their provision is the best means of preventing plants running prematurely to seed in dry weather-the time when Spinach is most likely to be scarce and bring a good price. The manure should, if possible, be well decayed, but this is not so imperative in the case of summer Spinach as for most other crops. For summer crops the manure may be given at the rate of from 20 to 40 tons per acre, according to the soil and its fertility, and this may be advantageously supplemented by several waterings with weak liquid manure or by nitrate of soda at the rate of $2 \mathrm{cwt}$. to the acre, given in two applications, one as soon as the plants have been thinned and the other a fortnight later. For the winter crop the farmyard manure can be reduced to half the above quantity. After the end of March apply nitrate of soda as for the summer crop.

Varieties:-For summer the round-seeded varieties are used, Victoria being a favourite amongst market growers; but there are several other sorts equally good, if not better, amongst which may be mentioned Lettuce-leaved, Flanders, Monstrous Viroflay, and Lorg-standing Round. For winter and spring Large Prickly is the favourite, because of its supposed superior hardiness, but it has been proved that the Lettuce-leaved and Flanders pass through the winter quite as well as the Prickly and make a more abundant growth in the spring, and as these varieties sell in the market more readily they should have the preference for autnmn sowing. 


\section{NEW ZEALAND SPINACH.}

Tetragonia expansa.

THE difficulty of getting a continuous supply of Spinach easily overcome by substituting New Zealand Spinach, which grows to perfection under such conditions. The plant will not bear frost, and for supplies early in the summer seed should be sown under glass about the end of March, the plants potted singly, and set out, after hardening, at the end of May. Or seed may be sown out of doors at the beginning of May. The plants should be sét in rows $3 \mathrm{ft}$. apart, and $2 \mathrm{ft}$. from plant to plant. In good soil they soon cover this space. Each plant makes a number of spreading stems with side shoots, and bears numerous small, thick, fleshy leaves; many of these rambling stems, if allowed to grow unchecked, will attain a length of from $2 \mathrm{ft}$. to $3 \mathrm{ft}$. Overcrowding tunts the growth of the plants and prevents them exhibiting their

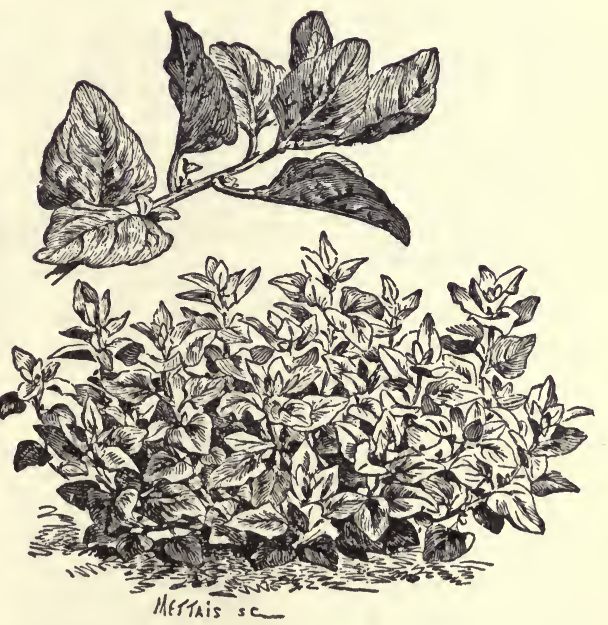

Copyright, V. A. \& Co.

New Zealand Spinach. true character and capabilities. The leaves are not picked singly, as those of the true Spinach are, but the tender shoots are pinched off. Growth is rapid and continuous throughout the summer, and the plant needs no attention beyond watering, which should be frequent and copious. 


\section{SPINACH BEET.}

\section{Beta Cicla.}

THE Perpetual Spinach, or Spinach Beet, is grown for its 1 leaves, of which it produces a continuous supply in the hottest summer, when true Spinach is difficult to obtain. The leaves are boiled and minced like Spinach, for which it makes a very satisfactory substitute, and indeed by many persons Spinach Beet is considered to be superior to Spinach. It is

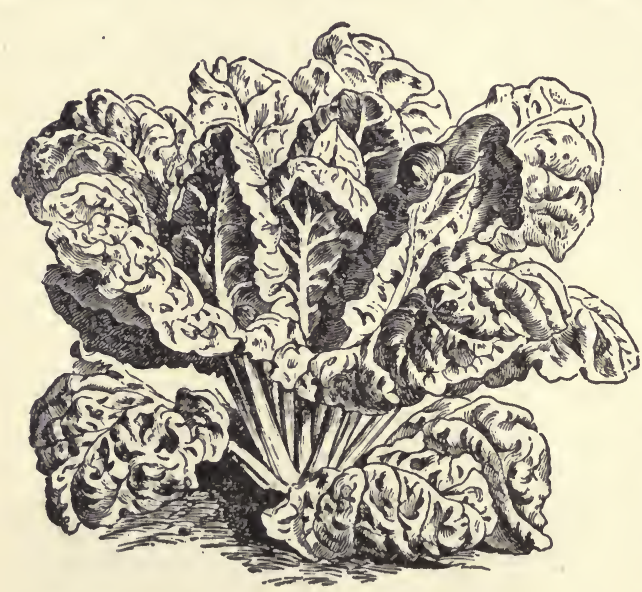

Copyright, V.A. \& Co.

Spinach Beet.

grown in the same way as the ordinary beet, except that the soil should be richer, to promote an abundant leaf growth, and it need not be so deeply dug. The seed is sown in April, and again at the end of July to ensure a supply until late in the season. Sow in rows $15 \mathrm{in}$. apart, and thin out to $8 \mathrm{in}$. from plant to plant. No further attention is then required beyond weeding and occasional watering. As soon as the leaves are large enough they must be gathered, even if not then wanted, so as to have a supply always young and tender. The plants are moderately hardy, being able to bear a few degrees of frost, and therefore continue to yield in the open ground until late in the season. When a supply is wanted through the winter the latest-sown roots may be lifted and grown in a greenhouse or frame. 


\section{STRAWBERRIES.}

\section{Fragaria.}

NO apology is necessary for introducing the consideration 1 of Strawberry culture into a work primarily intended to discuss the profitable production of vegetables. True, the Strawberry is a fruit-one of the choicest and most popular we possess-but it is also an essential feature in most gardens, and fits in so admirably with the general crop rotation of market garden work, that its omission would be a serious mistake. In its season the Strawberry is always in good demand, being a general favourite with both rich and poor, and although it is already produced in this country in enormous quantities, that fact need be no deterrent to laying down further plantations in suitable localities, providing its culture is entered upon with thoroughness. At times and for short periods the markets are glutted with the fruit, but it

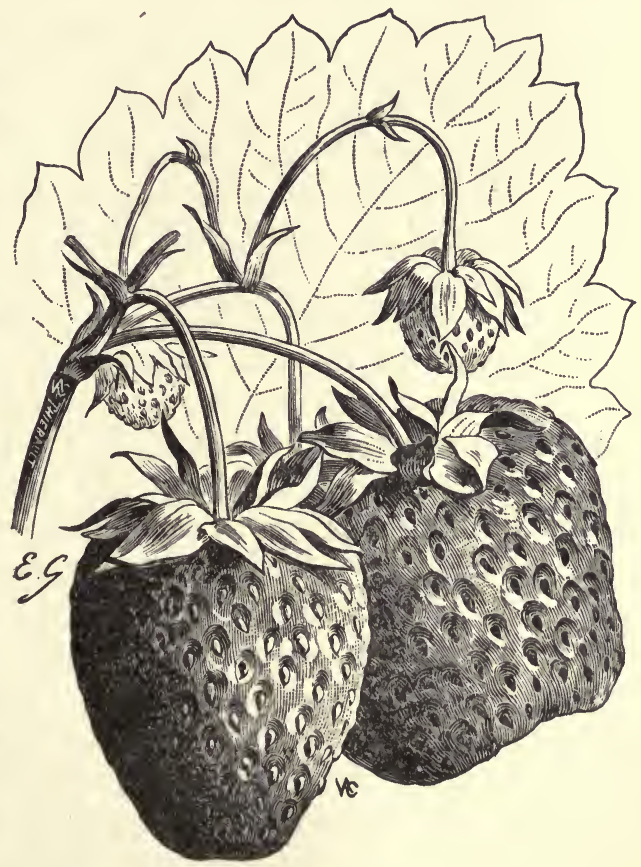

Copyright, V.A.\& Co.

Royal Sovereign Strawberry. is mostly of second and third rate quality, and even then the growers make its production pay very well, on the whole. There are never too many choice Strawberries offered for sale, the demand for them seeming insatiable. The grower who lays himself out to raise only the best fruit and to offer it for sale 
in the pink of condition will find Strawberry culture to be one of the most profitable lines in his business; the more so if he extends his season by forwarding an early variety on the one hand and grows a breadth of a late variety on the other, and so evades the necessity of having to offer the whole of his crop for sale at the time of greatest general production.

Locality.-As indicated above, the locality of the plantation is a matter of the utmost importance-not necessarily in the production of the fruit, but in relation to its disposal. The Strawberry is a soft fruit and will not bear rough handling or close confinement in masses for more than a very short time. To be at its best it should be disposed of early in the same day it is gathered-almost before the morning dew has dried upon it, and whilst its bloom and brilliant colour are unimpaired. To secure this condition in perfection the fruit needs gathering soon after daybreak, packing immediately, and despatching by road to its destination, where it should arrive by $8 \mathrm{a} . \mathrm{m}$. or soon after, without re-handling. If such an ideal situation is not possible, the next best is one in close proximity to a main line of railway, where there is a suitable service of through trains, preferably those with fruit vans attached. By this means the fruit can be put upon the market in good condition early in the same day it is gathered, with a minimum of re-handling and consequent damage from shaking and rough usage. In places where the railway service is direct but not convenient for delivery of the fruit early enough to be disposed of at that day's market, it may be made fairly satisfactory by gathering and packing the fruit when quite dry, before the evening dew begins to fall, and despatching it by a train which will ensure delivery of the packages soon after the opening of the market the following morning. The worst possible situation which can be selected for the culture is one remote from populous centres, from which there is no possibility of direct delivery by road, either to market or to shops, and where the only available outlet is by a branch line of railway. Under such circumstances the fruit, however carefully it may be packed, is frequently ruined by delays and rough handling; in the numerous changes of vehicles or trains to which it is subjected before it finally arrives at its destination, it gets so jolted and 
bruised that it is often partially reduced to a pulp, and if not also mouldy and altogether worthless (Strawberries under such conditions will go mouldy in less than twenty-four hours) the value of the consignment is so seriously reduced as to cause a considerable loss to the grower.

The Soil and its Preparation.-The best soil for Strawberries is one of a substantial nature-a deep heavy loam inclining to clay being generally the most esteemed, although it must not be overlooked that heavy crops of excellent quality are taken from plants growing on well-cultivated soil which is distinctly sandy or stoney. The fact is, that although the Strawberry will not thrive in a dry soil or climate, it will yield paying crops on any well-cultivated fertile soil which can be kept in a moist condition during the summer months-but, other things being equal, a heavy loam will give the best results, and should receive the preference for all but the earliest crops. The aspect of the land and composition of the soil have both great influence in determining the time of ripening. The chief points favouring earliness are-a soil of sandy composition with a porous subsoil, an aspect inclining slightly to the south or south-east, and plants of a proved early variety. Lateness is secured by planting on heavy cold soil, with a north or northwestern exposure, and selecting a late variety. The grower should therefore make the best of his circumstances, planting the bulk of his crop to suit the formation of his land, whether early or late; if he has the choice of a variety of soils and situations he should make such selections and combinations as will suit his particular purpose, remembering that the more his season is extended in either direction, the more likely he will be to escape the losses occasioned by being obliged to sell on a glutted market.

Drainage should be attended to before a new plantation is made, and if not satisfactory it should be made so, for whilst the Strawberry thrives best in a moist soil, stagnant water is fatal to its well-being. The drainage being satisfactory, the next step is to work the ground thoroughly and deeply, incorporating well-rotted manure at the same time-it is of little use attempting to grow Strawberries for market in soil in a low condition of fertility, When the plants are to occupy the 
ground for several years, small areas should be bastard trenched and large areas subsoil ploughed, but when the plantation is only to be cropped for one or two seasons good ordinary cultivation will serve every purpose. Newly-broken pasture land is unsuitable; it should have been previously cultivated for at least one season, to reduce such pests as wireworms, surface caterpillars, leather jackets and cockchafer grubs, which harbour in old grass fields, and also so that the soil, by the decay of the sod, may be brought into the compact condition in which the Strawberry thrives best.

For summer or autumn planting, the preparation of the soil should be completed as long as possible beforehand, so that it may become settled down before the plants are set out. For spring planting it is advisable, when possible, to ridge up the soil before winter, so that it may be made mellow and friable by the action of the weather.

Runners. - When the Strawberry plant begins to flower it puts forth long, slender, bare, cord-like branches, known as "runners." When these branches have attained a certain length their extremities become swollen and bear a cluster of leaves, and from the under surface roots are emitted. These roots enter the soil as soon as they come in contact with it, and thus

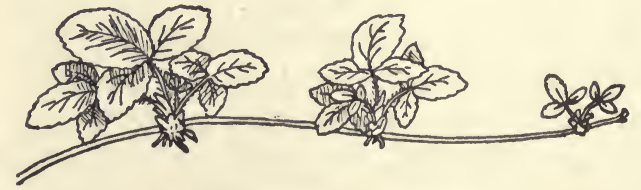

Strawberry Runner. the cluster begins a separate existence at a short distance from the parent plant. The runners do not end with the production of one cluster of leaves, but each continues growing throughout the summer until four or five new plants have been formed in succession. If the runners are cut off the plant will produce fresh ones. All varieties are not equally prolific in the production of runners, some few being rather shy in this respect. In any batch of plants there are often a few "blind" onesthose which form neither flower nor fruit-and such are always fine looking plants with bold foliage, and are the most prolific in the production of early and vigorous runners; they should be searched for when the plants are blooming and destroyed, as plants propagated from them are likely to be barren also. 
General Culture.-After a plantation is established, weeds should be kept down rigorously. Runners should be removed as fast as they appear, serious neglect in this particular being likely to ruin a plantation, and in any case when runners are allowed to grow they do so at the expense of the following season's crop. At all times during spring and summer, except when a mulch prevents, the surface soil should be kept in a loose condition by frequent stirring with hoe or cultivator; this will promote root action and ensure vigorous growth, the crop of the following season depending on the growth the plants have made in the previous year. After the fruit has been gathered and the runners removed, all the torn and withered old foliage should be carefully cut away, and with the litter and any other rubbish on the field, gathered together in heaps and burnt. In the autumn a mulch of rich compost or well decayed manure is given, and on large plantations a plough is then run between the rows, which puts the plants on ridges and keeps the roots well drained; in the spring a horse-hoe is used to level the ground again. Where horse labour is not used, digging between the rows must not be permitted, but in the winter a light forking over, about 3in. deep, will sweeten the soil and leave a friable surface to facilitate the work of hoeing. After the spring hoeing is done a mulch of long manure or clean straw is laid along the sides of the rows and between the plants to keep the soil from splashing on the fruit during heavy rains.

Strawberries do much better when grown by themselves, in an open situation away from bushes and trees, but sometimes they are grown between rows of young gooseberry and currant bushes, where they succeed fairly well for two or three years, until the bushes grow large and shade them; thus, they enable the grower to pay expenses until the bushes become remunerative. A plantation will usually bear well for three seasons, and it is even possible under good management to take fair crops from plants which have been established ten or twelve years. But it is very inadvisable to let them crop for more than three seasons, and many good growers turn the plants in directly they have borne two crops, and find this the most profitable method, the second crop usually being the heaviest the plants will bear. 
When the production of extra fine fruit is the principal aim of the grower the plants should only be permitted to produce fruit once, digging them in immediately afterwards. The first crop, although not so abundant as the second, always yields the finest fruits, and annual plantations, as described later in the paragraph "Strawberries in Beds," will be found the best method to adopt in gardens where the soil is worked intensively, as not only are the individual fruits much finer, but from a given space the total crop is very much heavier than can be obtained by ordinary methods.

Few growers, especially those who produce the fruit on an extensive scale, realise the importance of irrigation when the fruit is swelling, particularly when the weather is dry; under such circumstances, when possible, copious supplies of water should be given, and will be found to greatly increase both the size of the fruit and the total weight of the crop. Where the plantation is inconveniently situated for giving water, a good mulch of long straw manure, along the sides, between, and partially over the plants, put on not later than the middle of March, will both feed the crop and keep the fruit clean. The foliage grows through fresh and strong, and by the time the fruit appears the straw is washed clean by the rains.

Plants.-The success of the plantation, both immediately and permanently, depends upon the quality of the plants used, and the importance of this fact cannot be too strongly impressed upon the inexperienced beginner in Strawberry culture. Where a plantation is being formed for the first time, the plants should be obtained from a firm of good standing and repute, who make the propagation of Strawberry plants a leading line in their business. The first cost of the plants will probably be a little more than would be the case if they were ordered haphazard from advertisers who offer them very cheaply, but it will be money well spent, and really far cheaper in the end, to make a start with good plants instead of with miserable, stunted specimens, gathered anyhow from fields which have been allowed to run wild; the misguided and unfortunate purchaser of such plants often receives them in the form of bags of sweating rubbish not worth the cost of railway carriage. The only plants fit for the intended purpose are those showing 
good growth, with plenty of leaves, and strong, abundant light-coloured roots; small stunted plants, small of leaf and sparse of root, or old plants with dark-coloured, withered roots, should always be rejected-they rarely become profitable.

The first runners from a plant are always the strongest as well as the earliest. Those from vigorous young virgin plants that have never been weakened by fruiting are still earlier and stronger than the best from the fruiting stock, and it is more than probable that if propagation from virgin plants was continued for some years a strain of any variety would be built up which would far exceed in vigour, healthfulness, and cropping powers that which had been propagated from plants debilitated by years of fruit production. . That being so, and an annual supply of such runners being quite easy to obtain, it is strongly recommended that at least on those limited areas where the quality of the fruit is the principal aim, the following method be adopted: During the winter prepare a bed or beds, $5 \mathrm{ft}$. wide and as long as necessary, by thoroughly digging and incorporating at the same time a generous dressing of well-decayed manure.' Towards the end of March, when the weather has been fine for a few days, stir the surface of these beds, and put on a 2 in. covering of rich compost or sifted old hot-bed manure, supplemented with a light sprinkling of sulphate of potash and superphosphates. Then carefully plant strong lifted runners or, preferably, plants from pots, in two rows $2 \mathrm{ft}$. apart, and 18in. from plant to plant, closing the soil well around the crowns and making it very firm about the roots. Remove all blossom as soon as it appears. As runners are put out peg down the earliest ones from each plant until the whole of the space is covered with young plants at about 6in. apart, after which all others must be rigorously removed. If the weather is dry an occasional soaking with water will assist rooting very materially. As soon as the runners are rooted strongly separate them from the old plants. By the middle of July the young plants will be growing vigorously, and if transplanted to their fruiting quarters before the end of August-but the sooner the better - they will yield a good crop of large choice fruit the following season. At the same time sufficient runners should be planted $6 \mathrm{in}$. apart each way in a nursery bed to make 
up fresh beds in the following spring for a further supply of plants, or they may be left where they are standing through the winter. The old plants, not yet having fruited, will yield a great crop the following season.

Summer Planting.-All things considered, the best time to make a new Strawberry plantation is early in August. This entails more labour than when the plantation is made either in autumn or spring, but if August planting is well done and the plants properly cared for afterwards, a good crop of fruit can be gathered from them the following season, whereas when planting is done on either of the other dates none can be had until the second season; therefore the additional labour receives an abundant recompense. One of the best crops to precede summer-planted Strawberries is early potatoes; the tillage and manuring which potatoes require cleans, aerates, and enriches the soil, and if it is harrowed and rolled after the crop is lifted it is in prime condition for receiving the plants. Some difference of opinion exists as to the best distance apart to set them; but much depends upon the vigour of the variety and the nature of the soil. A safe rule on the average is to set the rows $2 \mathrm{ft}$. apart, and the plants $18 \mathrm{in}$. apart in the rows, but some varieties are all the better for $6 \mathrm{in}$. more space each way, whilst others need not be more than $1 \mathrm{ft}$. apart in the row. It is a good plan to omit every third row for convenience of gathering and cultivation, as then there will be no need to trample amongst the plants, for although the Strawberry thrives best in firm soil this does not mean a bed almost as hard as concrete, which is the condition most heavy soils would be in when dry, if trampled on when wet. This space can be filled with lettuce or some similar crop which is cleared before gathering begins, and there is thus little or no loss. Dull cloudy weather, when the soil is moist, should be chosen for the work when possible, but do not plant when the soil is wet and pasty, or the roots will not run freely. Do not plant with a dibber, but use a garden trowel, and see that the roots are spread out evenly, then fill in with fine friable soil, which should be pressed quite firmly round the roots, further consolidating the earth by treading in afterwards. The collar of the plant when all is finished should be just level with the 
surface-not in a hollow or it will hold moisture and induce decay, and not raised above the surface, because the tendency of the plant is to rise out of the ground and this must be counteracted as much as possible. If the weather is dry, every

Right and Wrong Ways to Plant Strawberries.

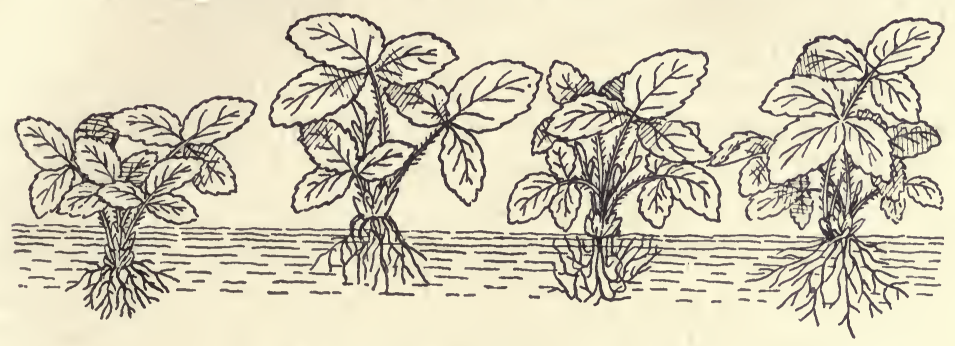

Buried Not planted The proper depth Well planted, too deeply. deep enough. but badly planted; at proper depth. roots turned up.

precaution must be taken to keep the roots of the plants moist. A box is better than a basket to carry the plants in, because the wind cannot blow through the sides, and it should be kept covered with a wet sack. When the plants have been obtained from a distance it is always best, before planting in dry weather, to dip the roots in a "puddle" (a mixture of soil or clay and water, of the consistency of cream). On light soils, as soon as planting is finished, it is a good plan to run a light roller over the whole area-plants as well, it will not hurt them. In dry weather water should be given unsparingly until the plants are established. Weeds must not be permitted at any time, and the surface soil should be kept constantly stirred during the growing season with hoe or cultivator; this, as has been frequently mentioned, not only keeps the weeds down, but helps to retain moisture in the soil and keeps it friable and aerated, with the result that the plants grow more vigorously, and so make stronger crowns.

Autumn Planting.-When planting cannot be conveniently done in the summer, autumn is the next best time, providing the operation can be completed by the end of October ; Strawberries may be planted up to the end of December in open weather, but it is very inadvisable to do the work so late, as the roots remain inactive in the cold wet ground, and it is almost 
certain that many of the plants will die and need replacing; therefore, if planting cannot be finished at latest by the end of October it is best to leave it until spring. Peas are one of the best crops autumn-planted Strawberries can follow; the ground should be broken up as soon as the haulms are carted away and the interval before planting allows ample time to get the soil into capital condition for the work. If the runners have been grown at home no more should be lifted than can be planted the same day, so that the roots will not get dried by wind. If they have come from a distance unpack immediately on arrival, spread out thinly in a shady place, and sprinkle lightly with water; if they cannot all be planted at once open a shallow trench on the north side of a wall or hedge and stand them thickly in this, covering the roots with moist soil. When planting time arrives trim off about one third of the roots with a sharp knife and remove all decayed leaves, then mark out the rows and plant as directed on pages 323-4.

Spring Planting has many good points which commend it to the favour of the busy grower, and there is not the least doubt that it is far better to plant in spring than late in the autumn. In spring the soil is cool and moist, the roots begin to work at once and the plants grow strongly from the start, so that there are very few losses, When this course is to be followed the runners should have been cleared from the fruiting plantations in autumn and heeled in on a bed of well-drained soil. Open a shallow trench wide and deep enough to take in the roots of the runners and so that the crown is just above ground level; stand them close together in a single row along one side, then open another trench, parallel with the first and about 6in. away from it, using the soil to cover the roots of the plants in the first trench. Cover the roots well and tread in the soil firmly so that every plant is bedded in tightly. Trenches may be repeated in this way until all the runners are disposed of, and they will then be found in first-rate condition for planting in the spring. The ground should have been well manured and ridged up in the preceding autumn, so as to get the full benefit of frosts in pulverising the clods and making the whole mellow and friable. After a few days of fine weather about the beginning of March, when the soil works well and is not wet 
or sticky, it should be harrowed down and levelled. Before planting remove any withered or dead leaves there may be on the runners and shorten the longest of the roots. The distance apart of the rows will depend upon the variety planted and the nature of the soil, but where horse-hoeing is intended it should not be less thān $2 \mathrm{ft}$. 6in. During the first season another crop may be grown between the rows, onions being a favourite one for this purpose. When this is the case two rows of onions, 9in. apart, are drilled in the spaces as soon as the Strawberries are planted. During the first season any blooms which show must be picked off as soon as seen and no runners should be allowed to form.

Strawberries in Beds.-Planting in single rows, as already described, is the customary method approved and carried out by the vast majority of growers; there is, however, a method of growing in beds, described below, which is worthy of serious attention from all who aim not only at the production of choice fruit but who also strive to "forward" a portion of their crop so as to have ripe fruit ready a week or ten days earlier than it would ripen naturally in the open. The method is simple and profitable, and if carried out thoroughly will ensure a heavy crop of fine fruit being taken off a comparatively small space.

The requisite number of good strong runners from maiden plants should be set out 6in. apart on a nursery bed, not later than September-the earlier the better. Here they remain until planted out permanently in the following spring. During the winter the land intended for the plantation should be bastard trenched-a good dressing of well-decayed farmyard manure being incorporated with the top spit at the same time -and thrown up into beds $5 \mathrm{ft}$. wide, with furrows or pathways, $12 \mathrm{in}$. wide and $6 \mathrm{in}$. deep, dividing the beds. The surface of the soil should be left rough for the weather to act upon. About the end of March, when the weather is fine and the soil is in nice working condition, prepare the beds and set two rows of plants on each, as described for the propagation of runners on pages 322 and 323. Lift the plants from the nursery beds with a garden trowel, each with a good ball of earth. Keep the surface of the soil stirred by frequent hoeing, but do not 
cut in more than 1in. deep. Remove all blossoms as soon as they show, as the plants must not be allowed to fruit. When runners appear peg down the earliest until the whole surface, except a 9in. margin along each edge, is covered with plants 9in. apart. They must not be closer than this or the plants will be overcrowded and the size of the fruit will suffer in consequence. The beds should be kept moist by frequent watering until the runners are rooted. As soon as this has taken place cut the old plants out. Each bed is now covered with young, vigorous, early-rooted plants, which by suffering no check from transplanting make extra fine crowns by the autumn. No further runners must be allowed to form, weeds must be kept down, the surface soil stirred, and if the summer should prove very dry the beds should occasionally be watered copiously-preferably in the evening-so as to help the plants to make all the growth possible, the crop of fruit depending largely upon the growth of the preceding season. The furrows between the beds will remove all surplus water in the winter and in conjunction with the deep cultivation will keep the plants free from stagnant moisture and ensure healthy root action. When growth begins in the spring apply the fertilizers mentioned later. When the plants are in bloom dress the bed with good equalized guano, and water copiously until the fruit begins to show colour. The result will be a very heavy crop of extra fine fruit which will surprise the grower who has adopted this method for the first time and will repay him abundantly for all the trouble he has taken.

To perfect this system, a portion of the plantation should be brought to the fruiting stage earlier than it would otherwise be under normal conditions; this procedure is known as "forwarding," and is accomplished by covering the plants, as soon as growth begins in March, with movable box frames. The most convenient size of frame for this purpose is that described on pages 69-71, which will fit comfortably on the $5 \mathrm{ft}$. bed with a margin of a few inches of earth on each side to give it a firm foundation. If the plants were kept $9 \mathrm{in}$. from the the edges of the bed, as directed, the nearest will be a few inches from the side-boards of the frame. After the lights are put on ventilate freely, never closing them entirely except in 
rough or frosty weather. On no account let the plants suffer from want of water, but on the other hand do not over-waterthe soil should be maintained in a nice moist condition suitable to free and uninterrupted growth. On the occasion of a warm gentle rain the lights may be removed altogether so that the plants may receive the full benefit of it. As the weather gets warmer raise the lights more and give a light watering over the leaves through a fine rose morning and evening. When the blooms begin to open this dewing over should cease unless the weather is exceptionally hot and dry. Fertilization of the flowers should take place daily, by brushing them lightly over with a rabbit's tail or bunch of feathers tied to the end of a stick; this scatters the pollen.

The plants on these beds, whether forwarded or fruited in the open, should only be allowed to bear one crop, and as soon as that is gathered the plants should be chopped out or dug in and the ground prepared for some other crop. A fresh plantation should be made each spring, and then each season there will be one in bearing.

The Forcing of Strawberries.-The preparation of the soil for forcing is a matter of importance and has a great influence upon the ultimate result. The principal ingredient should be good turfy loam, cut from meadow land if possible. This should be cut and stacked, grass side downwards, in the previous autumn, adding at the same time alternate layers of well-decayed manure-about one-fourth manure to three-fourths loam-and a sprinkling of powdered lime, bone meal, and kainit between each layer; if there are wireworms in the sod, one of the advertised wireworm destroyers should also be added to each layer. Make the heap fully large enough for the intended work, as any surplus will be found useful for many other purposes. Early in the spring cut the heap down, thoroughly mixing it and chopping up the turf with a sharp spade in the process. Stack it again and repeat the turning and chopping twice more at intervals of five or six weeks; the largest of the pieces then should not exceed the size of a walnut. The soil should be nicely moist and if not in this condition it must be watered well at each turning; liquid manure used for one watering will still further improve the soil. At the second turning sufficient 
should be passed through a screen to fill the pots for layering, the lumps being thrown back on the heap. For this purpose the soil needs to be in smaller particles than for potting at a later stage, so that the delicate rootlets may enter it easily. When there is an opportunity for doing so it is a good plan to fill the pots a few days before they are needed and then there need be no undue delay in getting them into position at the proper time. Before filling them soak the pots in water and see that the soil is moist; also be sure to provide sufficient crocks or other drainage material. When filled, stack them in a cool shady place, where they will be safe from the direct rays of the sun and also from rain; a few wet sacks thrown over them will help to keep the moisture in the soil.

Strong well-rooted runners of a good forcing variety should be lifted at the end of July and potted in 32's, either one or two to a pot; or they may be layered in small 60's, and after becoming well rooted, potted singly in 32's. When the runners are to be rooted directly into the small pots these should be sunk in the ground up to the rim, and so disposed as to leave a

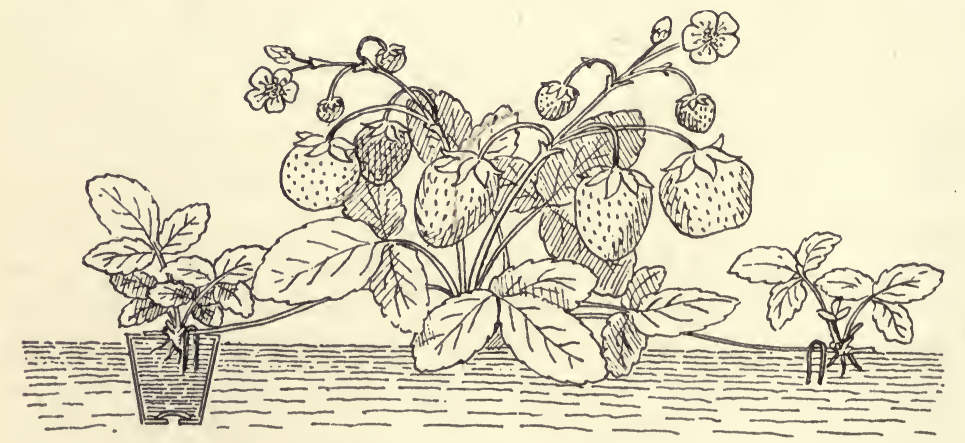

$\begin{array}{cc}\text { Two Methods of Layering } \\ \begin{array}{c}\text { Runner Layered into } \\ \text { a 60's Pot. }\end{array} & \text { Strawberry Runners. }\end{array}$

Runner Layered, into the Ground.

clear path between every two rows for convenience in giving water, which matter which must on no account be neglected. Do not take more runners from one plant than is absolutely necessary, and when possible confine these to one on a stalk, that nearest the parent plant being usually the best. Examine each runner before layering it to see that it contains a centre 
of embryo leaves; those without this centre are almost sure to be blind and should be discarded. Always layer enough plants in excess of the actual requirements to allow for losses and for rejecting poor plants. Having plunged the pot and selected the runner cut off the continuation of the stalk or "string" about half an inch beyond the tiny plant, then fix this on the soil in the middle of the pot. The fixing may be done in a variety of ways; in many places a lump of earth or a small stone placed on the string is considered sufficient, whilst in others forked twigs or bits of bent wire are employed; common hairpins are as cheap and convenient for the purpose as anything that can be used. Be sure that the soil is fairly firm in the pot and the runner pressed down upon it and fastened securely. The soil in the pots must be kept moist by watering daily, and as the plants grow and the pots fill with roots this attention will be required twice daily, especially if the weather is very hot, as it usually is in July and August.

When the runners are allowed to root, in the ground the surface should first be well hoed and then covered with 1 in. of old hot-bed manure, finely sifted, and the whole thoroughly watered. The same care and attention in selecting, pegging down, and watering will be required in this case as when pots are used, but watering will not need doing so frequently.

Early in August the runners should be ready for placing in the fruiting pots (32's), whether layered in small pots or rooted in the ground. In the latter case the plants must first be well watered and then lifted with a good ball of earth to each, only lifting so many at a time as can be potted immediately. Each pot must be provided with plenty of drainage material, carefully arranged so that water can pass away freely, as nothing is more harmful to the plants or more likely to cause the whole operation to be more or less of a failure than the presence of stagnant water, which causes the soil to become soddened and sour. A layer of the roughest pieces of soil should be put over the crocks, and then the pot should be partially filled, leaving enough space so that when the plant from the 60's pot or that with a ball of earth is placed inside, the collar of the plant will be about lin. below the rim of the large pot, the crocks in the small pot having been first removed. Fill round graduaily 
with soil, making it quite firm with a wooden rammer as the pot is filled, bringing the new soil about half an inch deep

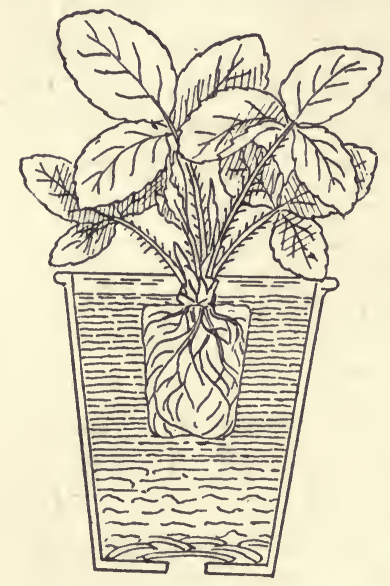

Section showing Proper Method of Potting Plant from Small Pot in a Large one. over the previous surface, so that the crown of the plant just stands above it. Firm potting is essential to success; satisfactory crops of Strawberries can never be obtained, either from plants in pots or from those in the open ground, when the soil about the roots is in a loose condition.

After potting, set the plants on a bed of ashes, 2in. deep; this will prevent the entrance of worms into the pots and keep the drainage holes from being blocked by earth. Where sufficient box frames are available it is a good plan to stand the pots inside these, without lights; they can then be very easily protected through the winter. In any case the pots must be so arranged that pathways are left between them at intervals for convenience of watering. Shade from the sun should be provided for a few days to enable the roots to quickly begin working in the new soil. Dew the leaves of the plants over daily but give no other water until the shade is removed. They must then be exposed to the full sunshine and will need a good watering. They must now be attended to with great care; only moderate quantities of water will be necessary at first, but as the pots get filled with roots copious supplies must be given to keep them growing freely-sometimes twice a day when the weather is very hot-and a syringing every afternoon will be beneficial and keep them free of insect pests. Runners must be cut off as soon as they show and the soil kept free from weeds.

When the weather becomes cool and wet in the autumn watering must cease, and it will be necessary to provide some protection for the pots, or many will get broken by the frost. If the pots were stood inside box frames, as suggested, the lights can be put on and no further protection will be required 
unless the weather gets very severe, when they may have an additional covering of mats. In this case the lights should never be closed down entirely except in hard frost. Where no frames are available it is a good plan to stand the pots close together, plunged up to the rim in ashes, the ashes being kept in place by boards on edge round the outer margin of the mass. In many places the pots are simply laid on their sides and stacked on the top of each other, with a covering of straw over the top layer; they do very well in this way except that the soil is apt to become too dry and each pot needs soaking in water before being taken in for forcing.

The first hot-beds for forcing are made, $2 \mathrm{ft}$. thick, at the end of January, according to the directions given on pages 128-130. When the heat has fallen to 50 degrees put on the frames, put fine soil inside, 2in. deep, and stand the pots on this, close together, packing soil round them until they are all immersed in it up to the rims. Give no water until growth begins, and then very moderately, increasing gradually as growth becomes stronger. Plenty of air should be given whenever the weather will permit. Dew over the plants with water through a fine rose every bright day until the bloom begins to open, when it must stop for a time until the fruit is "set." In order that the pollen of the flowers may be readily scattered, and so ensure proper fertilization, the atmosphere inside the frame must be kept as dry as possible during the blooming period, dampness in the atmosphere being very detrimental to a good "set" of fruit. During the same period, whilst avoiding cold draughts, as much air must be given as the state of the weather will permit, and the flowers must be lightly brushed over daily, about mid-day, with a rabbit's tail.

During this time watering at the roots must not pe neglected, but it must be done carefully, avoiding wetting the foliage. As soon as a sufficient number of fruits are seen to be set, which will be in ten or twelve days after the first flowers open, dewing over daily must be resumed, the atmosphere of the frame now requiring to be kept moist to assist the swelling of the fruit. The soil must never be allowed to become dry at this period, and liquid manure should now be used alternately with clear water. Give a little air during the day but close 
down early in the afternoon. When the fruits are about half coloured stop dewing, give more air, and leave the lights slightly raised at nights if the weather is mild; a free circulation of air whilst the fruits are ripening will improve their flavour. The fruit should be propped up with forked twigs, to keep it from touching the soil. Mats must be used to cover the lights every night whilst there is any danger of frost. A fair amount of warmth must be kept in the bed, and to this end the sides and ends of the bed should be pulled down occasionally and the cold manure replaced with some that is fresh and hot, banking it up to the top of the frameboard.

About the third week in February another hot-bed, $18 \mathrm{in}$. thick, should be made for a second batch of plants, and a third, $1 \mathrm{ft}$. thick, early in March. These will carry on the supply until those being "forwarded" are ready. The last lot do better if turned out of the pots and planted directly in the soil, otherwise the treatment is the same in each case.

Varieties:-The following is a selection of a few varieties, all good and worthy of the market growers' attention, although the list is by no means exhaustive of the best. At the same time it must be remembered that some Strawberries succeed remarkably well in one situation and are very unsatisfactory in another; therefore any variety which has not been proved to succeed in a district should not be planted largely until it has first been tested on a small scale.

\section{Early :-}

Royal Sovereign.-Fruit very large and firm, with a pleasant flavour; heavy cropper; vigorous grower, succeeding almost anywhere; one of the best for forcing; in great favour with growers for market; where only one variety is grown this should be chosen.

The Laxton.-This variety has all the good points of Royal Sovereign except that it does not force well.

NoBLE.-Fruit very large and handsome but of rather poor flavour; very prolific; vigorous grower, succeeding in most places.

Viscountess Hericart de Thury (Garibaldi). - Fruit medium size, firm, and of excellent flavour; enormous cropper; robust grower; forces well; one of the best in any position and succeeds well under trees.

Mid-season :-

SiR Joseph PAXTON.-Fruit large, handsome, firm, and of good flavour; heavy cropper; vigorous grower; forces fairly well; a favourite variety with market growers. 
PRESIDENT.-Fruit large, handsome, and of superior flavour; carries well ; heavy cropper; robust grower; good for forcing and one of the best for main-crop.

FilLBASKET-Fruit fair size and of excellent flavour; very heavy cropper ; requires good culture.

BEDFORD CHAMPION.-Very large fruit of good flavour; vigorous grower; forces well; needs good culture.

LAXTON's REWARD.-Fruit large, firm, and of excellent flavour; heavy cropper, vigorous grower.

DR. HogG.-Fruit moderate in size, firm, handsome, and of exceptionally fine flavour; fair cropper; compact grower; needs good culture; should not be kept over two years.

Late :-

Newton Seedling.-Fruit of medium size, firm, good colour and fair quality; very prolific bearer; exceptionally vigorous in growth.

Givon's LATE Prolific.-Fruits very large, firm, handsome, and of good flavour; heavy bearer, vigorous grower.

WATERLOO.-Fruit very large, firm, of dark colour and moderate flavour; fair cropper; not very strong in growth.

LAXTON's LATEST.-Fruit very large, firm, handsome, and of excellent flavour; fair cropper; robust grower.

All the late varieties should be watered while the fruit is swelling.

Manures:-Well-decayed farmyard manure is undoubtedly the best manure that can be used for Strawberries, as it not only provides the necessary food for the plant but gives to the soil a greater moisture-retaining power, which is a very important feature in this culture. At the same time it would be a mistake to give heavy dressings to a soil already rich with manure; if it is in high condition the plants may go in without any further manure, but if not, apply from 20 to 40 loads to the acre, the heavier dressing being for the lighter soils, and in addition, 1 to $2 \mathrm{cwt}$. superphosphate (or 2 to $3 \mathrm{cwt}$. basic slag), and 3 to 5 cwt. kainit. On soils well manured for the preceding crop the larger quantities of concentrated fertilizers alone will suffice. When growth begins in spring, for each acre mix $2 \mathrm{cwt}$. superphosphates with $1 \mathrm{cwt}$. sulphate of potash, and sprinkle this along the sides of the rows, followed a week or two later by a light dusting over the foliage of lime and soot. If growth is backward give $\frac{1}{2}$ cwt. nitrate of soda. Where very large fruit is desired, after the blossom has fallen ring the plants with good guano and water in several times, or give liquid manure between the rows. 


\section{TOMATOES.}

\section{Lycopersicum esculentum.}

WITHIN a comparatively few years the consumption of the Tomato has grown enormously. Well within living memory the "love-apple" was regarded by the multitude with a mild curiosity on the rare occasions it was exposed to view in the windows of a few large shops, and the only purpose it served was that of a tit-bit for epicures. Now it has become

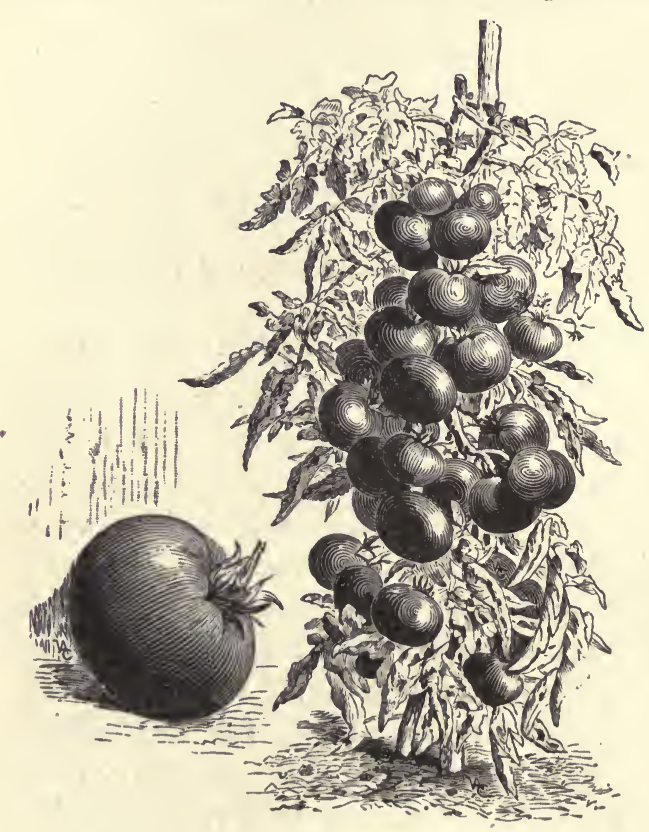

The Tomato. such a popular article of consumption, with rich and poor alike, that the crop forms the main-stay of the huge glasshouse industry in Britain and the Channel Islands which has sprung into existence coincidently with the rise of the Tomato into public favour. Under the circumstances no grower doing a direct trade can afford to ignore the steady and persistent demand for Tomatoes which prevails throughout the summer season. Of course, the matter of supply is simple enough where the grower has glasshouses for the accommodation of the crop, but that method of culture is outside the scope of this work, which only deals with the Tomato so far as its growth in the open-air is concerned. Thousands of tons are so grown in the southern and midland counties every year, and there is no good reason why. the culture should not be extended much further north, 
providing the hottest part of the summer is utilized more for ripening the fruit and less for growing the plant.

Tomato plants in the open-air, when well grown and properly managed, bear far heavier crops for the time they occupy the ground than they do under glass. The growth is sturdier, healthier, and shorter-jointed; the bunches of flowers are closer together, and owing to the better natural conditions almost every flower gets fertilized and produces a fruit; the individual fruits are larger and more solid and, providing they are ripened on the plant, they are of better flavour, although there is the slight drawback of the skin being somewhat tougher through exposure. Whether they begin to bear early or late they continue cropping in profusion until their abundance is brought to a sudden end by the autumn frosts.

But at the same time it must be remembered that the Tomato is a sub-tropical plant, and needs, for its healthy growth a moderately high temperature, a dry atmosphere, abundance of air, and full exposure to sunlight. The climate of Great Britain, from its humidity, changeableness, and frequent lack of sunshine is a very unreliable one for this crop; under the best circumstances very little more than four months is the whole extent of the season when it can be grown in the open-air, and this limited period is frequently shortened by cold cutting winds at the beginning and rain or mists, which encourage disease, at the end.

Under such conditions Tomato growing in the open-air is undoubtedly a speculative business. In a warm dry season it yields good profits, even though the ripe fruit has to be put on markets more or less glutted, when prices rule extremely low, but if the summer is cold or the autumn should prove to be wet the chances of profit are small indeed. And yet a little consideration should make it clear that the element of uncertainty may be considerably reduced, although not eliminated. The grower's efforts are naturally concentrated upon securing the utmost return for his expenditure of capital and labour, but he makes a mistake by supposing that this object is best attained by setting out the largest possible number of plants his limited conveniences will allow him to raise and find accommodation for. As a result of this proceeding the plants 
are necessarily small and frequently drawn; they are planted out in cold soil from which the frost has but lately departed, and in which the roots cannot work until the temperature rises by several degrees. Thus they get a severe check, and no appreciable growth is made for several weeks, the best part of the summer being past before the plant has ripened any fruit. A better method, and one calculated to bring a much greater return for the outlay is to raise fewer plants, to grow them under cool and airy conditions with ample space for development and sturdy growth, and to harden them thoroughly before they are planted out. This should not take place until the soil is warm and the weather settled, so that the plants will feel no check but will begin at once to grow away and to form fruit. By following this course picking would begin much earlier and the fruiting season would be lengthened by several weeks, thus practically doubling the crop besides ensuring higher average prices. The grower who gives his plants proper attention may thus reasonably expect to receive a greater return, and with more certainty, from half an acre of plants than from one acre handled in the usual way.

The Soil and its Preparation.-The Tomato is not at all particular as to soil. The writer has seen plantations bearing excellent crops on soil which appeared to be almost pure sand, and on the other hand has seen acres of plants literally weighed down with fruit growing on heavy clay land. What is most needed in the soil, apart from manurial applications, is thorough working to a good depth, compactness, and perfect drainage. Stagnant water about the roots of a Tomato plant is fatal; the roots decay and the plant speedily collapses.

On light or medium soils, cropped intensively and manured and cultivated accordingly, the Tomato may follow any crop which is cleared away soon enough to allow the soil to be dug over before the plants are set out. The digging should be followed immediately by levelling and rolling. The preceding crop will probably have drawn heavily upon and considerably reduced the soil moisture, and it will therefore be imperative in such a case to give frequent copious waterings as soon as the weather gets hot, and to check evaporation from the soil by surface stirrings or mulches. 
Heavy soils, or any subjected to ordinary cultivation, should be prepared by deep working during the autumn or winter, so that the particles will become settled and compact before planting time, when a shallow cultivation of the surface is all the further working necessary before the plants are set out. On very heavy soils, or any with unsatisfactory drainage, excellent results can be obtained by laying the soil in ridges, $2 \mathrm{ft}$. $6 \mathrm{in}$. apart, at the approach of winter, putting a little well-decayed manure in the furrows during a spell of frost, and splitting the ridges over this not later than February. About the middle of May the ridges are rounded by drawing a light harrow or rake along them, and the plants are set out down the middle of each mound, or rounded bed. This method ensures the soil about the roots lying warmer and drier in any weather, and at the same time provides ample moisture when the season is dry. Although the Tomato plant does not send its roots deeply into the soil it must not be supposed that therefore shallow preparation is sufficient. It is not. The plant revels in hot bright sunshine, and on soil that is deeply worked it appears to flourish the more the hotter and drier the weather is, because moisture is continually rising and feeding it, but under such conditions on soil that has only received a shallow working it would wilt from lack of moisture and growth would be almost stationary.

This is the principal reason for the early preparation of soils; they then become friable and kindly by the dessicating influence of the weather, the particles settle into a compact but not solid mass, and the whole gets saturated with aerated moisture, a large quantity of which is held in suspension as a film surrounding each particle; this moisture rises to the surface during the summer by capillarity, and so affords a continuous supply to the plant. On the other hand, when soil is prepared late in the spring, unless it is in mellow condition by constant working and the frequent addition of humus, it forms into hard clods which can seldom be brought to a good tilth; when undisturbed through the winter it lies more solidly and so contains less moisture, and what it does contain escapes more freely by evaporation, so that late-worked cloddy soil soon dries out, or in the expressive phrase of the countryman, it "lets in the drought." 
Raising the Plants.-Before the time for sowing arrives consideration should be given to the question of what labour is available for pricking out the seedlings, and what accommodation can be provided for the protection of the plants in their later stages. Where only a small area is to be planted this matter may be easily disposed of, but it presents more difficulty where the planting is on a large scale. When the seedlings have grown to the proper size for pricking out, that operation should be attended to at once or, as they are then growing rapidly, they are liable to become drawn and spoiled. Where a large number have to be handled it is a good plan to decide first how many can be pricked out in one day and then to make a daily sowing of sufficient seed to provide for that number. For instance, suppose the area to be planted is one acre; with single-stemmed plants at $3 \mathrm{ft}$. by $18 \mathrm{in}$. apart 9,800 would be required, and to provide for these there should be at least 10,000 good seedlings transplanted. If seed sufficient for 2,000 is sown each day, when they are ready for handling that number can be pricked out daily for five consecutive days, and the last batch will be in the same condition as the first was.

There is no better way of raising Tomato plants than on a mild hot-bed. This should be made about the end of February, $2 \mathrm{ft}$. deep, of fresh stable manure which has been. well sweetened by turning four or five times at intervals of two days. Seed should be sown in the middle of the first week in March, but when a large number of plants have to be raised, sowing can be done a few days earlier and later. The bed should be covered with soil 3in. deep and the seed may be sown either in this or in boxes, but boxes are preferable, because they are convenient for carrying to the place where pricking-out is done. The strips of wood forming the bottom of the box should be nailed on $\frac{1}{4}$ in. apart to allow of drainage. The soil for seed sowing should be of a light sandy nature; a good mixture for the purpose is one-third each of sifted loam, leaf mould or cocoa-nut fibre (or failing either, thoroughly decayed sifted old hot-bed manure), and sharp sand or finely-sifted furnace ashes. In filling the boxes put over the bottom a layer of the lumps thrown out in sifting, then fill to $\frac{1}{2}$ in. from the top with the fine material. Fill the boxes a week previous to sowing, then soak, 
each with boiling water and leave them to drain. Sow the seed in drills $\frac{1}{4}$ in. deep and 1 in. apart, dropping it in thinly; then cover, and press down the top of the soil evenly. Put the boxes in the frame on the hot-bed; they should be within about $6 \mathrm{in}$. of the glass. Cover the lights with mats; these must be removed as soon as the.seed begins to germinate but must be replaced each night afterwards. If the seed in the boxes near the outsides of the bed germinates slowly, or the seedlings are slow in growth, change places with the boxes near the middle of the bed so that all may come along evenly. As soon as the seedlings can be handled thin out to $\frac{1}{2}$ in. apart in the rows, leaving the strongest. Give a little air on mild days, but guard against cold draughts. When required, give tepid water through a fine rose, but be careful in this, as on no account must the soil be kept in an over-wet condition.

- When the young plants have made two rough leaves, which will be about the end of March, they must be transplanted, 2in. apart, into other boxes, about 3in. deep and of any convenient size. The soil now used should be composed of one-half fibrous loam, one quarter sifted old hot-bed manure, and one quarter sharp sand or sifted ashes, with a dash of air-slaked lime or powdered limestone (calcium carbonate). In using lime care must be taken that it does not retain any "quick" or caustic properties, or the roots of the plants may be seriously damaged. The compost should be turned two or three times to get it properly mixed, chopping up the lumps with a sharp spade at each turning; it should then be passed through a screen with $\frac{1}{2}$ in. mesh. In filling the boxes, first put a layer of the largest pieces of soil over the bottom to promote drainage, then fill up with the finest. " The mass of soil should be moist throughout, so that no watering of the plants will be necessary until the roots have begun to work. Handle the young plants tenderly, inserting them in the soil almost up to the seed leaves; make them quite firm, but be careful not to bruise the stems or roots by using unnecessary pressure.

As the boxes are filled they must be placed in frames on a mild hot-bed about $1 \mathrm{ft}$. thick. The bed'should extend $18 \mathrm{in}$. beyond the frames, with the manure brought to the top edge of the frame-board all round the outsides of the bed: this will 
prevent the plants near the outsides of the frames from being chilled, and the gentle warmth of the bed will cause the roots to begin to work at once. Following up the previous calculation for plants required for one acre, seven shallow three-light box frames (described in detail on pages 69 to 73) will be needed to accommorate them, with about 18 or 20 tons of manure for the hot-bed. . Having placed the frames on the bed, cover the manure inside with $1 \mathrm{in}$. of soil and set the boxes on this. As the frames are filled shut down the lights and shade for a few days, then remove the shade and give a little air, gradually increasing this until the lights are entirely removed on warm bright days. The lights must be closed early and covered with mats each night; this precaution should be strictly observed, as a sudden keen frost might destroy the plants when the lights are left uncovered. In watering use tepid water, and with judgment; the soil should be kept moist but never sodden with wet-the too-free use of the water-can is a great cause of disease amongst young tomato plants.

By the end of April the plants will be strong and sturdy and will again need transplanting - this time to 4 in. apart each way. But before this work is begun, suitable accommodation for the plants should be provided. They still need efficient protection from frost, but bottom heat may be omitted. The illustration on the opposite page shows how the plants may be well and cheaply protected, under conditions which ensure the hard, sturdy, short-jointed growth which is so necessary to success. Some expense must, of course, be incurred, but the cost ( $£ 61$ s. 3d. per 9,700 plants) is very small in comparison with the space covered, and the appliances will last for a number of years; moreover, they can be used for many other purposes, such, for instance, as protecting early lettuces and radishes, and still be at liberty for protecting the Tomato plants by the end of April.

The method employed is similar to that of the cheaply constructed cold frames described and illustrated on pages 131 to 133 , but with modifications; instead of lights and mats for covering, ordinary wooden hurdles such as are used by farmers for penning sheep are used, thatched with straw, and these are laid on only at night, being removed entirely during the daytime. 'The frames are $12 \mathrm{in}$. high in front, $18 \mathrm{in}$. high at the 


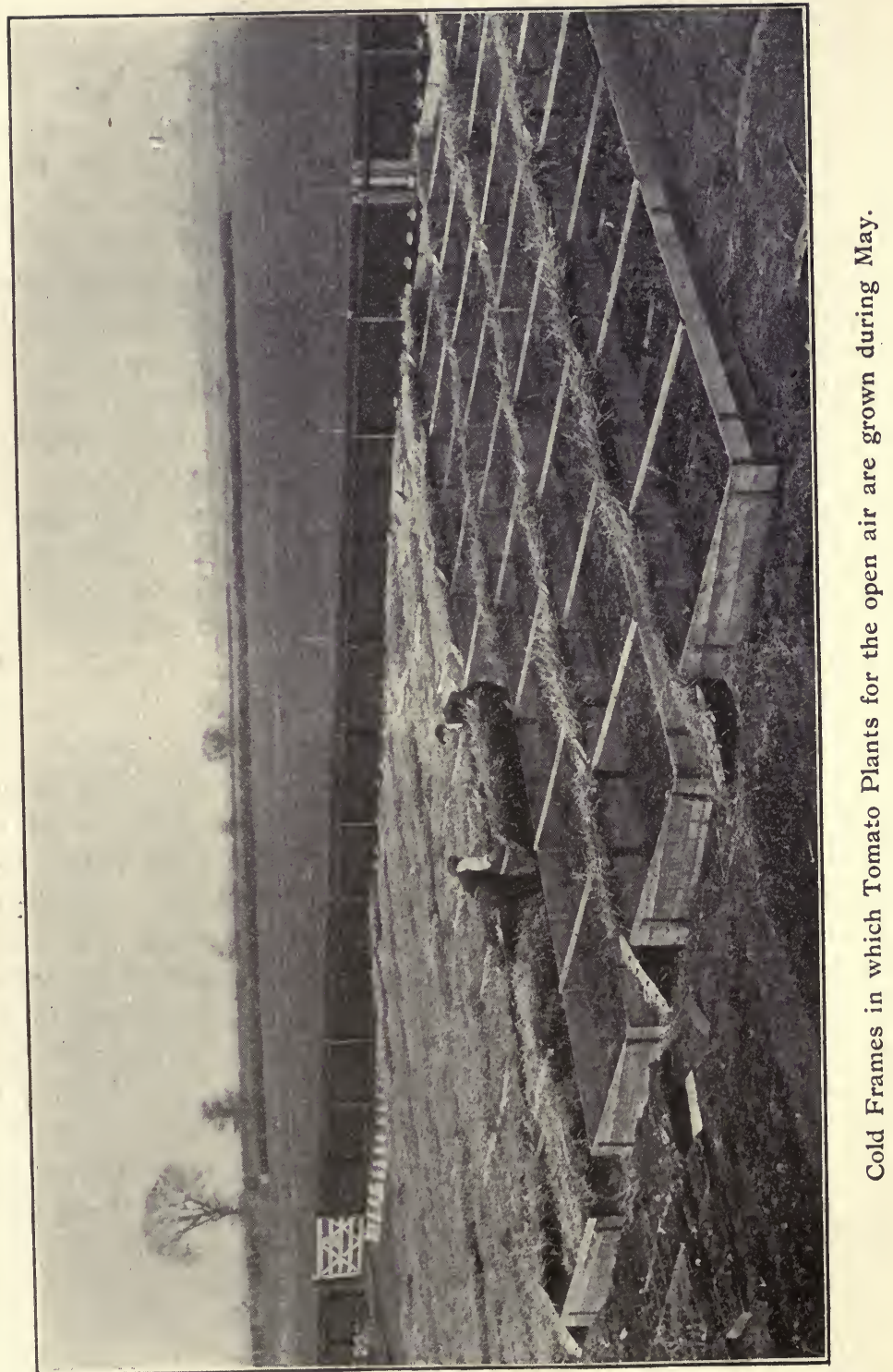


back, $6 \mathrm{ft}$. wide, and $60 \mathrm{ft}$. long, three of them providing space for the plants needed for one acre.

The timber used in the construction is $6 \mathrm{in}$. by $1 \mathrm{in}$. unplaned yellow pine boards, in $12 \mathrm{ft}$. lengths. Two boards for the front and three for the back are held together, one above another, with cross-pieces of $3 \mathrm{in}$. by $\frac{3}{4} \mathrm{in}$. lath, nailed on. The $60 \mathrm{ft}$. frame is thus constructed in five 12ft. sections. The back and front boards are stood on edge and held in position at the foot by pegs driven into the ground at suitable intervals, and at the top by $3 \mathrm{in}$. by $1 \mathrm{in}$. battens, nailed across from back to front at intervals of $6 \mathrm{ft}$. The end boards each take $2 \frac{1}{2}$ pieces $6 \mathrm{in}$. by $1 \mathrm{in}$. $6 \mathrm{ft}$. long, the top board being sawn diagonally from corner to corner throughout its whole length, thus forming the necessary slope from back to front. The hurdles for covering are $6 \mathrm{ft} .6 \mathrm{in}$. long by $3 \mathrm{ft}$. high, and each has four horns, two at top and two at bottom, projecting about 6in. Straw, about $2 \mathrm{in}$. thick, is laid across the hurdle to the extremity of the horns, so covering a depth of $4 \mathrm{ft}$., and this is held in place by three sticks laid across the straw, lengthways of the hurdle, and secured by nails.

Two hurdles cover one $6 \mathrm{ft}$. section of the frame, the lower one being laid on first; the bottom edge of the upper hurdle overlaps on the lower one, thus forming a roof which is impervious to any ordinary rain or frost. One end of each hurdle rests on the batten which crosses from back to front of the frame and the other end overlaps on the preceding hurdle. A space of $3 \mathrm{ft}$. is left between the frames. When the hurdles are taken off each morning they are leaned against the back of the frame in such a way as not to project above it and so keep direct sunlight from a portion of the frame behind; or they may be utilised during the daytime as a fence round the frames to shield the plants from cold wind.

l'ne approximate cost of the materials (delivered within a reasonable distance) required for completing these three $60 \mathrm{ft}$. frames is as follows:-

83 boards, $12 \mathrm{ft}$. long, $6 \mathrm{in}$. by 1 in., at $6 / 3$ per $100 \mathrm{ft}$. run ... £3 26

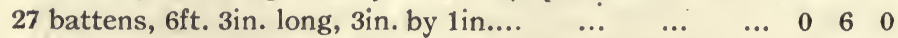

150ft. 3 in. by $\frac{3}{4}$ in., 3/9; 72 pegs, (say) $5 /$. ; nails, (say) $2 / . \ldots 00109$

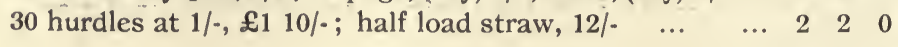


Some growers prefer two stems to their open-air Tomato plants, in which case one-third less plants and one-third less protective appliances would be needed for a given area. When this method is to be followed the top of each plant should be pinched out during transplanting, to cause two stems to break away. If more than two branches show they should be removed as soon as seen, as also should any side branches on either double or single-stemmed plants, so as to concentrate all the strength of the plant in the main stems.

Having made the necessary provision for protection, the plants are lifted very carefully, with as much root and soil as possible, and set out, very firmly, 4in. apart, in other boxes, which are at once placed in the frames. The soil should be similar to that used before, except that the sand and decayed manure should be only one-eighth each of the whole instead of one-quarter. It does not need sifting, but should be well mixed and chopped over until there are no pieces larger than a small walnut. It should be in a moist condition, so that no watering will be needed for several days after transplanting-until the roots begin to work. Then water must be given cautiously, remembering that to keep the soil in a sodden state is sure to make the roots rot and so cause serious mischief, although, on the other hand, copious supplies must be given when the plants are growing freely, as then the boxes dry out quickly, especially under a hot sun.

Planting Out.-By the end of May the plants are fine sturdy specimens, thick-set and hard, about 7in. or 8in. high; in fact, just in the condition in which Tomato plants for the open-air ought to be. There should be no hurry about planting out; if the weather is warm and appears settled at the beginning of June the work may then be begun, but it is best to defer it for a week, or even a fortnight, rather than plant out when the ground is cold and the wind harsh and biting. The soil in the boxes will by this time be filled with roots. . The day before planting, cut the soil into square blocks by passing a sharp knife both ways between the plants to the bottom of the box; then water thoroughly. Each plant will now lift out with its roots practically intact and carrying a mass of soil; it can therefore be planted out without getting any appreciable check; 
no more than if it had been grown in a pot, whilst it is raised with more certainty and much less trouble. Before planting, care must be taken that the soil about the roots is moist throughout; if dry it would remain so for a long time afterwards, and as a consequence growth would be very slow and uncertain. The plants could, of course, be watered immediately after they are set out, but that would not moisten the ball of soil about the roots so effectually as when done beforehand, and in any case watering directly after transplanting ought always to be avoided when possible, as the roots begin to work more quickly in the new soil if the ball of soil round the roots is moist and no further water is given until growth is perceived. Care must be taken not to set the plants too deeply in the ground. A hole should be made just deep enough to allow the mass of soil and roots to be covered with $\frac{1}{2}$ in. of new soil, and then each plant should be trodden in very firmly. Plants raised and set out in the manner described will begin to grow and bloom right away, and every bloom will carry abundance of pollen, so that there will be no doubt about the fruit setting, huge trusses being formed within a few inches of the ground in the time softer plants are taking to get established.

When the growth is to be confined to a single stem, the plants should be set from $15 \mathrm{in}$. to $18 \mathrm{in}$. apart in the row; with two stems, the distance between the plants should be from $2 \mathrm{ft}$. to $2 \mathrm{ft}$. $6 \mathrm{in}$. On strong or rich soil the greater distance is the best, as there is more lost than gained by too close planting. The rows should run north and south, at an average distance of $3 \mathrm{ft}$. apart, though this can be varied by arranging them at $2 \mathrm{ft}$. $6 \mathrm{in}$. and $3 \mathrm{ft}$. $6 \mathrm{in}$. alternately, the wider spaces being more convenient for working amongst the plants and carrying baskets of fruit.

Supporting the Plants.-Some kind of support must be given to the plants to keep them from sprawling on the ground, and whatever shape this takes it should be in place before planting out is begun. Where it is an easy matter to procure sufficient stout stakes, $4 \mathrm{ft}$. to $5 \mathrm{ft}$. long, nothing better is needed, and these should be fixed firmly in the ground, $1 \mathrm{ft}$. deep, at the required distance apart; at the same time it is a wise precaution to run a wire along each row, a few inches below the tops of the 
stakes, to which they should be securely tied; otherwise, when the plants get heavily laden with fruit, after a high wind many will be found blown to the ground, and few left standing upright. Bamboo canes are sometimes used instead of stakes but are not very satisfactory, being so smooth that the ties are gradually pulled downward by the weight of the fruit. A single wire, about $18 \mathrm{in}$. above the ground, is an efficient and cheap substitute for stakes; the wire is attached to a stout stake at each end of the row, drawn tight, and supported on short stakes every $10 \mathrm{ft}$. or $12 \mathrm{ft}$. The plant is allowed to grow about $2 \mathrm{ft}$. long without support, and is then drawn up and hung over the wire, one slack tie of stout raffia being usually sufficient for the whole season. The drawback to this method is that the fruit and foliage hang together in a dense mass through which the rays of the sun cannot penetrate or the wind blow, and in wet times damp is thus held about the plants and makes them more susceptible to disease. A better plan, and one which appears to fulfil every requirement, is to strain three wires to each row, beginning at $1 \mathrm{ft}$. above the ground, with $1 \mathrm{ft}$. spaces between; the wires should be attached by staples to stout stakes fixed firmly in the ground at intervals of $12 \mathrm{ft}$. The best wire for the purpose is 15 's gauge, galvanized, costing about 18s. per cwt. delivered (retail price). Each cwt. contains about 1,900 yards, and $2 \frac{3}{4}$ cwts. are needed to run a single strand in rows a yard apart over one acre, or $8 \mathrm{cwt}$. for three strands.

Training and Culture.-As soon as planting is finished, the soil should be lightly hoed over so as to provide a loose surface, and this condition of the soil should be maintained throughout the season. When planted on ridges or raised beds, which on heavy soil is always advisable, care should be taken to provide means for the rain-water to pass away readily, as an excessive amount of moisture standing about the roots for any length of time is always harmful. As soon as the plants begin to grow freely they must be systematically relieved of side shoots; these grow at a great pace, and their removal whilst still small must on no account be neglected. To allow these shoots to remain on the plant until they are a foot or more in length is a foolish proceeding, and one of the most certain means of preventing an early or profitable crop in otherwise favourable 
circumstances. The plants should be gone over very frequently so that they may be rigidly confined to the one or two main branches they were originally started with; by doing so the strength of the plant is concentrated on making; swelling and maturing fruit, instead of being dissipated and wasted in making growth which is ultimately cut out and thrown on the ground. Not only that, but plants which are thinly disposed so that the wind can blow freely through the foliage and the sun shine on every part, dry quickly even after the heaviest rain, and make a firmer and healthier growth, so that they are in the best condition to resist attacks of disease.

Tying must be, regularly attended to. When each plant has a separate stake the first tie should be made as soon as planting is completed and afterwards for every 6 or 8 inches of growth. Good quality raffia is the most suitable material to use for this purpose. In tying leave space for the stem to swell, which it does very rapidly, but do not make the tie so slack as to allow the plant to swing about in every wind. When the plants are supported by wires the stems cannot, of course, be tied until they have grown long enough to reach from one wire to the next, and this is all the more reason for not allowing them to swing free for an unnecessary length of time.

Stopping.-In the first week of August the plants should be "stopped" (that is, the main stem is cut off and no further growth permitted) at the last fully developed truss of flowers. In a cold wet autumn the last trusses will even then probably fail to mature, but on the other hand in a warm genial autumn, or "Indian summer," such as we are frequently favoured with, most of the fruit on the last trusses will ripen and thus make a considerable addition to the total crop. When the plants are stopped later than this the growth is made at the expense of the weight and early maturity of the fruit already set. After the plants are stopped, side shoots are pushed out with increased vigour; at that time the fruit is ripening rapidly, and all hands are liable to be engaged in gathering and packing, so that the removal of these late shoots is apt to be neglected, but this should be carefully guarded against, or the plants become a thicket of shoots, and get in a really worse condition than if they had never been stopped at all. 
Thinning the Foliage. - That an abundance of healthy foliage is necessary to the production of a heavy crop of fruit is beyond question; it therefore follows that to remove any of the leaves cannot of itself be a good thing to do. On the other hand, for reasons already given, it is a bad thing to allow the foliage to form into a dense mass which excludes sunlight and air; so that we are obliged to choose between the alternatives of setting the plants wider apart or reducing the foliage. Before deciding, since the ultimate object of the grower is to obtain the largest possible return from a given area, it is necessary to know what will be the effect of either course upon the crop. Plants which are given plenty of space and allowed to retain the whole of their leaves yield heavy crops, but the additional weight of fruit per plant does not amount to the loss sustained by there being fewer plants in bearing; whilst if close planting is carried to an extreme and the foliage severely thinned the weight per plant is so small that the total crop is still lighter than from wide planting. The conclusion, therefore, is that the best all-round results are obtained when the plants are set as closely as may safely be done without overcrowding, followed by a judicious thinning of the foliage, the amount removed being sufficient to admit light and air without materially damaging the plants.

For many years past the following method has met with complete success: The leaves are left intact until the first bunch of fruit shows signs of colouring, then all from the bottom to the first one above the bunch are stripped off; this admits sunshine to the fruit and so hastens its ripening, and at the same time permits the pickers to see at a glance what fruit is ready for removal. As the higher bunches begin to colour the leaves are shortened to half their length, first to the second bunch and then to the third and so on. This system provides for a gradual reduction of foliage, always of the oldest and least useful, and leaves the youngest and most active working leaves near the top of the plant uninjured. The nature of the season is also taken into consideration, the thinning being more moderately done in hot dry weather, and rather more severely in cold wet weather, with the object of keeping the foliage as dry as possible and hastening ripening. 
Spraying.-Most vegetables receive treatment for disease only when the occasion demands it, but Tomatoes growing in the open-air form an exception. In our humid and changeable climate they are particularly liable to attack from fungoid diseases,-so much so that the careful cultivator never'omits, as an insurance against serious loss, to make periodical spraying with fungicides part of the regular routine of Tomato culture. There is seldom a season when these diseases are quite absent; such a fortunate occurrence sometimes happens when the weather is warm and dry throughout most of the summer, but these occasions are so rare that they may be left out of the reckoning, and the probability of attack must always be taken into serious account. At the same time, as has been already indicated, much can be done towards securing conditions which will offer no encouragement to disease,- - good drainage, an open situation, sturdy cool-grown plants, with ample space for sun and air to pass freely through the foliageand if these conditions are accompanied by systematic spraying it will indeed be a bad season when the grower fails to obtain at least a fair crop. Full directions regarding fungicides will be found in the chapter devoted to Pests and Diseases.

Gathering the Fruit.-The general temperature and the possibility of damage by birds are the two principal factors to be taken into account in deciding when to gather the fruit. Of late years blackbirds, and in a lesser degree thrushes, have become a perfect pest to the open-air Tomato grower, as indeed they are throughout the summer to all growers of fruit. Where these birds are troublesome, the fruit on the bottom bunches should be gathered and carried under cover to finish as soon as it shows the first faint signs of colour. Beyond the point where they can peck the fruit whilst standing on the ground the birds do no serious damage, and it should then be left on the plant until ready for market. Many growers continue throughout the season to gather the fruit half green, to be finished under cover, but this is a mistake as Tomatoes are of far better quality and appearance, and consequently realise better prices, when despatched to market immediately they are taken from the plant. The prevailing temperature and the destination of the fruit should be taken into consideration in 
deciding when to gather. In the heat of the summer it ripens very quickly after it is packed, and if left on the plant until fully ripe it would arrive at its destination too soft, and much depreciated in value. The proper degree of under ripeness of the fruit when packed therefore calls for a considerable amount of judgment; when the weather is very warm, and particularly when the packages are likely to be delayed before being exposed for sale, the colour should not be deeper than pink; as the weather gets cooler ripening proceeds more slowly, and therefore the colour should be allowed to get more and more advanced before packing, the object being to ensure that it shall be firm, well-coloured, and attractive in appearance when offered to the purchaser. The same procedure should be followed when the fruit is sent direct to private customers, except that it should be allowed to arrive at a stage nearer ripeness before packing, because under these circumstances it is usually wanted for immediate use.

About the end of September the fruits still hanging may be destroyed by sharp frosts, but if they then escape they will probably be safe for several weeks longer. After September it is useless to expect them to ripen well in the open-air, and they should then be gathered green, but full-grown, and ripened under cover. At this period, owing to the cold, dripping, misty nights, the fruit is very liable to be affected by a fungus known as botrytis cinerea, which usually finds a lodgment at the point where the stem and the fruit join. The attack of this fungus is almost imperceptible, but very deadly. Its presence is usually first indicated by green fruit parting from the stem and falling to the ground, although sometimes it remains hanging with a white mould showing distinctly at the base. When the disease is prevalent it is almost useless to gather the green fruit, as although apparently sound when taken indoors the fungus has usually affected the greater proportion, and decay speedily sets in, so that the quantity of sound ripe fruit ultimately obtained scarcely pays for the labour involved. This disease may be kept at bay, or its ravages much reduced, by following the instructions for spraying Tomatoes in the chapter dealing with Pests and Diseases. When the final pickings of green fruit are comparatively free from disease they add very materially 
to the total returns obtained from the crop. No fruit which is not fully-developed (and mere size is no criterion of this) should be taken in-doors for ripening, as although immature ones may. colour they do so with a tough shrivelled skin and are really useless. The green fruit may be ripened in the dark, in boxes or trays or on benches, in a temperature of about 50 degrees; it also ripens very well when packed in sawdust or peat dust.

Extra Early Tomatoes from the Open.-The foregoing instructions are all concerned with the main-crop, but where convenience exists for protecting earlier-sown plants so that they may go out at the beginning of June with a bunch of fruit already set and swelling, it is quite possible to obtain ripe Tomatoes from the open-air before the middle of July. For this purpose seed should be sown about the middle of February, all the previous instructions being carefully followed and care being taken to keep the plants steadily moving, with a gentle bottom heat until the beginning of May. Of course transplanting must be done earlier, and the plants must go at least 6in. apart when transplanted the second time.

Strong plants may also be set out early in May with a little warm manure under the roots and protected overhead by cloches; each cloche rests on three sticks standing $1 \mathrm{ft}$. or so out of the ground, with notches on the inner edge, 2in. apart, like the teeth of a saw. As the plant grows the cloche is raised on the notches, and is removed altogether early in June.

Varieties:-The large number of varieties of Tomatoes is bewildering to the grower who is inexperienced in their culture. Those claimed as especially suitable for open-air culture are certainly fewer in number, but the writer having experimented over a number of years by growing most of the better-known indoor varieties in the open-air, under both favourable and adverse conditions, has invariably found that the so-called open-air varieties are neither earlier, hardier, nor more prolific than most of the indoor sorts, whilst they are very much inferior in shape and appearance. Many persons appear to think and act as though open-air Tomatoes must of necessity be a rough coarse product, and this notion appears to influence the manner of placing the fruit on the market. But it is all a great mistake-Tomatoes grown in the open-air, when 
ripened, graded, and packed in a proper manner are scarcely distinguishable from those grown in glasshouses. Appearance has a considerable money value, good-looking packages invariably realizing the highest prices, and the production of handsome fruit, followed by grading and smart packing should be the object of every grower.

The ideal points of an open-air Tomato are-(1) Hardy constitution; (2) robust short-jointed growth; (3) earliness; (4) prolific bearing; (5) good-shaped, smooth, medium-sized fruit; (5) bright scarlet colour. After numerous experiments the writer has found none which have all these characteristics in perfection, those most nearly approaching the ideal being-

Carter's Sunrise and Holmes' Supreme,

whilst amongst other varieties which have given satisfacion the following are especially worthy of notice-

$\begin{array}{ll}\text { Lord Roberts, } & \text { Princess of Wales, } \\ \text { Up-to-Date, } & \text { Hillside Comet, } \\ \text { Sutton's Satisfaction, } & \text { Lawrenson's No. 3, } \\ & \text { Early Ruby. }\end{array}$

But whilst any of the varieties in this selection will, under fair conditions, render a good account of themselves, Sunrise and Supreme have outstanding merit. If choice had to be made between the two, it would be unhesitatingly given in favour of Sunrise. This variety answers to the description of the ideal open-air Tomato given above except on one point-the fruit is apt to come rather small unless the plants are plentifully supplied with food and moisture. With good culture and rich soil the fruit is perfect in every particular. The accompanying illustration is of a typical bunch grown in the open-air in the cold summer of 1910. Every fruit on the bunch was evenly ripe. It was not selected for its size (there were hundreds

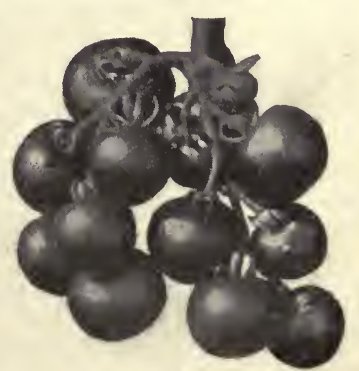

Typical Bunch of Carter's Sunrise Tomato.

Weight, 2lbs. $1 \frac{1}{2} \mathrm{oz}$. larger), nor for any other special features, but simply that it was fairly representative of the whole crop. On the following page is an illustration of Sunrise growing against a fence, 
354

The Profitable Cultune of Vegetables.

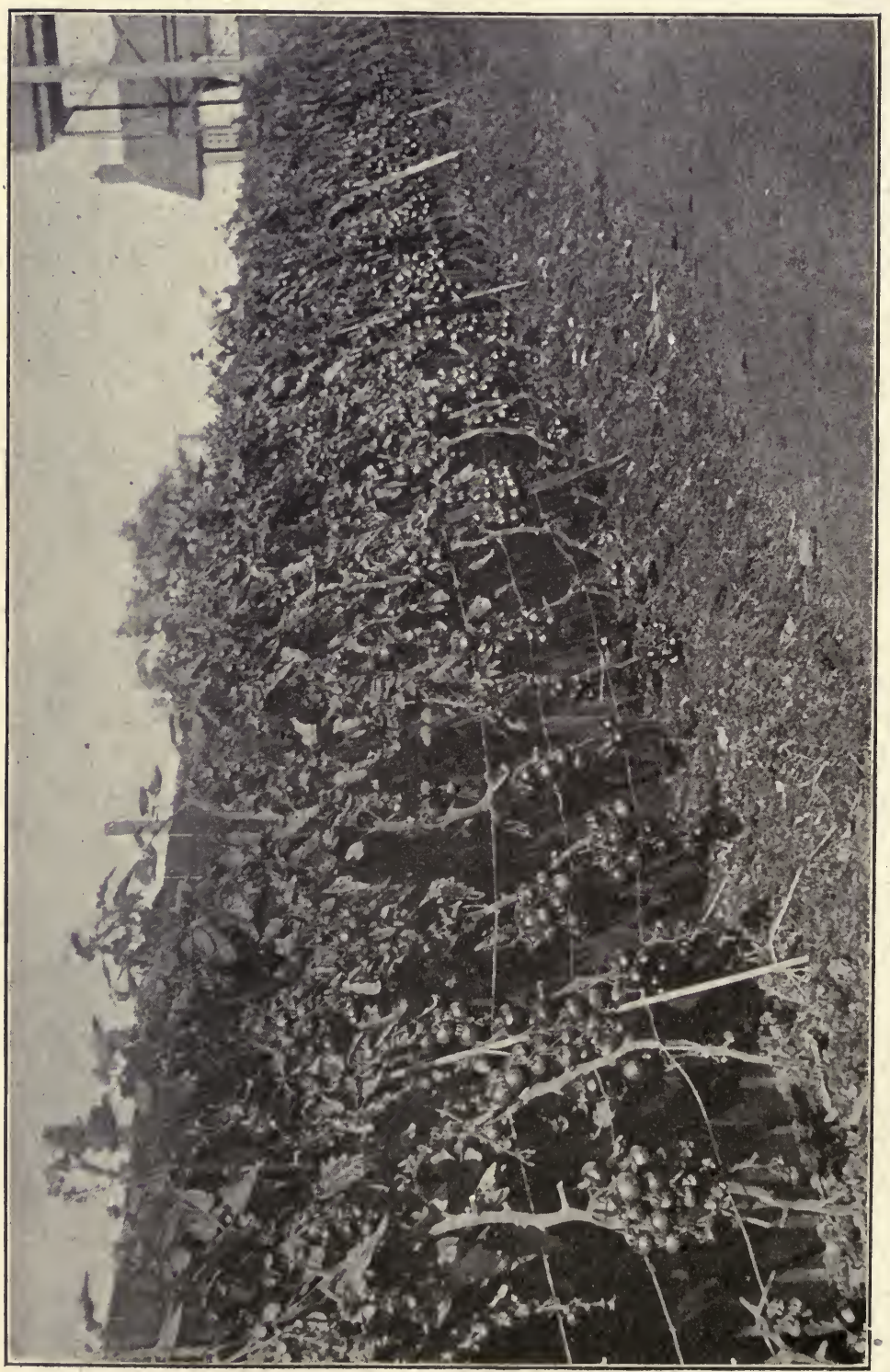

ริำ

एँ

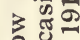

응

के है

$\Xi$

०

3

तี

के

ชัญ

空

요 है

픔.

드

깅

든

음..

这压

$3 \times \frac{\pi}{2}$

范 这

림

का

...

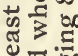

0,0

이월

๘

U....

远

$\approx 5$

㟧

तु

तथ

5...

응.

00

웅

क क

ํํㄹ.

悉焉

is 
facing due east-a by no means ideal position. Most of the fruit had been gathered from the bottom bunches before the photograph was taken. The plants were well-fed and the fruit came of good marketable size, averaging about six to the pound. Supreme would probably prove more satisfactory than Sunrise on light soils unless the plants were abundantly supplied with food and moisture.

Manures:-Of late years the Tomato, like its near relative the Potato, has show an increasing susceptibility to attack from fungoid diseases, and crops grown in the open-air are now almost as liable to be ravaged by the potato disease, phytophthora infestans, as is the potato crop itself. This tendency has naturally engaged the attention of many persons more or less expert in Tomato culture, with the result that some have condemned the use of farmyard manure in the preparation for the crop, attributing to it a softening of the tissues of the plant which renders it more vulnerable to attack, and have advocated the use of artificial fertilizers alone, to the exclusion of natural manures. With this conclusion we cannot agree. That a luxuriant, sappy growth is highly objectionable there is not the slightest doubt; not only because it invites disease but also because it is unfruitful. It must be remembered, however, that farmyard manure produces this result only when it is lavishly used in a fresh rank condition, or when the soil is very loose, and that the same soft growth is just as readily brought about by the injudicious use of concentrated nitrogenous fertilizers; thus the mischief is seen to lie not so much in the material used as in the method of its application.

From the experience derived from a large number of practical experiments in manuring for the Tomato crop, extending over many years, the writer has arrived at the following definite conclusions: (1) Heavy crops of Tomatoes cannot be obtained unless the plants are supplied with an abundance of food; (2) potash in some form is indispensable to both weight and quality in the fruit; (3) although good crops may be obtained by the use of artificials alone, especially when the soil is already in "good heart," the best crops are invariably obtained when these are used to supplement a moderate dressing of farmyard manure; (5) farmyard manure should always be applied in a 
thoroughly decayed condition-never fresh and rank; (6) when the plants are swelling the second truss of fruit they are greatly benefitted, and enabled to bear a heavier crop, by one or two light dressings of nitrate of soda or other quick-acting nitrogenous manure; (7) available phosphates are necessary to early ripening. It will be seen from the foregoing, that a moderate dressing of farmyard manure in a thoroughly decayed condition is considered necessary to a first-class crop; in this connection it will be useful to glance again at the illustration on page 354. In this case a number of plants of Sunrise-which is an ideal variety in every way except that the fruit runs rather small-were set out at the foot of a fence facing east, and in a shallow trench below the plants old hot-bed manure was put, 3in. thick and $6 \mathrm{in}$. broad, with $6 \mathrm{in}$. soil on top; after planting, a little sulphate of potash was sprinkled along the row and hoed in, then the soil was made very firm; about the beginning of July, after a good soaking with water, a mulch of short manure, 3in. thick, was spread over the surface, water being given several times afterwards. The object of the experiment was to test the effect on the size and quality of the fruit of a liberal quantity of well decayed manure within reach of the roots, in such a position that it would also act as a reservoir of moisture. The crop was superb both in weight and quality, whilst the size of the individual fruits was increased over the average by at least one-third; when the photograph was taken most of the fruit had been gathered from the bottom bunches. The plants were sprayed three times with Bordeaux mixture. Although the summer (1910) was cold and wet there was no trace of disease. The result of using manure was very favourable.

In a general way a suitable manuring would be the following: Well-decayed manure, at the rate of 12 to 20 tons per acre according to fertility, dug or ploughed in during winter or early in spring. In addition to the manure, on heavy soil give $6 \mathrm{cwt}$. basic slag in winter and $1 \frac{1}{2} \mathrm{cwt}$. sulphate of potash before planting; on light soil give 4 cwt. kainit as early as possible and 3 cwt. superphosphates before planting. In either case a sprinkling of nitrate of soda along the rows early in July, say $1 \frac{1}{2} \mathrm{cwt}$. per acre in two applications with a fortnight interval, will increase the crop, but this dressing is not essential. 


\section{TURNIPS.}

\section{Brassica Rapa.}

TURNIPS as a market garden crop are practically indispensable; being quick in growth they form one of the most useful subjects for catch crops, and in one way or another afford supplies all the year round. The demand is general, and although the returns are very low at some periods they are high at others, so that on the average the crop yields a very fair margin of profit. The earliest supplies are produced on mild hot-beds, and for these there is usually a steady demand at good, and sometimes high,

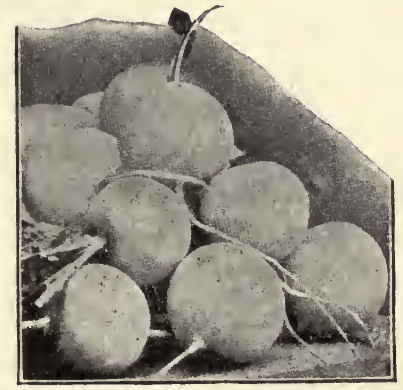

Copyright, S. \& S.

Sutton's

Early Snowball Turnip. prices. Immediately following these come the tender young roots from sheltered situations in the open which can also be depended upon to sell readily at good prices. Then follow the ordinary spring and summer crops, grown either in beds by themselves or in rows between other slower-moving vegetables and a crop is thus taken from spaces which would otherwise be wasted; these supplies sell well at the beginning but usually meet with a gradually slackening sale as the summer advances. The demand revives with the advent of cold weather and continues fairly steady all through the winter, the round of the year being finished by the production of turnip tops early in the spring. These are sold as bag greens, and as they come at a time when green vegetables are scarce, especially if the winter has been a severe one, they are often welcome and sell at very fair prices.

The Soil.-The best Turnips are grown on a friable sandy loam, but with good culture very fair samples can be grown on most soils. Where it is possible to make a choice, a light sandy soil is to be preferred for very early or late crops, but a cool 
retentive staple will be found to give more satisfactory results in warm weather. The difficulty which arises in connection with Turnip growing on light sandy soils in summer is that these are liable to get droughty, and as a consequence the seedlings are often destroyed by the flea beetle, and such plants as pass safely through this ordeal may run to seed before making useful roots. On such soils success may be assured by the addition of plenty of well-decomposed manure, which has the effect of retaining moisture and pushing the growth of the young plants quickly into the rough leaf, when they are comparatively safe from the flea beetle.

Early Crops.-The earliest sowings of Turnips are made on beds of warm manure, leaves, or other fermenting material, from the end of January to the end of February. A bed may be

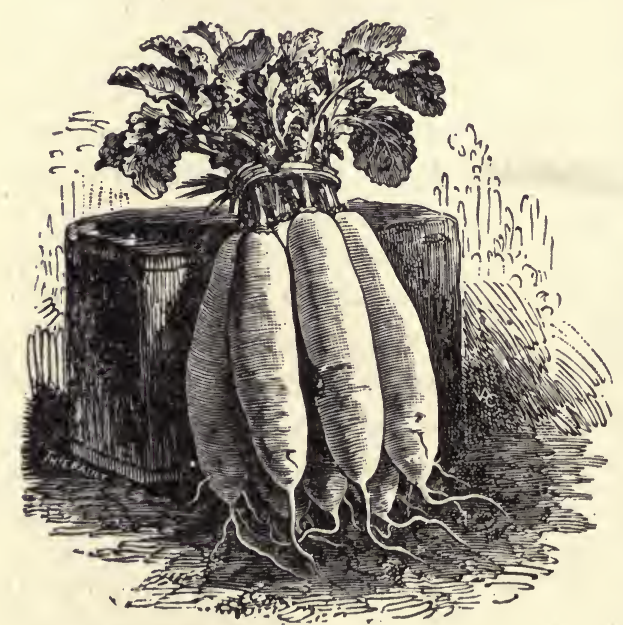

Copyright, V.A.\& Co.

Half-long White Forcing Turnip. made on the surface of the ground and covered with box frames, or in brick pits, or in a trench in the ground and protected by mats or litter. A very gentle warmth at the roots is all that is necessary, as Turnips will not stand hard forcing, and from the time the seedlings show until the roots are ready for pulling the plants must be given plenty of air and daily moderate waterings. The first method is the one followed in French gardens, where the production of early Turnips is part of the regular routine. In this case, when spare frames are available, beds $15 \mathrm{in}$. thick are made specially, or beds which have already served to produce a crop of radishes and lettuces are turned over and re-made about the end of February, then trodden down well and covered with $3 \mathrm{in}$. of light rich compost, which is also made firm. The seed may be sown broadcast, 
but a method usually preferred is to make holes $1 \mathrm{in}$. deep and $4 \frac{1}{2} \mathrm{in}$. apart into each of which two or three seeds are dropped and the holes closed up. To make the holes, a framework of laths is constructed of a size which will fit the frame easily in the space occupied by one light; the laths are nailed together in a kind of square lattice-work, about $4 \frac{1}{2} \mathrm{in}$. from centre to centre at the places where they cross, and at each of these points a peg is fixed, which projects $1 \mathrm{in}$. By laying this contrivance on the soil and pressing down, all the holes necessary under one light are made at one operation. When the seedlings appear, all but one at each place are removed. When the seed is sown broadcast the seedlings must be thinned to about 4 in. apart as soon as they can be handled.

When hot-beds are made without frames the soil is thrown out $6 \mathrm{in}$. deep, $5 \mathrm{ft}$. wide, and of any length. Hot manure is then laid in and well trodden down until it is a uniform depth of $1 \mathrm{ft}$., then the soil which was thrown out is spread over the manure and rolled or trodden down firmly. The seed is then sown thinly in drills, 5in. apart, lightly. covered, rolled or trodden in, and the whole well watered. Hoops made from pliable tree branches are then fixed over the bed, on which mats are laid, where they remain until the seed has germinated, after which they are removed daily and replaced each night. As soon as the plants are half grown the mats are left off altogether and used to form a screen round the bed to keep off cold winds.

Sometimes the only protection given to

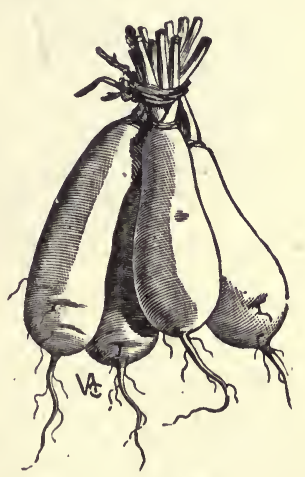

Copyright, V.A. \& Co.

Half-long White Jersey Navet. the hot-bed is a light covering of loose litter, which is scattered over each night until the plants are established. Good and early crops are taken in this way, although a week or two later than those from beds which have been protected.

General Culture.-Turnips always repay good cultivation, whether early or late in the season. For the earliest open-air crops the warmest and most sheltered spots at command should be selected. In the early part of March, as soon as the 
surface of the ground is dry enough to bear working on, it should be brought to a fine tilth. The seed may be sown broadcast or in drills, covered lightly with soil and pressed down firmly. If the soil contains sufficient moisture, germination will take place at once. Thinning should be done as soon as the seedlings are large enough to handle, first reducing all thick clusters and then going over them carefully so that none stand nearer than 4 in. apart all over the bed. This allows enough room for the early roots, which are never grown large, the aim being to grow them quickly and market them as soon as three-parts grown, whilst tender and of good flavour.

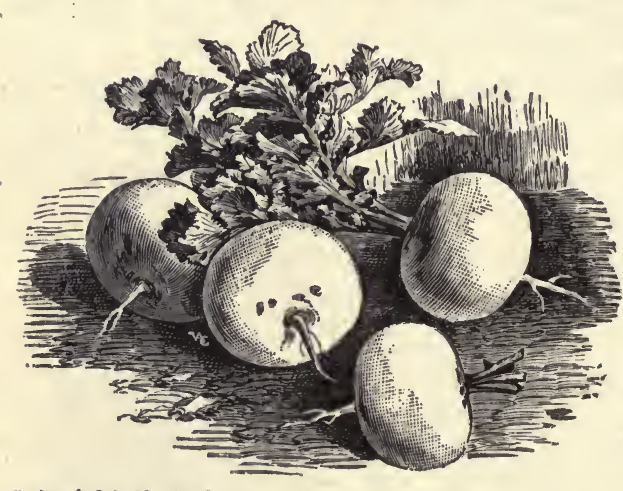

Copyright, V.A. \& Co.

Early Six-weeks, or Jersey Lily Turnip.

For succession, sowings may be made in more open situations, advantage being taken of spaces between rows of peas and other vegetables, from which catchcrops of a fast-growing variety of Turnips can be taken before either crop is inconvenienced. These later sowings should always be made in drills and if in more than single rows not nearer than 12in. apart, and the plants thinned to 6in. apart in the row. A sowing in May should be the last for summer supplies, and this should be made, when possible, in a situation sheltered from the hot mid-day sunnot that the Turnip will not thrive in full sunshine, but moisture is imperative if good roots are to be produced. If the soil gets dry, and is allowed to remain so, many of the plants will "bolt" without bulbing, and such roots as do swell will be hot and stringy. Where there is a large breadth the idea of watering cannot be entertained, and the crop has to take its chance until rain comes, but on small-sized patches the crop could often be made secure by one good soaking with water. At all times the surface soil should be kept loose and free from weeds; this assists quick growth and checks evaporation of soil moisture. 
Seed is sown for autumn and winter crops from the middle of July to the end of August (usually after peas and early potatoes), in drills $18 \mathrm{in}$. apart, the plants being thinned to 6in. apart in the rows; the roots intended to stand in the ground through the winter should be left at $1 \mathrm{ft}$. apart, each alternate root having been removed by a first pulling in the late autumn. When "tops" are required in the spring a special sowing is made early in September, in rows $2 \mathrm{ft}$. apart, sowing thinly and leaving the plants unthinned.

Storing.-Storing Turnips is not very generally practised in market gardens except where there is a necessity for maintaining a regular supply. Then storing is a useful procedure, for apart from the possibility of damage to roots in the open during a sharp frost, there is the probability of the ground sometimes being frozen so hard that they cannot be lifted. When storing is resorted to, the tops should first be be cut off, leaving $\frac{1}{2}$ in. of the neck, but the tap root must not be cut; then lay the roots in small heaps and cover, first with straw and then with soil, in the same way that a potato clamp is covered.

Manures:-In growing Turnips care should be taken that lime in some form is present in the soil, and that the crop is not repeated on the same land without a sufficient interval, fresh soil not only producing roots of a better flavour, but also reducing the possibility of trouble from pests and diseases. In manuring, the aim should be to secure quick healthy growth whilst avoiding coarseness. Like all other vegetables, Turnips need a complete plant food-nitrogen, phosphates, and potashbut of the three a supplementary supply of phosphates is the most necessary and should seldom be omitted for the main-crop. Enough nitrogen is usually present in soil which is kept in good condition by a proper rotation of manuring. Very early crops in the garden form an exception to this, as then the aim is to secure partly-developed roots in as short a time as possible, and to this end the soil should always be very rich with welldecayed manure. Successional supplies grown in the form of catch-crops will receive the benefit of the preparation the soil has received for the main-crops amongst which they are grown, and so will seldom need more than a sprinkling of superphosphates along the drills previous to sowing the seed. Main-crop 
Turnips, for autumn and winter supplies, usually follow a crop for which the ground has been well prepared, and in such a case excellent results would be obtained by applying 3 cwt. kainit and 3 cwt. superphosphates (or limphos or basic slag, according to the nature of the soil). Poor soils or those of a very sandy nature cannot be expected to yield satisfactory crops without the assistance of natural manure, and this should be given in a well-decayed condition, from 10 to 15 tons per acre, according to the nature and condition of the soil, with the addition of kainit and superphosphates as above, distributed over the surface and well harrowed in before seeding.

Varieties :-For hot-beds, cold frames, and early borders: (long) Early Long White Frame, Jersey Navet; (flat) Early Red Milan, Early White Milan; (round) Early White Strap-leaf. For early open borders and catch-crops, also for autumn pulling : Early Snowball, Early White Dutch, Early Six-weeks. For summer: Veitch's Red Globe. For "tops": Green Globe.

\title{
VEGETABLE MARROWS.
}

Cucurbita Pepo ovifera.

\begin{abstract}
$\triangle$ LTHOUGH the Marrow crop is not of great importance $A$ it is nevertheless very useful. Large quantities are grown for market, and as the culture is simple and the plant productive, in a favourable season the supply often overruns the demand, with the result that the market becomes glutted and prices rule extremely low, especially after the middle of the summer. In the early part of the summer, however, supplies are limited, prices high, and the demand good. An effort should therefore be made to get them on the market as early as possible. With proper care the plants continue to bear until the middle of September; in some few cases, where the expenses for carriage are very low, it may pay to continue marketing the crop as late as this, but in the majority of cases it is a better plan to clear the ground of the plants in August and occupy it with some other crop.
\end{abstract}


Preparation of the Land.-The Marrow will grow and fruit abundantly in any good well-drained soil, if provided with plenty of manure and moisture at the root, accompanied by an abundance of sunshine. Apart from being a regular field crop, Marrows are set out in all sorts of odd corners and on refuse heaps, where they make the unsightly both beautiful and profitable. As a main-crop, they generally follow one for which a liberal manuring has been given and which is cleared off the ground by the beginning of May; this allows time, if the work is done immediately, to prepare the land for planting in the latter part of the month. When the ground is cleared, furrows are made with either plough or spade, about 9in. deep and $1 \mathrm{ft}$. wide, which are filled with hot, half-decayed manure. This is well trodden down, after which the soil is turned back over it, forming a ridge. The manure soon generates a gentle bottom heat, which enables the plants to quickly establish themselves. The distance between the furrows depends on the variety to be grown, whether the bush or the trailing Marrow. Between rows of the former the space allowed is $4 \mathrm{ft}$., and of the latter, 6ft. On very light soils which are liable to soon suffer from drought, the furrows should be broader and deeper, and each should be finished off so that it forms a shallow trench instead of a ridge; this

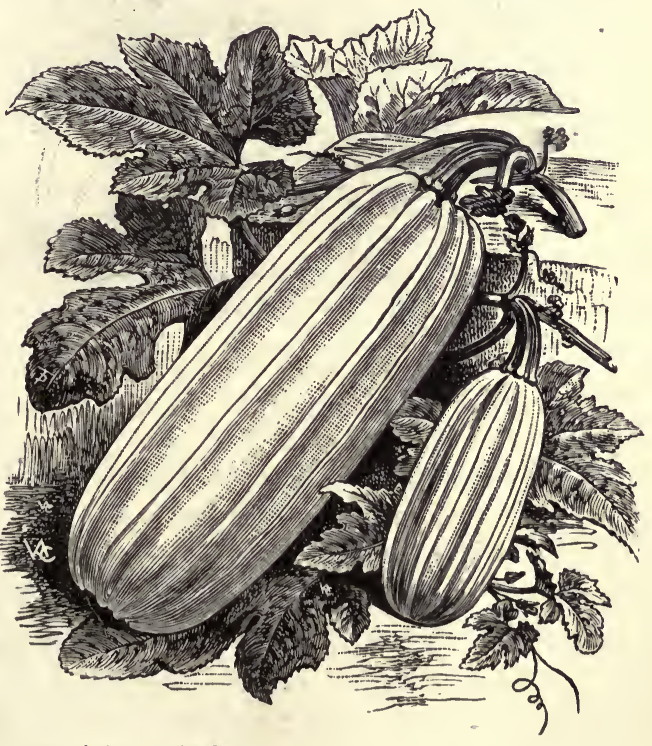

Copyright, V.A. \& Co.

White Trailing Marrow.

formation ensures more moisture being retained about the plants from every fall of rain.

Sowing in the Open.-The seed may be sown in the position 
where the plants are to remain, but this method is not recommended on account of the lateness of the crop. There is certainly a great saving of time and labour, and the plants grow vigorously and crop abundantly, but there is the great drawback that they do not begin to bear until the markets are well supplied and prices are low. When this course is to be followed, trenches filled with manure should be made as above,

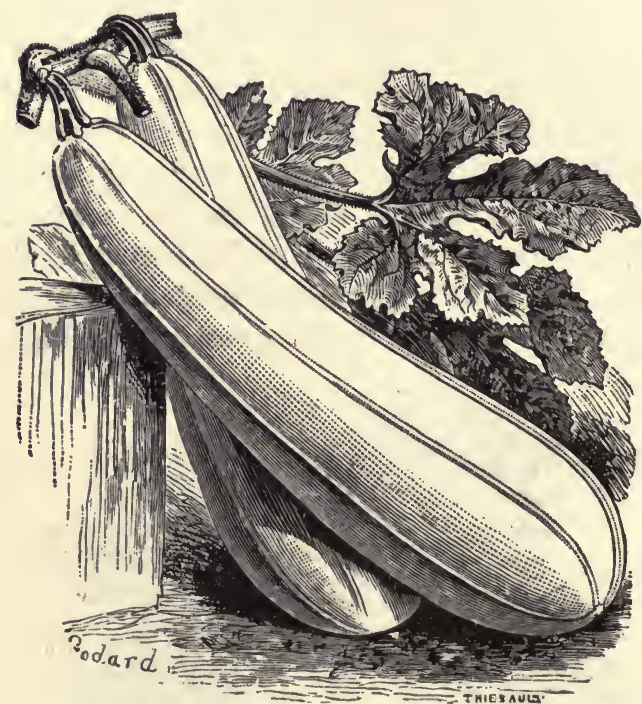

Copyright, V.A.\& Co.

Long White Bush Marrow.

and the seed should be sown in the middle of May, three in a triangle, 2in. apart and 1 in. deep, at intervals of $3 \mathrm{ft}$. Cover each patch of seeds with a flower-pot, inverted. As soon as the seedlings have pushed through the soil, remove the pots during the day but replace them each night for about a week. As soon as it is clear which plants are taking the lead reduce them to one at each patch.

Plants and Planting.-A better method is to set out strong plants; these will come into bearing three weeks earlier, which will make a great difference in the returns. To raise the plants, make up a hot-bed, about $2 \mathrm{ft}$. deep, in the second week of April, and cover it with 4in. of fine soil. Fill sufficient large 60's pots with a mixture of good turfy loam, well chopped $\mathrm{up}$, and spent manure, half of each, and put a seed in each pot, $1 \mathrm{in}$. deep, then plunge the pots up to the rim in the soil on the hot-bed. Keep the frame close and covered with mats until the seedlings are through the soil, then remove the mats during the day but cover at night for another week or so. Give air gradually, increasing the quantity with the growth. Keep the 
soil moist, but be careful not to over-water. In the first week of May remove the plants to a cold frame to harden off.

At the first opportunity after the third week of May, when the weather is mild and the ground dry, the plants may be set out in their permanent positions over the fermenting manure. Water the plants well the day before and set them a yard apart, turning each out of the pot without breaking the ball of soil. Bring about $1 \mathrm{in}$. of new soil over that from the pot, then press the soil gently but firmly round." Each plant should be protected at night for a week or more, according to the weather ; this may be done by covering them with hand-lights, cloches, paper cones, or baskets.

The after treatment consists in keeping the ground free from weeds and the surface soil stirred for a yard round the plants in order to conserve the soil moisture. When the plants begin to run and have extended about 18in., it is a good plan to pinch out the end of each leader to cause them to branch. Plenty of moisture is necessary to enable them to bear continuously; in fact, if the plants' requirements in this respect are attended to they will continue to bear until cut down by frost, but if allowed to become dry they soon become spent. A mulch of long manure spread round the plants before they have extended far is very useful in keeping the soil moist.

The Marrows should be cut as soon as they are fit for salefrom half to three-parts grown. This matter should be strictly attended to, as it means doubling or trebling the crop compared with what it would be if the plants were allowed to become exhausted by producing seed in fruits which have developed to their full size.

Varieties:-The varieties of Vegetable Marrows grown in market gardens are practically limited to two-The Bush and the Trailing Marrow, and these are again each divided into two-the Green and the White. The Bush Marrow is favoured by many because the plant, although a prolific bearer, is compact, and does not occupy nearly so much space as the Trailer for the same amount of crop. Where a high-class trade is done the Pen-y-Byd is a very valuable variety; this is an abundant bearer of small, oval-shaped, cream-coloured fruits, of first-class flavour. 
"A necessary condition of success in work on the land is communicativeness-continual friendly intercourse with your neighbours. A book gives general advice only, while every acre of land has its own individuality, which depends upon the soil, the position, the prevailing winds of the locality, and so on. These things can only be learnt by local residents of a long experience-an experience which represents the collective knowledge of the local population. Let every beginner remember that the superior gardening of the French, the Flemish, the Jersey and Guernsey gardeners, and the work of the English greenhouse growers and florists, is the result of their collective experience. Every gardener may have his own secrets on this or that special point, but the bulk of the general knowledge which has developed in a given locality is the result of collective experience, and of the continual talk among the gardeners about matters which interest them. Beginners who appreciate that talk and turn it to good account will find that advice is never refused by neighbours."

Prince Kropotkin, Preface to "French Gardening." 


\section{REMINDERS OF WORK TO BE DONE MONTH BY MONTH.}

In these "Reminders" a division is made between "General" and "French Gardening" operations, but where crops are grown more or less intensively such a separation is almost impossible in practise. The gardener is therefore advised to consult both divisions before planning his month's work, but he may be reminded that it is unwise to attempt too much; many of the crops mentioned may very well be omitted and attention concentrated upon those most in demand.

\section{JANUARY.}

WORK on the land now depends upon the weather. If the ground is frozen hard, manure may be wheeled or carted to the place where it is required. Ploughing or digging still remaining to be done should be pressed forward on every suitable occasion, but the soil should never be turned over when frozen or covered with snow, nor should it be poached by trampling on when wet.

Where French gardening is done the site of the hot-beds should be covered with long litter to keep the ground free from frost or snow, and manure, frames, compost, mats and other materials likely to be required should be accumulated close at hand so that the work can proceed speedily when begun.

\section{GENERAL OPERATIONS :-}

Asparagus forcing in beds where grown should now begin $\quad \ldots \quad \ldots 152$

Beans (Long-pod) may be sown $\quad \begin{array}{lllllllll} & \ldots & \ldots & \ldots & \ldots & \ldots & & \ldots & 155\end{array}$

Beans (Broad) may be sown in a cold frame for transplanting ... $\quad . .155$

Chicory may be forced $\quad \ldots \quad \begin{array}{lllllllll} & \ldots & \ldots & \ldots & \ldots & \ldots & \ldots & \ldots & 197\end{array}$

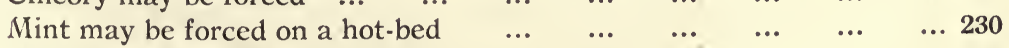

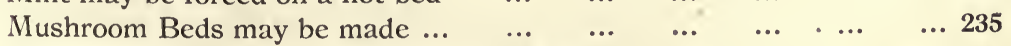

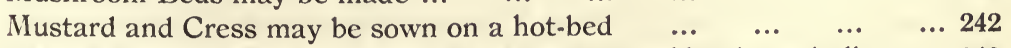

Onions may be sown in boxes on a hot-bed for making large bulbs $\quad . .249$

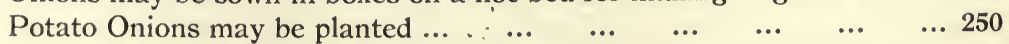

Peas for early supplies may be sown in 60's pots on a gentle hot-bed ... 258

Peas (first-early) may be sown on rich well-drained ground $\quad \ldots \quad$... 259

$\begin{array}{llllllll}\text { Potatoes should be boxed for sprouting } & \ldots & \ldots & \ldots & \ldots & & \ldots & 269\end{array}$

$\begin{array}{llllll}\text { Radishes may be sown in a dry sheltered situation } & \ldots & \ldots & \ldots & 285\end{array}$

Rhubarb may be forced, either lifted or in the ground ... 291 and 292

Seakale crowns may be forced ... $\quad \ldots \quad \ldots \quad \ldots \quad \ldots \quad, \ldots, \quad \ldots 302$ to 306 


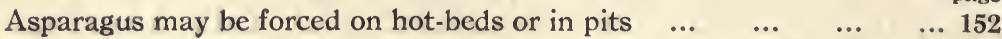

As soon as weather is favourable sow Radishes and plant Lettuces in

cold frames, and Hardy Cab. Lettuce in the open 98, 105, 106 and 220

Begin making hot-beds for frames in the second week $\quad . . \quad \ldots 91$ and 128

Begin making hot-beds for cloches in the last week $\quad \ldots \quad \ldots \quad \ldots 96$

Sow frame hot-beds with Radishes and Carrots, and plant with Cabbage

$\begin{array}{lllllllllll}\text { Lettuces } & \ldots & \ldots & \ldots & \ldots & \ldots & \ldots & \ldots & \ldots & \ldots & 93\end{array}$

Sow cloche hot-beds with Carrots and plant with Cos and Cabbage

$\begin{array}{lllllllllll}\text { Lettuces } & \ldots & \ldots & \ldots & \ldots & \ldots & \ldots & \ldots & \ldots & \ldots & 97\end{array}$

Strawberries may be put on a hot-bed for forcing $\ldots \quad \ldots \quad \ldots \quad \ldots \quad \ldots 333$

Turnips may be sown on mild hot-beds at the end of the month $\quad . .358$

\section{FEBRUARY.}

DRING this month all manuring, ploughing, and digging of vacant ground should be completed as far as possible, as the time for sowing in earnest begins next month. Tidiness should now be manifest, and all weeds rigorously kept down; groundsel in particular should be got rid of, as it is now coming into flower and if allowed to seed will be a nuisance all the summer through.

In the French garden the hot-beds made last month should be carefully watched; the linings round the frames must be kept up, and renewed as the heat declines. The frames and cloches must be covered with mats every night, and a little ventilation given in the middle of the day on the opposite side to the wind whenever the weather is favourable. Radishes must be thinned out where they are overcrowded, and decayed leaves removed from lettuces. As soon as the bulk of the radishes are ready the bed should be cleared, and no small ones must be left behind or they will be a nuisance, and a hindrance to the other crops.

\section{GENERAL OPERATIONS :-}

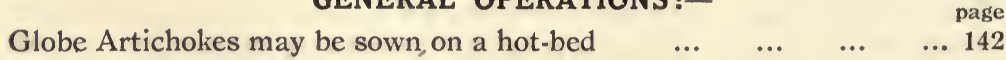

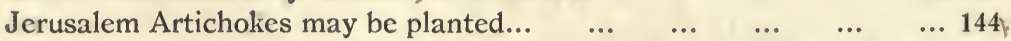
Asparagus beds on light or medium land should be covered with soil ... 150 $\begin{array}{llllll}\text { Asparagus may be forced where grown, for succession } & \ldots & \ldots & \ldots & 152\end{array}$

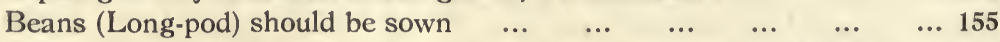
Brussels Sprouts for an early supply may be sown in a cold frame $\quad . .168$ $\begin{array}{llllllllll}\text { Chicory may be forced } & \ldots & \ldots & \ldots & \ldots & \ldots & \ldots & \ldots & \ldots & 197\end{array}$ Cabbage Lettuce from cold frames should be planted in sheltered beds 222 
Mint may be forced on a hot-bed

Cold frames should be put over Mint beds for forwarding $\quad \ldots \quad \ldots 230$

Mustard and Cress may be sown on a hot-bed or in a cold frame $\quad$... 242

Peas (early or second-early) should be sown $\quad \ldots \quad \quad \ldots \quad \ldots \quad \ldots 259$

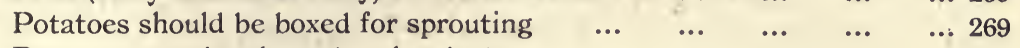

$\begin{array}{lllllll}\text { Potatoes may be planted on hot-beds ... } & \ldots & \ldots & \ldots & \ldots & \ldots & 277\end{array}$

Radishes may be sown in a dry sheltered situation $\quad \ldots \quad \ldots \quad \ldots \quad \ldots 285$

$\begin{array}{llllllll}\text { Rhubarb may be sown or planted } & \ldots & \ldots & \ldots & \ldots & \ldots & \ldots & 288\end{array}$

Rhubarb may be forced, either lifted or in the ground $\ldots . \quad 291$ and 292

Seakale crowns may be forced ... $\quad \ldots \quad \ldots \quad \ldots \quad \ldots \quad \ldots \quad \ldots 302$ to 306

$\begin{array}{lllllllll}\text { Shallots should be planted } & \ldots & \ldots & \ldots & \ldots & \ldots & \ldots & \ldots & 309\end{array}$

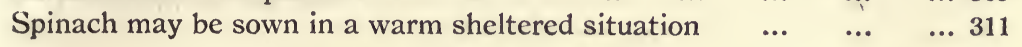

\section{FRENCH GARDENING :-}

Finish making and planting hot-beds for cloches early in the month $\ldots 96$

$\begin{array}{lllllll}\text { Asparagus may be forced on hot-beds or in pits } & \ldots & \ldots & \ldots & \ldots & 152\end{array}$

Cauliflower should be sown on a mild hot-bed in the second week $\quad . .180$

Celery (early) should be sown on a hot-bed in the third week ... ... 184

Cos and Cabbage Lettuce should be sown on a mild hot-bed in the third

week for succession to those wintered $\ldots \quad \ldots \quad \ldots \quad \ldots \quad \ldots \quad \ldots 218$

Make up more cold beds and sow and plant with Radishes, Carrots,

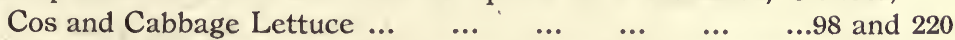

For "forced" Melons sow seed on a good hot-bed in the second week.. 225

Melons for an "early" crop must be sown in the last week $\quad . . \quad$... 225

Radishes should be sown between other crops and in the open 104 and 106

Strawberries may be put on a hot-bed for forcing $\ldots \quad \ldots \quad \ldots \quad \ldots \quad \ldots 333$

Tomatoes may be sown on a hot-bed for early supplies $\quad \ldots \quad \ldots \quad \ldots 352$

Turnips may be sown on a mild hot-bed, either in a frame or in the open 358

\section{MARCH.}

FARLY-SOWN seed-beds need examination and deficiencies E must be made good. Most common seeds may be sown this month if surface soil is dry, but it is better to wait a week or two for really favourable conditions than to muddle things in and then suffer for it all the season afterwards. Read carefully Chapter XVI, on Seeds, Sowing, Thinning, and Transplanting.

Crops in the French garden will now be coming along fast and they must not be kept on the beds a moment longer than necessary, so as to relieve the following crops which need more space, and to keep all the appliances fully utilized. The heat of the beds must be kept up by fresh linings round the outsides 
and between the frames. As the sun gains power ventilation must be increased, especially for cold frames. By the middle of the month cloches will need whitening on the south side to prevent scorching of the lettuce. Water must be given to such frames as need it and especially to carrots.

GENERAL OPERATIONS :-

See

page

Globe Artichoke suckers may be planted; seed may be sown in the open; seedlings from February sowing should be potted in 60's ... 142

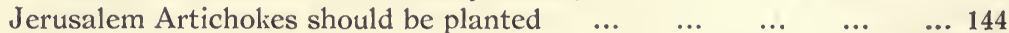
Asparagus may be sown or planted at the end of the month $\ldots 146$ and 148 Beans (Broad and Long-pod) should be sown $\quad \ldots \quad \ldots \quad \ldots \quad \ldots 155$ Broccoli should be sown for cutting before Christmas $\quad \ldots \quad \ldots \quad \ldots 166$ $\begin{array}{lllllllll}\text { Brussels Sprouts should be sown } & \ldots & \ldots & \ldots & \ldots & \ldots & \ldots & 168\end{array}$ Cabbage should be sown for cutting in summer $\quad \ldots \quad \ldots \quad \ldots \quad \ldots 172$ Carrots (stump-rooted) should be sown on a warm border $\quad \ldots \quad \ldots 176$ Carrots (main-crop) should be sown after the middle of the month $\quad . .177$ Cauliflowers for cutting in summer should be sown on a mild hot-bed... 180 Cauliflowers (hard, wintered plants) should be set out $\quad \ldots \quad \ldots \quad \ldots \quad \ldots \quad 182$ Celery (main-crop) should be sown on a hot-bed in the second week ... 185

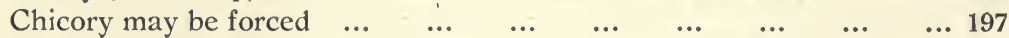
Cucumbers (Frame) should be sown on a hot-bed in the last week ... 201

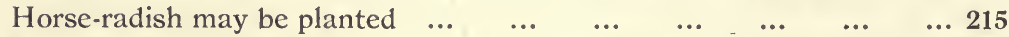

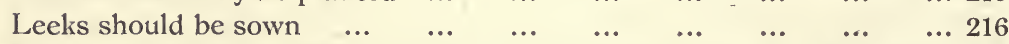
Lettuce (Cabbage and Cos) should be planted out, and more seed sown 222

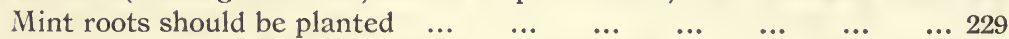
Mustard and Cress may be sown on a hot-bed or in a cold frame $\quad . .242$ Onions should be sown early and autumn sowings transplanted 245 and 247

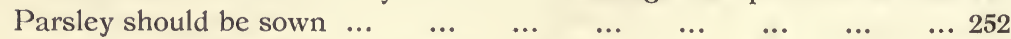

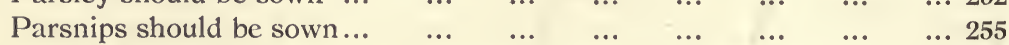

Peas in pots should be planted after the middle of the month ... $\quad . .258$

Peas (main-crop) should be sown in first and third weeks $\quad \ldots \quad \quad \ldots 260$

Potatoes may be planted in a sheltered place or in cold frames... ... 276

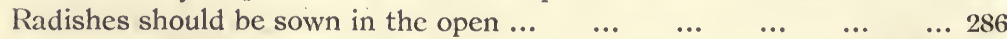

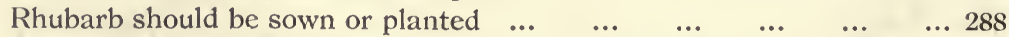

Rhubarb may be forced, either lifted or in the ground $\quad \ldots \quad 291$ and 292

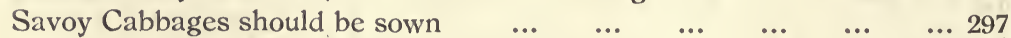

Seakale thongs should be planted or seed sown $\quad \ldots \quad \quad \ldots \quad 299$ and 300

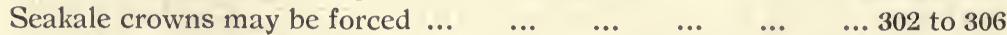

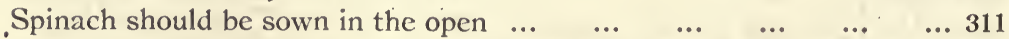

New Zealand Spinach may be sown in heat at the end of the month ... 315

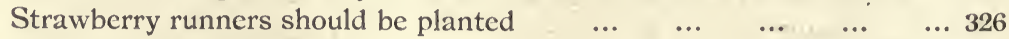

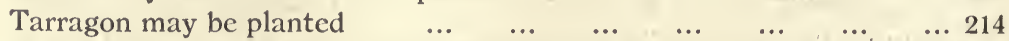

Tomatoes should be sown on a hot-bed in the first week and should be

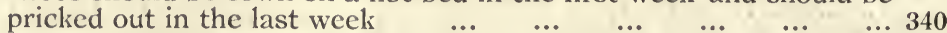

Turnips should be sown early in the month, on sheltered beds ... .. ... 359 
Beans (Dwarf) may be sown in a cold frame, or may be sown on a hotbed for transplanting later to a cold frame $\quad \ldots \quad \ldots \quad 156$ and 157

Carrots should be sown in cold frames or on sheltered beds in the open with wintered Cabbage Lettuces or Radishes on same bed... $\quad$... 176

Celeriac should be sown on a mild hot-bed in the second week ... $\quad \ldots 196$

Cauliflowers and Lettuces sown last month should be pricked out in cold frames as soon as fit to handle.

Cauliflowers should be set out, four to a light, amongst the Carrots on the hot-beds, after the Lettuces are cleared, providing the Carrots are making good progress; if not, the Caulifiowers must be planted a week or two later, when the Carrots are stronger ... $\quad \ldots \quad$... 95

Cos Lettuces should be planted alone or between Hardy Cab. Lettuces 105 Cauliflowers (well hardened) should be planted in the open, with Cabbage

Lettuces, Radishes, or Spinach between $\ldots \quad \ldots 181,222$ and 286

Melons sown for "forced" fruit last month must be potted in 60's and plunged in a mild hot-bed in the first week, and the beds should

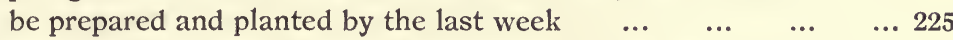
Melons sown last month for an "early" crop must be potted up and plunged in a mild hot-bed in the second week ... $\quad \ldots \quad \ldots \quad \ldots \quad \ldots 225$ Melons for "main-crop" should be sown in the last week $\quad \ldots \quad \ldots 225$ Strawberries may be put on a hot-bed for forcing ... $\quad \ldots \quad \ldots \quad \ldots \quad \ldots 333$ Strawberry beds should be covered with frames, for "forwarding" ... 328 Tomatoes sown last month should be pricked out in the second week... 341 Turnips should be sown in cold frames or on sheltered beds in the open 359

\section{APRIL.}

SPRING is fairly in now and everything is moving rapidly$\checkmark$.. weeds faster than anything else. The hoe should be frequently in evidence, stirring the soil; this not only keeps weeds down but admits air, sunshine and rain to the roots of the plants, to their great benefit. The man who means to end the season well must now work long and laborious days, but if the various operations are intelligently and conscientiously carried out they will be found both interesting and profitable.

By the end of the month carrots and cauliflowers on hot-beds should be hardened sufficiently to allow the frames to be taken away; plants in cold frames should also be now fully exposed to the weather. All the available frames will then be taken to another place to be used for growing cucumbers or melons, for which purpose they should be used without delay. 
Asparagus planting and sowing should be finished early in month 146 and 148

Beans (Dwarf) may be sown in a sheltered situation at end of month... 157

$\begin{array}{lllllll}\text { Beet should be sown in the last week... } & \ldots & \ldots & \ldots & \ldots & \ldots & 162\end{array}$

Kale should be sown at the beginning of the month $\quad \ldots \quad \ldots \quad \ldots 163$

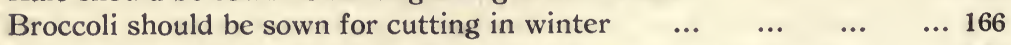

Cabbage should be sown for cutting in late summer and autumn $\quad . .172$

Cardoons may be sown in the last week $\quad \ldots \quad$...

Carrots (main-crop) should be sown about the middle of the month $\quad . .177$

Cauliflowers should be sown in the open about the middle of the month 180

Celery (late) should be sown in the open in the second week $\quad \ldots \quad \ldots 185$

$\begin{array}{llllllllll}\text { Chicory may be forced } & \ldots & \ldots & \ldots & \ldots & \ldots & \ldots & \ldots & \ldots & 197\end{array}$

Prepare frames for Frame Cucumbers in the last week $\ldots \quad \ldots \quad \ldots 203$

Cucumbers (Ridge) may be sown on a hot-bed in the middle of month.. 208

Cos Lettuce should be sown in first and last weeks $\quad \ldots \quad \ldots \quad \ldots 222$

Herbs may be sown about the middle of the month $\quad \ldots \quad \ldots \quad \ldots 212$

Mustard and Cress may be sown in a cold frame or in the open $\quad$... 242

Onions from boxes should be planted out early in the month $\quad \ldots \quad$.. 249

$\begin{array}{llllll}\text { Pickling Onions should be sown on poor ground } & \ldots & \ldots & \ldots & \ldots & 250\end{array}$

Peas (main-crop) should be sown in first and last weeks ... $\quad \ldots \quad \ldots 260$

Potato planting should be completed during the month $\quad . . \quad \quad \ldots \quad \ldots 272$

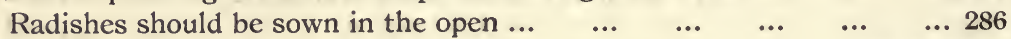

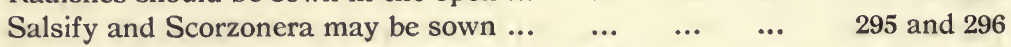

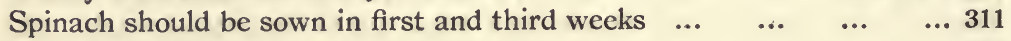

\begin{tabular}{llllllll} 
Spinach Beet may be sown & $\ldots$ & $\ldots$ & $\ldots$ & $\ldots$ & $\ldots$ & $\ldots$ & $\ldots$ \\
\hline
\end{tabular}

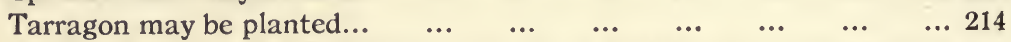

Tomatoes should be transplanted and put in cold frames in last week... 342

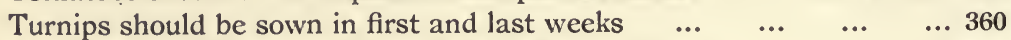

Marrows should be sown on hot-bed in second week $\quad \ldots \quad \ldots \quad \ldots 364$

\section{FRENCH GARDENING :-}

Beans (Dwarf) should be sown in a cold frame for transplanting $\quad \ldots 157$

Cauliflowers should be planted amongst Carrots on hot-beds $\quad \ldots \quad$... 95

Celery (early) sown in February must be pricked out in a cold frame ... 185

Cos Lettuce under cloches - when the first batch are gone plant Cauli-

flowers in their places and put the cloches over the second batch... 98

Cabbage Lettuce in cold frames-as soon as these are gone plant Cauli-

flowers on the beds and sow Spinach between the rows.

Melons for " early" crop must be planted out in frames in the first week 225

Melons for " main-crop" sown last month must be potted in 60 's in the

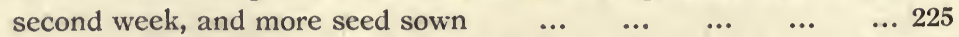

Strawberries should be covered for forwarding as frames are available 328

Tomatoes pricked out last month should be transplanted to 48's pots or

to boxes, 4 in. apart, and set on a mild hot-bed in the second week... 342

$\begin{array}{llllllll}\text { Turnips should be sown in the open } & \ldots & \ldots & \ldots & \ldots & \ldots & \ldots & 359\end{array}$

At the end of the month remove all frames from Carrots and cold beds and use them for Melons. 


\section{MAY.}

SEED-BEDS should be examined, and if any deficiencies $S$ exist they should be made good by re-sowing in rich moist soil, to encourage quick growth. Seedlings of all kinds should. be thinned out early, as there is nothing more likely to result in second-rate crops than to allow them to become drawn and weakly by overcrowding. Cauliflowers, lettuce, \&c., should be planted out at every opportunity. Stations for marrows, ridge cucumbers, and other tender subjects should be prepared by the middle of the month, and stakes or wires fixed on the tomato ground preparatory to planting. After the middle of the month those who have no conveniences for raising tender plants on hot-beds may sow seed in the open, on well-prepared stations; but some means of protecting the young plants should be kept at hand, if only dry litter, or after they come through the ground there is still the danger of late frosts cutting them down. The hoe should be kept regularly at work stirring the soil.

In the French garden one of the most important matters is the planting and training of Melons, with which most of the frames are filled as they are removed from other crops. Watering must also receive constant attention; this is one of the principal factors in producing the abundant and rapidlymaturing crops for which this system is famous. In particular, carrots and cauliflowers on the manure beds need watering daily, and strawberries being forwarded in cold frames need frequent applications of water and liquid manure.

\section{GENERAL OPERATIONS :-}

Globe Artichoke suckers may be planted for succession ... $\quad \ldots \quad$... 142

Beans (Dwarf) should be sown for main-crop in first or second week ... 157

Beans (Runner) should be sown for main-crop in second or third week.. 159

Beet should be sown about the middle of the month $\quad \ldots \quad$... $\quad \ldots 162$

Broccoli should be sown for spring and summer cutting ... $\quad \ldots \quad \ldots 166$

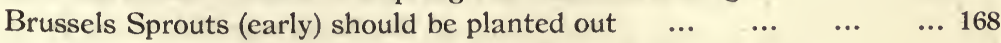

Cauliflowers should be sown at the beginning of the month $\quad . . \quad$... 180

Celery (early) should be planted in trenches or on broad beds ... 186 to 190

Chicory should be sown towards the end of the month $\quad \ldots \quad \ldots \quad$... 197

$\begin{array}{lllllllll}\text { Cos Lettuce should be sown } & \ldots & \ldots & \ldots & \ldots & \ldots & \ldots & & \ldots\end{array}$ 
Cucumbers (Ridge) may be planted out early in the month, if protected, with warm manure under; seed may be sown in the open in the

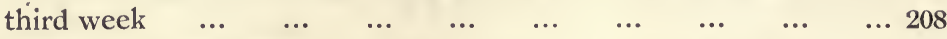

Marrows should be put in a cold frame to harden in the first week and

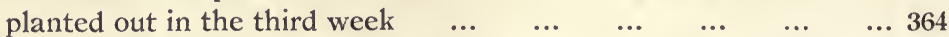

Marrows may be sown in the open after the middle of the month $\quad \ldots 365$

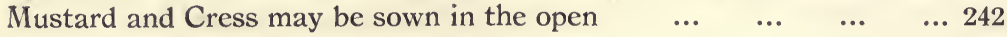

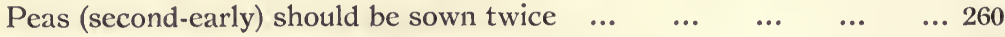

Radishes should be sown in cool moist places $\quad \ldots \quad \ldots \quad \ldots \quad \ldots \quad \ldots 286$

Spinach should be sown in cool moist places $\quad \ldots \quad \ldots \quad \ldots \quad \ldots 311$

New Zealand Spinach should be planted out at the end of the month... 315

Tomatoes should be set out in last week if weather is genial $\ldots \quad$... 345

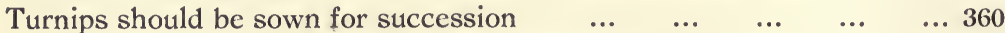

\section{FRENCH GARDENING :-}

Cauliflowers should be planted in the open as ground comes vacant and

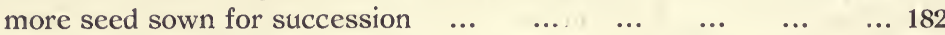

Celery (main-crop) and Celeriac must be pricked out in the open early

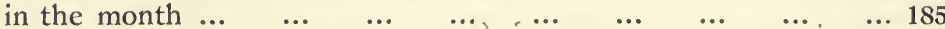

Cucumbers should be sown on a hot-bed in the first week and potted in the last week, to fill frames which come off forwarded Strawberries 201 Dwarf Beans from cold frames should be planted in a sheltered place.. 157 Endive may be sown in the first week.

Melons must be planted as beds are prepared $\quad \ldots \quad \ldots \quad \ldots \quad \ldots 225$ Strawberries being forwarded need water and liquid manure frequently 328 Tomatoes should be planted out over warm manure and covered with cloches early in the month... 104

\section{JUNE.}

TOMATO, vegetable marrow, and ridge cucumber planting should be finished as early in the month as the weather will permit. Lettuces, cauliflowers, and early broccoli should be planted out whenever an opportunity occurs. Potatoes will need earthing-up. Crops grow rapidly now but not so quickly as weeds do unless they are constantly kept down; still, there is some satisfaction in knowing that the operation of stirring the soil to destroy weeds is also one of the best possible means of increasing the vigour of the crop, also that the oftener it is done the easier it becomes. Now also is the time when it pays to give water to some of the crops, but when this course is decided 
upon beware of driblets; watering should be done thoroughly or not at all. A mulch of long manure after a good soaking prevents undue evaporation and by retaining the moisture in the soil for the use of the plants has a marvellous effect in promoting vigour in a dry season.

In the French garden the only things which need special mention are the necessity for regular watering of all crops and proper attention to stopping and training cucumber and melon plants, in connection with which it is advisable to study the chapters dealing with those subjects.

\section{GENERAL OPERATIONS :-}

Asparagus cutting should cease from the middle to the end of month... 150 Brussels Sprouts should be planted out

... 168

Celery (main-crop) should be planted in trenches or on beds $\quad . .186$ to 190

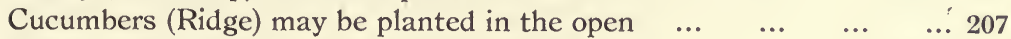

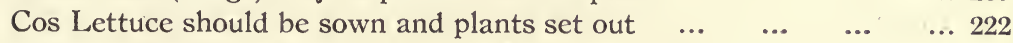

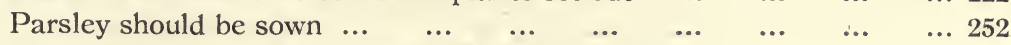

Peas (first-early) may be sown in the first week $\quad \ldots \quad \ldots \quad \ldots \quad \ldots 260$

$\begin{array}{llllll}\text { Radishes may be sown in cool moist places ... } & \ldots & \ldots & \ldots & \ldots & 286\end{array}$

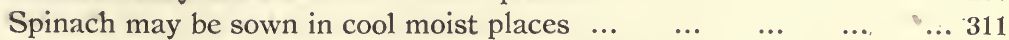

$\begin{array}{llllll}\text { Strawberry runners should be layered for forcing } & \ldots & \ldots & \ldots & \ldots & \ldots 30\end{array}$

Tomato planting should be finished in first or second week $\quad \ldots \quad$... 345

Turnips should be sown again for succession $\quad \ldots \quad \ldots \quad \ldots \quad \ldots 360$

The planting of spring-sown Brassicas (Sprouts, Broccoli, Kale, and

Savoys) should be proceeded with at every opportunity this month.

\section{FRENCH GARDENING :-}

Celery (early) should be planted on manure beds after Cauliflowers, or on any well-dug ground which is covered 3 of 4 inches deep with

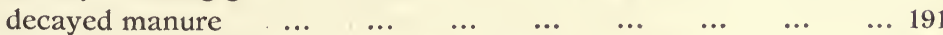

Celeriac should be planted as soon as ground is available $\quad \ldots \quad \ldots 196$

Cucumbers should be planted in the frames which have been removed

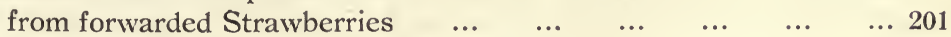

Endive should be planted as soon as ground is vacant, and two weeks later Celery or Cauliflower can be planted between $\ldots \quad \ldots \quad \ldots \quad \ldots 105$

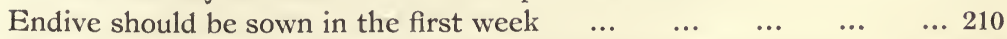

Melons should receive close attention in stopping and watering $\quad \ldots 226$

"Forced" Melons will now be showing plenty of ripe fruit, whilst the

"Early" ones are fast approaching ripeness; they will therefore need careful watching, removing the fruit on the proper point or it $\begin{array}{llllllllll}\text { may be spoiled } & \ldots & \ldots & \ldots & \ldots & \ldots & \ldots & \ldots & \ldots & 228\end{array}$

Strawberries (maiden plants) intended to produce runners should have bloom removed, and runners should be layered $\quad \ldots \quad \ldots \quad \ldots 323$

Tomatoes should now stand in the open and be tied to stakes ... $\quad . .349$ 


\section{JULY.}

$\triangle$ PART from gathering and marketing the crops as they A come ready, the principal work of this month is to set out plants at every opportunity, to keep down weeds, and to keep the crops moving steadily forward. Sometimes July is a rather wet month, in which case the combined heat and moisture causes vegetation to grow luxuriantly, but when showers are few growth often comes practically to a standstill for lack of moisture. Watering over a large area is impracticable, but the use of the hoe is not, and repeated stirrings of the surface soil, either by horse or hand labour, by forming a soil mulch to check evaporation is of immense benefit to the plants, and should be systematically carried out (see pages 17 to 21 ).

In the French garden the planting of main-crop celery forms one of the principal tasks of the month; as the period allowed for growth is short the work should be pressed forward rapidly.

\section{GENERAL OPERATIONS :-}

Globe Artichokes may be cut down to produce suckers for Chards $\quad . .143$ Beans (Dwarf) may be sown in the first week for late crop $\quad \ldots \quad \ldots \quad 157$

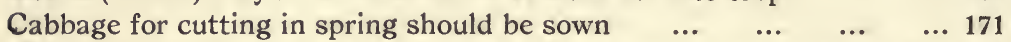
Carrots for pulling young in autumn may be sown early in the month... 178 Celery (late) should be planted in trenches or on broad beds ... 186 to 190

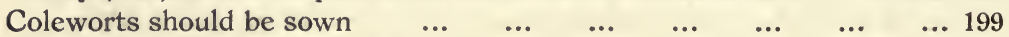
Cucuimbers and Melons need frequent attention in watering, thinning growths, and gathering fruit $\quad \ldots \quad \ldots \quad \ldots \quad \ldots \quad 205$ and 226

Herbs should be gathered for drying as they come into flower ... $\quad . .212$

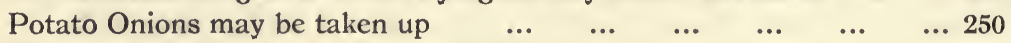

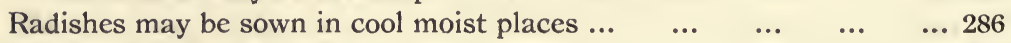
\begin{tabular}{llllllll} 
Shallots should be harvested & $\ldots$ & $\ldots$ & $\ldots$ & $\ldots$ & $\ldots$ & $\ldots$ & $\ldots$ \\
\hline
\end{tabular} $\begin{array}{lllllllll}\text { Spinach Beet may be sown } & \ldots & \ldots & \ldots & \ldots & \ldots & \ldots & \ldots & 316\end{array}$ Tomato plants should be regularly tied and trimmed $\quad \ldots \quad \ldots \quad \ldots 347$

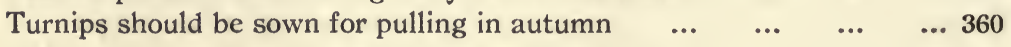

\section{FRENCH GARDENING;-}

Carrots, for autumn bunching, may be sown after Cauliflowers... ... 178

Cauliflowers should be planted on Melon beds, from the beginning to

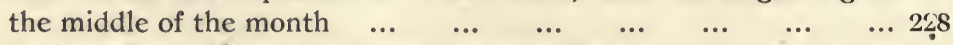
Celery (main-crop) should be planted on broad beds $\quad \ldots \quad \ldots . \quad \ldots l 191$ Endive (Summer) should be sown in the first week $\quad \ldots \quad \ldots \quad \ldots 210$ Endive (Hardy) should be sown in the third week ... $\quad \ldots \quad \ldots \quad \ldots 210$ If weather is genial remove lights from Melons in the middle of month.

Strawberry runners should be layered and watercd $\quad \ldots \quad \ldots \quad \ldots 323$ 


\section{AUGUST.}

THE general instructions for August do not differ very 1. materially from those for July. There is still the same need for keeping the ground free from weeds and the crops moving steadily along. During the month, as opportunity occurs but the sooner the better, the planting of late broccoli and all winter greens must be completed. When the ground is dry the plants must either be watered in or the roots should be "puddled." Tomatoes should be stopped in the first week and as the fruit should now be ripening quickly, gathering will need close attention, remembering that it is of much better quality and appearance when ripened on the plant than when gathered half ripe and finished off under cover.

In the French garden there is, of course, that need for regular and systematic watering of the crops which forms an integral part of the system. Melons, when ripening, form an exception to this rule; they must then be kept rather dry, but as soon as fruit and haulms are cleared the beds must receive a copious watering for the benefit of the cauliflowers.

GENERAL OPERATIONS :-

Cabbage for cutting in spring should be sown in first and third weeks... 171

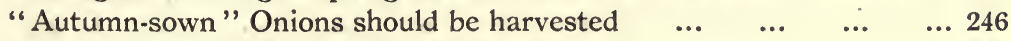

"Autumn-sown" Onions should be sown $\quad \ldots \quad$...

"Spring Onions" for pulling green should be sown $\quad \ldots \quad$... $\quad \ldots 250$

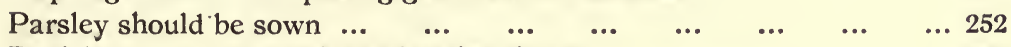

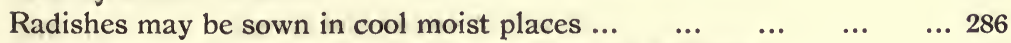

$\begin{array}{lllll}\text { Spinach should be sown for autumn and winter picking } & \ldots & \ldots & \ldots & \ldots\end{array}$

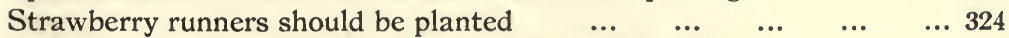

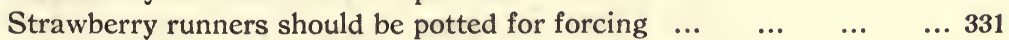

Strawberry plantations should be cleared of old leaves, runners and

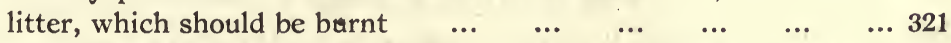

Tomatoes should be stopped in the first week and regularly trimmed... 348

Turnips should be sown for pulling in winter $\quad \ldots \quad \ldots \quad \ldots \quad \ldots 360$

\section{FRENCH GARDENING :-}

Carrots may be sown on beds which can be covered later by frames ... 178

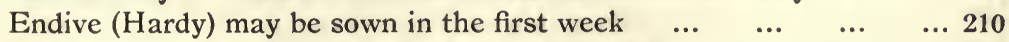

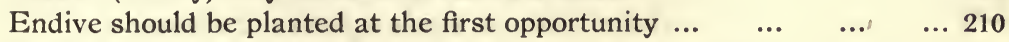

Endive should be tied up for blanching as it comes ready $\quad \ldots \quad \ldots 211$

Celery (late) should be planted early in the month $\quad \ldots \quad \ldots \quad \ldots l 19$

Celery (early) should be covered with mats for blanching $\quad \ldots \quad \ldots 192$

Strawberry beds should be planted and plants for forcing potted..324 and 332 


\section{SEPTEMBER.}

WEEDS are always with us, and may be regarded either as a blessing or a curse, according to the point of view. In moderate quantities, when they have not yet grown large enough to do any particular harm, but are sufficiently in evidence to make their destruction imperative, they may be regarded as a disguised blessing, because the operation necessary to their removal is a decided benefit to the crops they grow amongst; but it needs a temperansent bright and cheerful far above the average to regard them otherwise than as a curse when a clean garden is again filled with seeds from foul and neglected land near by. This usually happens in September, and as, at present, there is no law to punish such neglect, the only thing to do is to "keep them down," or worse will follow.

GENERAL OPERATIONS :-

Globe Artichoke suckers may be blanched for Chards at end of month.. 143

Cabbage plants for spring cutting should be set out $\quad \ldots \quad \ldots \quad \ldots 171$

$\begin{array}{llllllll}\text { Cardoons should now be blanched } & \ldots & \ldots & \ldots & \ldots & \ldots & \ldots & 173\end{array}$

$\begin{array}{lllllllll}\text { Celery should be earthed up } & \ldots & \ldots & \ldots & \ldots & \ldots & \ldots & \ldots & 188\end{array}$

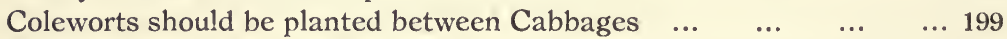

Hardy Cos and Cabbage Lettuce should be sown in the second week... 222

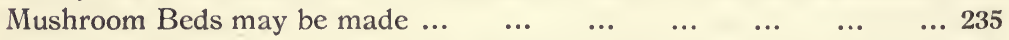

Trim large leaves off Parsley and arrange to protect in frost or snow... 254

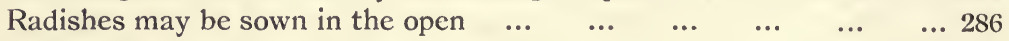

$\begin{array}{lllllll}\text { Spring-sown Onions should be harvested } & \ldots & \ldots & \ldots & \ldots & \ldots & 246\end{array}$

Spinach should be sown on a dry bed for winter and spring $\quad \ldots \quad \ldots 312$

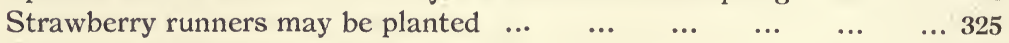

$\begin{array}{lllllll}\text { Tomatoes should be regularly trimmed } & \ldots & \ldots & \ldots & \ldots & \ldots & 347\end{array}$

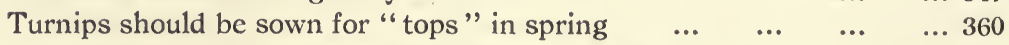

FRENCH GARDENING :-

Celery (main-crop should be covered with mats for blanching ... $\quad . .192$

Cabbage Lettuce (Hardy) for standing in open-air beds through the winter, should be sown in the middle of the month and pricked out in nursery beds about a week later

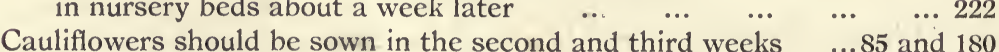
Endive should be tied up for blanching as it comes ready $\quad \ldots \quad \ldots 211$ Melon beds should be cleared of fruit and haulms and the Cauliflowers $\begin{array}{lllllllll}\text { copiously watered } & \ldots & \ldots & \ldots & \ldots & \ldots & \ldots & \ldots & \ldots 229\end{array}$ Radishes may be sown on the manure beds after early Celery $\ldots . \quad \ldots 286$ At the end of the month prepare beds, frames, and cloches for Cauli-

flowers and Lettuces to pass through the winter $\quad \ldots \quad 181$ and 220 


\section{OCTOBER.}

CLEAR away rubbish and decaying leaves from every part of the garden. Pull yellowing leaves from cabbages, brussels sprouts, and other brassica. Put that which will readily decay into a compact heap, mixing in a good sprinkling of lime as the heap is made; lay the remainder, including potato, tomato, and melon haulms on one side for burning, and take every opportunity to get and keep them dry. Begin manuring and digging vacant land.

GENERAL OPERATIONS :-

Asparagus beds should be cleared of foliage and weeds and then covered

with a mulch of manure, 2in. deep

... 149

Late Potatoes, Carrots, and Beet should be lifted and clamped $\quad . .280$

Cos and Cabbage Lettuce for wintering under protection should be sown

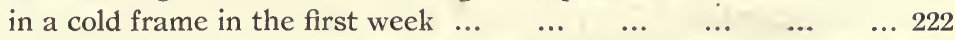

Hardy Cos and Cabbage Lettuce should be planted in the last week ... 222

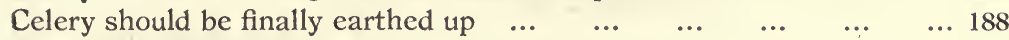

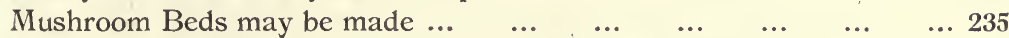

Onions may be sown in boxes in a cold frame for making large bulbs... 248

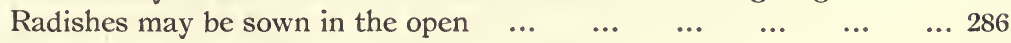

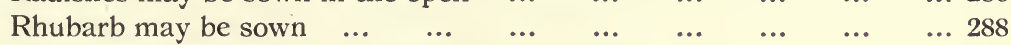

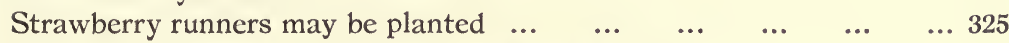

\section{FRENCH GARDENING :-}

Cabbage Lettuce (Hardy) should be planted out in a dry position at the end of the month

Celery (main-crop) should be covered with mats for blanching ... $\quad . .193$

$\begin{array}{llllllll}\text { Celeriac should be lifted and stored } & \ldots & \ldots & \ldots & \ldots & \ldots & \ldots & 196\end{array}$

Endive should be protected and blanched $\quad \ldots \quad \ldots \quad \ldots \quad \ldots \quad \ldots \quad \ldots 211$

Strawberries in pots for forcing should be protected $\quad \ldots \quad \ldots \quad \ldots 332$

Lettuce (all varieties), to be wintered under protection, must be sown in small batches during the first and second weeks, and pricking out of the seedlings under cloches or in cold frames must be done in the third and fourth weeks $\quad \ldots \quad \ldots \quad \ldots \quad \ldots 87$ and 220

Cauliflowers sown last month should be pricked out in frames in the

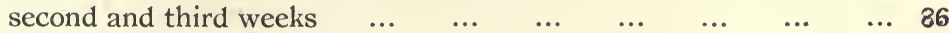

Carrots sown in August should be protected by frames $\quad \ldots \quad \ldots \quad \ldots \quad \ldots 178$

All ground cleared of crops should now be manured and dug.

The old hot-beds must be cleared away and the soil below thoroughly dug and limed; about one-third of the decayed manure should be well broken up and then wheeled into position for making next season's hot-beds (see page 91), the remainder being used partly to manure such ground as is in need of it and partly made into a heap for preparation as compost for general purposes 


\section{NOVEMBER.}

I $\mathrm{N}$ this month the working of the land should be taken in hand 1 in earnest. In addition to ordinary digging or ploughing, bastard trenching or subsoil ploughing should be done on that portion of the land where deep cultivation falls due in the proper rotation. Land intended for spring planting or seeding should be left rough on the surface or be ridged up, so as to get the full benefit of "weathering"; it will then lie warmer and drier, and can be got into excellent condition in a very short time when wanted. Read pages 10 to 19 . Lime should be given now to land requiring it. Where kainit and basic slag are to be used this is the best time for applying them so as to get full benefit in next season's crops. Means of protection should be provided for all crops needing it.

\section{GENERAL OPERATIONS :-}

Asparagus beds on heavy land should be covered with soil from alleys.. 150 Asparagus to be forced in beds should be covered with compost . $\quad . .152$

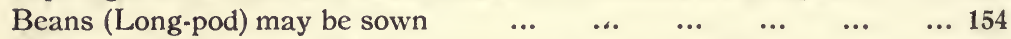
Chicory roots should be lifted and may be forced at once $\quad \ldots \quad \ldots 197$ $\begin{array}{llllllll}\text { Mint may be forced on a hot-bed } & \ldots & \ldots & \ldots & \ldots & \ldots & \ldots & 230\end{array}$

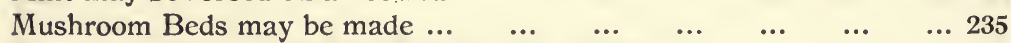
Mustard and Cress may be sown on a hot-bed $\quad \ldots \quad \ldots \quad \ldots \quad \ldots \quad \ldots 242$ Peas for early supplies may be sown in 60's pots in a cold frame $\quad . .258$

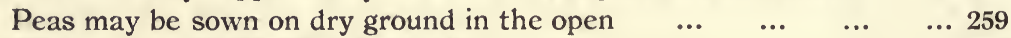
$\begin{array}{llllllll}\text { Rhubarb may be lifted and forced } & \ldots & \ldots & \ldots & \ldots & \ldots & \ldots & 291\end{array}$

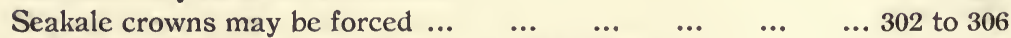

\section{FRENCH GARDENING :-}

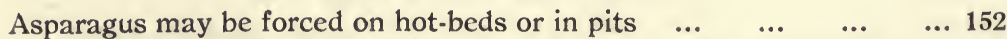
Celery (late) should be protected and put in frames for blanching $\quad . .193$

Cos Lettuce for forcing should be transplanted about the end of the month, or early in next month, and given more space $\quad \ldots \quad$.. 87

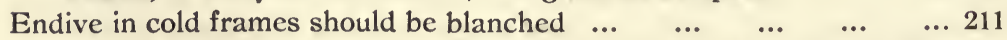

All rubbish should be cleared away and the garden made neat and tidy; remains of vegetables which will decay readily should be made into a heap, freely sprinkled with lime, to be dug into the ground at the end of the following season; all the remainder should be burned

Continue breaking up old hot-beds and digging vacant ground.

Frames not in use should be cleaned, repaired and stacked away until they are wanted in January; spare Lights should be taken under cover to be put into thorough repair and repainted; spare Mats should be thoroughly dried under cover and stored away. 


\section{DECEMBER.}

PAY particular attention to the drainage of the land; examine all outlets and clear all pipes which may have become blocked; on heavy land see that all furrows are clear so that rain-water can pass away freely. Pools of stagnant water. standing about on the land should not be tolerated; there is usually some simple means of removing such surplus water, either by pipes or by surface drains (see pages 7 to 10), but if, unless for some extraordinary reason, it cannot be got away, it may safely be concluded that such land will not pay for cultivation. All the burnable rubbish should now be gathered together for making "smother" or "smoulder" fires. As the name implies, these fires must be managed so as to burn slowly, or smoulder. When the fire has got a good hold of the rubbish it is cased all over with earth, and further coverings are put over any red fire which breaks through. The resulting black ashes are excellent either as a fertilizing material or for improving the texture of seed beds, and form a very valuable ingredient of any compost.

\section{GENERAL OPERATIONS :-}

Beans (Broad) may be sown in a cold frame for transplanting ... $\quad . .155$

$\begin{array}{llllllllll}\text { Chicory may be forced } & \ldots & \ldots & \ldots & \ldots & \ldots & \ldots & \ldots & \ldots & 197\end{array}$

$\begin{array}{llllllll}\text { Mint may be forced on a hot-bed } & \ldots & \ldots & \ldots & \ldots & \ldots & \ldots & 230\end{array}$

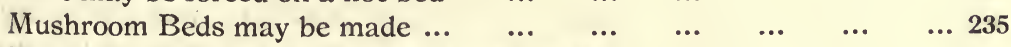

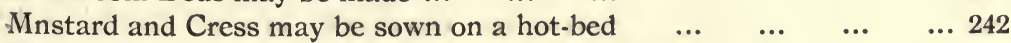

Radishes may be sown in a dry sheltered situation $\quad \ldots . \quad \ldots \quad$... 285

$\begin{array}{llllllll}\text { Rhubarb may be lifted and forced } & \ldots & \ldots & \ldots & \ldots & \ldots & \ldots & 291\end{array}$

$\begin{array}{llllll}\text { Seakale crowns may be forced } \ldots & \ldots & \ldots & \ldots & \ldots & \ldots \\ 302 & \text { to } 306\end{array}$

Seakale beds are "soiled" to produce "natural kale" $\quad \ldots \quad \ldots \quad \ldots \quad$... 307

\section{FRENCH GARDENING :-}

Asparagus may be forced on hot-beds or in.pits $\quad \ldots \quad \ldots \quad \ldots \quad \ldots \quad \ldots 152$

Cauliflowers may need transplanting deeper and further apart if the

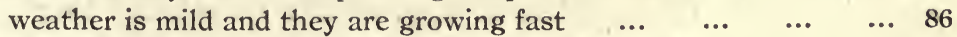

Continue digging vacant ground and repairing lights, \&c.

Give plenty of ventilation to all plants in frames and under cloches

(with the exception of Forcing Cabbage Lettuce) whenever the weather will permit.

When the weather is frosty close all lights and shut down cloches; if severe, all must be covered every night with mats, and dry litter should be scattered amongst and half-way up the cloches. 


\section{GRADING, PACKING, AND MARKETING.}

THE work of the market gardener is by no means finished motive behind all his operations is to obtain a reasonable return in net profit on the skill, labour, and capital expended. In order to secure such a return his produce must be sold at remunerative prices, and the knowledge of how to go to work to get such prices is quite as important as the ability to raise the crops.

Some growers-happily a decreasing minority-still contend that the labour involved in washing, grading, and careful packing does not result in sufficiently enhanced prices to make it worth while, and consistently with their opinion often put their produce on the market in a more or less rough and dirty condition, with no real attempt at grading-good, bad, and indifferent being frequently mingled in one consignment. Such methods have no redeeming feature; some who follow them, by being favourably situated in close proximity to the markets, and so being subject to very little expense for carriage, are no doubt able to make fair profits on the whole, but to others without such advantages these methods must prove disastrous in the end. One of the worst features of this "rough and ready" business is that those who follow it are not the only persons to suffer from its bad effects; if that were so there would be little cause of complaint. But the fact is that when such consignments are placed on the market in appreciable quantities they have the effect of lowering the quotations for the whole of that particular variety of produce, and those who go to the trouble and expense of proper grading and packing, although they may still depend upon getting higher prices, do not get as much as they otherwise would, and so are to some extent penalised for the wrong-doing of others. 
In spite of this drawback, however, there is not the least doubt that proper grading and careful packing does pay well, by ensuring returns far greater than recoups the grower for extra expense entailed. That this is so is becoming generally recognised, and the day is probably not far distant when dirty, ungraded, or slovenly consignments will receive scant respect in, or may even be refused admission to, the most important markets.

An attractive appearance is one of the most potent factors in inducing ready sales. It does not need a very keen faculty of observation to be aware of the favourable effect which a good appearance has upon the general public. This may be seen in every department of life, but in nothing is it more noticeable than in the purchase of food-stuffs. An article of only moderate or even of poor quality if attractive in appearance will sell much more readily and often at a higher price than one of superior quality which is offered in an untempting or repellant way. This fact importers of foreign produce have been quick to discover and take advantage of, and if home growers are to hold their own against the constantly-increasing volume of importations it behoves them to follow the same course.

The first point, therefore, which the grower needs to get firmly fixed in his mind in connection with marketing is that a good appearance has a distinct cash value.

Imported produce of many kinds has now gained a commanding position in our markets, and in many cases, even in competition with the same variety of home-grown produce, buyers show a decided preference for it. The cause of the preference does not lie in the superior quality of the importations, because oftener than not the advantage in that respect is on the side of the home productions; nor is attractiveness the only reason. There are several causes, of which attractive packing is certainly one, but another and an equally important cause is reliability. When a certain weight, number or quantity is specified, or when a number of packages are sold by the sample of the top layer of one, the purchaser of imported produce is fairly certain in the great majority of cases of getting what he pays for, both in quantity and quality. With home-grown produce the reverse is often the case-weight 
or quantity may be deficient or grading badly done, whilst "topping" with a layer or two of a superior sample to that of the bulk is frequently resorted to.

The third point of importance in connection with successful marketing is to so arrange the crops that regular and continuous supplies of a given product can be sent all through the season when it is usually in demand. Here again the methods of the home grower leave much to te desired, and where he makes it easy for the foreigner to displace him in the estimation of the buyer. A sound position in the market can never be established if produce is sent in to a given salesman only by fits and starts. Whether the grower be in a large or a small way-whether the consignment amounts to a hundred baskets at once or only half a dozen-every effort should be made to send them in with regularity. It is very probable that the salesman would be inclined to consider this as the most important point of all in connection with successful marketing. He desires to know, as nearly as he can, the kind and quantity of the produce he has to deal with on any given day, so that he can make arrangements accordingly. He has his regular customers just as the shopkeeper himself has. In many cases some kinds of produce on which reliance can be placed is sold in advance, and never enters the market at all. If these customers buy produce which suits their trade and finds a ready sale they desire to continue dealing in it, and it must be very inconvenient and annoying to both salesman and customer to find the supply of an article of which both approve suddenly cease in the height of the season, or only come in erratically. When this happens the price obtained is lower in consequence. Not only that, but the salesman naturally places a higher value upon a sender whose supplies he can rely upon, and takes more interest in his consignments, with the result that he usually does his utmost to realise the best prices so as to keep the sender satisfied and so retain him as a regular client.

Of course, when the grower is a beginner at the business he very properly desires to feel his way, both with regard to the crops he grows and the salesmen to whom he consigns them, but this experimental period ought not to be too prolonged. In all large markets there are many salesmen with a reputation for 
fair dealing, and the grower would be well advised, at any rate until he has personal knowledge or some good recommendation, to entrust his produce only to those with good credentials. Then he ought to decide as soon as possible upon the particular crops he means to specialise in, a decision in which he will no doubt be influenced by the character of the soil, the situation, the demand in the most accessible markets, and his personal preference or skill. Whatever the character and number of the subsidiary lines may be, he ought to produce some main crops in quantity with his utmost skill, so that he will become known as a grower of those particular products, who may always be depended upon for quality and regular supplies.

An occasional walk through the market, and a chat with some of the salesmen after the rush of business is over for the day, is very advisable; the grower will then be able to compare the quality of the produce exposed for sale with that of his own, and so get an idea of the general standard expected, as well as an insight into the various methods of packing. The salesmen are generally courteous and obliging, and quite ready to give valuable advice which the grower will do well to profit by; not only that, but if a salesman is not in a position to deal with any produce offered him he will usually recommend one or two reliable men who can handle it.

To summarise, the essential points necessary to permanent success in placing produce for sale on a public market are: (1) To place the article before the buyer in as attractive a manner as possible; this implies washing, trimming, and neat bunching of the common vegetables quite as much as the smart packing of those of greater relative value. (2) To guarantee reliability; this implies accuracy in weights, measures, and counts, as well as careful grading to ensure a parcel being of even quality throughout. (3) To ascertain the size of packages or weights and quantities most in favour with buyers, and as far as possible to adhere to them without variation. (4) To specialise in the production of a limited number of staple crops, and to consign supplies to the same market regularly and continuously throughout the season when such produce is usually in demand. (5) Having found a satisfactory salesman, or one who is as satisfactory as can reasonably be expected under the 
circumstances, to continue regular business relations with him, and not to change the salesman without sufficient cause. If these methods are followed, and are supported by good quality in the articles offered, success in marketing should be certain in spite of any competition, foreign or otherwise.

No more need be said except that the grower can generally obtain free from the salesman such empties-baskets, bags, boxes, or other receptacles-as may be necessary for the proper packing of his produce, as well as printed labels with which to address it. In some cases it will perhaps be found more advantageous for the grower to possess his own empties for certain lines, and the use of "non-returnables" may be found preferable for some of the more valuable products, but experience will prove the best guide in these matters.

ARTICHOKES (GLOBE).-The heads of Globe Artichokes are cut as soon as they are fully grown but before the scales begin to open; they are then tender and of good flavour. Each head is cut with an inch or so of stem. They are packed in baskets in regular layers, a little soft material being put between each layer and over the top. They should be marketed in as fresh a condition as possible, and the number of heads in the basket should be marked clearly on the label.

ARTICHOKE (JERUSALEM)。-Lifting may begin in October and continue throughout the winter. Lifting should be finished by February, or fresh growth will take place. The tubers are sorted over, the smallest being rejected. They are packed in half-bushel baskets, with a little hay over the top, the whole being fastened down by two sticks crossed over the top, the ends of each being inserted between the canes at the top of the basket.

ASPARAGUS.-Cutting of Asparagus begins when the tips of the shoots have grown $3 \mathrm{in}$. or $4 \mathrm{in}$. above the soil. It is usually cut about $4 \mathrm{in}$. below the surface of the soil, so that the total length of each shoot is 8in. to 9in. The portion above the soil is green and tender, whilst that below is white, tough, and uneatable; for this reason some growers allow the green portion to grow longer and then, instead of cutting, break off the shoots just below the surface, so getting a rather shorter shoot but one that is of much better quality by being almost entirely eatable. All the shoots long cnough are cut, whether thick or thin, and are then sorted into two or three grades, "special," "ordinary," and "sprue,"-the thickness, length, and general appearance of the sticks being the guide. They are then tied up into bundles or bunches. The size of the bundle varies with the season, the market to which it is sent, and the custom of the district in which it is grown. For instance, in the London district a market bundle of "grass" is usually 100 sticks, whilst those sent from the Evesham district contain 120, each bundle being composed of six small bundles of 20 sticks each. Each bundle has 
two ties of raffia, or two rubber bands, one near the top and one near the bottom ; for the large bundles the tie is sometimes a slender willow "twig." Various devices are used for arranging the sticks into bundles neatly and expeditiously; one of the simplest but must useful of these contrivances is the cradle illustrated at page 151. In making the bundles the heads of the sticks are kept level, and the bottoms are trimmed level with a sharp knife. The bundles are wrapped in paper or leaves (the latter having the effect of keeping them fresher) and are packed for market in baskets with or without lids, hay or similar material being placed over the bottom and round the sides, and also over the top when no lid is used, to protect the contents from being bruised. The produce should be sent to market as soon as possible after cutting as it quickly deteriorates. Different qualities must be packed separately, and the label on each basket should be plainly marlied with the quantity and quality of the contents.

BEANS (BROAD).- - The Beans must be gathered as soon as the pods reach maturity, choosing a dry day for the purpose. All old or dirty pods must be rejected. Gathering should be done twice a week to ensure the best results. The pods should be put in bushel baskets, covered with freshcut grass, and fastened down with sticks laid across. The Beans should be sent to market as soon as possible after gathering.

BEANS (DWARF, or FRENCH).-On good land in a favourable season French Beans mature very quiclily. The plants must therefore be closely watched, and the pods picked the moment they are ready. If allowed to hang too long the plants cease to bear and the pods become stringy and worthless. The plants should be gone over two or three times a week, as the oftener the Beans are gathered the better the quality and the greater the yield. The pods of the main-crop are carefully laid in peck baskets, lined and covered with blue tissue paper, with a layer of soft hay or grass on top secured by wooden splinths. Beans which have been brought along early are usually marketed in overhandle baskets ; these are carefully packed as before, being either covered with a lid or with blue paper laced over the top with string or raffia. Each package should be marked with the weight of the contents and all should be uniform.

BEANS (RUNNER).-Scarlet Runners, like the dwarfs, must be gathered very frequently, or the pods become tough, stringy, and worthless. The Beans are usually picked by women on piece-work; before packing it is necessary to examined the baskets to see that the Beans are clean, free from leaves or rubbish, and that no old pods are mixed in. They are put in half-bushel or bushel baskets, covered over the top with a layer of soft hay and secured with sticks. Send them to market promptly so that they will arrive in fresh plump condition.

BEET.-The marketing of Beet usually begin . October and continues through the winter, the roots being taken from the clamp as required. Only medium-sized roots of even shape, and none that are broken or damaged in any way should be sent to market. The roots are packed in bushel baskets with a covering of hay or straw securely fastened down. 
BORECOLE, or KALE.-There is not much sale for Kale until the weather gets severe; then the demand usually becomes good and the price remunerative. For this reason the crop should, if possible, be allowed to stand until wanted. When they are picked, only the young growths and perfect leaves should be packed, decaying and discoloured foliage being rejected. The "greens" are packed in bags or in baskets, according to the requirements of the saleșman, and care should be taken to pack as tightly as possible, as when the receptacles are only partly filled dissatisfaction is caused and low prices realised.

BROCCOLI.-The cutting of Broccoli begins with the cold weather, as soon as the autumn cauliflowers are over, and continues to the beginning of the following summer, according to the season, the successional sowings made, and the varieties grown. The crop is usually arranged that the bulk of the supplies are placed on the market from March onwards. The heads are cut so as to be surrounded with a fringe of leaves, and these in turn are trimmed so as to expose the flower, but projecting a little beyond it to afford a slight protection. They are graded into two classes- "bests," consisting of large, clean, compact, white heads, and "seconds," which are composed of those smaller and less perfect. Discoloured or damaged heads, or those which are overgrown and open, should not be sent to market. They are packed in crates and are sold by the "tally" of five dozen.

SpRouting Broccoli is generally most in demand after the turn of the year, when cabbages and savoys are getting scarce and white broccoli has not yet appeared on the market in quantity. The sprouting heads are broken off with a small piece of the stem attached, and packed firmly in bags or bushel baskets. Care should be taken only to pack young growths with tender stems, old and tough stems being very objectionable.

BRUSSELS SPROUTS. - The picking of Brussels Sprouts usually begins in October and continues through the winter months until about February, by which time the crop is generally finished. The plants are, as a rule, gone over two or three times, the largest only being removed each time, but some growers will wait until a breadth of plants are ready, then have them pulled up by the roots and carted to the sheds, where the Sprouts are stripped and graded into two qualities and the tops cut off and bagged. In a few provincial towns it is customary to send the whole plant into market after cutting off the roots. Several methods of marketing Sprouts are employed ; in some markets "pot" baskets are used, in others, especially late in the season, they are sold in $\frac{1}{2} \mathrm{cwt}$. bags, but for the most part they are packed in half-bushel baskets of 20lbs. early in the season and in bushel baskets of 40lbs. later. After the Sprouts are cleared the tops are cut off and sent to market in bags containing $\frac{1}{2} \mathrm{cwt}$. Where the crop is grown in quantity picking is usually done by women; the customary price paid is $2 \frac{1}{2} \mathrm{~d}$. for picking and packing a half-bushel ready for despatch, or $2 \mathrm{~d}$. when the basket is not made up.

CABBAGES. - The cutting of spring Cabbages usually begins in February, when alternate plants and rows from close-set plantations are cut out and 
sent to marliet half-grown, paclied in crates. At this time choice greenstuff is getting rather scarce and these Spring Greens or small Cabbages meet with an excellent demand at good prices. Following these, marketing of larger heads should be begun as soon as possible, the field being gone over and those selected which have made good firm hcarts. The earlier they are marketed the higher is the price obtained. Early Cabbages are usually forwarded to London salesmen in light wicker crates known as "tallies," each of which contains five dozen heads. Later in the season Cabbages are packed directly on wagons and, where possible, sent to market by road; in some cases they are loaded directly into railway trucks and so forwarded to market.

CARROTS.-The pulling of young Carrots begins at the second thinning, as soon as the young roots are from $\frac{1}{2}$ in. to $\frac{3}{4}$ in. through at the thicliest part. They are at once bunched, then washed and packed, and sent to market. When Carrots are grown on hot-beds the crop is thinned early to the proper distance apart, before they have attained any size, and are then left until the bulk are ready, when the whole bed is cleared. These forced roots are bunched and washed in the same way as the young roots from the main-crop. The size of the bunch varies with the season and the custom of different markets,-in some cases a dozen roots will be sufficient whilst in others fifty may be required, and the price obtained varies in proportion. The tops are left on, each bunch is tied up neatly with raffia, and they are usually paclied in lidded hampers, or "pads," though occasionally any other baskets or boxes are used as is convenient. They should be consigned in even numbers with the quantity in each receptacle marked plainly on the label.

Main-crop Carrots are lifted in October. Those not immediately sent to market have the tops twisted off, leaving $\frac{1}{2}$ in. or so above the crown. They are then stored in sand or in clamps (see page 178), and are sent to market through the winter, as required, in baskets or bags. These mature roots are marketed both washed and unwashed, but a clean and even sample makes by far the best price.

CAULIFLOWERS.- - Under ordinary culture cutting of Cauliflowers begins in August and continues to the end of October, but under intensive culture cutting begins early in June. As a general rule the earlier they are placed on the market the better are the prices obtained. When the heads begin to come ready the plantation should be gone over every two or three days so as to cut them just at the right time, as they quickly get past their best by becoming too open in the flower, which should be allowed to develop to its full size but be cut whilst it is still quite firm, close, and compact, and the flower should have been liept white and clean by breaking the midrib of one of the large leaves and bending this over it when it is half formed. Each head is cut with a fringe of large leaves and these are shortened so as to reveal the flower but standing about an inch higher so as to afford a slight protection. The heads are graded into two qualities"bests," which embraces all the large and perfect ones, and "seconds," in which is included all the small and imperfectly formed ones, but not those 


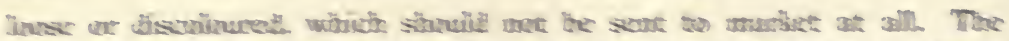

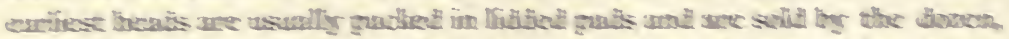

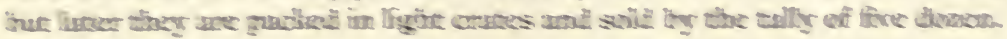

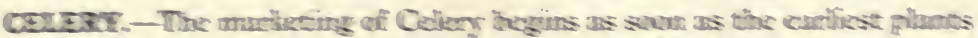

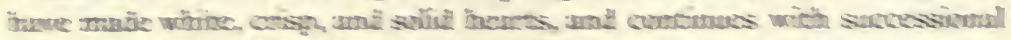

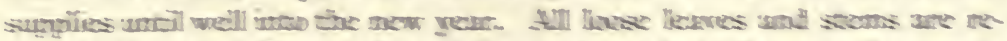

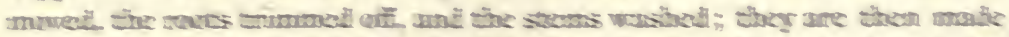

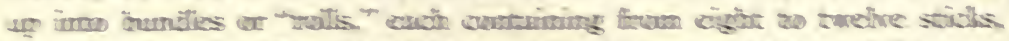

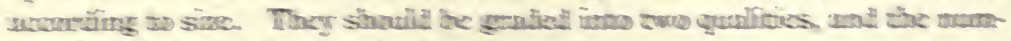

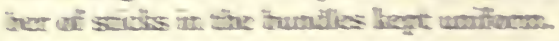

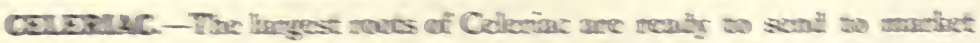

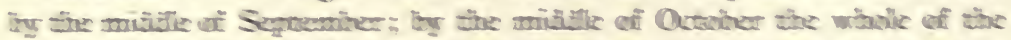

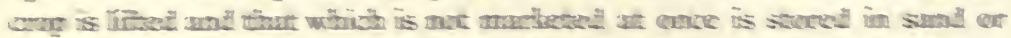

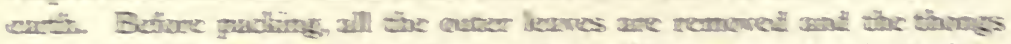

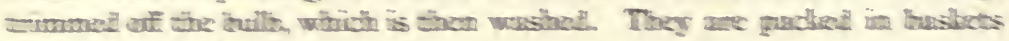
and saili tos the busen.

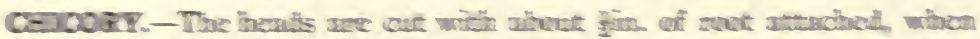

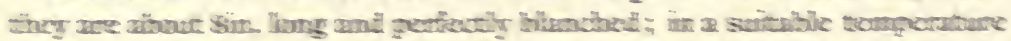

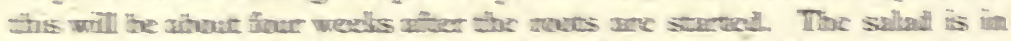

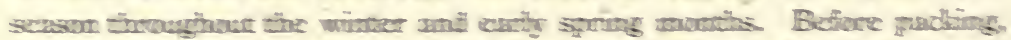

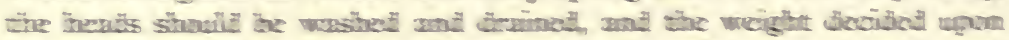

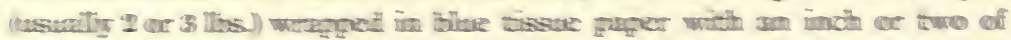

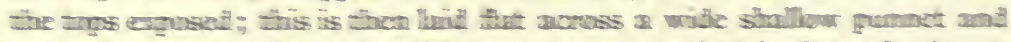

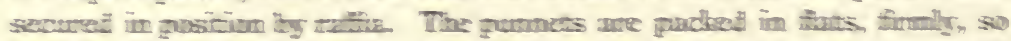

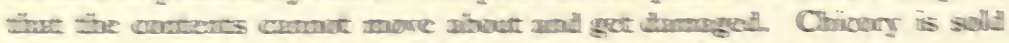

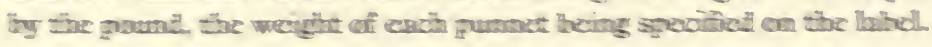

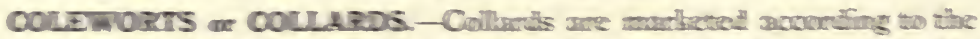

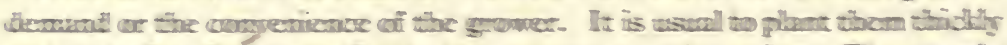

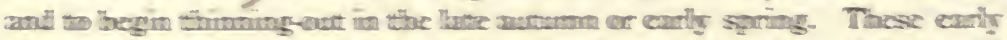

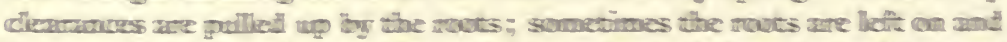

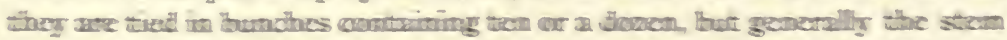

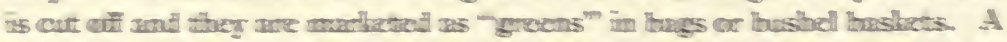

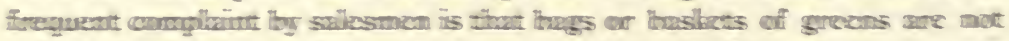

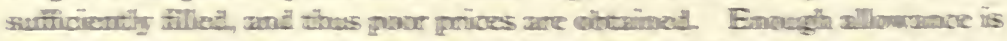

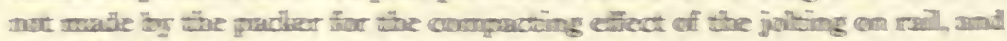

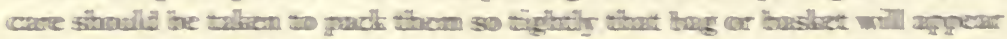

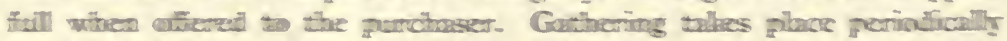

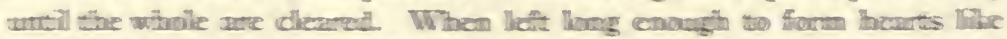

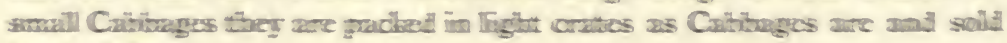
iny the wally-

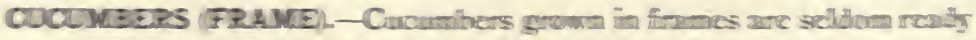

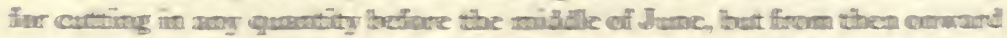

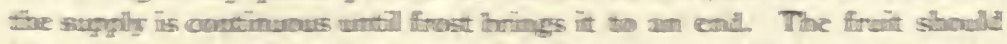

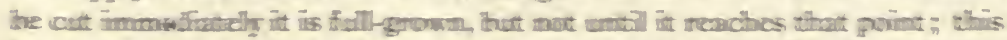

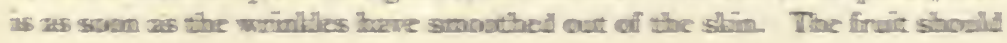


be gathered two or thece tintes each weeli so that none is allowed to semant on the platis too long. They should be properily sraded in three qualities-

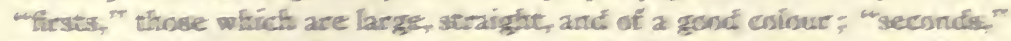
those which are smaller or crosked, or pale in colour, but otherwige of comparatively good quality : and "thirds," those which dis mot answer to either of the two precedirg descriptions-these shrould, as a rule, lie liept. at home and either destroved or suld to hawliers, as it mever pays on send them to marliet except on the rare occasions when there is a shrortage of of Frame Cucumbers in summer. The fruit is pached in strallow fidded basirets, of "Wiats," which bold from two to three doren. according to the sime. The method of paching is to put a layer of grass or soit hay at the bottoms of the flat and cover this with a sheet of tissue pager, agosn witrich a layer of "Cures" is placed, sile by side. These are crverch with tissue paper, a lietie sort hay to fill wo the foilows and malie all level, another sifeet of tiswue paper and another layer of Cues. and so on untel the fat is full, covering the last laver with paper, then with fray on too and fown the sides, so that the whole contents are pached firmily and secure from movement. If the Cires are at all lowse in the bashet it is probabie that mant will arsive at the marlet broken atrea a journey by rail.

CUCUMaers (RDGE)-Cutting of Rifige Cucumiters begins earin in July. In marlicts where they are lnown and agpreciated as they deserve

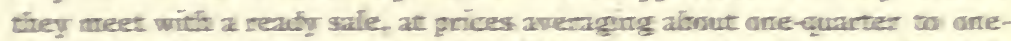
thired as much as the fonme variety- This, fowever, is not proporsinnatelv so low as it seems when the heavy crogching and sntailer amount of attention required is talien imto consifiestion. The first few fruta are gerereally

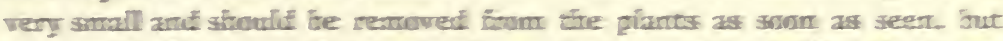

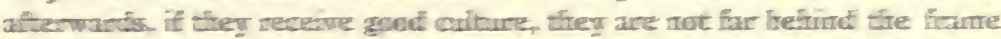
wariety in appencance. The plants sfrould be gone ower and the fint

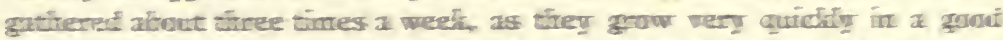

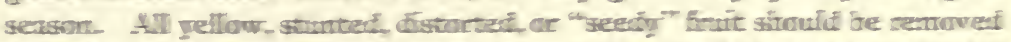

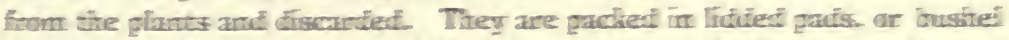

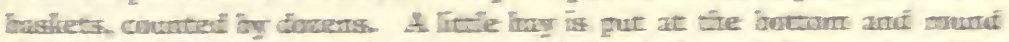

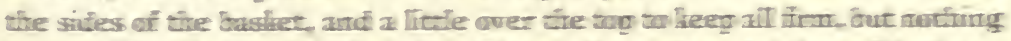
approwching the trouble of paching Frnme Cucurmbers is when with theseWhem a reallin geed smmpie is grown it pans wo pad a selection of the test

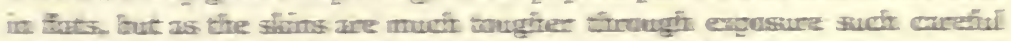
paching as the Frame Cucrmihers receive is mot required.

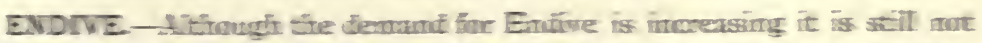

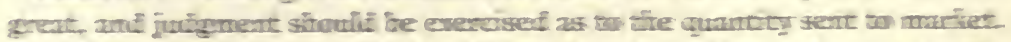

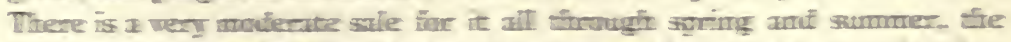

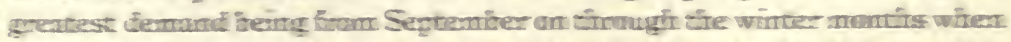

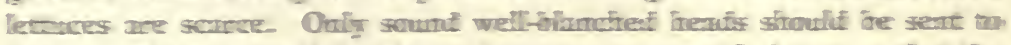

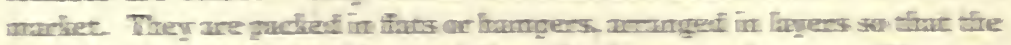

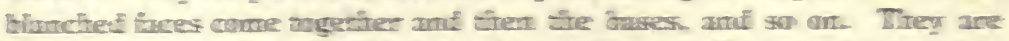

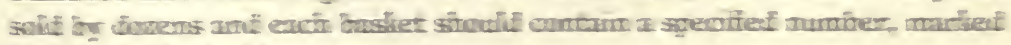
plaimity on the laicel. 
HERBS.-With the exception of Mint and Parsley, which appear under separate heads, and in a lesser degree of Sage and Thyme for which there is a moderate sale, the culture of herbs for market, except in some few special cases, is not worth the grower's attention. When there is any sale the various herbs are in the majority of cases made into small bunches and sold by the dozen.

HORSE-RADISH.-As indicated in the article on the culture of this root the trade in it is almost entirely in the hands of continental growers. Still, there is a steady though limited demand, and there is no good reason why the grower who can produce a good sample should not enter into competition. The roots should be straight, $10 \mathrm{in}$. to $12 \mathrm{in}$. long and from $1 \frac{1}{2} \mathrm{in}$. to $2 \mathrm{in}$. in diameter. They must be washed and tied in bundles of about a score. It is useless to send to the market thin or badly-shaped roots. Those not marketed immediately after lifting can be kept in moist sand, where they will remain in good condition for a considerable time.

LEEKS. - There is not a great demand for Leeks, so that they should be sent to market only in moderate quantities at any one time. The plant is quite hardy, and the crop can be left in the ground to be lifted as required. The outer leaves are stripped off but the roots are left on, then they are graded into sizes and tied together into flat fan-shaped bunches containing six or eight heads, according to size, but the average is usually seven. The tie is made just at the bottom of the green portion, so that the white stems will spread out and display themselves. The leaves are then shortened to one uniform length, and the bunches well washed to improve their appearance. They are packed in crates or baskets, and as they are sold by the dozen bunches the number of dozens in each package should be plainly marked on the label.

LETTUCES (CABBAGE). - The earliest consignments of Lettuces sent to market are the Cabbage Lettuces grown in French gardens, on hot-beds and in cold frames, and these are followed by those grown in sheltered situations in the open in market gardens generally throughout the country. The earliest cutting in any appreciable quantity begins in March and continues increasingly until about the middle of May, by which time Cos Lettuces are appearing on the market in quantity and the demand for the Cabbage variety rapidly diminishes; there continues, however, to be a limited demand throughout the season as long as they are available. They should be cut as soon as they have good firm hearts, and then graded into "bests" and "seconds." If the lower leaves of those grown in the open are much discoloured they should be removed, otherwise the root is the only portion cut away. They are packed in light wooden crates or in flats, in layers, the bottom layer being put root part downward, the next layer root end up, and so on. They are sold by the dozen, and should be packed in even numbers, with the quantity and quality in each package marked plainly on the label.

LETTUCES (COS).-The earliest Cos Lettuces, grown under cloches or handlights, or in cold frames, begin to come ready about the middle of 
April, and when they are well-grown, with good solid hearts, realise very good prices. The roots and broken outer leaves are trimmed off, and in all cases a tic of raffia is put round the Lettuce to hold the leaves compactly together, even though it may not seem to be required. These early supplies should be graded into three qualities, and they are packed on their sides in crates or flats, in even dozens or half-dozens, with the number and quality of each parcel marked clearly on the label. Later in the season less trouble is taken with the packing, and they are then put into hampers or larger crates, or when grown in considerable quantities they are packed on market wagons or loose into railway trucks. Frequently these supplies are pulled and sent to market with root and soil attached to the plants, but this method is not to be recommended; very little time is occupied in cutting off the roots and removing the rough outer leaves, and the greatly improved appearance which results is well worth the time and trouble. They should be graded into two qualities, 'the poorest being kept at home, as they certainly do not pay to send to market in the face of the heavy consignments of good quality which arrive in the height of the season. These later supplies are usually sold by the score.

MELONS (CANTALOUP). - The first cutting of Cantaloup Melons from frames is made in June, and supplies continue from then onward to September. Great care is required to cut the fruit just at the right time; for one or two weeks after it is full-grown, according to the general temperature, it does not appear to change, but the ripening processes are at work in the interior. At the end of that time cracks begin to appear round the stalk, then the rind assumes a yellowish tinge, and the fruit gives off a slight but unmistakeable perfume which gets stronger as the ripeness advances. At this stage it is in perfect condition for eating, and can be left to so ripen for local customers to whom it can be delivered by hand, but it would be a great mistake to allow it to get to this stage of ripeness before cutting for market as it would go soft in places and probably begin to decay before reaching the consumer. On the other hand it must not be cut too soon or it will never ripen satisfactorily, and the interior will be more like a turnip than a ripe melon. The proper time to cut is when the cracks appear round the stalk and the other indications of approaching ripeness are present but still faint. If sent to market at that stage it will usually be in perfect condition when it reaches the consumer, but some further discrimination must be used according to the season-when it is very hot the fruit can be cut a day or two earlier and when cold it can remain on the plant a little longer. The plants should be examined frequently, so that no fruits are allowed to remain on too long. When they cannot conveniently be sent to market at once, as at the end of the week and especially if it is hot weather, they should be put for a day or two in a cool place, such as a cellar, so that ripening may be retarded. The fruit is cut with about $2 \mathrm{in}$. of stem attached, and in handling and packing the greatest care must be exercised not to break this off or the selling value will be seriously lowered. The fruit is graded into "bests," "seconds," and "thirds," and for extra fine specimens 
there may be an occasional consignment of "specials." In packing, each is first wrapped in tissue paper, then bedded in and surrounded by wood wool. Boxes or flats are generally used in which to send them, a flat holding from two to five, according to the grade.

MINT.-Mint is marketed in bunches varying in size with the season; a bunch of forced Mint during winter usually contains from twenty to thirty shoots, but as the season advances the size is increased until it is as large as can be comfortably held in one hand. Early in the season when supplies are small they are packed in any convenient receptacle, but later, flats, pads, and hampers are used.

MUSHROOMS.-When Mushroom beds begin to bear, gathering should be done two or three times a week, and all should be taken, both big and little. Allowing the Mushrooms to get too fully open before gathering tends to exhaust the bed and shorten the crop. They should not be broken or cut off, but should be pulled out of the bed with a slight twist, so as to bring away the base cleanly. Any broken parts should be at once cut out with a knife and the holes filled up with fresh soil. Great care must be taken in handling the Mushrooms as the least touch on the gills will cause them to become discoloured. In gathering, the base of the stem should either be placed carefully downward in the basket or it should be cut off at once, otherwise dirt will fall into the gills. They should be graded as gathering proceeds into three separate baskets-one for the largest fully-open ones, known as "broilers," a second for the smaller half-open and small round undeveloped ones, known as "cups" and "buttons," and the third for the rough and broken ones. Before packing, any soil adhering must be cleaned off with a piece of flannel. They are packed, stalks downwards, in handle baskets or pecks, lined and covered with blue tissue paper, then tied down and labelled, with the grade and weight marked plainly on each.

MUSTARD and CRESS.-As soon as the seed leaves are fully developed, Mustard and Cress is cut, a little above the roots, with a broad sharp knife. The cut should be made boldly, taking a swathe about 3in. wide, - then the Mustard or the Cress should be taken up with both hands and stood upright in punnets, the tops being kept as level as possible. Enough should be taken to well fill the punnet at the first attempt; this may be rather difficult to the inexperienced but with a little practice it becomes easy, and makes a much quicker and neater job than when the punnet is filled with several small lots. Special punnets are made for this work, known by the makers as punnets for " Hot and Cold," and this is also the term generally used for Mustard and Cress by salesmen in the market. The full punnets are packed in boxes which take several layers, or in flats, and if a sheet of paper is put between each layer they may stand one on top of another without injury, but they must be packed tightly or they may be damaged on rail.

ONIONS.-Autumn-sown Onions are disposed of as opportunity occurs, from the time they are harvested to the end of the summer, as they do not keep well. Spring-sown Onions are put on the market from harvesting 
throughout the winter, according to demand and prices. They should be firm, sound, and clean, cleared of loose skins, graded into two or three sizes, and packed in bags containing $\frac{1}{2} \mathrm{cwt}$. or $1 \mathrm{cwt}$.

The bunching of Spring or Green Onions begins as soon as the plants are large enough, generally early in March, and continues through April and May. The size of the bunches varies in different districts. In many places they are tied in small bunches containing twelve, and twelve of these are tied together to make a large bunch; in other districts the large bunch contains a score of small ones. Before tying into large bunches they are well washed. Where quantities are grown the washing and bunching is generally done by piece-work. They are despatched to market in hampers. SPRING-SOwn Onions are often sent to market when they are half or three-parts grown, in bunches containing from six to twenty, according to the size of the Onions and the market they are sent to.

PARSLEY.-The demand for Parsley continues practically all the year round. The plants are sometimes pulled up by the roots and bunched in that condition, but it is much better to make the bunches of foliage only, which should always be clean and bright. The size of the bunch varies with the season, being as much as can be held in one hand during the summer when it is plentiful, and not more than a quarter that size in winter when it is scarce. It is sent to market in flats, pads, or hampers, and is sold by the dozen bunches.

PARSNIPS.-These are ready for use in October and supplies are sent to market continuously throughout the winter, either from store or lifted fresh from the ground, as required. In the latter case the roots are in better condition and of superior flavour, but it is not always convenient for the grower to allow them to continue occupying the ground. They are often sent to market in a very rough and dirty condition, but this is a bad practice and should be condemned. They should be washed and graded into two even samples, whilst the rough and ill-shaped roots should be disposed of for cattle feeding. They are sent to market in various ways as appears the most convenient-bushel baskets, hampers, sacks, boxes, and barrels all being used, and where they are grown largely they are frequently sent loose, in road wagons or railway trucks.

PEAS.-Picking of the earliest Peas should begin as soon as the pods give evidence that the enclosed seed has developed to a useful size. Some growers are in such a hurry to get early Peas on the market that they send stuff which is practically all pod, the Peas which they should contain being an almost negligible quantity. Such a proceeding is not a long way from dishonesty, and brings early produce into disrepute with the deluded purchaser. The first pickings should be consigned in half-bushel baskets, covered with grass or vegetable leaves, and fastened down with crossed sticks. Different varieties should not be mixed together when it can be avoided, and where a good class direct trade is done it may be sometimes 
advisable to divide the pods of one varicty into two grades. As the season reaches its height the Peas are consigned in bags supplied specially for the purpose by salesmen, vast quantities being sent to market in this way. As soon as the rush of supplies is over half-bushel baskets are again used to the end of the season. When picking once begins the plants need going over every two or three days, as the pods swell rapidly, and to allow them to become too old not only spoils the sample but brings the bearing of the plants to a speedy end. Where Peas are grown extensively it is a common practice to wait until the bulk is ready and then turn into the field a gang of women and children who pull up the haulms and strip them of pods, completely clearing the ground as they go. When this method is followed a large field is sown in sections, at intervals of a few days, so that none will get too old before being gathered.

POTATOES.-Very early Potatoes are usually sent to market in halfbushel baskets, and later in pads, hampers, pots, and barrels with wicker lids,-in fact, in anything in which they can be conveniently packed, this being a matter in which the choice generally rests with the salesman who sends the empties. The important thing is to properly sort and grade them, rejecting altogether all damaged, diseased, or very small ones, and to handle them very carefully so as not to bruise them or break the skin. In packing, a little soft material, such as Potato tops or rough hay, is put at the bottom of the receptacle.and a little more on the top, which is then fastened down with splinths. "Topping" should never be practised, but the tubers should be of even quality throughout, and of even weight in each package, the weight being marked plainly on the label.

Main-crop Potatoes do not require the same care in handling that earlies do, because being matured they do not so easily bruise and the skin is tougher. They are sent to market in bags; in the. London district these usually contain from $1 \mathrm{cwt}$. to $2 \mathrm{cwt}$. each, but further north they are consigned by the "load" or "half-load" (a "load" consists of 18 stones of $141 \mathrm{bs}$.$) . When prices are good at least a portion of the crop is usually$ despatched to market direct from the field, in which case a weighing machine is kept close to the pickers, and the Potatoes are put into bags which are immediately weighed, tied, and labelled. Women are employed for picking up the Potatoes, and the grading is usually done at the same time, one collecting the largest sound tubers, lnnown as "ware," another the middle-sized ones, known as "seed," and a third the smallest, and diseased or damaged ones, known as "chats" and "tail." The ware is sent to market, and when the size of these is very irregular it pays to sort them into two samples each of fairly even size; the seed is usually disposed of at home, though some salesmen will undertake the sale of it, and in times of great scarcity it is often sorted over again and the best sold as ware; the tail and chats are disposed of locally for pig feeding. The Potatoes not dispatched directly from the field are clamped, or stored in a dry cool shed where they will be safe from frost, and they are then marketed as opportunity and prices dictate. 
RADISHES. - Radishes mature very quickly, and as soon as they are seen to be swelling the beds should be examined frequently and the most forward roots pulled. They should not be allowed to get too large. Now-a-days it it is useless to grow big, coarse, strong-flavoured Radishes, the demand being for small, crisp, delicate-flavoured roots. They are bunched for market, the size of the bunch varying with the season; in the early spring months twelve or fourteen roots go to a bunch, but later in the season they contain from twenty to thirty roots. Long Radishes are made up into flat bunches, and olive-shaped or Turnip Radishes into round bunches. The roots in each bunch should be, as far as possible, of equal size, and the bunches should be carefully washed before packing. They are sent to market in flats, hampers, or bushel baskets, and are sold by the dozen.

RHUBARB.-Forced Rhubarb is made up into small bundles containing from two or three sticks in the early part of the season to eight or ten later. The sticks should be pulled as soon as ready, when they are from 12in. to 15in. long, or they will become soft and spongy. The pulling of out-door produce begins when the sticks are from $6 \mathrm{in}$. to $8 \mathrm{in}$. long, and these are made up into bundles weighing about $3 \mathrm{lbs}$.; later, as the crop gets more plentiful, the bundles are made to weigh 5 or $61 \mathrm{bs}$. When the leaves get well developed they are cut off to within about $2 \mathrm{in}$. of the stalks, which are then laid with the heads reversed alternately, so as to make a neat and even bundle, secured by two ties, one near each end.

SALSIFY and SCORZONERA.-These roots are lifted in November, care being taken not to injure them. They may be marketed at once or stored and marketed in small quantities through the winter. The roots are graded into even sizes and tied up in bundles of about a dozen. They are packed in flats, with a little soft hay at top and bottom to prevent damage.

SAVOY CABBAGES.-The cutting of Savoys usually begins in October and continues to February or March, the largest and firmest heads being selected at each cutting until the field is cleared. They are sent to market in large wicker crates holding a tally, or five dozen heads, loose in railway trucks, or by road packed on wagons.

SEAKALE.-Seakale is in season from November to the following spring. The heads are cut when about $6 \mathrm{in}$. long, with a small piece of root attached. None should be sent to market which has become coloured by exposure to light, as then the flavour is very strong and the quality inferior. After cutting, the heads should be washed. In packing, first wrap the heads in blue tissue paper, making a flattish bundle and leaving an inch or two of the upper part displayed; then lay the bundle flat across a shallow punnet, and secure it with raffia. The weight of a punnet varies from $1 \mathrm{lb}$. to $3 \mathrm{lbs}$. according to the season, but some growers maintain a regular weight of 2lbs. per punnet throughout. The punnets are packed in flats, in which they must be very carefully secured to prevent damage in transit, as the stalks are easily broken and spoiled. 
SHALLOTS. - The crop is lifted in July, and after being allowed to dry for a few days the bulbs are then divided and cleaned. They are usually consigned to market in autumn, in peck or half-bushel baskets, weighing 12lbs. and $24 \mathrm{lbs}$.

SPINACH.-When the plants have made strong growth the largest leaves are picked singly. In this way the plants will yield several times, but care must be taken not to pick them too closely, especially in winter when growth is slow, or the plants will be ruined. During spring and summer many growers wait until the plants are well-grown and then cut them off close to the ground, so securing only one gathering from each sowing but saving much on the labour bill. The leaves are packed in baskets and pads. When open-topped baskets are used the Spinach is covered with leaves or freshly-cut grass, and fastened down with crossed splinths.

STRAWBERRIES.-To be at its best the Strawberry should be put on the market within a few hours of the time it is gathered, whilst it still retains its bloom and brilliant colour. This is only possible where the plantation is within easy distance of the market or of a main line of railway. In such cases gathering begins soon after daybreak, and the fruit arrives on the market while the day is still young. Where it is impossible to secure these conditions the fruit should be gathered and packed when quite dry, and sent to market by a train which will ensure its delivery in the small hours of the following morning. It must always be borne in mind that Strawberries will not, under any circumstances, stand rough handling or long confinement, and their tenderness in this respect is emphasised in a wet season, when they need handling with the greatest care and under dry conditions. Watery fruit which has been packed for a number of hours and subjected to the continuous jolting of a long journey by rail often arrives at the market in a practically worthless condition, by being semi-pulped and mouldy. Forced or forwarded Strawberries and choice fruit from the open beds should be packed in $\frac{1}{2} \mathrm{lb}$. and $1 \mathrm{lb}$. punnets, or in a single layer in shallow wooden boxes holding $11 \mathrm{~b}$. In all cases punnetted or boxed fruit should have leaves below and above, as well as between the individual fruit so that none touch; they should be packed firmly but without crushing, and in such a way that, given fair treatment, there is no chance of movement during the journey. The punnets should be packed in stout wooden boxes, specially made for the purpose; these are fitted with shelves and each hold from one to three dozen punnets, the lid being tied on with string. These boxes have to be provided by the grower, are returnable, and with care will last for several years. The next-best fruit from the field should go in chip baskets holding any given weight from $3 \mathrm{lb}$. to $6 \mathrm{lb}$. according to the custom of the market or the desire of the salesman. Large quantities are sent to market in peck baskets holding 12lbs., but for fruit of good quality this is too heavy a weight to go in one package, and peck baskets should be reserved for second quality fruit and clearings, especially as chips are so cheap and convenient. 
TOMATOES. - Gathering begins from the middle of July to the middle of August, according to the method of culture and the warmth of the season, and in a mild autumn generally continues until about the middle of October. The fruit is always of better quality when allowed to remain on the plants until ready for packing, but where blackbirds are troublesome the earliest should be gathered as soon as they show a slight change of colour and finished under cover (read carefully pages $350-351$ ). The fruit should be gathered with the calyx and stalk attached, the fresh green calyx adding materially to its attractiveness. Three grades should be made-"bests," consisting of smooth round fruit, perfect in quality and of even size; "seconds," which are those irregular in size and shape but still of good quality ; and "thirds," which embraces all the rough, ugly, and small fruit. None that is cracked or bruised should be included, and any which is diseased should be at once burned. The two better grades are generally packed in handle baskets or pecks, each holding 12lbs., and the thirds are sent in pecks or half-bushels. During the past few years small wooden boxes holding $121 \mathrm{bs}$., provided by the grower and non-returnable, have been largely used for the best quality, and these have much to recommend them, as they are cheap, the salesman handles them for a smaller commission, they sell readily, and by being the grower's own property he is not restricted in choice of markets during a period of glut. In packing, a little wood wool is placed over the bottom of the basket or box, then the sides and bottom are lined with tissue paper-pink for "bests," blue for "seconds," - of which sufficient must overhang the edge to cover over the top when full. The best fruit is arranged in layers with the stalks downward; the second and third grades do not receive so much care, the fruit being left just as it falls into the receptacle, but the top layer of seconds is usually arranged with the face upwards.

TURNIPS.-Early Turnips, whether grown in frames or in the open, are make up into bunches containing about twelve roots, after which they are well washed and packed in pads, hampers, or bushel baskets; they are sold by the dozen bunches. Later they have the tops and tap root removed, and after being washed are consigned to market in bushel baskets or bags, being sold by the cwt. or ton. TURNIP Tops are cut as soon as they begin to grow freely in spring, whilst they are still young and tender, and are usually consigned in salesmen's bags, but sometimes in crates or hampers.

VEGETABLE MARROWS. - Marrows started early should begin to bear in the first or second week of July. The fruit should be cut before it has reached full size, as it is then of better flavour and the plants continue to bear longer. In gathering they should be handled carefully, so that the tender surface will not get bruised and disfigured. For a few weeks the earliest Marrows are packed in flats, bedded in soft hay, and are sold by the dozen, when they generally realise good prices. As they get more plentiful they are consigned in large wicker crates, and in the London markets are usually sold by the tally of five dozen. Large growers often consign them loose in carts or wagons or in railway trucks. 


\section{INSECT PESTS \& FUNGOID DISEASES}

\section{WHICH ATTACK VEGETABLES;}

BEING A DESCRIPTION OF THOSE MOST IMPORTANT, WITH PREVENTIVE MEASURES AND REMEDIES.

THE difficulties to be overcome before a profitable crop of vegetables can be grown are many and great enough when the effects of bad weather and other unsuitable conditions alone are considered, but in practice these difficulties are greatly increased by the liability of so many crops to attack from insect and fungoid enemies. Some knowledge of these enemies and of their life-history is of importance to the grower, to enable him to take steps to prevent their spreading and to minimise the damage to the crop. A brief account of the most important of these pests and diseases, and the treatment appropriate to each, will be found in the pages following.

Before dealing with remedies it will be worth while to consider general preventive measures which, though they cannot ensure immunity from attacks, will generally lessen their number and virulence, and prevent their becoming epidemic.

All crops should be grown under conditions which approximate, as nearly as is practicable, to those natural to the plant; the further these conditions are departed from, the more unhealthy the growth and the greater the liability to damage from pests and diseases.

Each plant must be allowed sufficient space for development: an overcrowded crop is generally unhealthy and seldom profitable.

Proper drainage, good cultivation, and suitable manuring, by inducing sturdy and robust growth, increase the powers of the plant to resist disease, and make it less liable to attack from insect pests. When nitrogenous manures are used in excess of 
the plants' requirements a soft unripened growth is made, which is very liable to attack from fungi.

Though a strict rotation is impossible and inadvisable in gardening it is always better, when practicable, to arrange the crops so that plants of the same families do not immediately succeed each other, and under no circumstances should a diseased crop, be followed with another of the same family, as this would almost certainly be affected by the same disease, and probably to a more serious extent than its predecessor.

Acid soils-i.e., those deficient in lime-are favourable to the development of certain pernicious soil fungi, such as that causing "finger and toe" in turnips, and when superphosphates or other acid manures are used on acid soils the crop becomes still more liable to attack. All such soils should be dressed with slaked lime before cropping, and a moderate dressing at intervals of three or four years will do much to improve their general condition and eradicate these objectionable fungi.

Crops which are especially subject to disease, like potatoes or tomatoes, should always receive one or more protective sprayings with a suitable fungicide, whether disease is visible or not. It is much easier to prevent serious infection than to kill the disease when it is established in the tissues of the plant.

The method of disposal of diseased plants, or parts of plants, is of great importance. They should not be dug into the ground or left lying about in rotting heaps, because even a small piece of tissue in which the fungus is present may produce spores and so act as a centre of infection for a future crop, whilst a rotting heap would disseminate the spores in millions and so endanger future crops over a large area. All such diseased remains should be burnt, or if burning is not practicable, buried after being covered with quicklime. Diseased plants or roots should never be fed to pigs or other stock unless first boiled. When this precaution is not observed the germs of the disease frequently pass uninjured through the digestive tract of the animals-indeed, in some cases they benefit by the process. Unconsumed pieces also become mixed with the manure and are carried on to the land to infect future crops.

Many weeds are able to act as hosts for the pests and diseases of cultivated plants, and do so act in the absence of the usual 
host. Therefore, apart from other considerations, the suppression of weeds is of importance in regard to the health of crops, and not only should those on cultivated land receive attention, but also those on headlands, in hedgerows, and on waste places.

\section{SPRAYING MACHINES AND THEIR USE, WITH MATERIALS AND FORMULE.}

SPRAYING MACHINES.-For the smaller holdings knapsack sprayers, of which there are several good makes on the market, are probably the handiest machines. They are cheap and effective, need only one man to work them, and will, with care, last many years. Those fitted with brass ball-valves should have the preference; some machines have rubber valves but these are liable to be injured by paraffin. Ordinary garden syringes are not suitable for spraying purposes; the spray is too coarse and much of the wash is wasted, whilst notwithstanding this, all parts of the plants do not get properly covered with the wash.

More powerful machines, mounted on wheels or runners, may be used. They will cover much more ground in a day than the knapsacks, but require more space between the plants, so that unless the crops are so arranged that all the plants can be reached by the spray when the machine is on a path, or unless the rows are a considerable distance apart, there is great difficulty in working them in a growing crop. They have the further disadvantages of greater cost and of generally needing three men to work them. It is therefore only on the larger holdings, or where a group of small holders combine in the purchase and working of one, that these larger machines are advisable.

Every machine should always be emptied and washed out with clean water immediately after using, and should never be allowed to stand with with any unused wash in it.

APPLYING THE WASH.-With most washes, a fine misty spray with plenty of force behind it is advisable. The spraying must always be done thoroughly and completely, but it is not necessary to make the plants dripping wet to ensure this; an even damping of the whole plant is quite effective and much more economical of material. Particular attention must be given to the lower surface of the leaves and to any leaves which are near the surface of the ground. Repeated sprayings may be necessary, but it should be borne in mind that one spraying thoroughly done is much more effective than two only partially done.

With many washes, and especially so with Bordeaux mixture, it is impossible to get an even distribution of the solid portion of the wash unless 
it is constantly agitated or stirred. With knapsack machines this can be done by the man carrying it giving it an occasional shaking, but larger machines should be fitted with some efficient means of agitating the liquid, and in purchasing it is important that this point is not overlooked.

MATERIALS. - There is some difference of opinion as to whether it is better for the gardener to mix his own washes or to buy them ready-made in a concentrated form from horticultural chemists. For the large grower, especially if he has had some practice in exact weighing and measuring, and has some knowledge of elementary chemistry, there are many advantages in buying the separate ingredients and mixing the washes at home. The quantities he will use and the better physical condition of some washes when newly-made make it worth his while to take the trouble to become efficient in the mixing of them. The case of the small grower is different; he uses relatively small quantities, and the extra convenience of concentrated washes generally outweighs any disadvantages they may have.

The following are the washes most generally useful to the vegetable grower:-

\section{INSECTICIDES.}

ARSENATE OF LEAD. - This is the best form in which to use arsenic for insecticidal purposes. Paris green and London purple also contain arsenic, but are much more likely to damage the foliage and are certainly no more effective than arsenate of lead. Of the latter there are many good brands now on the market, and it is unwise for the grower to attempt to make his own. Directions for use are given with the purchased chemical. The amount to use will be from 3 to 12 ozs. in 10 gallons of water, varying with the particular insect to be dealt with. This compound is very poisonous and should be kept under lock and key when not in use; it should not be used on crops within six weeks of harvesting.

CARBON BI-SULPHIDE.-This is ueful to destroy soil insects on small areas, but for extensive use its cost is prohibitive. It is a very inflammable and volatile liquid and requires careful handling. It has a strong and disagreeable odour. A "Vermorel" injector, which has a long nozzle and a sharp point, is a very suitable instrument with which to apply it. The nozzle is thrust about 6in. below the surface of the soil, the liquid injected, and the soil pressed back over the hole left by the nozzle. Use 2ozs. to the square yard.

HELLEBORE POWDER.-This is a yellowish-brown powder, made from the root of Veratrum album and $V$. viride. It is poisonous, but less so than arsenate of lead. For effective use it must be freshly ground, as it soon loses its poisonous properties on exposure to the atmosphere; hence it is particularly adapted for use on crops which are badly attacked by caterpillars within a few weeks of ripening. Two applications should be given with a short interval between. It may be used dry, either alone or with 
once or twice its bulk of flour, and dusted evenly over the foliage; or it may be mixed with water in the following proportions and sprayed over the foliage :-

Hellebore Powder (fresh), $10 z$.

Water; 3 gallons.

LIME.-This has some insecticidal and fungicidal propertics if used as a dressing to the soil or dusted on the foliage, although it is used chicfly as a preventive. Applied to the soil it prevents and corrects acidity, and when dusted on the leaves makes them distasteful to insects and checks egglaying. It is particularly valuable for use against slugs. Slalicd lime is generally preferable to quicklime, and air-slaked lime is inferior to that properly water-slaked; in the latter case it falls into a much finer poyder and adheres better. In slaking lime no more water should be used than will thoroughly wet the lumps of quicklime. A great heat is then produced and in the course of $\mathbf{1 5}$ or 20 minutes a very fine dry powder will be obtained. Care should be exercised to avoid using an excess of water or a sloppy mess will be formed which is difficult to distribute and which will contain imperfectly slaked lumps. Lime may be mixed with sulphur or soot before being dusted on the foliage, and the dusting should be done whilst the plants are damp with mist or dew.

NICOTINE makes an excellent wash for soft-bodied insects, such as aphides, but it is expensive. It forms the basis of many proprietary insecticides. It may safely be used on plants which are too tender for paraffin emulsion. A solution guaranteed to contain $98 \%$ of nicotine should be purchased. Use $10 z$. of this and $\frac{1}{2} \mathrm{oz}$. of soft soap to 10 gallons of water.

PARAFFIN EMULSION is one of the best washes for aphides and other sucking insects, and will prevent the attacks of celery fly, \&c. It is easy to prepare, but care must be taken to see that the paraffin forms a proper emulsion with the soap and is not floating on the surface, otherwise damage to foliage will probably result from its use.

To make the emulsion take

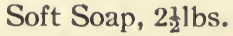

Paraffin, 1 pint.

Soft Water to make 10 gallons.

Boil the soap in $\frac{1}{2}$-gallon of water, and while it is very hot add the paraffin in small amounts, churning it in well each time with a syringe fitted with a rose jet. Continue the churning for a few minutes after the last addition of paraffin, and then with the syringe transfer the mixture to another vessel, using plenty of force. A creamy emulsion should now be formed which should be permanent, but if, after standing for a little time, the paraffin separates and rises to the surface, re-heat carefully (in the open for fear of accident) and churn again with the syringe.

Dilute to 10 gallons before use. 


\section{FUNGICIDES.}

BORDEAUX MIXTURE.-This is the most generally useful and effective fungicide. On some plants, and especially in continuously damp weather, it may injure the foliage, and it may also be objectionable on ripening fruit, as it leaves a visible stain. In the latter case cupram may be used as a substitute. A really fine misty spray, backed with plenty of pressure in the machine, is necessary to get the best results from this mixture. It should be used within twenty-four hours of mixing; when left longer than this it is difficult to keep the ingredients in suspension. The same tendency to settle out quickly is found in the ready-prepared powdered forms of Bordeaux mixture sold under various names. A ready-made misture is handier to use than a home-made one, and it is probably safer in inexperienced hands, and the Woburn Bordeaux paste is probably the best ready-made form.

To make ordinary Bordeaux mixture take-

Copper Sulphate (98\%), $4 \mathrm{lbs}$.

Quicklime (in lumps), $4 \mathrm{lbs}$.

Water, 50 gallons.

If the sulphate is obtained from a reliable source the powdered form is best, as it will then dissolve in water much more quickly than when in crystals. Tie it in a coarse bag and suspend in half the quantity of water in a wooden vessel (a vessel of iron or tin must not be used). Put the lime in a pail with a small quantity of water. If it is fresh and in good condition it will heat up well and crumble to a fine powder in about fifteen minutes. Stir up the lime in the remainder of the water and run it through a medium strainer, then pour gradually into the copper sulphate solution, stirring well all the time. The mixture should be allowed to settle and the clear liquid tested for free copper. To do this, put a little in a white saucer and add a few drops of a $10 \%$ solution of potassium ferrocyanide. If a brown precipitate forms add more lime to the mixture and test again. Before using pass through a strainer with $\mathbf{3 5}$ to 40 holes to the linear inch.

The following modification of an Italian formula is given by Mr. S. U. Pickering, of Woburn, and has given excellent results with us :-

Copper Sulphate (98\%), $2 \frac{1}{2}$ lbs.

Lime Water, 34 gallons.

Water to make 40 gallons

Dissolve the sulphate in 2 gallons of soft water. Slack 2lbs. good quicklime, as directed above, and put the powder in a tub with about 60 gallons of water; stir once or twice and allow it to settle. Add 34 gallons of the clear liquid to the copper sulphate solution, stirring well; test as in the first formula, and add more lime-water if necessary,

It is claimed for this mixture with lime-water that it is more economical than the ordinary mixture, is more quickly effective, is less liable to be knocked or washed from the foliage, and is more easily applied. 
CUPRAM (Ammonia-Copper-Carbonate).-This mixture, although a valuable fungicide, is less effective than Bordeaux mixture, and should only be used on ripening crops, or in other cases where the "white-washing" effect of the Bordeaux is objectionable.

Copper Carbonate, $1 \frac{1}{4} \mathrm{oz}$.

Liquid Ammonia (26 \% Baumé), 16 fluid ozs.

Water to make 10 gallons.

Dilute the ammonia with 12 pints of water and add the copper carbonate. Add only a small quantity at a time and let this be well dissolved before any more is put in. Dilute to 10 gallons before use.

SULPHATE OF COPPER (Blue Vitriol or Bluestone).-This is a useful fungicide for many purposes, but it must not be applied to growing plants or it will burn the foliage. It may be used to wash down glasshouses, lights and frames after an attack of disease, to clean canes or stalies which have been used to support an infected crop, to dress seed which may be suspected of carrying disease, or to dress ground which has carried a diseased crop. It must not be dissolved in iron or galvanised vessels.

Copper Sulphate, $\frac{1}{2} \mathrm{lb}$. to $11 \mathrm{~b}$.

Water, 12 gallons.

SULPHIDE OF POTASSIUM (Liver of Sulphur).--Valuable for surface mildews, and when mixed with soft soap may be used against red spider on cucumbers or melons.

Use from 2 to $8 \mathrm{ozs}$. to 10 gallons of water, according to the tenderness or otherwise of the foliage. If soft soap is added, use $1 \frac{1}{2}$ lbs. of soap to 10 gallons of wash.

The solution must be used at once after preparation, as it quickly loses "strength," and any undissolved sulphide liept in stock must be liept in tightly corked bottles.

SULPHUR, either alone or mixed with equal parts of slalied lime, is valuable for use against surface mildews, such as strawberry mildew. It may be applied on small areas with an "insect powder" bellows, and on more extensive places with a knapsacli powder pump. It adheres to the foliage better, and is therefore more effective, if applied when the plants are damp with dew or mist.

\section{INSECT PESTS.}

\section{INSECTS HARMFUL IN GENERAL.}

APHIDES, or Plant Lice.-Aphides are known under numerous names, of which that of "green fly" is perhaps the most common, although there are green, blacli, and red varieties. They are small soft-bodied insects, and are both winged and wingless; as a rule both forms occur in each generation. Each has a sharp beak at the head, capable of piercing the foliage of plants, and generally two protuberances or hollow 
tubes near the end, through which it is supposed that they pass excretions. Aphides injure plants both by sucking out the sap and so weakening their vitality, and also by interfering with the functions of the leaves by blocking up the stomata or pores with their excretions, known as "honey-dew,"a sticky substance much relished by ants; which often ascend the plants to obtain it. Some aphides cause the leaves to curl, so enclosing them and making it difficult to reach them with washes.

Aphides are almost inconcievably prolific. They not only produce eggs which hatch out in due course, but produce young alive. They not only breed in the ordinary way but the fecundation of one female is sufficient to render twenty succeeding generations fertile, each of the young aphis being able in a very short time to produce further living young. There is scarcely a culti-

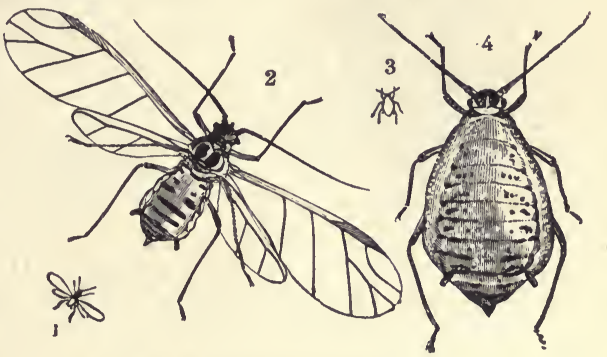

Cabbage Aphis.

1 and 2. male; 3 and 4 , wingless female; natural size and magnified.

vated crop which does not suffer more or less from aphide attacks, almost every variety of plant having its own particular aphis, of which the Cabbage Aphis illustrated may be taken as a fair sample of the type. When their extraordinary powers of reproduction are considered it will be seen that if allowed to multiply unchecked they would soon over-run and cripple a crop. Dry hot weather which is unfavourable to the growth of plants is very favourable to the increase of aphides, and if they are allowed to get a firm hold of a crop under such circumstances they may totally destroy it.

Treatment:-Spray the plants with paraffin emulsion or nicotine; or soft soap may be used ( 6 to 10lbs. of soft soap to 100 gallons of soft water) where the attack is not severe. In all cases it is important to deal with their attacks in the early stages, before the plants have become badly infested, and this is particularly the case with leaf-curling aphides.

CHAFER BEETLES, or White Grubs.-Chafer beetles may be recognised by their antennæe or "feelers," which are club-shaped, with several flattened "leaves" or divisions at the ends. The grubs are thick, fleshy, and of a whitish colour, with the tail curved downwards and swollen, and darker in colour than the rest of the body; the head is large and brown, the mouth being armed with strong mandibles. They belong to several genera, of which the Cockchafer, the Summer-chafer, the Garden-chafer, and the Green Rose-chafer are occasionally more or less troublesome to gardeners. In habits and general appearance the grubs are similar, but when full-grown there is a marked difference in size, those of the cockchafer and green rosechafer being much the largest, attaining a total length of one-and-a-half inches. They are all voracious feeders, the damage they do in the larval 
or grub state being sometimes very serious, whilst the beetles feed on the leaves of various trees, occasionally quite stripping them of foliage.

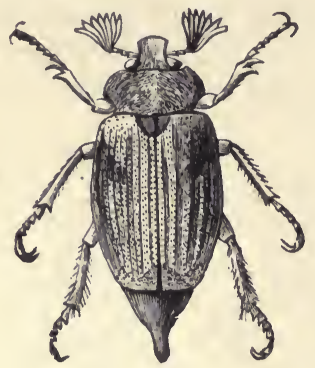

A

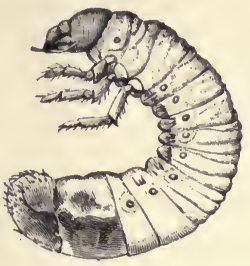

B

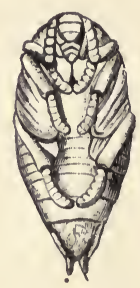

C

The Large Cockchafer (Melolontha vulgaris).
A-Perfect insect ;
B-Larva ;
C-Pupa :
All natural size.

Treatment:-The beetles may be collected from trees and destroyed during early summer. The coclichafer and summer-chafer are night-flying insects and may be collected during the hotter hours of the day; the garden and rose-chafers fly during the day-time and may be collected in the evening. They may be shaken down on to boards covered with tar or other sticky substance. The grubs may be trapped with thick pieces of turf laid on the ground, grass side down, under which they will congregate and may be collected and lilled. When the ground is vacant of crops it should be dressed with gas-lime or lainit; or one of the advertised soil fumigants may be tried.

DADDY LONG-LEGS. - There are two species of this well-known fly, one appearing from May to August and the other from July to September. The habits of both are identical. Their larva or grubs, popularly known as "leather-jackets" on account of their tough leathery skins, are very destructive to many crops in the garden, especially on newly-brolien grass land, eating them at or just below the ground line. The grub is about an inch in length, somewhat variable in colour, but generally of a greyish brown; it has a blacli head, furnished with strong jaws for biting, and although it has no legs it moves with comparative ease.

Treatment:- Same as for Surface Caterpillars, which see.

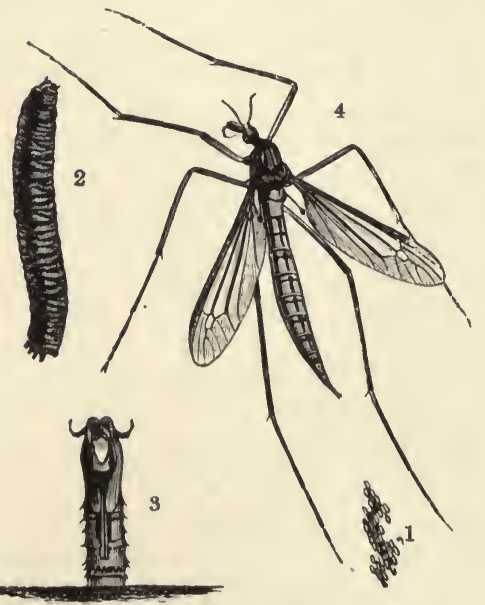

Daddy Longlegs, or Crane Fly.

1. Eggs; 2, Larvá, or "leather-jacket"; 3, Pupa-case (standing up in the ground); 4 , Female Fly (Tipula oleracea). 
DIAMOND-BACK MOTH (Plutella maculipennis).-In some years the caterpillars of this moth do much damage to cabbage, turnips, and other cruciferous plants, by feeding on the green tissue on the under-side of the leaves. The caterpillars are about half an inch in length, green in colour, and spindle-shaped - tapering to both ends.

Treatment:- Dressings of stimulating manures will assist the plants to grow away from the attack. Dusting the leaves when they are wet, and especially the under-side, with a mixture of three parts of soot to one of lime will checli the pest; apply the mixture forcibly with a powder pump.

If not nearer than about six weelis of harvesting, the crop may be sprayed with arsenate of lead.

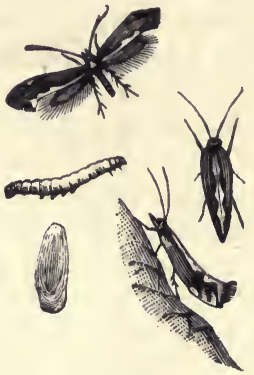

Diamond-back Moth.

Moth flying and Moths resting, Caterpillar and Cocoon; all natural size.

Cruciferous weeds harbour the caterpillars and should be destroyed.

FLEA BEETLES (Haltica).--These bectles are' often very destructive to young seedlings of turnip, cabbage, and other brassica, especially in hot dry weather and on light soils. The seed leaves are eaten away directly they appear above ground, and unless the seedlings are assisted or the

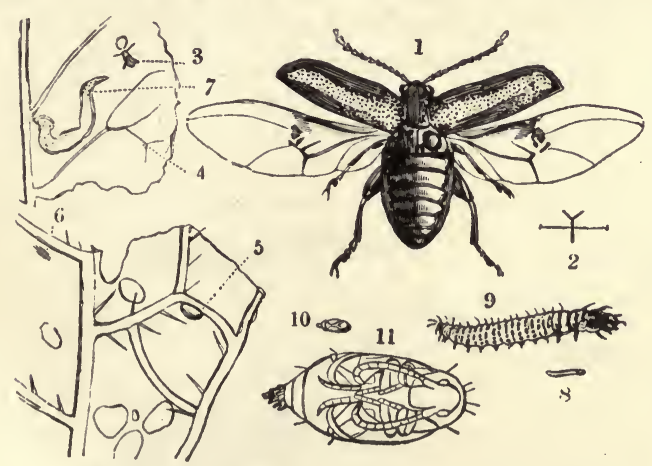

1, The Turnip Flea Beetle (much magnified); 2. Natural length and wing expanse; 3 , Natural size; 4,5 , Egg, natural size and magnified; 6, 7, Mine, and cuticle eaten away by läva ; 8, 9. Larva, natural size and magnified; 10, 11, Pupa, natural size and magnified. weather becomes more favourable it is often impossible to get a "plant." Under congenial conditions the beetles increase very rapidly, and clear off every particle of growth as fast as it appears, so that in such seasons successive sowings have been made three times and each has proved a failure. The beetles are very small, being only about one tenth of an inch in length; the maggots of the Turnip Flea (Phyllotreta nenorum) burrow into the tissues of the leaves and make holes in them, whilst those of the Cabbage Flea (Haltica oleracea) feed on the surface of the leaves and do not make holes.

Treatment:-Sow only on ground which has been ploughed or dug some time previously-long enough for it to have settled and become mellow on the surface. This will ensure a good tilth for the sced and moisture at the 
roots. Avoid freshly-worked land unless it is in very kindly condition, as when it is rough and cloddy it loses moisture rapidly. In sowing, mix superphosphate bulked up with fine screened ashes or dry soil with the seed. Roll or press the surface immediately after sowing to assist germination, and where it is reasonably possible water regularly in dry weather. If the beetle is in evidence give a light top-dressing of nitrate of soda or other stimulating manure until the plants have grown away from the pest.

When the plants are infested the ground should be rolled to crush the clods and then a light frame-work of boards, fixed on wheels so as just to clear the plants, and covered with fresh tar or cart grease, is run over them. The beetles, being disturbed, jump and are caught on the boards and held by the tar. If a piece of sacking is nailed in front of the boards so that it hangs two or three inches below the boards and drags over the foliage the disturbance of the beetles will be more complete and the contrivance more effective. The masses of beetles must-be scraped off as they accumulate, and the tar or grease renewed and kept moist.

For Cabbage Flea the plants should be sprayed with arsenate of lead.

All cruciferous weeds, such as charlock and shepherd's purse, should be kept down, as they harbour the beetles.

MILLIPEDES and CENTIPEDES.-These are not strictly insects, but belong to a group of the animal kingdom known as the Myriapoda. They may both be usually found in dark and damp places, in decaying wood or under heaps of decaying vegetable matter. Millipedes (also known as Julus Worms) are vegetable feeders, and often cause injury to the roots and other underground parts of plants, whilst centipedes are carnivorous, feeding on insects, larva, worms, snails and slugs, and are therefore useful to the gardener. For this reason care should be talien to distinguish between them.

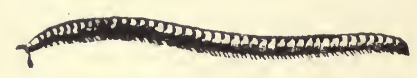

Millipede, Julus pulchellus.

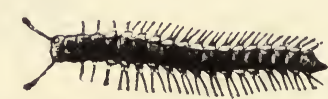

Millipede, Polydesmus complanatus.

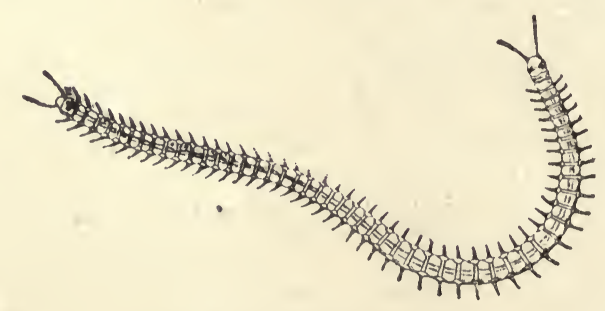

Centipede, Geophilus subterraneous,

In millipedes the body is usually round (in the species Polydesmus complanatus the body is fiattened), from half an inch to one inch long, blackish or pinkish in colour, with numerous segments, the front four of 
which have one pair of legs each, whilst the remainder have each two pairs of legs close together at the bases; the antennxe is short. The centipedes may be distinguished from millipedes by generally having flattened bodies, brownish in colour, each segment having only one pair of legs, and their antennæ are longer.

Treatment:-On small areas injections of carbon bi-sulphide may be used to kill the millipedes in the ground. Traps of pieces of mangold, scooped out and buried an inch or two below the surface of the soil will attract them, when they may be caught and killed; or pieces of cabbage leaf dipped in a solution of arsenate of lead and laid about on infested ground will poison many of them. All ground in which they are present should receive a good dressing of quicklime or gas-lime.

RED SPIDERS (Tetranychus, \&c.)-These mites, variable in colour, are difficult to see with the naked eye. Their presence on plants is indicated by a yellowish scorched appearance of the leaves. They flourish most in a dry arid condition of the atmosphere, and are therefore most in evidence in greenhouses or frames which have been allowed to get too dry, or on fruit trees on walls or in other dry situations, and especially on plants in shallow soils in a droughty season.

Treatment:-The most obvious thing in dealing with greenhouses or frames or other confined spaces is to take measures to prevent an attack, by maintaining sufficient moisture at the roots and amongst the foliage. When the attack is slight frequent and forcible spraying with clear water is often sufficient to eradicate it. In more decided cases paraffin emulsion may be used (but not on cucumbers or melons) or potassium sulphide and soft soap. Before spraying, leaves badly attacked should be carefully removed and burnt; the mites are very active and if shaken off the leaves will speedily climb on to the plants again, therefore it is a wise precaution to place badly-infested leaves immediately in a pail with a little paraffin at the bottom. The mites cover the underside of infested leaves with a fine

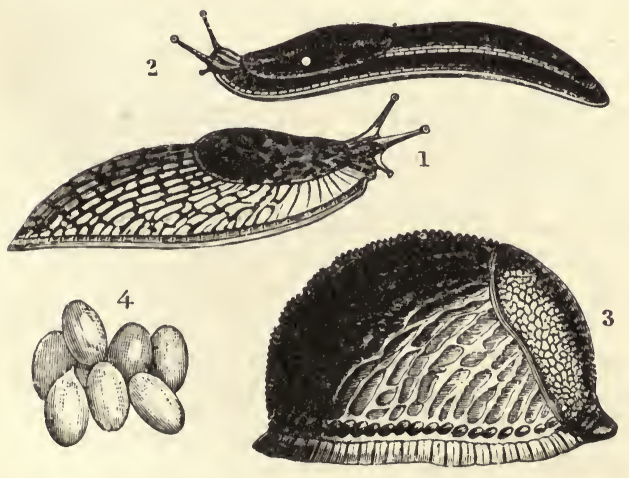

1, Grey Field Slug, Limax agrestis; 2, Black Slug, Limax ater (less than life size); 3, Limax ater in repose; 4, Eggs. web, which makes it difficult to reach them with insecticides, therefore a considerable amount of force must be used in spraying.

\section{SLUGS and SNAILS. -} Of these there is a num. ber of varieties, some with shells and some without. They are very destructive to green vegetation, particularly so to tender seedlings, large numbers of which they will completely destroy in a short 
time. These pests feed chiefly at night, but are active during the day in dull showery weather. They are protected by a mucous slime which they exude copiously, and this makes it very difficult to kill them with contact remedies.

-Treatment:-Decaying vegetable matter and other refuse lying at the foot of walls or hedges aflords a harbouring place for slugs and snails and should be cleared away.

Thrushes devour large numbers and should be encouraged, as it is easier to guard against any injury they may do to fruit than to withstand the ravages of slugs and snails. Where it is possible to do so without injury to the crops, ducks or poultry may be run over infested gardens early in the morning, when they may be depended upon to discover and devour large numbers. On small areas hand-picking by lamp-light, if done persistently for several successive nights will soon considerably reduce their numbers.

Choice plants and rows of seedlings may be protected by having cinder ash, powdered colie, or powdered lime scattered closely round them.

Baits of bran-mash or moist oatmeal placed about the garden will attract slugs, which may then be collected and destroyed. Cabbage leaves laid here and there will form a trap for snails, which hide underneath them.

Dressings of lime and soot, repeated at short intervals, will do much to lieep the pests at bay.

Where a piece of ground is badly infested it may be dressed very early in the morning with a mixture of fresh lime in a finely-powdered condition and caustic soda -4 parts of caustic soda to 96 parts of powdered lime, well mixed and applied dry. Two or three dressings should be given at intervals of fifteen or twenty minutes, and will then prove very effectual in destroying most of the slugs with which it comes in contact. Such ground should be dressed with gas-lime and trenched in the winter.

A weak solution of permanganate of potash is said to destroy slugs.

SNOWY FLY (Aleyrodes proletella).-This tiny white fly is in some seasons very troublesome on cabbage, sprouts, and other members of the same family. They congregate beneath the leaves in myriads, and when disturbed rise above the plants like a thin white cloud. The larvæ is fixed beneath the leaves and protected by a waxy covering. Affected leaves turn yellow or brown from loss of sap, and the plants become dirty and disagreeable from the exudations of the pest.

Treatment:-Collect and burn affected leaves. Spray plants with paraffin emulsion, frequently and forcibly, getting well underncath the leaves.

SURFACE CATERPILLARS.-The large caterpillars of several species of moths (particularly of the Heart and Dart, the Yellow Underwing, and the Common Dart or Turnip Moths) are very injurious to potatoes, turnips, cabbage, and many other crops. They attack the plants at or just below the ground line, often eating entirely through the stem. They hide under clods and stones and beneath the surface soil during the day, 
fecding at night. The mature caterpillars are about one and a-half inches in length, brownish or greyish in colour, with spots and bands of darlier colouring.

Treatment :-On small areas, hand picliing at night is an effective though very slow method of dealing with these pests, and is only practicable in a crop where the plants have been set out at some distance apart, such as cabbages or tomatoes. To discover the caterpillars, the ground immediately round the plants is worked about with a blunt stick.

A useful bait which will destroy many consists of bunches of fresh-cut clover or - other greenstuff, previously sprayed with arsenate of lead, laid about amongst the plants.
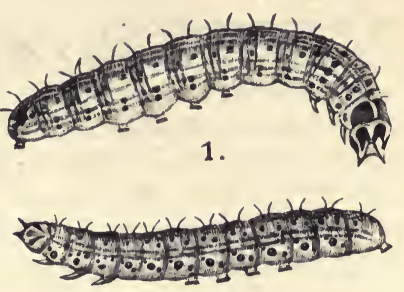

2.

1. Caterpillar of the Turnip or Common Dart Moth, Agrostis segetum.

2, Caterpillar of the Heart and Dart Moth, Agrostis exclamationis.

On small areas bi-sulphide of carbon would prove very useful if injected in the ground at intervals amongst the plants.

"Ringing" the plants with liainit or muriatc of potash not only acts as a fertilizer but is said to repel the caterpillars. A mixture of three parts of fincly powdered lime to one of soot freely sprinliled close to the plants and well hoed in stimulates growth, as well as to some extent protecting them from attack. Frequent light top-dressings of any stimulating fertilizer would probably have a beneficial effect.

Land which has been subject to attack should be dressed with gas-lime and deeply worked as soon as the crop is cleared, or it should be treated with one of the advertised soil fumigants before planting.

WIREWORMS. - Wireworms are probably more dreaded by the gardener than any other pest by which his plants are afflicted. There is scarcely a
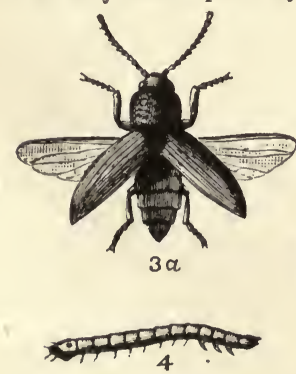

1 and $1 a$, Agriotes lineatus,

2 and $2 a$, Asriotes sputator.

3 and $3 a$, Agriotes obscurus.
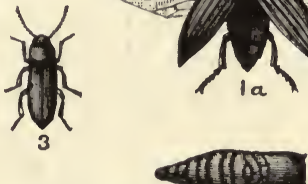

5
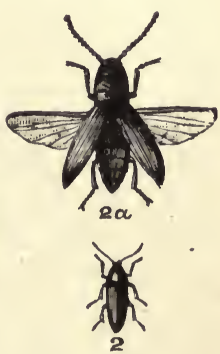

5. Pupa.

Natural size and magnified.

Natural size.

crop which does not suffer more or less from their ravages, their attack being frequently deadly in effect. They are the larva of beetles popularly 
known as "Click" or "Skip Jack" Beetles, from their power of springing a few inches into the air with a clicking sound when turned on their backs. The beetles are from half to two-thirds of an inch in length, and of a dull brown colour; they fly well, and after pairing in spring lay their eggs near the roots of plants, those on grass or other undisturbed land appearing to be preferred. The larvæ which hatch from these live in the soil from three to five years, during the whole of which time they are actively mischievous except during hard frosts, when they go deeper into the earth for protection. Wireworms are of a yellowish colour, with tough shiny skins; they vary from half to seven-eighths of an inch in length and have three pairs of legs-one pair to each of the first three segments of the body-a swelling or "foot" below the last segment, and a pair of very strong jaws well adapted for biting roots.

Treatment :-Wireworms are always the most abundant in old pastures ; the longer the soil of any field has lain undisturbed the more likely it is tobe infested with wireworm. Newly-broken grass land which may be badly infested, if subjected to regular cultivation will gradually become less afflicted with the pest, and in the course of three or four years comparatively free. This clearance is not brought about by any measures taken for the destruction of the pest, though of course these have some effect, but because the beetle prefers to lay its eggs in a situation where the soil is undisturbed, and when the pupa hatch out of land under constant cultivation the emerging beetles fly away to situations more to their liking. From this it is obvious that frequent stirring of the surface soil, especially during the first half of the year, is not only of great benefit in many other ways to the crops, but is also the best possible means of reducing the wireworm pest to within narrow limits.

On small areas carbon bi-sulphide injected into the ground may be used, and will be found to reduce effectively the numbers of wireworms and other soil insects; it will also act beneficially if injected in heaps of grass sods which may have been cut and stacked for special purposes and found infested with the pest. Heaps of soil, compost, or manure which are to bc left standing for a time should be covered with gas-lime to repel the beetle and other pests which will lay their eggs there if the heaps are allowed to get over-grown with weeds. Several proprietary substances are advertised as eradicators of wireworm; these may be applied at much less cost than carbon bi-sulphide, but as the results from their use varies in different localities they should be tried first on a small scale and their use extended if they prove satisfactory.

Gas-lime has often been recommended as a specific for wireworm and other soil insects, but unless heavy dressings are applied and ploughed under immediately whilst in a crude condition it is comparatively useless for the purpose. When fresh from the works it contains compounds which are deadly to both plant and insect life. In this condition it should be spread over grass land or clover lea prior to breaking it up, at the rate of from four to eight tons per acre, according to the extent of the infestation. The land cannot be cropped for several months 
after, but if such a dressing is applied at the beginning of winter the land may be safely cropped the following spring and will be found to have benefitted in many ways.

Rape calie dust has been recommended for wireworm. They appear to be fond of it and will leave the young plants for it, but it has no permanent good effect; on the contrary it promotes the rapid development of the wireworms and so increases their ability for mischief, and its presence in the soil probably has the effect of encouraging the beetle to deposit its eggs there, and so the pest is perpetuated.

Mustard sown and turned in as green manure has not only the effect of improving the fertility of the soil but has been observed distinctly to reduce injury from wireworm.

Pieces of carrot, mangold, or potato may be used as traps for wireworm; they should be buried an inch or so beneath the surface of the soil and frequently examined, when the wireworms they attract may be collected and killed. The beetles may be trapped during May and June by laying bunches of clover or lucerne about the ground and covering them with boards. These serve to attract the beetles, which congregate underneath to deposit their eggs. The traps should be examined occasionally and the beetles destroyed. When the boards are finally removed, an inch or so of the surface soil underneath should be taken away and burnt, so as to destroy any eggs which may have been deposited there.

WOODLICE (Oniscus armidillo).-Woodlice, known as "Sow-bugs" and "Slaters," are not often very troublesome to crops in the open-air, but frequently do much mischief in frames to cucumbers or strawberries, in mushroom houses, or in places where rhubarb or seakale is being forced. They feed in the dark and during the daytime hide in crevices in walls, under heaps of dry litter, and in similar places. A favourite lurking place is the space between a bed and the wall or boards, where the soil or manure has shrunk through dryness.

Treatment:-Discover their hiding places and pour boiling water in. Lay dry hay or moss at the foot of a wall or along the edge of a bed and cover it with a board; this hiding place will attract many and they can then be destroyed with boiling water. If these measures are followed systematically their numbers will soon be brought within moderate limits.

Toads are fond of feeding on woodlice, and a few kept in frames or houses where they abound will soon have the effect of considerably reducing their numbers. There are several advertised poisonous compounds which may be tried for killing the pests. 
INSECTS WHICH ATTACK CERTAIN PLANTS.

ASPARAGUS BEETLE (Crioceris asparagi).-The asparagus beetle is a well-known pest on asparagus plantations in the southern parts of England, but is practically unknown north of the midland counties. It is

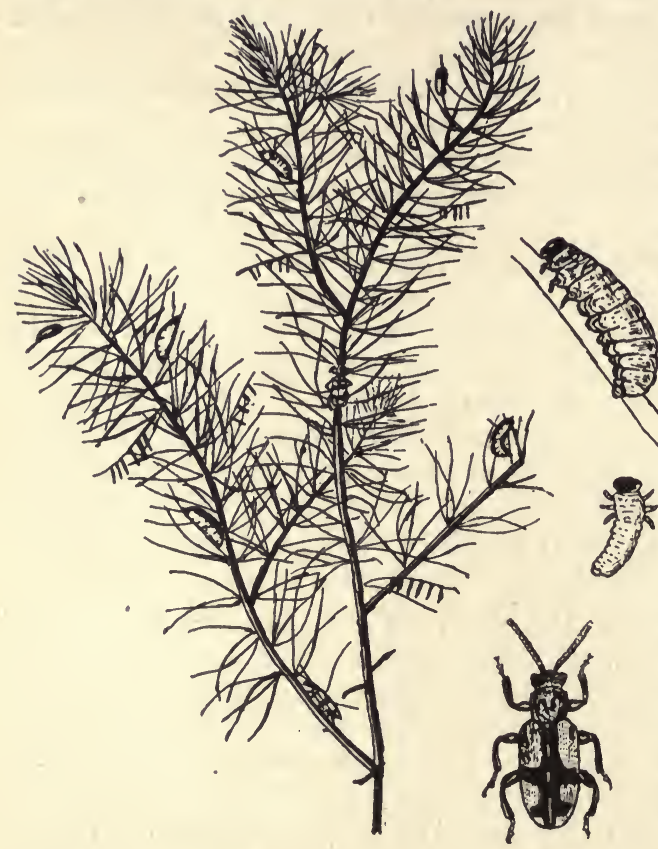

Spray of Asparagus attacked by the Beetle, showing Beetle and Larvie (in two stages) much enlarged, with Eggs attached to foliage, slender and graceful in form, from one-fifth to one-quarter of an inch in length. Its body is shiny black, with a bluc tinge; its head is black. It has red and yellowish marl. ings, with a black cross on its back. It deposits eggs from June onwards, first on the asparagus shoots and later on the feathery foliage after it has developed. The.eggs are spindle-shaped and oval, greenish brown in colour, and are fixed by their ends to the plants, occasionally placed singly but usually occuring in rows of from three to five, and occasionally up to eight in number. The eggs hatch in from five to seven days. The larva or grub is nearly half an inch long and is variable in colour, being generally greyish or slate-coloured but sometimes almost yellow. Both beetle and grub feed on the asparagus plant, at first disfiguring the shoots as they are formed and later attacking the stems. In a bad attack the shoots become defiled and useless from masses of sticliy eggs and from a darkcoloured sticky fluid emitted by the larvæ.

Treatment:-As soon as infestation is observed a few shoots should be left uncut at intervals along the bed; these will serve as traps for the beetles, which will ascend them to pair and deposit their eggs. Once a week these should be cut down and burnt, others being left to fill their place. In this way the infestation may be kept in check until cutting is finished. In the meantime eggs and larva may be cleared from young shoots by running them through the hand.

After cutting is finished for the season the plants should be thoroughly sprayed with arsenate of lead. 
ASPARAGUS FLY (Platyparea poeciloptera).-This is a small hairy fly, brownish in colour, with lighter bands on the abdomen and brownish bands on the wings. The larva is a yellowish glossy maggot, with a dark head and without legs. The fly lays its eggs from early in April to the middle of July, and the larvæ hatch out from two to three weeks later. They at once begin to bore into the tender young shoots, following a downward course. The affected shoots become dwarfed and yellowish, and rot at or below the ground line.

Treatment:-Cut out close to the root and burn all affected shoots. In the autumn burn all tops and dig up and burn all dry stumps.

The flies may be collected in the early morning from the tips of the shoots. Sticks smeared with banding grease or tar and stuck into the bed at intervals will catch numbers of flies as they settle.

Early in the spring following an attack it would probably serve to check another attack by the fly if the beds were dressed with one of the advertised soil fumigants, lightly forked in before the shoots began to grow.

BEAN APHIS (Aphis faba).-This aphis is popularly known as the "Collier" and "Black Dolphin Fly." Large clusters form at the tops of the broad bean plants, and if allowed to remain, increase at such a rate that the shoots become covered either with the flies or with a sticliy excrement which besides making the plants disagreeable to handle interferes with the functions of the leaves and prevents any prospect of a profitable crop.

Treatment:-As soon as the aphis is observed on the plants the tips of the shoots where they
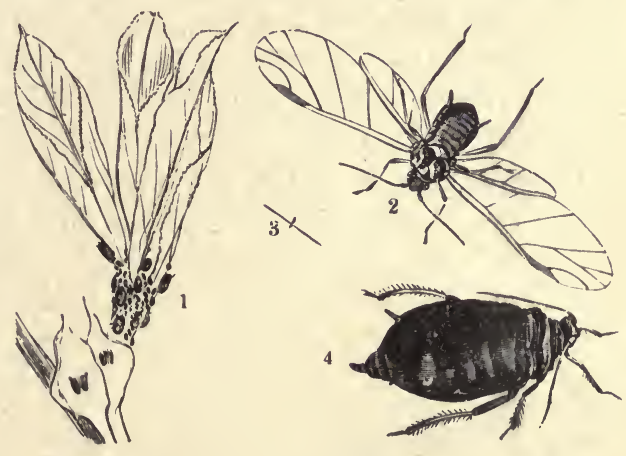

Bean Aphis, or Black Dolphin,

1, Infested Bean shoot; 2, Male Aphis, magnified; 3, Lines showing natural size; 4, Female Aphis, magnified.

congregate should be cut off. These should be put in a pail containing a little paraffin and carried away and destroyed; if they are thrown about on the ground many of the aphis will get on the plants again and much of the labour will be lost. Early-sown plants often escape this pest.

See under Aphides for washes.

BEET AND MANGOLD FLY (Pegomyia beta).-This fly lays eggs on the leaves of the plants during June and July. Small maggots hatch out and burrow into the leaves, eating the green inner tissues. Blisters and blotches are formed, the leaves shrivel, and the growth of the plant is severely checked.

Treatment:-Dress affected nlants with some stimulating manure, such 
as nitrate of soda, to enable them to grow away rapidly and so escape serious damage.

Leaves showing injury and any plants very stunted or killed should be collected and destroyed; they should not be fed to stock or any larvæ present may develop into flies.

Paraffin emulsion sprayed on the foliage will keep the flies away.

Weeds liable to attack by this fly, such as thistle and dock, must be kept down.

CABBAGE APHIS (Aphis brassica),- This aphis is of a greenish blue colour, and is common to all the members of the cabbage family, attacking them on the undersides and in the folds of the leaves. It is most prevalent in the latter part of a hot dry summer and in the autumn. It increases very rapidly, and being protected by a waxy covering which throws off spray, it is more difficult to eradicate than most aphis.

Treatment:-When the season is unusually hot and dry it is a wise precaution to take preventive measures to prevent any considerable infestation, and whilst this applies to any brassica crop it is especially necessary with Brussels sprouts, as these are rendered unsaleable when badly infested with aphis. The best spray for the purpose is paraffin emulsion, and several applications may be necessary, but spraying must not be done when the crop is nearly ready for gathering. In case of a bad attack at such a time it is scarcely practicable to do anything beyond removing and destroying the worst infested leaves.

CABBAGE BUTTERFLIES and CABBAGE MOTH.-The cabbage tribe is subject to attack by the caterpillars of three kinds of butterfly-the Large

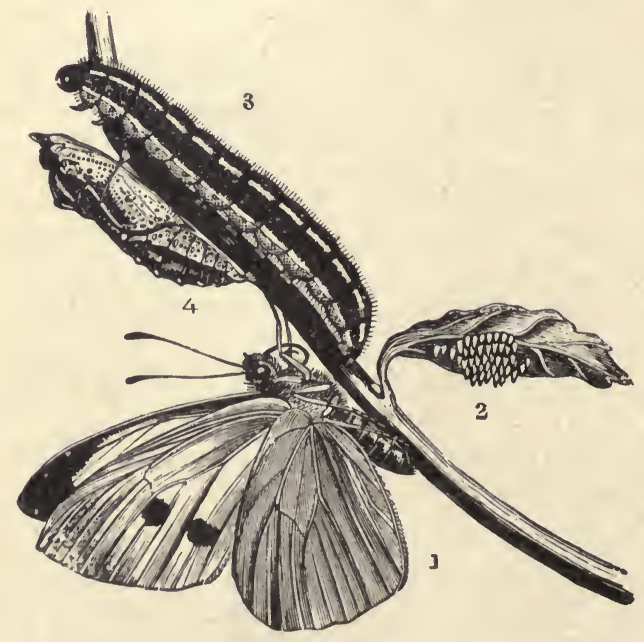

1, Large White Cabbage Butterfly ; 2, Eggs; 3, Caterpillar; 4, Chrysalis.
White (Pieris brassica), the Small White (Pieris rapa), and the Green Veined (Pieris napi); also by the caterpillar of the Cabbage Moth (Mamestra brassica). Both butterflies and moth deposit their eggs on the leaves, especially those of cabbages; these eggs hatch out in six or seven days, and the caterpillars at once begin to attack the leaves; when on cabbage they eat their way to the heart, disfiguring and often completely spoiling it, besides covering the leaves with a disgusting 
mass of excrement The Cabbage Moth, although chiefly a cabbage pest, by no means confines its attention to that family; there are very few plants in the garden which altogether escape its ravages.

Treatment:-Spraying with paraffin emulsion or dusting with lime and soot will check egg-laying; a hot dry summer is favourable to the rapid increase of butterflies and moths, and repeated sprayings in such a season would probably keep the crop fairly free from caterpillars, but spraying must cease before the cabbage begins to head in. After then, spraying with water heated to 140 degrees is said to be effective, or sprinkling freely with salt is said to kill the caterpillars without injuring the plants.

On small areas hand-picking should be practised before the caterpillars have left the outer leaves, and portions of leaves containing clusters of eggs should be removed and burnt.

CABBAGE ROOT FLY AND MAGGOT (Phorbia brassica).- The Cabbage Root Fly somewhat resembles the common house fly but is rather smaller. It is a great pest to all members of the cabbage family and also attacks cruciferous weeds. The female fly begins laying its eggs during April and May, and there are probably two or three generations during the summer. The eggs are deposited in cracks in the ground, as close to the plant as possible In a weeh or more the maggots hatch out and burrow first into the smaller roots, then into the larger roots, and finally into the stem. Plants attacked are stunted, with yellow and shrivelled leaves, and they rot off at the stem.

Treatment:-This pest is very difficult to deal with. Numerous preventive measures may be practised, such as fitting pieces of tarred paper closely around the stem at time of planting or by mixing half a pint of paraffin to a peck of sand and sprinkling this round the stems of the plants wcekly; but as these measures to be effective must be carried out before an attack it is quite certain they will not be adopted, at any rate in commercial work, until the attacks of the pest become more serious and persistent than at present. Probably if the ground was dressed just previous to planting with one of the advertised soil fumigants it would have the effect not only of clearing the soil of many pernicious soil insects but also of repelling the fly and so keeping the crop clear of maggots. After planting, a dressing of nitrate of soda, at the rate of one and a half cwts. per acre, would make the ground somewhat disagreeable to the fly and would stimu. late the plants to grow away from the pest.

All plants which show signs of attack by turning a dull colour and drooping should be at once pulled up and burnt. Bi-sulphide of carbon injected in the ground near the plants will kill the maggots, but it must not be allowed to touch the roots.

When a crop has been badly infested, as soon as it is cleared the ground should be dressed with fresh gas-lime at the rate of from two to four tons per acre; this should be ploughed in at once and the ground left uncropped for three or four months. No cruciferous crop should be allowed to follow and all crucifcrous weeds should be rigorously kept down. 
CABBAGE AND TURNIP ROOT GALL WEEVIL (Ceutorhynchus sulcicollis).-These weevils lay their eggs in holes which they make in the root or at the base of the stems of cabbages and other brassica. The irritation thus set up causes small lumps or swellings to form which are known as "galls." If these are cut open the grubs of the weevil will be found in the cavity they have eaten out.

Treatment:-Rotation of crops; avoid planting any members of the brassica tribe on affected soil. Burn all infested roots.

Dig gas-lime or one of the soil fumigants into beds which have produced infested plants.

CARROT FLY (Psila rosa).-The Carrot Fly is shiny black or dark green in colour, about the fifth of an inch long, with a wing expanse of nearly half an inch. When the carrots are well established the flies lay eggs upon them just below the ground. The maggot is without legs, of a yellowish colour and almost transparent, and nearly a quarter of an inch long. It has no distinct head, but its fore-end tapers to a point; the hindend is blunt. As soon as the maggot is hatched out it goes down and bores

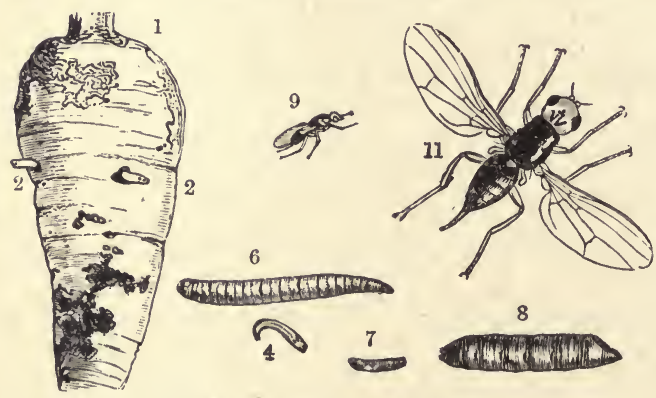

Carrot Fly and Maggot.

1 and 2, Affected Root, showing "rust" spots and Maggots protruding; 4 and 6 , Maggots; 7 and 8, Pupa; 9 and 11 , Fly each natural size and magnified. holes in the lower part of the root, then tunnels upwards, with frequent holes to the outside. The effect upon the roots is to cause them to become brown or "rusty" and finally rotten. An attack is indicated by the outer leaves going yellow and withered; when such are observed the roots should be carefully forked up so that no part is left in the ground, and destroyed.

If the flies are observed on or near the carrot plants these should be at once sprayed with paraffin emulsion; or sawdust, sand, or ashes impregnated with paraffin or carbolic acid may be scattered over the bed and will serve to repel the flies.

Carrots grown early for bunching are seldom injured by the fly, which does not, as a rule attack them until after the end of May. It is considered that the loosening of the soil about the roots caused by thinning and singling the plants offers inducements to the fly to deposit its eggs there; to guard against this the plants should be thinned early, and as part of the work is completed the earth should be drawn close around the stems and trodden tightly in on both sides of the row. Hcavy watering immediately afterwards tends to further consolidate the soil and ward off attack, besides helping the growth of the carrots. In a district where the fly is common, spraying with paraffin emulsion should follow. 
CELERY AND PARSNIP FLY (Acidia heraclei).-The Celery Fly makes its first appearance in April. It is a small fly, about one-eighth of an inch in length with a wing expanse of nearly half an inch; tawny brown body with a lighter colour underneath. The eyes are deep green and the legs dark yellow. The wings are transparent with dark brown markings. The eggs are laid singly on the upper surface of celery and parsnip leaves; these hatch out in about six days and the larva or grubs immediately burrow between the upper and lower epidermis of the leaves, eating the green
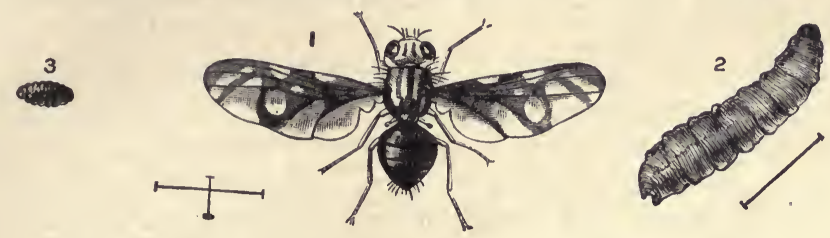

1, Fly, magnified; 2, Larva, magnified (lines show natural size of each);

3, Pupa, natural size.

tissues and doing much damage by checking the growth of the plants. Celery subjected to a bad attack is stunted, will not blanch properly, and is bitter in flavour, whilst parsnips come small and of a bad shape. The grubs change into papa in about fourteen days, sometimes remaining in the leaf and sometimes falling to the ground. From these, flies hatch out in about six days and another attack begins, and so one brood follows another through the summer, and when the weather is mild the pest continues until late in autumn.

Treatment:-Where celery is grown extensively the wisest plan is to take measures to prevent an attack. To this end, whilst the plants are young they should be sprayed two or three times with paraffin emulsion, or they may be dusted occasionally whilst the leaves are wet with a mixture of equal parts of slaked lime and soot, though probably the spraying would be most effective.

Where preventive measures are not adopted a sharp look-out should be kept for evidence of the fly. All infested portions of leaves should be picked off and burnt until no trace of the grub is seen, then the plants should be at once sprayed or dusted as indicated above. It is important that the first brood should be thoroughly dealt with, and then the chances of attack by later broods will be considerably lessened, and probably avoided altogether. Where there has been a bad attack the plants should receive a moderate dressing of nitrate of soda mixed with a little agricultural salt, followed by copious waterings; this will force rapid growth and enable the plants to grow away from the pest, besides repairing any damage it may have done.

MUSHROOM PEST (Sciura ingenua).-Mushroom beds, especially those under cover, are often infested with these active little insects, which are often present in great numbers, and do a great deal of damage by eating the inner part of the fungi and leaving only the outer shell. 
Treatment:-The pest may be liept in check by sprinkling the beds, as frequently as is possible without making them over-wet, with brine composed of one ounce of salt to one gallon of warm water.

As a preventive measure remove old beds as soon as they are unproductive. Before making fresh beds spray the floor, walls, and roof of the house with paraffin emulsion or a $5 \%$ solution of carbolic acid. If the house is quite empty burn sulphur inside and close up tightly. Leave the house immediately the sulphur is ignited, as the fumes are fatal to both animal and plant life. Leave for twelve hours and ventilate well before cntering again.

ONION FLY (Phorbia cepetorum).--The Onion Fly is a little over a quarter of an inch long with a wing-spread of about half an inch, dark grey in colour, with red eyes and black legs. The first deposit of eggs is made about the beginning of May, and there are several generations through the summer. The eggs are white and somewhat oval, and are laid in batches

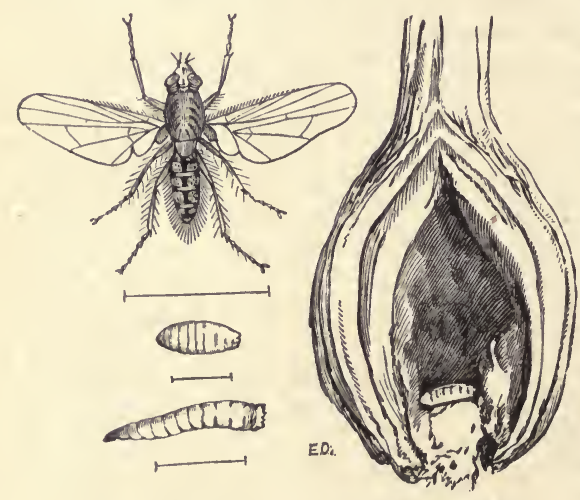

Onion Fly, Pupa, and Maggot, magnified. Lines showing natural size. Pupa in stored Onion. of six to eight upon the neck of the plant, just above the ground. The maggots hatch out in from five to seven days; they are of a dirty white colour, without legs, with a pointed head and a broad tail, and when full-grown are about one third of an inch long. As soon as they are hatched they begin to burrow between the sheathing leaves and work their way into the young bulbs. The first indications of infestation are shown by the plants flagging and the leaves becoming yellow. When plants presenting this appearance are scen they should bc examined, when in all probability it will be found that the maggots are at work.

Treatment:-Similar to that recommended for Carrot Fly, which see.

PEA AND BEAN THRIPS (Thrips pisivora).-There are many species of thrips, some being serious pests under glass and others attacking plants in the open. Occasionally considerable damage is done to peas and beans by thrips popularly known as the "Black Fly" or "Thunder Fly." They are tiny insects, about one-twelfth of an inch in length, blackish brown in colour, with a lighter-coloured head. The adult insects have four narrow wings, fringed with fine hairs, although the males are often wingless; they have six very short legs and a mouth formed for both biting and suction. The females appear in spring and lay their eggs upon the unopened flowers of the pea and bean plants. The larvæ hatch out in eight or ten days; 
they are very active, similar to the adult insect in form, but are orangecoloured and wingless. It is probable that more than one generation occurs in the year.

The foliage of the plants does not appear to be attacked, the damage being done almost entirely to the blossom, from which the sap is sucked away, causing them to become deformed and ultimately to fall off, with the result that although the plants may look perfectly healthy and have made a good show of blossom they are almost, and sometimes completely, barren of useful pods.

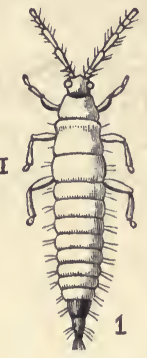

1, Thrips, much magnified.

2, Distorted pod.

Treatment:-In the case of blossom attacks there seems to be, up to present, no known remedy for the mischief. Spraying is of little use. As the adult insects hibernate through the winter under the rough bark of pea and bean sticks and in similar places, future attacks may be rendered less possible by burning sticks and haulm of infested crops and dressing the ground with gas-lime. Peas or beans should not be grown on such ground for several years following.

PEA AND BEAN WEEVILS (Sitones $s p$.)-Peas, beans, and other leguminous plants often suffer serious injury from Pea and Bean Weevils, which devour the leaves and young shoots, whilst their larvæ feed on the roots. It is not easy to see them at work as they fall to the ground at the least alarm, where their general dark grey colour serves to make them indistinguishable amongst the soil. For this reason the damage they do is often mistakenly attributed to slugs or birds. Crops in gardens are quite as liable to damage from them as are those in fields.

There are several varieties of these weevils, the commonest being the Striped Pea Weevil (illustrated). This is of a dark grey colour, with lighter stripes on the wing-cases and thorax, and about a quarter of an inch in length. The adult weevils hibernate through the winter in the bottoms of hedgerows and other similar sheltered places; early in spring they become very active on the wing and attack young peas and beans as soon as they appear above ground. At the same time they lay eggs on or near the roots of the plants. From these eggs larvæ appear; they are small white maggots, with brown heads, which live on the roots and do a great deal of damage.

Treatment:-Spray the plants with arsenate of lead, or with diluted paraffin emulsion. Or the plants may be powdered whilst damp with a mixture of lime and soot. The soil on each side of the rows should be firmed so as to check the movements of the weevils in the ground.

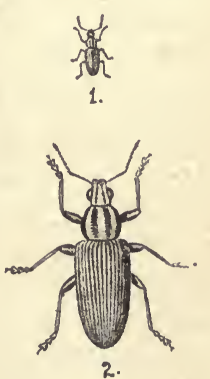

Striped Pea Weevil, Sitones.lineatus. 1, Natural size. 2, Magnified. 


\section{FUNGOID DISEASES.}

ASPARAGUS RUST (Puccinia asparagi).-Asparagus is subject to the attacks of several fungoid diseases, that known as "rust" being the most destructive. It does not appear until after midsummer. When a plantation is badly affected its general appearance is that of an unusually

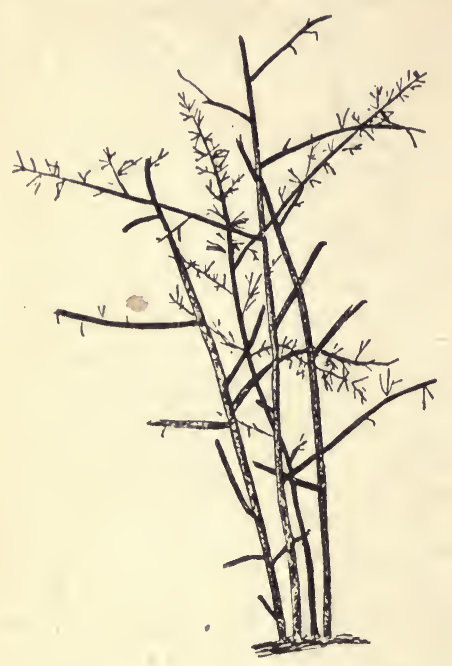

Asparagus Plant affected with Rust, and portion of rusted stem. early maturing of the foliage. Instead of the glossy green appearance which healthy plants present, the foliage shows a yellowish brown colour, whilst the stems will be seen to have raised patches of blistered skin. Underneath this slin are large numbers of the spores of the fungus, which are of a reddish colour. These spores are carried by the wind and lodge on other plants, and so the disease is spread far and wide. As the autumn advances the spores become darker, and the shoots seem almost black. The fungus seriously weakens the plant and if not eradicated ultimately kills it.

Treatment:-A thorough spraying with Bordeaux mixture will check the disease. There will be some difficulty in getting the spray to stick to the glossy leaves and stems, but if a very fine spray is used with plenty of pressure this obstacle may be overcome.

Diseased stems and foliage should be burned in the autumn, and they should be handled as little as possible before burning to avoid distributing the spores.

Good cultivation and watering to obtain a vigorous and sturdy growth will do much to prevent attacks of rust.

BEAN POD CANKER (Colletotrichum Lindemuthianum).-This fungus attacks the pods of French and runner beans, in the form of dark irregular-shaped spots and patches, edged with a red line. These spread and often run into each other, becoming sunken, and are then more or less covered with a thin whitish crust. Sometimes the fungus passes through to the seed inside the pod, making yellowish or brownish pits or wrinkles upon them. Although as a rule the disease is not noticed by the gardener 
until the pods are attacked, it first appears on the stem, on which it makes brownish sunken patches, and sometimes on the leaves, the diseases parts of which soon become dry and drop out, leaving irregular holes. If the

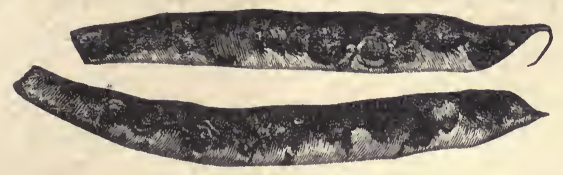

Bean Pods, showing Canker. (Reduced.)

disease can be detected and dealt with at this stage, before the pods are formed, the crop may be saved. Infected seed should never be sown or the plants will probably be killed before they reach the flowering stage.

Treatment:-Remove and burn all diseased plants before spores are produced. Spray in the early stages with Bordeaux mixture at half the normal strength; after the pods are set and until they are half grown spray with sulphide of potassium solution.

Avoid planting beans in damp low-lying places and use only healthy seed.

BEET RUST (Uromyces beta).-This fungus sometimes badly attacks the foliage of beet, and seriously cripples the growth of the plants. It may be recognised by the rusty-red powder (spores) produced from numerous small raised points on the diseased leaves.

Treatment:-Repeated sprayings with Bordeaux mixture will keep the rust from becoming serious. When the beet is lifted all diseased leaves should be collected and burnt.

CABBAGE BLACK ROT (Pseudomonas campestris).-This disease is caused by bacteria; it attacks cabbages, cauliflowers, sprouts, turnips, and all other members of the crucifer family, causing the plants to rot into a pulpy, foul-smelling mass. The bacteria enter the plant through wounds, injured leaves, broken roots, or through the water-stomata of the leaves. They multiply rapidly and work into the leaf-stalks and stems, causing blackening of the vascular bundles and rotting of the plants.

It is considered that the disease is sometimes introduced with the seed.

Treatment:-All diseased plants should be carefully collected and burnt; they should never be given to stock or put on dung or rubbish heaps, or a further infection of the land will follow sooner or later. Destroy all cruciferous weeds.

Dress infected soil with lime and keep clear of cruciferous plants for some years.

Previous to sowing, doubtful seed should be soaked for 15 minutes in a solution of corrosive sublimate, 1 part to 1,000 of water (1oz. to 61 gals.).

CELERY LEAF DISEASES.-There are three fungoid diseases which attack the leaves and stems of celery, thereby causing more or less serious damage to the crop.

1. Cercospora Apii (Rust or Sun Scald).-This disease usually appears 
about midsummer in hot, dry seasons, and appears to be caused by too little moisture at the roots and amongst the foliage. The first evidence of its presence is in small yellowish spots appearing on the leaves; these spots enlarge until they run together and the leaf turns yellow and brown, finally causing its destruction. If neglected the greater part of the crop may become affected and worthless.

2. Phyllosticta Apii.-This fungus first appears in the form of one or more large blotches on the leaf, the colour of which is at first dull brown, becoming paler, dry, and studded with small black spots. When the spores are ripe the leaf crumbles and falls to the ground, spreading the infection.

3. Septoria Petroselini.-In this case watery areas appear on leaves and stems, and these become studded with small brown spots bearing slender black points. This disease generally appears first in the seed beds, and as it appears probable that the infection can be carried by the seed, any showing black dots should be rejected. Prompt measures should be taken to eradicate this disease as if neglected it is liable to become epidemic.

Treatment:-Each of these diseases can be suppressed by spraying at frequent intervals with Bordeaux mixture at half the normal strength; previous to spraying leaves and plants which are badly affected should be carefully removed and burnt. The sprayings are likely to be more effective if backed with good cultivation, sufficient moisture, and one or two light dressings of a stimulating manure.

CLUB-ROOT or ANBURY (Plasmodiophora brassica).-This disease, also known as "Finger-and-Toe," causes malformation of the roots of

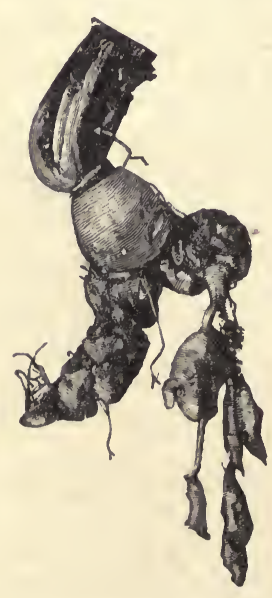

Turnip attacked by Finger-and-Toe. (Much reduced.) cabbages, turnips, radishes, and other brassicx; it also attacks cruciferous weeds, such as charlock and shepherd's purse. It is caused by a minute organism in the soil which enters the plant through the fine roots, multiplying rapidly in the tissues and inducing distortion and decay. The disease is very widespread and destructive. It is not carried in the air as most fungoid diseases are, but is extremely contagious, and is readily spread by carrying soil from a diseased area on boots, tools, \&c., or by feeding diseased roots to stock, from whence it is returned to the ground in the manure. Where no proper measures are taken for its eradication it can remain in the soil for years in a quiescent condition, but immediately makes its presence known when the ground is cropped again with brassicæ. The disease is most prevalent on soils deficient in lime, and especially so when such soils are sour by reason of defective drainage.

Treatment :-Burn or cover with lime diseased roots. Dress the ground 
heavily with slaked lime or gas-lime immediately the diseased crop is removed. Avoid cropping diseased ground with any lind of brassicæ for several years. Drain wet land. Keep down cruciferous weeds. Avoid the use of acid manures, such as superphosphates or dissolved bones.

CUCUMBER AND MELON MILDEW (Erysiphe Cichoracearum).This fungus produces a white network of mycelium on the leaves of ridge cucumbers, marrows, \&c. It is very prevalent after the middle of the season, or earlier when the weather is very dry.

Treatment:-Keep the plants mulched and watered. Spray with potassium sulphide or with Bordeaux mixture at half strength as soon as the mildew is noticed; or sulphur applied with a powder pump may be dusted over the leaves whilst they are wet.

CUCUMBER AND MELON ROT.-In damp sunless weather melons and cucumbers growing in frames are subject to attack from a fungus (probably a Botrytis) which settles upon and causes rapid decay at the cut ends of the shoots, stubs of leaves, or abraded portions of the stem. If not checlied the rot spreads to other parts and destroys the plant.

Treatment :- Carefully cut out and burn all parts affected with the rot; handle the pieces gently so as not to scatter the spores, or the disease will be spread broadcast. Dress the fresh cut ends with flowers of sulphur, and scatter slaked lime beneath the plants.

Keep the frames and plants as dry as possible consistent with healthy growth. Put a piece or tile or slate under each fruit to keep it from contact with the damp soil.

LETTUCE MILDEW (Peronospora ganglioniformis).-This fungus most frequently attacks tender young plants growing under damp conditions in a stagnant atmosphere during winter and spring. It appears as a white powdery growth, chiefly on the under surface of the leaves, but if unchecked it spreads over and destroys the whole of the plants.

Treatment:-Winter the plants in a dry and airy situation; an exposed position with a low screen to break the rough wind is preferable to one at the foot of a wall where the atmosphere is more or less stagnant. Give plenty of ventilation to plants in frames or under cloches.

Where the plants are badly affected remove and burn them. In case of a mild attack dust the plants with flowers of sulphur applied with a powder pump, or use a very fine spray of Bordeaux mixture or cupram, in either case getting well underneath the leaves. Where disease has occurred, water the ground with copper sulphate solution.

MINT RUST (Puccinia mentha).-Mint in beds is frequently attacked by this fungus. It appears first in orange-coloured raised patches on the leaves and stems, causing them to become distorted and spoiling the crop. The plants become brown and die down early in the season.

Treatment:-Mint appears peculiarly subject to this disease and once it has got hold fungicides are of little or no use; then the only safe course is clear the whole bed of roots and tops, which should be carefully collected 
and burnt. After such a clearance spray the ground thoroughly with copper sulphide solution then dress it with lime. Where the disease is very prevalent it would probably be beneficial as a preventive to spray the bed early in the spring with Bordeaux mixture, following this at intervals with cupram.

Stocks may be kept comparatively clear of the disease by forming a fresh plantation with healthy plants on new ground each year, and not allowing the plants to occupy the same ground more than two years in succession.

MUSHROOM DISEASE (Hypomyces perniciosus).-This disease frequently attacks cultivated mushrooms. When affected by it they fail to develop properly into a cap and stem, but the latter becomes much swollen

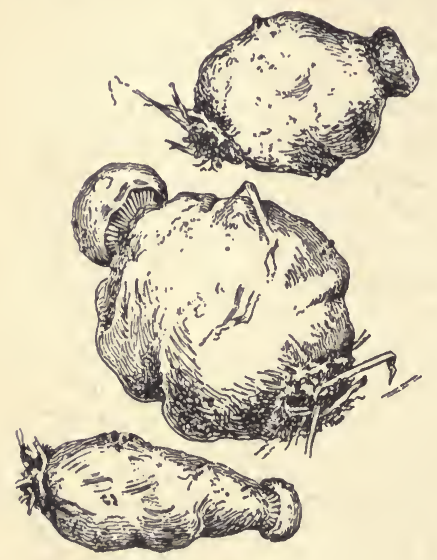

Diseased Mushrooms. (Reduced.) and distorted, whilst the cap is very small and deformed. The cause of the disease is a small parasitic fungus which grows up with the mushroom. After a time the mushroom becomes a soft putrid mass.

Treatment:-If the greater part of the mushrooms are diseased the entire bed should be removed and put where there is no possibility of contact with other mushroom beds or manure. Then clean and disinfect the interior of the house, the ground, and all tools used in taking away the bed. A solution of copper sulphate (11b. to 10 gallons water) sprayed over the walls, floor, and roof of the house is very effective if repeated two or three times at intervals of from seven to ten days.

If only a small proportion of the mushrooms are affected the beds should be looked over every day or two and the diseased mushrooms, with the soil adhering, taken out and burned.

The spawn used may be the cause of infection, therefore care should be taken to procure it only from a reliable source.

PEA MILDEW (Erysiphe Martii).--Peas are very liable to attack in late summer and carly autumn from a fungus which appears on the leaves, pods and stems in the form of a white downy mildew, which stops the growth of the plants and ruins the crop.

Treatment:- Owing to the waxy covering on the leaves it is not easy to make liquid fungicides adhere. Hence it is better to use powders-lime and sulphur or strawsonite. Apply whilst the leaves are damp (not wet) with rain or dew. Repeat at intervals and after heavy rain.

In the case of a bad attack recovery is practically hopeless, and the best proceeding is to pull up and burn the plants. 
ONION MILDEW (Peronospora schleideni).-This disease of the onion is very well-known and wide-spread. It appears first in the form of small yellowish patches on the leaves, which gradually increase in size until the whole of the leaves assume a yellowish, wilted appearance. The surface of the leaves becomes covered with a white powder, which soon changes to a dingy lilac colour.

The bulb itself is not attacked, but its growth is completely arrested, whilst at the same time the "neck" between the bulb and the base of the leaves rapidly increases in length, this elongation being a certain sign of the existence of the disease. The attack is usually made in the early stages of growth, and then unless remedial measures are at once taken the crop is completely destroyed.

Treatment:-The disease first appears in one or more isolated patches in the crop, which are indicated by the yellowing of the leaves. If prompt measures are adopted at this stage the disease can be held in check.

Remove entirely all plants showing a trace of disease and burn them; be sure to destroy them as if any are left lying about to decay the disease is almost certain to appear again the following season. After the diseased plants are removed spray the remainder with Bordeaux mixture, or dust them with quicklime and sulphur whilst the leaves are wet. Either spraying or dusting should be repeated at intervals of two weeks.

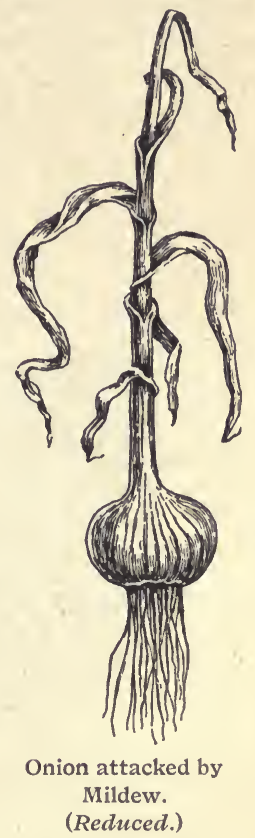

POTATO BLACK-LEG or STEM-ROT (Bacillus phytophthorus).-This disease, which is becoming increasingly prevalent, is caused by a bacterium. Affected plants become yellowish and shrivelled from the bottom upwards, and finally die. The stem below the soil is first affected; this turns brown in patches, and the discolouration increases in size and extends up the stem until the whole plant becomes black and rotten. Sometimes isolated plants are affected in the midst of healthy ones, but more frequently the disease spreads from one to another. It is most prevalent during June and July, and appears to be encouraged by close damp weather.

Treatment:-So far, the only known lines of treatment consist of a rotation of crops and the planting of clean seed. Where the disease has occurred the sets should not be cut but should be planted whole, and the use of nitrate of soda or sulphate of ammonia to force growth should be avoided.

POTATO BLACK SCAB or WART DISEASE (Synchytrium endobioticum).-This disease has been known for some years, chiefly as attacking crops on allotments or other limited areas where potatoes have been grown on the same ground year after year. Latterly, ordinary field crops have 
been attaclied, and the disease is now classed as a notifiable one, under the Destructive Insects and Pests Act. It first appears near the "eyes" of the tuber, causing the young sprouts to assume a brownish colour, and then wrinliles or warts appear. These warts gradually increase in size and grow together, forming a brown spongy mass which almost envelopes the tuber and finally becomes black. The progress of the disease is well shown in the illustration below.

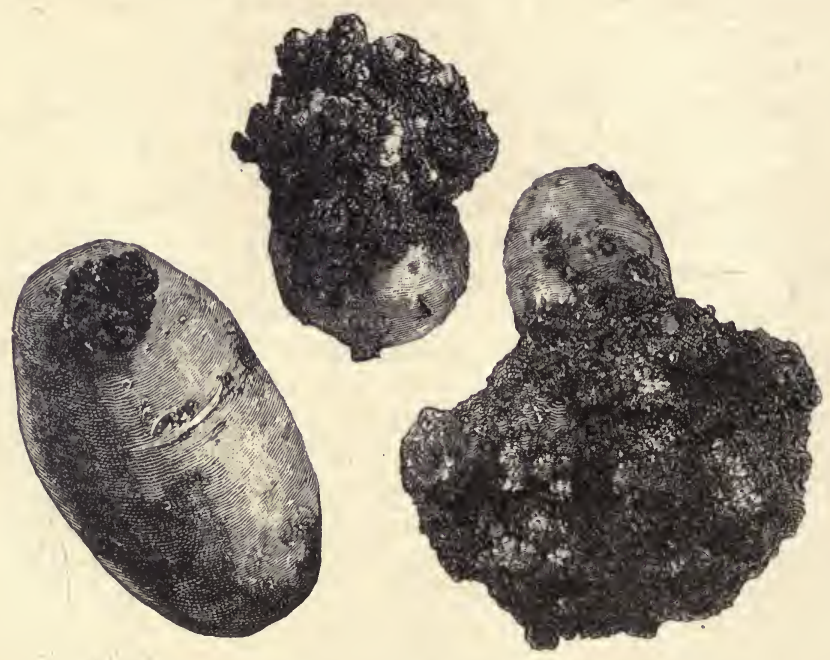

Potatoes infected with Black Scab or Wart Disease, in different stages of development. (Reduced.)

Infected seed is most frequently the means of introducing this disease into clean ground, and when it gets a footing the infection gradually spreads, either through the agency of diseased haulms and tubers or by infected soil being carried about on boots and tools, until all the ground is

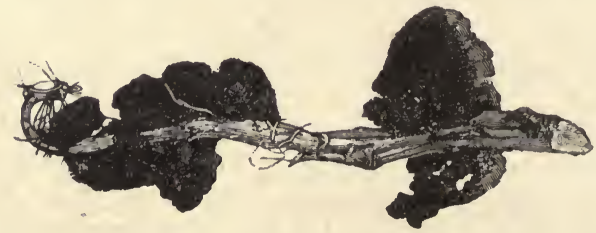

Potato Root infected with Black Scab or Wart Disease. (Reduced.)

infected. The disease will survive in the ground for about six years after the last crop of diseased potatoes has been taken.

Treatment:-This is entirely preventive; nothing short of destroying the tubers can kill the disease when established in the tissues. Diseased tubers should be boiled or burned, and all haulm burned immediately the 
attack is noticed. Dress the ground where they have grown and for some distance outside the margin with gaslime, and disinfect all tools and other implements or articles which have come in contact with the soil during the process of lifting. Avoid planting potatoes on this ground again for several years, and before planting again dress the tubers with flowers of sulphur, which should also be worked into the ground at the rate of 3 or 4 ozs. to the square yard.

"Greening" tubers intended for seed by exposure to light in the auturnn, and then boxing them for sprouting, has been shown to give some degree of immunity to the disease.

"Snowdrop," "Maincrop," and "Conquest" are varieties which have been proved by experiment to be more resistant than others to Black Scab.

\section{POTATO "DISEASE"- Blight or Rot - (Phytophthora infestans).-}

This is the commonest as well as the most destructive disease to which potatoes are subject. It is known to growers as the potato disease, and not without good reason, for whilst other diseases to which the potato is subject are only occasional incidents this is always present to a greater or less degree, ready to play havoc with any unprotected crop in a season favourable to its development, and must therefore always be taken. into the reckoning. It is always the most destructive in wet seasons and especially so if the wet is accompanied by what is known as a "close" or "muggy" condition of the atmosphere.

The first sign of its activity is indicated by brown patches on the leaves and stems. If left untreated these patches or spots rapidly increase in size, the leaves curl, the colour becomes darker, until finally the whole plant, including the tubers, is enveloped and becomes rotten.

The disease is caused by a fungus which develops great numbers of spores; these are scattered by the wind or by anything which disturbs the foliage, and as every spore which settles upon a damp potato leaf is capable of forming a

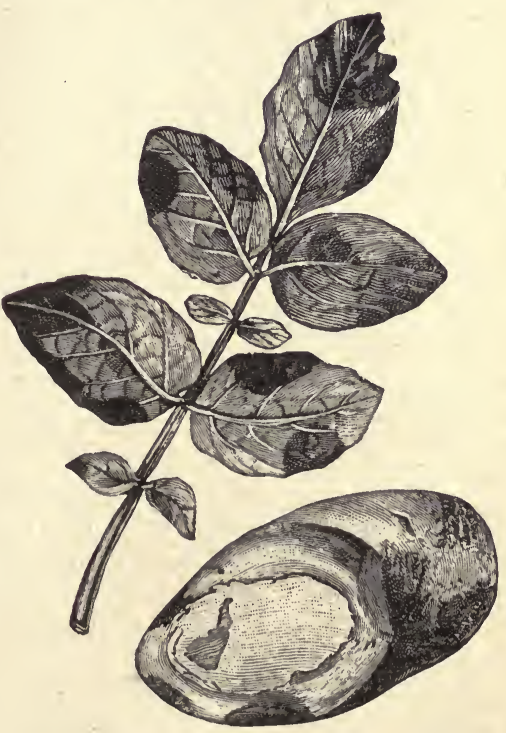

Diseased Leaf and Tuber of Potatoes. (Reduced.) new centre of infection the disease spreads with startling rapidity.

Treatment:- To obtain sound crops of potatoes with any measure of certainty the culture should be undertaken with the clear understanding that the disease is always lurking about, and that the extent of its ravages 
depend more or less upon (1) the soundness of the seed, (2) the suitability of the soil, (3) the space between the plants, (4) the climatic conditions, and (5) the timeliness, frequency, and efficiency of any protective spraying the crop may receive.

It is of the greatest importance that tubers kept for planting or any sced purchased should be saved from a perfectly sound crop; any showing the slightest taint should be at once rejected.

Potatoes should never be planted on low-lying wet land; crops on a water-logged soil are almost sure to be attacked by disease.

The seed should be set at such distances apart as will allow the sun and air free play amongst the plants. In an overcrowded crop the haulm grows in a close mass which prevents free access of light or air ; thus the growth is soft, and beneath the surface of the foliage there is a damp stagnant atmosphere in which the disease runs riot immediately it finds a lodgment.

Although the first three of the points enumerated above are all excellent and necessary steps towards securing a sound crop, they alone cannot be depended upon to ward off disease in an unfavourable season, and to secure comparative immunity these measures should be accompanied by timely sprayings with Bordeaux mixture-first about the end of June and again three weeks later. This work should be done, when possible, in fine dry weather; if it is persistently wet the mixture must be applied more frequently and at greater strength. The underside of the leaves must receive particular attention, because it is here that the disease first appears.

Should spraying have been neglected and the disease appear, the operation will then be comparatively useless, and the only safe course is to at

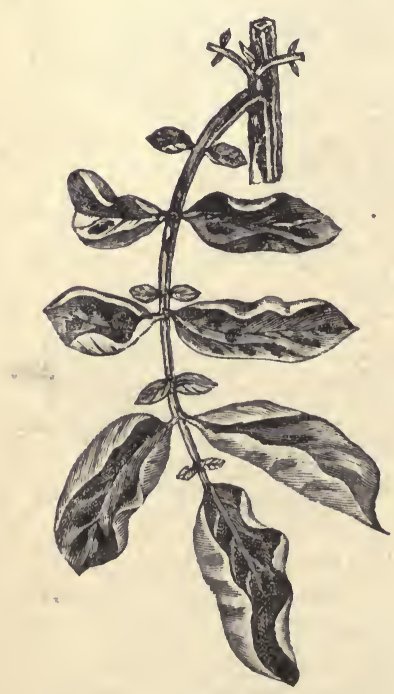

Potato Leaf Curl. (Reduced.) once cut off the diseased haulm and burn it.

Land which has borne a diseased crop should be dressed with gaslime, and kept free from potatoes for the next two or three years.

The rows of potatoes should always be well earthed up, because the spores of the fungus which fall to the ground from diseased leaves are washed through the soil by rain, and when the young potatoes lie near the surface they thus become readily infected; a good covering of soil over the tubers affords a measure of protection.

\section{POTATO LEAF CURL (Macrosporium} solani).-Frequently in rows of potatoes some plants will be found which are stunted in growth, the leaves being small and curled and blackish patches being present on leaves and stem. The tubers are generally infected before planting, though infection may take place after planting from spores 
present in the soil. Seed potatocs lifted before they are fully grown are seldom infected; the fungus appears to pass down to the tubers at a late stage in their growth.

Treatment:- Spraying is of no use. As indicated above, lifting tubers for seed before they are mature is probably the best prevention.

The haulm and tubers of diseased plants should be collected and burnt.

POTATO SCAB (Oospora scabies).-This fungus is very wide-spread; it attacks the tubers whilst they are quite small, forming rough scabby patches on the surface, and these increase in size with the growth of the tuber, generally remaining more or less isolated, but sometimes extending to such an extent that when the tuber is full-grown its whole surface is covered with scab.

Although the market value of the potatoes is depreciated when much scab is present, they are really none the worse for cooking purposes.
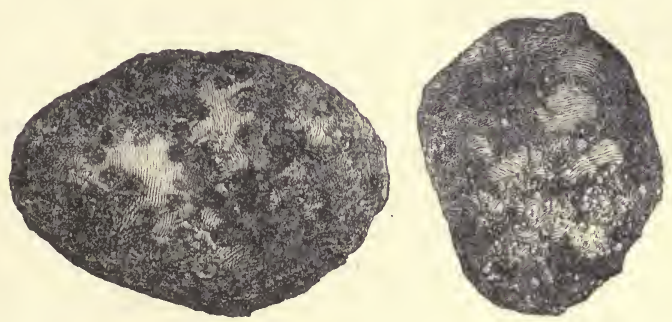

Potato Tubers infected wlth Scab (reduced to half size).

Treatment:-When land has produced scabbed potatoes no further crop should be grown there for at least three years; neither should beet, turnips, carrots, and cabbages be planted there, as they also are attaclied by the fungus and thus help to perpetuate it. Green manuring is said to have a good effect in clearing the ground of the fungus, whilst lime favours its development and should not be used. Acid manures (superphosphates and dissolved bones) are the most suitable for use on infected ground. On small areas infected by the fungus an attack may be warded off by sprinkling flowers of sulphur in the trenches before planting the yotatoes.

Only clean seed should be used when possible, but if the use of scabby seed cannot be avoided it may be disinfected by the following methods :-

(a) For small quantities:-

1. Soak the seed for two hours in a solution of $\frac{1}{2}$ pint of formalin to 15 gallons of water.

2. Soak the sced for one and a-half hours in a solution of $1 \mathrm{oz}$. of corrosive sublimate to 8 or 9 gallons of water.

3. Roll the seed in sulphur, using $300 \mathrm{lbs}$. sulphur to the acre; any sulphur which does not adhere to the seed is sown in the rows.

(b) For large quantities:-

Place the seed in bushel crates or shallow slatted trays in an airtight room. Allow $23 \mathrm{ozs}$. of permanganate of potash and 3 pints of 
formalin to each 1,000 cubic feet of air-space. Spread the permanganate evenly in a pan or bucket and pour the formalin over it. Leave the room at once and keep it closed for two days.

In any case be careful not to bring disinfected seed in contact with diseased tubers, or with the bags or hampers which have contained them.

POTATO WINTER ROT (Nectria solani).-This fungus is very common amongst potatoes which have been stored through the winter, and sometimes reaches the proportions of an epidemic after a hot dry' season. Such conditions favour the development and spread of the fungus in the field;

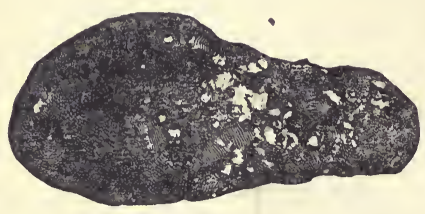

Potato Tuber attacked by Winter Rot. (Much reduced.) the tubers are attacked when they are quite young, but the disease is not, as a rule, noticeable when they are lifted. If they are stored when perfectly dry and under dry airy conditions no further development takes place, but if they are badly stored-that is, before being perfectly dry, in large badly ventilated clamps-sweating takes place, the temperature rises, and the fungus begins to develop.

Treatment:-When the disease is common apply kainit as a top-dressing before the final earthing. Use it at the rate of 3 to $5 \mathrm{cwts}$. per acre, and work it into the ground round the plants.

When an attack has been severe, the ground which has produced the diseased crop should not be planted with potatoes for several seasons afterwards.

The potatoes should be quite dry before clamping, and the clamp only of moderate size, with a dry base, and provided with ample ventilation.

Where this disease is common it is generally an indication of a deficiency of lime in the soil.

\section{SCLEROTIUM DISEASE (Sclerotinia} sclerotiorum; Botrytis cinerea).-Most cultivated plants and many weeds are liable to be attacked by this disease. The Botryt is or summer form of the fungus produces a white velvetty growth on the stem, leaf or fruit attacked. Although it usually attacks the stem or leaves just above the ground its operations are often conducted at a higher point, as in the case of tomatoes in the open-air, which are attacked at the point where fruit and stem join, a great amount of loss being often occasioned in

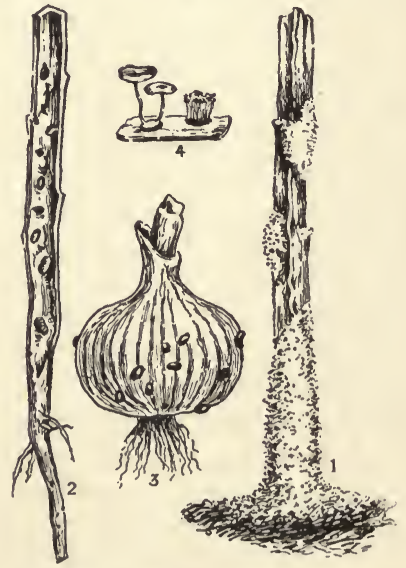

Sclerotium Disease.

1. Portion of a potato haulm with the Botrytis form starting from the ground line.

2. Portion of a potato hatulm split open showing black sclerotia inside.

3. Onion with sclerotia of S. bulborum on the scales. (All reduced.) 
the autumn from this cause. The development of the fungus is most rapid in a damp, still atmosphere. In the summer the fungus produces large numbers of spores, each of which is capable, under suitable conditions, of acting as a fresh centre for the spread of the diseasc. On the approach of winter, or other unfavourable conditions, it produces numerous resting bodics, known as Sclerotia, irregular in size and form and brown or black in colour; these germinate in spring and again give rise to the botrytis form. In many plants, such as potatoes and beans, these sclcrotia are formed inside the stem.

Certain other sclerotium-forming fungi (S. bulborum, \&c.) attack bulbous plants, such as the onion, the sclerotia being formed in the scales of the bulb.

Treatment:-Cut off all diseased plants or portions of plants, or any leaves or fruit which may be affected. Do this thoroughly as well as gently and carefully, as any small portion left or any scattered spores may start a fresh epidemic. Burn them at once. Dust the plants and the surface of the soil with lime and sulphur. Keep both plants and surroundings as dry as possible.

Persistent spraying with Bordeaux mixture or cupram will keep the disease in check.

The soil should be limed before cropping again.

STRAWBERRY LEAF SPOT (Spharella Fragaria)-This disease first appears as small purplish spots on the leaves. These spots gradually increase in size, and the colour changes to reddish-brown with a purple edging. The disease is often very serious on some varieties. By injuring the leaves its effect is to reduce the crop-bearing powers of the plants, often to a serious extent.

Treatment:-Spray with Bordeaux mixture when growth starts in spring and again when first flowers are open. When crop is gathered cut old leaves, removing and burning them. This is safer than the method sometimes recommended of burning off leaves whilst on the plant. In either case spray new growth two or three times with Bordeaux mixture, at intervals of several weeks.

STRAWBERRY MILDEW (Spharotheca Castagnei).-This appears first as a white cobweb-like growth on the underside of the leaves, and afterwards spreads to the fruit.

Treatment:-Spray with Bordeaux mixture, or dust the plants whilst wet with a mixture of lime and sulphur. See that the spray or powder reaches the underside of the leaves.

"POTATO DISEASE" ON'TOMATOES (Plytophthora infestans).Tomatoes grown in the open-air are liable, especially during wet sunless periods in the latter part of summer, to attacks of this disease, sometimes to a serious extent. The symptoms are similar to those found when potatoes are attacked, i.e., dark brown blotches appear on the stems and leaves. These blotches increase in size and number until, in a bad attack, the 
wholc plant becomes a brown rotten mass. The fruit, of course, suffers equally with the rest of the plant. Under conditions favourable to the spread of the disease practically the whole of the crop may be lost.

Treatment:-As in the case of potatoes, the only safe course with this crop is to include preventive spraying with a fungicide as part of the routine of culture. In normal summers two applications of Bordeaux mixture, the first in the middle of July and the second a fortnight later, will generally be sufficient to ward off the disease, but in an unfavourable season the sprayings should be continued at fortnightly intervals. The under surfaces of the leaves should receive particular attention. When the fruit is ripening cupram may be used instead of Bordeaux as it stains the fruit less, but if disease is actually present, or if conditions are favourable to its development, the use of Bordeaux should be continued even though its use necessitates the wiping of the fruit.

BLACK SPOT OF TOMATOES (Macrosporium Tomato).-This fungus generally makes its presence known when the fruit is about one-half grown. The point of attack is usually at the pistil (the point furthest from the stalk). A small black spot develops first, gradually increasing in size until often half the fruit is involved, the surface being sunken and the pulp below black and decayed. The writer has observed that this disease has invariably selected for attack the fruit on those plants which have had insufficient moisture at the roots, whilst those under better growing conditions have escaped.

Treatment:-Collect and burn diseased fruits. Spray regularly with Bordeaux mixture or cupram. See that the plants have sufficient moisture at the roots, and avoid planting in very dry situations.

VIOLET ROOT ROT (Rhizoctonia violacea).-Most cultivated plants -the grasses and ccreals forming notable exceptions-are liable to the attacks of this fungus. Generally the attack is confined to the roots and other underground parts, but in dull moist weather the disease may extend up the stem to the leaves and fruit. It is easily recognised by the network of red or purplish mycelium which grows closely round the organ attacked.

The leaves of diseased plants become yellow and drooping. From the mycelium are produced hard roundish bodies-sclerotia-which are masses of closely interwoven mycelium, and which carry on the disease from year to year. Carrots, beet, potatoes, beans, and peas are the garden crops most likely to be attacked.

Treatment:-An acid condition of the soil is necessary to the proper development of the fungus, hence the application of lime and proper drainage will tend to keep it in chech.

All diseased roots, \&c., should be carefully collected and burnt; on no account should they be fed to stock without previous boiling. 


\section{MISCELLANEOUS INFORMATION.}

\section{Approximate Quantity of Seed required to Sow an Acre, or to produce 1,000 good Plants.}

Asparagus... 3 to $5 \mathrm{lbs}$.

$\begin{array}{llllllllllll}\text { Beans }(\text { Broad) } . . & \ldots & \ldots & \ldots & \ldots & \ldots & \ldots & \ldots & \ldots & \ldots & \ldots & 2 \text { to } 3 \text { bushels. }\end{array}$

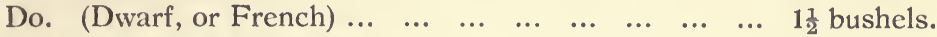

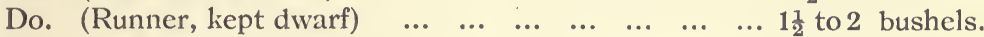

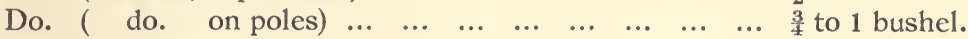

$\begin{array}{lllllllllllllll}\text { Beet } & \ldots & \ldots & \ldots & \ldots & \ldots & \ldots & \ldots & \ldots & \ldots & \ldots & \ldots & \ldots & \ldots & 6 \text { to } 81 \mathrm{bs} .\end{array}$

Borecole, or Kale ... $1 \mathrm{oz}$. for each 1,000 plants ... drilled 4 to $6 \mathrm{lbs}$.

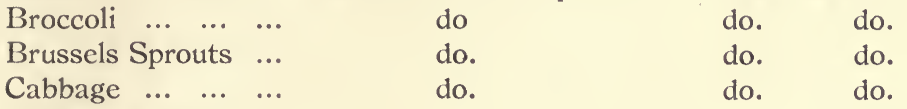

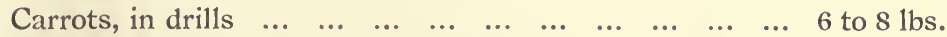

Cauliflowers (raised in heat and priclicd out)... $\frac{1}{2}$ oz. for each 1,000 plants.

$\begin{array}{llllllll}\text { Celery do. do. } & \ldots & \frac{1}{4} \mathrm{oz} . & \text { do. }\end{array}$

$\begin{array}{llllll}\text { Celeriac do. do. } & \ldots & \frac{1}{4} \text { oz. } & \text { do. }\end{array}$

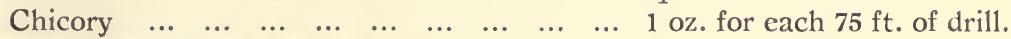

Cucumbers, Ridge (sown in the open)

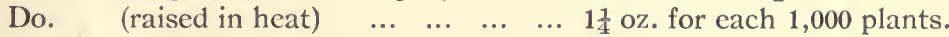

$\begin{array}{llllllllll}\text { Endive (transplanted) } & \ldots & \ldots & \ldots & \ldots & \ldots & \ldots & \frac{1}{2} \mathrm{oz} . & & \text { do. }\end{array}$

Leeks (sown in drills)

Do. (transplanted)

$\begin{array}{lllllllllll}\text { Lettuce } & \text { do. } & \ldots & \ldots & \ldots & \ldots & \ldots & \ldots & \frac{1}{3} \mathrm{oz} . & & \text { do. }\end{array}$

$\begin{array}{lllllllllllll}\text { Melons } & \ldots & \ldots & \ldots & \ldots & \ldots & \ldots & \ldots & \ldots & \ldots & 1 \frac{1}{4} \mathrm{oz} . & & \text { do. }\end{array}$

Mushrooms $\quad \ldots \quad 2$ bricks (16 to the bushel) to one square yard of surface.

Onions (for harvesting)

Do. (for pulling green)

$\begin{array}{lllllllllllllll}\text { Parsley } & \ldots & \ldots & \ldots & \ldots & \ldots & \ldots & \ldots & \ldots & \ldots & \ldots & \ldots & \ldots & 6 \text { to } 8 \mathrm{lbs} .\end{array}$

$\begin{array}{llllllllllllll}\text { Parsnips } & \ldots & \ldots & \ldots & \ldots & \ldots & \ldots & \ldots & \ldots & \ldots & \ldots & \ldots & \ldots & 6 \text { to } \mathrm{s} l \mathrm{lbs} .\end{array}$

$\begin{array}{lllllllllllllll}\text { Peas } & \ldots & \ldots & \ldots & \ldots & \ldots & \ldots & \ldots & \ldots & \ldots & \ldots & \ldots & \ldots & \ldots & 2 \text { to } 3 \text { bushels. }\end{array}$

$\begin{array}{llllllllllllll}\text { Potatoes } & \ldots & \ldots & \ldots & \ldots & \ldots & \ldots & \ldots & \ldots & \ldots & \ldots & \ldots & \ldots & 12 \text { to } 16 \text { cwts. }\end{array}$

$\begin{array}{llllllllllllll}\text { Radishes } & \ldots & \ldots & \ldots & \ldots & \ldots & \ldots & \ldots & \ldots & \ldots & \ldots & \ldots & \ldots & \frac{3}{4} \text { bushel. }\end{array}$

$\begin{array}{llllllllllll}\text { Savoys } & \ldots & \ldots & \ldots & \ldots & \ldots & \ldots & \ldots & \ldots & \ldots & 1 \text { oz. for each } 1,000 \text { plants. }\end{array}$

$\begin{array}{llllllllllll}\text { Shallots }(\mathrm{secd}) \ldots & \ldots & \ldots & \ldots & \ldots & \ldots & \ldots & \ldots & \ldots & \ldots & \ldots & 6 \text { to } 8 \\ \mathrm{llbs}\end{array}$

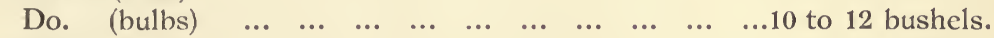

$\begin{array}{llllllllllllll}\text { Spinach } & \ldots & \ldots & \ldots & \ldots & \ldots & \ldots & \ldots & \ldots & \ldots & \ldots & \ldots & \ldots & 10 \text { to } 12 \mathrm{lbs} .\end{array}$

$\begin{array}{llllllllll}\text { Tomatoes } \ldots & \ldots & \ldots & \ldots & \ldots & \ldots & \ldots & \ldots & \ldots & \frac{1}{2} \mathrm{oz} \text {. for each } 1,000 \text { plants. }\end{array}$

$\begin{array}{llllllllllllllll}\text { Turnips } & \ldots & \ldots & \ldots & \ldots & \ldots & \ldots & \ldots & \ldots & \ldots & \ldots & \ldots & \ldots & 3 \text { to } 4 \mathrm{lbs} .\end{array}$

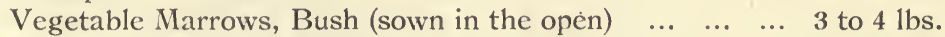

Do. Running do. $\quad \ldots \quad \ldots \quad \ldots \quad 2$ to $3 \mathrm{lbs}$.

Do. $\quad$ (raised in heat) $\quad \ldots \quad \ldots \quad 6$ oz. for each 1,000 plants. 


\section{Approximate Averages of Yield, Cost of Production, and Gross Returns per Acre of various Vegetable Crops.}

These average yields are calculated from crops grown with good ordinary cultivation, under suitable conditions, in a normal season; the cost of producing the crop includes, in addition to all expenses of cultivation, such items as the value of plants where these are set out, and gathering, bunching, washing, or packing, but not carting to rail or market; the gross returns are subject to deductions for carriage and salesmen's commissions.

Description of Crop.

Artichokes, Globe Asparagus ... ... ... Beans, Broad ... ... Beans, Dwarf, French Beans, Runner ... .... Beet $\ldots . . . \quad \ldots \quad \ldots$

Broccoli $\quad \ldots \quad \ldots \quad$...

Do. Sprouting ...

Brussels Sprouts ... 300 bushels, 50 bags tops . Cabbages ... $\quad \ldots \quad \ldots \quad 1,000$ to 1,200 doz. ... $\quad \ldots$

Carrots, Early ... ... 1,200 to 1,500 doz. 12's ...

Do. Maincrop ... Cauliflowers $\quad \ldots . . .$. Celery, in trenches ...

Do. in broad beds. Cucumbers, Ridge ... Kale Leeks ... Lettuce, Cos

Do.

Cabbage

Onions, Dry

Do. Green, bunched Parsley

Parsnips Potatoes, Early Do. Late..

Radishes

Rhubarb

Seakale, Natural … Savoys

Shallots

Spinach

Tomatoes

Turnips, Early ....

Do. Maincrop ... Vegetable Marrows...
Average amount of Produce.

10,000 to 15,000 heads

1,500 to 2,000 bundles

120 to 180 bushels

250 to 350 bushels

300 to 400 bushels

...

14 to 16 tons $\quad \ldots . . .$.

500 to $700 \mathrm{doz}$. heads

15 to 20 tons

500 to 800 doz.

1,000 to 1,200 rolls

2,500 to 3,000 rolls

4,000 to $6,000 \mathrm{doz}$.

\begin{abstract}
12 to 16 tons
\end{abstract}

\section{...}

$\begin{array}{ll}\cdots & \cdots \\ \cdots & \cdots\end{array}$

.....

......

40 to 45

... $\quad \therefore \quad 25$ to 35

... ... 20 to 25

.. 500 to 1,000 doz. bunches.

14 to 18 2,500 to 3,000 doz. 4,000 to 5,000 doz.

\section{0 to 15 tons}

...

6,000 to 8,000 market bun. 500 to 600 doz. bunches ...

25 to 35

.. 25 to 35

.. 20 to 25

40 to 45

20 to 25 14 to 16 tons $\quad \ldots \quad \ldots \quad \ldots \quad 13$ to 15 100 to 200 bushels ... ... 16 to 20

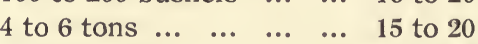
8 to 10 tons... $\quad \ldots \quad \ldots \quad \ldots \quad 15$ to 20 5,000 to 6,000 doz. ... ... 40 to 45 15 to 20 tons $\quad \ldots \quad \ldots \quad \ldots \quad 30$ to 40 3,500 to 4,500 lbs. $\ldots \quad \ldots \quad 25$ to 30 600 to $800 \mathrm{doz}$... ... ... 18 to 20

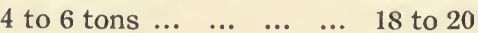
500 to 800 bushels ... ... 20 to 25 7 to 10 tons $\quad \ldots \quad \ldots \quad \ldots \quad 30$ to 40 300 to $350 \mathrm{doz}$. buh. of 12 . 25 to 35 15 to 20 tons $\quad \ldots . \quad \ldots \quad \ldots \quad 12$ to 14 1,000 to $1,500 \mathrm{doz}, \ldots . . . \quad 15$ to 20
Gross Returns.

... $£ 45$ to $£ 65$

... 75 to 100

... 20 to 30

... 20 to 30

... 20 to 35

... 40 to 50

... 50 to 60

... 25 to 40

... 40 to 60

... 40 to 60

... 50 to 80

... 30 to 40

... 40 to 80

... 45 to 65

... 100 to 125

... 45 to 75

... 30 to 40

... 40 to 50

... 60 to 80

... 40 to 100

... 50 to 80

... 60 to 90

... 40 to 60

... 25 to 35

... 20 to 35

... 30 to 45

... 25 to 35

... 75 to 110

... 50 to 70

... 50 to $\mathbf{7 5}$

... 35 to 45

... 40 to 50

... 40 to 50

... 80 to 100

... 45 to 65

... 25 to 30

... 40 to 45 


\section{Average Time required for Garden Seeds to Germinate.}

\begin{tabular}{|c|c|c|c|c|c|c|c|c|c|}
\hline Asparagus & ... & $\ldots$ & $\begin{array}{l}\text { Days. } \\
14 \text { to } 21\end{array}$ & Melons (i & n her & at) & & & $\begin{array}{l}\text { Days. } \\
3 \text { to } 6\end{array}$ \\
\hline Beans & $\begin{array}{lll}\ldots & \ldots & \ldots\end{array}$ & $\ldots$ & 7 to 14 & Mustard & $\ldots$ & ... & $\ldots$ & $\cdots$ & 3 to 4 \\
\hline Beet ... . & $\begin{array}{lll}\ldots & \ldots & \ldots\end{array}$ & $\ldots$ & 10 to 18 & Onions & $\ldots$ & ... & $\ldots$ & $\ldots$ & 10 to 16 \\
\hline Brassica & (all sorts) & $\ldots$ & 5 to 10 & Parsley & $\ldots$ & $\cdots$ & $\cdots$ & $\cdots$ & 15 to 26 \\
\hline Carrots & $\ldots \quad \ldots$ & $\ldots$ & 12 to 18 & Parsnips & ... & ... & $\ldots$ & $\ldots$ & 10 to 20 \\
\hline Chicory & ... & • & 5 to 10 & Peas ... & $\ldots$ & ... & $\cdots$ & $\ldots$ & 7 to 14 \\
\hline Cress... & $\begin{array}{lll}\ldots & \ldots & \ldots\end{array}$ & $\ldots$ & 4 to 6 & Radishes & $\ldots$ & ... & .. & $\cdots$ & 3 to 6 \\
\hline Cucumbers & s (in the o & en) & 7 to 14 & Spinach & $\cdots$ & ... & 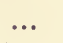 & $\cdots$ & 7 to 10 \\
\hline Do. & (in heat) & .. & 2 to 4 & Tomatoes & (in 1 & heat & & $\cdots$ & 6 to 10 \\
\hline Endive & .. & $\ldots$ & 5 to 14 & Turnips & $\ldots$ & $\ldots$ & $\ldots$ & $\cdots$ & 4 to 10 \\
\hline Leeks... & $\ldots \quad \ldots$ & $\ldots$ & 10 to 14 & V. Marro & ws (it & n & le op & en) & 7 to 14 \\
\hline Lettuce & $\begin{array}{lll}\ldots & \ldots & \ldots\end{array}$ & $\ldots$ & 6 to 10 & Do. & & $n$ he & eat) & $\ldots$ & 3 to 5 \\
\hline
\end{tabular}

\section{Average Longevity of Garden Seeds.}

\begin{tabular}{|c|c|c|c|c|c|c|c|c|c|c|c|}
\hline Asparagus & $\cdots$ & $\cdots$ & & & \begin{tabular}{l}
\multicolumn{2}{l}{ Years. } \\
$\ldots . \quad 3$
\end{tabular} & Mustard... & $\cdots$ & & $\cdots$ & .. & $\begin{array}{l}\text { Yea } \\
\ldots\end{array}$ \\
\hline Basil & ... & $\ldots$ & ... & $\ldots$ & $\ldots 8$ & Onions ... & $\ldots$ & $\ldots$ & $\cdots$ & $\therefore$ & ... \\
\hline Beans ... & $\ldots$ & $\ldots$ & $\cdots$ & $\because$ & $\ldots$ & Parsley ... & $\ldots$ & $\ldots$ & $\ldots$ & ... & $\cdots$ \\
\hline Beet & ... & $\ldots$ & ... & $\ldots$ & .. 6 & Parsnips & $\ldots$ & $\ldots$ & $\cdots$ & $\ldots$ & $\cdots$ \\
\hline Borage ... & $\ldots$ & $\ldots$ & $\ldots$ & $\ldots$ & ... & Peas & $\ldots$ & $\ldots$ & $\cdots$ & $\ldots$ & $\cdots$ \\
\hline Brassicæe & $\ldots$ & ... & ... & ... & .. & Radishes & ... & $\ldots$ & $\cdots$ & ... & $\cdots$ \\
\hline Cardoons & $\ldots$ & $\ldots$ & ... & $\cdots$ & $\cdots$ & Rhubarb & ... & $\cdots$ & *. & $\cdots$ & $\cdots$ \\
\hline Carrots ... & ... & $\ldots$ & ... & $\ldots$ & .. 4 & Rosemary & $\ldots$ & $\therefore$ & $\cdots$ & ... & $\ldots$ \\
\hline hicory ... & $\cdots$ & $\ldots$ & ... & $\cdots$ & ... & Sage & $\ldots$ & $\ldots$ & $\cdots$ & ... & $\cdots$ \\
\hline Cress & ... & $\ldots$ & ... & $\cdots$ & ... & Salsify $\quad .$. & ... & $\cdots$ & $\cdots$ & $\ldots$ & $\cdots$ \\
\hline ucumbers & $\cdots$ & $\ldots$ & .. & $\cdots$ & ... & Savory, Sur & ame & r or & Wi & ter & ... \\
\hline Endive ... & $\cdots$ & $\cdots$ & $\cdots$ & $\ldots$ & ... 10 & Scorzonera & $\cdots$ & $\cdots$ & $\cdots$ & ... & ... \\
\hline Fennel ... & $\ldots$ & $\ldots$ & .. & $\cdots$ & $\ldots 4$ & Seakale ... & ... & $\ldots$ & $\ldots$ & ... & ... \\
\hline Leeks & $\cdots$ & $\ldots$ & $\cdots$ & $\cdots$ & $\ldots 3$ & Spinach (all & vari & ieties & & $\cdots$ & $\cdots$ \\
\hline Lettuce ... & ... & $\ldots$ & ... & $\ldots$ & $\ldots 5$ & Thyme ... & $\ldots$ & $\ldots$ & ... & ... & ... \\
\hline Marjoram, & Swe & & ... & $\cdots$ & 3 & Tomatoes & ... & $\cdots$ & $\cdots$ & $\cdots$ & $\cdots$ \\
\hline Do. & Win & & $\ldots$ & $\cdots$ & .. 5 & Turnips ... & $\ldots$ & $\ldots$ & $\cdots$ & $\cdots$ & $\cdots$ \\
\hline lelons & $\ldots$ & & $\ldots$ & $\ldots$ & ... 5 & Vegetable $N$ & Iarr & ows & ... & ... & 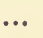 \\
\hline
\end{tabular}

\section{Approximate Sizes of Flower Pots.}

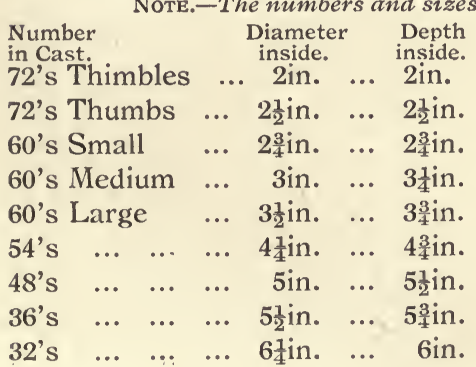

\begin{tabular}{|c|c|c|c|c|c|c|}
\hline \multirow{2}{*}{\multicolumn{2}{|c|}{$\begin{array}{l}\text { Number } \\
\text { in Cast. } \\
24 \text { 's .. }\end{array}$}} & \multicolumn{4}{|c|}{ Diameter } & \multirow{2}{*}{$\begin{array}{l}\text { Depth } \\
\text { inside, } \\
6 \frac{3}{4} \text { in. }\end{array}$} \\
\hline & & $\ldots$ & $\ldots$ & 7 in. & $\ldots$ & \\
\hline 18 's & $\cdots$ & $\ldots$ & ... & $7 \frac{1}{2} \mathrm{in}$. & $\ldots$ & 7 in. \\
\hline 12's & $\ldots$ & $\ldots$ & $\cdots$ & $8 \frac{1}{2} \mathrm{in}$. & ... & sin. \\
\hline 8's & $\cdots$ & $\cdots$ & $\ldots$ & $10 \mathrm{in}$. & $\ldots$ & $9 \frac{1}{2}$ in. \\
\hline 6's & $\ldots$ & $\ldots$ & $\ldots$ & $11 \mathrm{in.}$ & ... & $10 \frac{1}{4} \mathrm{in}$. \\
\hline 4's & .. & $\ldots$ & $\ldots$ & $12 \mathrm{in}$. & $\ldots$ & $11 \mathrm{in}$. \\
\hline 3's & ... & $\ldots$ & $\cdots$ & $14 \mathrm{in}$. & .. & $12 \mathrm{in}$. \\
\hline 2's & $\ldots$ & $\ldots$ & $\cdots$ & $16 \mathrm{in}$. & ... & $13 \mathrm{in}$. \\
\hline 1's & ... & $\ldots$ & $\ldots$ & $18 \mathrm{in}$. & $\ldots$ & $14 \mathrm{in}$. \\
\hline
\end{tabular}


Number of Plants for an Acre, at given distances apart.

(Adapted from Bailey's Horticulturist's Rule Book.)

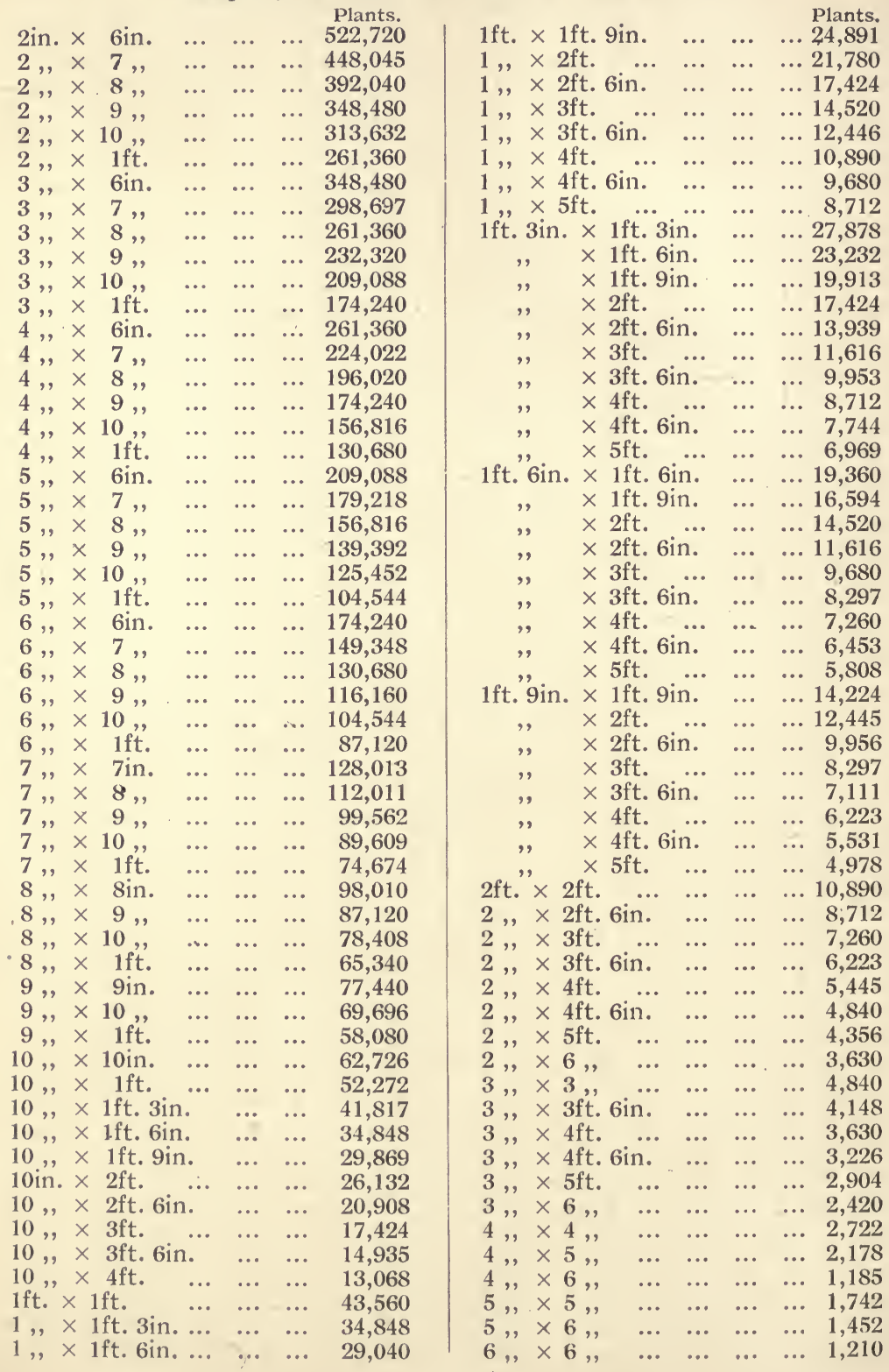




\section{Receptacles, Weights, Measures, and Terms used in Marketing Produce.}

NoTE.-In packing produce for market the most important points to observe are that it is good, clean, and attractive, of equal quality throughout, of the full weight or measure described, and in parcels of convenient and equal size and shape. Granted these points, the particular kind of receptacle used is to some extent immaterial,in fact some of those described below are gradually being displaced by others, and so becoming obsolete. Still, it is not wise to disregard local or trade customs without a good reason, and before doing so the salesman who is to handle the produce should be consulted.

BAG.-A sack holding from $\frac{1}{2}$ to $1 \mathrm{cwt}$, according to nature of contents.

Bunch.-A quantity of vegetables or herbs tied together, the size and number varying with the season and the market to which they are sent.

BundLE.-Such vegetables as rhubarb, asparagus, and seakale, which consist almost entirely of stem with little or no foliage, are made up in bundles, the size of which varies according to the season and market. A bundle of rhubarb contains from 2 or 3 sticks at the beginning of the forcing season to 20 or 30 in the summer; asparagus, 100 to 120 shoots; seakale, 12 to 18 heads.

Bushel BASKET.-A wicker basket of the capacity of 8 imperial gallons. Used for various kinds of vegetables and fruit. In most cases the contents require to be heaped before they arc considered to be a full bushel.

CHIP.-A basket made of thin strips of wood, interwoven. Used principally for strawberries and raspberries, but also occasionally for tomatoes, mushrooms, \&c. Of various sizes, the holding capacity running from 3 lbs. to $12 \mathrm{lbs}$.

CRATE.-A wicker-work basket used for packing cauliflower, broccoli, and early spring cabbage, the holding capacity being 5 or 6 dozen.

EмptiEs.-A term used to denote empty baskets and other receptacles which are sent to the grower by the salesman, to be filled with produce and consigned back to him.

FLASkET.-A basket half the size of a "Load" basket, which see.

FLAT.-An oblong shallow lidded basket holding a bushel, used principally, though not exclusively, for marketing cucumbers, of which it holds from $2 \frac{1}{2}$ to $3 \frac{1}{2}$ dozen, according to their size. Occasionally it is used for choice vegetables, and frequently for some kinds of fruit.

FLY.-A receptacle formed of cane, with open wide mesh, used for conveying herbs to market.

HALF-Bushel.-A basket of the capacity of 4 imperial gallons, used for similar purposes to the "Bushel Basket."

HALF-Sieve.-See "Half-Bushel."

Halves.-Same as "Half-Sieve" and " Half-Bushel." 
HANDle BASKet.-A term used to describe an oval shallow wicker basket, with a cross-over handle and a movable lid. Capacity about a peck. Much used in the Channel Island trade for tomatoes, French beans, early peas, \&c. Also used for similar purposes inland, especially when the produce is of good class.

HAMPER.-A basket used for potatoes and other produce in the Liverpool, Manchester, and other markets in the northern counties.

HAND.-A term used to describe a bunch of long radishes, which are tied up in such a way that the roots are spread out fan-shaped. The hand contains from 12 to 20 roots.

JUNK.-A measure containing two-thirds of a bushel.

KIPE.-A Worcestershire measure, round in shape, 18in. wide at top, $1 \mathrm{ft}$. wide at bottom, and $12 \mathrm{in}$. deep.

LOAD.-An oblong basket, 30in. long, 26in. wide, and $16 \mathrm{in}$. deep, provided with 4 handles and detached lid. Will hold about 3 bushels of runner beans or 2 cwt. parsnips.

In the Manchester and other markets in the northern counties, a "load" of potatoes weighs 18 stones ( $14 \mathrm{lbs}$. to the stone).

PAD.-A lidded basket of oval shape, larger at top than bottom, holding about a bushel. Used for conveying to market new potatoes and various other vegetables.

PEck.-A round basket holding two gallons, or a quarter of a bushel. Used for strawberries, tomatoes, mushrooms, \&c.

PokE.-A bag used for marketing onions. Narrow in shape, and holds about half a bushel.

Рот.-An oblong basket much used in the Midlands for conveying fruit and vegetables to market; length 21 in., width 14 in., depth 15 in. Roughly, its capacity is about $1 \frac{1}{2}$ bushels.

PUnNet.-A receptacle made in various sizes, of plaited "chip," or thin shavings of wood; used for salading, strawberries, seakale, mushrooms, \&c.

PUP OR PIP.-A round basket with a broad rim, of the capacity of one gallon; used for raspberries and strawberries, of which they hold 6lbs.

QuARTER-Sieve.-See " Peck."

RoLL.-A term used to denote a bundle of celery.

SACK-A "Bag" to hold $1 \frac{1}{2}$ or 2 cwt.

ScORE.-A number by which certain classes of vegetables are sold; the market "score" is usually taken as 22 .

Sieve.-See "Bushel Basket."

STONE.-A weight of $141 \mathrm{bs.}$; used chiefly in the northern markets.

STRIKE.-A round basket used for similar purposes to a "Peck," and of the same capacity, but wider and not so deep.

In some of the northern markets a "Strike" has the capacity of about $1 \frac{1}{2}$ bushels.

TALLY.-A term used in the London markets, denoting 5 dozen. 


\section{Avoirdupois Weight.}

$\begin{array}{lllll}16 \text { Drams make } & . . & \ldots & \ldots & 1 \text { Ounce. } \\ 16 \text { Ounces } \ldots & \ldots & \ldots & \ldots & 1 \text { Pound. } \\ 28 \text { Pounds } \ldots & \ldots & \ldots & \ldots & 1 \text { Quarter. } \\ 4 \text { Qrs. or } 112 \text { lbs. } & \ldots & \ldots & 1 \text { Cwt. } \\ 20 \text { Hundredweights } & \ldots & \ldots & 1 \text { Ton. }\end{array}$

Corn, Dry, or Heaped Measure.

2 Pints make $\quad . . \quad \quad$... $\quad$... 1 Quart.

4 Quarts ... ... ... ... 1 Gallon.

2 Gallons or 16 Pints ... ... 1 Peck.

4 Pecks or 8 Gallons ... $\quad . . . \quad 1$ Bushel.

8 Bushels or 2 Coombs $\quad . . .1$ Quarter.

\section{Long Measure.}

12 Inches make ... ... 1 Foot.

3 Feet or 36 inches ... 1 Yard.

$5 \frac{1}{2}$ Yards or $16_{2}^{1}$ feet ... 1 Rod, Pole or Perch

40 Perches or 220 yards. 1 Furlong.

8 Furlongs or $1,760 \mathrm{yds}$. 1 Mile.

\section{Surface Measure.}

144 Square Inches make ... 1 Square Foot. 9 Square Feet ... $\quad . . .11$ Square Yard. $30 \frac{1}{4}$ Square Yards ... ... 1 Square Rod.

40 Square Rods ... $\quad \ldots 1$ Rood.

4 Roods or $4,840 \mathrm{Sq}$. yards 1 Acre.

Fertilizing Values of Poultry Dung and Farmyard Manure, Given in Pounds per Ton.

Ducks ... $\quad . . . \quad$... Nitrogen $27 \mathrm{lbs} . .$. Potash $13 \mathrm{lbs}$... Lime $23 \mathrm{lbs} . .$. Phosph. Acid $31 \mathrm{lbs}$.

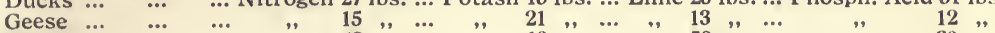

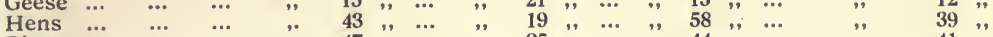

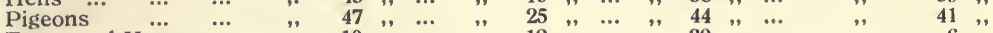

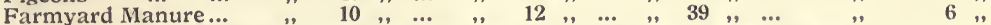

Equivalent Dressings from One Square Yard to One Acre.

1 cwt. per Acre equals... 28 lbs. per Rood... $\frac{3}{4} 1$ bs. per Square Rod... $\frac{3}{3}$ oz. per Sq. Yard (about)

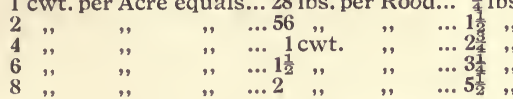

\section{WEATHER INDICATIONS.}

A steady barometer indicates a continuance of the weather then existing.

A slowly rising barometer usually indicates fair weather.

A rapid rise usually indicates unsettled weather or the approach of a storm; or it may mean the breaking-up of an existing storm.

A slowly falling barometer indicates the approach of a severe storm.

A rapid fall of the barometer indicates high winds and probable rain.

If contiguous clouds move in various directions rain is liliely very soon.

When small black clouds scud over an overcast sky, heavy rain and bad weather may be expected.

A pale and diffuse sun at setting portends a storm.

A deep red morning sky is usually followed by bad weather.

A sonorous condition of the atmosphere foretells approaching rain.

Gaudy hues of blue and purple at sunset prophesy rain and wind.

When the sun rises bright and clear and shortly after becomes overcast it is an indication that rain is near.

A halo round the moon indicates approaching rain.

Fleecy or cirrus clouds arranged in horizontal bars or ribs in the upper sky, known as a "mackerel sky," indicate wet or foul weather.

Cumulus clouds that preserve a well-rounded form and float high in the air indicate fair weather.

Anvil-shaped cumulus clouds usually indicate thunderstorms.

Cirro-cumulus clouds-like bunches and fleeces of wool scattered high in the sky-are indications of still and dry weather.

When the rays of the rising sun shoot far up into the sliy fair weather may be expected.

A bright red sunset means fair weather for the morrow, but a coppercoloured sunset usually portends high winds.

A grey or pale rose morning sky means good weather.

Haziness-due to dust in the atmosphere-is indicative of dry weather.

When haziness suddenly disappears and the sun sets pale and the sky is very clear, rain is probable.

Heavy dew indicates fair weather; absence of dew for two or three mornings in succession in summer is a precursor of rain.

In winter, hoar frost two or three mornings in succession indicates rain, 


\section{INDEX.}

Acid, phosphoric, 24.

Acid soils, sweetened by lime 26 ; liable to pernicious fungi, 401 .

Aeration of soils, 7.

Air and sunshine, 140.

Allotments and cottage gardens, intensive culture on - explanation and system, 109-112; diagrams for cropping, 112-117.

Ammonia, sulphate of, 27.

Anbury, club-root or, 426.

Aphides, 404, 406.

Aphis, bean, 417 ; cabbage, 418.

Approximate cost of fertilizing units, 38.

Applying the wash (spraying), 402.

April reminders, 371 ; general operations, French gardening, 372.

Arrangement and plan of market garden holding, 53-54.

Arsenate of lead, 403.

Artichole, globe, see Globe.

Artichoke, Jerusalem, see Jerusalem.

Asparagus, 139, 145; raising the plants, essential points in forming a plantation, 146; planting, 148; general routine, 149; cutting and bunching, 150; forcing, 151 ; manures, 153 ; varieties, 154 ; to pack for market, 386.

Asparagus beetle, 416 ; fly, 417 ; rust, 424.

Aspect of land, best, for a small holding, 43.

August reminders, general operations, French gardening, 377.

Autumn cultivation, 19.

Bacteria, soil, 16.

Barren soils, 17.

Basic slag, 30.

Basil, sweet, 212.

Bastard trenching, 11; diagram, 12.

Bcan aphis, 417; pod canker, 424; thrips, 422 ; weevils, 423.

Bcan straw for mats, 116.

Beans, broad, see Broad.

Beans, dwarf, sce Dwarf.

Beans, runner, sce Runner.

Bed, the seed, 119.
Beds, raised, with slope to south, 137; diagram, 138.

Beds, warm, for melons and cucumbers, 99 .

Beet, 59, 113, 123, 161; sowing, cultivation, manures, 162 ; varieties, 163 ; to pack for market, 387.

Beet and mangold fly, 417 ; rust, 425 .

Beetle, asparagus, 415.

Beetles, flea, 409.

Black, fly, 422 ; scab or wart disease, potato, 429; leg or stem rot, potato, 429 ; spot of tomatoes, 436 .

Blood, dried, 28.

Bone meal and steamed bone flour, 31.

Bones, dissolved, 31.

Borage, 212.

Bordeaux mixture, 402, 405.

Borecole or kale, 105 ; sowing, cultivation, manures, varieties, 164 ; to pack for market, 388.

Brassicas, transplanting, 123.

Broad beans, 57, 116, 117, 138, 154 ; sowing, succession, cultivation, 155 ; manures, varieties, 156 ; to pack for market, 386.

Broccoli, 58, 114, 117, 165 ; sowing, cultivation, heeling-in, 166 ; manures, varieties, 167 ; to pack for market, 388.

Broccoli, sprouting, 167.

Brussels sprouts, 58, 114, 116, 167 ; soil, sowing, succession, planting, 168 ; intercropping, cultivation, gathering, manures, varicties, 169 ; to pack for market, 388 .

Brushwood screen for seed bed, 122.

Business methods for a small holding, 46.

Cabbage, 24, 57, 58, 99, 113, 138, 170 ; sowing, planting, intercropping, 171 ; succession, manures, varicties, 172 ; to pack for marliet, 388 .

Cabbage aphis, 418; black rot, 425 ; butterflies and moth, 418 ; root fly and maggot, 419 ; and turnip root gall weevil, 420 .

Cabbage, red, 172; savoy, 296. 
Calcium carbonate, 14, 15, 27.

Calico and paper shields, 134 .

Canker, bean pod, 424.

Capital required for French gardening, 66 ; for small holding, 39 .

Carbon bi-sulphide, 403.

Cardoons, 173.

Carrot fly, 420.

Carrots, 58, 96, 99, 100, 104, 112, 113, $117,123,131,136,174$; forcing, 93 , $95,97,98,101,106,175$; early crops from the open, 176; main-crops, 177; lifting and storing, young roots in autumn, 178; to pack for market, 389.

Castor seed meal, 29.

Caterpillars, surface, 412.

Cauliflower, 58, 85, 95, 96, 98, 99, $100,101,106,110,112,114,115,116$, 180 ; sowing, 180 ; protection in winter, 181 ; planting, 182 ; cultivation, manures, varieties, 183 ; to pack for market, 389 .

Celery, 58, 96, 100, 101, 104, 105, 106, $113,114,184$; sowing, $184-5$; planting, 185,187 ; preparation of trenches, 186 ; general treatment, 188 ; earthing-up, 188; the broad bed system-English and French-189, 191 ; blanching on broad beds, 190 , 192 ; storing and blanching late crops-in frames 192, in cellars 194; marketing, manures, varieties, 195 ; to pack for market, 390.

Celery and parsnip fly, 421; leaf diseases, 425.

Celeriac, 100, 101, 105, 196 ; to pack for marliet, 390 .

Centipedes, 410.

Chards, 143.

Chafer beetles, 407 .

Chervil, 212.

Chicory, $100,101,105,139,197$; to pack for marliet, 390 .

Chives, 212.

Clay soils, 24 ; effect of lime on, 14, 52 ; effect of nitrate of soda on, 28 ; , drainage of, 9 .

Cloches, 68, 73, 81, 88, 101, 105, 122, 133 ; method of using, with diagrams, 75, 97; to store or repair, 75 .

Cloche carrier, 73 ; peg, 74.

Classification of soils, 6 .

Club root or anbury, 426.

Cold frames, construction of, 132 , $342-4$; uses of, $98,101,131,345$.

Cold frames covered with paper or calico, 123.
Coleworts or collards, 57, 113, 116, 198 ; to pack for market, 390.

Composition of soils, 6,16 ; plants. 22 ; farmyard manure, 25.

Compost heap, 27 ; for seed-beds and hot-beds, 84 .

Conditions necessary to success in a small holder, 39.

Co-operation, 48.

Cost of fertilizing units, 38 .

Cost of production, 438 .

Cottage gardens and allotments, in. tensive culture on, 109-117.

Crane fly, 408.

Cress, mustard and, 242.

Cropping a small holding, 53-59.

Cucumber and melon mildew, rot, 427

Cucumbers, frame, 95, 99, 101, 105 , 129, 130, 200 ; site for frames, 200 ; sowing, making hot-bed for seed, 201 ; management of young plants, 202 ; preparing the beds, 203; planting, training and general management, 204 ; manures, varieties, 206; to pack for market, 390.

Cucumbers, ridge, 58, 100, 114, 207 ; sowing, planting, protection, cultivation, 208; gathering, varictics, 209 ; to pack for marliet, 391.

Cultivation, spring, autumn, $19 ; 140$.

Cultivation, manuring, and cropping, rotations of, 50-52.

Cultivation of soils, deep, 10.

Cultivation of vegetables, details of the, 141-365.

Cultures, nitro-bacterine, 17.

Cupram, 406.

Daddy long-legs or crane fly, 408.

December reminders, general operations, French gardening, 381.

Deep cultivation, 10, 140; on clay soils, 12.

Description of French gardening, 63.

Details of construction of frames and lights, 69-71.

Devices for forcing, forwarding, and protecting, 127-139.

Diagrams of intercropping on allotments, 112-116.

Diamond-baclied moth, 409.

Dibbers, 124 ; how to use, 122.

Difficulties in the way of a perfect rotation, 51 .

Disease, celery leaf, 425 ; mushroom, 428 ; potato, 431 ; potato black scab or wart, 429 ; sclerotium, 434 ; on tomatocs, potato, 435 . 
Diseased plants, 401.

Discases, fungoid, 24, 400, 424.

Dissolved bones, 31 .

Drain, how to, 8.

Drainage, $7,19,44,65,140$; of clay soils, 8; surface furrows, for, 8, 12.

Drainage on small holding, 44.

Drain pipes, sizes of, 10 ; alternatives to, 10.

Dried blood, 28.

Dwarf or French beans, 57, 98, 100, $112,113,115,156$; early crops, 156 ; succession, sowing in open, 157 ; intercropping, gathering, seed saving, manures, 158; varieties, 159 ; to pack for market, 387 .

Early crops, French garden, 85-89.

Effect of draining, 7,8, 19; of ridging, 12.

Endive, 96, 100, 101, 105, 106, 131, 209 ; sowing, cultivation, 210 ; blanching, varieties, 211 ; to pack for market, 391.

Estimate of annual income and outlay, French garden, 108.

Essentials of successful gardening, 140.

Evaporation, effect of, on soil, 8.

Equalized Peruvian guano, 32.

Farmyard manure, its nature, analysis, comparative cost, value and use, 25,26 ; condition in which to use, 140 ; for potatoes, 282 ; fertilizing value compared with poultry dung, 443.

February reminders, general operations, 368; French gardening, 369.

Fennel, 213.

Fertilizers - nitrogenous, 27 ; phosphatic, 30 ; potassic, 31 ; miscellaneous, 32 ; mixtures which may and may not be made, 34 ; notes on using, 34 ; valuing of, 35 .

Fertilizing units, approximate cost of, 38.

Fertility of soils, 6, 7, 13, 17.

Finger and toe or anbury, 401.

Fires, smother or smoulder, 381.

Fish guano, 33.

Flea beetles, 409.

Flower pots, approximate sizes of, 439.

Fly, snowy, 412; asparagus, 417 ; cabbage root, 419 ; carrot, 420 ; celery and parsnip, 421 ; onion, 422 ; black or thunder, 422 .
Forcing, forwarding, and protecting, devices for, 127-139.

Forcing pit, cheaply constructed, 139.

Frames and lights, details of construction, 69-71.

French beans, 57, 98, 100, 112, 113, $115,156$.

French gardening, 63, 108; general description of, 63 ; capital required for, 66 ; profits to be expected, 67 ; frames and lights, 69; cloche, cloche-carrier, 73; cloche-peg, 74; to repair and store cloches, to use cloches, 75 ; mats, frame for straw mats, 76; how to make mats, 77 ; water, 78 ; preparation of soil, 81-82; manure, 82-83; preparing plants, 85 ; protecting plants, 89 ; intercropping, 90 ; hot-beds for frames, with diagram, 93 ; sowing and planting frames, 93 ; routine work, 94 ; alternative methods, 95 ; hot-beds for cloches, with diagram, 96 ; cold beds or cold frames, 98 ; warm beds for melons and cucumbers, 99 ; various other methods of forcing and forwarding; open-air crops, 100.

French garden of quarter-acre, 101 ; arrangement and equipment, 102 ; illustration of tools, 103; prices obtained for produce, 104 ; details of cropping and sales from the various beds, 105-107; summary of estimated expenditure for equipment, with annual outlay and receipts, 108 .

Frost-proof bed, 136.

Fungicides, 405.

Fungoid diseases, 24, 400, 424 .

Furrows, cross or water, 8, 12.

Gas-lime, 15 ; for wire-worm, 414.

Gardening, essentials of successful, 140.

Garden seeds, germination of, longevity of 439 .

Glass-covered protectors, 136-7.

Globe articholke, 141; to pack for market, 386.

Grading, packing, and marketing, 382.

Green manuring, 27.

Growing for market, 46 ; for direct supply, 47.

Guano-Peruvian, equalized Peruvian, 32 ; dissolved Peruvian, fish, phosphatic, meat, 33. 
Hall on "soil moisture," 18.

Hellebore powder, 403.

Herbs, 212; to pack for market, 392.

Hocing and mulching, 20, 140.

Horse radish, 215 ; to pack for market, 392.

Hot-beds for frames, 91 ; for cloches, 96 ; to make, 128 ; to manage, 130.

How to drain, 8.

Humus, 16, 25, 27, 140.

Insect pests, 406 .

Insect pests and fungoid diseases which attack vegetables, 400 .

Insecticides, 403.

Introduction, 1.

Intensive cropping for three years, plan of rotation and, 60 .

Intensive culture on small holdings, 41,56 ; on allotments and cottage gardens, 109 ; see also French gardening.

Intercropping, 90.

Illustrations, diagrams, and plans, list of, 451-2.

January reminders, general operations, 367; French gardening, 368. Jerusalem artichokes, 144 .

July reminders, general operations, French gardening, 376.

June reminders, 374 ; general operations, French gardening, 375.

Kainit, 25, 32.

Kale, 58,163 ; to pack for market, 388.

Kropotkin on "French gardening," 63 ; on "friendly intercourse," 117. King on "soil moisture," 18.

Lath screen for seed-bed, 121.

Laying-out, cultivating, and intensively cropping a market garden holding, 53.

Lead, arsenate of, 403.

Leaf-curl, potato, 432.

Leaf-spot, strawberry, 435.

Lecks, 216; manures, varieties, 217 ; to pack for market, 392 .

Leguminous plants, 24.

Lettuce, cabbage, 58, 85, 87, 95, 96, $99,100,101,104,105,106,112,113$, $114,115,116,117,131,138,218$; forced, 219 ; cold frames, sowing, 220 ; pricking out, protecting, 221 ; early from open-air, main-crop and summer, 222 ; manures, 223 ; varieties, 224 ; to pack for market, 392.
Lettuce, cos, 87, 97, 99, 101, 104, 106, $114,115,116,218$; forced, 219; frames, sowing, 220 ; pricking out, protecting, 221; early from the open, main-crop, and summer, 222 ; manures, 223 ; varieties, 224 ; to pack for market, 392.

Lettuce mildew, 88, 427.

Lime, its effect on clay, quantities to apply, 14; its functions and effects, 25 ; for acid or " manure-sick" soils, 16, 26 ; periodical dressings, 51 ; a base for fertilizers, 27, 30, 52 ; to test soils for, 52 ; in rotation, 54 ; general effect of, 140 ; for pests and diseases, 404.

Liming, cultivation, manuring, and, rotation of, 50 .

Limphos, 30.

Liquid manures, when to use, 35.

List of illustrations, diagrams, and plans, 451-2.

Longevity of garden seeds, 439 .

Long measure, 443.

Machines, spraying, 402.

Magnesia, 25.

Management of hot-beds, 130.

Manure, its general application, 140 ; for French gardening, 79, 82; for hot-beds, 91, 128.

Manures and fertilizers, 22-38; farmyard, 25 ; green manuring, compost heap, sulphate of ammonia, 27 ; nitrate of soda, nitrolim, dried blood, 28; rape dust, castor seed meal, soot, shoddy, 29 ; superphosphates, limphos, basic slag, 30 ; bone meal, steamed bone flour, dissolved bones, sulphate of potash, muriate of potash, 31 ; kainit, Peruvian guano, equalized Peruvian guano, 32; dissolved Peruvian guano, phosphatic guano, fish guano, meat guano, 33 ; mixtures which may and may not be made, notes on using fertilizers, 34 ; valuing fertilizers, 35; unit values of fertilizers, 38 .

Manuring, cultivation, and cropping, rotations of, 50 .

Manure-sick soid, 26.

Manures for-globe artichokes 143 Jerusalem artichokes, 144 ; asparagus, 153; broad beans, 156; French beans, 158; runner beans, 161 ; beet, 162 ; kale, 164 ; broccoli, 167 ; Brussels sprouts, 169; cabbage 
172 ; carrots, 179 ; cauliflowers, 183 ; celcry, 195 ; cucumbers, 206 ; leeks, 217; lettuces, 223; mushrooms, 232 ; onions, 251 ; peas, 264 ; potatoes, 281 ; rhubarb, 293 ; savoy cabbage, 297 ; seakale, 308 ; spinach, 314 ; strawberries, 335 ; tomatoes, 355 ; turnips, 361.

March reminders, 369 ; general operations, 370; French gardening, 371.

Market gardener, the small holder as a, 39.

Market garden holding, arrangement and plan, 53.

Market, growing for, 46.

Marketing, grading, packing, and 382-399.

Marketing produce, receptacles, weights, measures, and terms used in, 441 .

Materials for spraying, 403.

Mat, straw 76 ; frame, 76 ; making, 77.

May reminders, general operations, 373 ; French gardening, 374.

Measure, surface, long, dry, 443.

Meat guano, 33.

Melons, cantaloup or rock, 224 ; sowing, management of plants, preparing beds, planting, 225 ; general management, 226 ; gathering, 228 ; varieties, 229 ; to pack for market, 393.

Melons and cucumbers, warm beds for, 99.

Mildew-lettuce, 88, 427; cucumber and melon, 427 ; pea, 428 ; onion, 429 ; strawberry, 435.

Millipedes and centipedes, 410.

Mint, to propagate, 229 ; forcing and forwarding, 230 ; to pack for market, 394.

Mint rust, 427.

Mixtures of fertilizers which may and may not be made, 34 .

Moisture, soil, see Soil moisture.

Monthly reminders, 368-381.

Moth, diamond-back, 409; cabbage, 418.

Mulching, hoeing and, 20, 140.

Muriate of potash, 31 .

Mushrooms, 230; manure, 232; spawn, 232; soil for casing, 233 ; preparation of the manure, 234 ; ridge beds, 234 ; flat beds, spawning, 236 ; casing or soiling, covering the bed, 237; heat of the bed, 238; watering, beds in odd places, 239 ; gathering, 241 ; cleanliness, 242 ; to pack for market, 394 .

Mushroom pest, 421 ; disease, 428 .

Mustard and cress, 242 ; to pack for market, 394.

Necessity for good seed, the, 118 .

New Zealand spinach, 315 .

Nicotine, 404.

Nitrate of soda, 28.

Nitro-bacterine cultures, 17.

Nitrogen, its functions and effects, 23.

Nitrogenous fertilizers, 27.

Nitrolim, 28.

Notes on using fertilizers, 34 ; on valuing fertilizers, 35 .

November reminders, general operations, French gardening, 380 .

Number of plants to an acre, at given distances apart, 440.

October reminders, general operations, French gardening, 379.

Onion fly, 422; mildew, 429.

Onions, $25,58,113,116,123,244$; preparation of soil for, spring-sown, 245 ; harvesting, 246; autumnsown, 247; large, 248; spring or green, pickling, potato, 250 ; manures, 251 ; varieties, 252 ; to pack for market, 394.

Open-air crops, French garden, 100.

Origin of soils, 5 .

Packing and marketing, grading, 382.

Paper shields, calico and, 134.

Paraffin emulsion, 404.

Parsley, 58, 90, 114, 131, 252 ; to pack for market, 395.

Parsnip fly, 421.

Parsnips, 59, 113, 254 ; to pack for market, 395.

Pea and bean thrips, 422 ; weevils, 423.

Pea mildew, 428.

Peas, 24, 58, 99, 114, 115, 116, 136, 256 ; soil for, preparation of soil for, 257 ; sowing in pots, 258; sowing in the open-air, 259 ; intercropping, succession, 260 ; mice and sparrows attacking, 261 ; sticking, 262 ; gencral culture of, watering and mulching, gathering, 263; manures, 264 ; varicties, 265 ; to pack for marlet, 395.

Peruvian guano, equalized, 32 ; dissolved, 33. 
Pests and diseases, lime for, 404.

Pests, insect, 400 ; mushroom, 421.

Phosphatic fertilizers, 33.

Phosphatic guano, 33.

Phosphoric acid, its functions and effects, 24.

Physique and character of smallholder, 40.

Pipe drains, see Drainage.

Pit, cheaply constructed forcing, 159.

Plan of French garden, with scheme of cropping, 101.

Plan of small holding for vegetable and fruit growing, 54 .

Plans of rotation and intensive cropping for three years, 60-62.

Plans, list of illustrations, diagrams, and, 452.

Plant foods in soil, 22.

Planting, sowing and, French garden, 93.

Plants, composition of, 22 ; leguminous, 24 ; structure of, 24 ; preparing, for French garden, 85 ; protecting, 89; diseased, 401.

Plants to an acre, number of, 440.

Potash, its functions and effects, 24; its abundance and deficiency in various soils, 24-25.

Potash, muriate of, sulphate of, 31 .

Potassic fertilizers, 31 .

Potato, black scab or wart disease, black leg or stem rot, 429 ; disease or blight, 431 ; leaf curl, 432 ; scab, 433 ; winter rot, 434 ; disease on tomatoes, 435.

Potatoes, 24, 57, 58, 99, 113, 115, 116, $131,265,401$; soil and situation for, preparation of soil for, 266 ; "seed" and its preparation, 267; boxing and sprouting, 269-71; distances apart and depth for planting, 271 ; planting and general culture, 272276 ; early, in the garden, 276; forcing in frames, 277 ; spraying, 278; lifting and storing, 279; manures, 281 ; varieties, 283 ; to pack for market, 396.

Poultry dung and farmyard manure, comparative fertilizing values of, 443.

Pricking-out, 125.

Private trade, growing for, 47-9.

Production, cost of, 438.

Profits expected from Fręnch gardening, 67, 108.

Protecting, devices for forcing, forwarding and, 127-139.
Protectors, glass-covered, 136 ; box, 137.

Preservation of soil moisture, 20, 21, $111,140$.

Quantity of seed to sow, 437.

Radishes, 58, 93, 96, 99, 101, 104, 106, $113,114,115,116,131,136,138,283$; crops from hot-beds, 284 ; early crops from the open, 285 ; successional sowings, varieties, 286 ; to pack for market, 397.

Raised beds, see Beds.

Rape dust, 29.

Receptacles, weights, measures, and terms used in marlieting, 441.

Red cabbage, 172.

Red spiders, 411.

Reminders, monthly, 367-381.

Returns from French gardening, estimated, 107.

Returns per acre of vegetable crops, gross, 438.

Rhubarb, 101, 105, 112, 139, 287 ; preparation of soil for, 287 ; propagation of, 288 ; planting of, routine of cultivation for, 289 ; gathering, 290 ; forcing, 291 ; manures, 293 ; varieties, 294 ; to pack for marliet, 397. Ridge cucumbers, 207.

Ridging soil, 12.

Rot, cabbage black, 425 ; cucumber and melon, 427 ; potato winter, 434 ; violet root, 436 .

Rotation and intensive cropping for three years, plan of, 60-62.

Rotations of cultivation, manuring, and cropping, 50.

Rotations, reasons for, 50.

Routine work, French garden, 94.

Runner beans, 58, 113, 159 ; to pack for market, 387.

Rust, asparagus, 424 ; beet, 425 ; mint, 427.

Sage, 213.

Salads, 129.

Salsify, 294 ; to pack for marliet, 397.

Savory, summer, winter, 213.

Savoy cabbage, 296 ; manures, varieties, 297 ; to pack for market, 397.

Scab, potato, 433.

Sclerotium disease, 434 .

Scorzonera, 296 ; to pack for marlict, 397.

Screen for seeds, lath, 121 ; brushwood, 122. 
Seakale, 100, 101, 105, 112, 139, 298 ; preparation of soil for, 298 ; propagation by seed, 299 ; propagation by thongs, forming a plantation, 300 ; forcing under cover, 302 ; forcing on hot-beds and in pits, 303 ; other methods of forcing in the open, 306 ; "'natural" seakale, 307 ; manures, varieties, 308 ; to pack for market, 397.

Seed bed, the, and its preparation, 119 ; brushwood screen for, 122.

Seeds, necessity for good, 118, 140 ; varieties to choose, 118 ; testing, 119 ; sowing, 120,140 ; quantity of, required, 437; average longevity of, 439 ; average time for, to germinate, 439.

Selection of a small holding, 42-45.

September reminders, general operations, French gardening, 378.

Shallots, $57,114,116,308$; to pack for market, 398.

Shoddy or wool refuse, 29.

Situation of a small holding, 42 .

Sizes of flower pots, 439.

Slugs and snails, 411.

Small-holder, the, as a market gardener, 39 ; constitution, physique, character, 40.

Small holdings, conditions necessary to success on, capital required for, 39 ; intensive culture on, spade work on, 41 ; situation of, 42 ; aspect of, 43 ; soil of, drainage of, water for, 44 ; manure for, tenure of, 45; method of business for, 46 ; rotations of cultivation, manuring, and liming for, 50 ; laying-out, cultivating, and cropping a, 53; plan of, 54 ; rotation of crops for, 55 ; plans of rotation and cropping of $a$, $60,61,62$.

Smother or smoulder fires, 381 .

Snowy fly, 412 .

Soda, nitrate of, 28.

Soil bacteria, 16, 23.

Soil, for small holdings, 44; for French garden, 81 ; for seed beds and hot beds, 83, 120 .

Soil moisture, 17 ; extracts relating to, from Hall and King, 18; to secure, 19; to conserve, 20, 21 , $111,121,140$.

Soils-origin of, 5 ; composition of, 6 , 16 ; well-balanced, aeration of, 7 ; fertility of, $6,7,13,17$; texture of, 13,14 ; barren, 17 ; chemical effect of lime on, 25 ; acid, 26, 401 ; warm, 110 ; richness of, 111.

Soot, 29.

Sowing, 120, 140; and planting, 93.

Spade work on small holdings, 41.

Specialization, advantages of, 45 .

Spinach, 57, 58, 99, 100, 113, 116, 131,

310 ; summer, 311 ; winter, 312 ; general culture, 313 ; manures, varieties, 314 ; to pack for market, 398 .

Spinach beet, 316 .

Spinach, New Zealand, 315.

Spraying machines, 402.

Spraying, materials for, 403 .

Spring cultivation, 19.

Sprouting broccoli, 167.

Sprouts, Brussels, see Brussels.

Steamed bone flour, 31 .

Stem-rot, potato black-leg or, 429 .

Straw, bean, 116; mats, 76, 135 ; manure, 21, 83.

Strawberries, 99, 131, 139, 317 ; locafor growing, 318 ; soil and its preparation for, 319 ; runners from, 320 ; general culture of, 321 ; plants of, 322 ; summer planting of, 324 ; autumn planting of, 325 ; spring planting of, 326 ; in beds, 327 ; the forcing of, 329 ; layering, 330 ; potting, 332 ; varieties, 334 ; manures, 335 ; to pack for market, 398.

Strawberry leaf spot, mildew, 435.

Structure of plants, 24.

Subsoil, 7.

Successful gardening, essentials of, 140.

Sulphate of ammomia, 27 ; of copper, 406 ; of potash, 31.

Sulphide of potassium, 406 .

Sulphur, 406.

Sunk hot-bed, 131.

Sunshine and air, 140 .

Superphosphates, 30 .

Surface caterpillars, 412 .

Surface furrows for drainage, 8, 12.

Surface measure, 443.

Table of unit values, 38 .

Tarragon, 214.

Testing soils for lime, 52; seeds germination, 118.

Texture of soil, 13, 14, 26, 29.

The soil and its treatment, 5-12.

The small-holder as a market gardener, 39-41; the business to be carried on, 46-49.

The laying-out, cultivating, and cropping of a holding, 53-62. 
Thinning-out, 122, 140.

Thrips, pea and bean, 422 .

Thunder fly, black fly or, 422 .

Thyme, common, lemon, 214 .

Tomatoes, $25,58,98,100,101,104$, $105,106,116,130,336,401$; soil for and its preparation, 338; raising the plants, 340 ; planting out, 345 ; supporting the plants, 346 ; training and culture of, 347; tying, stopping, 348 ; thinning the foliage of, -349 ; spraying of, gathering the fruit, 350 ; extra early from the open, varieties, 352 ; manures, 355 ; to pack for market, 398.

Tomatoes, black spot on, 436 ; potato disease on, 435 .

Tools, French garden, illustrated, 80.

Transplanting, 123, 140.

Trenching, bastard, 11.

Turnip root gall weevil, 420 .

Turnips, 58, 96, 99, 100, 101, 104, 106, $115,131,136,357$; soil for, 357 ; early crops, 358 ; general culture, 359 ; storing, manures, 361 ; varieties, 362 ; packing for market, 399.

Unit values, table of, 38.

Valuing fertilizers, 35.

Vegetable marrows, 58, 98, 100, 136, 138,362 ; preparation of soil for, sowing in the open, 363 ; plants and planting, 364 ; varieties, 365 ; packing for marliet, 399 .

Vegetables, details of the cultivation of, 141.

Violet root rot, 436 .

Warm bed for cucumbers and melons, 99.

Wart disease, potato black scab or, 429.

Wash for spraying, to apply, 402.

Water furrows, 8, 12.

Watering, 65, 111.

Water-logged soils, 44 .

Water, necessity for abundant supply, 44; copious use on French garden, 65, 66, 102 ; arrangement of pipes on French garden, 78.

Weather, 103 ; signs, 443.

Weeds, 401.

Weevil, cabbage and turnip root gall, 420 ; pea and bean, 423.

Well-balanced soils, 7 .

Weights, measures, and terms used in marketing produce, 441 .

Weight, avoirdupois, 443.

Winter rot, potato, 434 .

Wireworm, 29, 82, 413.

Woodlice, 415.

Wool refuse, shoddy or, 29.

Yield, cost of production, and returns, 438.

\section{LIST OF ILLUSTRATIONS, DIAGRAMS,}

\section{AND PLANS.}

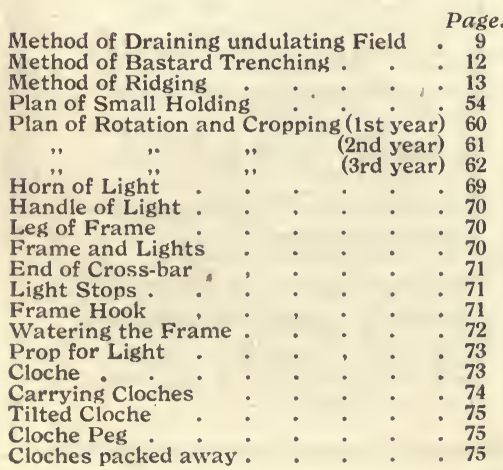

Page.

Repaired Cloche . 75

Arrangement of Cloches in relation to

Frame .75

Frame for Mat-making : . . . 77

Arrangement of Water Pipes-French

Garden
Arrangement of Soil for Hot-beds : $\quad: 99$

Diagram shewing Manure Linings to

Frames on Hot-beds . 94

Diagram explaining working of Cloches 97

Plan of Model French Garden (1 acre) . 101

French Garden Tools . . 103

Diagrams showing Intercropping 112 to 116

Sowing Seed by Hand . . . .120

Lath Screen . . . . . . 121

Brushwood Screen , . $\quad .122$

Tilted Cloche : $: 122$

How Leaves and Roots are Shortened

in Transplanting . . . . . 124

Samples of Dibbers . . . . . . 124

Cloches packed away: $: \quad \vdots \quad: \quad 7^{*}$ How the Dibber is Used $: \quad: \quad: \quad 125$ 
List of Illustrations, \&c. (continued).

Hot-bed on Top of Ground
Hot-bed Sunk in Ground
Arrangement of Cold Frames
The Cloche
Cloche made from Wire and Paper:
Calico Screen laid over Willow Wands
Movable Shield, covered with Calico or
Mlats.

Glass-covered Plant Protector : : 136

Box Plant Protector . : : : 137

Glass-covered Trench ${ }^{\circ} .137$

Raised Beds, with slope facing south 138

The same converted into Warm Beds' 138

Diagram of Planting Raised Beds . 138

Roughly-made Forcing Pit . . 139

Globe Artichole . . . 141

A Good Sample of Globe Artichoke : $\quad .142$

Jerusalem Artichoke . . . . 144

Bundle of Giant Asparagus . $\quad . \quad 145$

Asparagus Knife : : $\quad .150$

Cradle for Bunching Asparagus . $\quad 151$

Seville Long-pod Bean . : . 155

Dwarf French Bean . $\quad 157$

Scarlet Runner Bean . . . . 160

Dell's Dark Crimson Dwarf Beet : 162

Intermediate Moss-curled Kale : . 163

Sutton's A 1 Kale . . . . . 164

Sutton's Snow-white Broccoli . : : 165

Brussels Sprouts . . . 168

Sutton's Flower of Spring Cabbage $\quad .170$

Early Etampes Cabbage . . . . 171

Ivory-white Cardoon . . . . . 173

Parisian Forcing Carrot . . . . 175

Dutch Horn Carrot : $\quad .176$

James's Scarlet Intermediate Carrot . 177

Sutton's Magnum Bonum Cauliflower : 180

Early Dwarf Erfurt . . : 181

Golden Yellow Large Solid Celery : 184

Celery after the Second Earthing : : 188

Celery Finally Earthed-up : : 189

American Method of Tying Celery : : 189

Celery planted in Broad Beds . $\quad 190$

Method of Earthing Celery on Broad Bed 191

Celery Stored in Frame . . 192

Method of Blanching Celery with Mats 193

Market Bundle of Celery . $\quad 195$

$\begin{array}{ll}\text { Celeriac, or Turnip-rooted Celery } & . \\ \text { Chicory (Whitloef) } & 196\end{array}$

Diagram showing intercropping of $\mathrm{Cab}$ -

bage and Colewort

Rollinson's Telegraph Cucumber : $\quad: 200$

Sutton's Every-day Cucumber 201

Diagram showing Method of Making

Cucumber or Melon Bed

Green Giant Ridge Cucumber : $\quad: \quad$\begin{tabular}{l}
204 \\
\hline
\end{tabular}

Green Curled Paris Endive : : : 209

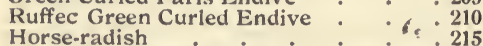

Horse-radish . . . 215

Hammersmith, or Hardy Green Winter Cabbage Lettuce

Sutton's Heartwell Cabbage Lettuce 218

Sutton's Whiteheart Cos Lettuce . : 220

Large Rock Prescott Canteloup Melon : 225

Melons in the open-air, mid July : : 227

Mushrooms : $: 231$

Ridge-shaped Mushroom Bed
Movable Mushroom Bed on Flat Board

Movable Mlushroom Bed against a Wall. 240

$\begin{array}{ll}\text { Mlustard and Cress, in Punnets } & .243 \\ \text { Giant Zittau Onion } & :\end{array}$

Double-curled Dwarf Parsley : $\quad .253$
Hollow-crowned Parsnip Page.

Gradus Pea : $\quad: \quad: \quad 256$

Gladstone Pea . . . . 257

Potatoes, Sprouting in Tray : $\quad . \quad 270$

Potato Trays, stacked . . . . 271

Seed Potatoes, sprouted . . . . 271

Section of Potato Clamp . . . . . 280

French Breakfast Radish : $\quad .284$

$\begin{array}{ll}\text { Scarlet White-tipped Turnip Radish } & .284 \\ \text { Forced Rhubarb } & .287\end{array}$

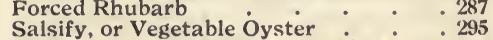

Sutton's Best of All Savoy Cabbage $\quad .296$

Seakale, blanched . . 298

Diagram showing method of intercrop-

ping with Seakale $. \quad . \quad .301$

Forcing Pit for Seakale, partly made . 305

The same, showing part of crop . .305

True Shallot . . . . . 309

Jersey or False Shallot : . $\quad 309$

Lettuce-leaved Spinach : $: \quad . \quad 311$

Viroflay Giant Spinach . . . . 312

Large Prickly or Winter Spinach . . 313

New Zealand Spinach : . . 315

Spinach Beet . . . . . . 316

Royal Sovereign Strawberry : . $\quad 317$

Strawberry Runner . . . . 320

Right and Wrong Way to Plant Straw-

berries . . . 325

Two Methods of Layering Strawberries 330

Proper Method of Re-potting Straw-

berries, from small to large pots . 332

The Tomato $\quad 336$

Cold Frames in which Tomato plants

for the open-air are grown during May 343

Typical bunch of Carter's Sunrise

Tomato . . . . 353

Sunrise Tomato, grown against a fence 354

Sutton's Early Snowball Turnip . . $\quad 357$

Half-long White Forcing Turnip . $\quad .358$

Half-long White Jersey Navet : : $\quad$. 359

Early Six-weeks, or Jersey Lily Turnip 360

White Trailing Mlarrow . . . 363

Long White Bush Marrow . . 364

Cabbage Aphis . . . . 407

The Large Cockchafer . . 408

Daddy Long-legs or Crane Fly : . 408

Diamond-back Moth . . . . . 409

Turnip Flea.Beetle : : . . 409

Millipedes and Centipedes : . 410

Slugs and Snails . . 411

Surface Caterpillars , . . . 413

Skip-jack Beetles and Wireworm : . 413

Asparagus attacked by the Beetle . . 416

Bean Aphis or Black Dolphin . . . 417

Large White Cabbage Butterfly : . 418

Carrot Fly and Mlaggot .420

Celery and Parsnip Fly and Maggot . 421

Onion Fly and Maggot . . . . 422

Pea and Bean Thrips . . . . 423

Pea and Bean Weevils . . . . 423

Asparagus affected by Rust : : : : 424

Bean Pods, showing Canker . . 425

Turnip attacked by Finger-and-Toe . 426

Diseased Nlushrooms . . . . 428

Onion attacked by Nildew $\quad . \quad 429$

Potatoes affected with Black Scab or

Wart Disease. . 430

Diseased Leaf and Tuber of Potatoes 431

Potato Leaf Curl . . . 432

Potato Tubers infected with Scab : $\quad .433$

Potato Tuber attacked by Winter Rot .434

Sclerotium Disease . . . 434 


\section{SEGURE PROFITABLE GROPS by using the COOPER SPEGIALTIES}

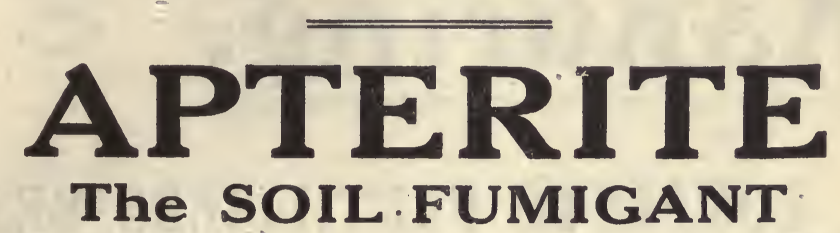

FOR THE ERADICATION OF SOIL PESTS.

A valuable preparation, which, when incorporated with the soil, destroys larvae of all kinds, including

\section{WIREWORMS}

and other pests which attack Vegetables. Useful also for the destruction of Slugs, Ants, \&c.

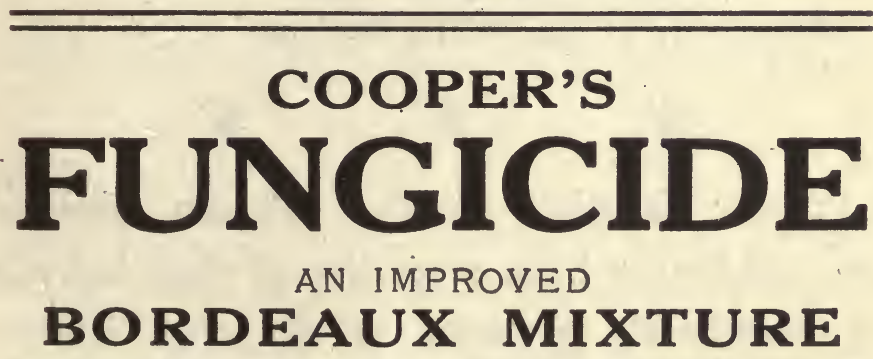

Invaluable for the treatment of POTATO DISEASE, and other fungoid troubles.

An immense improvement on older preparations, and superior to home-made mixtures.

\section{SPRAYS WELL STIGKS WELL}

\section{OF AGENTS EVERY WHERE}

Sole Mfrs., Willm. COOPER \& NEPHEWS, Berkhamsted. 


\section{Profitable}

Manuring.

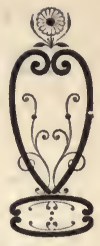

\section{COMPLETE FERTILISERS BEST.}

"Of the elements of fertility, ammonia or nitrogen,

" potash, phosphates, and lime are necessary always.

"Mixtures in which these four elements are blended

" to suit different crops are the best Manures for

"the garden, as they are for the farm." - -

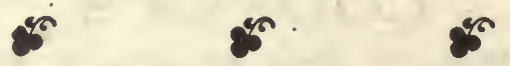

Our Premier Fertiliser contains nitrogen, phosphates, potash, and lime, a large proportion of these ingredients being immediately available to the crop, while the remainder comes into use as required : a healthy growth is thereby maintained from start to finish. $1 \mathrm{cwt}$. bag 10s. 6d., $56 \mathrm{lb}$. bag $7 \mathrm{~s}$., rail paid. Send postal order

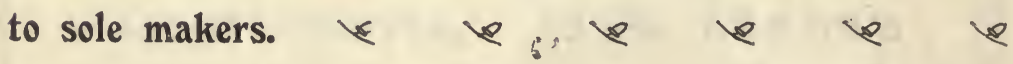

\section{NORTHERN GUANO CO.,}

Brook Street, BRADFORD. 


\section{Four Good Things for Fruit Growers and Market Gardeners.}

\section{"THE FRUIT, FLOWER \& VEGETABLE TRADES JOURNAL."}

Full of Interesting and Instructive Reading for Commercial Horticulturists. Expert cuitural advice free to Subscribers.

Id. Weekly. Through all Newsagents.

Or will be posted direct for twelve months on receipt of $\mathbf{6 / 6}$.

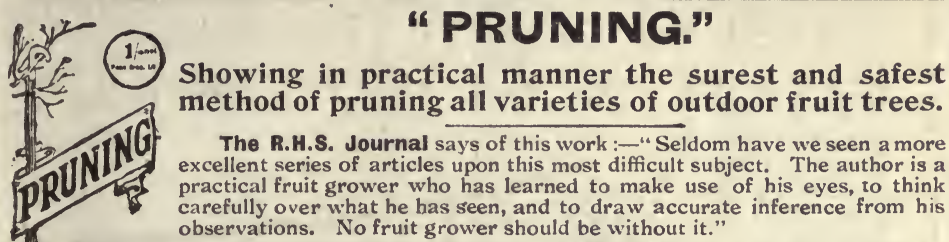
observations. No fruit grower should be without it."

\section{"THE SCIENCE AND PRACTICE OF MANURING."}

\section{Is. Post Free, Is. Id.}

IN 12 CHAPTERS:-Origin and History of Manures. Plants and their Food. Intluence of Manures on Crops. Soils and their Influence on Manuring. Facts to Guicie Cultivators. General Manures. Concentrated Fertilizers, Concentrated Fertilizers (con. tinued). Fertilizers for Vegetables. Fertilizers for Fruit. Fertilizers for Flowers. Points to Remember when Manuring.

The Guernsey Press says of this work:- "Every chapter seems to embody something that is new, or old facts presented with new dress and a better style and a more practical applicability than in other similar works."

The Jersey Evening Post says:- "This is an extraordinary silling's worth, and is the work of a commercial horticulturist, the result of actual experience. Mr. Dyke deals in admirable detail with facts for the guidance of cultivators in, respect to general and concentrated fertilizers. A careful study of Mr. Dyke's experiences will repay any grower, and the price is a mere bagatelle. As a matter of fact it is a half-guinea book obtainable for 1s."

The Field says of this work:- "The Science and Practice of Mlanuring" is the title of a useful little manual by Mr. W. Dyke, F.R.H.S., published by the Lockwood Press at Is. Mr. Dyke discusses the broad question in systematic fashion, explaining in the first place the peculiar character of the different manures, and in the second the requirements of the various crops, with suggested suitable mixture."

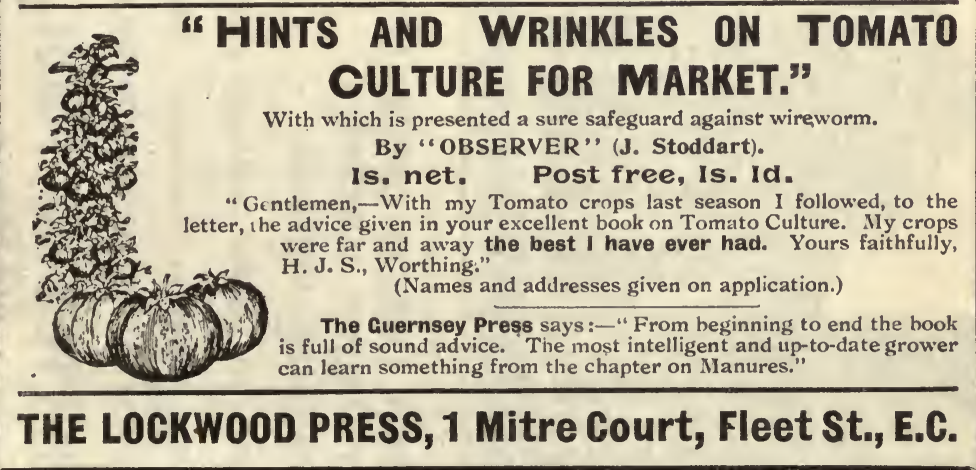




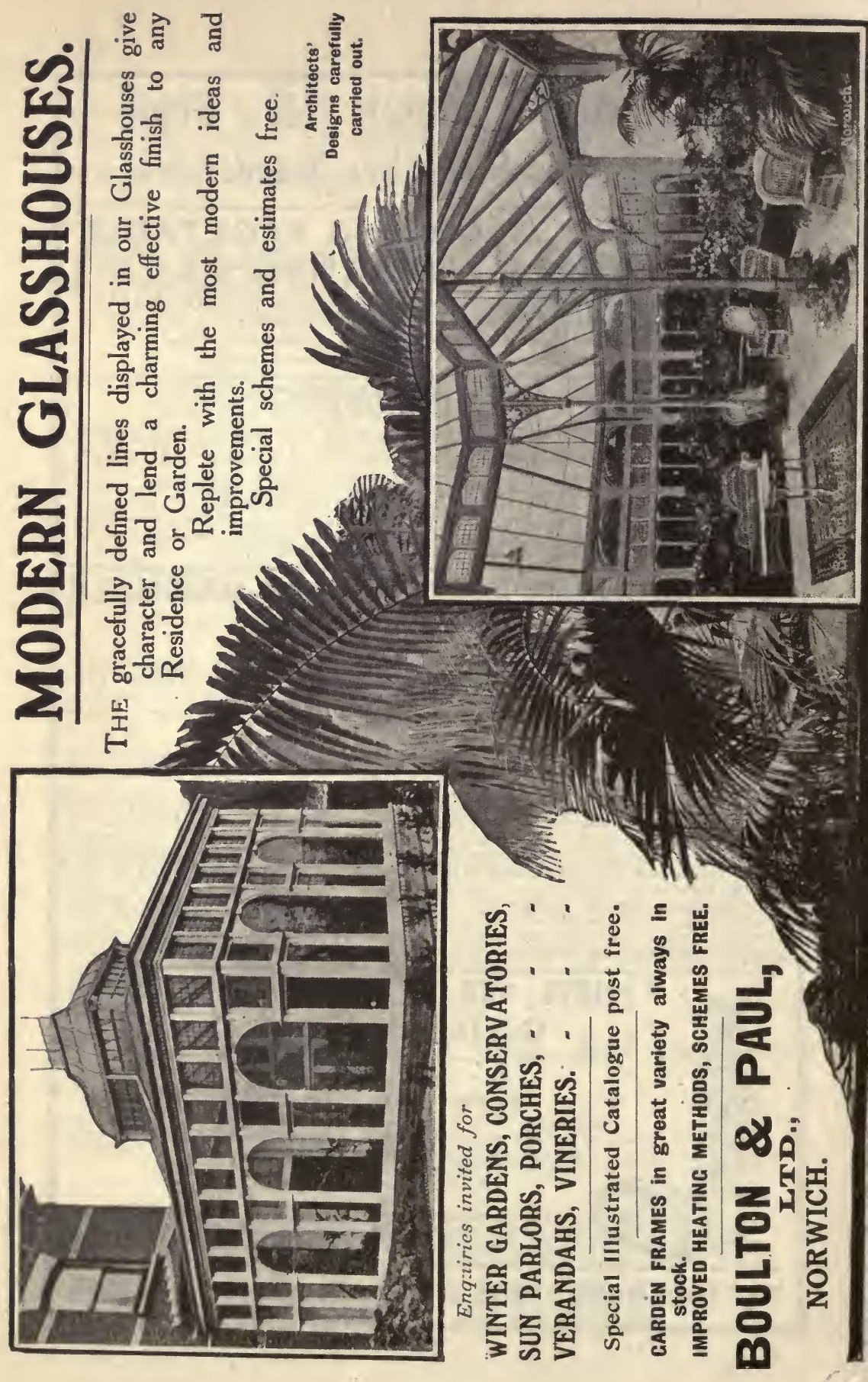




\section{A. MAURY,}

\section{Quineaillerie et Taillanderie.}

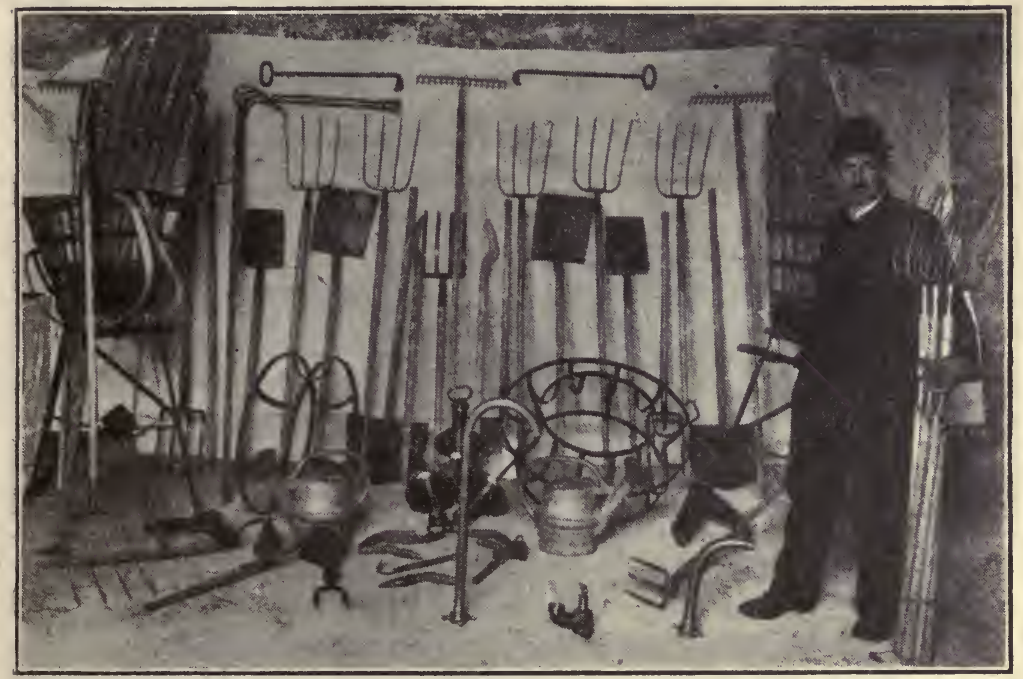

BEST QUALITY. MODERATE PRICES.

First-Class Tools for French Gardens.

Any inquiry in English sent to above address will be answered in English by return of post.

5 Rue de la Recette, CRETEIL '(Seine), FRANCE. 


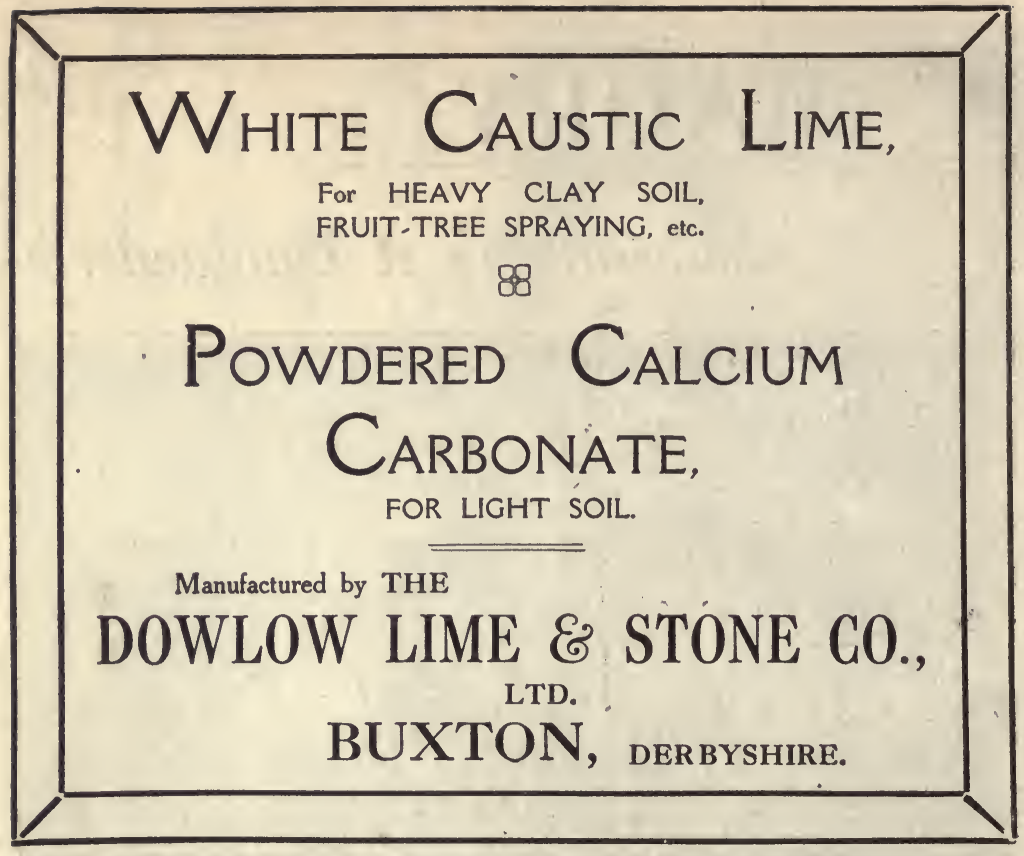

RELIABLE GARDEN HELPS

That will enable you to get the best results from your garden. We can confidently recommend the undermentioned articles ; they are the outcome of years of careful experiments by practical Horticulturists, and annually give satisfaction to thousands of users. Send for our Catalogue and Booklets.

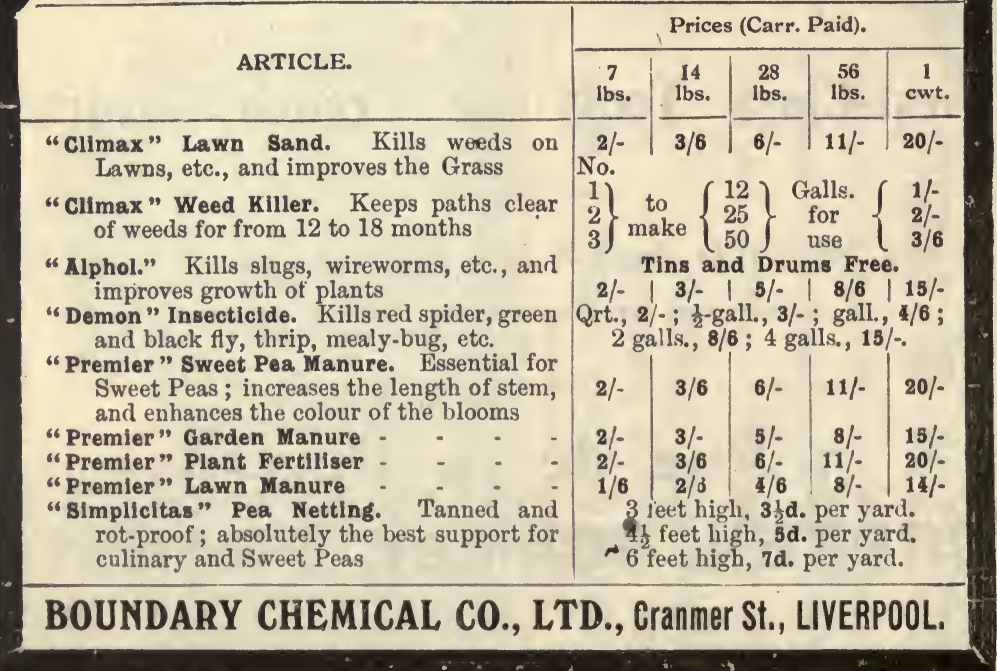




\section{CHAS. TOOPE (F.R.H.S.) \& SON,}

Heating Engineers and Experts,

7a Stepney Square, High Street, Stepney, LONDON, E.

'Phone-E 3497

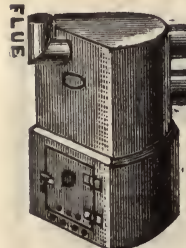

Telegrams- “ TOOPES, LONDON"

a.m

Send for Free Catalogue, and give rough sketch of House or Frame, for Estimate.

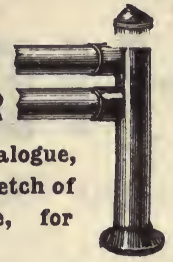

Patentees and Manufacturers of all kinds of Heating Apparatus for Greenhouses, Hothouses, Conservatories. Garden Frames, etc.

\section{Propagators for Growing Seeds and Outtings.}

HEATERS for oil, or Coal, to suit all sizes of Frames or any number of ranges of Frames.

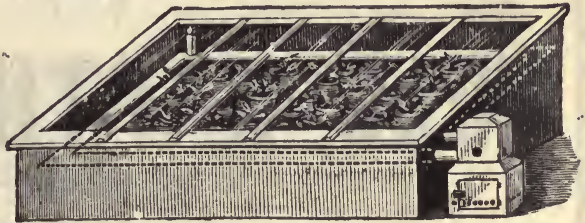

Toope's NEW CULT HEATER, for French Intensive Culture, to replace Manure. Will last for years.

Syringes, Sprayers, Fumigators, Hose, etc. Superior Goods, Moderate Prices, and Prompt Delivery.

Telegrams : "BARR, LONDON".

Telephone: 2991 CENTRAL.

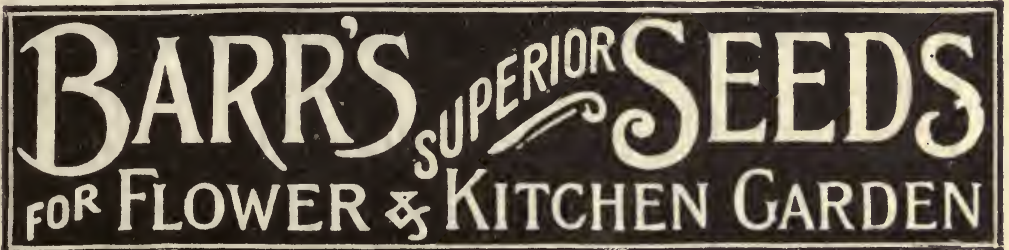

TWO GOLD MEDALS AWARDED

By the National Vegetable Society, I9I0 and I9II.

BARR'S SEED GUIDE contains a Select List of the Best Vegetables and the most beautiful Flowers for Garden and Greenhouse. It is full of practical hints, and will be found invaluable to Gardeners, Amateurs, and Exhibitors. Sent on application.

BARR'S COLLECTIONS OF BEST VEGETABLE SEEDS Contain a liberal selection of Vegetable Seeds for One Year's Supply.

$5 / 6,7 / 6$ and $I 2 / 6,2 I /=, 42 /=, 63 /=$ and $I 05 /=$. Full particulars on application.

BARR'S COLLECTIONS OF CHOICE FLOWER SEEDS The most Useful and Decorative Annuals Perennials, etc.

$2 / 6,5 / 6,10 / 6$ and $21 /=$. Full particulars on application.

BARR' a HARDY PLANT CATALOGUE contains a Descriptive List of the best Hardy Perennials and Alpines, with many useful hints on Culture. Free on application.

BARR'S AUTUMN BULB CATALOGUE for the best Daffodils, Hyacinths, Tulips, Lilies, etc. Free on applic..tion.

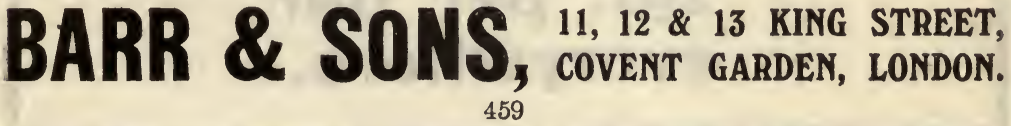


FOR THE SURE AND ECONOMICAL DESTRUCTION OF
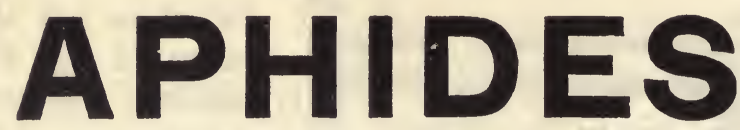

(Green Fly or Plant Lice),

AND OTHER SMALL SOFT-BODIED INSECTS.

USE

\section{FELS-NAPTHA SOAP}

Use 2 to 4 ozs. of soap to 3 gallons of water, according to the severity of the attack. First cut up the soap into thin flakes, and pour over sufficient warm water to cover. When the soap is dissolved pour into the full quantity of warm water and stir well. Syringe or spray the affected plants thoroughly and with force. One application is usually effective, but in a very bad attack repeat on the following day. Twenty-four hours after using the soap, spray vigorously with clean water.

\section{$2 \frac{1}{2}$ d. per bar everywhere.}





\section{FOURTEEN DAY USE}

RETURN TO DESK FROM WHICH BORROWED

This book is due on the last date stamped below, or on the date to which renewed.

Renewed books are subject to immediate recall.

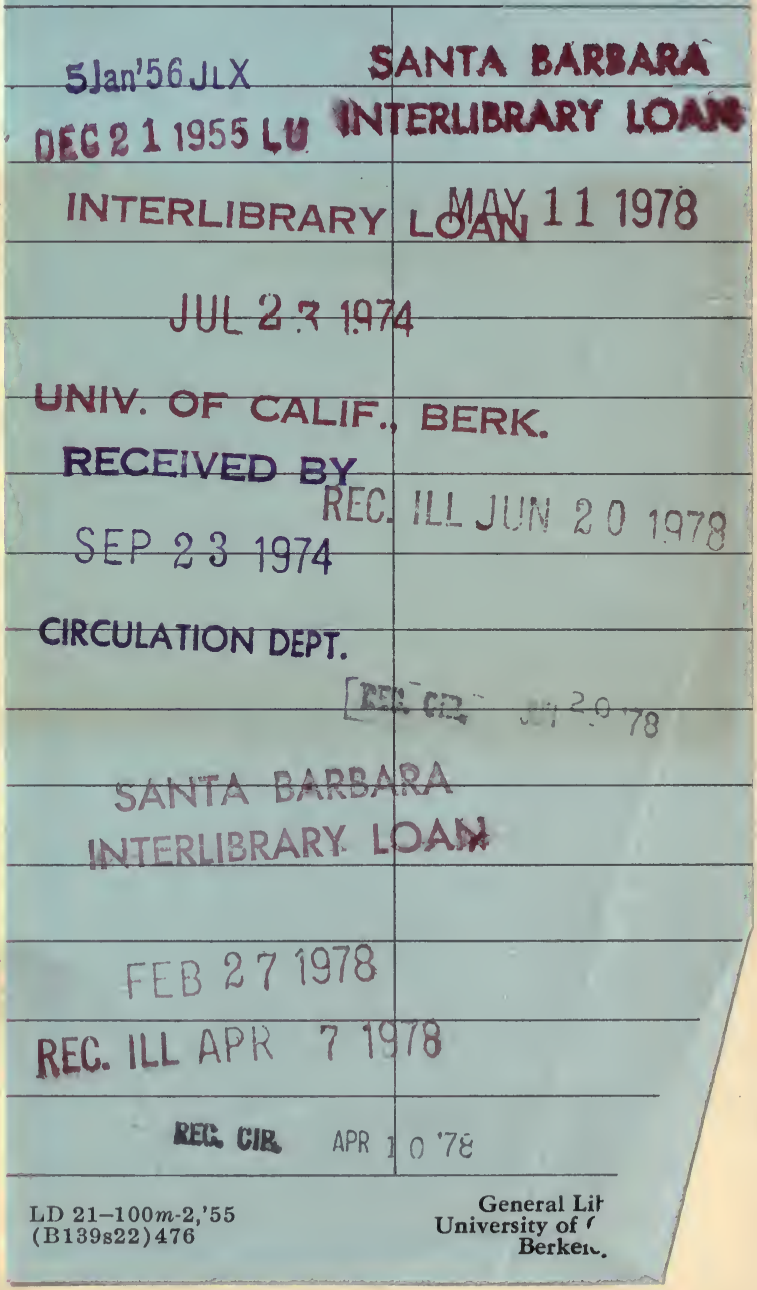




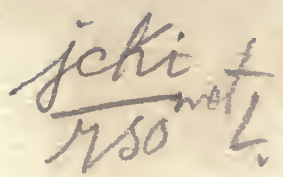

\section{YC 61974}

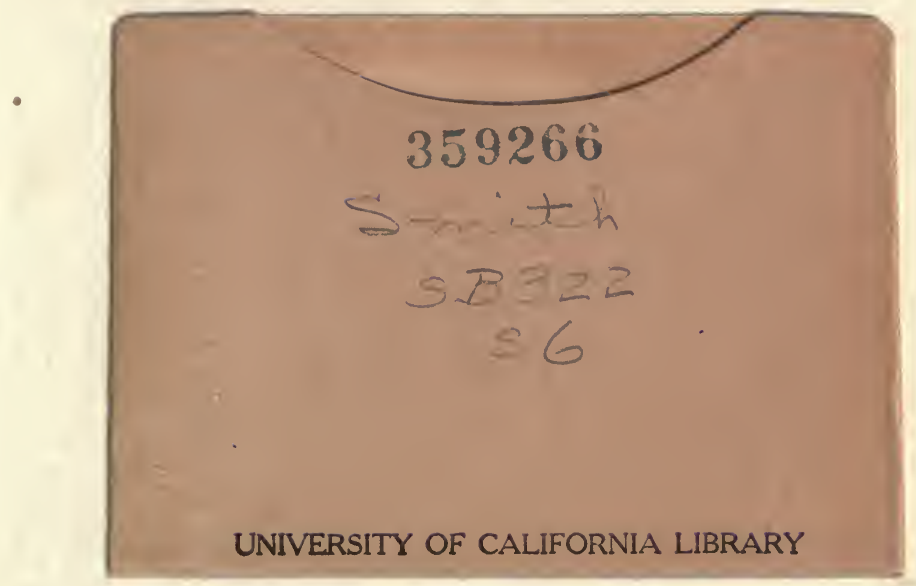


